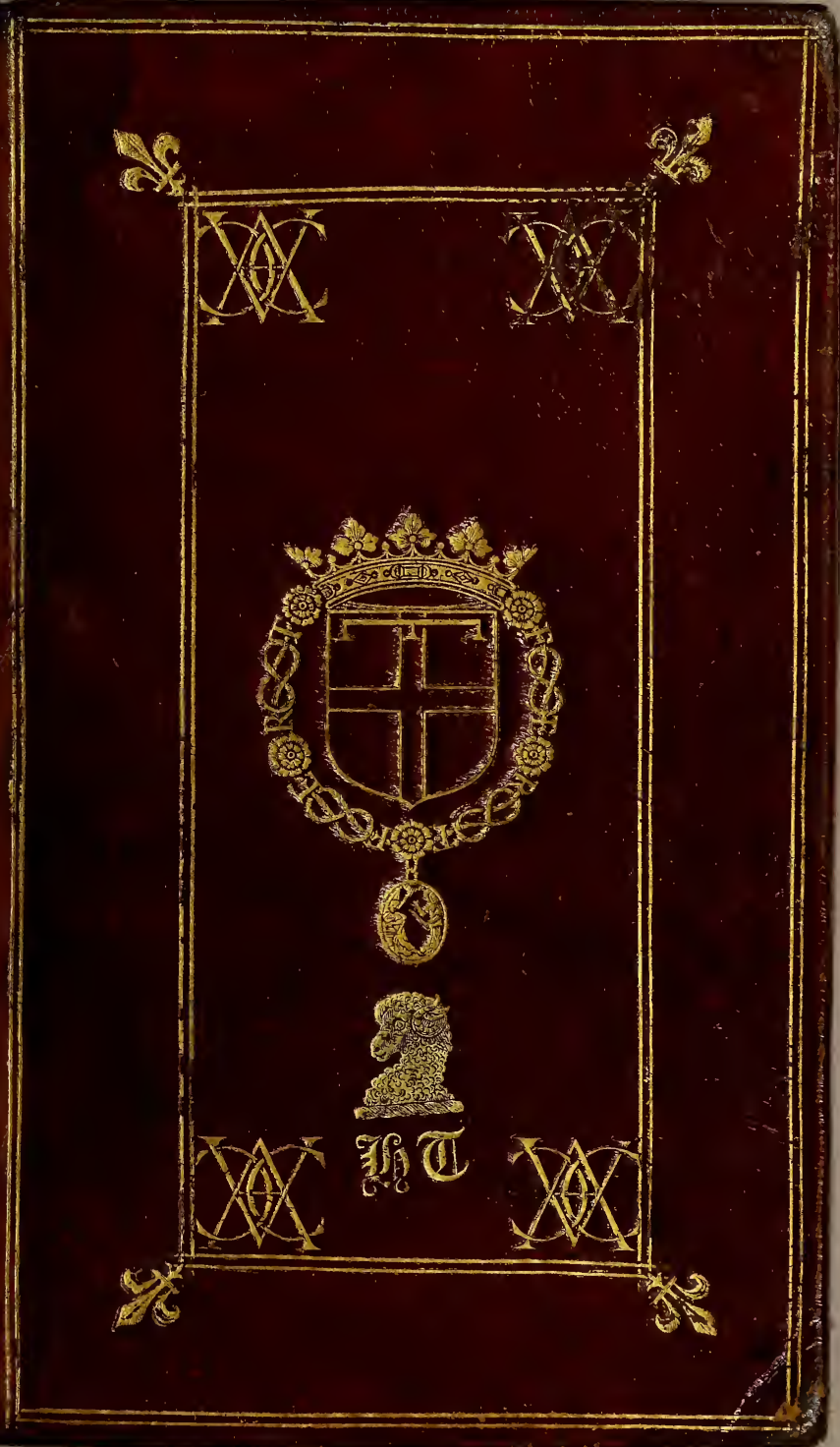




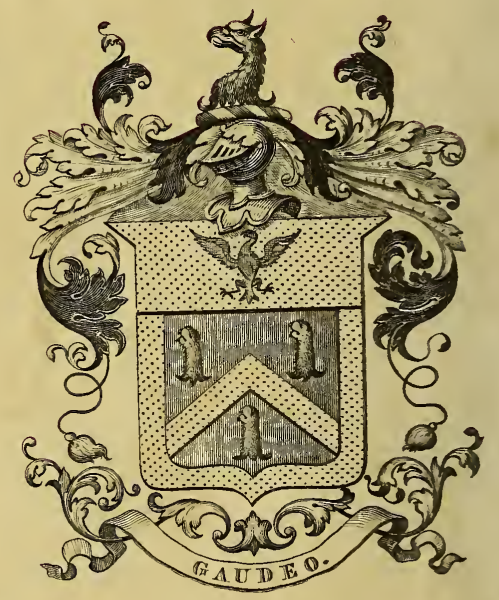

Johnt Carter Bntwir. 


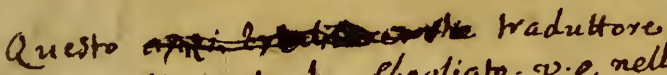
in molte eose ha slagliato ov ig nella carta 143 col.2. 1.5.amanti il fince dice en certe cause il gaste le thresar des Indes Loscena dire il employe ou dapense, gastar dineros, nued dire dependre argent. mà e piò bello rella carta 18 . 2.6. aunntit fine dorve dice, insquá cetter region Bolacque in vece di dire Lolaire, Shimando che" l'autare parlasse della Eolonia. 
3.

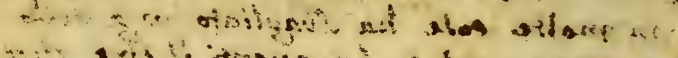

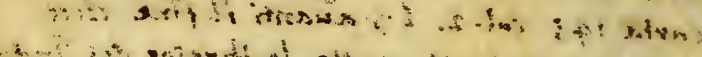

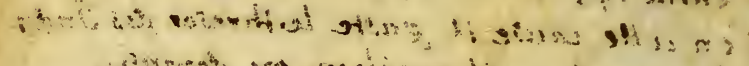

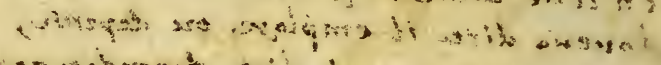

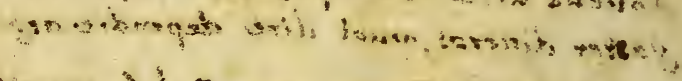

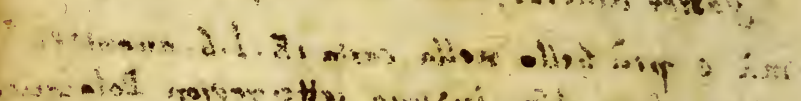

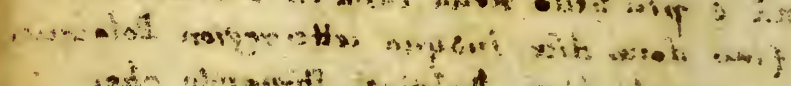

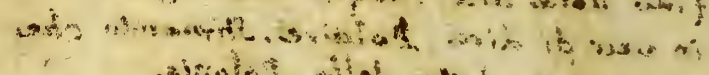

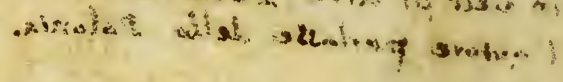





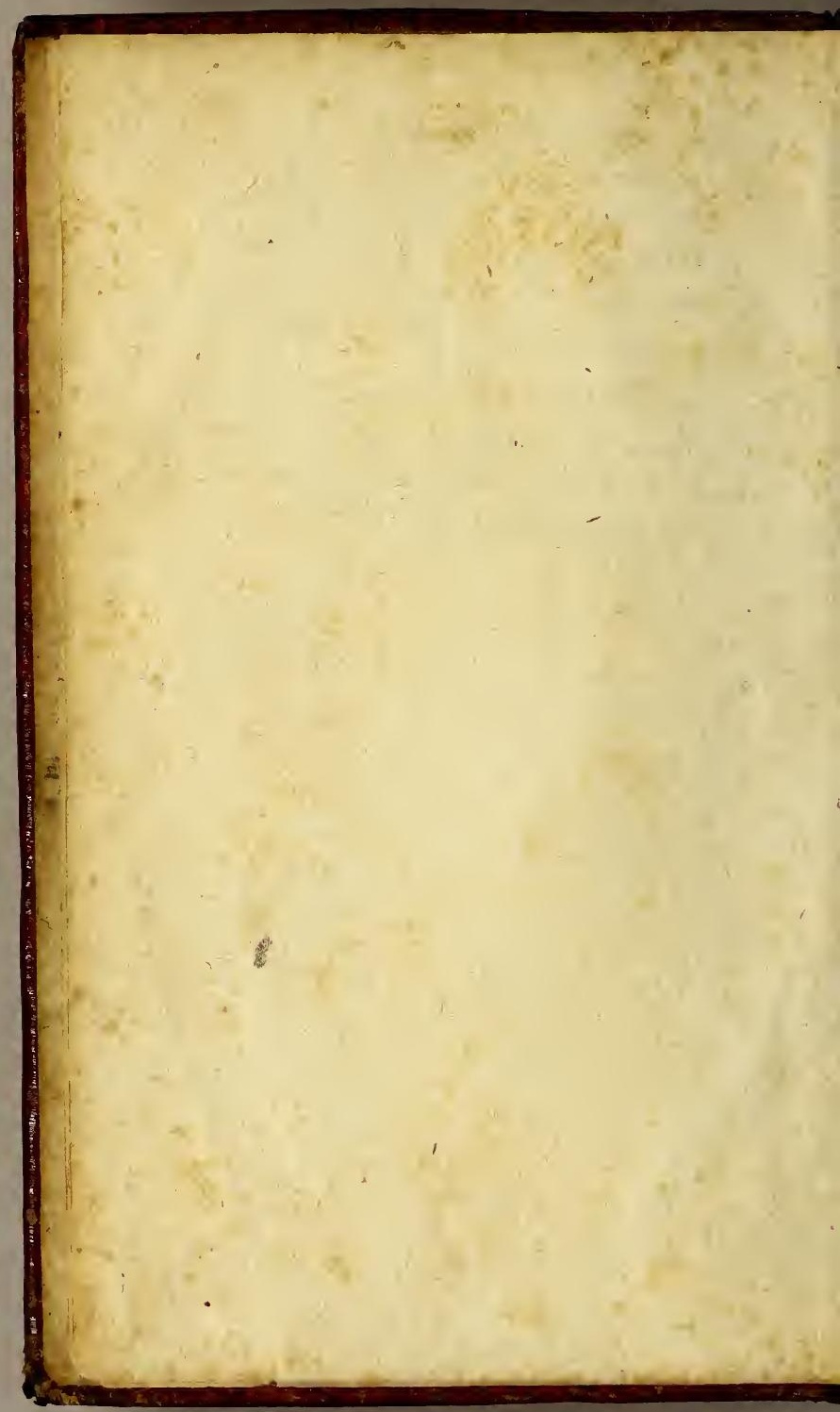


- ne $: 1$ 


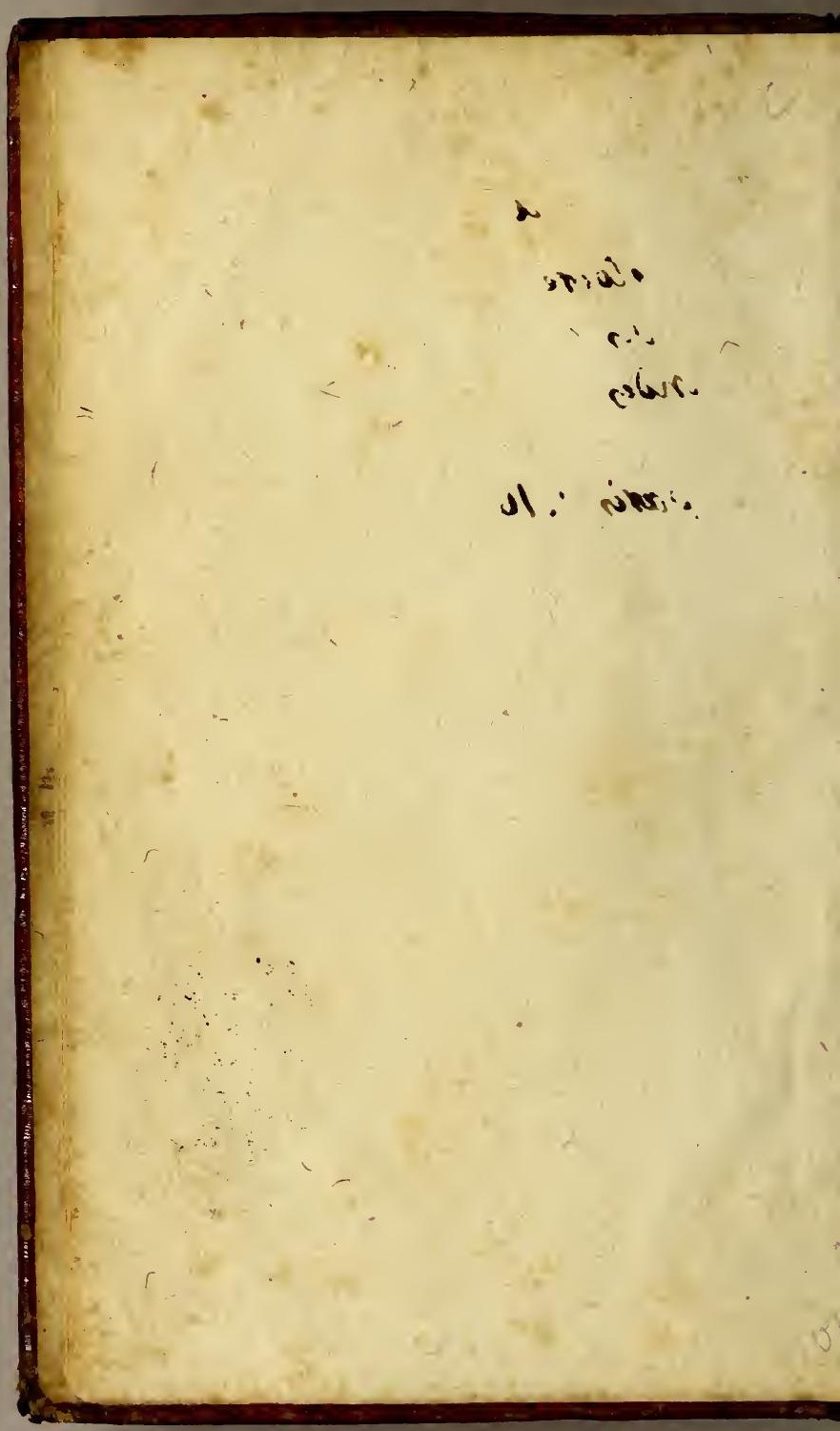


Exlibns (ondreg Mithronif Taurin

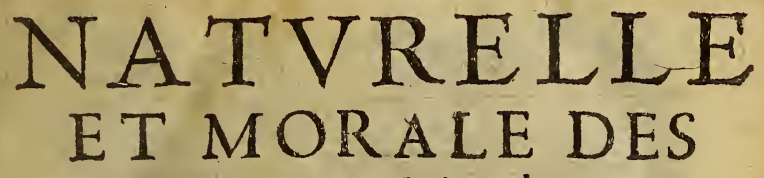

Indes, tant Orientales, qu'Occidentales;

où il eft traicté des chofes remsarquables du Ciel, des Elemens, Metaux, Plantes, \& Animaux qui font propres dece pays; enfemble des mours, ceremonies, loix, gounernemens ó guerres des mefmes Indiens:

Compofee en Cafillan par I O SE P H A c OSIA, traduicte en François par R O B ER I REGNAVI D Cauxois.

DEDIEE AV ROY.

DERNIERE EDITION,REVIVE, ET corrigee de vonurean.

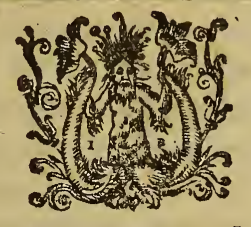

A P A R I $S$;

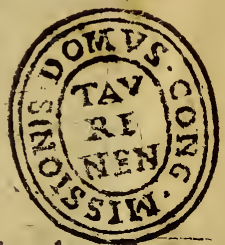

CheZ ADRIAN TIFFAINE, ruë des deux Portes, d l'image noftre Dame.

M. DC. XVI: 


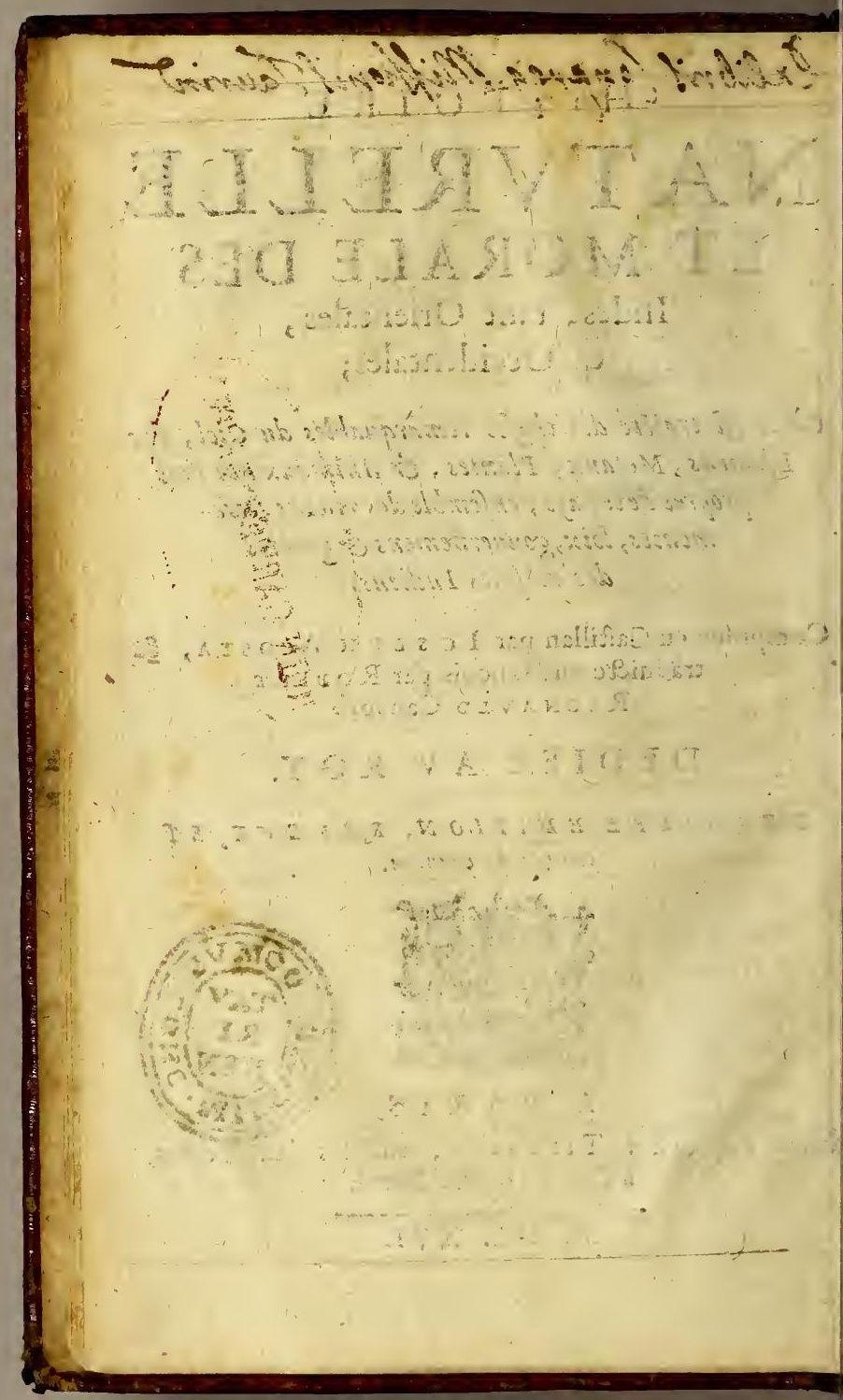




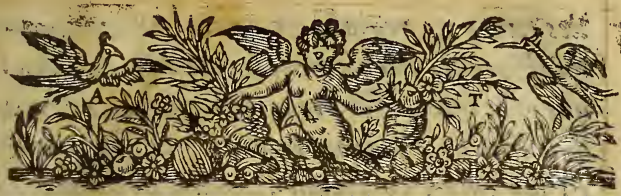

AVROY TRES.CHRESTIEN

DEFRANCEET DENAVARBE, HENRY I V. de ce nom.

\section{Trons IRE,}

a. 1 -

Cét admirable of inuinetle (1) guerrier Alexandre, itdis Rojeles (2) Macedoniens, qui par fa valcur, o beyreule fortune rangea foubs fon potuoir

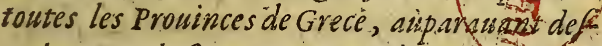
onies en plufieurs Cantons \& Republiques, puis paffant la mer de l'autre cofté, Jubiugua le tres-grand or tres-opulent Royaume de Perfe, of de là continuant plus outre, fft retenitr jes armes iuf ques bien auant deduns l'Inde orientale, borne de Jes àefjeins, \& pour lors la plus renommice, $O$ plus heureuje region de la terre. Entremille grandes ó belles affections quilogeoient en fon ame generente of guerrieri, auoit cefte-cy, qu'il defiroit \&o devaincre, of furmonter tous les autres, nompoint feulement. envaleur \& reputation d'armes, mais aufien.

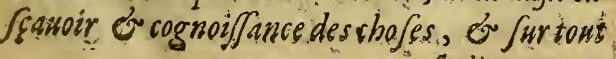
ä $i j$ 


\section{E PISTRE}

desterves of regions eftranges. De telle fagon quil faifoit curieufement rechercher, os à quelgue prix gue cefuft, tousles liures rares o exquis que lion pounoit recountir de fon temps. Et luy encore fort ieune, comme les Ambaffadeurs de Perfefuffent vernus vn iour deners fon pere, illes enquift f particulierement de la nature, grandeur, \&. Jituation du Royaume de Perfe, des villes, flewues, \& montagres d'iceluy, mesme des maurs du peuple, of de ta gendarmerie, qu'il apprit par leur bouche tout ie quils auoient en leur Royaume de plus grand. o. deplus finguilier, dont il/geut bienfaire forn proftipar apres, of ne ceefa iamais depuis, iufques à ce quil euft conquis' ce grand \& foriffant Empire; de: forte gu'on pourroit dire anec xaifon que les propos o aduertiffemens deces Ambaffadeurs furent comme la premiere eftincelle, ou caufe des grandes victoires é beureux fuccez qui luy arriverent depuis. Dequoy me reffourenant, SIRE, of de la compayaifor gue pluffeurs font auiourd'buy de fa valeur, clemence, É bonne fortine, à la voftre, voire de pluffeurs autres dons \& vertus heroïques dont. ilefoit doiie, qui vous font pareillement communes. Outrece, que tous deux puiffans of redoutez Princes, eftes yfus, quoy quien diwers. fecles, d'vn mefme eftoc de nobleffe; \& ras 


\section{A $\mathrm{V} R \mathrm{R}$.}

ae d'Hercules, luy par Cananus, ó vôus, $S$ I RE, par Charlemagne, qui, fuiuant les. anciens tefmoignages, en eftoit aulsi defcen$d t$, o de la race duquel vous.effes extraict. par le Roy fainct Loys, \& les autres Roys de France vos predeceffeurs, y/fus de la race dis. mefme Charlemagne par fexe freminin. Le. me fuis enbardy de traduire enlangue Francoife libifoire naturelle \& morate des Indes Orientales, nouvellement compofee en $\mathrm{Ca}$ fillan par Io/eph Acofta, homme certainement docte, \& fort curieux, pour la prefenter aux pieds de voffre Maiefté, fous efpoir que ce luy feroit chofe agreable, pour la delecíable varieté o nousueauté deschofes qui y forit contenuës; comme ie croy qu' Alexandre mefme loiroit fort volontiers fil vinoit en ceprefent frecle, buy qui tant de fois de for temps defara gri il fuftencore. wn autre monde, afin d'auoir on plus large champ d'exercer fesproïefes. Etce quiplus m'a incité de lèntreprendre, a efté que les Efpagnols. ialoux ò enuieux. de ce bien, ayans fait brufler par Edict public (comme l'on m'a aduerty depuis quelquie temps) tous les exemplaires de cefte hiffoire, afind'en priver les autres nations, \& leur celer la cognoiffance des Indés; $i^{2}$ ay pen. Sé que ie ferois faute fis ic laiffois perdre à thas France (a curicufe deschafes rares do belles).

a iij 


\section{E P I S T R E}

wnfiriche ioyau, \& vne figentille bifoire, que i:Autbeur a compolec, la plus grande part a veïe d'ail, \&o fur les me/mes lieux, d'vn tel? ordre \& brieueté, qu'auec bonne raifon it peut eftre appellél' Herodote, \& le Pline de ce monde nounellement defcouuert. Bref ie peux dire de ce Caftillan, SI R E, que c'eft on prifonnier d'entre vos ennemis, lequel i' ay /urpris en far terre, luy ayant appris tellement quellement nofre langue Françoife, pour vous le prefenter, afin quilvous conduife, of faffe voir les fingularitez plus exquifes de ie nouneau monde, fans crainte \& danger de naufrage. 2 ue $\sqrt{2}$ comme Alexandre founerain d'vine grande region de l'Europe en la partie d'Orient, a voulu tourner Jes deffeins. /urlinde orientale; ainfe

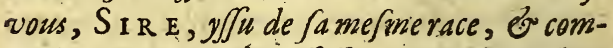
meluy, prince, \& poffeffeur triomphant d'vn grand \&o floriffant Royaume de l'Europe en la partie d occident, veiuillez außi voir, \&o regarder depluspresces Indes Occidentales, encores plus riches er renommees à prefent, que ne furent oncques les Orientales: ceftuy me fme rous y feruira de guide, \& de tres-fidelle epion, pour vous adwertir des ports, villes, \& montagnes d'iceluy, \& de lordre o nature du peuple, dont il vous dira dauantage, que se firent onca. les Ambajfadeurs de Perfe au Roy Alexandre. 


\section{$\overline{\mathrm{A}} \mathrm{V} \mathbf{K} \overline{\mathrm{O}}$.}

Ilplaira danc àvoftre Maiefté, SIR E, reces woir de bonnepartce threfor eftranger que vous offre lounde vos humbles oo fidelles Jubjects, pour te (moignage du feruice quil vous doit, $t^{\circ}$. vous a voïe pour toute fa vie.

Du Haure de Grace, le premier ianr de De: cembre, $1597^{\circ}$.

Voftre tres-humble, \& tres-obeyffant fubję \& feruiteur, ROBERI REGNAVLD:

$$
\text { 举 iiij }
$$



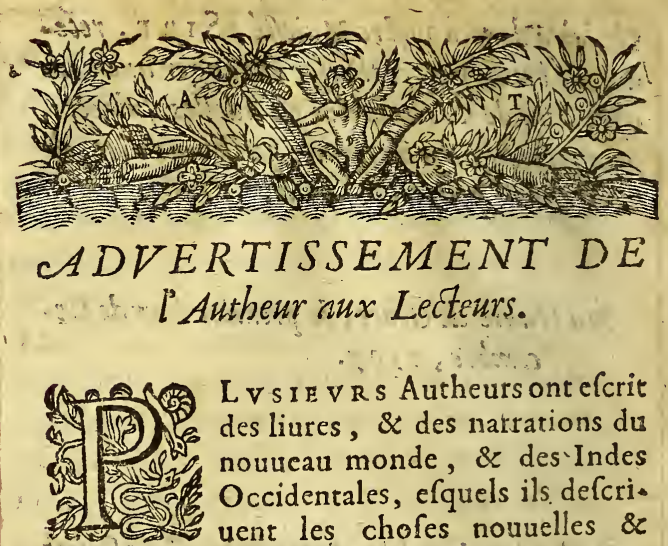

L VSIEVRS Autheurs ont efcrit des liures, \& des narrations du noulueau monde, \& des-Indes Occidentales, efquels ils defcri uent les chofes nounelles \& eftranges que l'on a defcourertes en ces parties Ia, les actes \& les aduentures des Elpagaols qui les ont conqueftees, \& peuplees. Mais iufques à prefent ie n'ay veu aucun autheur qui traitte, $\&$ declare les caufes \& raifons de telles nounueautez \& merueilles de nature, ny mefme quien faffe aucun difcours \& recherche. Ie n'ay point vea auff liure qui faffe mention des beftes \& hiftoires des mefmes Indiens, anciens \& naturels habitans du nouueau monde. A la verité ces deux chofes font affez difficiles; la premiere, . d'autant que cefont cuures de nature qui fortent, \& font contraires d la Philofophie ancienne, receüe \& practiquee, comme de monftrer que la region qu'ils appellent Torride, eft fort humide, \& en plufieurs endroits fort temperee, \& quil pleut en icelle quand le foleil en eft plus proche, \& autres femblables chofes. Car ceux 
qui ont efcrir des Indes Occidentales, n'ont pas fait profelfion de tant de philofophie, voire $l_{2}$ plus part d'iceux efcriuains ne fe font pas apperceus de telle cho te. La feconde eft, qu' elle traicte des beftes;, \& hiftoire propre des Indiens, laquelle chofe requeroit beaucoup de communication, \& de progrez dansle pays auecles mefmes Indiens, ce que la plus-part de ceux qui ont traicté des Indes, n'ont peu faire, ou pour n'entendre leur langue, ou pour ne vouloir rechercher leurs antiquitez, rellement qu'ils fe font eontentez de racótcr quelque chofe d'eux, qui eftoir le plus commun \& fuperficiel. Defirant donc auoir quelque plus particuliere cognoiffance de leurs chores, $i$ ay fait diligence de m informer des hommes les plus experimentez, \& verfez en ces matieres, pour tirer \& recueillir de leurs difcours \& relations, ce qui m'a femblé fuffire pour donner cognoiffance des faits \& couftumes de ces peuples. Er en ce qui eft du naturel du pays, \& de leurs proprietez, ie l'ay apprins par l'experience de plufieurs amis, \& par la diligence quei'ay faite de chercher, difcourir, \& conferer auec perfonnes fages \& experimentez. $11 \mathrm{me}$ femble mefme qu'en ce faifant il fe prefente quelques aduertifiements, qui pourront feruir \& proffiter à d'autres efprits meilleurs, afin de chercher la verité, ou de paffer plus outre, en trouuant agreable ce quils trouueront cy dedans. Ainfi combien que le nouueau móde n'eft plus nouueau, mais vieil, veu le beaucoup que l'on a efcrit d'iceluy, ce neantmoins cefte hiftoire pourra eftre 
tenuè en quelque façon pour nouuelle, d'autaryt qu'elle eft en partie hiftoire, \& en partie philofophie, \& non feulement d'autant que ce font ouureș de nature, mais auffi celles du liberal arbitre, qui font les faits \& couftumes des hommes, ce qui m'a donné occafion de luy donner nom d'Hiftoire Naturelle \& Morale des Indes, comprenant ces deux chofes.Il eft fait mention és deux premiers liures de ce qui touctie le ciel, temperature, \& habitation de ce monde, lefquels liures i'auois premierement efcrits en Latin, \& maintenant les ay traduits, vfant plus de Ia licence d'autheur, que de l'obligation d'interprete, pour m'accommoder mieux à ceux pour qui elle eft efcrite en vulgaire. Es deux liures fuiuans eft traicté ce qui touche ces elements \& mixtes naturels, qui font netaux, plantes, \& animaux, \& ce qui femble remarquable aux Indes, le refte des liures difcourant ce que $i$ 'ay peu difcourir au certain, \& ce qui m’a femblé digne de memoire des hommes, de leurs beftes, (ie veux dire des mefmes Indiens) de leurs ceremonies, couftumes, gouuernement, guerres, \& aduentures.Il fera dit en la mefme hiftoire, commei’ay peu apprendre, \& cognoiftre les beftes des anciens Indiens, veu qu'ils n'auoient aucune efcriture, ny charactere, comme nous auons;ce qui n'eft pas peu d'induftrie d'auoir peu conferuer leurs antiquitez fans l'vfage des lettres. En fin l'intention de ce trauail eft, afin qu'ayant la cognoiffance descuures naturelles, que le fage Autheur de toute la nature a faites, l'on loiie \& glorifiele haut Dieu, qui eft merueilleux en 
Cout \& par tout; \& quayant cognoiffance des couftumes $\& x$ choles des Indiens, lon leur ayde plus facilement à fuiure, \& perfeuerer en la haute vocation du S. Euangile, à la cognoiffançe de laquelle leSeigneur a voulu amener cefte nation fi aueuglee en ces derniers fiecles. Outre toutes ces chofes, vn chacun pourra mefme tirer pour foy quelque fruiat, attendu que le fage tire toufiours quelque chofe de bon de quelque petit fubiect que ce puiffe eftre, comme l'on peut tirer des plus vils \& petits animaux vne grande philofophie. Il refte feulement d'aduertirle Lecteur, que les deux premiers liures de cefte hiftoire, ou difcours, ont efté efcrits eftant au $\mathrm{Pe}$ ru, \&c les autres cinq depuis en Europe, lobedience m’ayant commandé de retourner par deçà : ainfi les vns parlent des chofes des Indes comme de chofes prefentes, \& les autres comme de chofes abfentes. C'eft pourquoy il $\mathrm{m}^{\prime}$ a femblé bon d'aduertir le Lecteur de cecy, afin que cẹte diuerfité de parler ne luy foit en; nuyeufe. 


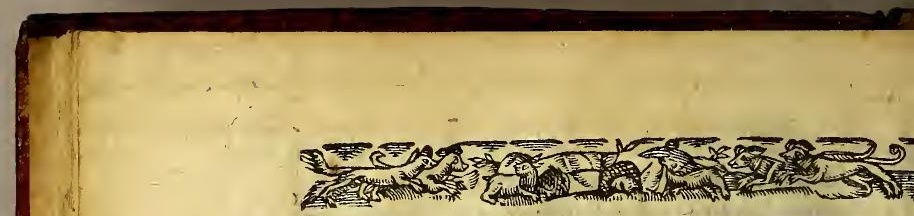 IN HISTORIAMIN- $D I \propto R V M \quad N \wedge T V R \wedge L E M$ à Iofepho Acofta Hippanico fermone compilatam,nuperà Roberto Reginal- do Gallicé redditam. \\ A D LECTOREM.}

I luftrare nouos retinere cupidine mundos,

Lataq; fi pelagi littora noffe cupis: Huc curfis difpone tuos, non naufea ladet,

Nec ftomachus ciuem te vetet effe matis. Nil opus eft velo, rimas farcire carinis, Aut magnetiaca pixide, nil opus eft. Alter Tiphys adeft, extremas ire per oras Edocet, \& populos, iam breuiore via: Sidera fub terris veteri non cognita feclo, Ortaq; in occiduo limine figna, refert. Temperiem Zon $x$, qux non habitabilis antcे Iudicio veterum, tunc habitata tamen: Novieris in curfu quo figno vtatur, \& aura, Vendicet arque fibi quidquid vterq; polus. Noueris \& montes, Germaniq; ora Typhœi Igniuoma, \& pifces, flumina magna, lacus, Templa,facerdotes, verique imitamina cultus, Chrifticolum ritus ve coluiffe putes. 
Annales, faftófq; libros, elementàq; regnä, Imperium, reges, pralia magna; duces. Terra ferax gemmis, fuluó q; referta metallo; Se peregrina tibi confpicienda dabit. Deniq; quod luftris; \& fumptibus haufit Ibêrus, Bis quarto poteris parcus adire die.

ANIONIVS BONDOR. 


\section{Ad Robertum Reginaldum Iraductorein.}

\section{Epigramma.}

TE Francifcis alit, quem nobis edidit $\mathrm{rrbs}$, 1 qua

Vellerij montis nomine, nomen babet. Betica'(demirans genium) mutare loquelam Inftitit, vt potius diceret effe fuum. Ipfe tamen patrix reducem te reddis, \& illa Qua fecreta cupit, cognitiora facis. Non te poniteat tanti, Reginalde, laboris; Hoctibi nam patrix pignus amoris erit: Parua videre putas victorem pramia Regerd Henricum, \& facras conteruiffe nuanus? Quigratus patrix; tum Regi,deferit auras, Rectiùs ille fuo munere functus abit

ANTONIVS BONDOR.

\section{Adeundern; de infcriptione libri.}

Cquid id?in prima promittit fronte libellus I Indos, eoos, occiduófque fimul. Attamen hefperias tantummodo detegit oras: Nulla ferè eoi eft mentio facta foli. Hoc, Reginalde, typis debetur, non tuus error (Error fi fuerit confpiciendus ibi.) Occiduus nobis, aliis oriturus habetur Phøbus:nil prius eft, pofteriúfve globo: ANTONIVS BONDORE 


\section{CHARLES REGNAVLD,}

A R O BE.R T REG NAVD fon frere, fur la traduction de l'Hiftoire Naturelle des Indes Oc. cidentales.

\section{S ONNET.}

N dit qu' Ret iadis Roy des Scythes-Colchoys? $\Lambda$ quila taijon d'or aroit efté donnee Pourr ungage fatal de fa vie honoree, Za faifout d' vn grand foing garder dedans wn bois. $\checkmark n$ dragon $\sigma^{\circ}$ deux beenfs, de qui l'horrible vois Remploit rout l'air de flamme, en deffendoient l'entrees' Mais Ia fon neantmoins, a Biftéde Medee, Es prit, o la fit vour à fon Prince Gregeois. Ainf i fais-et, Regnauld; car malgréles exce? Des foldats Espagnols, qui en gardeni accet? Malgré tous leurs canons, O leur naualle armee, Tuf ais voir aux François ces Threfors retenurs, Et dis riche Perules fecrets incognus, Bref, dun autre Colehos la toifor defires. 


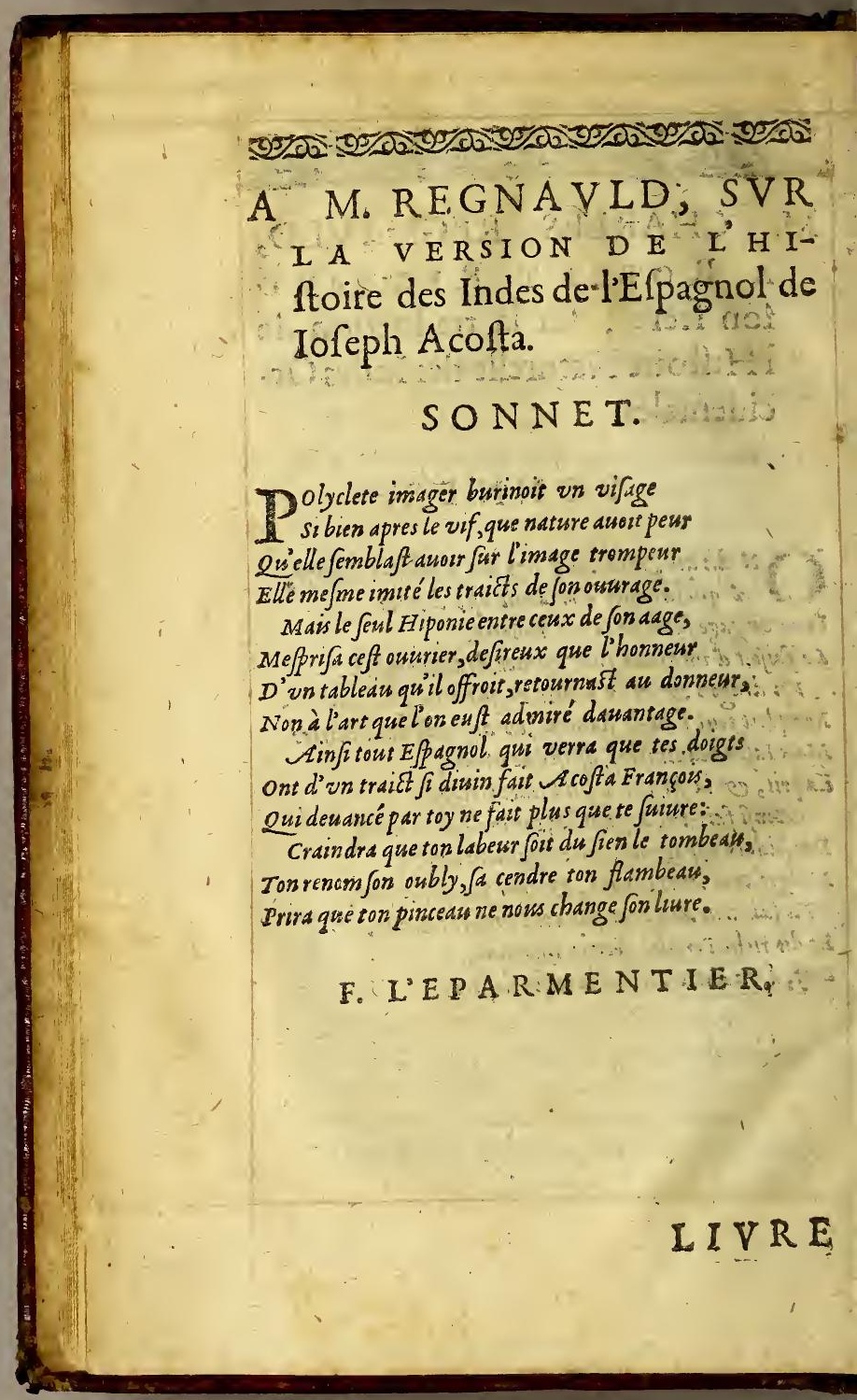




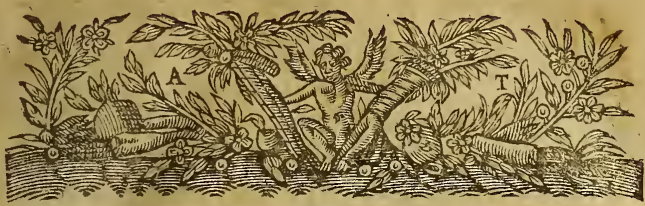

LIVRE PREMIER DE

L'HISTOIRE NATVRELLE' ET morale des Indes, tant Orientales, qu'Occidentales.

De l'opinion que queliques Autheurs ont eüe, penfans que le Cielne feftendoit iufque's. au nowneau Monde.

CHADITRE PREMIER.

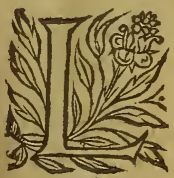

E $s$ anciens ont efté fi efloignez de penfer qu'il y euft peuple, ou nation habitante en ceftuy nouueau monde, que pluficurs mefme d'entr'eux n'ont peu fimaginer que de ce cofté cy y euft feulement terre, \& qui plus eft digne de merueille, f'en font troutué aucuns qui ont nié tout ouuertement que le ciel que nous y voyons à prefent, y peuft eftre: car iaçoit que la plus grand' part, voire les plus renommez entre les Philofophes, ayent bien recogneu que le ciel eftoit tout rond (comme ets effect il l'eft) \& que par ce moyen il entouroir, $\&$ ceignoit toute la terre, l'enferrant $\&$ comprenant dedás Coy; neantmoins plufieurs du nom: 


\section{Hiftoire naturelle}

bre mefme des Docteurs facrez, de plus grande authorité, ont eu fur ce point differentes opinions, f'imaginans la fabrique de cét v niuers à la façon d'vne maifon, en la quelle le toikt quila couure, circuit \& f'eftend tant feulement en la partie d'enhaur, \& non pas par toutes lés autres parties, alleguans pour leur raifon, que la terre autrement demeureroit fufpenduë au milieu de l'air. Ce qui leur fembloit chofe du tout hors d'apparence; \& tout ainfi que l'on void en tour baftiment le fondement \& l'affiette fituez d'vne part, \& le toiat \& couduerture d'vne autre op.pofite \& contraire, ainfi qu'en ce grand edifice de l'vniuers tout le ciel demeuraft en la partie chryjogt. ho- d'enhaut, $8 c$ la terre en la partie d'embas. Le 'mil. 14. 6y gloricux Chryfoftome, cóme homme qui fent 17. in cpryf. Plus occupé en l'êfude des lettres facrees, que non pas aux fciences d'humanité ; femble eftre de cefte opinion, quand il fe rit en fes Commentaires fur l'epiftre aux Hebrieux, de ceux-la qui afferment la rotondité du ciel. Et femble que la fainute Efcriture ne veuille fignifier autre chore, appellant le ciel, Tabernacle, ou Taudis

Hebr. 29. fait de la main de Dieu. Et fur ce fubjet il paffe zdem Chrys. plus outre, difant que ce qui fe meut $\&$ chemihomil. 6. 13. ne, n'eft pas le ciel, mais que c'eft le foleil, la luin Gencf. of ne, \& les eftoilles qui fe meunent au ciel. En la homil. r2.ad façon que les paffereaux \& autres oyfeaux fe pop. Antio- meuuent parmyl'air, tout au contraire de ce

Theodoret. aucec la mefme roüe. Theodoret autheur fort graue fuit en cefte opinion, Chryfoftome, \& 


\section{des Tndes. Liure 1.}

2

Theophile aufi, felon quil a de coufume pref- theoph in a qu'en toutes chofes. Mais Lactance Firmian de- 8. ad Hebr. uant tous les deffufdits ayant la mef́me opinion, Lact libr. 3 . fe mocque des Peripateticiens \& Academiques, diuin. infito. qui donnent vne figure ronde au ciel, confi- $c_{a p} .24^{*}$ tuans la terre au milieu du monde, pour autant que ce luy femble chofe ridicule que la terre demeure fulpenduë en l'air, cüme il eft deuant dis. Par laquelle fiẻne opinion il fe conforme à celle d'Epicure, quitient que de l'autrepart de la terre il n'y a autre chofe qu'vn chaos, ou abyfme infiny. Et femble mefme que S. Hierofine sapproche aucunement de cefte opinion, efcriuant fur l'epiftre aux Ephefiens en ces termes: Le Pbilofophe naturel par fa contemplation penetne iufques Fier. inepis: ad Ephof. li. 2. in caspo. 4 . ar haut disciel, o'del aztre part il trouse vn grand vuide aux profords e aby fmes de la terre. On dit auffi que Procope affirme (ce que ie n'ay veu toutefois) fur le liure du Genefe, que l'opinion d'Ariftote rouchant la figure \& mouuement circu- Sixtus Senes laire du ciel, eft contraire \& repugnant d̀ la fain- thec, anno. zo fe Efcriture. Mais quoy que difent \& tiennent: là deffus tous les anciens, il ne s'en faut efmouaoir, pource qu'il eft tout cogneu $\&$ approuué qu'ils ne fe font pas tant fouciez des feiences \& demonftrations de Philolophie, pour autant tqu'ils fe font occupez à d'autres de bien plus grande importance. sais ce qui plus eft à efmerueiller, eft que S. Auguftin mefme, zant verfé en toutes les fciences naturelles, voire fort do. Aary 1.20 ate en l'Aftrologie \& Phyfrque, neantmoins de de Genef. meure toufiours en doute, fans fe pounoir re. lit. $6 x p .23$ foudre fi le ciel circuir la terre de toures parts,

$$
\text { A ij }
$$




\section{Hifoire naturelle}

-Auguft. in on non: Que me forcie-ie (difoit-il) que nous perso P falm.35. Sions que le crel comme vne boule enferre en foy la terre de toustes parts, ef ant icelle an miliew du mande, comme ars pelotton de fil le fondreau; au que nous difions qu'il n'ef: pas ainfi, mais que le ciel counure la terre par vne part fewlement, tout ainfi qu'vn grand plat qui eft parle de Jus. Au mefme lieuque deffus il femble demonftrer, voire dit clairement, qu'il n'y a demonftration cerraine pour affermer la figure ronde du ciel, mais feulement de fimples coniectures. Efquels lieux alleguez, \& en d'autres endroits mefmes, ils tiennent pour chole dout eufe le mouuement circulaire du ciel. Neantmoins on ne fe doit offenfer, ny auoir en moindre eftime les docteurs de la faincte Eglife, fi en quelques poinds de la Philofophie \& fciences naturelles, ils ont eu differente opinion à ce qui eft tenu \& receu pour bonne Philofophie; veu que toute leur eftude a ef́é de cognoiftre, prefcher, \& feruir le Creareur de toutes chofes, en quoy ils ont efté excellents, \& comme ayans bien employé leur eftude en chofe plusimportante, c'eft peu de chofe en eux de n'auoir cogneu toutes les particularirez concernantes les crearures. Mais bien dauan. tage font à reprendre les Philofophes vains de ce fiecle, qui artaignans iufques à la cognoiffance de l'eftre, \& ơrdre des creatures, du cours $\&$ mouuement des cieux, ne font pas paruenus (mal-heureux qu'ils font) à cognoiftre le Creareur de toutes les chofes. Et f'empefchans du rout en fes œuures, n'ont point monté par leurs Sap. 19. imaginations iufques à cognoiltre l'A utheur Eonv. $x$. Couuerain d'icelles; ainfi que nous enfeignela 


\section{des Indes. Liure $I$.}

faincte Efcriture; ou bien s'ils l'ont cogneu, ne l'ont point feruy \& glorifié comme ils deuoiét, aueuglez de leurs inuentions, dequoy les accufe \& reprend l'A poltre.

Que le ciel eft rond de toutes parts, fe monwant en fon tour de foy mejme.

ChAPITRE II.

Fenans à noftre fujer, il n'y a point -(.9) I de doute que l'opinion qu'ont eu Ari(1) Ato \& les autres Peripareticiens auec po'ut. depldles Stoïques, que la figure du ciel eftoit 2, cap. 2. . ronde, \& fe mounoit circulairement en fon tour; eft fi parfaictement veritable, que nous qui fommes, \& viuons à prefent au Peru, le voyons de nos propres yeux. En quoy l'experience doit valoir dauantage, que toute autre demonftration philofophique, dautant que pour faire cognoiftre que le ciel eft tout rond, \&. qu'il comprend \& circuit en foy la cerre de rous coftez; \& pour en efclaircir tout le doute que l'on en pourroit auoir, il fuffit que i'aye veu \& contemplé en ceftuy noltre hemifphere la partie \& region du ciel qui tourne autour de cefte terre, laquelle n'a efté cogneïe des anciens, oubien d'auoir veu \& remarqué, comme î̀y fait, les deux poles elquels le ciel fe tourne, comme dars fes fiches. Te dy le pole Arofique, ou Septentrional que voyent ceux de I Europe; \&l'autre Antarctique, ou Meridional, duquel Auguftl. fainot Auguttin eft en doute, \& lequel nous A iij

de 3 inef. ad list. cong. 10 . 


\section{Hiftoire naturelle}

changeons \& prenons pour le Nort icy au $\mathrm{Pe}$ : $\mathrm{ru}$, ayans paffé la ligne equinoctıale. Il fuffit finalement que iaye couru par naugation plus de feptante degrez du Nott au Sud, fçauoir, q̨uarante d'vn cofté de la higne, \& vingt-trois de l'autre. Lailfant quant à prefent le telmoignage des autres, qui ont beaucoup plus naugé que moy, \&z en plus grande hauteur, eftans paruenus prefque iufques à feptante degrez au Sud. Qui dira que la nauire appellee $V$ ctoire, digne certanement de perpetuelle memoire, n'aye gagné le prix \& le triomphe d'auoir le meux defcoutert $\&$ circuit la rondeur de la terre, mefme le chaos vain \& le vuideinfiny, que les anciens Philofophes difoient eftre au delfoubs de la terre, ayant fait tout le tour du monde, \& circuit l'immenfité du grand Occean. Qui eft done celuy qui ne recognoiftra par cefte nauigation, que tolite la grandeur de la terre, quoy qu'elle puiffe eftre plus grande qu'on ne la dépeint pas, ne foit fubjecte alix pieds d'vn hóme, puis qu'il la peut mefurer? Ainfi fans aucun doute le ciel eft de figure ronde \& parfaicte; \& la terre aufiz s'embraffant \& joignant auec l'eau, faít vn globe, ou boule ronde compofee de ces deux elemens, ayans leurs bornes \& limires dans leur propre rondeur \& grandeur. Ce qui fe peut luffifamment proúter, \& demonftrer par raifons de Philofophie \& Aftrologie, laiffant arriere les fubtiles definitions que l'on peut alleguer communement; Q''au corps le plus parfaiet (qui eft le ciel) fe doit attribuer la plus parfaicte fi. gure, qui eft fans dowte la figure ronde. Duquel 


\section{des Fndes. Liure $I$.}

encores le mouuement circulaire ne pourroit eftre ferme \& égal en foy, s'il auoit quelqque coing, ou deftour en quelque part, ou s'il eftoit tortu, comme ille faudroit dire par necelfité, fis lefoleil, la lune, \& les eltoilles ne faifoient le tour, \& circuiffoient tout le monde. Mais fans confiderer toutes ces raifons, il me femble que la lune teule eit fuffifante en ce cas, comme vn fidelle tefmoing du ciel mefme; veu que fon ecclyple aduient feulement lors quie la rondeur de la terre s'oppole diametrallement entre elle $\&$ le foleil, \& par ce moyen empefche que les rayons du foleil ne donnent fur icelle. Ce qui ne pourroit certainement aduenir, fi la terre n'eftoit au milieu du monde, circuite \& entouree de tout le ciel. Il y en a eu aucuns qui ont douté iufques là, fil la refplendeur qui eft en la rog. ad Ialune, luy eftoit communiquee de la lumiere du nuar. $c_{0} 4$ 。 foleil. Mais c'eft par trop douter, puis qu'il ne fe peut troutuer autre caufe raifonnable des ecclyples, du plain, \& quartiers de la lune, que la communication de la refplendeur \& lumiere qui procede du foleil. Aufi fi nous voulons diligemment rechercher cefte matiere, nous trouuerons que l'obfcurité de la nuict n'eft caufee d'autre chole que de l'ombre que fait la terie, empefchant la clarté du foleil de paffer del'autre cofté du ciel, où il neiette fes rais. Si donc il eft ainfi que le foleil n'outrepaffe point, \& ne iette fes rais furl'autre partie de la terre, ains feulement fe deftourne à fon coucher, faifant efchine à la terre par vn tournoyement (ce que par force fera contrain a d'accorder celuy quis 


\section{Hiftoire naturelle}

voudra nier la rotondité du ciel, puis qu’à leur dire le ciel comme vn plat feulement couure la face de laterre.) Il s'enfuir clairement quel'on ne pourra remarquer la difference que nous voyons eftre entre les iours \& les nuicts, lefquels en quelques regions font courts \& longs felon les faifons, \& en d'autres perpetucllement efgaux. Ce que fainet Auguftin efcrit aux Eanguft. li. liures, de Genef. ad litteram, que l'on pourra bien de Genef. ad comprendre les oppofitions, conuerfions, eflelit.c. . . uations, defcentes, \& tous autres afpects, \& difpofitions des planettes, \& eftorlles, quand nous cognoiftrons qu'elles fe meuuent, \& que neantmoins le ciel demeure ftable, \& immobile. Chofe qui me femblebien ayfee à entendre, \& le fera à tout autre, m'eftant permis de feindre ce qui me vient en la fantaifie. Car fi nous pofons le cas que chaque eftoille \& planette foit vn corps en foy, \& qu'elle foit demenee \& conduitte par vn Ange, en la façon que

Dam. is is: fut porté Habacuc en Babylone: qui lera, ie vous prie, celuy tant aueuglé, qui ne voye bien que tous les afpects diuers qu'on void apparoir aux planettes \& eftoilles, peuuent proceder de la diuerfité du mouuement que celuy qui les mene \& conduit, leur donne volontairement? Cependant l'on ne peut dire auec raifon, que cefte efpace \& region, par où l'on feint que marchent \& roullent continuellemët les eftoils les, ne foit elementaire, \& corruptible, puis qu'il fe diuile \& fepare quand elles paffent, lefquelles certainement ne paffent pas par vn liets Vuide. Que fila region en laquelle les eftoil- 


\section{des Indes. Liure I.}

les \& planettes fe meunent, eft corruptible, par raifon donc les eftoilles \& planettes le doiuent eftre elles mefmes de leur propre nature, \& par confequent fe doinent changer, al. terer, \& finablement prendre fin; pource que naturellement le contenu n'eft pas plus durable que le contenant. Or dire que les corps celeftes foient corruptibles, cela ne s'accorde point auec ce que l'Efcriture dit an Pfalme, Que P Palm. 14: $D$ reu les fift posur tonfours: Et encore moins fe rap. porte à lordre \& conferuation de ceft vniuers. Ie dy dauantage pour confermer cefte verité, que ce quife meut, font les mefmes Cieux, \& en iceux les eftoilles cheminent en tourn yant. Chole que nous pounons cognoiftre auec les yeux, puis que nous voyons que non feulement les eftoilles fe meuuent, mais auffi les regions \& parties entieres du Ciel Ie ne parle point feulement des parties luifantes \& refplendiffantes, comme celle que l'on appelle, la voye laiate, quele commun appelle, le chemin fainot Iacques; mais ie dy cela dauantage, pour les autres parties noires \& obfcures qui font au Ciel. Pour-ce que nous y voyons realement comme destaches \& obfcuritez, qui font fort manifeftes, lefquellesie n'ay point fouvenance d'auoir iam ais veües en Europe : mais au Peru, en ceft autre hemifphere, ie les ay veruës plufieurs fois fort apparentes. Cestaches font de la couleur \& forme dela portion de la Lune eclipfee. \& luy reffémblent en noirceur \& obfcurité. Elles marchent attachees aux mefmes eftoilles, \& goufours d'vne mefme teneur \& figure, com. 


\section{Hiftoire naturelle}

me nous l'auons cogueu \& remarqué parexperience tres-claire. Parauenture cela femblera à quelques-vns chofe nouuelle, \& pourroiét demander d'où procede tel genre de taches au Ciel;ie ne puis certes refpódre autre chofe pour lheure, finon que, comme difent les Philofophes, quela voye lactee eft compofee des parries du Ciel les plus denfes \& efpeffes, \& qui pour cefte caufe reçoiuent plus grande lumiere: ainfi par contraire raifon il y a d'autres parties fort rares, deliees, \& tranfparentes, lefquelles pour receuoir moindre lumiere, femblent plus noires \& obfcures. Que cecy en foit la vraye raifon, ou non, (ie n'en peux rien affermer de certain) fieft-il pourtant veritable, que felon la figure que ces taches ont au Ciel, elles fe meuuent auec vne mefime proportion quant \& leurs eftoilles, fans aucunement fe feparé d'elles. Q ui eft vne experience certaine \& remarquee par plufieurs fois tout expres. Il s'enfuit de tout ce que nousauons dict, que fans doubtele Ciel contienten foyde toutes parts, la terre, tournoyant continuellement à l'entour d'icelle, fans que l'on puiffe plus propofer queftion là deffus.

2uela faincte Efcriture nous enfeigne que la terre eft ou milieu du monde. CHAPITRE III.

Fin Ombien quil femble à Procope, à Ga* ze, \& à aucuns autres de fon opinion, que ce foir cútreuenir à la faincte Ef 


\section{des Indes. Liure I.}

criture, de figurer la terre au milieu du monde, Fefter I3: \& de dire quele ciel eft tout rond: fi eft-ce que $\begin{aligned} & \text { II. } 18 . \\ & \text {. }\end{aligned}$ à la verité cefte doctrine non feulement ne luy $P$ falm.91.7. eft point contraire, mais auffi fe trouue du tout $23.39 .97 \%$ conforme à ce qu'elle nous enfeigne. Car ${ }^{106.37 .}$ lailfant à part lestermes dont vie la mefime Ef- Ecclef: I. criture en plufieurs endroits: La rodeur de la terre: (\& ce qu'en autre endroit elle dit, que tout ce qui eft corporel, eft circuit \& entouré du Ciel, \& comme embraflé de fa rondeur) à tour le moins ne peut-on nier que le pafiage de l'Ecclefiafte ne foit fort clair, où il eft dict : Le soleil naift.fe couche, o retourne en fon mefme leew, o v va recommençart à narftre : ilprend for chemin posr le mi$d y$, fe tournant iufques an Septentrion, ceft esprit chemi-

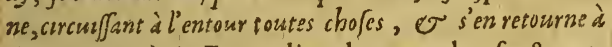
for mefmeendroit. En ce lieu la paraphrafe \& expolition de Gregoire Neocefarien, ou Nazianzene, dit: Le Soleil ayant couru toute la terre, sen reniet comme en cournoyant iuf gres à fon mefme poinet $\sigma$ terme. Ce que dit Salomon interpreté par Gregoire,ne pourroit certainement eftre vray, fi quelque partie de la terre delaiffoit d'eftre circuite du Ciel. Et ainfi l'entend fainct Hierofme efcriuant fur l'epiftre aux Ephefiens, de cefte ma 3 ad Ephes. niere. La plus commune opinion afferme ( Je conformät auec l'Ecclefafte) que le Ciel eft rond, fe mounuant en circuita la maniere d'vne boule. Et eft chofe certaine qu'aucune figure ronde ne tient ny latitude, ny longitude, ny hauteur, ny profondeur, pource qu'en toutes ces parties elle eft efgale \&. pareille. Par cela il appert felon fainct Hierofsue, que ceux qui tienent quele Ciel eft rond, 


\section{Hiftoire naturelle}

non feulement ne font pas contraires à la fain:

Baf. hom. 1. Ece Efcriture, ains au contraire fe conforment prope finem. à icelle: attendu principalement que S. Bafile 82 S. Ambroife (quil imite ordinairement aux liures appellez Hexameron) fe trouuent vn peu douteux en ce poinct. En fin toutesfois ils reuiennent à conceder la rondeur de ce monde. Ambrl. io Il eft vray que S. A mbroife ne demeure point hexam. c. 6. d'accord de cefte quintelfence qu'Ariftote attribueau Ciel. Et certainement s' eft chofe belle de voir auec quelle grace, \&z quel ftyle accomply la faincte Efcriture traicze de la fituation de la terre $\&$ de fa fermeté, pour caufer en nous vne grande admiration, \& $z$ non moindre contentement fur l'ineffable puiffance $\&$ fageffe du Createur. D'autant qu'en vn endroict

Pfalm. Dieu nous refere que ç'a efté luy qui a êftably les colomnes qui fouftiennent la terre, nous domnant à entendre, comme bien l'explique S. Ambroife, que le poids immenfe de toute la Asmbr.r.be- terre eft fouftenu parles mains du diuin pousain c. 6. uoir. La faincte Efcriture a de couftume deles appeller ainfi; \& vfer de cefte phrafe, les nommant colomnes du Ciel \& $\mathrm{x}$ de la terre, non point celles de l'autre Atlas, qu'ont feint les Poëtes, mais celles propre de la parole eternelle de Dieu, qui par fa vertu fouftient les 7ob 9. 26. Cieux \& la terre. Dauantage la fainote Efcriture $\mathrm{cn}$ autre lieu, nous demonftre comme la EIcbr. I. terre, ou grande partic d'icelle, eft ioincte \& enuironnee del'element de l'eat, difant generallement que Dieu mir la terre fur les eaux. Et en aurre endroiat, qu'il fonda la rondeur de la 


\section{des Indes. Liure I.}

eerre furla mer. Er encore que faind Augutin naccorde pas que de ce paffage (comme de fentence de foy) l'on puiffe inferer quela terre $\&$ Palm.135. l'eau faffe vn globeau milieu du monde, pretendant par ce moyen donner autre expofition à ces paroles du Pfalme; ce neantmoins il eft - tout certain, que ce qui eft porté en ces paroles du Pfalme, nous veut dóner à entendre quuil $n^{3} y$ a d'occafion d'imaginer autre ciment, ou liaifon à la terre, que l'element de l'eau, lequel, quoy quil foir facile \& muable, neantmoins fouftient \& enceint cefte grande machine dela zerre. Ce qui a efté faict par la fageffe du tresgrand Architcece. L'on dit que la terre eff fondee \& baftiefur les eaux, \& fur la mer : mais au contraire la terre eft pluftoft au deffous de l'cau, que non pas deffus, pour ce que felon limagination \& iugement commun, ce qui eft de l'autre cofté de la terre que nous habitons, femble eftre au deffous de la terre, \& par mefme moyen les eaux \& la mer qui ceignent la terre de l'autre part, font au deffous, \& la terre au deffus. Neantmoins la verité eft fulement, que ce qui proprement eft en bas, eft ce qui eft toufiours plus au milieu de l'vniuers: mais la faincte Écriture s'accommode à nofitre façan d'imaginer \& parler. Quelqu'vn pourra demander, puis que la terre eft eftablie fur les eaux (comme ditla faincte Efcriture) fur quoy font cftablies les mefmes eaux, ou quel appuy les fouftient? Et fi tant eft que la terre \& l'eau font vne boule ronde, où fe peut fouftenir toute cefie horrible machine? A cela refpond en autre endroict la fain. 


\section{Hifioire naturelle}

Ae Efcriture, nous donnant bien plus grande admiration de la puiffance du Createur : Et dit

106.26. ces propos: La terre s'eftend vers Aquilon fur wn vuide, $\sigma$ demeure pendië fur vien. Ce que certes eft trefbien dit, pour-ce que realement il femble que cefte machine de la terre \& de la mer. eft affife lur rien, quand on la depeindroit au milieudel'air, comme en verité elle y eft. Mais cefte merueille que les hommes admirent tant. Dieu nel'a-il pas luy-mefme efclarcie, demanPfalm.38. dant au mefme Iob en ces termes : Dy moy fa tu Şais quia zettéle plomboula ligne pour la fabrique dis monde, $\sigma$ arec quel ciment ont efté a $\beta$ zi $\sigma$ roincts fes fondemens? Finalement, afin de nous faire entendre la trace $\&$ modelle de ce merueilleux edifice

Pfalm.ro3. du monde, le Prophete Dauid accouftumé de chanter \& loiier les aeuures diuines, dit fort bien en vn Pfalme compofé fur cefte matiere en ces propos, Toy qui as fonde la terre fur la mefme fabilité $\sigma$ fermeté, Jans quielle chancelle, ny tourne d'var cofteny d'autre, pour touficours ó à vamais. Voulant dire la caufe pourquoy la terre eftant affife au snilieu de l'air ne tombe, ny ne chancelle d'vn cofté ny d'autre, eft, pour-ce que de fa nature elle a des fondemens affeurez, qui luy ont efté donnez par fon treffage Createur: afin que de foy-mefme elle fe fouftienne; fans auoir befoin d'autres appuis, ou fouftenemens. Donc en cét endroit fe trom pe l'imagination humaine, cherchant d'autres fondemens a la terre, que les fufdits: \& vient leur faute de mefurer les chofes diuines, à la façon des humaines. Ai fi ne doiton craindre, que quelque grande \& pefante que 


\section{des Indes. Liure I.}

femble cefte machine de la terre fufpenduë en 1aur, quelle puiffe tomber, ou contourner s'en diffus deffous: nous eftans alfeurez fur ce point, par-ce que le mefme Plalme dit, que pour iamais elle ne fe renuerfera. Certes auec raifon $7 \int_{a l m} 10_{\%}$ Dauid apres aucir contemplé \& chanté l'eftat de fi merueilleufes ceuures du Seigneur, ne ceffe de fe refiouir auec luy en icelles, difant3 o combiers les counres du sezgneur font aggrandies accreviës, il appert bien que towtes font forties de fon $\int y_{\text {ga- }}$ zuoir. Et en verité fi ie dois raconter ce qui $f e$ paffe fur ce propos: ie dy que foutentesfois que i'ay voyagé, paffant les grands golphes de l'OCcean, \& cheminant par les autres regions de terres fi eftranges, m’arreftant à cótempler ' $x$ confiderer la grandeur de ces cuures du Seigneur, ie fentois vn admirable contentement de celle fouveraine fageffe \& grandeur du Createur, qui reluit en ces mefimes ouures, en comparaifon defquelles tous les Palais, Chafteaux, \& baftimens des Roys, enfemble toutes les inuentions humaines, femblent bien peu, voire chofes baffes \& viles, au refpect d'icelles. O combien de fois me venoit en la penfee, \& en la bouchece paffage du Pfeaume, qui dit ainfi : Grande recreatisrs m'ane'Z donné, seigneur, par vos amures, or ne cefferay. de me refaryyr en la contemplation des cewures de vos mains. Realement \& de fait, les œuures diuines ont ne fçay quelle grace \& vertu cachee \& fectette, qui combien qu'elles foient contemplees plufieurs $\& z$ diuerfes fois, neantmoins caufent toufiours vn nouueau gouft \& cótentement: au contraire les cutures humaines, encor qu'elles foient con- 


\section{If fitoire naturelle}

Aruites auec vn exquis artifice, touresfois eft ans veucs fouuent, ne font plus eftimees, aus contraire deuiennent ennuyeufes, foit que ce forent Iardins tres plaifans, ou Palais, ou Temples magnifiquement baftis, foit Pyramides de fuperbe edifice, foit peintures; fculprures, ou pierres d'exquife inuention \& labeur, quoy qu elles foient doiices dé toutes les beautez qu'il eft poffible : toufiours c'eft chofe certaine qu'en les contemplant deux ou trois fois auec attention, les yeux fe diuertiffent toft de cefte veuë à vne autre, cftans incontinent foulez d'icelles. Mais fi auec attention vous confiderez la mer, ou quelque haute montagne, yffante hors la plaine d'vne eftrange hauteur, ou les champs reueftus de leur naturelle verdure, $\&$ de belles fleurs, ou bien le cours furieux de quelque fleuue, qui fans ceffer bat continuellement les rochers en bruyant, finalement quelques œuures de nature que ce foient, quoy qu'elles foient contemplees plufieurs fois, toufiours caufene nouvelle recreation, \& iamais ne s'ennuve $1 \mathrm{l}$ veuë. Ce qui reffemble vn banquet manifique \& abondant de la diuine fageffe, qui fans iamais ennuyer, caufe toufiours nouuelle confideration.

Contensing 
Contenant la refponfe à ce qui eff allegué de la Jaincte Efriture contre la rondeur de la serre.

CHAFITRE IIII.

erea Euenant donc dे la figure du Ciel, ie (6) 5) ne fçay de quelle auctorité de $\mathrm{l}_{3}$ faincte Efcriture on ayt peu tires 20 2quelle ne foit pas ronde, ny fon Q. 5 mounement circulaire, pource que ie ne voy point que ce queS. Paul appelle le Hebr. : Ciel tabernacle, ou taudis, que Dieu a eftably, \&z non point l'homme, puiffe eftre appliqué à ce propos. Car quoy qu'il nous dife quil eft faict par Dieu, l'on ne doit pour cela entendre que le Ciel, tout ainfi comme vn toid, couure la terre d'vne part feulement, ny mefme que le Ciel foir bafty fans fe mouuoir, comme il femble que quelques-vns l'ont voulu dóner à entẽdre. $L^{\prime} A$ poftre en ce lieu traittoit de la cóformité du ta bernacle ancié de la loy, disät là deffus que le ta: bernacle de la loy nouuelle de grace, eft le Ciel, auquel eft entré le grand Preftre IEsvs-CHRIST vne fois,par fon fang, \& de là s'entend qu'il y a autant de preéminence, du nouueau tabernacle au vieil, comme il $y$ a differềce d'entre l'autheur du nouueau,qui eft pieu, \& cil du vieil qui a efté l'homme,encor qu'il foit vray que le vieil taber. nacle fuft auffi bien bafty par la fageffe de Dieu quil'enfeigna à fon outrier Befeleel, \& ne doiron penfer que ces cóparaifons, paraboles \& alle. gories fe puiffent rapporter en tout \& par tout à ce dे guoy ellesfont accommgdees, comme le 


\section{Hiffoire naturelle}

chryfoft. in bien-heureux Chryfoftome a bien fceu dire $\$$ $20 . \operatorname{cap}$. ce propos. L'autre authorité que rapporte $S$. Auguftin alleguee d'aucuns, pour monftrer que Pfalm.103. Le Ciel n'eft pas rond, eft telle en difant, Le Crel seftend comme vne peau. Dont ils concluent qu'il r'eft pas rond, mais plat en la partie d'enhaut. A quoy refpond fort bien $\&$ fort familieremét le mefme $S$. Docteur, mais donnant à entédre que 'ce paffage du Pfalmifte ne parle,ny s'entềd pro: prement de la figure du Ciel,mais dit cela leulement, afin de nous demonttrer auec quelle faci-

Auguft.2. de Gen.ad liter.c.9.

\section{$\checkmark$}

2faye.66. lité Dieu baftit vn Ciel fi grand, ne luy ayăt efté non plus difficile de baftir vne fi immenfe cou uerture, comme eft le Ciel, qu'il (eroit à nous de defployer vne peau double, ou bien pretendant le Pfalmifte nous donner à ent endre, la grande majefté depieu, auquel le ciel fert, qui eft fibeau \& fi gräd, de mefme façon que nous feruent les tentes ou couuertures aux cham $p s$. Ce qui a efté fort bien declaré par vn poëte, difant: Le tardis dis clair Ciel. Mefmele paffage d'Ifaye qui dit.Le Ciel. me fert de cbaire, o la terre d'efcabeau pour mes pieds. Que fi nous enfuiuons l'erreur des Anthropomorphites, qui attribuoient des membres corporels à rieu felon fa diuinité, nous aurions occafion fur le dernier paffage de rechercher com. ment il feroit poffible que la terre fuft l'efcabeau des pieds de Dieu, \& comme le mefme pieu pourroit tenir ces pieds d'vne partie \& d'autre; \& plufieurs teftes tout à l'entour, puis qu'il eft en tout \& par tout le monde, qui feroit chofe vaine \& totalement ridicule. Il faut done conclure qu’aux faindtes Efcritures nous ne de- 


\section{des Indes. Liure. I.}

uons pas fuiure la lettre qui tuë, mais l'efprit qui viuifie, comme dit fain ct Paul.

Dela façon \& figure du Ciel du nouneass monde.

CHADITRE V.

Lufieurs en Europe demandent quelle S la la façon \& figure de ce Ciel qui $\mathrm{eft}$ - en la partie du Sud, pource qu'il ne f'en peut trouuer chofe certaine aux liures des anciens, lefquels encor qu'ils accordent $y$ auoir vn Ciel en cefte autre part du monde, ce neantmoins n'ont peu atteindre iufques à la cognoiffance de la façon \& figure, quoy que à la verité ils faffent mention d'vne belle \& grăde eftoille, Plin.lib. 6. qui fe void en ces parties cy, laquelle ils appellét sap.22. Canopus. Ceux qui de nouveau ont nauigé en ces parties, ont accouftumé d'efcrire \& racóter chofes grandes de ce Ciel, à fçauoir qu'il eft fore refplendiffant, $y$ ay ant grand nombre des belles eftoilles. Et en effect les chofes qui viennent de loing, fe defcriuent ordinairemêt anec augmentation. Mais il me femble tout au contraire, tenant pour certain, qu'en noftre cofté du Nort, il y a plus grand nombre d'eftoilles, \& de plus illuftre grandeur, ne fe voyant point par deçà eftoilles qui excedent la pouffiniere, ny le cha. riot. Il eft bien vray quela Croifee de deçà eft fort belle \& agreable à voir. Nous appellons Croilee, quatre eftoilles notables \& apparentes qui font entrelles vne forme de Croix,

$$
\rightarrow B \text { ij }
$$




\section{Hiftoire naturelle}

affifes efgalement \& auec proportion. Les igno: rans croyent que cefte Croifee eft le Pole du Sud; d'autant qu'ils voyent les mariniers prendre leur hauteur par icelle, comme nous auons icy accouftumé de la prendre par le Nort. Mais ils fe trompent. Et la raifon pourquoy les mariniers le font de cefte façon, eft, pource que de ce conté du Sud il n'y a aucune eftoille fixe, qui marque le Pole, comme à noftre Pole le faict l'eftoille du Nort. Et ainfi ils prennent leur hauteur par l'eftoille du pied de la Croifee, diftante du vray \& fixe Pole Antarctique, de trente degrez, comme de là l'eftoille du Nort eft diftante du Pole Arctique de trois degrez, ou peu dauantage. Et ainfi il eft plus difficile de prendre la hauteur en ces parties, pource que ladicte eftoille du pied de la Croifee doit eftre droicte, ce qui aduient feulement en vne heure de la nuiat, qui eft en diuerfes parties de l'an, en differentes heures, \& bien fouuent en toute $l_{2}$ nuitt ne fe montre:qui eft chofe fort mal commode pour prendre la hauteur. Par ainfil les plus experts pilotes ne fe foucient de la Croifee, prenans la hauteur du foleil par l'Aftrolabe, par lequel ils cognoiffent la haureur où ils fe trouuent. En quoy communement les Portugais font plus experts, comme nation qui a grand difcours en l'art de nauiger fur toutes les autres nations. Il y a auffi de cefte partie du Sud d'autres eftoilles, qui en quelque façon reffemblent à celles du Nort. Ce qu'ils appellent la voye lactee, s'eftend beaucoup, \& eft fort refplendiffant en ce cofté du Sud, fe voyant en 


$$
\text { des } 7 \text { ndes. Liure I. }
$$

icelle ces taches noires tant admirables, defquelles cy deuant nous auons faict mention. Pour les autres particularitez, d'autres les diront auec plus grande curiofité, \& nous fuffit pour l'heure de ce quauons dict.

2u'il y a terre \&o mer foubs les deux Poles.

CHADITRE VI.

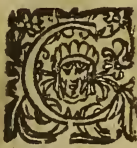

ne nous eft point peu de chofe fai. cte, d'eftre fortis de cefte matiere auec cefte cognoiffance \& refolution qu'il y a vn Ciel en ces parties des Indes, quiles couure, comme à ceux d'Europe, d'Afie \& Afrique. Et nous fert ce point quelquesfois contre beaucoup d' $E$ pagnols, qui par deçà foufpirent pour leur $E$ fpagne, ne fçachans dequoy parler que de leur pays, lefquels fefmerueillent, voire fe fafchent contre nous autres, eftimans que nous auons oublié, \& faifons peu de cas de noltre patrie. Aufquels nous refpondons, que pour cela le defir de retourner en Efpagnene nous trauaille point. Pource que nous trounons que nous fommes auffi proches du Ciel eftans au Peru, comme nous en fommes eftans en $\mathrm{E}$ fpagne:comme dit fort bien S. Hierofme efcriuantà Pauline, fçauøir quela porte du Ciel eft auffi proche de Bretagne,com. me de Hierufalem. Mais encor que le Ciel circuife le monde de tous coftez, il ne faur pas pour cela penfer, que neceffairement il y ayt terre de tous coftez du monde. Car eftant ainfî

B iij 


\section{Hifoire naturelle}

que les deux elemens de la terre \& l'eau, com. pofent vn globe, ou boule ronde, felon qué la

plutarq.l. plus-part, \& les plus renommez autheurs des placitis phil. \& comme on le prouue par demonftrations 6.9. $10 \mathrm{II}$ tres-certaines l'on pourroit conjecturer que la mer occupaft toure cefte partie qui eft foubs le Pole Antarctique ou Sud,de telle façon qu'il ne reftaft aucune place en ces parties pour la Augvo. l.16. terre; felon que S. Auguftin reprent fort doctede Cimi. c. 9. ment contre ceux qui tiennent les Antipodes; difant, qu'encor que l'on faffe preuue, \& que l'on croye que le monde foit de figure ronde, comme vne boule, il ne faut inferer de cela, que en cefte autre partie du monde la terre foir defcouuerte \& fans eau. Et fans doubte S. AuguAtin dit fort bien en ce poinct, ce neantmoins le contraire de ce ne fe prouue, \& ne s'enfuit non plus, fçauoir qu'il y aye terre defcouuerte au Pole Antarctique. Ce que l'experience nous a ja monfréà veiie d'œil eftre ainfi cóme, en effêt ill'eft. Car iaçoit quela plus grande partie du monde, qui eft foubsle Pole Antarotique, foit occupee de la mer; ce neantmoins elle ne l'eft pas entierement: mais y a terre, de forte qu'en toutes les parties du monde, la terre \& l'eaüe fe vont embraffans l'vn l'autre, qui eft veritablement vne chofe pour nous faire admirer \& glo.

Gene. à. rifier l'art du fouuerain Createur. Nous fçauós donc par la faincte Efcriture, qu'au commen. cement du mondeles eaux furent affemblees, \& feioignirent en vn endroit, tellement que la terre demeuta defcouverte. Dauantage , la 


$$
\text { des Fndes. Liure } I_{\text {. }}
$$

mefme Efcriture faincte nous enfeigne, que ces affemblemés d'eaux s'appellerent mer, \& comme elles font plufieurs, il eft de neceffité qu'il y ayt plufieurs mers. Et non feulement eft cefte diuerfité des mers en la mer Mediterranee, les vnes s'appellans Euxine, les autres $\mathrm{Ca}$ fpie, autre Erythree, ou rouge, autre Prefique, autre d'Italie, \& ainfi plufieurs autres. Mais auffi bien au grand Occean que l'Efcriture fainete a accouftumé d'appeller abyfme, encore que realement \& enverité cerke foit qu'vne mer, maís en plufieurs $\alpha$ differentes manieres: comme au refpect de tout le Peru \& de toute l'A merique, ilsappellent l'vnela mer du Nort, \& l'autre la mer du Sud;en l'Inde Orientale l'vne s'appelle la mer d'Inde, \& l'autre de la Chine. Et ay remarqué tắ en ce que i’ay nauigé moy-mefine, que par la relation des autres, que iamais la mer ne fe fepare de la terre de plus de mil lieuës. Er quoy que fe puiffe eftendre la grandeur del'Occean, fi eft-ce qu'il n'outrepaffe iamais cefte mefure. Ie neveux pas pour cela dire que lion ne nauige plus de mil lieuës de la mer Occeane : qui feroit contre la verité, puis que nous fçauons que les näuires de Portugal ont nauigé quatre fois autant, voire dauanta$\mathrm{ge}$, que tout le monde en rond fe peut nauiger par mer, comme en ce temps nous l'auons defia veu, fans que plus on en puiffe douter. Mais ce que ie dy \& afferme, eft qu'en ce qui eft aujourd huy defcounert, aucune terre n'eft diftante \& eflongnee par ligne directe de l'autre terge ferme, ou Ines; quil luy foient plus proches, $B$ iiij 


\section{Hiftoire naturelle}

au plus que de mil lieuës, \& que par ainfi entre deux terres il n'y a point plus grand efpace de mer, le prenant par les parties des terres plus proches les vnes des autres. Pource que de la fin de l'Europe, ou de l'A frique, $\&$ de leur $\mathrm{co-}$ fté, les Canaries, les Açores, les. Ifles du Cap devert, \& les autres qui font en ce pareilles; ne font diftantes de plus de trois centslieuës, ou cinq cents de la terre ferme. Defdites Ines prenant fon cours vers les Indes Occidentales, a peine y a-il neuf cents lieuës iufques aux Ifles S. Dominique, les Vierges, la bien-heureufe \&c les autres, \& les mefmes Ifles vont courant par leur ordre, iufques aux Ines de Barlouente, qui font, Cuba, Efpagnolla, \& Boriquen. D'icelles iufqu'z̀ la terre ferme à peine y a-il deux cents ou trois cents lieuës, \& en l'endroit le plus proche beaucoup moins. La terre ferme court vn efpace infiny, depuis la terre de la Floride; iufquà la terre des. Patagons, \& de l'autre cofté du Sud, depuis le deftroir de Magellan,iufqu'au Cap de Mendoce, court vne terre tres-longue, mais non beaucoup large: car le plus large gift le trauers du Peru; qui eft diftáte du Brefil, d'enuiron mil lieuës. En cefte mefme mer du Sud encor qu'on ne fçache rencontrer la fin, en tirant vers le Ponant, neantmoins il y a peu de réps que l'on defcouurit les Ifles, qu'ils ont appellees de Salomon, qui font plufieurs \& grandes, diftătes du Peru comme huiat cents lieaës. Et pource que l'on obferue, \& fe trouue ainfi, que là, où il y a plufieurs \& grandes Ifles, la terse ferme en elt peu ellongnee: de là vient que 


\section{des Fndes. Liure I.}

plufieurs, \& moy-mefme auec eux, ayansopinion qu'il y a quelque grande terre ferme proche defdites Ifles de Salomon, laquelle refpond à noftre Amerique du cofté du Ponent; \& feroit poffible qu'elle couruft par la hauteur du Sud iufques au deftroit de Magellan. Ontient que la neuue g uinee eft vne terre ferme, \& quel. ques doctes la peignent fort pres des Ifles de $\mathrm{Sa}$. lomon; de forte que c'eft chofe vray femblable de dire qu'il y a encor vine bonne partie du mon. de à defcounurir, puis qu'aujourd huy les noftres nauigent en cefte mer du Sud iufques à la Chine \& Philippines, \& difons que pour aller du Peru en cesparties la, quiils paffent v́ne plus longue mer, que non pas allant d'Efpagne au melme Peru. Dauantage, on cognoift que c'eft par le tant fignalé deftroit de Magellan, que ces deux mers. fe joignent \& continuent l'vne atiec l'autre (ie dy la mer du Sud auec la mer du Nort) par la partie du Pole Antaretique, qui eft en hauteur de st. degré. Mais c’eft vue belle \& gräde queftion où plufieurs fe font employez, Içauoir fices deux mets fe joignent, \& continuent auffi bien da cofté. du Nort. Maisie n'ay point cognoiffance que iufqu'auiourd'huy aucun aye peu atteindre à ce poinct, fi ce n' eft feulement par ie ne fçay quels indices \& coniectures auelques-vns afferment quil y a vn autre deftroit fous le Nort, àl'oppofite de celuy de Magellan: toutefois pour noftre fujet, il fuffift de fçauoir maintenant au vray quil y ayt terre de ce cofté du Sud, \& que c'eft vne terre aufli grande comme toutel'Europe, l'Afie \& l'Afrique mefme 


\section{Hifoire naturelle}

que à tous les deux Poles du monde, l'on trouve \& récontre terre, \& mer , embraffees l'vne auec l'autre Enquoy les anciens ont peu entrer en doute \& le contre-dire par faute d'experience.

Pour reprouuer l'opinion de LaEtance, qui tient qu'il n'y a point d'Antipodes.

CHAPITREV VII.

Than Vis dóc que c'eft chofe cogneuë, quil

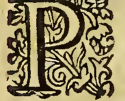
y a terre au cofté du Sud, ou pole Antarctique: refte maintenát de voir sil y a des hommes habitans en icelle, qui a

Lact. lib. 7 . efté au temps paffé vne queftion fort debatuë. Inffit.dinin. sap. 23. ceux qui afferment les Antipodes (qui vautauLactance Firmian \& S. Auguftin fe mocquér de Augufflibi. tant à dire comme hommes qui one leurs pieds 16. de cinit. rap.9. au contraire des noftres.) Mais encor que ces deux autheurs saccordent en cefte mocquerie, ce neantmoins aux railons, \& motifs de leur opinion, font fort differents l'vn de l'autre,comme ils eftoient fort diuers' d'efprit, \& d'entendement. Laêtance fuit le vulgaire, eftimát chofe ridicule de dire que le ciel eft formé en rond \& circuit: \& que la terre foit au milieu enuironnée. \& enclofe d'iceluy comme vne pelotte. Ez pour ce il efcrit en ces termes. Quelle raifan $y$ a. is a ce que quielques vas veulene dire, quilly a des Antipodes, qui ont leurs pas contraires aux noftres? Eft al poßible quilly ait hömes filourds, $\sigma$ figroßsers, qui croyezse quil $y$ ait vn peuple, ous nation cbeminane les pieds eers bault, o la sefte en bas, or que les chofes, quis font icy. 


\section{des Indes. Liure I.}

injifes, $\sigma$ arreftees d' une façon, foient de ceffe autre part pendantes, $\sigma$ renuer fees, au contraire:que les arbres, $\sigma$ les grains croiffens la contre bas, or que la pluye, la neige, Ola grefle tombent, $\mathcal{O}$ 'sefcoulent de terre contremont? puis apres quelques autres propos, le mefme Lactance tient ces propos: L'opinion $\sigma$ imagination que quelques vns ont eixe eftimansle ciel rond, a efté la caufe $\sigma$ le motif dinuenter ces Antipodes Juppendus es l'air,par ainfi ie ne puis que dire de tels Philo ofophes, finon quay ans vne fois erré, lls pour fisivent, $\mathcal{O}$ sobftinent roufiours en leur opinion, Se deffendans les vns les autres. Iufques icy font les propos de Lactance. Mais quoy qu'il die, nousautres qui pour le prefent eftans au Peru, habitons la partie du monde contraireà l'A fie, \& fommes leurs Antipodes, (ainfi que les Cofmographes l'enfeignent) ne nous voyons pas cheminans. fufpendus en l'air, la tefte en bas; ny les pieds en haut. Certainement c'eft chofe merucilleufe de confider er que l'efprit \& entendement humain ne peut atteindre \& paruenir à la verité, fans vfer d'imagination; \& d'autre part qu'il luy eft impoffible qu'il n'erre, \& ne faille, f'il f'en veut totalement abftenir. Nous ne pouuós comprendre que le ciel foit rond, comme il l'eft, \& que la terre foir au milieu, fans l'imagination. Mais fi cefte mefme imagination n'eftoit corrigee, \& reformee par la raifon, \& que nous l'enfuiviffions du tout, en fin nous nous trouuerions trompez. D'où nous pouuons conclure vne experience affeuree, que en nos ames il yia vne certaine lumiere du ciel, parlaquelle nous voyons \& iugeons, voire les mefmes images, \& formes interieures qui fe 


\section{Hiftoire naturelle}

prefentent a nous, pour les cognoiftre, $\&$ par cefte mefme lumiere nous approuuons \& rejerrons ce que l'imagination nous reprefente. Et de là voit-on clairement comme l'ame rationel. le eft par deffus toute la nature corporelle, \& comme la force $\&$ vigueur eternelle de la verité prefide au plus eminent lieu de l'homme, mefme on recognoift facilement comme cefte lu. miere fi pure eft participante, \& procede de cel. le premiere \& grande lumiere; que qui ne fçait cela, ou qui en eft en doute, nous pouuons dire deluy, qu'il ignore, ou doute f'il eft homme,ou non. Ainfi fi nous demandons à noftre imagination ce qui luy femble de la rondeur du ciel, à la verité elle ne nous refpondra autre chofe, finon ce que dit le mefme ractance, fçauoir que fi le ciel eft rond, le loleil \& les eftoilles deuroient tomber lors qu'ils fe meuuent, \& qu'ils changent de place, \& f refleuent en tirant au $M y$. dy. Tout de mefme que fi la terre eftoit penduë en l'air, les hommes qui habitent en l'autre partie d'icelle, doiuent cheminer les pieds en haut, \& la tefte en bas, \& que les pluyes ne tombent point d'enhaut, mais coulent de bas en amont, \& plufieurs autres monftruofitez ridicules. Mais fil'on confulte la force de la raifon, elle fera peu de cas de toutes ces peintures vaines, \& fera que I'on n'efcoutera non plus l'imagination, qu'vne vieille folle. Mais auec celte fienne grauité \& integrité refpondra la raifon, que c'êt vn er zeur fort grand de fabriquer en noltre imagination tout le monde en la façon d'vne maifon, en luy donnant pour fondement la terre, \& le 


\section{des Fndes. Liure 1 .}

ciel pour toiat \& counerture. Et dira dauantage, que comme aux animaux la tefte eft la partie la plus haute $\&$ la plus efleuee (bien que tous les animaux n'ayent pas la tefte pofee en mefine fituation, les vns l'ayans au plus haut, comme l'homme; les autres trauerfantes, cúme les brebis; les autres au milieu, commeles fefches, \& aragnees: ) ainfi le ciel, en quelque endroit qu'il foit, eft toufiours en haut; \& la terre ny plus ny moins, en quelque endroit qu'elle foit, demeure toufiours en bas. Parquoy eftant ainfi que noftre imagination eft fondee fur le téps \& le lieu, lefquels elle ne peut pas mefme comprendre $\&$ conceuoir vniuerfellement, mais feulement en particulier; il f'enfuit que quand on la veut efleuer à la confideration des chofes qui excedent, \& furpaffent le temps \& lieu qui luy font cogneuz, auffi toft elle defchet, \& ne peut bonnement fubfifter, fi la raifon nela fouftient, \& fouffeue, \& elle ne peut bonnement fe tenir en pied. De mefme nous voyons que fur le difcours de la creation du monde noftre imagination extrauague pour chercher vn temps auant la creation d'iceluy , \& pour fe baftir le monde elle remarque vnlieu : mais elle ne paffe pas outre a confiderer que le monde pouuoit eftre fait d'v ne autre façon; cóme ainfi foit neantmoins que la raifon nous appréd quil n'y a point eu temps auant qu'il y ayr eu mouuemét, duquel le temps eft la mefure, \& qu'il n'y a eu aucun lieu auparauant l'vniuers, qui comprend $\&$ contient en foy tout lieu. En quoy l'excellent Philofophe AriItote fatisfair clairement, \& en peude paroles, 


\section{Hiftoire naturelle}

d̀ l'argument qu' on fait contre le lieu de la terre, Ariff. s. de f'aydant de noftre mefme vfage d'imaginer, lors celo cap. 3. qu'il dit, \& auec verité: Qu'au monde ce mefme liers de la terre est au milievo o en bas, or que tant plus vne chofe ef au miliew, tant plus eft-elle en bas. Laquelle refponfe ayant efté alleguee, \& mife en auant par Ladtance Firmian, luy-mefmeneantmoins paffe fans la debattre $\&$ confuter d'aucune raifon, fe paffant de dire quil ne fy peut arrefter, pour traitter \& aduancer d'autres chofes.

\section{De la caufe pourquoy fainct Auguftin a nié les Antipodes.}

\section{Chapitre V.III.}

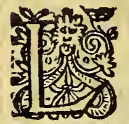

A raifon qui a meu fainct Auguftin de nier les Antipodes, a efté bien autre que celle prealleguee, comme eftant d'vn entendement plus fublime; pour. ce que la raifon quaauons déduite cydeuant (qui eft que les Antipodes chemineroient au reuers). eft deftruite par le mefme fainct Docteur en fon liure des predications, par ces paroles: Les an-

Augusf. li. categoriarum cap. 10. in cienstiennent que la terre de tous coste $Z$ eft en bas, $\sigma$ le ciel par deffus: pour raifon dequoy les Antipodes quisls di. x. tomo. Sent cheminer au contraire de nous, ont de mefme nous le ceel au deffus de leurs teftes. Puis donc que fainct Auguttin a recogneu cela ainfi fi v ray - femblable, \& conforme a bonne Philofophie; quelle fera la raifon, dirons-nòus, pour laquelle vn perfonnage fidocte $\&$ fi fuffilant que luy, aye efté pouffé d'enfuiure l'opinion contraire? Pour certain qu'il en a tiré le motif \& la caufe, des en: 
erailles de la facree Theologie, felon laquelle leslettres diuines nous enfeignent que tousles hoinmes du monde defcendent d'vn premier homme, qui fut Adam. Et de dire que les hommes cuffent peu paffer au nouueau monde tra. uerfans le grand Occean, cela fembleroit incroyable, \& vn pur menfonge. Et à la verité fí le fuccez \& experience de ce que nous auons veu en nos fiecles, ne nous euft efclaircy fur ce point, l'on euft tenu iufques à maintenant ceAte raifon pour bonne. Mais encores que nous fçachions que cefte raifon n'eft pertinente, ny veritable, ce neantmoins voulons-nous bien y donner refponfe, en declarant de quelle façon, \& par quel chemin le premier lignage des hom. mes peut paffer icy; comment, \& par quel endroit ils vindrent pour peupler, \& habiter ces Indes. Or parce que parcy apres nous traicterons ce fubject fort fuccinctement, il fera bon d'entendre pour le prefent ce que ce grand Docteur fainct Auguftin difpute fur cefte matiere, aux liures dela Cité de Dieu, difant en cester- Li.r6.ca.9. mes: Ce nest point chofe que l'on doine croire, ce que quelques vons afferment, qu'lly a des Antipodes, c'est is dire, des hommes qui habitcnt del'autre partie de la terre, en la region defquels le foleil fe leue lors $\sigma$ ars temps quid Se couche en la noftre, $\mathcal{O}$ que leurs pas fort au rebours, $\sigma$ au contraire des nostres, puis qu'ils ne l'afferment point par reuelation certaine quils en ayent, mars feulement par wn difcours de Philofopbie quills font, par lequel ils coneluent que la terre eftant au malieu du monde, de touses parts enuironnee, of counerte efgalement du siel, necesfairement dois estre le plus bas lien celuy qui 


\section{Hiftoire naturelle}

le plus eft an milleu du monde. Puis apres il contiane ens ces termes, la farnite Efcriture n'erre, ny fe trompe en aucune maniere, la veritéde laquelle eft fibues approunee ess ce quielle propofe des chofes qui font paffees, pour autant que ce quelle a propheilié deuoir aduenir, eft de point en point arrué, commzé nous le voyons. Et eff chofe hors de toute apparence, de dire que les bommes ayent peu paffer dece continent vicy, en lautre noureau monde, $\mathcal{O}$ trauer fer cefe immenfité de la mer Occeane, puis que d' ailleurs al fe troure impo ßible que les hommes ayent paffée en ces partieslà, eft ant chofe certaine que touss homomes defcendent de ce premier homme. En quoy l'on recognoift que toutc la difficulté que fainet Auguftin y troume, n’a point efté autre que lincomparable grandeir
- sreg. Naz de ce large Occean. Sainct Gregoire de Nazianepiff. 27. ad zepe a eu la mefme opinion, affeurant (comme I'oftumianü. chofe fans doute) que paff'́l le deftroit de Gibal. tar, il cft impoffible de nauiger plus outre; \& fur ce fujet efcrit en vne fienne epiftre: le m'accorde bien arsec le dire de Pindare, que dit que paffé Cadit. la mer eft innanigable aux hommes. Et luy-mefme en l'oraifon funebre qu'il fift pour fainct Bafile dir: Qu'iln'a efté permis à aucun nanigeant la mer, de paffer le defroit de Gibaltar. Et eft veritable que ce paffage de Pindare, où il dit : Quil eft deffendu aux fages $\mathcal{G}$ aux folsde f̧auoir ce quieft plus outre quele defiroit de Gibaltar: a efté prins \& receu pour prouerbe. Auffi voyons-nous par l'origine de ce prouerbe, combien les anciens fe font fichez $\&$. arreftez obftinément fur cefte opinion, comme auffi par les liures des Hiftoriographes \& Cof mographes anciens, que la fin \&borne de la terre a efté mife en Cadiz d'ESpagne, oùilsfa- 


\section{des Findes. Liure 1 .}

Climites de l'Empire Romain, là ils dépeignenê. les limites du monde. Et non feulement les lettres prophanes en parlết de cefte façú, mais auffi les fainetes Efcritures pour s'accōmoder à no. Itre lang age, difent que, L'edict d' Augufte Cefar fui publié, afin que tout le möde fut enregifté: \& d'Alexandre le Grand, quilleftendit fon Empire ius ques aux fins $\sigma$ limites de la terre. Et en autre endroit ils difene que $l$ Ewangile a fructifié o creu en tout le monde onsserfel. Car la faincte Efcriture par vn Atyle qui lus eftcommun, appelle tout le monde ce qui eft la plus grảde partie d'iceluy, \& qui iufqu'auiourd'huy a efté defcouuert \& cogneu. Et ont ignoré les anciens, quela mer del'Inde Orientale,ny cefte autre de l'Occidentale, peuft eftre nauigee; en quoy ils fe font generalemét accordez. Pour raifon dequoy Pline efcrit comme chofe certaine, queles mers qui font entre deux terres, nous oftét l'entiere moytié de la terrehabitable:pource (dit-il) que dicy nous ne pouvons aller-là,ny de là non plus venir icy. Et finalement, Tulle, Macrobe, Pomponie Mele, \& les anciens efuains ont cefte mefme opinion.

De l'opinion d' Ariftote touchät le nousueau monsde, of ce quil l a deceu pour luy faire nier.

$$
\text { Cha PITRE IX. }
$$

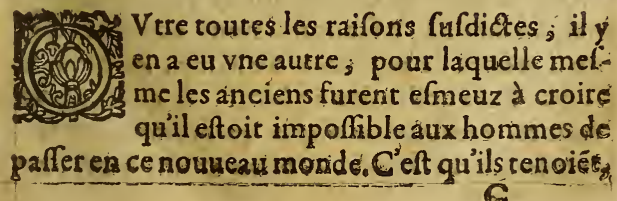

$$
\text { G. }
$$




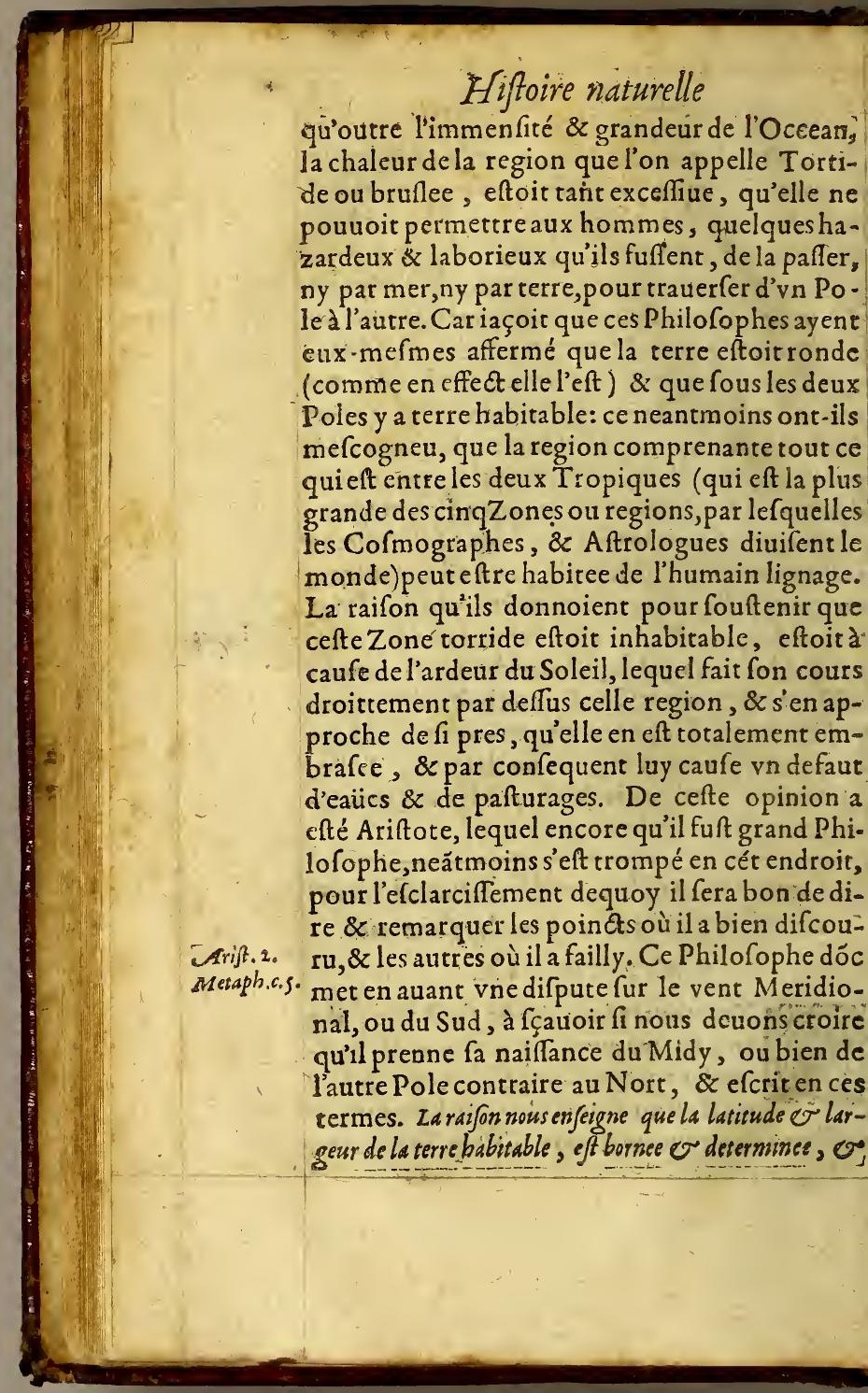




\section{des Indes. Liure. I.}

jusantmoins toute cefte terre babitable ne peut eftre consointe $\sigma$ contrnuee l' vne à l'autre; pour autant que la region du mileew eft tróp intemperee. Car il efs certain que es falongitude, qui eft d'Orrent an Ponent, ln'y a point de trop grand frood, ny d'exceßine chaleur, mais il eft en fa lattinde $\sigma$ haureur, qui est d’ vn Pole à la ligne EquinsoEliale. Et par ainfiz pourroit-on cheminer $\mathcal{O}^{-}$trasserfer touste la terre en fa longitude, ji la grandeur de la'mer, tanquelle conioint les terres enfemblément, ne donnoit empef $\mathrm{f}$ chement. Iufques icy il n'y a rien a contredire en ce que dit Ariftote, $\&$ a fort bonne raifon de dire que la terre par falongitude, qui eft d'Orient: au Ponent, court plus vniment, \& eft toufiours plus commode à la vie \& habitation humaine, que non pas par falatitude, qui eft du Nort $2 u$ Midy. Ce qui eft veritable, non feulement pour cefte raifon fufdite d'Ariftote, à fçauoir pource qu'ily a vne mefme \& toufiours femblable téperance du Ciel, de lOrient au Porient: attendu qu'elle eft efgalement diftante, \& du froid feptentrional, \& de la chaleur du Midy: Mais auffi pour vne autre raifon, qui eft qu'en allát \& cheminant toufiours en longitude, l'on trouue $8 z$ apperçoit-on les iours \& les nuiats fuccedans les vns aux autres alternatiuement. Cequi ne peut eftre en allant par la latitude; d'autant que par neceflité il feroit befoin d'arriuer iufques Gefte regió polacque, en laquelle il y a nuict continuelle de fix mois, chofe grandement incommode pour la vie humaine. Le Philofophe paffe plus outre, reprenant les Geographes, qui defçriuoient la terre en fon temps, \& dit ainfí L'on peus bien cognoiffre ce que iay dis, par les chemons. 


\section{Hiftoire naturelle}

que l'on peut faire par terre, $O$ par les narigations maritimes. Car il y a grande difference entre la longitude, o la latitude, d'autant que l'eppace o $\mathcal{O}$ interualle qui eft depuis les colonnes d' Hercules, on deftroit de Gibaliar, iu fques il'Inde Orientale, excede de la proportion de plus de cing à crois, celle qui eft depuis l'Etbiopic, iufques au lac Meosis o derniers confins de scytbie: ce qui eft approusué par le compse des iournees des chemins, $\mathcal{O}$ de la nauigation que nous 〔̧̧auons à pre Jent par la me fme experience. D'autre part, nous awons aufsi cognoiffance de la terre babirable, irsques aux parties d'icelle, qui ont inhabitables. Et certes en ce point l'on doibt pardonner à Ariftote, puis que de fon temps lon n'auoit point encore defcouuert plus outre que la premiere Ethiopie appellee exterieure, qui eft ioignăr l'Arabie, \& l'A frique; \& que l'autre Ethiopie interieure a efté totalement incogneuë de fon temps, merme toute cefte grande terre que nous appellons auiourd'huy la terre de Prete-Ian. Comme aufi n'ont point eu cognoiftance du refte de la terte qui git foubs l'Equinoxe, \& $z$ va courant iufques à outrepaffer le Tropique de Capricorne, pour s'arrefter au Cap de bonne efperance, fi bien cogneu \& renommé par la nauigation des Portugais; que fi l'on mefure la terre depuis ce Cap iufques a la Scythie \& Tartarie, il n'y a point de doubte quecefte elpace \& latitude fe trounera auffi grande comme l'efpace \& la longitude qui eft depuis Gibaltar iuf́ques à l'Inde Oriensale. C'eft chofe certaine, que les anciens n'ont point cogneu les commencemens $\&$ fources $d u$ Nil, ny la fin de l'Ethiopie; \& pour cela Lucain reprend la curiofité de Iules Cefar, de vouloir 


\section{des Indes. Liure I.}

rechercher \& enquerir la fource du Nil, difane par ces vers.

Que te fert il Romain, de prendre tant de peine

A rechercher du Nill les fources $\sigma$ fontaines?

Lucan.10. Phayfal.

Et le mefme Poëte parlant auecle Nil, dit:

Pris que ta prime fource eft ficachee encor, -

Que qui tur fois, ô Nil, tous l'vnicers ignore.

Mais par la fainete Efcriture mefme l'on peut entendre que cefte terre eft habitable. Car fi elle ne l'eftoit, le Prophete Sophonias ne diroit, parlant de ces nations appellees à l'Euangile:Les fils de mes dasperyez(ainfi appelle-illes Apoftres $m^{\prime}$ apporteront des prefens de plus outre que les riuages d'Ethropse. Neantmoins, comme il a efté dit, il eft raifonnable de pardonner au Philofophe d'auoir creu les hiforiens, \& Cofmographes de fon temps. Pourfuiuons donc maintenant, \& examinons ce qui s'enfuit du mefme Arifto- Soph.s.3. re. Vne partie du monde (dil-il) qui eft la Jeptentrionale, fotruee aw Nort outre la Zone temperee, eft inbabitable pour l'exce 7 de froidure: l'autre partie, qui eft au mi$d y$, de mefme ne peut estre habitee outre le Tropique, pour l'exceßsiue chalewr qui y est. Mais les parties du monde font $\sigma$ gifent outre l'Inde, d'vn cofté, $\sigma$ les coulomnes d'Hercules del'autre, pour certain ne fe perurent ioindre. o continuer $l$ ' vne a $l$ autre: de telle façon que toute la terre habitable fe tieane en vin feul continent à caufe de la mer qui les fepare. En ce dernier poinct il dit la verité, puisil pourfuittouchant l'autre partie du mon. de, \&e dit: il eft receffaire que la terre aye mefme prose portion anec fon pole Anearctique, que cefte nostre partise

C iij 


\section{Hiftoire naturelle}

Babitable a auec le fren, qui ejt le Nort, or n'y a point de doute qu'en l'autre monde toutes cho fes doiuent eftre difpofees comme en cestury-cy, pecialemêt en la naifance $\sigma$ or a dres des vents. Et apres auoir mis en auant d'aurres raifons hors de propos, conclud le mefme Ariitote, difant: Nous debuons donc confeffer par neceßité, que le Meridional eft le mefme vent quifouffle, or procede de cefte regiö embrafee de chaleur:laquelle region pour estre fort proche du soleil, defaut $\mathcal{O}$ manque d'eaux, $\mathcal{O}$. de pasturages. Cecy eft l'opinion d'Ariftote, \& à la verité , l'humaine coniecture à grand peine a peu palfer plus ourre. D'où foumentesfois ie viens à confiderer, (par vne contemplation

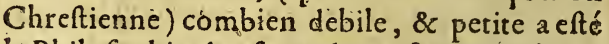
la Philofophie des fages de ce fiecle, en la recherche des chofes diuines, puifque mefme aux chofes humaines, où ils femblent fi bien verrez, ils ont tnaintefois erré. Ariftote eft d'opinió; \& afferme que la terre habitable au Pole Anrarctique en longitude elt trel-grande, qui eft d'Orient au Ponent, \& qu'en latitude du.Pole Antarctique à la ligne equinoctiale elle eft tres. petite. Ce quieft fi contraire à la verité, que route l'habitation prefque qui elt en ce cofté du Pole Antarctique, a fa fituation en la latitu. de, (i'entens du Pole à la ligne, ) \& èn la longi tude d'Orient au Ponent eit tant petite, que la latipude l'excede trois parts, voire dauantage. L'autre opinion eft, qu'il afferme que la region du milieu eft du tout inhabitable, pour eftre fous la Zone Torride.embrafee de l'exceffiue chaleur que luy caufe la prochaineté du Soleil, \& par cefte raifon n'a point d'eaux. 


\section{des Fndes. Liure I.}

ny de pafturages, Ce qui eft auffi tout au contraire, d'autant que la plus grande part de ce noulueau monde eft fituee entre les deux Tropiques fous la mefine Zone Torride : 2 neantmoins fe trơue fort peuplee, \& habitee d'hommes, \& d'autrés fortes d'animaux, eftant la region la plus abondante de tout l'vniuers en eaiies \& pafturages: \& qui plus eft, fort temperee en la plus grande partie. Ce que la volonté de Dieu a difpofé de telle façon, afin de monftrer comme mefme aux chofes naturelles il a renuerfé \& confondu la fageffe de ce fiecle. En refolution il faut croire que la Zone Torride eft fort bien peuplee \& habitce, quoy queles anciês l'ayent tenu pour chofe impoffible. Mais l'autre Zone ou region, qui eft entre la Torri. de \& la Zone du Pole Antarctique; encore que en fon affiete elle foit fort commode pour la vie humaine, ce neantmoins eft peu peuplee \& habitee, puis que l'on ne cognoift autre ha. bitation en icelle, que le Royaume de Chillé, \&. vne petire portion ioignant le Cap de bonne efperance. Le refte eft occupé de la mer Occeane, bien que plufieurs foient d'opinion ( $l_{2}-$ quelle ie veux bien enfuiure de ma part) qu'il y a beaucoup dauantage de terre, non encore defcouuerte, laquelle doit eftre rerre ferme à loppofite du Royaume de Chillé, qui va courant plus ourre, quele cercle ou Tropique de Capricorne. Que sil y en a, fans doute ce doir eftre vne terre d'excellếte téperature, pour eftre au milieu des deux extremitez, \& fituee en mef-i

me clinat, que la meilleure region de l'Europe. 


\section{Hfiftoire naturelle}

Et pour cefte confideration eft fort bonne la coniecture d'Ariftote: mais parlant de ce qui eft auiourd'huy defcouuert, ce qui eft en cefte $\mathrm{Zo}$ ne eft peu de chole, en comparaifon de la gran. de efpace de terre habițee eftenduë faus la Zonẹ Torride.

\section{2ue Pline o les anciens ant ex la me fme opinion qu' Ariftote.}

\section{Chapitre X.}

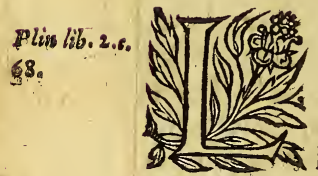

'Opinion fufdicte d'A riftote a efté fuiuie \& renuë par Pline, qui dit ainfi: La temperature de la region du milieu du monde, par où \& à mendroit de laquelle continuellement chemine le Soleil, eft embrafee \& bruflee comme d'vn feu prochain, ioignát icelle region du milieu. Il y en a deux autres aux deux coltez, qui pour eftre entre l'ardeur de cefte Torride, \& lo froid cruel des deuxautres extremes, font fort remperees, \&ne peuuent auoir communication les vnes auec les autres, à caufe de l'ardeur exceffiue du Ciel. Qui a efćla mefme opinion des anciens, general ement d'efcrite par le Poëte en ces vers.

Tout le Ciel eft circuit de cing Zones dont l' vne Que Phebus ard touf fours d' une brai Te importure, Rend la terre audefous touste ronge d' ardeur. Et le mefme Poëre en autre lieu, oyez $\sqrt{2}$ quelque gent habite en celle part 


\section{des Indes. Liure I.}

31

Qui fors la large fone a fon quartier à part, Que Phabres ars milieu des quatre autres allume.

Er vn autre Poëte dit plus clairement:

ll y a fur la terre autant de regions,

Comme au ciel quion diuife en ces cing portions,

Dont celle diu miliess parl'ardeur excitee

Deschauds rais du foletl, eft toute inhabitee.

Les anciens ont fondé leur opinion communę fur vne raifon quileur a femblé cerraine, \& in expugnable: car voyans que tant plus vneregion approchoit du Midy, tant plus elle eftoit chaude (laquelle preuue eft fi certaine en ces regions, que pour cefte mefme raifon, en la Prouince d'Italie la Poüille eft plus chaude que $\mathrm{l}_{2}$ Tofcane; \& en Efpagne, l'Andalufie plus que Ia Bifcaye; chofe fi apparente, que iaçoit qưil n'y ait point de difference entre $P$ 'vne $\&$ l'autre de plus de huict degrez, \& encores moins, on void que l'vne eft fort chaude, \& l'autre au contraire, bien froide. De là ils inferoient que la re gion fi proche du Midy, ayant le foleil droict pourZenith, neceffairement deuoit eftre continuellement embrafee de chaleur. Ils voyoient dauantge, que toutes les diuerfitez des faifons de l'annee, du Printemps, de l'Efté, dél'Autóne, \& de l'Hy uer, eftoient caufees de l'approchemét \& efloignemét du foleil. Voyans auffi que combien quils fuffent fort efloignez du Tropique, par où chemine le foleil en Efté, ce neantmoins lors qu'il fapprochoit d'eux en la mefine faifon, ils fentoient de terribles chaleurs, 8 de là ils itageoient que fils euffent eu le foleil fi proche d'sux, qu'il cheminalt au deffus de leurs teftes, 


\section{Hiftuire naturelle}

\& rout le long de la nuee la chaleur feroit tant infupportable, que fans doute elle confumeroit \& embraferoir les hómmes par fon excés. C'a efté la mefme rairon qui a efmeu les anciens à croire que la region du milieu n'eftoit point habitable, \& pour cela l'appellerent-ils la Zone bruflante. Er à la verité fi l'expérience oculaire que nous en auons, ne nous euft efclarcis fur ce point, nous dirions aujourd'huy que cefte rai. fon eftoir fort peremptoire, \& Mathematicienne; d'où nous pouuons voir combien foible eft noftre entendement, pour comprendre feulement ces chofes naturelles. Mais ores que nous pouuons dire quil eft efcheu au grand heur $\&$ felicité de noftre fiecle, d'auoir la cognoiffance de ces deux grandes merueilles, à f̧̧auoir que l'on peut fort facilement nauiger la grande meE Occeané, \& que fous la Zone rorride les hommesiouyffent d'vn ciel fort temperć (chofe que les anciens n'ont peu iamais croire.) De la derniere de ces deux merueilles, touchant la qualité \& habitation dela Zone Torride, nous en traitterons auecl'ayde de Dieu fort amplement au liure enfuiuant. Et pource me femble conuenable de difcourir en ce liure de l'autse, qui eft de la maniere de nauiger l'Occean, d'autant que cela nous importe beaucoup pour le fuject de cét ounure. Mais auant que de venir à ce poinct, il fera bon de dire ce que les anciens ont renu de ces nouueaux hommes, que nous appel lons Indiens. 


\section{Hiftoire naturelle}

un temps felos le cours de ce monde, f̧̧auoir fi d aduexture il nous veut faire entendre qu' $u l y$ ayt vn autre frecle, qui ne foit, ny dépende point de ce monde, mais d'autres mondes, defquels efcrit Clement en fon epiftre, l'occean, o les mondes qui font par dela l'occean. Ce font les termes de fainct Hierofme. Mais à la verité ie ne peux trouuer quelle epiftre foit celle de fainct Clement que cite fainct Hicrofme; neantmoins fans doute ie croy que fainct Clement l'a efcrite, puis que fainct Hierofme l'a mis en auant. Et auec raifon dit fainct Clement, que par delà la mer Occeane il y a vn autre monde, voire plufieurs mondes, comme c'eft la verité, puis qu'il y a fi grande diftance d'vn nouueau monde à lautre nouueau monde ( $j$ 'entends dire du Peru $\&$ des Indes Occidentales, à la Chine \& Indes Orien-

Plins.lib.2. sap. 67 . tales.) Dauantage, Pline qui a efte fi diligent rechercheur des choles eftranges \& admirables, rapporte en fon hiltoire naturelle, que Hannon Capitaine Carthaginois nauigea par l'Occean, depuis le deftroit de Gibaltar, coftoyant toufiours la terre, iufques aux confins d'Arabic, \& qu'il laiffa par efcrit cefte frenne nauigation. Que fil eft ainfi comme Pline l'efcrit, il ' 'enfuit que Hannon nauigea autant, comme nauigent aujourd'huy les Portugais, trauerfans deux fois par deflous l'Equinoxe, qui elt vne chofe efpouuentable. Et qui plus eft, le mefme Pline rapporte de Corneille Nepueu autheur fort graue, \& dit que le mefme chemin a efté nauigé par vn autre homme, appellé Eudaxius, rourefois par chemins contraires; d'autant que cét Eudaxius fuiuant le Roy des Latyres, Cortit par la mes 


\section{des Fndes. Liure I.}

couge dans l'Occean, \& en tournoyant paruint iufqu'au deftroit de Gibaltar; ce que le mefme Corneille Nepueu afferme eftre aduenu de fon remps. Comme aufi d'autres autheurs graues efcriuent qu'vn nauire de Carthaginois pouflé par la force des vents dans la mer Occeane, arriua en vne terre qui iufques à ce tem ps n'auoit efté cogneu, \& qu'eftant de retour d Carthage, donna vn grand defir \& enuie aux Carthaginois de defcouurir, \& peupler cefte terre; ce quele Senat voyant, par vn rigoureux decret deffendit telle natigation, craignant quauec le defir de nouuelles rerres l'on delaifart à aymer fon pays. De tout cecy on peut tirer que les anciens ont eu quel que cognoiffance du nouteau monde, encores que parlant de noftre Amerique, \&: de toute cefte Inde Occidentale, à peine en troulue-t'on chofe certaine és liures des Efcriuains anciens. Mais de l'Inde Orientale, ie dis qu'il y en a affez ample mention, non feulemét de celle de par delà, mais auffi de celle de par de. çà, qui anciennement eftoit la plus efloignee, pource qu'on y alloit par contraire chemin, que celuy qu’on fait aujourd'huy. Pourquoy n'eft if pas aylé de trouuer aux liures anciens Malaca, qu'ils appelloient le doré Cherfonefe; le Cap de Comorni, qui f'appelloit le Promótoire de Cori; \& la grande \& renommee Ifle de Sumatre. tant celebree par l'ancien nom de Taprobane? Que dirons- nous des deux Ethiopies, des Brachmanes, \& dela grande terre des Chinois? Qui doute qu'aux liures des anciens il n'en foit faite mention plufieurs fois ? Mais des Indes Occi- 


\section{Hifoire naturelle}

plin. li, 6 . dentales nous ne trouuons point dedaris Pline $\cos 2$. qu'en cefte nauigation l'on paffaft les Ines $\mathrm{Ca}$ naries, qu'il appelle Fortunees, la principale defquelles il dit auoir efté nommee Canarie; pour la multitude des chiens qui eftoient en icelle. Mais à peineil y a aucune apparence aux liures anciens de la nauigation que l'on fait aujourd'huy plus outre que les Canaries, par le golphe, quauec fort bonne raifon ils appelloiét grand. Ce neantmoins beaucoup ont opinion que Seneque le Tragique a prophetifé de ces Indes Occidentales, parce que nous lifons en $f_{2}$ tragedie de Medee, en vers Anapeftiques, quị reduits én vers François, difent ainfi:

Sen, in Meo dea act. 2 . in fire.
- Il viendra for le dernier aage

in fiecle nounean bien-tewrenx,

oit noftre accedn pacienx

Eftendra plus loing fon riuges

vone grand" terre fe verra

Nunigeant sefte mer profonde, Et lors vn autre noureau monde Aux bumains fe defcounrira.

La Tullee par tout renommee Pour vn biut dis monde egloigné, Tantoft apres ce poind gagne's sera pour vorfine contree.

Cecy raconte Seneque en cesvers, \& he pous uons bonnement nier que la prenant à la lettre, fa prediction ne foit veritable: car fi l'on conte les longues annees quil dit, à commencer dés le temps du Tragique, lon trouuera plus de mil \& quatre cents ans palfez, \& fi c'eft dés le temps de Medee, il y en aura plus de deux mal. Ce que 


\section{des Fndes. Liure 1 .}

nous voyons aujourd'huy à veüe d'ceil telle. ment accomply, veu qu'il n'y a point de doure quel'on n'aye trouué le paffage de l'Occean in long temps caché, \& que l'on a defcouaert vne grandeterre \& nouueaumonde habitee, plus grande que tout ce continent de l'Europe, \& de PAfe. Mais ce que l'on peut en cela raifonnablement difputer, eft, à fçauoir fi Seneque a dit cela par diuination, ou fi ç'a efté poëtiquement, \& a la volee. Et pour en dire mon opinion, ie croy qu'ill'a prognoftiqué auecla façon de deuiner qu'ont les hommes fages $\&$ aduilez; attendu qu'en fon temps on entreprenoit delia de nouuelles nauigations \& voyages par mer. Il co. gnoiffoit bien auff comme Philofophe, qu'il y auoit vne autre terre, contraire \& oppofite a nous, qui eftoir celle qu'ils appellent Antichthon. Et par ce fondement il a peu confiderer que la hardieffe \& induftrie des hommes en fin pourroit atteindre iufques là que de trauerfer la mer Occeane, \& l'ayant trauerfee, pourroient defcouurir de nouuelles terres, \& vn aurre monde; attendu que du temps de Sen eque l'on ąuoit cognoiffance du fuccés de ce naufrage que Pline raconte, par lequel on paffa le grand OCcean. Ce qui appêrt auoir efté le motif de la prophetie de Seneque, comme ille donneà entendre parles vers cy deuant recitez; apres lefquels ayant acheué d'efcrire le foucy \& la vie. peu malicieure des anciens, il fuit en cefte façon :

Luiourd'buy c'eft on autretemps:

Car ls mer contente, ou forcee, .2 


\section{Hiftoire naturelle}

se void del hardy trauerfee, qui n'y prend que du paffetempis.

Et plusbas il dit ainfi :

Tout batteau fans craindre nds froge

se iette or' Jur la baute mer,

Et ia le boiitlant paffager

Tient pour bref un filong voydge:

Il rieft plas rien à defcousuir,

Ny licux qui foient encor à prendre:

Celuy-là qui fe veut deffendre,

D'vn nouueau mur fe doit courrit.

Tout eft renuersé par le monde.

Rien n'eft en fon lieu demeuré,

Rien fecret, ny riend' affeuré

N'y a parmy la terre ronde.

on void que le chaud Indien

Boitl'Araxe en froideur extrefme;

Et l'Elbe, o le Rhin tout de mejme,

Lauent le peuple Ferfien.

Et de céte fi grande hardieffe des hommes Seneque a conjecturé ce qu'il a efcrit, comme le dernier point qui doit arriuer, difant: Il viendra fust le dernier âge, $\mathcal{\sigma} c$. ainfi qu'il a efté mis cy deffus.

De lopinion que Platon a eïe des Indes occidentales.

Chapitre XI?

Tr fi quelqu'vn a traicté plus particuz (๕9) lierement de cefte Inde Occidentale, ton, qui en fon Timee dit ainfí : En ce temps lon ne porroit namger ce Golphe (il entend de la mer Atlantique 


\section{des Indes. Liure 1 .}

tiơue, qui eft l'Occean qui fe rencontre au fortit du deftroit de Gibaltar) pource que le paffage eftort clos à la bouche des colomnes d' Herculés (qui efit le mefme deftroit de Gibaltar.) Et cefte ifle eftout ioincte ers re temps à la bousche fufdite, $\mathcal{O}$ eftoit de telle grandeur, qu' elle excedout toute l' $\Omega$ fie e $l$ ' Afrique en femblement: oralors al y ariout vn paffage pour aller de ces Ifles à d"aum tres, $\mathcal{O}$ de ces autres 1 fle son alloit d la terre ferme qui eftoit proche; enuironnee de la vraye mer. Cela elt raconté par Critias en Platon. Et ceux qui fe perfuadent que cefte narration de Platon eft vne vraye hiftoire, déduite \& contenuë fous ces termes, difent que cefte grande Ine appellee Arlantique, laquelle excedoit en grädeur l'Afrique \& l'A fie tout enfemble, occupoit alors la plus grande part de la mer Occeane, appellee Atlantique, que les Efpagnols nauigent aujourd'huy, \& qué les autres Ines qu'il difoit eftre proches de cefte grande, font celles que maintenant nous appellons Inles de Barlouente, à fçauoir Cube, ETpagnolle, fainct Iean du Port-riche, Iamaïque, \& autres thles de cefte contre ; mefme que la terre ferme dont il fait mention, eft celle qu'aujourd'huy nous appellons terre ferme, a fçauoir le Peru \& l'Amerique, \& que ceite vraye mer qu'il dit, eft ioignante icelle terre ferme, fçauoir la mer duSud, qu'il appelle vraye mer, pource qu'en comparaifon de fa grandeur, les autres mers Mediterranees, voire la mefme Atlantique, font comme petites mers: Bar cela à la ve rité ils donnent vne interpretation fort inge'nieufe \& artificieufe à ces propos de Platort: Mais ff cefte interpretation doit eltre terue 


\section{Fiftoire naturelle}

pour veritabe, ou non, j'ay deliberé l'efclaircir' en autre lieu.

2 2uequelques vns ont eu opinion qu' aux lieux

de l'E/criture faincte, oì il ef fait mention d'opbir, on le doit entendre de noftre Peru.

\section{ChapItre XIII.}

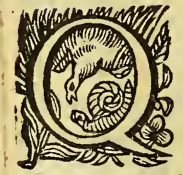

VEL QVES-VNS ont cefte opinion quil eft fait mention en la faincte Efcriture de cefte Inde Oc. cidentale, prenans la region du Peru pour cét Ophir tant celebré en icelle. Robert Eftienne, ou pour mieux dire, François Vatable, homme fort verfé en la langue Hebraïque (commeiay ouy raconter d no. Itre Precepteur qui fut fon difciple) dit auxanIn 3.1 . Reg. notations fur le neufiefme chapitre du troifiefcap. 9 . me liure des Roys, que l'Inle Efpagnolle que trouua Chriftophle Colomb, eftoit celle d'O. phir, dont Salomon faifoit apporter quatre cents vingt, ou quatre cents cinquante talents d'ortres. fin \& tres-pur; pource que l'or de $\mathrm{Ci}$ In Appar. bao queles noftres apportent de l'Efpagnolle, Biblia Reg. eft de telle façon \& qualité. Et fe trouuent enimphaleg 0.9 cores plufieurs autres qui afferment que ceftuy noftre Peru eft Ophir, déduifans, \& tirans va nom del'autre, lefquels croyent que dés lors 2. Paral. 9. que le liure de Paralipomenon fut efcrit, l'on 30 Reg. 10. l'appelloit Peru (comme aujourd'huy ils fe fondent) en ce que la fainote Efcriture rapports 


\section{des Indes. Liure I.}

que l'on apportoit d'Ophir de l'or trefpur, \&t des pierres forr precieufes, auec du bois qui eftoit fort beau \& fort rare : lefquelles chores font abondantes au peru, comme ils difent. Mais (à mon opinion) c'eft chofe fort efloignée de verité, quele Perufoit Ophir tant celebré par leslettres facrées. Car jaçoir qu'en ce Peru ily ait affez grande abondance d'or, ce n'eft pas toutesfois de telle façon, que l'on le doiue efgaler à la renommee des richeffes qu'a eüe ancienne- 2. $P_{\text {ar }}$ at 3 . ment l'Inde Orientale. le ne trouue point que 4. Reg. $2 \hat{z}^{\prime}$ en ce Peru il y ayt des pierres fi precieufes, ny 3. Reg. $\xi_{-}$ debois fi exquis, quel'on n'en ayt iamais veus de femblables en Hierufalem. Car encores qu'il y ayt des efmeraudes exquifes, \& quelques arbres d'vn bois dur \& aromatique, ce neantmoins ie n'y trouue point chofe digne de telle loïange que la faincte efcriture donne aे Ophir. Mefme il me femble qu'il n'eft pas vray-femblable que Salomon euft laiffé l'Inde Oriêtale tresriche \& opulente, pour enuoyer fes flottes de trauires à cefte derniere terre. Que fi elles y eftoient venuës tant de fois (ainfi comme il eft efcrit) certainement nous trouucrions plus de refte, \& de tefmoignage d'icelles, que nous n'auons pas. Dauantage, l'etymologie du nom d'Ophir, \& le changement, ou reduction d'iceluy au nom du Peru, me femble chofe peu cornfiderable, eftant affeuré que le nom du. Perts n'eft pas fort ancien, ny commun à toute cefte contree. L'on a eu de couftume ordinairement en cesdefcounertures du nouueau monde, de doriner nom aux terres \& ports de mer, felon 


\section{Hiffoire naturelle}

loccafion qui fe prefentoit alors de l'arriuce, $\&$ croy que le nom du Peru a efté ainfi trouué, \& mis en vfage : car nous tenons icy que le nom a efté donné à toute cefte terre du Peru, à caúe d’vn fleuue ainfi appellé par les naturels du paîs, auquel les Efpagnols arriuerent quand ils firent la premiere defcounerté. Et de là nous difons que les mefmes Indiens naturels du Peru ignorent, \& ne fe feruent aucunement de ce nom \& appellation, pour fignifier leur terre. Il femble dauantage, que les mefmes autheurs veulent dire que Sepher, denommee en la faincte Efcriture, eft ce qu'aujourd'huy on appelle les Andes, qui font des montagnes tres-hautes du Peru. Et cefte reffembláce des mots \& appellations n'eft.

Zectan filins Heber.Gen. Io.

Iecjan filius Abrahe ext Cetura.Gen. 25: pas chofe fuffifante: car fi cela auoit lieu, nous pourrions auff bien dire que Iectan eft Iecfan, mentionné en la faincte Efcriture. Auffi nous ne pouuons dire que les noms de. Tite \& Paul, defquels ont vfé les Rois Ingwas de ce Peru, foient prouenus des Romains, ou Chreftiens; d'autant que c'eft vn argument trop foible, \& trop leger, pour tirer conclufion de chofes ff grandes. L'on void clairement que c'eft chofe contraire à l'intention de l'Efcriture faincte, ce que quelques-vns ont efcrit que Tharfis, \& Ophir n'eftoient en vne mefme route \& Prouince, en conferant le chapitre vingt-deuxiefme du quatriefine liure des Rois, auec le chapitre vingtiefme dufecond liure du Paralipomenon; d'autant que ce qui eft dit au liure des $\mathrm{R}$ ois que Iofaphat dreffa vne flotte de nauires en Afiongaber, pour aller querir de l'or à Ophir, 


\section{des Indes. Liure I.}

eft auffi referé au Paralipomenon, que cefte mefme flotte fut dreffee pour aller à Tharfis。 D'où l'on peut facilement iuger qu'en ces liures fufdits, quand l'Efcriture parle de Tharfis , \& Ophir, elle entend vne mefme chofe. Quelqu'vn me pourroit demander fur cecy, quelle region ou Prouince eftoit cét Ophir, où alloit de Salomon, auec les mariniers de Hyram Roy de Tyr \& de Sidon, pour rapporter de l'or, \& où pretendant aller la flotte du Roy Iofaphat, perit, \& fift naufrage en Afiongaber, comme rapportel'Efcriture. En cecy ie dis que ie m'accorde fort volontairement à l'opinion de Iofephe en fesliures des Antiquitez, où il dit que c'eft vne Prouince de l'Inde Orientale, laquelle fut fondee par cét Ophir fils de Iectan, duquel il eft fait mention au Genefe dixiefme, \& eftoit Gene. ra: celle Prouince abondante d'or tres.fin. De là eft venu que l'on celebre tant l'or d'Ophir, ou d'O. phas, ou felon quaucuns veulent dire que ce mot d'Obrife vaut autant comme qui diroit lOphirife; pource qu'y voyant fept forres \& efpeces d'or ( comme refere fainct Hierofme) celuy d'Ophir eftoit tenu pour le plus fin, comme icy nous loüons \& eftimons l'or de Valdiuia, ou de Caranaya. La principale raifon qui me fait croire qu'Ophir eft en l'Inde Orientale, \& non en cefte Occidentale, eft, pource que la flotte de Salomon ne pouuoit venir icy fans paffer toute l'Inde Orientale, toute la Chine, \& autre grande efpace de mer, n'eftant pas vray-femblable quils euffent trauerfé tout le monde, pour venir icy chercher de l'or, princi-

D iij 


\section{Hiftoire naturelle}

palement eftant cefte terre de telle façon, que Pon n'en peut auoir cu cognoiffance par aucun voyage de terre, \& moniltrerons apres queles anciens n'auoient cognoiflance de lart de nauiger dont nous vfons aujourd'huy, fans lequel ils n'euffent pea fengouffrer, \& auancer fi auant dans la mer. Finalement en ces chofes quand il n'apparoit indices certains, mais feulement coniectures legeres, l'on n'elt obligé d'en croire da. uantage que ce qu'il en femble à vn chacun.

2uefignifie en la faincte Efcriture, T haryss,
\& Ophir.

Chatitre Xiv,

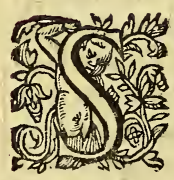

I les opinions \& coniectures d'v $\mathbf{n}$ chacun doiuent eftre receües, ie tiens quant à moy, qu'en la fain. ote Efcriture ces mots de Tharfis fente fient aucun lieu determiné, mais que c'êt vn mot \& fignification generale aux Hebrieux, comme en noftre vulgaire ce mot des Indes nous eft general en noftre vfage \& façon de parler: car nous entendons par les Indes, des rerres fort riches, efloignees, \& eftranges des nottres. Ainfi nous autres Efpagnols indifferemment appellons Indes, le Peru, le Mexique, la Chine, Malaque, \& le Brefil; \& de quelconques parties de celles-cy que viennent lettres, nous difons que ce font lettres des Indes, eftans neantmoins lefdites terres \& Royaumes de 


\section{des Fndes. Liure 1 .}

grande diftance \& diuerfité entr'elles; iaçoir auffi qu'on ne puiffe nier que le nom des Indes Pentend proprement de l'Inde Orientale. Et pource qu'anciennement l'on parloit de ces Indes comme d'vne terre fort efloignee, de là eft venu qu'à la defcouuerte de ceş autres terres auffi bien efloignees, 'a-t’on donné le nom des Indes, pour eitre diftantes des autres, \& tenuës comme le bout du monde. Et de mefme façon il me femble que Tharfis en la faincte ECcriture le plus fouuent ne fignifie ny lieu, ny partie determinee, mais feulement des regions fort efloignees, \& felon l'opinion du peuple, fort riches, \& fort eftranges: car ce que Iofephe \& quelques-vns veulent dire que Tharfis eft Tarfo, felon l'intention de l'Elcriture, il me femble auec bonne raifon auoir efté reprouué par fainet rịierofme, non feulement dautát que Fieron.ad ces deux vocables f'efcriuent par diuerfes let-Marcel. ir tres, l'vn auec vne afpiration, \& l'autre fans af- $z_{a}$ tomo. piration, mais auffi pource quel'on efcrit beaucoup de chofes de Tharfis, qui ne peuuent pas bien conuenir, ny fe rapporter à Tarfo Cité de Cilicie. Il eft bien vray qu'en quelques endroits del'Efcriture il eft dit que Tharfis eft en Cilicie. Ce qui fe trouue au liure de Iudith, quand il eft parlé d' nolofernes, duquel il eft dit qu'ayant Iudith. 20: paffé les limites d'Affyrie, il paruint iufques aux grands monts d'Ange ( qui par aduenture eft Taurus:) lefquels monts font à la feneftre de Cilicie, \& qưil entra en tous les chafteaux, où Plin.ili. s. il affembla toutes fesforces, ayant deftruit cel6.27. le tans renommee Cité de Melothi, defpoüilla,

$$
\text { D iiij }
$$




\section{Hiftoire naturelle}

\& ruina rous les fils de Tharfis \& d'Ifraèl, qui eftoientioignant le defert, \& ceux qui eftoient au Midy, vers la terre de Cellon, \&z de là paffa l'Euphrates : mais comme iay dit, ce qui eft ain. fi efcrit de Tharfis, nefe peut accommoder à la Theod. in x. Cité de Tarfo. Theodoret \& autres, fuiuans Zoain. linterpretation des Septante, en quelques enArtafmon. droits mettent Tharfis en Afrique, vaulans dire. ibid. $\%$ in que c'eftoit la ville mefme, qui anciennement Alphabeto f'appelloit Carthage, \& aujourd'huy Royaume Apparatus. de Thunes; \& difent que c'eftoit là où Ionas vouloit aller, quand l'Efcriture rapporte qu'il f'enfuyoit du Seigneur en Tharfis. Autres veulent dire, que Tharfis eft vne certaine region Ffieron. ad des Indes, comme il femble que fain $\mathrm{t}$ Hier of Marcell: me f'y veuille incliner. Ie ne veux pas à prefent debattre ces opinions : mais ie veux bien dire que l'E friture fur cefte matiere ne fignifie pas toufjours vne region, ou partie du monde certaine, \& determinee. Il eft certain que les $\mathrm{Ma}$ ges ou Rois qui vindrent adorer Iefus-Chrif, eftoient d'Orient, \& auffi dit l'E Criture, qu'ils: eftoient de Saba, Epha, \& Madiam. Er quelques hommes doctes font d'opinion qu'ils eftoient $d^{\prime}$ ethiopie, d'arabie, \& de rerfe; \& neantmoins PPalm. 44. le Pfalmifte \& l'Eglife chante d'eux : Les Roys de Tya. 60. Tharfss apporteront des prefens. Nous-nous accordons donc auec $S$. Hierofme, que Tharfis eft vn mat qui a plufieurs \& diuerfes fignifications en l'EScriture, \& que quelques fois il fignifie la pierre Chryfolithe, ou Iacinthe; tantoft quelque certaine region des Indes, tantoft la mer mefme, qui eft de couleur de Iacinghę à la reuerberation 


\section{des Fndes. Liure I.}

du Soleil. Mais auec raifon le mefme fainet Docteur nie que Tharfis foit region des Indes out vouloit fuyr Ionas, puis que partant de Ioppé, il luy eftoit impoffible de nauiger iufques és Indes par icelle mer. Pource que Iòppé ( quau iourd'huy nous appelions laffe) n'eft pas vn port de la mer rouge, laquelle eft iointe auecla mer Indique Orientale, mais de la mer Medicerranee, qui n'a point d'iffuë par la mer Indique. D'où il appert clairement, que la nauigation que faifoit la flotte de Salomon, partant de Afiongaber (où fe perdirent les nauires du Roy Iofaphat) alloit par la mer rouged Tharfis \& Óphir, ce qui êt expreffément attefté en l'Efcriture. Et a efté cefte nauigation fort differente de celle que pretendoit faire Ionas à Tharfis, puifque Afiongaber eft le port d'vne Cité d'Idumee, affife fur le deftroit, où la mer rouge fe ioint auecle grand Occean. De ceft Ophir l'on apportoit à Salomon de l'or, de l'argent, du morphie, des monnes; \& coqs d'Inde, \& eftoit leur voyage de trois ans, toutes lefquelles chofes fans doubte doiuent eftre entenduës de l'Inde Orientale, qui eft feconde \& abondante en tout ce que deffus, ainfi que Pline l'enfeigne, \& que nous en auons à prefent certaine cognoiffance. De noftre Peru certainement ils n'euffene peu apporter du morphie, d'autant que les elephans y font du tout incogneus: mais il euffene bien peu apporter del'or, de l'argent, \&z de fore plaifantes \& gentilles monines. Finalement il me femble que l'Efcriture faincte entend communement par ce mot de Tharfis, ou la grande 


\section{Hiftoire naturelle}

mer, ou des regions fort efloignees \& eftranges. Par ainfiil fuppore queles Propheties qui parlent de Tharfis(puifque l'efprit de prophetie peut tout (çauoir) fe peuuent bien fouuent accommoder aux chofes de noftre nouu eau móde.

Dela Praphetie d'Abdias, que quelques-vns interpretent eftre des Indes.

\section{CHAPITRE XV.}

Guido Boderian. in epiad Philippu Cathol. re. gễin s. Com. facr. Bibl. in Marraz. in 20 Lufieurs difent \& afferment qu'en Bifpan.hift. ainfi: A la tranjmigration de ceft exercite des enfans d'if:- rael poffedera tourtes les chofes des Chananeers ungques en sarepte, o la tran fmigration de Hierufalem, qui eft aus Bopphore,poßedera les Cite $Z$ du Midy, $\sigma$ monteroo les $\int a w$. ueurs au mont de sion pour inger le mont d' $E$ fau, o fera le Ludouicus Royaume pour le seigneur. Cecy a elté mis ainfi en Leo Awgu. vulgaire fuiuant la lettre. Mais les autheurs que ftiniarn. irscó- i'entens en l'Hebrieu lifent ainfi: Et la tranfmigrament. Super tion de ceft exercite des enfans d'I frael (qui font les) $\mathrm{Ca}$ sibdia. naneäs iufques à Zarphat (qui eft France) $\sigma$ la träfmigration de Hicrufale, quie eft en sapharad (entédez pour Efpagne)poffedera pour beritage les Cite $Z$ du Midy, of monterone ceux qui procurent la faluation au mont de sion, pour inger le mont d'E fau, o fer a le Roy aume pour le Seigreur. Toutesfois aucuns d'eux n'alleguent fuffi: 


\section{des Fndes. Liure. I.}

ant tefmoignage des anciens, ny raifon perinente, pour móftrer que Sapharad, que S. Hieofme interprete le Bofphore ou deftroit, \& les eprante Interpretes, l'Euphrate, doiue fignifier 'Efpagne, que leur feule opinion. Les autres lleguent le Paraphrafe Chaldaïque, qui eft de cefte opinion, \& mefme les anciens $R$ abis qui 'expliquent de celte façon, comme auffi ils ex pliquent Zarphat eftre France (que noftre vulgaire \& les Septante difent eftre Sarepte.) Et ailfant cefte difpute, qui appartient aux gens plus de loifir, quelle necefité y a-il de croire que les Citez de l'Aufre, ou de Mageb (ainfi qu'efcriuent les Septante) foient les gens de ce nouueau monde? Dauantage, quel befoing eft -il de croire, \& de prendre la nation Efpagnolle pour la tranfinigration de Hicrufalem en Sapharad, fi ce n'elt que nous vueillons prendre Hierufalem fpirituellement, \& que pour icelle nous entendions l'Eglife?. De forte que par la rranfmigration de Hierufalem en Sapharad, le Faina Efprir nous demóftre les enfans de la faincte Eglife, qui habitent aux fins de la terre, 8 aux riuages; pource cela en langue Syriaque eft dict Sapharad, \& fe rapporte bien à noftre efpa. gne, qui felon les anciens, eft la fin \& le bour de I2 terre, eftant prefque toute enuironnee de la mer. Or parles Cirez d'Auftre, ou de Sud, l'on peut entendre ces Indes:attendu que la plus grande part dece nouveau monde eft affife au Midy, \& la meilleure partie duquel regarde le Pole Antarctique. Ce qui s'enfuit eft facile à inxerpreter, , çauoir, ceux qui procurent la Saluatio, men- 


\section{Hiftoire naturelle}

teront au mont de sion pour iugerlemont d'E aus : parce qu'on peut dire que ceux-là fe retirent à la doetrine, \& au fort de la S. Eglife qui pretendent rompre \& diffiper les erreurs profanes des gentils, car cela peut eftre interpreté iuger le mone d'Efau. D'où il s'enfuit bien, qu'alors le Royaume nefera pour les Efpagnols, ny pour ceux d'Europe, mais pour IESVS.CHRIST noftre Sauueur. Quiconque roudra expliquer de cefte façon la Prophetic d'A bdias, ne doit eftre reprins, puis qu'il eft certain que le fainct Efprit a fceu $\&$ cogneu tous les fecrets long temps auparauant. Et femble qu'il y a grande apparence de croire qu'il eft faict mention en la faincte Efcriture d'vne affaire de telle importance, comme eft la defcoutserture des Indes \& nouneau

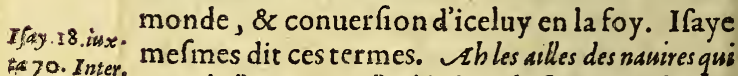
Eta 70 . Inter. vont de l'autre part d'Ethiopie. Plufieurs autheurs tres-doctes declarent que tout ce chapitre eft entendu des Indes, \& le mefme Prophete en \$faye 66. d'autre endroit dit: Que ceux qui efchaperont d'I frael,

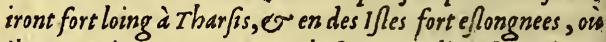
ils convertiront aus sergneur plufieurs $\mathcal{\sigma}$ diverfes nations. Entre lefquellesil nommela Grece, l'Italie, \& l'Afrique, \& beaucoup d'autres. Ce qui fans doute fe peut bien rapporter à la conuerfion de ces nations des Indes. Car eftant chofe affeuree \$4tash.24. que l'Euangile doibt eftre prefchee par tout l'vniuers, ainfi quele Sauueur nous l'a promis, \& qu'alors viendra la fin du monde, il s'enfuit, $\& z$ ainfi le doibt-on entendre, qu'en toute l'eftenduë du mondeil y a beaucoup de nations a 


\section{des Indes. Liure I.}

guil zs v S-C н r is T r'a efté annoncé Partant hous debuons de là recueillir, qu'il eft demeuré , grande partie du monde incogneuë aux anciens, 3 quauiourd'huy ily en a encore vne bonne partie à defcouurir.

Par quel moyen ont pew arriuer aux Indes les premiers bonmes, 's quililn'y font arriuez degré, \& felon leurixtention.

\section{CHAPITRE XVI.}

Fe Aintenant il eft temps de refpódre

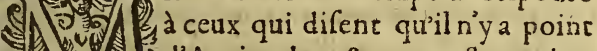
e 12 IfAntipodes, \& que cefte region 13. A où nous viuons, ne peut eftre habitee. L'immenfe grandeur del'Occean efpouuenta tellemét fainct Auguftin, qu’il ne pouuoit penfer comment le lignage humain euft peu paffer à ceftuy noftre nouueau monde. Mais puis que d'vne part nous fçations de certain que paflez font plufieurs ans, qu'il y a des hommes habitans en ces parties cy, \& d'autre part ne pouuós nier ce que la faincteEfcritures nous enfeigne clairement, que tous les humains font procedez d'vn premier homme, que fans doute ferons contrain ets de croire \& confeffer que les hommes feront paffez icy de l'Europe, de l'Afie, ou del' Afrique : toutesfois ce pendant il nous faut rechercher \& difcourir par guel chemin ils y ont peu venir. Il n'eft pas 


\section{Hiftoire naturelle}

rray-femblable qu'il y ait en vne autre arche dé Noé,en laquelle les hommes puiffent eftre arriuez aux Indes, \& moins encore que l'Ange ait zranfportéles premiers hommes de ce nouueau monde, attachez \& furpendus par les cheueux; comme itfit le Prophete Habacuc, car nous ne traittons pas de la toutc- puiffance de Dieu, mais feulement de ce qui eft conforme à la raifon \& a l'ordre \& difpolition des chofes humaines. C'eft pourquoy ces deux chofes doiuent eftre renuës pour admirables, \& dignes de -merueille, voire d'eftre comptees entre les fecrets de Dieu. L'vne que le genre humain ayt peu paffer vne fi grande trauerfe de mer, \& de terre. L'autre qu'y ayanticy figrand nombre de peuple; ils ayent efté neantmoins incogneus par tant de fiecles. Pour cefte caufe ie demande par quelle deliberation, force \& induftie, le lignage des Indiens a peu paffer vne fir large mer, \&z qui poutuoir eftre l'inuenteur d'vn paffage fi eftrange. Veritablement ie l'ay plufieurs fois recherché \& ruminéà moy-mefme, (comme plufieurs autres ont fait, ) \& iamais n'ay peu trouuer chofe qui me peuft fatisfaire. Toutes. fois i'en veux bien dire ce que i'en ay conceu, $\&$. qui me vient à prefent en la fantafie, puis que les tefmoins ine mánquent lefquels ie puiffe fuiure, \& melaiffer aller par le fil de la raifon, (quoy qu'il foit fore delié) iufques à ce qu'il fe difparoiffe du tout de deuant mes yeux. C'eft. vine chofe certaine que les premiers hommes font venus en la terre du Peru par l'vne de ces deux ssanieres, fçauoir ou par terre, ou par. 


\section{des Indes. Liure. I.}

neŕ. Que s'ils font venus par la mer, c'à efté u fortuitement \& par hazard, ou de gré \& ropos deliberé. I'entens par hazard, eftans ietez par quelque orage \& force de tourmente, comme il aduient en temps rude, \& tempezueux. I'entens auffi de propos deliberé qu'ils euffent dreffé leur nauigation, pour chercher $8 *$ defcourir de nouuelles terres. Outre ces deux manieres, ie trouue qu'il n'eft point poffible d'en trouner d'autres, fi nous voulons fuiure le cours des chofes humaines, \& ne nous arrefter a fabriquer des fictions Poëriques \& fabuleufes. Car il ne faut pas que quelqu'vn fe perfuade de trouuer vn autre aigle, comme celle de Ganimede, ou quelque cheual volant, comme celuy de Perfeus, qu'il maintieune auoir ap. porté les premiers Indiens par l'air, ny que par aduenture ces premiers hommes fe foient feruis de poiffons, comme Serenes, ou Nicolas, pour les auoir paffés là. Mais delaiffant arriere ces propos de menfonge, \& dignes de rifee, examinös vn peu chacune de ce deux manieres inifes en auant, attendu que cefte dif pute fera plaifante \& vtile, Premierement il me femble que ce neferoit pas chofe trop elloignee de raifon de dire, que les premiers \& anciens peuples de ces Indes font venus, ont defcouuert, \& peuplé parla mefme façon que nous autres à prefent y venons iournellement, à fçauoir par l'art de nauiger, \& l'ayde des pilotes, lefquels fe conduifent par la hauteur \& cognoiffance du Ciel, $\&$ auec l'induftrie qu'ils ont de changer \& manier les yoiles, felon le temps qui fe prefente. 


\section{Hiffoire naturelle}

Pourquoy cela ne pourroit-il pas bien eftre? faut -il croire que nous feuls hommes, \& en cefiny noftre fiecle tant feulement, ayons comprins \& cogneu l'art de nauiger l'Occean? Nous voyons que de ce temps melime l'on nauige, 8 trauerfe encor b'Occean pour defcourir nouuelles terres;comme peu de temps y a qu'A luaro Mendana \& fes compagnós ont nauigé, eftans partis du port Lima, \& fuiuy la toute du Ponene pour defcouurir la terre qui gift à PEft, où eft le Peru, \& au bout de trois mois, defcounirent les Ifles quils appellerent, Ines de Salomon, qui font plufieurs \& fort grandes. Et y a grande apparence qu'elles gifent ioignant la nounelle Guynee: ou pour le moins qu'elles font fort proches d'vne autre terre ferme. Et cncore auiourd'huy parle commandemét du Roy, $\&$ de fon Confeil, l'on delibere d'apprefter vne nounelle armee pour aller à ces Ifles. Puis done qu'il eft ainfi, pourquoy ne dirons nous pas que les anciens auffi bien nayent peu auoir le courage, \& refolution de voyager par mer à mef. me deliberation de defcouurir la terre, quils appellent Antiatthon, oppofite à la leur, \& que felon le difcours de leur philofophie, deuoit efte auec deffein de ne $s^{3}$ arrefter iufques à la veiie des terres qu'ils cherchoient ? Certainement il n'y a aucune repugnance ou contrarieté, que ce que nous voyons a uiourd'buy arri-

uer, foit ainfi anciennement arriué : attendu

mefne que la fance Efcricure tefmoigne que

3. Reg..10. Salomon print des maittres pilotes de Tyr \& de Sidon, fort adroits \& experimentez aे la 


\section{des Indes. Liure. I.}

ner, \& que par leur indintrie, l'on fir cefte na. ingation de trois ans. A quel propos pêrez vous u'elle remarque l'arr des mariniers, \& leur cience, enfemble leur nauigation fi longue de rois ans, finon pour nous donner à entendre jue la flotte de Salomon nauigeoit le grand Jccean? Il y en a beaucoup qui font de cefte pinion, aufquels il femble que fainct Augutin uoit peu de raifon de s'ef pounenter, \& efmereiller de la grandeur de l'Occean puifqu'il pouoit coniecturer qu'il n'eftoit fi difficile à nauier, veu ce qui eft rapporté de la nauigation de alomó. mais pour dire la verité, mó opinion efé ien autre, \& ne me puis perfuader que les preniers Indiens foient arriuez en ce nouueau mó. le par vne nauigation ordonnee, \& faite à proos. Mefme ie ne veux pas accorder que les aniens ayent cogneu l'art $\&$ induftrie de nauiger, ar le moyen duquel les hommes auiourd'huy rauerfent la mer Occeane de quelque partie tue ce foit, à quelconque autre qu'il leur prene fantafie. Ce qu'ils font auec vne incroyable iffeffe \& refolution, attendu que ie ne troune n toure l'antiquité aucun refte, ou tefmoignae d'vne chofe fi notable, \& de fi grandeimporance. Et ne trouue qu' aux liures des anciens foir aite aucune mention de l'vfage de la pierre 'aymant, ne de l'Efguille à nauiger, voire, ne roy-ie point quils en ayent eu aucune conoiffance. Que fi l'on ofte la cognoiffance de Efguille à nauiger, l'on cognoiftra facilemenr u'il eft impoffible qu'ils ayent trauerfé l'eftenuë du grand Occean. Ceux qui ont quelqua 


\section{Hiftoire naturelle}

* cognoiffance de la mer, entendent bien ce que ie dis. Pource qu'il eft auffi facile de croire que les mariniers eftans en plaine mer puiftent dreffer ta proüe de la nauire où ils voudront, fi l'aiguille de nauiger leur deffaur, comme de penfer que l'aueugle puiffe monftrer anec le doigt cequi eft proche, ou ce qui eft efloigné en quelque endroit. Et eft vne chofe efmerusillable que les anciens ayent ignoré par tant de tempsvne fi excellente proprieté de la pierre Plin lib.3.c. d'aymant, \& qu'elle ait efté defcounerte \& co6 \& lib.34. gneüe par les modernes. 11 appert bien que les 6.1.14. O anciens ont ignoré cefte proprieté, en ce que 3ib. 7.c.4. Pline, qui eft fi curieux hiftorien des chofes na. turelles, neant moins parlant de cefte pierre d'ay. mant, ne dit aucune chofe de cefte vertu \& 2 praprieté, qu'elle a de faire toufrours tourner de. uersle Nort le fer qu'elle aura touché, qui eft Diofso l.l. la vertu la plus admirable qu'elle ayt. Ariftote Theophrafte, Diofcoride, Lucrece, ny aucun: .ro. Lucret.l. 6. hiftoriens, ny Philofophes naturels queitay veu; n'en font aucune mention, encore qu'ils trai. Aug.de Ci- Etent de la pierre d'aymant. Sainct Auguftin ef uit. Dei.c.4. criuăt d'autre part plufieuss \& diuerfes proprie vbi multa demagriete:

tez, \& merueilleufes excellences de la pierr d'aymant, aux liures de la Cité de Dieu, n’er parle nullemènt. Et eft certain que toutes le: merueilles que lon cóte de celte pierre, ne fon rien au refpect de cefte propricté fi eftrang: qu'elle a de regarder toufrours au Nort, qui ef va grand miracle de nature. Il y a encore vn au. plir. l.7.c. tre argument, qui eft que Pline traictant des pre 56. miersinuenteurs de la nauigation, \& racontan 


\section{des Indes. Liure 1.}

ous les infrumens $\&$ appareils, ne parle aucu nement de l'aiguille à nauiger, ny de la pierre l'ay mant: mais ie dy leulement que l'art dere:ognoiftre les eft oilles a efté inuenté des Pheniiens. Et n'y a point de doute que ce que les anciens ont fçeu \& cogneu de l'art de nauiger, n'etoit qu'au regard des eftoilles, \& remarquăs les iuages, Caps, \& differéces des terres. Ques'ils $\{e$ rouuoient fi auant en haute mer, que du tour ils erdiffent laveuë de la terre, ils ne fçauoient en quelle part dreffer la prouie pàr autre difcours, inon par les eftoilles, foleil, \& la lune, \& cela eur deffaillant, (comme il aduient en temps neouleux, \& couuert $\left.{ }_{2}\right)$ ils fe goutuernoient par la fualité du vent, \& parconiectures da chemin quils pouuoient auoir faict, finalement aloient conduits de leur inftinct. Comme en ces ndes les Indiens nauigent vn long chemin de ner, conduits feulemét par leur induftrie $\&$ intinct naturel. Et fert beaucoup à "ce fubject ce ju'efcrit Pline, des infulaires de la Trobane, 'qu'auiourd'huy nous appellons Sumatra) diant en cefte façon, lors qu'il traicte de l'art $\$$ nduftrie dont ils v foient à nauiger: Ceux de la $T_{B}$ robane ne voyent point le Nort, $\sigma$ pour naviger, Juppleen ce deffaut, poitás atuec eux cerfainspetits oyjeaux, lesquels ls laiffent aller fouruent, o comme ces petits oy fearux par saturel infinet vollent couf fours vers la terre, les mariniers Ireffent leur proüe'à leur fuitte. Qui doubte donc que ils euffent eu cognoiffance de l'aiguilte, ils ne fe fufsét aydez pour guide de ces petits oy feanx, pour defcouurir la terre? Bref il fuffir pour môArer que les anciens n'ons cogneu ce fecret de 


\section{Hiftoire naturelle}

la pierre d'aymant, de voir que à chofe fi rémarquable, il n'y a aucun mot, ny vocable Latin, ny Grec,ny Hebreu, qui luy foit propre. Car vne chofe de telle importance n'cuft point mäqué de nom ences langues, s'ils l'euffent co. gneu. De là vient qu'auiourd'huy les Pilotes, pour faire dreffer la roure', à celuy qui tient le gouternail, fe feent au haut de la pouppe, qui eft à fin quill puife de ceft endroir regarder llef. guille, là où anciennemét ils feoient en la proiie, pour regarder les differences des terres \& des mers, \& duquel lieu ils commandoient au gouuernail. Cóme auiourd'huy l'ó v fe encore à l'entrer ou fortir de quelque port \& haure, \& pour cefte occafion les Grecs appelloient les Pilotes Proritas, pource qu'il fe tenoient en la prouë.

De la proprieté ó vertu admirable de la pierre d'aymant, pour le fait de la nauigation, to queles anciens n'enant en $\checkmark$ cognoiffance.

\section{Chapitre XVII.}

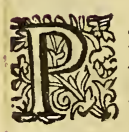

Ar ce qui eft dit cy deffus, il appertque l'on doit tenir la nauigation des Indes, fi briefue \& fi certaine, que nous l'auós de la pierre d'aymant. Comme auiourd'huy nous voyons plufieurs hommes qui ont voyagé de Lisbonne à Goa, de Seuille à Mexique, à Panama \& en toure cefte autre mer dusud, iufques à la Chine, \& au deftroir de 


\section{des Indes. Liure. I.}

Magellan \& ce auffi facilement \& cerrainenent, comme le laboureur peut aller de la meairie en la ville. Nous auons veu auffi des nommes qui ont faict quinze voyages aux In tes, voire dixhuift, \& auons entendu parler d'aucuns anciens lefquels ont fait plus de vinge yoyages, paffans $\&$ repaffans la largeur de ce grand Occean, aufquels ils n'ont apperceus aucuns reftes, ny apparences de ceux qui auoient pallé, ny rencontré voy agers à qui demander le chemin. Car (comme dit le Sage) la nauire coupe l'eaüe \& fes ondes, fans laifler veftiges par où elle paffe, ny faire chemin dans les ondes. Mais par la vertu \& proprieté de la pierre d'aymant, 1 fe faiet en ceft Occean comme vn chemin rracé \& defcounert, le tres-haut Createur de toutes chofes luy ayant communiqué telle vereu, que par fon attouchement au fer, il luy communique cefte proprieté, d'auoir fon mouuement \& regard vers le Nort, fans y faillir, en quelque partie du monde que ce puiffe eftre. Quelques-vns recherchent quelle eft la caufe de cefte proprieté merueilleufe, \& veulent dire, \& s'imaginer ie ne fçay quelle fympathie: mais quant à moy, ie prends plus de plaifir \& de contentement confiderant ces merueilles, loïer la grandeur \& pouvoir du Tout-puiffant, \& me refiouyr en la contemplation de fes ceu= ures admirables, \& à dire auec Salomon, parlant fur ce props: o Pere, duquel la pronidence gonuerne $\sigma$ maintient un bois, luy donnant vn chemin affeuréfor la mer, $\mathcal{O}$ au milieu des bondiffantes ondes, pour monff trer'

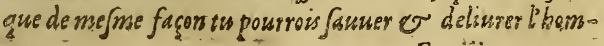




\section{Hiftoire naturelle}

sne de sout peril or naufrage, encor quil fuft fans narire aus milleu de la mer. Mais d'autant que tes ceunres font * pleines de fageffe, les bominues mettent $\sigma$ baZardent leurs vies fur von peu de bois, or pour traner fer la mer, s'efchappent $\odot$ fe laiffent aller en vn bafteau. Er fur ce mefme propos le Pfalmifte dit : Ceux qui montent fur mer en des nauires, or qui font leurs affairesen trawerfant les eaux, Sont ceux qui au profond de la mer ont ver les cauures du seigneur, or Jes merueilles. Et à la verité ce n'eft pas vne des moindres merueilles de Dieu, que la force d'vne pierre fi petite commande à la mer, \& contraigne l'abyfme infiny de lity obeir \& fuiure fon commandement. Mais pour autant que c'eft chofe qui fe void tous les iours, \& femble fi facile, les hommes ne s'en efmerueillent point, \& ne fe fouuiennét pas d'y prendre garde:\& d'autant que cefte liberalité eft telle, les ignorans pour cela en font moins d'eftat. Neantmoins ceux quile veulent confiderer de pres, font conduits parla raifon a benir la fa, geffe de Dieu, \&r luy rendre graces d'vn fi grand benefice. Eftant donc ordonné du Ciel que ces nations des Indes, qui tant de temps ont efté cachees, fuffent cogneües \& defcounertes, $\&$ que cefte route fut hantee $\&$ frequentee, afin que tát d'ames vinffent à la cognoiffance de IEsvs-CHRIST, \& gaignaffent le falut eternel, il a efté pourueu de guide affeuree pour ceux qui font ce chemin, fçauoir l'aiguille de nauiger, \& la vertu de la pierre d'aymant. On ne peur lçauoir au certain, depuis quel temps ceft vfage $\&$ art de nauiger a efté mis en lumiere: mais quane moy, ie tiens porr certain qu'il n'eft pas fort 


\section{des 7 ndes. Liure I.}

36

ancien, d'autant qu'outre les raifons déduites au chapitre precedent, ie n'ay leu en aucun autheur ancien, traittant des horloges, quil foit faizt aucunemention de la pierre d'aymär. Et neantmoinsil eft certain quele principal $8 \%$ plus neceffaire inftrument des cadrans au foleil, dont nous vfons auiourd'huy, eft l'aiguille de fer touchee de la pierre d'aymant. Quelques autheurs approuuez efcriuent en l'hiftoire des. In. des Orientales, que le premier qui commença à defcouurir ce fecret fur mer, fut Vafco de Li.r. de Ita. Gama, lequel à la hauteur de Mozambique ren-iliufr. regnio contra certains mariniers Mores, qui vfoient ${ }^{13}$. de l'aiguille de nauiger, \& que par le moyen d'i. Plin l.z. ca. celle aiguille il nauigea ces mers: toutesfois ils ${ }_{c a p . v l t .}^{7 r} \cdot \vec{l}$. n'efcriuent point de qui ils auoient apprins ceft 0 zorins ds artifice: \& quelques-vns d'entr'eux mefries font rebus gefir de noftre opinion, qui eft, que les anciens óne Emmian. ignoré ce fecret. Dauantage, ie diray vne autre lib.s. \& plus grande merueille de l'aiguille de nauiger, quel'on pourroit tenir pourincroyable, fi Ion nel'auoir veu \& cogneu par experience fi affeuree \& manifefte. Le fer touché \& frotté delapierre d'aymant par la partie d'icelle pierre, qui en fa naifance regarde le Sud ou Mi$\mathrm{dy}$, a cefte vertu de fe tourner \& encliner toujours \& en tous lieux versle contraire, qui eft le Nort : toutesfois en tous lieux ilne le regarde pas directement, mais y a certains paints \& climats, où il regarde droitement le Nort \& f'y arrefte : mais paffant ou changeant de ce climat, il coftoye vn peu, ou à l'O rient ou Ponent, tant plus qu'il le va efloignant de ce climaet, c'e \& E iiji 


\section{Hiftoire naturelle}

ce que les mariniers appellent nordefter, or nortoefter. Nordefter vaut autant à dire com. me coftoyer, s'inclinant au Leuant, \& nortoefter s'inclinant au Ponent. Et eft chofe de telle confequence, \& qui importe tant de fçauoir cefte declinaifon, \& coftoy erment de l'E Eguille, que fi l'on n'y penfoit, \& regardoir de pres, (quoy qu'elle foit petite) l'on s'efgareroit merueilleufement en la nauigation, \& arriueroie l'on en autre lieu que celuy où l'on pretendoir aller. Vn iour vn pilote Portugais fort experimenté me difoit qu'il y auoir quatre' points en rout le monde, où l'E Eguille fe dreffoir au Nort, \& me les contoit par leurs noms, que n'ay retenus, vn d'iceux eft la hauteur de linte de la Cor. ne en la Tiercyere, ou Alçores, qui eft chofe fort cogneuë à tous; mais tirant outre de là à plus de hauteur, il nortoefte, qui eft à dire decliner au couchant. Mais tirant au contraire à moins de hauteur, vers l'Equinoctial, il nordefte, qui eft incliner a l'Orient. Les maiftes en ceft art pourront enfeigner de combien \& iufques où; de ma part ie demanderois volontiers aux bacheliers qui prefument fçauoir tout ce qui eft, qu'ils me diffent la caufe de ceft effect, \&x pour quelle raifon vn peu de fer frotté à la pierre d'aymant, reçoit tant de vertu que de regarder toufiours au Nort : mais encor auec telle dexterité, qu'il cognoit les climats \& diuerfes. fituations du monde, $\&$ où il fe doit ficher 8 . dreffer, où s'incliner en vn cofté ou en l'autre, aufi bien quaucun Philofophe \& Cofmographe qui foit. Que fi ne pourons bonnements 


\section{des Indes. Liure I.}

defcoúurir la caufe \& la raifon de ces chofes que nous woyons iournellemét à l'œil, qui fans doute feroient fort difficiles à croire, fi nous ne les voyons ainfi ouuertement. Certesl'on cognoift bien par là noftre folie \& vanité, de nous vouloir faire luges, \& aflujettir à noftre raifon \& difcours, les chofes diuines, \& fotrueraines. C'eft pourquoy il vaut mieux, comme dit Gregoire Theologien, que la raifon falfujettiffè à la foy, puis qu'en fá mairon mefme elle ne fe peur pas bien gouverner. Mais cecy nous doit fuffire; retournons à noftre propos, \& concluons que l'vfage de l'aiguille à nauiger n’a point efté cogneüe des anciens, d'où l'on peut refoudre qu'il leur a efté impoffible de faire voyage de propos deliberé, partans de l'autre monde, pour venir en ceftuy-cy parl'Occean.

Reponfe à ceux qui difent qu'autermps pajsé, .' comme auiourd'buy, l'on a nawigé fur l'occean.

\section{ChAPITRE XVIII.}

$E$ que l'on allegue au contraire de ce qui a efté dit que la flotte de Salomon nauigeoir en trois ans, n'eft pas preuue uffifanie, puis que les fainctes Efcritures n'afferment pas expreflement que ce voyage duraft trois ans, mais bien qu'il fe faifoit vne fois en trois ans. Et encore que nous accordions que $l_{3}$ nauigation duraft 3 . ans, il pounoit eftre, comme il eft plus vray-femblable, que cefte fiorte aquigeant vers l'Inde Orientale, fur retardee de 


\section{Heftoire naturelle}

faroute, pour la diuerfité des ports \& regions gu'elle alloit recognoiffant, cóme aujourd'huy en toute la mer du Sudl'on nauige depuis Chilé iufqu'à la neuue $E$ Cpagne; laquelle nauigation encore qu'elle foit plus certaine, neantmoins elle eft bien plus longue à caufe de ce tournoyement qu'elle cft contrainte de faire par les coAtes, \& le retardement qu'elle peut auoir en diuers ports. Et à la verité ie ne trouue point és liures des anciens qu'ils fe foient beaucoup advancez \& engolphez enl'Occean, \& ne peux croire que ce qu'ils en ont nauigé, ayt efté autrement, que de la façon qu'on nautige encores aujourd'huy en la mer Mediterranee. Quidon. ne occafion aux hommes doctes de croireque anciennement l'on ne nauigeoit point tans rames, d'autant qu'on alloit toufiours coftoyane

Ion. so. Ia terre; \& femble que l'E fcriture le veiiille ainfi donner à entendre, quand elle parle de cefte fa. meufe nauigation du Prophete Ionas, où il eft dit que les mariniers eftans forcés du temps, r’amenerent à terre.

शue lon pent coniecturer que les premiers perpleurs des Indesy font arriatz par tours

mente, or contre lesur volonté.

$\mathrm{CH}_{\text {hatrRe XIX. }}$.

Y Y A monfté qu'il n'y a point (1) (2) d'apparence de croire que les pre12a miers habitans des Indes y foien: venus de propos deliberé, il f'en202 fuit doncques que fils y font venus par mar, ça efté par cas fortuit, \& par for 


\section{des Indes. Liure 1.}

38

ce detourmente \& tempefte; ce qui n'cht pas incroyable, quelque grande que foit la mer Occeane, puis qu'il en eft tout autant aduenut de noltre temps, lors que ce marinier (duquel nous ne fçauons encores le nom, á celle fin qu'en v $n$ cuure fi grand, \&. de fi grande importance, ne f'attribuë point à d'autre autheur qu'à Dieu) ayant par vn terrible \& mauuais temps recogneu ce nouneau monde; laifla pour paye de fon logis où il l'auoit receu, à Chriftophle Colomb, la cognoiffance d'vne fi grande chofe. Ainfi a-r'il peu arriuer que quelques hommes del'Europe, ou Afrique, au temps pallé ayent efté poulfez par la force $\&$ violence du vent, $\&$ iettez à des terres incogneïes par delà la mer Occeane. Qui elt-ce qui ne fçait point que plufieurs, ou la plusgrande part des regions que l'on a defcouuertes en ce nouueau monde, a efté par ce moyen, defquelles on doit pluftoft attribuer la defcouverture ála violence des temps $\&$ orages, que non pas à l'efprit \& induftrie de ceux qui les ont defcouuertes? Et afin quelion recognoiffe que ce n'a pas efté de noftre temps feulement quel'on a fait, \& entreprins detels voyages, pour la grắdeur de nos nauires, valeur $\&$ hardiere de nos hommes, on peut voir dedans Pline que plufieurs des anciens ont fait de femblables voyages. Il dit donc de cefte façon: $I^{\prime}$ on raconte que Caius Ce Jar filsd' Arguste, eftant en pii. $l 2$. charge fur la mer d'Arabie, l'on vid or recogneust cap. 69. despreces $\sigma$ reftes de naurres Efpagnols quin y aworent pery. Er dit apres: Nepos raconite du curcuit Sepientriogal, que l'on aptorta Quintis Metellus Celer s compa. 


\section{Hiffoire naturelle}

gुroos är confulat de Cä̈us Affranius, effant lors iceluy Metellus Proconful en Gaule, certains Indiens qui suoiens efré prefentés parle Roy de sueve, lefquels Indiens narigeans de l'Inde pour leur commerce, furent iettés en Germanie par la force destempeffes. Pour certain fi Pline dit verité, les Portugais ne nauigent point aujourd'huy dauantage, que firent ceux là en ces

Plin, li. 6. deux naufrages, l'vn depuis l'Éppagne iufqueen Gap. 22. la mer rouge, \& l'autre depuis l'Inde Orientale iufqu'en Allemagne. Le melme Autheur efcris. en vn autre liure, qu'vn feruiteur d'Annius Plo. canius, quitenoir la ferme des droits de la mer rouge, nauigeant la routed Arabie, furuint des vents du Nort furieux, tellement qu'en quinze iours il paffa la Carmanie, iufqu’à recognoiftre Hippures, port de la Taprobane, quaaujourd'huy nous appellons Samatre. Mefmel'on raconte d'vn nauire de Carthaginois, qui de la mer de Mauritanie fut pouffé d'vn vent de bize iufqu'à la veuie du nouu eau monde. Ce qui n'eft pas chofe nouuelle à ceux qui ont quelque experience de la mer, d'entendre que quel quefois vne tempefte dure fil long temps \& obftinémët, fans appaifer fa fureur. Il meeft aduenuallăt aux Indes, que partant des Canaries iay def́couuert \& apperceu en quinze iours la premiere terre peuplee des Efpagnols. Et fans doute ce voyage euft efté plus bref, fi les mariniers euffent appareillez toutes leurs voiles à la bize qui couroit. Ainfi me femble-il chofe vray-femblable, que au temps paffé les hommes foient arriuez aux Indes contre leur intention, pouffez, \& vaincus de la fureur des vents. Ils font au Peru grande 


\section{des Fndes. Liure I.}

39

mention de quelques Geans qui ont efté ences quartiers, les os defquels fe voyent encores ausjourd'huy en Manta, \&. Port-vieil, d'v ne grandeur enorme, \& à leur proportion ces hommes deuoient eftre trois fois plus grands que les Indiens d'aujourd'huy. Ils racontent que cesceans vindrent parmer, \& faifoient la guerre à ceur du pays, qu'ils baftirent defomptueux edifices, dont ilsmonftrent encore aujourd huy vn puits fait de pierre de grand valeur. Ils difent dauantage, que ces hommes cómettans pechez enormes, \& fpecialement celuy contre nature, furent embrafez \& confumez du feu qui vint du ciel. Mefme racontent les Indiens d'Y $\mathrm{Ca} \& \mathrm{~d}^{2} \mathrm{~A}$ rica, qu'ils fouloient anciennement nauiger for: loing à des Ifles du Couchant, \& faifoient leur nauigation en des cuirs de loup marin enflez; de façon qu'il n'y a point faute de tefmoignages pour monftrer quón ayt nauigé la mer du Sud deuant que les Efpagnols y vinfent. Ainfi pouuons-nous penfer que le nouneau monde a commencé d'eftre habité par des hommes qui y' ont efté iettez par la tempefte des vents, \& la force du Nort, comme finalement on l'a yeüe defcouverte en noftre temps. Il eft ainfil (chofe bien confiderable) que les ceuures de nature de grande importance, pour la plus gráde part ont efté trouuees fortuitement fans y penfer, \& non pas par l'induftrie $\&$ diligence humaine. La plus part des herbes medicinales, des pierres, des plantes, des metaux, des perles, de l'or, aymant, ambre, diamant, \& la plufpart de chofes femblables, \&xleurs proprietez \& vertus font pha- 


\section{Hifloire naturelle}

ftoft venués en la cognoiffance dés hỏmes pàe accident, que par art, \& par leur induftrie; afin que l'on voye que la gloire \& loiiange de telles merueilles, fe doir pluttof atrribuer à la prouidence du Createur, que non pas à l'entendemét humain, pour autant que ce qui nous femble arriucr fortuitement, procede toufiours de l'ordonnance \& difpofition de Dieu, qui fait toutes chofes auec raifon.

Que neantmoins tout ce qui a efté ditcy deffus, eft plus vray. femblable de penfer que les premiers peuplcurs des Indes y font vinus par terre.

\section{CHABITRE XX.}

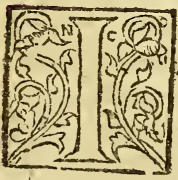

E cóclus donc quil eft bien vrayCemblable de penfer queles premiers qui arriuerent aux Indes, fut par naufrage, \& tempefte de mer : mais il fe prefente fur ce poinct vne difficulté, laquelle me trauaille grandement, qui eft, qu'encores que nous accordions que les premiers hommes foient venus a desterres fi efloignees que celles-cy, \& que les natiōs que nous voyons icy, foient forties d'eux, $\&$ fe foient tellemét multipliez comme ils fon à prefent; neantmoins ie ne me puis imaginer par quel moyen, ny de quelle façon les beftes \& animaux, dont il le trouue grande abondass: 


\section{des Indes. Liure I.}

ce aux Indes, y ayent peu arriuer, n'eltant pas croyable que l'on les yayt embarquez, \& porrez par mer. La raifon pour laquelle nous fommes contraints de dire que les premiers hommes des Indes font venus de l'Europe, ou de l'A fie, eft pour ne contredire à la fain cte Efcri- Gew. \%' ture, qui nous enfeigne clairement que tous les hommes fone fortis d'Adam. Parainfi nous ne pouuós donner autre origine aux hommes qui font és Indes, veu que la mef́me Efcriture nous dit que toutes les beftes \& animaux de la terre perirent, finon celles qui furent referuees en l'arche de Noé, pour la multiplication \& entretien de leur efpece. Defaçon que nous deuons necelfairement referer $\mathfrak{l}_{a}$ multiplication de tous les animaux fufdits, à ceux qui fortirent de l'arche de Noé aux monts d'Araraat où elle farrefta, \& par ce moyen nous deuons rechercher, tant pour les hommes que pour les beftes, le chemin par lequel ils fon paffez du vicil monde au nouneau. Sainct Auguftin traictant cefte queftion, pour quelle railon l'on troutue ep certainesintes desloups, des tigres, \&zautres beftes rauiffantes, qui n'apportene aucin profit aux hommes, veu qu'il n'y a point de doure que les elephans, cheuaux, bæufs, chicns, \& autres animaux dont fe feruent les hommes, y ont efté portez tout expres en des nauires, comme nous voyons aujourd huy que l'on les porte depuis l'Orient iufques en l'Europe, \& de l'Europe au Peru, encores que les voyages en foient filongs. Et par quel moyen ces animaux qui font de nul profie, au contraire font dom- 


\section{Hiftoire naturelle}

mageables cóme les loups, \& autres de telle riàture farouche, ayent peu pafler aux Indes, fuppolé (comme il eft certain) quéle deluge noya toute la terre.Sur lequel traicté ce doate \& faint homme effaye à fe démefler de ces difficultez, difant qu'ils peurent pafier à nage en ces lfes, ou que quelqu'vn les y a portez exprespourle déduit de la chafle; ou bien que parla volonté de Dieu ils euffent cfé creez toutde nouueau de la terre, en la mefme forte $\&$ manicre dela premiere creation, quand Dicu dift: Quela terreproGenef. I. duife tout animal viname en fon genre, anmmaux reptiles, o beftes faurages deschamps felon leur e $\beta$ ece. Mais fi nous voulons appliquer cefte folurion à noftre propos, la chofe en demeurera plus amba* raffee : car cúmençant au dernier point, il n'eft pas vray-femblable, felon l'ordre de nature, ny n'eft pas chofe conforme à l'ordre du gouuerne. ment que Dieu a eftably, que les animaux parfairs, comme les lyons, les tigres, \& les loups, fiengendrent de la terre fans leur generation, comme l'on void que les rats, les grenoüilles, les abeilles, \& tous autres animaux imparfaicts fengendrent communement. Dauátage, à quel propos eft-cequel'Efcriture dit, \& repete tant de fois: Tu prendras de tous les animaux o oy $\int e a u x: d u$ Genel. 7. ciel, fept $\circlearrowleft$ Jept, mafles $\sim$ femelles, afin queleur generation sentretienne fur la terre: fi tels animaux apres le deluge deuoient eftre creez derechef par vne nơuelle maniere decreation, fans la conjon¿tion du mafle \& femelle? Er furce, pourroit encores fefaire ine autre queftion; pourquoy tels animaux naiffans de la terre, felon cefte opi. nionse 


\section{des Indes. Liure 1 .}

thion) il n'y en a pas auffi bien en toutes les autres parties de la terre ferme, \& és autres Ifles, puifque nous ne deuons pas confiderer l'ordre naturel de la generation, mais feulement la liberalité du Createur. D'autre part, que l'on ayt paffé quelques-vns de ces animaux pour le déduit de la chaffe (qui eft fon autre refolution) ie ne le veux pas tenir du tout pour chofe incroya. ble, d'autant que nours voyons foulentefois que les Princes \& gtäds Seigneurs tiennent \& nourriffent en leurs cages, pour leur plaifir \& gran. deur tant feulement, des lyons, des ours, \& autres beftes fauuages, principalemét quand elles font amenees de terres loingtaines. Mais de dire cela des loups, renards, \& autres animaux qui n'apportent aucun profit, \& qui n'ont rien de rare, ny de bon, que de faire dommage au beftial; \& de dire auffi qu'ils ont prins la peine de les apporter par la mer pour la chaffe, certainement c'eft chofe qui n'a point de raifon. Qui eft ce qui pourra penfer qu'en vre nauigation $f i$ longue $\&$ infinie il y ayt eu deshómes qui ayent prins la peine de porter au Peru des renards, principalement de ceux qu'ils appellent anas, qui eft vne efpece des plus ords \& infects que i'aye iamais veu? Qui voudra dire anfli qu'ils y ayent apporté des tigres $\&$ des lyons, certainement c'eft chofe digne de rifee \& mocquerie de le vouloir penfer : car c'eftoit affez, voire beaucoup aux hommes, pouftez malgré eux par l'orage \& la tempefte en vn fil loingtain \& incogneu voyage, de pouuoir efchapper du danger de la mer leurs propres vies, fans famufer à poso 


\section{Hiftoire naturelle}

Eer des renards \& des loups, \& les nourrir par la mer. Si donc ces animaux font venus par mer, il faut croire que ç’a efté à nage; ce qui fe peur faire en quelques inles peu diftantes \& efloignees des autres, ou de la terre ferme, comme l'on ne le peut nier, veu l'experience certaine que nous en auons, \& que nous voyons que ces animaux eftans preffez, nagent iour \& nuict fans fe laffer, \&zen fin ils f'efchappent de la façon. Mais cela f'entend en de petits golphe's \& trauerfes, pource qu'en noftre Occean l'on fe mocqueroir de tels nageurs; veu que les aifles faillent aux oyfeaux, mefme de grand vol, fur le paffage d'vn fi grand abyfrne. Et combien qu'il fe trouue bien des petits oyfeaux qui volent plus de cent 'lieies, comme nous l'auions veu plufieurs fois en voyageant, toutefois c'eft chofe impoffible aux oyfeaux, à tout le moins fort difficile, de pouuoir paffer toute la mer Occeane. Or tout ce que nous auons dit cy deffus eftant veritable, par quelle part ferons-nous le chemin à ces beftes fauuages $8 z$ aux oyfillons pour les paffer aux Indes; \& comment dirons-nous qu'ils font paffez d'vn monde à l'autre? Ie conjecture donc par le difcours que j'ay fait, que le nouueau monde, que nous appellons Indes, n'eft point du tout diuifé, ny feparé de l'autre monde, \& pour en dire mon opinion, il y a jà fort long temps que i’ay penfé que l'vne \& l'autre terre fe ioignent, \&x continuent en quelque part, où à tout le moinsfauoifinent \& approchent de bien pres. Et toutefois encor iufques à prefent n'y a aucuze certitude du contraire, pource que vers le 
de's Indes. Liure I.
ole Arctique, que nous appellons le Nort; oute la longituide de la terre n'eft pas defcouerte \& cogneüe, \& y en a plufieurs qui affer. nent 'qu'au deffus de la Floride f'eftend au Sepentrion vie terre fort large, qu'ils difent fe veiir rendre iufqu à la mer Scytique, ou Germanijue. D'autres adjouftent qu'il y a eu vn naurire, hui nauigeant en ces parties, raconte awoir veu. a colte de Bacaleos, quif'eftend quafi iufques ux fins de l'Europe. Dauantage, l'on ne fçait ion plus iufques où feitend la terre qui coure uu deffus du cáp de Mendoce, en la mer du Sud, inon que l'on dit que c'eft vne terre fort grante, \& qui court vne longueurinfinie; \& retour pant à l'autre Pole du Sud, il n'y a pas homme gui fçache où farrefte la terre qui eft de l'autre cofté du deftroit de Magellan. Vn nauire de l'Eaefque de Plaifance qui paffa le deftroit, raconreñauoir perda la veiie de la terre, le mefme dit Hernande Lamer pilote, qui par tourmente palfa deux ou trois degrez au deffus dudic deltroit. Ainfin'y a-il raifon; ny experience qui contredife mon imagination, ou opinion, fçawoir eft, que toute la terre fe ioint \& continue cn quelque endroit, oud tout le moins qu'elle f'approche fort l'v ne de l'autre. Si cela eft vrays comme en effer il y a de l'apparence, la refponfe elt ayfee au doute fidifficile que nous auions propofé, comment peurent paffer aux Indes les premiers pcupleurs d'icelles; pource que l'on doit croire qu'ils ne peuuent pas tant $y$ eftrevenus nauigeans par la ner, comme che minans par terre, \& auroient peu faire ce che

E ij 


\section{Hiftoire naturelle}

min fans y penfer, en changeans peu à peu leur. terres \& habitations. Les vns defquels peuplan les terres qu'ils tencontroient, les autres et cherchant d'autres nouuelles, vindrent en fir par la longueur du temps à remplir, \& peuple les terres des Indes de tant de nations, gens, \& langues que nous y voyons.

De guelle façon or maniere les animaux of be fiaux domeftiques pafferent aux Indes.

\section{Chapitre XXi.}

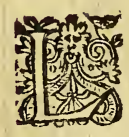

Es fignes $\&$ argumens qui fe prefen tent à ceux qui font curieux d'exami ner la façon \& maniere des Indiens aydét beạucoup à fouftenir l'opinio: fuldite, pour autant quel'on ne trouue poin d'hommes habitans és Ifles qui font beaucou elloignees de la terre ferme, ou des autres Ines comme la Bermude, dont la raifon eft, pourc que les anciens ne nauigeoient qu'aux cofte prochaines, \& toufiours à veüe de terre. Sut quoy l'on rapporte qu'il ne f'eft trouué, en au cune partic des Indes de grands nauires, qu fuffent capables de paffer tels golphes, mais feu lement y a t'on trouué des ball $a s$, barquettes or canoes, qui toutes font moindres que challop pes, defquelles fortes de vaiffeaux feulemen $\checkmark$ fent les Indiés, auec lefquels ils ne pourroien fengolpher en vne fi grande trauerfe, fans vi manifefte danger de naufrage, \& ores qu'ils euf fent eu des nauires fuffifans, ils ne fçatoient l'as 


\section{des Fndes. Liure $I$.}

le l'aiguille, aftrolabe, ou cadran. Que fils eufent efté 8 . ou ro.iours fans voir la terre, il eftoir mpoffible qu'ils ne fe perdiffert, fans pouuoir ecognoiftre où ils euffent efté. Nous recognoifCons pluficurs iffes fort peuplees d'Indiens, \& eur nauigation fort vfitee : mais c'eltoit celle qu'ils poumoient faire en canoes \& barquettes ansl'aiguille de nauiger. Quandles Indiens du Peru qui demeuroient en tombes, virent la premiere fois nos nauires $E$ fpagnols natigeans au Peru, \& recogneurentla grädẹur des voiles ten. dus, \& du corps des nauires, demeurerent fort eftonnez, \& ne pouuans fe perfuader que ce fuffent nauires, pour n'en auoir iamais veu de telle forme \& grandeur, fimaginoient quece fuffent des roches. Mais voyans qu'ils aduançoient fansf'enfoncer, demeuroient tous rauis \& tranfportez d'ef poutuentement, iufques à ce que regardans de plus pres, ils recogneurent des hommes barbus qui cheminoiêt en iceux, qu' ils eftimerent alors deuoir eftre quelques dieux, ou gens du ciel. D'où il appert combien c'eftoir chofe incogneiie aux Indiens d'auoir de grands. nauires. Il y a encore vne autre raifon qui nous fait croire, \& tenir pluftoft l'opinion fufdite fçauoir que ces animaux, defquels nous difons n'eftre pas croyable qu'ils ayent efté embarqués par aucuns hommes pour porter és Indes; nefe tiennent qu'en la terre ferme, \& non point aux. Ifles qui font aे quatre iournees de terre ferme. T'ay fair cefte recherche pour faire preuue de ce$c y$, d'autant qu'il m'a femblé que c'eftoit vra point de grande importance, pour me refous F iij 


\section{Hifoire naturelle}

dre en l'opinion que i'ay dite, que la terre des Indes, d'Europe, d'Afie \& d'Afrique, ont quelque communication enfemble, ou à tout le moins qu'elles f'approchent fort par quelque partie. Il y a en l'A merique \& Peru beaucoup debeftes fautuages, comme deslyons, encores qu'ils ne foient femblables en grandeur, fierté, ny en la mefme couleur de roux, aux renommés lyons de l'A frique. Il y a aufi grand nombre de tygres qui font fort cruels, $8 z$ plus communementaux Indiens, que non pas aux Efpagnols, Il y a auffi des ours, non pas toutesfois en fort grande abondance. Des fangliers $\&$ des renards vn nombre infiny. Neantmoins fi nous voulons chercher de toutes ces efpeces d'animaux en l'Ine de Cuba, Efpagnolle, Iamai que, la Marguerite, ou la Dominicque, il ne f'en trouvera aucuns. Tellement qu'efdites Inles, quoy qu'elles fuffent fertiles, \& de grande eftenduë, 11 n'y auoit aucune forte d'animaux de feruice, quand les Efpagnols y arriuerent. Mais pour le prefent ily a fi grand nombre de trouppeaux de cheuaux, boufs, vaches, chiens \& pourceaux, qui ont multiplié de telle façon, que jà les trouppeaux de vaches n'ont plus de maiftre affeuré, mais appartiennent au premier quiles tuë, \& jartiere, foit en la montagne, ou aux champs; cequeles infulaires font feulement pour auoir le cuir dont ils font grand traffic, laiffans perdre la chair fans la manger. Les chiens y ont tellement multiplié, qu'ils marchent en trouppes, \& endommagent fort le beftial, \& font autant de dégant que les loups, qui eft vne grande incon 


\section{des Indes. Liure 1.}

modité en ces Ines là. Il n'y a pas feulement faute de beftes fauuages en ces Inles, mais en la plus grande part, d'oyfeaux, \& oyfillons. Pour les perroquets, ily en a beaucoup qui ont vn grand vol, \& 8 vont par bandes: mais il y en a peu commei'ay dit, \& d'autres forres d'oyfeaux. De perdrix il ne me fouuient pas d'y en auoir veu, ny entendu qu'il y en aye comme au Peru. Aufi peu y a-il de ces beftes qu'ils appellent au Peru guancos, \& Vicunas, qui font comme chevres. fauuages, fort viftes, en l'eftomac defquelles fe srouue la pierre bezaar, que plufieurs eftiment de grand prix, \& f'en trouue quelquefois d'aufi groffes qu'vn auf de poulle, voire la moitié dauantage. Ils n'ont non plus d'autre forte de beftial, que de ceux que nous appellons moutons d'Inde, lefquels, outre la laine \& la chair, de laquelle ils fe nourriffent, \& fe veftent, leur feruent d'alnes, \& de voictures à porter charge. Iis portent la moitié de la charge d'vne mule, $\&$ font de peu de frais à leurs maiftres, pource qu'ils n'ont befoin ny de ferrures, ny de bas, ny d'auoine pour leur viure, ny en fin d'autre harnois, d'autant que de tout cela ils en font pourueuz de nature, qui a voulu en ce fauorifer ces pauures Indiens. De rous ces animaux, \& de plufieurs autres fortes, dont ie feray mention en fon lieu, la terre ferme des Indes eft fore abondăte \& remplie. Mais il ne f'en troutue aux Ifles que ceux que les Efpagnols y ont apporrez. Il eft bien y ray qu'vn de nos Freres vid vn jour vntygre en vne Inle, comme il nous a raconté fur le propos d'vne fienne peregrination

F iisj 


\section{Hiftoire naturelle}

\& naufrage. Mais interrogé combien cefte Ine eftoit efloignee de terre ferme, refpondit comme de fix à huit lieües pour le plus, laquelle traverfe de mer les tygres peuuent aifément paffer nage. On peut inferer par ces argumens \& aures fenblables, que les premiers Indiens one paffé pour peupler ces Indes plus par le chemin de terre quede mer; ou fil y a eu nauigation, qu'elle n'a efté ny grande, ny difficile, pource que c'eft chofe indubitable qu'vn monde doit eftre ioint \& continué auec l'autre, ou à tout le moins eftre en quelque endroit fors prochel'vn de l'autre.

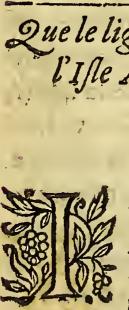

nage des Indiens n'eft point paßépar l'y fle Atlantique, comme quelques-uns

\section{simaginent. \\ Chapitre XXII.}

Sap. I2。

L y en a quelques-vns qui fuiuans l'a: pinion de Platon, mentionnee cy def: fus, rapportent que ces gens la partirent de l'Europe, ou bien d'A frique, pour aller en cefte tant fameufe, \& tant renommee Inle Atlantique, \& que de là ils paffevent d'Ifle en autre, iufques à paruenir à la terre me des Indes; pource que le Crifias de Platon en fon Timee, en difcourt de cefte maniere. Car fil'inle Atlantique eftoit auffi grande com me toute l'A fie \& l'A frique enfemble, ou bien encore plus grande, comme veut dire Platon, elle deuroit par neceffité comprendre tous loccean Atlantique, \& paruenir prefque iuf- 


\section{des Indes. Liure. I.}

ques aux Isles du nouueau monde. Et dit dauantage Platon, que par vn grand \& eftrange deluge fon Isle Atlantique fe noya, \& par ce moyen rendit cefte mer innauigable, pour la grande abondance des bancs, rochers, \& impetuofité des vagues qui y eftoient encore de fon temps. $M a i s$ qu'en fin les ruines de cefte Isle noyee, $\mathrm{fe}$ raffirent \& rendirent cefte mer nauigable. Cecy a efté fort curieufement traikté \& difcouru par aucuns hommes doctes, \& de bon entendement; \& neantmoins eftant de presconfideré, à vray dire fe treuuent chofes ridicules, qui reffemblent plus les fables, ou contes d'Ouide, qu'vne hiftoire, ou Philofophe digne d'eftre mife en auant. La plus part des interpretes \& expofiteurs de Platon, afferment que c'eft vne vraye hyftoire tout ce que Crifias raconte de l'eftrange origine de l'Isle Atlantique, de fa grandeur \& profperité, des guerres qu'ils ont elies contre ceux de l'Europe, $\&$ plufieurs autres chofes. Ce qui fait croire dauantage que c'eft hiftoire vraye font les paroles de Crifias, que Platon introduit en fon Timee, difant, que le fubiect qu'il veut traiter eft de chofes eftranges, mais qui font neantmoins veritables. Les autres difciples de Platon confidetans que ce difcours a plus d'apparence de fable, que non pas d'hiftoire, difent, que l'on doit entendre cela par allegorie, \& que ç'a efté l'intentiorfde leur diuin Philofophe. De cefte opinion eft Procle, \& Porphyre, voire Origene, lefquels eftiment tant les efcrits de Platon, que quand ilsen parlent, il femble que ce foient les liures 


\section{Fif toire naturelle}

đe moýfe, ou d'efdras, \& là où il leur femble que les efcrits de platon ne font pas vray-femblables, difent qu'on les doit entendre en fensallegoric \& myftic. Mais pour dire la verité, ie ne porte point tant de refpect à l'authorité de Platon, quoy qu'ils l'appellent diuin; qu'il me femble trop difficile de croire qu'il ayt peu efcrire ces chofes de l'Isle Atlantique, pour vne vraye hiftoire, lefquelles pour cela ne laiffent point d'eftre de pures fables: veu qu'il confeffe ne l'auoir àppris que de Critias qui eftoit petit enfant, \& entre autres chanfons chantoit celle de l'Isle At. lantique. Quoy que c'en foit, que Platon l'ayt ef. crit pour hiftoire, ou pour fable, quant à moy, ie croy que tout ce qu'il a efcrit de cefte Isle, commençant au dialogue du Timee, \& pourfuiuant à celuy de Critias, ne peut eftre tenus pour chofe vraye, finon entre les enfans \& les vieilles. Qui ne tiendra pour fable, de dire que Neptune s'en amoura de Clyté,\& out d'elle cinq foisdes gemeaux d'vne ventree, \& que d'vne montagne il tira trois pellottes rondes de mer; $\&$ deux de terre, qui fe reffembloient fi bien, que l'on euft dit qu'elles euffent efté faictes toutes en vntour? Que dirons-nous dauantage de ce temple de mil pas de long, $\&$ de cinq cents de large, duquel les parois par dehors eftoient toutes couvertes d'argent, tout le lambriod'or, \& le dedans d'yuoire cifellé \& entrelaffé d'or, d'argent, \& de perles? En fin parlant de fa ruine finale, il conclud ainfiau Timee: $E_{n}$ vn iour $\mathfrak{O}$ vne nuit furtint vn grand deluge, par lequel souss nos foldats furent engloutis a monceanx dans la ser. 


\section{des Indes. Liure. I.}

46

Yie, or de cefte façon l'Ile Atlantique estant fubmergee, diparut en la mer. Pour certain ce fut bien à propos que cefte Inte difparut fi fubitement, veu qu'elle eftoit plus grande que l'Afie \& l'Afrique enfemble; \& qu'elle eftoit faicte par enchantement. C'eft chofe auffi de mefme fort à propos, de dire queles ruines de cefte Inle fi grande fe voyent au fonds de la mer, \& que ceux. quiles voyent, qui font les mariniers, ne peuuent nauiger par là. Dais il adioufte: Pour ceste caufe sufques awiourd'buy cefte mer ne fe narige poins, ny repeute eftre rsanigee pour raifon dis banc, qua pers à peu sest formi en ceßze Ifle fubmergee. Ie demanderois volontiers quelle mer a peu englontir vae relle infinité de terre, qui eltoit plus grande que toute l'A fie \& l'Afrique enfemble, \& qui re confinoir iufques aux Indes, \& encore l'engloutir de telle façon, qu'il n'en foit demeuréà prefent aucuns reftes, ny apparences quelconques : veu qu'il eft tout cogneu \& efprouné que les mariniers ne trouuent aucun fond (quoy. quelongue foit leur fonde) en la mer où ils difent auoir efté cefte Ine. Toutesfois ce pourra fembler chofe indifcrete \& efloignee de rain fon, de vouloir difputer ferieufement les chofes qui ont efté racontees par paffetemps feulement; ou bien fil'on doit atuoir tant de refpect à l'authorité de Platon (commeil eft bien raifonnable) on les doit pluftoft entendre, pour fignifier fimplement, comme en peinture la prof perité d'vne ville, \& quant \& quant fa perdition. Car largument qu'ils font pour prouwer que reellement \&z de faict cefte Ine A lanti- 


\section{Hiffoire naturellé.}

que ayt efté, difans que la mer en ces parties 12 retient encor auiourd'huy ce nom d'Atlantique, eft de peu d'importance; veu que nous fçauons

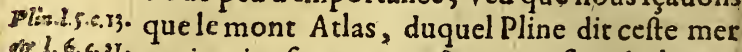
3 1.6,c,3\%? auoir prins fon nom, eft aux confins de la mer - de Mauritanie. Et fil le mefme Pline raconte que ioignant le mont fufdit il y a vne Ine nommee Atlantique, qu'il dit eftre fort petite $\&$ de fort peu de valeur.

2 ue lopinion deplufieurs qui afferment que los premsiere race des Indiens vint des I uifs, rieft point veritable.

\section{ChAPITRE XXIII.}

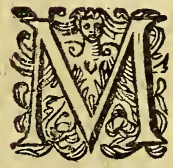

Aintenant que nous quons möftré 1 qu'il n'eft point vray-sëblable que les premiers Indiens ayent paffé aux Indes parl'Ine Atlantique, il y ena d'autres qui difent \& ont opi-

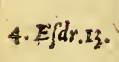
nió que ce fut par ce chemin dont parle Efdras liure quatriefme, difant ainfi: $E$ e pourcequetw vids quilla afembloit vne autre troupe o multitude d'hommes paifibles, tu fgauras que ceux- la font les dix tributs quifurent mene en captiunté au temps du Roy o Zee, que salma.

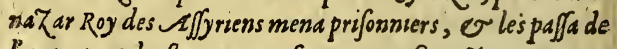
$l$ aucre part du flewue, o furent tran porte $Z$ en vne als- ore terre. Ils arrefterent $\sigma$ refolurent entr' eus de laifger las smaltitude des Gentils, $\sigma$ de pajer en autre region plus efloignee, oì iamais les humains n habiterent, afin de garder leur loy quils s'ausoient peu conforver en lewr terre; ils pafereme donc par deschemins effroits du feenue Eus. 


\section{des Fndes. Liure I.}

phrate car alors Diew monftra fes merueilles en leur endroit, arrefs ant le cours du fleune iu fques à ce qu w uls euffent pafé, d'autant que le chemin pour aller en cefte region eftoit tres-long, $\mathcal{O}$ d'vn an $\mathcal{O}$ demy, $\mathcal{O}$ 'sappelle ceffe region Arfareth. Alors ilsy demeurerent infänes aux derniers temps. Maintenant quand ils consmenceront a reuenir, le Tout-puiffant retiendra derechef vne autre fois le cours du fleune, afin quivils puiffent paffer, o pour ceftse. caufe tu as ven cefte multitude arecpaix. Quelques. vns veulent accommoder cefte efcriture d'Efdras aux Indiens, difans qu'ils furent:conduits de Dieu où iamais n'babita genre humain, \&e que la terre où ils demeurerent eft fi clloignee, quil y 2 yn an \& demy de chemin pour y aller, eftant cefte nation naturellement paifible, \&E qu'il y a de grands indices \& argumens entre le vulgaire de ces Indiens, pour faire croire qu'ils defcendent de la race des Iuifs, d'autant que l'on les voit communément efchars, rabairfez, ceremonieux, \& fubtils en meníonge. Et difent dauantage que leurs habirs reffemblene fort a ceux dont vfoient les Iuifs, pour ce quils portent vne tunique ou chemifolle, \& vn manreaubrodé tout au tour, vont les pieds nuds, ou feulemeut auec des femelles attachees de courroyes fur le pied, qu'ils appellent Ojotas. Et difent qu'il appert par leurs hiftoires, comme auffi par les anciennes peintures, qui les reprefentent en cefte façon, que ccft habit eftoit l'ancien veftement des Hebrieux, \& que ces deux fortes d'habits dont les Indiens vfent tant feulement, eftoient ceux dont vfoir Sam que l'Efcriture appelle, Tumbam, \& sindonews 


\section{Efifoire naturelle}

gui eft le mefme queles Indiens appellent che mifollc \& manteau. Mais toutes ces coniectures font legeres, \& pluftoft contr'eux, que pour eux : car nous fçauons bien que les Hebrieux $v$ foient de lettres, \& il n'y en a aucune apparence entres les Indiens. Les autres eftoient fort amys de l'argent, \& ceux-cy n'en ont point de cure. Les Iuifs s'ils n'eftoient circoncis, ne s'eftimeroient pas Iuifs, \& les Indiens au contraire ne le font ny peu, ny point, \& iamais n'ont vfé de ceremonie qui en approche, cóme plufieurs des Orientaux. Mais quelle apparence ya-il de conie Eurer cecy, veu que les Iuifs font tant diligens à conferuer lcur langue íc leurs antiquit $f$, de forte qu'en toutes les parties du monde où ils font, ils different; $\&$ les cognoit-on toufiours d'auec les autres, \& neantmoins qu'aux Indes feulement ils ayent oublié leur lignage, leur loy, leurs ceremonies, leur meffie, \& finalement tout leur Iudaïfme? Ence qu'ils difent que les Indiens font efchars, rabaiffez, fuperfticieux \& fubtils en - menfonge; pour le premier c'eft chofe qui n'eft point commune à tous: car il y a des nations en- tre ces Barbares exemptes de cessicices. Il y en a d'autres genercux \& hardis, il y en a aufi de groffiers, \& fort lourds d'entendement. Quant aux ceremonies \& fuperftirions, les Gentilsen ont toufiours fort vić. De leur façon d'habits, commeil a efté defcrit cy deuant, ils-en vfent ainfi, pour ce que c'eft le plus fimple \& naturel du monde, fans artifice, \& qui prefquea efté cómun, nen feulemenț aux $\mathrm{H}$ cbrieux, mais à tou tes les autres nations. Veu mefme quel'hiftoire 
des Jndes: Liure. I.

Efdras (fi nous deuons adioufter foy aux ECitures apocryphes) eft plus contraire, qu'elle e fe rapporte a leur intention. Car il dit en ce aflage, quie les dix tributs s'enloignerent de la ultitude des Gentils, pour garder leur foy $\&$ remonies, $\&$ l'on voir que les Indiens font adonnez à toutes les idolatries du monde. Et eux qui ont cefte opinion mef me, voyent bien les entrees du fleuue Euphrate vont iufques ux Indes, \& s s'il eft neceiffaire aux Indiens de reaffer par là, comme il eft dit au lieu preallegué. utre ce, ie ne voy point comme ils fe puiffene ommer pacifiques, veu quils fe font cótinuelment guerroyez les vns les autres. En concluon ie ne voy point que l'Euphrate de l'apocryhe Efdras, foit vn paffage plus propre pour al: er au nouueau monde, que l'enchantee \& fabueufe Ifle Arlantique de Platon.

Pour quelle raifon lion ne peut bien trouner. lorigine des Indiens.

CHAPITRE XXIV.

17 L eft plusay fé de refurer \& contredire 24 L les fauffes opinions mifes en auant fye 19 l'origine des Indiens, que non pas d'en dire $\&$ arrefter vne refolution certaine \& veritable: pour autant quil n'y a aucune efriture entreles Indiens, ny memoires ceraines de leurs fondateurs; Et que mefme il 'eft fait aucune mention de' ce nouueau mon- 


\section{Hiftoire naturelle}

de és liures de ceux qui ont eu cognoiffance des lettres: nos anciens ont tenu quen ces parties là n'y auoit ny hommes, ny terre, ny Ciel A raifon dequoy celuy là fembleroit fort temeraire \& prefornptueux, qui penferoit defcoururir \& monftrer la premiere origine des Indiens, \& des premiers hommes qui ont peuplé les Indes. Mais nous pouuons de loing donner iugement par le difcours que nous ausons mis en atrant cy-deffus, que ce peuple des Indes eft venu, s'aduançát peu à peu iufques à ce qu'il foit arriué au nouueau monde, \& ce par l'ayde \& le moyen de la continuité ou voifinage de terres, ou bien par quelque nauigation. Ce qui me femble auoir eftéle moyen, par lequel ils y font venus, \& non pas quils ayent fait armee pour y aller de propos deliberé, ny qu'il leur foit arriué aucun naufrage, ou tempefte quiles y ay t portez: combien qu'en quelque partie des Indes aucunes de ces chofes puiffent eftre arriuees, d'autant que ces regions eftans fi grandes qu'elles comprennent en elles des nations fans nombre, nous pouuons croire queles vns y font venus pour peupler d'vne forte, \& les autres d'vne autre façon. Mais en fin ie mérefoudsà ce point, que la vraye $\&$ principale caufe $\&$ moyen de peupler les In des, a elté pource que les terres \& limites d'icelles fe ioignoient \& continuoiêt en quelques extremitez du monde, ou qu'à tout le moins elles eftoient fort proches. Et croy qu'il n'y a pas plufieurs miliers d'annees, queles hommes habitent ce nouueau monde, \& Indes Occidentales, mefme queles premiers hommes qui yes: 


\section{des Indes. Liure. I.}

entrerent, \& eftoient pluftoft hommes fauuaes, \& chaffeurs, que non pas efleuez \& nourr is n Republique ciuile \& policee, \& qu'lls arrierent au nouueau monde, pluftoft s'eftans perlus de leur terre, ou s'y eftans trounez en trop rand nombre, \& en neceffité $y^{\prime}$ 'en chercher ne autre, laquelle ayant trouuee, ils commenerent peu à peu da la peupler, n'ayans point d'aureloy, qu'vn peu d'infinct naturel,' ' $\&$ encor ort obfcur, \& pour le plus, quelques couftumes ui leur font demeurees de leur premiere parrie. it bien qưils fuffent fortis de terres policees \& ien gouuernees, fi eft -ce qu'il n'eft pas incroyale de penfer qu'ils euffent oublié le tout pour a longueur du temps, \& le peu d'vfage:veiu que 'on fçait qu'en Efpagne \& en Italie mefme, l'on rouue des compagnies d'hommes qui n'en óne ien quela figure $\&$ gefte feulement, d'où l'on eut conic Curer que de la façon les moeurs barbarefques \& inciuils, font venus en ce nouueat. monde.

Dece que les Indiens racontent de leur origine.

\section{CHADITRE XXV.}

Du ce de fçauoir ce que les mefmes Indiés (1) 5 ont accouftumé de raconter de leur a commencement \& origine, ver qu'ils effemblent plus leurs fonges que vrayes hiftoices.lls font entr'eux grande mention d'vn delu. ieaduenu en leurs pays, mais l'on ne peut pas 


\section{Hiftoire naturélle}

bien iuger fi ce deluge eft l'vniuerfel, dont parlel'Efcriture, ou fi ç'a efté quelque autre doluge, ou inondation particuliere des regions où. ils font. Ancuns hommes experts difent que l'on voit en ces pays-là, plúfieurs notables apparences de quelque grande inondation, \& fuis de Popinion de ceux qui penfent que les veftiges \& marques qu'il y a de ce deluge, ne font de celuy de Noé, mais de quelquautre particulier, comme de celuy que raconte Platon; ou celuy. gue les Poëtes chantent de Deucalion. Quoy qu'il en foit, les Indiens difent que tous les hommes furent noyez en ce deluge, \& racon. tent que du grand lac Titicaca, fortit vn $\forall$ iracocha qui s'arrefta en Tiaguanaco, où l'on voit auiourd'huy des ruines \& veftiges d'anciens edifices fort eftranges, \& de là vint à $\mathrm{Cu}$ co : ainfrrecommença le genre hunıain à fe multiplier: Ils monftrent en ce mefme lac vn petit Iflet, où ils feignent que le foleil fe cacha \& s'y conferua : \& pour cefte raifon ils liay faifoient de grands facrifices en ce lieu, non feulement de brebis, mais d'hommes mefmes. D'autres racontét, que fix, ou ne fçay quel nombre d hommes fortirent d'vne certainé cauerne, parvne feneftre, qui donnerent commencement à la multiplication des hommes, \& à cefte occafion les appellent Pacaritampo. C'eft pourquoy ils font d'opinion que les Tambos eft la race la plus ancienne des hommes. Ils difent que Mango Capa, lequel ils recognoiffent pour fondateur $\&$ chef des Inguas, eftoit yffu de cefte race là, \& que de luy fortirent denx familles \& ligna: 


\section{des 7 ndes. Liure 1.}

es, l’vn de Hauă Cufco, \& l'autre de Vrni Cufo.lls difent dauantage, que quand les roys Inuas entreprenoient guerre, \& conqueftoient iuerfes Prouinces, ils donnoient couleur, \& renoient pretexte de leur entreprinfe, difans ue tout le monde les deuoit recognoiftre: our autant que tout le monde s'eftoir renouellé de leur race \& de leur patrie. Et mefme une la vraye Religion leur auoit efté reuelee lu Cicl. Mais que fert d'en dire dauantage, veu ue tout y eft plein de menfonge $\&$ de vanité, $x$ du tout efloigné de raifon? Quelques homnes doctes efcriuent, que tout ce dont les Inliens font mention, \& n'eft plus ancien que de puatre cents ans, \& tout ce qu'ils difent du paauant, n'eft qu'vne confufion embroüillee de i obfcures tenebres, qu'on n'y peut trouuer auune verité. Ce qui ne doit fembler eftrange, l'autant que les liures \& efcritures leur defaillent, au lieu defquellesils fe feruent de leur conte de leurs Quipocanayos, qui leur eft pariculier. Par lequel conte tout ce qu'ils peuent rapporter ne peut eftre plus long que de quatre cents ans. M'informant diligemmen. d'eux, pour fçauoir de quelle terre, $\&$ de quelle ation ils pafferent autres fois là où ils font, \&z riuent à prefent, ie les ay trouuć fi elloignez de pouuoir donner raifon de cela, qu'ils tiennent pour certain qu'ils font creez de leur premiere origine en ce nouueau monde, où ils habitent. Mais nous leur auons ofté cefte erreur par no. Are foy, qui nous enfeigne que tous les homAT.17\% mes procedent d'vn premier homme. Il y $G$ ij 


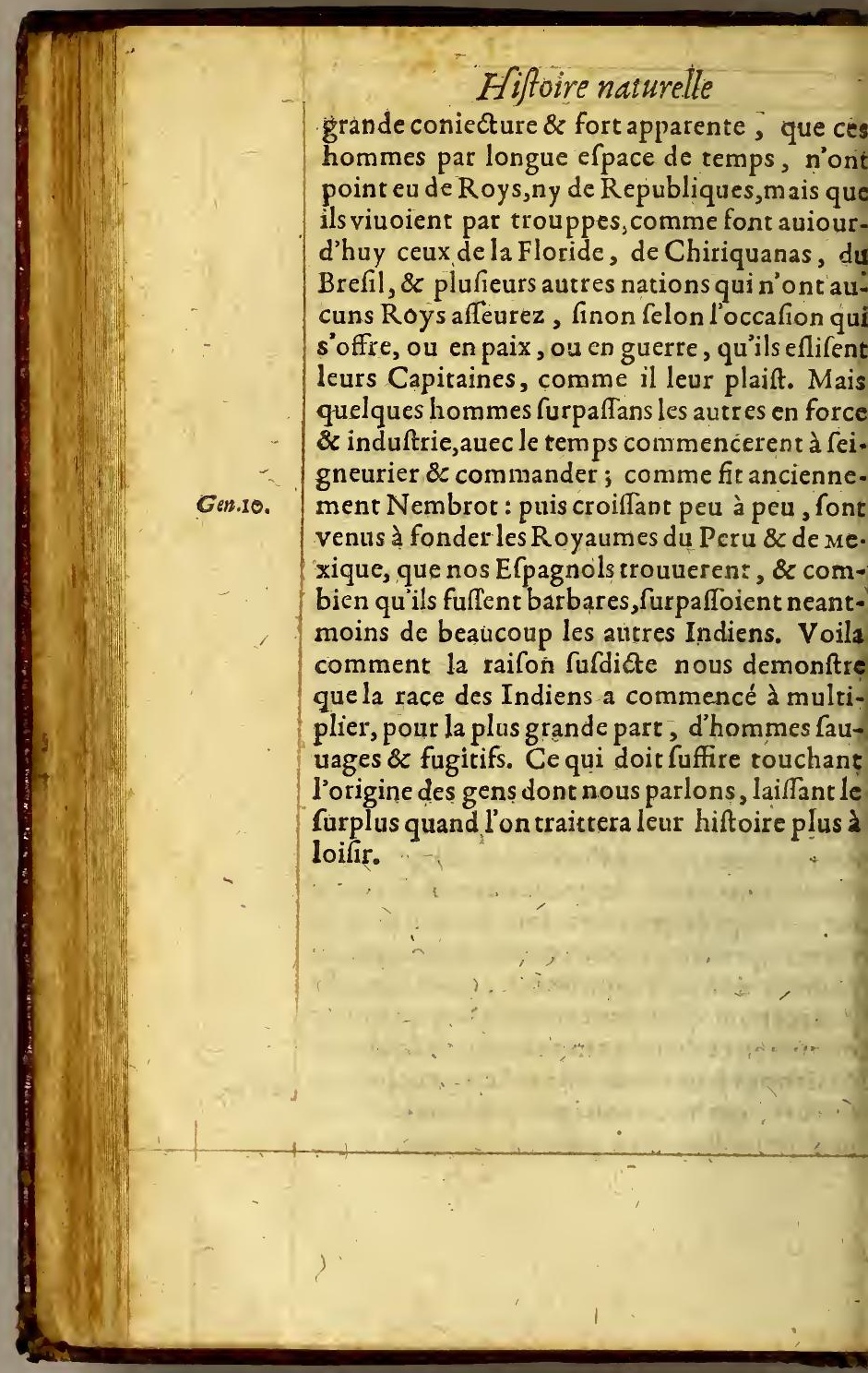




\section{Hiftoire naturelle}

le monde les iours \& les nuicts efgaux; mefmes que ceux qui habitent au deffous d'icelle, iouyf fent tout le lóg de l'annee de cefte mefme efgalité des iours \& des nuidts. Or en cefte ligne zqui. noxialle, nous trouuons tant d'admirables pro. prietez, que c'eft auec bóne raifon que l'entendement humain ferefueille $\&$ trauaille pour en rechercher les caufes, n'eftant point tant, efmeu à ce par la doctrine des anciens shilofophes, que par la mefme raifon \& certaine experience.

Pour quelle raifon les anciens ont tenu que la Zone Torride pour certain eftoit.

\section{inhabitable.}

Chatitre II.

Echerchant à prefent ce fuject dés (6) (1) fon cómencement, aucun ne pour10 ra nier ce que nous voyons claire12. mét,que le foleil en s'approchant Q 20 efchauffe, \& refroidit en s'elloignant. Tefmoinsen font les iours \& les nuicts, tefmoins l'hyuer \& l'efté, la varietć defquels \& le froid \& le chaud eft caufé par l'approchemét $\&$ efloignemét du foleil. D'autre part, il eft auffi certain, que plus le foleil s'approche, \& iette fes rayons directement, plus la terre en eft arfe \& einbrafeè,ce qu'on void clairemét en la chaleus du midy \& en la force de l'efté. D'où l'on peut iuger (à ce qu'il me femble) que tant plus vno terre eft efloignee du cours du foleil, tant plus eft -elle froide. Ainfi nous experimentús que les terres \& regions qui s'approchét dauantage du 


\section{des Indes. Liure. II.}

Septentrion ou Nort, font les plus froides, \& au contraire celles qui s'approchent du Zodiaque, où chemine le foleil, fe trouuent les plus chaudes. Pour cefte caufe l'Ethiopie furpafte l'A frique \& Barbarie en chaleur, la Barbarie farpalfe l'Andalouzie,l'Andalouzie, Caftille \& Arragó, \& Caftille \& Arragá furpalfent auffi la Bifcayc \& la France. Er d'autant plus qu'elles font Septentrionalles, d'autát moins font elles chaudes: par confequent celles qui s'approchent le plus du foleil, \& font plus à plomb frappces de fes rayons, fe reffentent dauantage de la chaleur du foleil. Quelques-vns mettent en auant vne au . tre raifon à cefte fin, qui eft que le mouuemene du Ciel eft fort foudain \& leger deuers les Trapiques; mais qu'à l'endroit des Poles au contraire il eft fort lent \& pefant: d'où ils concluent quela region que le Zodiaque circuit \& contient, eft embrafee de chaleur, pour trois caufes \& raifons; l'vne pour le voifinage du foleil, l'autre pour receuoir directement fes rayons, la troificfine, pource qu'elle participe \& fe reflent aucunement de ce plus viftc \& foudain mouuement du Ciel. Voila ce que la raifon \& le difcours nous enfeignent, touchant la caufe du froid \& chaleur des regions de la terre. mais que dirons-nous des deux autres qualitez, qui font l'humidité \& la fecherefle ? tout le mefme. Car la fechereffe femble eftre caufee par l'approchement du foleil, \& l'humidité de fon efloignement, d'autant que la nuict eftant plus froide que le iour, eft aufi plus humide, \&z le ious eft phusfec, comme eftant le plus chaud. L'hywer

$$
G \text { iiij }
$$




\section{Hiftoire narurelle}

pendant que le foleil eft plus efloigné, fe void plus froid \& plus pluuieux, \& l'Efté au contraire, auquel Soleil eft plus proche, certainemenr eft plus chand \& plus fec.Pource que tout ainfi quele feuala proprieté de cuire \& de brufler, auffi l'a-il pareillement de deffecher l'humidité. Confiderans donc ce que deffus, Ariftote \& les autres Philofophes attribuen a la region du Midy, qu'ils appellent Torride, vne exceffiue chaleur, \& vne fechereffe tout enfemble. C'eft pourquoy ils difent que cefte region eftoit merweilleufement embrafee \& defechee: \& que par confequent elle n'auoit point d'eaux, ny de pafturages, caufe pour laquelle elle decoit eftre par neceffité fort contraire \& fort incommode à la vie humaine.

Que la Z one Torride eft fort bumide, contre lopinion des anciens.

Chapitre III.

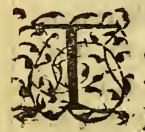

O V T ce que nous auons propofé cy deffus, femble certainement eftre vray $\&$ bien à propos, \& neantmoins. la conclufion quils en veulent tirer, fe trouue appertement faufe: : d'autant que la region du Midy, qu'ils appellent Torride, eft p'euplec \& habitee d'hommesrealement \& de faict; \& nous-mefmes y auons demeuré. long temps : auffi eft-elle fort commode, plaifante $\&$ agreable. Si donc il eft ainfi, comme on ne le peut nier, que d'vne propofition veritable lon ne peut tirer vne conclurion fauffe, 


\section{des Fndes. Liure II.}

2 que neantmoins cefte conclufion foit faufe, omme elle l'elt, il nous eft befoin de retourner riere par les inefimes pas, pour confiderer, \& egarder vn peu de plus pres cefte propofition $z$ d'où procede l'erreur \& la faute. Nous dions donc premierement quelle eft la verité, fe. on quel'experience certaine nous le montre, ux apres nous le prouuerons (combien que ce oit chole fort difficile) \& mettrons peine d'en lonner la raifon, fuiuant les termes de Philofohie. Le dernier point que nous auons propofé $y$ deffus, que la fechereffe eft plus grande lors uue le foleil eft plus prochain de la terre, femle chofe certaine $\&$ veritable, \& ne l'eft pas outefois, au contraire eft totalement faufe: car il n'y a iamais plus grande abondance de oluyes en la Zone Torride, quelors quele foeil paffe par deffus, \& en eft fort proche. C'eft :ertainement chofe admirable, \& digne d'eftre emarquee, que l'air eft plus ferain, \& fans pluyes, fous cefte Zone Torride, lors que le focilen eft plus efloigné; \& au contraire qu'il y a plus de pluyes, de neiges, \& de brouillards, au cemps quele foleil en eft plus proche. Ceux qui n'ont point efté en ce noutueau monde, paraduenture tiendront cecy pour chofe incroyable, \& femblera eftrange mefme à ceux qui y ont efté , fils n'y ont prins garde: mais les uns \& les autres $f^{\prime} y$-accorderont volontiers, en remarquát l'experience certaine de ce qui a efté diten ce cofté du Peru, qui regarde le Pole du Sud, ou Antarctique, le foleil en eft plus efloigné lors \& au-mefme temp̀s qu'il ent plus proche del'Euro- 


\section{Hiffoire naturelle}

pe à fçatoir , en May, Iuin, Iuillet, \& Aouf; qu'il fait fon cours au Tropique de Cancer, dusrant lefquels mois au Peru y a vne grande ferenité \& tranquillité de l'air, \& n'y tombe alors aucune neige, ny pluye. Tous les fleuues $\&$ riuieres y diminuent fort, \& quelques-vns y tariffent du tout. Mais comme l'annee fiadnance, 8* que le foleil f'approche du Tropique de $\mathrm{C}_{3}$, pricorne, alors commencent les eaux, pluyes, $\&$ neiges, \& fe font les grandes creïes des riuieres, qui eft depuis Octobre iufques en Decembre; puis apres, le foleil fe retirant du Capricorne, lors que fes rays donnent droittement fur les teftes de ceux du Peru, e'eft alors que la force $\&$ fureur des eaux eft grande, c'eft le temps des pluyes, neiges, \& grands débordements des riuieres, qui eft en la mefme faifon de l'annee qu'il y a plus grande chaleur, fçauoir depuis lanuier iufques à la my-Mars. Et eft chofe fi vraye, \& fi certaine, que perfonne ne le peut contredire, \& tout le contraire alors fe rencontre és regions du Pole ArCtique ourre l'Equinoxe, ce qui pro. cede d'vne mefme raifon. Mais voyons maintenant de la temperature de Panama, \& de toute cefte cofte, tant de la neuue Efpagne, des Ifles de Barlouente, de Cuba, Efpagnolle, Iamaïque, que de fainet Iean de Port-riche, nous trouuerons fans faute que depuis le commencement do Nouembre iufques en Apuril, ils y ont l'air \& le ciel fort clair \& fort ferain, dont la raifon eft, pour autant que le foleil paftant par l'Equinoxe pour aller au Tropique de Capricorne, il fe va elloignant de ces regions plus qu'en autre faifon 


\section{des Indes. Liure II.}

de l'annee, Et au contraire, ils y ont de grofles pluyes, \& de fort grands rauages d'eaux, quand le foleil retourne vers elles, \& qu'il en eft plus proche, qui eft depuis Iuin iufques en Septembre, pource qualors fes rayons donnent plus fort fur eux. On void aduenir le femblable en l'Inde Orientale, comme nous l'apprenós iour. nellement par les lettres qui en viennent. Par ainfi c'eft vne regle generale (bien qu'en aucuns Lieux il y ayt exception) qu'en la region du Midy, oude la Zone Torride, qui eft vne mefme chofe, l'air y eft plus ferain, \& y a plus de fecherelle alors que le foleil en eft plus efloigné; \& au contraire, que quand il fen approche, il y a plus de pluyes \& d'humiditez, \& tout ainfir que le foleil fraduance, ou fe retíre peu, ou plus; ainfila terre abonde, ou manque d'eaux, ou d'hu. midité.

Qu'au regions qui font hors des Tropiques il y aplus d'eaux lors que (le foleil en eft pliss efloigné, tout aucontraire de ce qui eft four? la Zone Torride.

\section{Chapitre IV. ,}

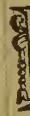

$S$ regions qui font hors les Tropiques l'on void tout le contraire de ce qui eft dit cy deffus, pource que la pluye fe melle ausec le froid, \& la lechereffe auec la chaleur; ce qui eft fort bien cogneu en toutel'Europe, \& en tout le vieil monde, com. 


\section{Hiftoire naturelle}

me on le void de mefme façon en tout ce nouueau; dont eft tcfmoing tout le Royaume de Chillé, qui pour eftre dehors le Tropique de Capricorne, \& en mefine hauteur que l'E pagne, eft fujet aux mefmes loix de l'hyuer, $\&$ de Pefté, excepté que l'hyuer eft là quand l'efté eft en Efpagne, d'autant qu'ils font en diuers poles. Par ainfi quand le froid eft en ces Prouinces, les eaux y font en fort grande abondance, qui eft, quand le foleil f'en enoigne le plns, depuis le commencement d'Auril iufques à la fin de Septembre. Finalement la difpofition des faifons y eft telle qu'en Europe, fçauoir, que la chaleur \& fechereffe y viennent quand le foleil y rerourne. Delà vient que ce Royaume de Chrlllé approche plus de la temperature del'Europe, quaucun autre des Indes, tant aux fruicts de là terre, qu'en la difpafition du corps \& $z$ de l'efprit des hommes. Ce quilis difent eftre de la mefme façon en cefte partie de terre qui elt deuant l'Ethiopie interieure, laquelle fe va eflargiffant en façon de pointe, iufques au Cap de bonne efperance. Ce quils tiennent pour vraye caufe des inondations du Nil qui font en efté, defquelles les anciens ont tant difputé; d'autant qu'en cefte region là l'hyuer\& les pluye's y commencent au mois d'Auril, quand le foleil paffe defia le figne d'Aries. Et ces eaux qui en partie procedent des neiges, \& en partie des pluyes, faffemblent, $\&$ font de grands lacs $\&$ eftangs, defquels procede, par bonne \& vraye Geographie, le fleuue du Nil. Et parce moyen'va peu à peu enlargiffant fon cours, iufques à ce qua apres auoir couru 


\section{des Indes. Liure II.}

in long chemin, il vient finalement au temps de l'efté inonder l'Egypte, qui femble chofe contre nature, \& neantmoins eft chofe qui $\Upsilon^{\prime} y$ rapporte: car au mefme temps quil eft efté en Egypte fituee au Tropique de Cancer, l'hyuer eft aux fources du Nil, qui eft en l'autre Tropique de Capricorne. Il y a en l'Amerique vne atr. tre \& femblable inondation que celle du vil, au Paraguey, ou autrement, ruuiere de la Platte (qui vaut autant à dire comme riuiere d'argent:) lequel tous les ans receuant vne infinité d'caux qui tombent des montagnes du Peru, vient à fe déborder fi terriblement de fon cours, \& va gagnant tellement cefte region, que les habitans Cont contraints, durant ces mois là, de fe retirer $\&$ fe tenir en des barques \& canoes, \& de quitter l'habitation de la terre.

2u'entre les deux Tropiques en Efté, ou temps dechaleur, eft la faifon où ily a plus grande abondance de pluyes; auec on difcours de l'Hyuer, or de l'Efté.

\section{Chabitre V.}

207 Ov refolution, l'efté eft toufjours fuiuy, \& accompagné de chaleur \& de fecherefe és deux regions, ou Zones temperees, \& l'hyuer auffi de froidure \& d'humidité. Mais en la Zone torride les fufdites qua, direz ne fe trouuent point enfemblede la mef- 


\section{Hiftoire naturelle}

me façon, d'autát que les pluyes y fuiuét la clis:leur, \& le froid y cft accompagné de fecherefle, \& d'vn air ferain. I'entends par le froid', le defaut de chaleur exceffiue, d'où vient que l'hyuer fe prend en noftre Europe pour le froid, \& le temps pluuieux \& sfté pour le temps de chaleur \& ferenité de l'air. Nos Efpagnols qui font au Peru \& en la neute Efpagne, voyans que ces deux qualités ne fe trótuoient point enfemble, comme elles font en Efpagne, appellent l'hyuer la faifon en laquelle il y a beaucoup d'eaux \& de pluyes; \& l'efté celle où il y en a peu, ou point. En quoy ils fe trompent euidément, quoy qu'ils veüillent dire par vne regle cümune, quel'E fté eft aux montagnes du Peru depuis le mois d'Auril iufqu'en Septembre, pource que les pluyes ceffent en ce temps-là, \& que l'byuer eft depuis le mois de Septembre infques au mois d'Aurit, pource qu'alors clles y reuiennent, \& parainfi il eft hyuer \& efté au Peru, lors, \& au mefme temps quill'eft en Elpagne; de forte que quand le foleil chemine au delfus de leur tefte, alors ils croyent que c'eft le fond del'hyucr, pource quil y a plus grande abondance de pluyes. Mais ceft chofe digne de rifee, comme venant de gens ignorans \& fans lettres: car tout ainfi comme la diuerfité qui eft entre le iour \& la nuict, procede de la prefence ou abfence du foleil en noftre hemifphere, felon le mouuem eri du premier mobile, qui eft la caufe du iour \& de la nuidt; ainfil la difference que nous voyons entre l'hyuer \& l'efté, procede del'approch ement, ou efloignement du foleil, felon le mous- 


\section{des Fndes. Liure II.}

ement du mefme foleil, qui eft en la propro unfe: Doricques à vray dire, il eft efté lors que foleil eft plus proche, \& hyuer quand il eft le lus efloigné. La chaleur, le froid, \& toute aue temperature, font caufees par neceffité de approchement, ou efloignement du foleil: ais le pleuwoir \& non pleumoir, qui eft l'husidité \& la fechereffe, ne fen enfuiuent pas neeffairement. C'eft pourquoy il eft aifé de iuger sutre cefte opinion vulgaire) qu'au Peru l'hyer elt ferain, \& fans pluyes, \&z que l'efté y eft luuieux, \& non pas au contraire, comme plueurs penfent que l'hyuer foit chand, \& l'efté it froid. Ils tombent en la mefme erreur fur difference quils font entre la plaine, \& les ontagnes du Peru, difans que quand il eft efté n la montagne, l'hy uer eft en la plaine, qui eft $n$ Auril, May, Iuin, Iuillet, \& Aouft; pource u'alors l'air eft fort clair \& ferain en la monane, fans aucunes pluyes, ny bruines, \& en ce emps là neantmoins l'on void ordinairement n la plaine des broüillard's quils appellent guaiia, qui eft comme v ne rofeefort douce, de lauelle eft counert le foleil : mais l'hyuer \& l'e:é, cómme il eft dit, font caufez del'approche. nent ' $z$ efloignement du foleil. Puis donc qu'il It ainfi, qu'en tout le Peru, tant en la montane, comme en la plaine, le foleil fen approhe, \& efloigne en vn mefme temps; il n'y a onc point de raifon de dire, que quand il eft fté en vne partie, l'hyuer foir en vne aurre. Coutesfois c'eft chofe de peu d'importance de lebatre fur la fignification des mots, quils l'ap- 


\section{Hiftoire naturelle}

peilent comme ils voudront, \& difent qu'il foi efté quand il ne pleut point, encoresqu'il faffe dauantage de chaléur. Mais ce où l'on doit auoir plus d'efgard, eft à la verité du fubjet qui eft de. claré, à fçausoir que la fechereffe, ou deffaut dè pluyes, ne font pas toufiours en plus grande abondance, quand le foleil f'approche le plus, ainfi quel'on void en la Zone Torride.

2ue li Zone Torride abonde en enu ó pafturages, contre lopinion d'Ariftote, qui a mis en aunt le contraire.

CHAITRE VI.

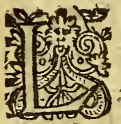

ON peut facilement entendre parle difcours precedent, que la Zone Tor. ride n'eft feche, mais abondante en eaux; ce qui eft tellement $v$ ray, qu'el. le furpaffe les autres regions du möde en abondance d'eaux, fice n'eft en quelques endroicts où il y a des fablons, ou terres de fertes, comme l'on trouue mefme és autres parties du monde. Quant eft pour les eaux du ciel, lon a defia monftré qu'il y a grande abondance de pluyes, neiges \& grefles, qui fpecialement abóndent en la Prouince du Peru: mais pour les eaux de la terre, comme font les riuieres, fontaines, ruif. feaux, puits, torrents \& lacs, ie n'en ay rien di iufques icy, toutesfois eftant chofe ordinaire que les eaux d'embas fe rapportent à celles d'enhaut, t'on doit entendre qu'il ne peut y en auoir faute. Er de vrayil y a vne telle \& fi grandeabon. 


\section{des Indes. Liure II.}

e abondance de fources, \& de fontaines, qu'il e fe peut trouuer lieu, region, ou contree deans tout le refte du monde, où il y ayt tant de cs, marefcages, \& de fi grandes riuieres : car x plus grande partie de l'Amerique eft prefque nhabitable, pourcefte trop grande abondan. e \& quantité d'eaux; d'autant que les riuieres nflees de grandes pluyes de l'efté, fortent zे ous coups de leur lict, auec vn'e telle furie $8 \tau$ mpetuofité, qu'elles rompent \& brifent tout. e qu'elles rencontrent, \& ne peut on en aucue façon cheminer en plufieurs endroits, à caue de la boüe $\&$ fange des marefcages $\&$ vallons 1 cefte occafion ceux qui demeurent proche $\&$ oignant le Paraguey, duquel nous auons faict nention cy deffus, preuoyans la creiie du fleute auparauant qu'elle aduienne, fe mettent en eurs canoes auec leurs meubles \& leurs hardes, ¿ prefque parl'efpace de trois mois, ou enuion, ils guarantiffent leurs vies \& leurs moyens in nageant. Puis apres, le fleuue retournant en on lict, ils reviennent en leurs maifons comne deuant, encores toutes moittes, \& degouantes de l'inondation. Ét eft cefleuue de telle randeur, quele Nil, le-Gange, \& l'Euphrate, ils eftoient amaffez tous enfemble, ne le pour.oient pas efgaler à beaucoup pres. Mais que lirons-nous de la grande riuiere de la Magdeaine, qui f'engolphe en la mer entre faindte Marthe, \& Carthagene, \& eft appellee auec onne raifon, grande riuiere? Nauigeant en ces parties-là, j’eftois grandement efmerueillé comme fon eau, qui eft tres-claire, demeuroir 


\section{Hifoire naturelle}

\&e s'efcouloit dans la mer plus de dix lieities auant, ayant en fa largeur deux lieiies, \& $\mathrm{da}$. uantage, fans qu'elle fe mellaft, ny peuft eftre vaincuë des vagues impetueufes de la mer $\mathrm{Oc}$. ceane. Que sil eft queftion de parler plus lon guement des fleuues, ce grand theuue appell par les vns la riuiere des Amazones, par les autres, Maranou, \& par les autres, riuiere d'Orel. lana, laquelle nos $E$ fpagnols nauigerent lors de leurs defcouuertes, doir efteindre la renommer de tous les autres. Et à la verité ie fuis en doute fi ie le dors appeller, ou riuiere, ou mer. Il fluc depuis les montagnes du Peru, defquelles il re çoit vne abondance infinie d'eaux, de pluyes, \& de riuieres, qu'il va recueillant, \& attirant? foy, puis paftant les grandes campagnes \& plai mes de Potiti, du Dorado, \& des Amazones, vient en fin s'emboucher dans l'Occean, pref qu'à trauers des Ifles de la Marguerite, \& de la Trinité. Il a fa couche fi large, \& fi fpacieufe principalement au dernier tiers de la longueur qu'il contient au milieu de foy plufieurs, \& grandes Ifles. Er ce qui femble incroyable, lor que l'on le nauige par le milieu, l'on ne voic que du ciel \& de l'eau. L'on dir bien dauanta. ge, que de ce milieu l'on ne peut pas voir, ny defcouurir à l'ail plufieurs grandes \& haute montagnes qui font à fon riuage, à caufe de grande largeur. Nous auons appris de bonn part, la grandeur \& largeur efmerueillable d ce fleuue (qui doit bien, ce me femble, merite le nom d'Empereur \& Monarque des fleuues qui fut par le rapport d'vn rrere de noftre Com 


\section{des Fndes. Liure II.}

agnie, lequel eftant ieune pour lors, le nauigea $\{$ la compagnie de Pierre d'Orfua, auec lequel fe trouua à toutes les aduentures de cefte fir trange entree \& defcoutuerte, \& aux feditions pernicieux actes de ce mefchant Diego d'Auirre, d'où Dieu luy fift la grace de fortir, \& en tre deliuré, pour le metrre de noftre Companie. Telles donc font les riuieres qui font en region qu'ils appellentZone Torride, \& la egion feche \& bruflee, en laquelle Ariftote \& s ancicns difent qu'il n'y a point d'eaux, ny de afturages. Mais d'autant que j'ay fait mention u. Aleuue Marannon, afin de monftrer l'abonance des eaux qui font en la Torride, il ne fera ala à propos de toucher quelque chofe de ce rand lac qu'ils appellent Titicaca, qui eft au ailieu de la Prouince de Collao. Il y a plus de ix fleuues fort grands, qui fe perdent en enrant dans ce lac, \& neantmoins n'a pour fa vuie qu'vn feul courant d'eau, qui eft petit, bien u'on dife qu'il eft tres-profond, \& de telle faon, qu'il eft impoffible d'y baftir, ou faire pont, our la profondeur defon eau, \& qu'on nele eut non plus paffer par batteaux, pour la graneroideur \& rapidité da courant. L'on le paffe ar vn gentil, \& remarquable artifice, propre, $x$ particulier aux Indiens, qui eft auec vn pont le paille poféfur la mefme eau; lequel, d'auant qu'il eft fait d'vne matiere fi legere, ne f'enonce point, \& neantmoins eft ce parfage fort eur, \& fort ayfé. Celac contient prefque qua re vingrs lieiies, trente-cinq en fa longueur, \& quinze lieies au plus large, Il y a plufieurs Ifles $\mathrm{H}$ ij 


\section{Hiftoire naturelle}

qui anciennement eftoient habitees, \& cult uees, mais aujourd'huy elles font defertes. produit vne grande abondance de joncs, qu les Indiens appellent totora, duquel ils fe fer uent en mille vfages : car il fert de mangeaill aux pourceaux, aux cheuaux, \& aux ho mim mefmes. Ils en font des maifons, du feu, $\&$ de barques. Bref les Vros trouuent en ceftuy leu totora, tout ce dont ils ont de befoing, \& fon ces Vros, vn peuple fi brutal \& fi lourd, qu'eux mefmes nefeftiment pas hommes. On racont d'eux, qu'eftans interrogez de quelle nation il eftoient, ils répondirent qu'ils n'eftoient pat hommes, mais Vros, comme fi c'eftoit quelqu genre d'animaux. 11 f'eft troulué des villages en tiers des vros, habituez en ce lac feulement dan leurs batteaux de totora, lefquels font liez en femble, \& arreftez à quelques roches, \& bier fouuent changent ainfi de lieu à autre, tout $k$ village enfemble. Par ainfi qui voudroit au jourd huy les chercher où ils eftoient hier, l'or $n^{\prime} y$ trouueroit aucun refte, ny apparence d'eux ny de leur village. Le cours \& vuide de ce grand lac ayant couru enuiron cinquante lieües, faid encores vn autre $l a c$, moindre toutesfois que $l_{e}$ premier qu'ils appellent de Parya, \& contien aufi en foy quelques Iffettes: mais l'on n'y void aúcuné yffué. Quel qués-vns penfent qu'il court deffous terre, \& qu'il va donner en la mer du Siid, mettant en auiant à cefte fin, qu'il y a vin bras de fleuve que l'on void naiftre \& entrer en Ia mer, fort prochề du riuage, fans en cognoiAre l'origine. Au contraire ie croy que les eaux 


\section{Hiftoire naturelle}

il pleut en ces pays-là au temps que le folei iette fes rayons directement furlaterre, \& qu en ce faifant, il a plus de force: mais quand 1 foleil s'en efloigne, la chaleur fe tempere, \& pour lorsil n'y tombe point de pluye. D'où l'o peut bien inferer que la force $\&$ ardeur du fo leil eft ce qui caufe les pluyes en telles regions Auffi l'on oblerue, tant au Peru, neuue Efpa gne, qu'en toute la Torride, que les pluyes viennent ordinairement apres midy, lors qu les rayons du foleil font au poinct de leur plu grande force, \& que c'eft chole rare de voi pleuaoir au matin. C'eft pourquoy les voya geurs y preuoyent, \& commencent leur iour nee de grand matin, afin de l'acheuer, \& fere pofer à midy, pource qu'ils tiennent qu'ordi nairement il y pleut apres midy. Ceux qui on hanté \& cheminé par ce pays.là, en peuuen parler fuffifamment : car mefmes il y en a au cuns qui y ay ans fait quelque refidence, difen que la plus grande abondance des pluyes e quand la.lune eft en fon plein, encores que pou direla verité, ie n'en ay peu faire preuue fuffi fante, bien que j'y aye prins garde quelquefois Dauantage, les iours, l'an, \& les mois donnen à entendre la verité de ce que deffus, affauoi qu'en la Torride l'exceffiue chaleur du fole caufe les pluyes. L'experience nous enfeign le mefme aux chofes artificielles, comme au alambics, aufquels on diftille les eaux des her bes, ou des fleurs: car la vehemence du feu en ferre, \& contraint, pouffe, \& efleue en hau vne abondance de vapeurs, lefquelles eftan 


\section{des Indes. Liure II.}

reffees, \& me trouuans yffuë, font conuerties $n$ liqueur \& en eaux. L'on void tout le mefme $n$ l'or \& en l'argent que l'on tire \& affine parle if argent, d'autant que fi le feu eft lent \& pe. it, l'on ne cire quafi rien du vif-argent: mais fil It afpre \& violent, il euapure beaucoup le vif. rgent, lequel fe rencontrant en haut contre le hapiteau qu'ils appellent, le tournent incontitent en liqueur, \& commence à degoutter en as. Ainfi la grande ardeur du foleil produit ces leux effets, quand elle trouue matiere difpofee, jui eft de leuer les vapeurs en haut; \& l'autre de es refoudre incontinent, \& les tourner enliqueur, lors qu'ily a quelque obftacle pour les onfumer \& refoudre. Er bien qu'il femble que e foient chofes contraires, qu'vn mefme foleil lanslaZone Torride, eftant proche, caufeles pluyes, \& que hors la Torride, eftant elloigné, $I$ caufe vn mefme effect; fi eft-ce que tout bien confideré, il ne l'eft pas reellement, \& de faict. Mille effects és chofes naturelles procedent de choles contraires par vn moyen diuers. Nous mettons fecher le linge au feu $\&$ a l'air, derquels neantmoins l'vn efchauffe, \& lautre refroidit. Les paftes font fechees \& endurcies par le foleil \& par lagelee. L'exercice mode. ré prouoque le dormir, fil eft trop violent, il l'empefche; fil'on ne met du bois au feu, finalement il frefteint; fi l'on y en met beaucoup, $\&$ trop, il f'efteint auffi: car la feule proporrion l'entretient, \& le fait durer. Pour bien voir vne chofe, elle ne doit eftre ny trop proche des yeux, ny trop loing, mais en diftance raifonna: H iiij 


\section{'Hiftoire naturelle}

ble \& proportionnee; eftant trop efloigné d'v: ne chofe, l'on en perd la veüe, \& trop proche auff, ne la peut voir. Si les rayons du foleil font foibles, ils nattirent pas les bruines des riuieres; fils font violens, auffi tolt qu'il a attiré les vapeurs, il les refoult \& confomme, mais la chaleur moderee les attire \& conferue. Pour ce. fte raifon les vapeurs ne s'efleuent point communement de puict, ny à midy, mais au matin, quard le foleil commence à entrer en $f_{2}$ force. Sur ce fubject il y a mille exemples dechofes naturelles, que l'on void proceder fouuent de chofes contraires; qui doit faire que nous ne nous deuons pas efmerueiller, file foleil pour eftre fort proche, engendre les pluyes, \& qu'il en fait tout autant eftant fort elloigné : mais qu'eftant fon approchement moderé, \& proportionné, il n'en produit, ny caufe aucunement. Cependant il refte encore vn poinct que l'on peut demander, pour quelle raifon en $\mathrm{l}_{2}$ Zone Torride l'approchement du foleil caufe les pluyes, \& hors d'icelle font caufees par fon enoignement. A ce que ie puis iuger, la raifon elt, que hors des Tropiques en hyuer, le foleil in'a point tant de force, qu'il foit fuffifant pour confumer les vapears qui f'efleuent de la terre \& de la mer: car ces vapeurs f'amaffent en grande abondance en la region froide de l'air, où elles font congelees, \& efpaiffies par la grande froideur, puis apres eftans preffees, fe refoluent \& conuertiffent en eau. C'eft pourquoy en ce temps d'hyuer, que le foleil eft plus efloigné, que lesiours font courts, \& les nuiats plus lon: 


\section{des Indes. Livre. II.}

unes, la chaleur du foleil a peu de force, mais uand le foleil s'approche de ceux qui font iors des Tropiques, qui eft au temps d'efté, la orce du foleil eft defia telle, qu'elle enteue les apeurs, \& tout enfemble les confomme, les liffipe \& refoult : car la chaleur \& la longueur les iours font caufees par l'approchement du oleil. Mais au dedans des Tropiques, en la egion Torride, l'efloignement du foleil a tout utant d'effect, que le plus grand approchement qui foit aux regions defdits. Tropiques. Au noyen dequoy il ne pleut pas en la Torride, lors que le foleil eft efloigné, non plus que ors les Tropiques, quand le foleil eft plus proche; d'autant qu'en ceft approchement \&zefoignement, le foleil demeure toufiours en ine mefme diftance, d'où procede vn mefme effeet de ferenité. Mais quand le foleil eft au periode de fa force en la Zoné Torride, \& qu'il ette fes.rayons directement fur la tefte des haoitans, il n'y a ny ferenité, ny fechereffe, comme il femble qu'il deuroit y auoir, mais pluftoft de grandes \& eftranges pluyes, d'autant que par la force exceffice de $f a$ chaleur, il attire $\&$ enleue prefque en vn inftant vne grande abondance de vapeurs de la terre, \& mer Occeane, lefquelles font fi efpaiffes $\&$ en fi gráde abondance, quele vent ne les poutuant difiper, ny refoudre facilement, elles viennent à fe fondre en eaiie, qui caufe les pluyes fi froides, \& en fil grande abondance: car la grande vehemence dela chaleur peut attirer en peu de temps beau. coup de vapeurs, lefquelles elle ne peut fi toft 


\section{Fiftoire naturelle}

confumer \& refoudre, \& eftans attirees \& affemblees par leur grande abondance fefondent $\&$ tournent en eaïe. Ce que l'on cognoiftra fort bien par ceft exemple domeftique $\&$ familier. Quand l'on met roftir vn morceau de porc, de moutó, ou de veau, fi le feu eft violent, $\&$ la viande en foit fort proche, nous voyons que la graife fe fond toft $\&$ degoute en bas, qui vient de ce que la grande chaleur attire $\&$ efleiie ceft humeur $\&$ graiffe de la chair, \& pour eftre en grande abondance ne la peut refoudre, $\&$ ainfi dittille $\&$ tombe dauantage. Mais quand le feu eft moderé , \& ce que l'on roftit eft en diftance proportionnee, nous voyons que la chair fe roftit proprement, fans que la graiffe diftille trop à coup, pource que la chaleur moderee attire l'humidité, qu'elle confomme \& refout en vn inftant. C'eft pourquoy les cuifiniers font le feu moderé, \& n'en approchent la viande, ny trop pres, ny trop loin, de peur qu'elle ne fe fonde. On le peut voir par vne autre experiéce aux chandelles de fuif \& de cire: car fi la melche en eft groffe, elle fait fondr e \& decouler le fuif \& la cire, pource quela chaleur ne peut confommer ce qui s'elleue d'humeur : mais fi la flame eft proportionnee, la cire ne fe fond, ny decoulle, pource que la flame va confommant peu à peu ce qui s'elleue. Ce qui me femble la vraye raifon pourquoy en l'Equinoxe, \& en la Torride, la grand'force de la chaleur caufe les pluyes, lefquelles en d'autres regions font caufees pas. la foibleffe \& peu de chaleur. 


\section{des Fndes. Liure II.}

Camment lon doit entendre ce qui a efté dict cy deffus de la Z one Torride.

\section{CHAPITRE VIII.}

D. (a) (f) phyfiques l'on ne doir rechercher de Gin 3 regle infaillible \& mathematique, mals ce qui eft ordinaire, \& ce qu'on void par experiéce, qui eft la pl ${ }^{9}$ parfaicte regle; il faut croire que ce que nous ations dit, quill y a plus d'humidité en la Torride qu'aux autres regions, \& qu'en icelle il ne pleut point lors que le foleil en eft plus proche, fe doit prédre \& entendre de mefme, $\&$ de vray c'eft bien ce qui eft le plus cómun \& le plus ordinaire. Mais ce n'eft pas pour empefcher les exceptiós que nature a voulu mettre à cefte regle, rendant quel ques regiós dela Torride extrememét feches Ce quon racóte del'Ethiopie, \& nous l'auons veu en vne grande partie du Peru, où toute la terre ou co. the, quilils appellent plaines, mäquent de pluyes, voire d'eaux dela terre, excepté quelques vallees où il y a des eaiies de riuieres qui defcendent des montagnes, le furplus font fablons \&e terresfteriles, où à grande peine l'on trouue des fontaines, mais bien quelques puits tres-profonds. Mais nous dirons (Dieu aydant) en fon lieu, quelle eft la caufe pourquoy il ne pleut point en ces plaines (chofe que plufieurs demădent ) car à prefent ie pretends de monftrer feulement quil y a plufieurs exceptions aux regles 


\section{Hiftoiré naturelle}

šarurelles, d'où vient qu'il peut aduenir en quelque partie de la Torride, qu'il ne pleut pas lors que le foleil eit plus proche, mais quand il eft plus efloigné. Bien que iufques auiourd'huy ie ne l'aye veu, ny entendu, toutesfois s'il y en a, on le doit attribuer à la qualité particuliere de la terre; mais aufi quelquesfois s'il aduient le contraire, l'on doit auoir ef gard qu'en ces cho. fes naturelles ilarriue plufieurs contrarietez \& empefchemens, par lefquels elles fe changene \& déffont les vnes les autres. Pour exemple, il peut eftre que le foleil caufera les pluyes, \& que le vent les empefchera, ou bien les rendra plus abondantes qu'elles n'ont accouftumé d'eftre. Les vents ont leurs proprietez \& diuers commencemens, par lefquels ils operent de differens effedts, qui font le plus fouuent contraires à ce que l'ordre \& la faifon requierent. Puis donc qu'en chacun endroit l'on void arriuer de grandes varietez en l'annee, qui prouiennent de la diuerfité des mouuemens $8 z$ afpeats des planettes, ce n'eft point chofe mal a propos de dire qu'en la Zone Torride l'on peut voir \& remarquer quelques choles contraires à ce que nous auons experimenté. Mais pour refolution, ce que nous auons conclu, eft vne verité bien certaine \& experimentee, à fçauoir la grande fechereffe que les anciens ont penfé eftre en la region du milieu, que nous appellons Torride, ny yefte point du tout, \& quaú contraire il y a beaucoup d'humidité, \& que les pluyes y font 2lors que le foleil en eft plus proche. 
des Indes. Liure. II.

2 ue la Torride n'ef point exceßinement chaude, maispluftoft moderee.

Chapitre IX.

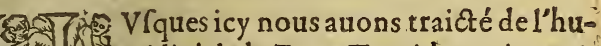
midité de la Zone Torride, maintenát il fera bon de parler de deux autres qualitez, qui font le chaud \& le froid. (9) Nous auons demonftré fur le commencement de ce difcours, comme les anciens ont tenu, que la Zone Torride eftoit chaude, \& feche exceffiuement,ce qui n'eft pas ainfi to utesfois; car elle eft chaude \& humide, \& en la plus grande partie, fa chaleur n'eft pas exceffiue, mais pluftoft remperee; ce que l'on tiendroit pour incroyzble, fi nous ne l'auions affez experimëté. Quand ie paffay aix Indes (ie diray ce qui m’arriua) ayant leu ce queles Poëtes \& Philofophes disết de la Zone Torride, ie me perfuadois quarriuant à l'Equinoxe, ie ne pourrois y fupporter cefte exceffue chaleur.Mais il m'aduint tout au contraire, car au temps que i'y paffay, qui fur alors que le foleil y eftoit pour Zenith, eftant entré au figne d'Aries, à fçauoir au mois de mars, i'y fenty fi grand froid que i'eftois contraint me mettre au foleil pour m'efchauffer : que poutuois-ie moins faire alors, que de me rire \& me mocquer des meteores d'Ariftore, \& de fa Philofophie, voyant qu'au lieu, \& en la faifon que tout y debuoit entre embrafé de chaleur, ruiuant fes regles, moy \& tous mes compa- 


\section{Hiftoire naturelle}

gnons auions froid? Il n'y a à la verité regiôn au monde plus douce, ny temperee, que fous l'Equinoxe, combien quelle ne foit pas ent tous endroits d'efgale ou femblable temperature, \& qu'il y ait beaucoup de diuerfitez. La Zone torride en quelques endroits eft fort temperee, cóme en Quitto, \& aux plaines du Peru; en quelques endroits fort froide, comme en Potozi ; \& aux autres fort chaude, comme en l'Ethiopie, Brefil, \& aux Mollucques. Cefte diuerfité done nous eftant certaine, \& toute cogneúe, nous deuons par force rechecher vne autre caule du froid $\&$ du chaud, queles rayós du foleil y font naiftre, veu qu'en vne mefine faifon de l'annee, \& en lieux qui font d'v ne mefme hauteur \& diftance du Pole \& de l'Equinoxe, on y retrouue vne fi grăde diuerfité, que les vns sút embrafez de chaleur, les autres de froidure, \& les autresfe

Plat.in Tim trouuent tempercz d'vne chaleur moderee. $\mathrm{Pla}$ $\checkmark$ in Critia. ton inct fa tant renommee Inle Atlantique fous la Zone Torride, puis dict qu'en certain temps de l'annee elle auoir le foleil pour Zenith, \& neantmoins qu'elle eftoit fort temperee, fort

Blin.lib.6. abondăte, \& fort riche. Pline dit que Taprobasap.22. ne, (quils appellent auiourd'huy Samatre) eft fous l'Equinoxe, comme cn effeut elle y eft, efcriuant qu'elle n'eft pas feulemétriche, \& heu. reufe, mais auffi peuplee d'hommes \& d'animaux.D'où l'on peut facilemét cognoiltre, qu'écor que les anciens ayent tenu la chaleur de la Torride infupportable; neätmoins ils pouuoiêt bien entendre qu'elle ne l'eftoit pas tant cóme ils difoient, Le tres-excellét Aftrologue \& Cof; 


\section{des Indes. Liure. II. $\quad 6 \overrightarrow{4}$}

nographe Ptolomee, \& l'infigne Philofophe $x$ medecin Auicenne, en eurent meilleure reolution, eftans tous deux d'opinion, que fous 'Equinoxe y auoir de fort cómodes habitatiós.

Que la chaleur de la Torride eft temperee pous l'abondance des pluyes, \& pour la briefuetédes iours.

\section{Chapitre X.}

Epuis que le nourueau monde à efté

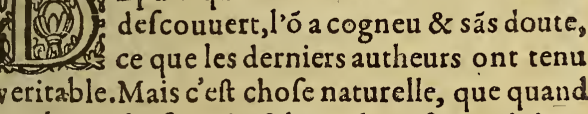
(a) defcouuert, l'ó a cogneu \& sás doute,
ce que les derniers autheurs ont tenu
veritable.Mais c'ett chofe naturelle, que quand quelque chofe qui eft hors de noftre opinion, nous vient à eftre cogneiie par l'experiêce, nous voulós incótinent en rechercher la caufe. C'eft pourquoynous defirós fçauoir pour quelle çauCe la regiô, de laquelle le Soleil eft plus proche, n'eft pas feulemét temperee, mais eft froide en plufieurs endroits. Confiderant cefte matiere general emét, ie trouue deux caufes generalles, pour rendre cefte region temperee; I'vne eft celle cy deuant declaree, d'autant que cefte region eft fort humide, \& fujette aux pluyes, \& n'y a point de doute que la pluye ne rafraichiffe, pource que l'efleuement de l'eauie eft de fon naturel froid, \& encor quel'eaüe par la force du feu s'efcauffe, ce neátmoins ne laiffe pas detếperer l'ardeur caufee des rayons du foleil purement. Ce qu'on void par experience en l'Arabie interieure, laquelle eft ombrafee du foleil, 


\section{Hiffoire naturelle}

polir n'y auoir aucunes pluyes qui temperent $f a$ furie. Les nuages \& bruines empefchent queles rayons du foleil n'offenfent tant, \& les pluyes qui procedent d'icelles mefmes, rafraichiffent l'air \& la terre, \& l'humectent auffi, quelque chaude qu'elle puiffe eftre. L'on boit l'eauie de la pluye, \& elle eftanche la foif, comme les noftresl'ont bien efprouué, ayant faute d'eaiie pour boire. De forte que la raifon \& l'experience nous enfeigne, que la" pluye de foy appaifela chaleur, \& parce moyen ayant jà monftré comme la Zone Torride eft fort pluuieufe? il appert auffi qu'il y a en icelle, chofe qui peut rendre fa chaleur temperee. A cecy i en diray encor vine autre raifon, qui merite bien qu'on entende, non feulement pour cefte maticre, mais auffi pour plufieurs autres: car pour le dire en peu de paroles; le foleil quoy qu'il foir fort chaud \& bruflant en l'Equinoxe, ce neantmoins c'eft pour peu de temps, de forte que la chaleur du iour y eftăt plus briefue $\&$ de moindre duree, ne fait pas tant d'embrafement. Ce quil conuient declarer $\&$ entédre plus parriculieremét. Ceux qui font verfez à la cognoiffance de la Sphere, enfeignent fort bien, que d'aurant plus que le Zodiaque eft oblique 8 trauerfant fur nofte hemilphere, d'autant plus lesiours \& les nuicts font inégaux; \& au conrraire où la Sphere eft droitte, \& les fignes mórent droirement, lesiours \& les nuicts y font égaux. C'eft pourquoy en toutela region qui eft entre les deux tropiques, il y a moins d'inégalité aux iours \& aux nuicts, que hors d'iceux, \&a plus 


\section{des Indes. Liure II.}

xplus approche de la ligne, moins y trouue-ori 'inégalité,ce que nous auons experimété en ces arties. Ceux de Quitto, pource qu'ils font at effoubs de la ligne, n'ont point en toute l'anee les iours, ny les nuicts pluscourts en vne faion qu'enl'autre, mais y font continuellement gaux. Ceux de Lyma, pource qu'ils font dians de la ligne prefque de douze degréz, a peroivent quelque difference entre les jours \& les uicts, mais c'eft fort peu, d'autant qu'en Decēre\&en Ianuier lesiours y croiffent d' he heure, u peu moins. Ceux de Potozi y recognoiflent eaucou p plus de difference, tant l'Hyuer que Efté , pource qu'ils font prefque foubs le Troique. Mais ceux qui font du tout hors des Troiques, remarquent d'autant plusla briefueté es iours de l'Hyuer, \& la longueur de ceux de Efté, qu'ils font esloignez de la ligne, \& font roches du Pole; comme l'on void qu'en Allelagne \& en Angleterre les iours font plus longs Efté, qu'en Italie \& Efpagne. C'eft chofe qui void, quela Sphere enfeigne, \& l'experience monftre clairement. Il faut adioufter vne aue propolition, qui eft aufsi vraye, \& bien conderable pour tous les effects dé la niattire, fçaoir la perfeuerance \& continuation de fa caufe ficiente à operer \& agir. Cela fuppofé, fi l'orn e demande, pourquoy en l'Equinoxe il n'y a oint de fi violentes chaleurs en Efté, qu il y a quelques autres regions, (comme en Andazie és mois de Iuillet $\&$ Aouft ) ie refpondray ource que les iours d'Efté font plus longs en ndaluzie, \& les nuiats y font plus courtes, \& le 


\section{Hiftoire naturelle}

iour comme chaud qu'il eft, enflame \& caufe la chaleur, la nuict aufsi comme froide $\&$ humide, donne du rafraichiffement. Suiuant quoy, au Peru iln'y a point tant de chaleur, pource que les iours d'Efté n'y font pasfil longs,ny les nuicts fi courtes, qui caufe que la chaleur du iour eft beaucoup tếperée par la fraifcheur de la nuiet. Mais là ou les iours font de quinze, oufeize heures, par raifon il doit $y$ auoir plus de chaleur, que là où ils ne font que de douze, ou de treize: $\&$ où il en demeure autant de la nuict pour rafraifchiffement. Et bien que laZone Torride foir plus proche du Soleil, que toutes les autres regions, fi eft-ce toutesfois que la chaleur du Soleil n'y demeure pas fi long temps: car c'eft cho. fe naturelle qu'vn feu encor qu'il foit petit, $s^{\prime \prime}$ perfeuere, efchauffe dauantage qu'vn plu grand qui durera peu, principalement s'il furuienț du ra fraifchiffemët. Qui voudra mettri done ces deux proprietez de la Torride en vn balance, fçauoir qu' elle eft plus pluuieufe au tép de fa plus grande chaleur, $\&$ que les iours y fon pluscourts, on pourrabien parauanture trou. uer qu'elles feront efgales à ces deux autre contrairesqui font que le Soleil y eft plus pro che \& plus droit qu'és autres regions, à tout 1 moins que l'on n'y recognoiftra pas beaucou: d'auantage. 


\section{des Indes. Liure II:}

2u'ily a d'autres raifons outre les de/duittes cy defsus, qui monftrent que la Torride eft

trmperée, principalement en la cofte de ta mer occeane.

Chapitre Xit.

Stant chofe refoluë que les deut S proprietez furdietes font commu。 10 nes \& vniuerfelles à toute la regiont 20.5 Torride, \& qu'en icelle neantmoins Ne- dil fe troute aucús lieux fort chauds $x$ les autres où il y a fort grand froid: Bréf la tenserature n'y eft efgale en tous lieux, ma is en vn nefme climat, vne partie eft chaude, 'autre froile, \& l'autre temperée tout en vn mefme temps: hous fommes contraints de rechercher d'autres aifons, d'ò̀ procede cefte grande diwerfité qui e troulue ainfi en la Torride. Difcourant doncques fur cefte queftion, i'en troune trois caufes pparentes \& certaines, \& vne quatriefme plus bffure \& cachee. Les caufes a pparentes \& ceraines font, la premiere l'Occean, la feconde 'afsiete \& fituation de la terre, \& la troifiefme e naturel \& proprieté de plufieurs \& diters yents. Outre ces trois que ie tiens pour manifeftes, ie croy qu'il y en a vne autre quatriefme; cachée \& moins a pparente, qui eft la proprieté de la mefme terre habitée, \& la particuliere influence de fon Ciel. Qui voudra confiderer de prez les caufes \& raifons generales, cy deffus defduites, on trounera que elles ne font fuffi: 


\section{Hiftoire naturelle}

fantes pour la refolution totale de cefte ma. tiere, veu ce qui arriue iơurnellement en di. uers lieux de l'Equinoxe. Manomota pa, \& gran. de partie du Royaume de Prefte-I ean, font $\mathrm{f}$ tućes delfous la ligne, ou fort proches, efquelles regions ils endurent de terribles chaleurs, \& y naiffent les hommes tous noirs; Ce qui n'eft pas feulement én ces parties de terre ferme, esloignées de la mer, mais aufsi en eft il de mefme és Isles enuironnées de la mer. L'Isle de fainct Ttomas eft foubs la ligne, les Isles de Cap de vert en font prochaines, \& enl'vne \& en l'autre y regnent de furieufes chaleurs, \& y font mefmes tous les hommes noirs. Soubs la mefme ligne, ou bien proche d'icelle, gift vne partie du Peru, \& du nouveau Royaume de Grenade, qui neantmoins font terres fort temperées, declinantes pluftoft à froidure, que non pasà chaleur, \& les hommes qui habitent en icelles, font blancs. La terre du Brefil eft en la mefme diftance de la ligne, que le Peru, \& neantmoinsle Brefil \& toute cefte cofte eft extremement chaude, encore qu'elle foit en la mer du Nort, \& l'autre cofté du Peru qui eft en la mer du Sud, eft fort temperće. Ie dis donc que qui voudra confiderer ces differences, $\&$ donner la raifon d'icelles, ne fe pourra contenter desgeneralles cy deffustraittees, pour declarer comme la Torride peut eftre we terre tem. perée. Entre les claufes \& raifons fpecialesi'ay mis pour la premiere la mer, pource que fans doute fon voifinage ayde à temperer, \& refroidir la chaleur. Car combien que fon cau foit 


\section{des Indes. Liure. II.}

allee, elle eft toufiourseau toutesfois, \& l'eau le fa nature eft froide, \& fi encore eft remarquable, que pour la profondité del'Occean, l'eaus 'en peut eftre efchauffee parla chaleur du So. eil, comme les eaux des riuieres. Finalement out ainfi comme le fel nitre (quoy qu'il foit du aturel du fel ) a la proprieté de refroidir l'eau : infi voyons-nous par experience en quelques orts \& haures que l'eau de la mer y rafraifchit, que nousauons veu en celuy de Callao, ou 'on mettoit rafraifchir l'eau ou vịn, pour boi= e dedans des cruches ou Hafcons mifes en la ner. D'où l'on peut fans doute recognoiftre quel'Occean a cefte proprieté de temperer \& -afraifchir l'excefsiue chaleur Pour ceite occaion l'on reffent dauantage la chaleur en la terre, qu'en la mer, caterisparibus, \& communement es terres fituees fur la marine, font plus frailches que celles qui en font esloignees, cateris parbus commei'ay diat. Ainfi la plus grande partie du nouneau monde eftant fort proche de la mer Occeane, nous pouuons dire auec raifon, encor qu'il foit foubs la Torride, qu'il reçoit de la mer vn grand benefice, pour temperer $f_{2}$ chaleur.

2 ue les plus bautes terres font les plus froides, or quelle en eft la raifon.

\section{Charitre XII.}

(2) $A$ is fi nous voulous encor rechercher 1. Particulierement, noustrouuerons qu'en 1e. 5 toute cefte terreiln'y a pas vne chaleur totalement efgale, quoy qu'elle foit en pareille 


\section{Hiftoire naturelle}

diftance de la mer, \& en mefme degré, veu qu'en quelques parties d'icelle il y a beaucolip de chaleur, \& en d'autres $y$ en a fort peu. IIn'y a point de doute que la caufe de cecy ne foit pourautant que l'vne eft plus baffe, \& que l'autre eft plus haute $\&$ plus esleuee, d'où vient que l'vne eft chaude, \& l'autre froide. C'eft chofe certaine que le fommet des montagnes eft plus froid que le profond de vallees, ce qui ne procede point feulement de ce que les rayons du Soleil ont plus de repercufsion auxlieux bas $\&$ profonds, encor qu' en foit vne grande raifon, maisil y en a vne autre, quieft que la region de l'air eft plus froide, d'autant plus qualle eft haute \& esloignee de la terre. Les plaines de Collao au Peru, \& de Popajan en la neuue Efpagne, font preuue fuffifante de cecy. Car fans doute toutes ces parties font terres hautes, \& pour cefte raifon aufsi font-elles froides, combien qu' eiles foient toutes enuironnees de hauts pics de montagne fort expofees aux rayons du foleil. Mais fi nous demandons pourquoy au Peru $\&$ en la neuue Efpagne, les plaines de la cofte font terres chaudes, $_{3} \&$ les plaines de la mefme terre du Peru \& de la neuue Efpagne fontau contraire terge froides: A la verité ie ne voy point qu'il s'en puiffe donner autre raifon, finon que les vnes font en terre baffe, \& les autres en terre haute. L'experience nous enfeigne que la moyen ne region de l'air eft plus froide que l'inferieure : \& pource tant plus les montagnes sapproa chent d'icelle region moyenne, tant plus elles 


\section{des Indes. Liure. II.}

ont froides, couuertes de neiges $\&$ de gelees. a raifon mefme f'y accorde, pource que s'il y a ine fphere ou region du feu, comme Ariftote \&: es autres Philofop hes difent, la region moyenne de l'air doit eftre plus froide par antiperiftae, la froidure eftant repouffee, \& ferefferrant en icelle, comme en temps d'Efté nous voyons aux puits qui ont de la profondité. Pour celte occafion, les Philofophes afferment que les deux extremesregions de l'air, celle d'enhaut, \& celle d'embas, font les plus chaudes, \& la moyenne plus froide. Que s'il eft ainfi, comms de fait l'experience le monftre, nous en tirerons encor vnargument $\&$ raifon remarquable, pour montrer quela Torride eft temperee; fçauoir que la plus grande partie des Indes eft vne terre haute, remplie de beaucoup de montagnes, qui par leur voifinage rafraifchiffent les terres prochaines. $L$ 'on void continuellement és fommets des mantagnes dont ie parle, de la neige, de la gresle, \& des eaux toutes glacees, \& le froid qu'il y fait eft fi afpre, que l'herbe en eft toute grefillonnee, tellement que les hommes \& cheuaux cheminans par là, y font tous engourdis de froid.Cecy, comme iay defia dict, eft en la Zone Torride, $\&$ aduient le plus fouruent quand ils ont le Soleil pour Zenith. Ainfi eftce chofe notoire \& conforme dे la raifon, que les montagnes font plus froides que ne font les vallees \& les plaines, d'autant qu'elles participent de la region moyenne de l'air, qui eft tresfroide. Or la caufe pourquioy la region moyen: ne de l'air eft plus froide, a efté mefme dikte cy.

I iiij 


\section{Fiftoire naturelle}

deuant, qui eft que la region del'air próchaine de l'exhalation ignee, laquelle (felon A riftote) eft fur la f phere de l'air, repouffe \& reiette arriere toute la froidure, laquelle fe retire \& re. ferre en la moyenne region de l'air par antiperiftafe, comme parlent les Philofophes. En a pres

CArist.M fi quelqu'vn me demande \& veut interroger de cefte façon, s'il eft ainfi que l'air foit chaud \& humide, comme tient Ariftote, \& comme l'on dit communement, d'où procede ce froid qui fe retire en la moyenne region de l'air, puis qu'al ne peut venir de la fphere du feu? Car s'il procede de l'eau ou de la terre, par cefte raifon 12 baffe region de l'air deuroit eftre plus froide que celle du milieu. Certes à refpondre au vray ceque i'en penfe, ie confefferay que ceft argument \& obiection m'elt tant difficile, que ie fuis prefque difpofé de fuiure l'opinion de ceux qui reprouuent les qualitez, fymboles \& diffymboles que met Ariftote aux elements, difant que ce font imaginations, lefquels pour cefte occafion tiennent que l'air de fon naturel eft froid, \& à cefte fin ilsfe feruent de plufieurs argumens \& raifons, du nombre defquels nous en propoferons vn affez vulgaire \& cogneu, laiffans les autres à part, fçauoir qu'és iours caniculaires nous auons accouftumé nous donner de l'air auec vn efuentail, \& trouuons qu'il nous rafraifchit: de forte que ces $A$ utheurs afferment quela chaleurn'eft vne proprieté parDionyf. cap. ticuliere d'aucun autre element que du feul feus
ss. de cat.

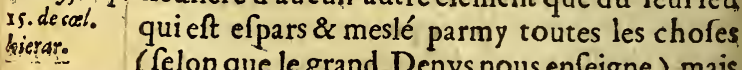
(felon que le grand Denys nous enfeigne) mais 


\section{des Indes. Liuré. II.}

qu'il foit ainfi, ou qu'il en foit autrement (car ie ne veux pas contredire à Ariftote, fi ce n'eft en chofe fort certaine ) en fin ils facordent tous que la moyenne region del'air eft plusfroide, que la plus baffe prochaine à la terre, comme mefme l'experience le monftre, puis qu'en cefte region du milieu, les neiges, les gresles, frimats \& autres indices d'extreme froid s'engendrent. Or donc la region du milieu qu'ils appellent Torride, ayant d'vn cofté la mer, \& de l'autre les hautes montagnes, l'on doit tenir cela pour caufes fuffifantes pour temperer \& rafraifthir fachaleur.

Que les vents froids font la principale canse de rendrela Torride temperee.

CHAPITRE. XIII.

5. A temperature de cefte region fe doit principalement attribuer à la 2) proprieté du vent qui court en forte terre là, lequel eft fort frais \& gracieux.La prouidẽce du grand Dieu, Createur de toutes chofes a efté telle, qu'il a ordonné qu'il y euft des vents merueilleufement frais en la region où le Soleil fait fon cours ( qui femble deuoir eftre du tout embrafee) afin que par leur fraifcheur, l'excefsiue chaleur duSoleil fuft temperee. te ne font pas ceux-là trop esloignez d'ap. parence de raifon, qui ont eu o pinion que le $\mathrm{Pa}$ radisterreftre eftoit fous l'Equinoxe, s'ils ne fe fuffent trompez eux-mefmes fur la caufe de seur opinion, ence qu'ils difoient que légalité 


\section{Hiftoire naturelle}

des iours \& des nuicts eftoit feule fuffifante caufe de rendre cefte Zone temperee, à laquelle opinion toutesfois plufieurs autres ont efté contraires, du nombre defquels a efté le Pc čie renommé, difant.

Famment aux cogion

Dis soleel, quid'illec iamais ne fe retire.

Donques la fraifcheur de la nuict n'eft pas telle, qu'elle foit feule fuffifante pour moderer \& corriger de fi afpres \& furieufes ardeurs du Soleil, thais pluftoft cefte Torride reçoit vne fi douce temperature parle benefice de l'air frais $\&$ gracieux, de telle forte que combien qu'elle ait efté tenuë des anciens, plus embrafee qu'vne fournaife ardente, \& ceux quil'habitent à prefent, la tiennent pour vn Printemps delicieux. Il appert par argument \& raifons fort euidentes, que la caufe de cecy gift principalement en Ia qualitédu vent. Nous voyons en vn mefme climat quelques regions \& villes mefmes plus chaudes les vnes que les autres, pource feulement quils fe reffentent moins des vents qui, rafraifchiffent. De mefme en eft-il en d'au tres terres, où le vent ne court point, lefquelles font toutes embrafees comme vn fourneau, \& y efton fifatigué de la chaleur, que d'y eftre, c'eft autant que de fe voir dans vne fournaife. Il ya beaucoup de ces bourgades \& de cesterresau Brefil, en Ethiopie \& au Paraguay, comme chacun fçait : \& ce qui eft plus confiderable, c'eft que l'on void ces differences, non feulement parmy les terres, mais auffi en la mer.Il y a des 


\section{des Indes. Liure I I.}

mers, oú l'on fent beaucoup de chaleur, comme ils racontent de celle de Mozambique \& Ormus, \& en l'Orient, \& de la mer de Panama, en Occident (laquelle pour cefte occafion engendre \& produit en foy des $C$ ayamans)cóme aufsi en la mer du Brefil. 11 y a d'autres mers, voire en mefme degré de hauteur, fort froides, cŏme eft celle du Peru, en laquelle nous eufmes froid, comme i'ay raconté cy deflus, quand nous la nauigeafmes la premiere fois, qui eftoit en Mars, \& au temps que le Soleil cheminoit par deffus. $A$ la verité en ce continent, où la terre $\&$ l'eau font de mefme forte, l'on ne peut imaginer autre occafion de fi grande difference, finon 12 proprieté du vent qui les rafraifchit. Que fil'on veut de pres aduifer à cefte confideratiô du vêt, dont nous auous parlé, l'on pourra refoudre plufieurs doutes qu' aucuns mettent en auant, \&qui femblent chofes eftranges \& merueilleufes, fçauoir pourquo y le Soleil donnant de fes rais fur la region Torride, \& particulierement au Peru, voire beaucoup plus violemment qu'il ne fait pas en Efpagne és iours caniculaires, neantmoins l'on refifte à fa chaleur auec vne fort legere couuerture, fi bien qu'au counert d'vne natte, ou d'vn fimple toiđt de paille, l'on eft mieux contregardé de la chaleur, que l'on n'eft pas en Efpagne deffous vn toict de bois, \& mefme d'vne voute de pierre. Dauătage pourquoy les nuicts d'Efté ne font chaudes, ny ennuyeufes au Peru, comme en Efpagne? Pourquoy aux plus hauts fommets des montagnes, \& mefme entre les mónceaux de neige, il y fait quel. 


\section{Hiftoire naturelle}

ques:fois de grandes \& infupportables cha: leurs. Pourquoy en toute la Prouince de Collao, quand l'on fe trouue a l'ombrage, quelque petit qu'il puiffe eftre, l'on y fent du froid, mais - quand l'on vient à en fortir aux rayons du Soleil, incontinent l'on vient à y fentir vne exceffrue chaleur. Pourquoy toute la cofte du Peru eftant pleine de fablons, neantmoins fe trouue fort temperee, \& pourquoy Putozi diftant de la cité d'A rgent tant feulement de dixhuict lieües $\&$ en vn mefme degré, eft toutesfois de fi differente temperature, que le pays eftant tres-froid, il eft fterille \& fec à merueilles: au contraire la ville d'Argent eft temperee, declinant à la chaleur \& à vn terroir fort gracieux \& fertile. C'eft donc pour certain le vent, qui principalement caufe toutes ces eftranges diuerfitez : car fans le benefice du vent frais, l'ardeur du Soleil eft telle, qu'encor que ce foit au milieu des neiges, elle brusle \& embrafe, mais aufsi quand 12 fraicheur de l'air reuient, aufsi toft toute la chaJeur s'appaife, quelque grande qu'elle foit: \& où ce vent frais eft ordinaire, \& regne fouuent, il empefche que les vapeurs terreftres \& grofsicres qu'exhale la terre, ne fe ioignent, \& caufent vne pefante \& ennuyeufe chaleur, dont le contraire aduient en Europe; d'autant que par l'exhalation de ces vapeurs, la terre demeure comme brusiee du Soleil du iour, qui eft caufe que les nuicts y font fi chaudes $\&$ ennuy eufes, tellement qu'il femble plufieurs fois quel'air forte comme d'vne fournaife. Pour cefte mefme raifon, au Peru cefte fraifcheur du vent caufe que 


\section{des Indes. Liure II I.}

par le moyen de quelque petit ombrage au coucher \& declin du Soleil, l'on y eft affez fraifchement: au contraire en Europe le temps le plus doux \& plus agreable en Efté eft le matin, \& le Coir eft le plus froid, \& le plus ennuyeux. Mais au Peru, en tout l'Equinoxe il n'en eft pas de mefme, d'autant que tous les matins, que le vent de la mer y ceffe, \& que le Soleil y commence ż ietter fes rayons, pour cefte raifon l'on y fent la plus grande chaleur aux matins, iufques au retour dudit vent qu'ils appellent autrement, $\mathrm{Ma}$ rée, ou vent de la mer, quifait qu'on commenceà fentir le froid. Nous auons experimenté tout cecy du temps que nous eftions aux Isles qu'ils appellent de Barlouente, où au matin nous fuy ons de chaud, \& à midy nous fentions vn bon frais pour ce que la bize ordinaire, qui eft vn vent frais \& gracieux, y fouffle alors.

Queceux qui habitent foubs l'Equinoxe, viuest d'vne vie fort donce of delicicuse.

\section{CHA PITRE. $\mathrm{X} V$.}

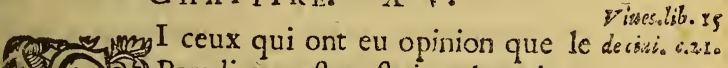
1) (1) Paradisterreftre eftoic en l'equino4 - 2 xe, fe fuffent conduits par ce dir(2) (A) cours, encor ne fembleroient-ils dent ent du tout hors du chemin non que ie vueille refoudre que le Paradis delicieux, dót parle l'Efcriture, foit en ce lieu Jà, d'autant que ce feroit temerité de l'affermer pour chofe certaine ; maisie dis, que fil l'on peut dire qu'il y ait quelque Paradis en la terre ce doif 


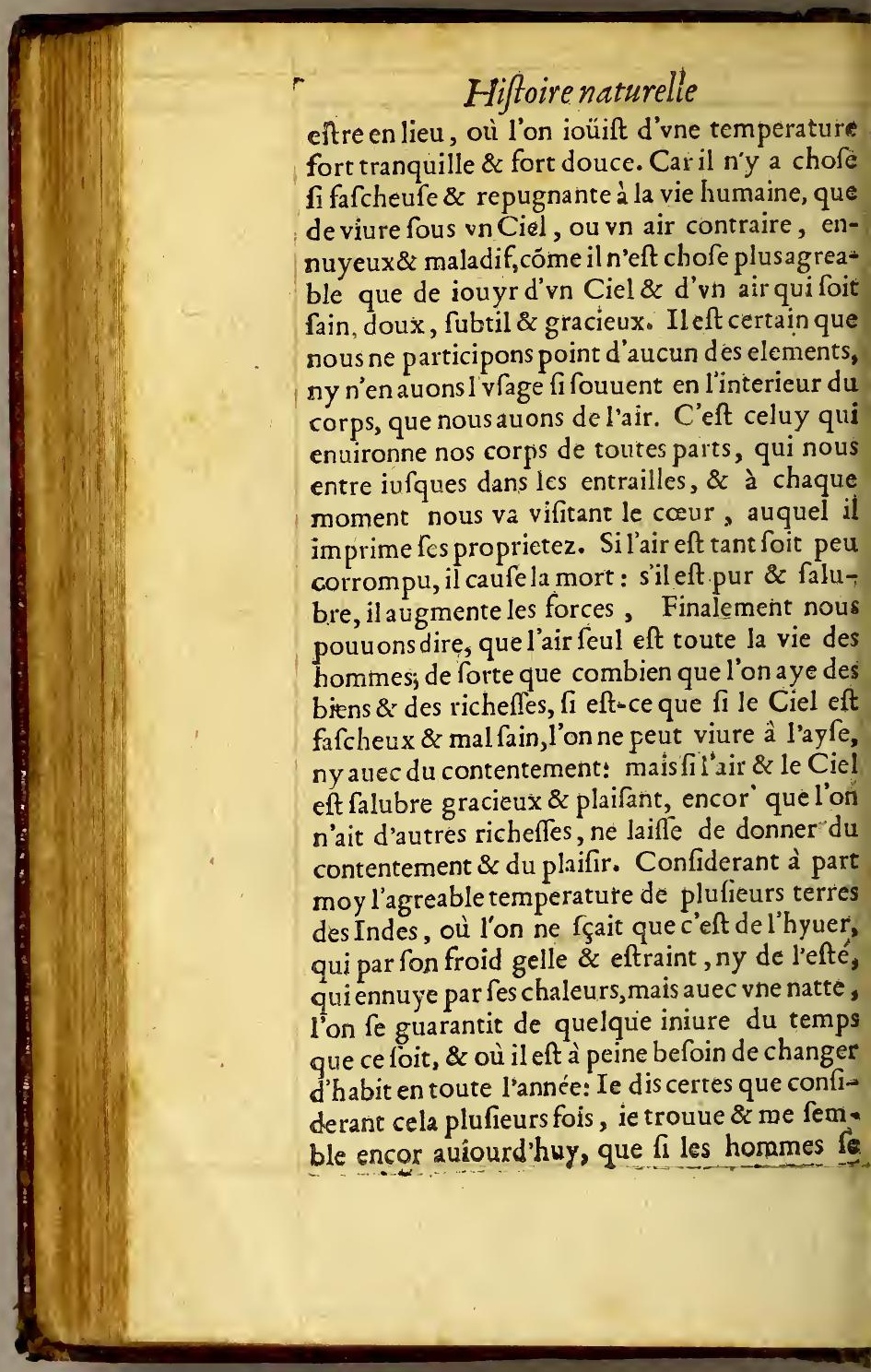




\section{des Indes. Liure. II.}

ouloient vaincre eux-mefmes, \& fe deslier les lacs que la cupidité leur dreffe, fe defiftans le plufieurs inutiles \& pernicieux deffeings; ans doute qu'ils pourroient viure aux Indes fort doucement $\&$ heureufement : car ce que les aures Poëtes chantent des champs Elifées, \& de la fameufe Tempé, ou ce que Platon raconte, ou feint de fon Isle Atlantique, certes les hommes les trouueroient en ces terres, fi d'vn cœurgenereux ils aymoient mieux eftre feigneurs de leur argent, \& de leur conuoitife, que d'en demeurer efclaues comme ils font. Ce que nous auons traitté jufques icy, fuffira touchant les qualitez de l'Equinoxe, du froid, chaud, fecherefle, pluyes, \& des caufes de fa temperature. Le difcours en particulier des diuerfitez des vents, eaux, des terres, des metaux, plantes \&e animaux qui y font, \& dont y a aux Indes grande abondance, reftera pour d'autres liures, carla difficulté de ce qui eft traitté en centuy-cy, quoy qu'au bref, le fera parauanture trouler pluslong qui'iln'eft. 


\section{- Aduertiffement au Lecteur.}

T E Lecteur doiteftre aduerty, que i e/crius Lles deux liures precedens en Latin, lors que i'efois au Peru, or pource parlent-ils des choles des Indes, comme de chojes prelentes: depuiseftant venuen E/pagne, me Jemblabon de les traduire en langue vulgaire, \& ne voulus changer la façon de parler quiy eftoit coucheé: mais aux cing liures fuiwans, parce que ie les. ayfaits en Europe, i'ay efté contraint de changer la façon deparler, or de traitter en iceux les chofes des Indes, comme terres of chofes abfen. tes, of parce que ceste diuerfité de parler pourroit auec raifon offenfer le Lecteur, ilm is femblé bon l'aduertir de cecy. 


\section{V R E TROISIESM E}

DE L'HIS T OIRE NAT Vrelle \& morale des Indes.

Que l'hiftoire naturelle des Indes eft plaifante os agreable.

\section{CHADITRE PREMIER:}

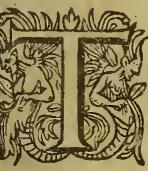

O v T E hiftoire naturelle de foy cft agreable, \& mefme eft vtile, \& de grand proffit à ceux qui veuléé efleuer leur difcours \& contemplation en haur, en ce qu'elle les xcite à glorifier l'Autheur de toute la nature, :omme nous voyons que font les fages \& faints. erfonnages, principalenièt Dauid en plufieurs $x$ diuers $\mathrm{Pf}$ feumes, où il celebre l'excellence $P$ fal. $10_{50}$ les ouures de Dieu. Et Iob auffi traitant des f 135.91 .920 rets du Createur; où le mefme Seigneur refond à lob fi amplement. Celuy qui fe plaira $\operatorname{Iob}_{28} 38$; Pentendre les vrayes œuures de cefte nature $\int_{3} 3940$. 4 I. liuerfe \& fi abondante, aura vrayement le plaiir \& contentement del'hittoire, \& plus encor quand il cognoiftra que ce ne font point fimples auures des hommes, mais du Createus mefme, \& gu'il palfera plus outre, \& paruiendro 㕍 


\section{Hiftoire naturelle}

à comprendre les caufes naturclles de ces ous ures, itfera occupé en vn vray exercice de Philolophie. Mais qui enleuera plus haut fa confideration, regardant au grand \& premier Ar-

- chitecte de toutes ces merueilles, cognoiftra la fapience \& grandeur infinie d'iceluy, pourrons dire qu'il traictera vne excellente Theologie, $\&$ par ainfi la narration des chofes naturelles peut beaucoup feruir pour plufieurs bonnes confiderations, combien que la foibleffe \& debilité deplufieurs appetits ayt accouftumé ordinairement de s'arrefter au moins profitable, qui eft le defir de fçauoir chofes nouuelles, appellé curiofité. Le difcours \& hiftoire des chofes naturelles des Indes, outre le commun contente. ment qu'il donne, il en a encore vn aurre, qui eft de traitter de chofes efloignées, la plus-part defquelles ont efté incogneuës aux plus excellens autheurs de telie profeffion, qui ay ent efté en. tre les anciens. Que s'il falloit efcrire ces chofes naturelles des Indes, auffi amplement comme elles le requierent bien, eftans chofes fir remarquables, ie ne doute pas qu'on n'en peuft faire des œuures, qui neferoient pas moindres que celles de Pline, Theophrafte \& Ariftote. Mais ic ne me repute point affez fuffifant, \& (encor que ie le fuffe) ce ne feroitmon intention, ne ten. dát à autre fin que de remarquer quelques cho. fes naturellks que i’ay veuës \& cogneuës eftanı aux Indes, ou bien que i'ay entenduës de per fonnes dignes de foy ; lefquelles me femblen: eftre rares, \& peu cogneues en l'Europe. A rai fon dequoy ie pafferay fuccinctement fur beau 


\section{des Indes. Liure. III.}

otup d'icelles, tant pource qu'elles font ià efcries par d'autres, ou bien quelles requierent daantage d'efclarciffiment \& de difcours, que ce ue ie leur pourrois donner.

Des vents, de leurs differences, proprietez os caufes en general.

CHAPITRE II.

P Y A I traitté aux deux liures pre(2) (a) cedens ce qui concerne le Ciel, \& l'habitation des Indes en general il nous conuient parler des trois elemens, l'air, l'eau, \& la terre, \& le leurs compofez, qui font les metaux, plantes 2 animaux; car pourle regard du feu, ie ne voy hofe fpeciale aux Indes qui ne foit és autres reiós, î quelqu'vn ne vouloit dire que la façú de irer du feu en frottant deux baftons l'vn contre 'autre, comme en vfent quelques Indiens; de cuire qurelque chole en des courges, y iettất vne oierre ardente, \& d'autres choles femblables fuffent à remarquer, aufi en ay-ie efcrit, ce que 'on en pouuoit dire.Mais de ceux qui font aux Vulcans ou bouches de feu des Indes, dignes

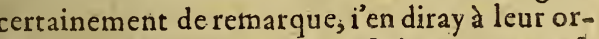
dre, en traittant de la diuerfité des terres, ef= quelles l'on troune ces feux ou Vulcáas.Parquoy pour commencer par les vents, ie diray premierement, que c'eft à bonne caufe que Salomons entre les grádes fciếces que Dieu luy auoit don. nzées, eftime beaucoup la cognoiffance de lo

$\mathrm{K}$ ij 


\section{Hiftoire naturelle}

force des vents, \& de leurs proprietez certaine ment adnirables. Pource queles vns font pluuicux, \& les autres fecs; Ics vns maladifs, \& les autres fains;les vins chauds, \& les auttes froids; les vns doux \& gratieux, \& les autres rudes \& rempeftueux; les vns fteriles \& les autres ferriles, auec vne infinité d'autres differences. Il y a des vents qui courent en certaines regions, \& font comme feigneurs d'icelles, fans fouffrir l'entrée ou communication de leurs contraires. En d'autres parties ils foufflent de telle façon, que tantoft ils font vainqueurs, \& tantoft font vaincus, \& bien fouuent il y a des vents diuers $\&$ contraires, lefquels courent enfemble tout en vn mefme temps, diuifans le chemin entr'eux, \& quelquesfois les vns foufflent en haut d'vne façon, \& les autres parle bas d'vne autre; quelquesfoisfe rencontrent violemment les vns les autres, qui fait courir de grandes fortunes ceux qui font lors fur mer. Il y a des vents qui ay dent à la generation des animaux, \& d'autres quil'empefchent, \& y font contraires. Il y a va certain vent de telle proprieté, que quand il fouffle en quel que contrée, il y fait pleuuoir des pulces, non point par maniere de dire, mais en fi grande abondance, qu'ils en troublent \& ob. fcurciffent l'air, \& en couurent tout le riuage de la mer, \& en d'autres endroikts il faic pleuuoir des petits crapanx. Ces diuerfitez \& d'autres qui font allez cogneües, s'attribuent communement au licu par où paffent ces vents, pource qu'ils difent, que de ces lieux ils prennent leurs qualitez d'eftre froids, chauds, 


\section{des Indes. Liure. III.}

ecs, ou humides, maladifs, ou fains, 8 ainfi le tout le refte, ce qui eft en partie veritaole, \& ne le peut-on nier, d'autant qu'en peu de diftance l'on void en vn mefme vent beaucoup de diuerfitez. Pour exemple, en Elpagne, le Solanus ou vent de Leuant eft communement chaud \& ennuyeux;en Murcia, c'eft e plus frais \& plus fain qui y foit, pource qu'il paffe par ces vergers, \& cefte fil large campagne qu'on void affez fraifche. En Carthagene, qui n’eft gueres efloignée de là, le mefine vent eft ennuyeux \& mal fain. Le Meridional, que ceux dela mer Occeane appellent Sud, \& ceux de la mer Mediterranee, Meziozorne, communement eft pluuieux \& molefte, \& en la même ville que ie dis, eft fain \& gracieux: Pline Plin lib.z. raconte qu'en Affrique il pleut du vết de Nort, cap. 47. \& $q$ que le vent de Midy y eft ferain. Qui voudra donc confiderer de presceque i'ay dict de ces vents, il pourra bien comprendre qu'en peu de diftance $\&$ efpace de terre ou de mer, vn mefme vent a plufieurs \& diuerfes proprietez, voire quelquies fois toutes contraires. D'où l'on peut inferèr qu'il tire \& acquiert fa proprieté \& qualité du lieu par où il palfe. Ce qui eft vray de celle façon, que l'on ne peut pas toutes fois dire infailliblement que ce foit la reule $\&$ principalle caufe des diuerfitez \& proprietez des vents. Car c'eft chofe que l'on apperçoit \& recognoit fort bien, qu'en vne region quiconzienne cinquante lieües de circuit, ie le mets ainfi pour exemple, le vent qui fouffle d'vn coftć eft chaud \& humide, \& celuy qui fouffle K iij 


\section{Fliftoire naturelle}

d'vn autre, eft froid \& fec. Toutesfois cefte diuerfité ne fe trouue point és lieux par où il paffe, qui me fait dire pluftoft, que les vents d'euxmefines apportent quant \& eux ces qualitez, d'où vient que l'on leur approprie les noms de ces qualitez. Pour exemple l'on attribuë au vét de Septentrion,autrement appellé Cierço, ou Nort, la proprieté d'eftre froid \& fec, \& de confommer les bruines. A fon contraire, qui eft le vent de Midy, Leuéche ou Sud, eft auffi attribué tout le cótraire, qui eft d'eftre humide $\&$ chaud, \& d'engendrer des brouillars. Cecy donc eftant general \& commun, l'on doit rechercher vne autre caufe vniuerfelle, pour donner raifon de ces effects, \& ne cuffit pas de dire que les lieux par où ils paffent, leur donnent ces proprietez quils ont, puis que paffans par de mefmes lieux, on void quils ont appertement effects tous contraires. Tellement que nous deuons confeffer par force, que la region du Ciel où ils foufflent, leur donne ces proprietez \& qualitez. Comme le Septentrional de foy eft froid; pource qu'il procede du Nort, qui eft la region plis efloignée du Soleil. Le Sud qui fouffle du Midy, eft chaud, \& pource que la chaleur de foy attire les vapeurs, il eft auffi humide \& pluuieux: au contraire le Nort eft fec \& fubtil, d'autant qu'il ne laiffe efpaiffir les vapeurs, $8 x$ de cefte façon l'on peut difcourir des autres vents, leur attribuans les proprietez des regions de l'air d'où ils foufflent. Mais confiderant cela de plus pres, cefte raifon encores ne me peut farisfaire. Parquoy ie veux demanders 
ue fait la region de l'air par où paffentr ces vếts, elle ne leur atrribuë point fa qualité. Ie le dy, ourautant qu'en Allemagne le Meridional eft haud \& pluuieux, \& en Afrique le Nort eft roid \& fec. Neantmoins il eft tres certain que e quelconque region d'Allemagne où s'engenIre le Sud, doit eftre plus froide qu'aucune d'Arique où s'engendre le Nort. Que s'il eft ainfi lonques, pour quelle raifon eft ce que le Nort it plus froid en d frique, que n'eft le Sud en $\mathrm{Al}$ emagne, veu quil procede d'vne region plus haude ? L'on me pourra refpondre que c'eft a aufe quall fouffle du Nort qui eft froid, inais cea n'eft pas chofe fuffifante, ny veritable; Car il eftoit annfi, lors que le Septentrional fouffle en Afrique 1 deuroit auffi courir \& continuer on mouuement en toute $l_{2}$ region iufques au Nort:ce qui n'eft pas toutesfois, car en vn méfme temps 1 l court des vents de Nort fort froids '́s terres qui font en moins de degrez, \& des vents d'embas, qui font fort chauds és terres Gtuees en plus de degrez, ce qui eft tout certain, couftumier \& notoire. D'où l'on peut, à mon iugement, inferer que ce n'eft pas saifon pertinente, de dire que les lieux par où paffent les vents, leur donnent ces qualitez, ny mefme qu'ils font diuerfifiez, pource qu'ils foufflent de diuerfes regions del'air, encor quel'vn \& l'autre en foit quelque raifon, comme i'ay dict. Mais il eft befoin de s'enquerir plus auant, pour fçauoir quelle eft la vraye $\&$ originelle caufe de ces differences fi eftranges 'qu'on void entre les vents.Ie n'en peux imaginer d'autre, frnon quo

$\mathrm{K}$ iiij 


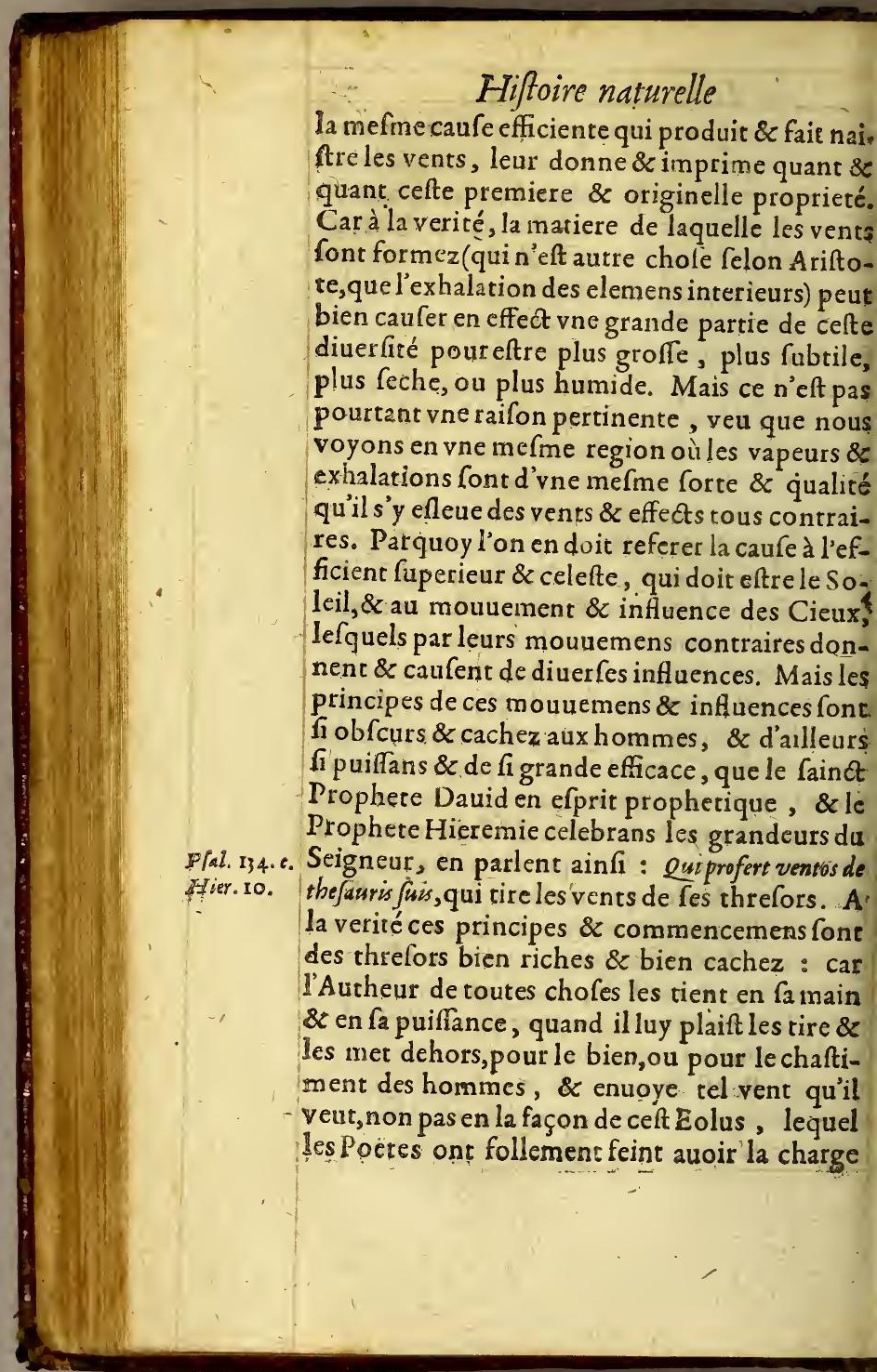




\section{des Indes. Liure III.}

e tenir les vents arreftez \& enfermez dans va ntre, tout ainfi que des beftes fauuages. Nous ie voyons point le commencement de ces ents, \&r. ne fçauons non plus combien ils doient durer, d'où îls procedent, ny iufques où ils loiuent aller. Mais nous vo yons \& cognoiflions ort bien les diuers effects \& operations qu'ils cont, ainfi que la fupreme verité, Aurheur de coutes chofes, nous l'a appris, difant : spiritus vbi vult fperat, of vocem eirs audis, of nefis vonde venit, iut quo vadit: L'efprit ou vent fouffle où bon luy emble, $\&$ bien que tu fentes fon foufflement, cu ne fçais pas toutefois d'où il procede, ny iufques où il doit arriuer; afin de nous enfeigner que comprenans fi peu és chofes qui nous font prefentes, \& communes, nous ne deuons pas prefumer d'entendre ce qui eft fi haut $\&$ fi caché, que les caufes \& motifs du faindt Efprit. C'eft pourquoy il fuftitt que nous cognoiffions fes operations \& effects, lefquels nous font fuffifamment defcoutuerts en fa grandeur $\&$ perfeetion, \& d'auoir en genéral philofophé ce peu des vents, \& des caufes de leurs differences; proprictez $\&$ operations que nous auons reduites en trois, qui font le lieu par où ils paffent, les regions où ils foufflent, \& la vertu celefte, principe \& motif des vents. 


\section{Hiftoire naturelle \\ D'aucunes proprietez de vents qui courent au nouueau monde. \\ Chaptitre III.}

Arifl. 2: Met.sa. s.

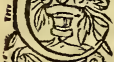

Ariftote, fçauoir fil le vent Aufter, que nous appellons Abreguo, ou Sud, a fouffle depuis le Pole Antaretique, ou bien tant feulement depuis l'Equinoxe $\& \mathrm{Mi}$ dy, qui eft proprement demander fi par dela l'Equinoxe il a 8 retient aufi la mefme qualité de chaud \& pluuieux que nous voyons icy; c'eft vn poinct fur lequel l'on peut, non fans raifon, entrer en doute: car encores qu'il paffe l'Equinoxe, il ne laiffe pas toutefois d'eftre vent d'Aufter ou Sud, puis qu'il vient du melme cofté du monde, comme le vent de Norr, qui court du cofté contraire, ne laifle pas auffi d'eftre Nort, encor qu'il paffe outrela Torride \& ligne Equinoxiale. Et femble bien par cela que ces deux vents doiuent retenir leurs premieres proprietez; l'vn d'eftre chaud $\&$ humide, $\&$ l'autre froid $\&$ fec; $l^{\prime}$ Aufter de caufer les bruines \& les pluyes, \& le Boree, ou Nort de les confommer, \& de rendre le ciel ferain, \& tranquille. Toutesfois Ariftote f'encline à la contraire opinion, pour autant qu'en Europe le Nord eft froid, pource qu'il vient du Pole, region extremement froide, \& le Sud au contraire, eft chaud, pource qu'il vient du Midy, qui eft auffi la region que le foleil efchauffe dauantage. Par céte raifon doncil fau. droit croire que l'Aufter feroit froid à ceux qui 


\section{des 7ndes. Liure III.}

abitent l'autre partie de la ligne, \& que le nort ur feroit chaud: car en ces parties l' a ufter viét a Pole, \& le wort vient du Midy. Er combien u'il femble par cefte raifon, que l'Aufter, ou ud, doiue eltre plus frold par delà, que n'eft as le Nort par deçà, atrendu quel'on tient la eg on du Pole du Sud plus froide, que celle du ole du Nort, à caufe que le foleil demeure fept ours dauantige par an, au Tropique de Caner, quiil ne faict pas au Tropique de Capricore, comme il appert par les Equinoxes \& foltices qu'il fait és deux cercles. En quoy il femle que la nature ayr voulu monftrer la preémiience $\&$ excellence que cefte moitié du monle qui elt au Nort, a fur l'autre moitié qui eft au ind; d'où il femble qu'ily ayt raifon de croire que ces qualitez des vents ie changent en pafant la ligne, mais à la vetité il n'en eft pas ainfi, ce que i’ay peu comprendre par l'experience de quelques annees que i'ay efté en ces parties des Indes, qui gifent au Sud, de l'autre cofté de a ligne. Il eft bien vray que le vent du Nort n'eft pas fi communement froid \& ferain par delà, comme il eft icy. En quelques endroits du Peru, comme en Lyma, \& aux plaines, ils experimentent que le Nort leur eft maladif, \& ennuyeux, \& par toure cente cofte, qui dure plus de cinq centslieiies, ils tiennent le sud pour vn vent fain \& frais, \& qui plus eft, tres-ferain, \& gracieux, mefme que iamais il n'en pleut, tout au contraire de ce que nous voyons en Euro. pe, \& en cefte partie delaligne. Toutesfois ce qui eft en la cofte du Peru, n'eft pas vne regle 


\section{Hiftoire naturelle}

generale, mais pluftoft vne exception, \& vn merueille de nature, de ne pleuroúr iamaise cefte colte là, \& qu'il y regne toufiours vn mef me vent, fans donner lieu à fon contraire; de quoy nous dirons apres ce qu'il nous en femble ra. Maintenant demeurons à ce point, quel Nort n'a point de l'autre cofté de la ligne, le proprietez que l'Aufter a par deçà, encor es que rous deux foufflet du sidy, à des regions \& par. ties du monde oppofites \& contraires : car ce n’eft pas regle generale par delà, que le nort foi chaud, ny pluuieux, comme l'aulter l'eft par de ç̀े; au contraire il pleut là auffi bien lors que no. Itre Aufter y regne, commel'on void en toure la Sierre, ou montagne du Peru, en Chillé, \& en la terre de Gongo, qui eft de l'autre cofté de la ligne, \& bien aduancee en la mer. Et en Potozi mefme, le vent qu'ils appellent Tomahani (qui eft noftre Norr, fi j'ay bonne memoire) eft extremement froid, fec, \& mal plaifant, comme il nous eft par deçà. Il eft vray que ce n'eit pas chofe couftumiere par delà que ce nort diffipe les nuages comme icy; au contraire (fi is ne me trompe)il caufe fouuentefois de la pluye. Et n'y a point de doute que les vents ne tirent, \& n'empruntent cefte grande diuer fité d'effects contraires, des lieux par où ils paffent, \& des prochaines regions d'où ils naiffent, cóme chaque iour l'on experimente en mille endroicts. Mais parlant en general de la qualité des vents, Yon doit pluftoft regarder aux coftes $\&$ parties du monde, d'où ils naiffent \& procedent, que non point pour eftre du cofté de deçà la ligne, 


\section{des Indes. Liure III.}

u autrement, comme il me femble quele Phiofophe en a eu opinion. Ces vents capitaux, ui font le Leuant \& le Fonent, n'ont point de ualitez fi v niuerfelles, ny fir communes en ce ontinent, ny en l'autre, comme les deux fuflits. Le Solanus, ou Leuant, eft icy ordinairement ennuyeux, \& mal rain; \& le Ponent, ou Zephyre, eft plus doux, \& plus fain. Aux Indes $x$ en toute la Torride, levent d'Orient quils tppellent brife, eft au cótraire d'icy fort fain \& delicieux. Du Ponent, ie n'en pourray dire choe certaine, ny generale, d'autant qu'il ne fouffle oint du tout, ou bien fort rarement, en la toride: car en tout ce que l'on natrige entre ces deux tropiques, le vent de la brife y eft ordinaire, mais pource que c'eft vne des merueilleufes ruures de nature, il ferabon d'en entendre 12 caufe \& l'origine.

2ue les brifes courent toufours en la Torride, Gubors d'icelle les vents d'abas \& les brifesy font touflours ordinaires.

\section{CHAPITRE IV.}

E chemin de la mer n'eit pas comme

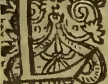

celuy de la terre, pour retourner par où l'on a paffé, il y a vn mefme chemin, dat le Philolophe, d'Athenes Thebes, que de Thebes à Athenes: maisil n ${ }^{2} e$ t pas ainfi en la mer, pource que l'on va par vn chemin, \& retourne- on parvn autre. Les premiers qui defcouucirent les Indes Occidenta- 


\section{- Hiffoire naturelle}

Joan.de Ga- les, voire Orientales, trauaillerent beaucoup cos in decada eurent de grandes difficulte $\mathrm{z}$ à trouuer la rou-

I. .4 . c.6. te, iufqucs à ce que l'experience, ' maiftreffe de cesfecrets, leur euft enfeigné, que de nauiger par l'Occean, n'eft pas cho:e femblable, que de paffer en Italie par la mer mediterranee, où l'on varecognoiffant au retour les mefmes ports \& caps, quel'on a veuz à l'aller, \& ne fait-on toufiours qu'attendre la faue ur du vent qui f'y chan. ge en vn inftant, \& encor quăd il leur deffaut, ils ont recours, \& fe feruent forr bien de la rame, $\&$ ainfi vont, \& viennent les galeres toufiours, en coftoyant la terre. En certains endroits dela mer Occeane on ne doit efperer autre vent que celuy qui court, parce quordinairement il y dure long temps. En fin celuy qui eft bon pour aller, nel'eft pas pour retourner: car en la mer outre le tropique, \& dedans la torride, les vents de Leuant y regnent toufiours, foufflans continuellement fans permettre leurs contraires, en laquelle region y a deux chofes merueilleufes, l'vnè, qu'en icelle (qui eft la plus grande des cinq en quoy ils dituifent le monde) regnent les vents d'Crient qu'ils appellent brifes, fans que ceux du Ponent \& Midy, qu'lls appellent vents d'abas, ayent lieu de courir en aucune farlon do l'annee. L'autre merveille eft, que ces brifes ne ceffent iamais de fouffler, \& le plus commiunement és lieux qui font plus proches de la ligne, efquels il femble que les calmes deuffent eftre plus ordinaires, d'autant que c'eft la partie da monde plus fubjette à l'ardeur du foleil. Mais ceft au contraire: car à peine on y roid des cal 
ies, \& fi la brife y eft beaucoup plus froide, \& dure plus long temps; ce quia a efté recogneu a toutes les nauigations des Indes. C'eft done l'occafion pourquoy la nauigation que l'on it allant d'Éfpagne aux Indes Occidentales, plus briefue, \& plus facile, voire plus affeuee, que celle quel'on faict au retour d'icelles $n$ Efpagne. Les flottes fortans de Seuille, ont plus de peine $\&$ de difficulté à paffer \& arrier iufques aux Canaries, d"autant que ce Golhe des Yegues, ou desiuments, eft variable, ftant battu de plufieurs $\&$ diuers vents: mais yant paffé les Canaries, elles vont baiffans iufues à entrer en la Torride, où ils trouuent inontinent la brife, \& y nauigét vent en pouppe e telle forte, quià peine eft befoing en tout le oyage de toucher aux voiles. Pour cefte raifon Is appellerent ce grand Golphe, le Golphe des ames, pour fa douceur \& ferenité. En apres, uiuant leur route, elles arriuent iufques aux Ifes de la Dominique, Guadelupe, Defiree, Maigualante, \& les autres, qui font en cét endroit :omme les fauxbourgs des Indes, Là les flottes e feparent \& fe diuifent, dont les vns (qui vont an la neuue $E$ fpagne) tirent à main droite, pour ecognoiftre l'E Ppagnolle, \& ayans recogneu le Cap fainct Antoine, donnent iufques à fainct lean Delua, leur feruant toufiours la mefme brife. Celles de terre ferme prennent la main gauche, \& vont recognuiftre la haute montagne de Tayrone, puis ayant touché en Carthagene, paffent outre à nombre de Dios, d'où par terre on va à Panama, \& de là par la mer du 


\section{Hiftoire naturelle}

Sud au Peru. Mais lors que les flottes retoutnent en Efpagne, elles font leur voyage en cefte façon. La flotte du Peru va recognoiftre le Cap fainct Antoine, puis entre en la Hatiane, qui eft vn fort beau port, de l'ifle de Cube, \& celle de la neuue Efpagne vient mefme toucher en la Hauane, eftant fortie de la vraye Croix, ou de l'Ifle de fainct Iean Delua; toutefois ce n'eft fans trauail, pource que là ordinairement ventent les brifes, qui eft un vent contraire pour aller à ce port de la Hauane. Ces flottes eftans joinctes pour retourner en Efpagne, vont chercher leur hauteur hors des Tropiques, où incontinent ils tromuent des vents d'abas, quileur feruentiufques à la veüe des Ifles des Açores, ou Tyerceres, \& de là à Seuille. De forte qu'ils font le voyage del'aller en peu de hauteur, nefeefloignans point de la ligne de plus de vingts degrez, qui eft jà dans les Tropiques: Mais le retour fe fait parle dehors d'iceux Tropiques, en 28 . ou trente degrés de hauteur pour le moins; ce qu'ils font pourla raifon fufdite, d'autant que dans les Tropiques continuellement regnent des vents d'Orient, lefquels font propres pour aller d'Efpagne aux Indes Occidentales, pource que $\mathrm{I}_{2}$ route eft d'Orient au Ponent, \& hors les Tropiques, qui eft en 23 . degrez de hauteur, l'on trouue des vents d'abas, lefquels font plus certains, \& ordinaires, plus l'on f'efloigne de la ligne; qui font propres pour retourner des Indes, d'autant que ce font vents de Midy \& de Ponent, qui feruent pour courir a l'Orient \& au Nort. Le mefme difcours eft aux nauigations que l'on 


\section{des Fndes. Liure III.}

ait en la mer du Sud, allant de la neutue $E$ fpane $\&$ du Peru, aux Philippines, ou à la Chine, r retournant des Philippines, ou Chine, à la euue Efpagne : car cela leur eft facile, pource u'ils nauigent toufrours 'd'Orient au Ponent, roche de la ligne, où ils tróuent continuelleaét le vent de brife, quileur donze en pouppe. in l'an quatre vingts quatre fortit de Gallao en yma vn nauire pour aller aux Philippines, leuel courut \& nauigea deux mille fept cents ieiies fans voir terre, \& la premiere qu'il defourit, fuft lifle de Luffon, où il alloit, \&y rint port, ayant fait fon voyage en deux mois, ans auoir eu aucune faute de vent, ny fouffert ucune tourmente, \& fut $f$ a route prefque touf. ours fous la ligne; pource que de Lyma qui elt douze degrez au Sud, il vint arriuer à Menill $a_{\text {, }}$ ui eft quafi autres tant au Nort. Le mefme eur accompagna Aluaro de Mandana, quand fut a la def counerte des Ifles appellees de $\mathrm{Sa}$ omon, pource quil eut toufiours le vent en ouppe iufques à la veüe de ces Intes, lefquelles outuent eftre diftantes du lieu du Peru, d'où ils ortirent; comme mil lieies, ayant fait fa route oufiours en vne mefme hauteur au Sud. Le reour eft comme le voyage des Indes en Efpane: car ceux qui retournent des Philippines ous chine à Mexique, a fin de trouuer les vents d'a. as, montentà beaucoup de haureur, iufques à e mettre au droit des Ifles de Iappo on \& venant recognoiftre les Calliphornes, retournent par a cofte de la neuue Efpagne, au port d'A capul. 0 , d'où ils eftoient fortis. De forte qu'il eft $\mathrm{L}$ 


\section{Hiftoire naturelle}

mefme prouué par cefte nauigation, que d'o: rient au Ponent l'on nauige fort bien dans les Tropiques, d'autant qu'il y regne des vents Orientaux: mais retournás du Ponét en Orient, l'on doit chercher les vents d'abas, ou du Ponent, hors des TrQpiques en hauteur de 27. degrés. Les Portugais experimentent le mefme en Ia nauigation qu'ils font à l'Inde d'Orient, bien qu'au rebours, pource qu'allant de Portugal, le voyage eft ennuyeux, \& de trauail, maisle retour eft plus ayfé, d'autant qu'à l'aller leur route eft du Ponent à l'Orient; tellement qu'il leur conuient monter iufqu'zे ce qu'ils ayent trouué les vents generaux qu'ils difent, qui font au deffus de vingt- fept degrez. Et au retourils recognoiffent les Tyercieres, mais c'eft plusayfément, pource qu'ils viennent d'Orient, enquoy les brifes ou Norts leur feruent. Finalement les mariniers tiennent jà pour regle \& obferuation certaine, que dans les Tropiques regnent continuellementles vents de Leuant, parquoy il y eft tres-facile de nauiger au Ponent. Mais dehors iceux Tropiques, ily a en quelques faifons des brifes, en d'autres, \& plus ordinairement, des vents d'abas; à raifon dequoy ceux qui nauigent du Ponent en Orient, procurent toufiours fortir de la Torride, \& fe mettre en hauteur de 27. degrez, \& pour cefte raifon les hommes fe font jà hazardez d'entreprendre des nauigations eftranges, \& à des parties elloignees, \& inco. gneiies. 
De la difference des brijes, of vents d'abas, enjemble des autres vents.

\section{CHAPITRE V:}

7) I E que ce qui a efté dit cy deffus, foit $\rightarrow$ vne chofe fi approuvee, \& fi vniuerfelle, neantmoins il me refte toufiours vn defir d'enquerir la caufe de ce fecret, pourquoy en la Torride l'on nauige toufiours d'Orient en Occident auec telle facilité, \& non au contraire, d'Occident en Orient. Qui eft le mefne que fil l'on demandoit pourquoy les briCes regnent là, \& non les vents d'abas, puis que felon bonnc Philofophie, ce qui eft perpetuel, vniuerfel \& de par foy (comme difent les Philo. fophes) doir auoir vne caufe propre, $\&$ de par foy. Or auant que m'arrefter à cefte queftion, qui me femble remarquable, il fera befoing de declarer ce que nous entendons par les brifes \& vents d'abas, à caule que cela feruira beaucqup pour ce lujet, \& pour plufieurs autres choles \& matieres des vents \& natigations. Les pilotes mettent trente-deux differences de vents, parce que pour conduire leur proiie au port defi. ré, ils ont befoing de faire leur conte fort pun-, etuellement, \& le plus diftinetement, \& au menu qu'sls peuuent, veu que pour peu qu'ils tiraffent en v n cofté, ou a l'autre, en fin de leur chemin, fe trouueroient grandement efloignez d'où ils penferoient aller, \& ne content plus dø trente-deux vents, d'autant que ces diuifions 


\section{Hiffoire naturelle}

fuffifent, \& ne pourroit-on auoir la memoire pour en retenir dauantage. Mais a la rigueur, commeils mettent trentre deux vents. l'on en pourroit conter 64.128 . \& 256 . finalement a!ler multipliant ces parties iufques à l'infing: car le lieu où fe trouue le nauire eftant comme le centre, \& tout hemifphere en circonference, qui eft ce qui empefche que l'on ne puifie conter des lignes fans nombre, leiquelles fortans dece centre, tirent droidt à ce cercle lineal en tout autant de parties, qui ferót autant dé vents diuers, puifque ainfieft, que le vent vient de toutes les parties de l'hemifphere, \& qu'on le peut diuifer en autant de parties que nous voutdrons imaginer ? Tourefois la fageffe des hommes fe conformant à la faincte Efcriture, remarque quatre vents, qui font les principaux de tous, \& comme quatre coings de l'vniuers, que l'on ferme, en faifant vne croix auec deux lignes, dontl'vne va d'vn Pole à l'autre, \& l'autre d'vn Equinoxeà l'autre, \& font d'vn cofté le Nott, ou Aquilon, \& l'Aufter, ou vent de Midy, foncontraire; \& del'autre coftél'Orient, qui procede d'où iort le foleil, \& le Ponent d'où il fe couche. Et combien que l'Efcriture faincte parle en quel ques endroits d'autres diuerfités de vents, comme de l'Eurus, \& Aquilon, que ceux dela mer Occeane, appellent nort d'eft, \& ceux de la mer Mediterranee Gregual, duquel il eft fait mention en la nauigation de fainct Paul, fi eft-ce que la mefme Efcriture faincte rapporre ces quatre differences remarquables que tout le monde cognoit, qui font comme il eft dit, Sep. 


\section{des Indes. Liure III.}

entrion, Midy, Orient \& Ponent. Mais d'autant que $I$ on troune trois differences au leuer, $\&$ naiffance du foleil (d'uù vient le nom d'Orient) (çauoir, les deux plus grandes declinaifons qu'il a accouftumáde faire, \& le milieu d'iceles, felon qu'il naift en diuers lieux en hyuer, 'efté, \& en celle qui tient le milieu de ces deux Caifons. Pour cefte raifon l'on conte deux autres vents, qui font l'Orient d'efté, \& l'Orient de hy uer, \& par confequent deux autres Ponents d'hyuer \& d'efté, contraires aux deffufdits. De Corte qu'il y a huit vents en huit points notables duciel, qui font les deux Poles, les deux Equinoxes, les deux folltices, \& leurs oppofires au mefine cercle, lefquels font appellez de diuers noms \& appellatiós en chacun lieu de la mer \& de la terre. Ceux qui nauigent l'Occean, ont accouftumé les appeller ainfí. Ils donnét le nomde. Nort aux vents fouffl ans de noftre Pole, qui retient le mefme nom de Nort, \& de Nordeft, Celuv quiluy eft prochain \& qui vient de l'Orient eftiual, ils l'a pellent eft; celuy qui fort du vray Orient, equinoxial; \& Sueft, celuy qui vient de l'Orient d hyuer. Au midy, ou Pole Antaretique ils donnent le nom de Sud, \& à celuy du Couchant d'hyuer, le nom de Suroefl; au vray Couchant Equinoxial, le nom de Oeft, \& au Couchant d'efté, celuy de Nort-oeft. Ils diuifent enrreux le relte des vents, \& leur donnent les noms, felon qu'ils participent, \& f'approchent des autres, comme Nort nortoeft, nortnoirdeft, eft nordeft, eft fueft, fur foroeft, fufueft, oeft, fur-oeft, oeft, nortoeft; deforte que parleurs 


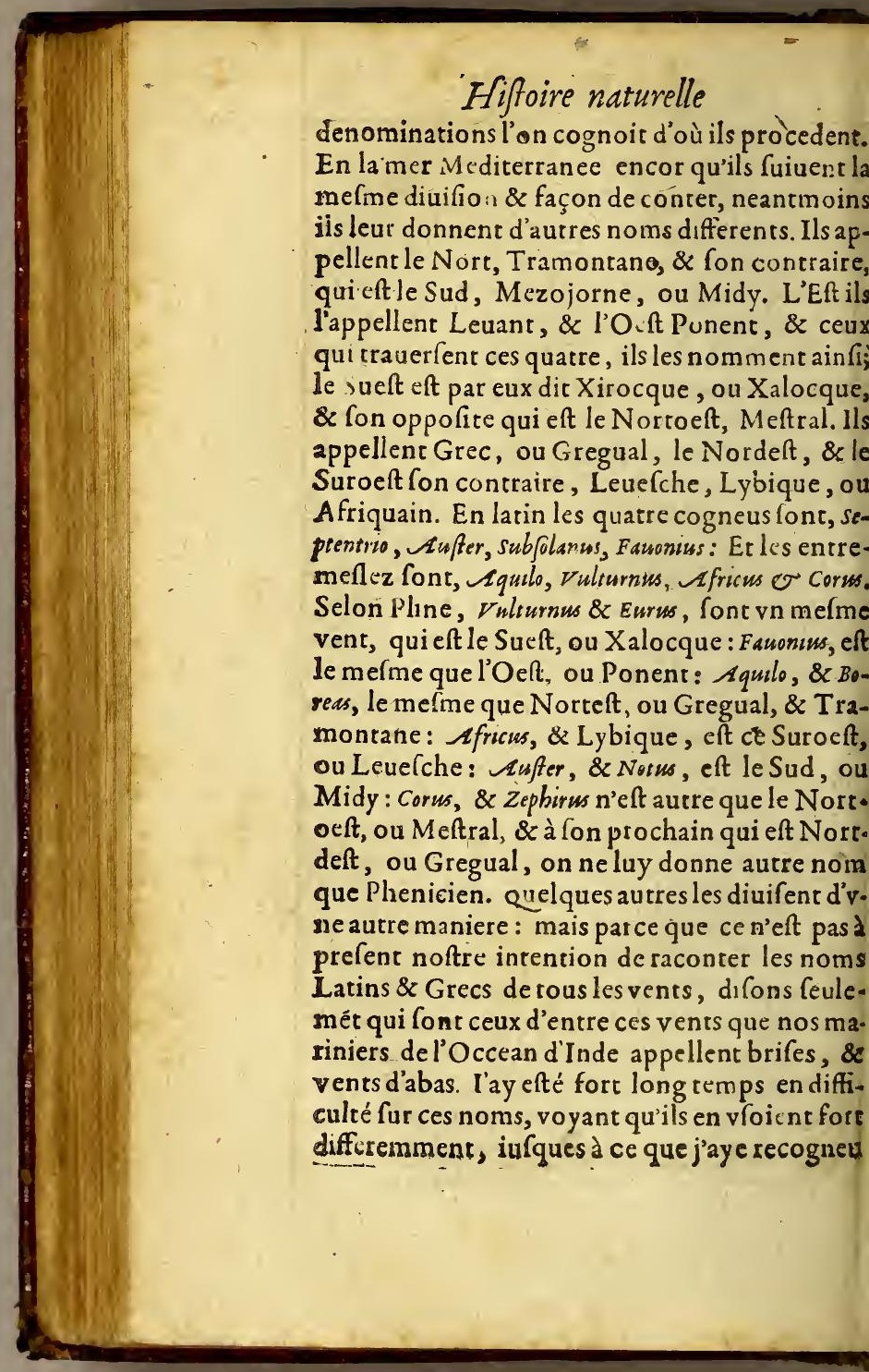




\section{des Indes. Liure 111.}

84 que ces noms font plus generaux, que propres, \& particuliers. Ils appellent brifes, ceux qui feruent pour aller aux Indes, \& qui donnent quafi en pouppe, lefquels par ce moyen cóprennent tous les vents Orientaux, \& ceux qui en dépendent; \& appellent vents d'abas, ceux qui font pres pour retourner des Indes, \& qui foufflene depuis le Sudiufques au Ponent eftiual; de maniere qu'ils font comme deux efcoiiades des vents de chacun cofté, les Caporaux defquelles font d'vne part le Nortdeft, ou Gregual; \& de J'autre le Surcelt, ou Leuefihe. Mais l'on doir entendre que du nombre des huict vents ou differences que nous auons cottez, il y en a cinq qui funt propres pour nauiger, \& non les trois autres. Ie veux dire que quand vn nauire nauige en la mer, il peut aller \& faire long voyage auec l'vn de ces cinq vents, encor qu'ils ne luy feruent pas efgalement: mais il ne fe peut point feruir d'aucuns des trois, cốme fi le nauire va au Sud, il nauigera auec le Nort, le Nortdeft, le Nortoeft, \& auec l'Eft, \& l'Oeft : car cenx des coftez feruent efgalement pour l'aller, \& pour le venir. Mais du Sud, il ve fen pourra feruir, pource qu'il luy eft directement contraire, ny de fes deux collateraux qui font Sueft \& Suroeft, qui eft v ne chofe fort triuialle, \& commune à ceux qui nauigent. C'eft pourquoy il n'eftoit befoing de le diduire icy, finon pour fignifier queles vents lateraux du vray Orient, font ceux qui communement foufflent en la Torride, qu'ils appellent prifes, \& les vents de Midy declinans ru Ponent, quileruent pour naviger d'Occi$\mathbf{L}$ iij 


\section{Hiftoire naturelle}

dent à l'Orient, ne font point ordinaires en la Torride, parquoy l'on les va chercher hors des Tropiques, de les appellent les mariniers des Indes communement vents d'abas.

2 welle eft la caufe pourquay natuigeant en $l_{a}$ Torride, ily a toufours des vents d' Orient.

Chapitre Vi.

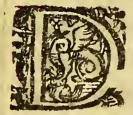

Is o s s maintenant ce qui tauchela queftion propofec, fçauoir, quelle eft la caufe pourquoy l'on nauige bien en la Torride d'Orient au Ponêt, \& non au contraire. Sur quoy nous de uós prefuppofer deux fondemés certains : l'vn eft que le mouuement du premier mobile, qu'ils appellent rauiffant, ou diurnel, non feulement ture \& efmeut quant \& luy les fipheres celeftes qui lay font inferieures, cóme il fe void chacun iour au foleil, lune \& eftoilles, mais auffi les elements participent de ce mouuement, entant qu'ils n'en fone point empefchez. La terre ne fe meut à caufe de fa grande pefanteur qui la rend mobile, \& qu'elle eft auffi beaucoup éloignee de ce premier mo. bile. L'element de l'eau ne fe meut non plus de ce mouuement diurnel, d'autant qu'il eft join $\mathrm{x}$ \& affemblé auec la terre, \& font enf mble vne Sphere; de façon que la terre l'empefche de fe mounoir circulairement: mais les deux autres elemens, le feu \& l'air, font plus fubtils, \& plus proches des regions celeftes, d'où vient qu'ils participent de leur moutement, \& font meus 


\section{des Indes. Liure. III.}

agitez circulairement ; comme les mefmes orps celcstes. Pour le regard du feu, il n'y a oint de doute qu'il n'ait fa Sphere, ainfi qqu' Aiftote \& les autres Philofophes l'ont tenu:mais our l'air (qui eft le point de noftre fubiet) il eft res-certain quil fe meut du mouuement diuriel, qui eft d'Orient à l'Occident, ce que nous oyons clairementés Cometes qui fe meuuê̌t 'Orient à l'Occident,montans, defcendans, \& inalement tournoyans en noftre hemifphere, le la mefine façon que les eftoilles fe meuuent un firmament. Car autremér ces Cometes eftăs in la region \& Sphere del'air, où elles s'engenirent, apparoiffent \& fe confomment, il leur feoit impoffible de fe mounoir circulairement omme ils fe meuuent, fi l'element de l'air où ils ont, ne fe mouuoit du mefme mouuement du remier mobile. Car eflans ces Cometes d'vne natiere enftammee, par raifon deuroient deneurer arreftees fans fe mounoir circulairenent, $f_{1}$ la Sphere oư elles font,demeuroit fans e mouuoir, fi ce n'eft que nous faignions que quelque Ange ou Intelligence chemine auecla Comete, la menant circulairement. En l'air 1577. apparut cefte merueilleule Comete (de figure reffemblant vn plumage) depuis l'horiCon prefque iufques à la moitie du Ciel, \& dura depuis le premier Nouembre iufques au huiotiefme de Decembre. Ie dis depuis le premice de Nouembre; car iaçoit qu'en Efpagne on la veid \& remarqua premierement au 9. de Nouembre (fuiuant le recit des. Hiftoriens de ce 'tês) neantmoins au Peru, où i’ eftois pour lors, 


\section{Hiftoire naturelle}

il me fouvient bien que nous la vifmes 2 re marquafmes huict iours deuant, \& tous les iour enfuiuans. Pour la caufe de cefte diuerfité, quel. ques-vns la pourront dire particulierement mais ie veux dire qu'en ces quarāte iours qu'el le dura, nous remarquafmes tous, tant ceux qu: eftoient en Europe, que nous autres aufi qu. eftions alors aux Indes, qu'elle fe mounoit cha. que iour du mouuement vnituerfel, d'Orient au Ponent, commela Lune \& les autres eftoilles D'où il appert que la Sphere de l'air eftant fa region, il faut que le mefme element fe meuue de cefte façon. Nous recogneufmes aufi, que outre ce moutement vniuerf $f$, elle en auoit en. cor vn autre particulier, par lequel elle fe nouuoit auec les planettes d Occidét en Orient: car chaque nuift elle deuenoit plus Orientale, ainf que font la Lune, le Soleil, \& l' $\in$ ftoille de Venus. Nous remarquafmes dauantage vn troifiefme moutuement particulicr, dór elle fe nouuoit au Zodiaque vers le Nort , d'autant que paffées quelques nuicts, elle fe trounoit plus conjointe aux fignes Septentrionaux. Et parauanture cela fut caufe pourquoy cefte grande Comete fuft pluftoft veuë de ceux qui eftoient plus Meridionaux, cóme le font ceux du Peru. Et d'autre part,ceux de l'Europe com mécerent à la voir plus tard, à caufe que par ce troifiefme mouuement quei'ay dit, elle s'approchoit plus des Septétrionaux. Toutesfois vn chacun a peu remarquer les differences de ce mouuement, de façon quel'on peut bien voir que plufieurs $\&$ dicers corps celeftes, donnent leur impreffion 


\section{des Indes. Liure. III.}

86

la Sphere de l'air, ainfi eft-il certain que l'air fe geur du mounemét circulaire du Ciel, d'Orient u Punent, qui eft le premier fondement mis en ua ut cy diffus Le fecöd $n$ eft pas moins certain, y notorre, qui eft que le mousemét de l'air aux arties qui font fous la ligne, ou proches d"icel$e$, eft tres-vifte \&leger, \& d'autăt plus qu'il s'aproche de l'Equinoxe, par confequent ce moutement elt d'autát plus lent \& pefant, qu'il s'efoigne de la ligne en s'approchant des Póles. La ailon de cecy eft manifefte, parce que le mounement du corps celefte, eftát la caule efficiente de ce mouuement de l'air, il doit par neceffité eftre plus prompt \& plus leger à l'endroit oùlle corps celelte a fon mouuement plus vifte. Or de voulorr enieigner la raifon pourquoy le Ciel a vn plus vilte mouuemét en la Torride, qui eft la ligne, plus qu'en aurre partie du' Ciel, ce feroir peusttimer les hommes, puis qu'il elt aifé de voir en vne roüe que fon mouuement eft plus tardif \& pefant à l'endroit de fa plus grande circonterence quà l'endroit de fa plus petite, \& qu'elle acheue fon grand tour au mefme efpace de temps, que la moindre acheue fon perit. De ces deux fondemens procede la raifon pour laquelle ceux qui nauigenr grands Golphes, d'O. rient au Ponent, trouuét toufiours vent ens poupe;allans en peu de hauteur, \& tant plus ils font proches de l'Equinoxe, tant plus letir eft certain \& durable le vent. Et au contraire nauigeans du Ponent à l'Orient, ils trouuent toufiours vent en proüe, \& contraire. Pource que le mouuement tres-vifte de l'E noxe, tire apres foy 


\section{Hif toire naturelle}

l'element de l'air, comme il fait le furplus des Spheres fuperieures. Par ainfil l'air fuit toufiours le mouuement du iour allant d Orient au Po. nant, fans iamais varier, \& le mouuemét de l'air vifte, amene mefme apres foy les vapeurs $\&$ exhalations qui s'efleuent de la mer, ce qui caufe en ces parties \& regions vn continuel vent de brife qui court de Le uant. Le Pere Alonfo Sanchez,qui eft vn Religieux de noftre Cópagnie, qui a voyagé en l'Inde Orientale \& Occidentale, comme homme ingenieux \& experimenté, difoit, qu'en nauigeant deffousla ligne, ou proche d'icelle,auec vn temps continu $\&$ dura. ble, il luy fembloit que c'eftoit le mefme air, meu du Ciel, qui conduifoit les nauires, \& theftoit pas proprement vin vent, ny exhalation, mais ceft air efmeu du cours iournalier du Soleil;pour preuue dequoy il mettoit en auant que le temps eft toufiours égal \& femblable au Golphe des Dames , \& és autres grands Golphes que l'on nauige en la Torride. Pour raifon dequoy les voiles des nauires y font toufiours de mefme façon, fans aucune impetuofité, \& fans qu'il foit befoing les changer prefque en tour le chemin. Que fi l'air n'eltoit efmeu du Ciel, il pourroir quelquesfois deffaillir, quelquesfois fe changer au cótraire, \& quel quesfois y auroit des tourmentes. Toutesfois combien que cecy foir dit doctement, l'on ne peut pas nier que ce ne foit vent, \& quili n'y en aye, attendu qu'il y a des vapeurs \& exhalations de la mer, \& que nous voyons quelquesfois que tantoft la brife eft plusforte, \&6 tanto? of lus foible, \& remife, 


\section{des Indes. Liure. III.}

le telle façon qu'il aduient quelquesfois que on ne peut porter toutes les voiles L'on doit lonc entendre, \&eft la verité, que l'air efmeu atire quant $\&$ foy les vapeurs quil trouue, d'auant que la force eft grande, \& qu'il ne trouue oint de refiftance, poúr raifon dequoy le vene l'Orient \& Ponent eft auffi continuel \& prefjue toufiours femblable és parties qui font roches de la ligne, \& prefque en toute la Toride, qui eft le chemin que fuit le Soleil entre es deux cercles du Cancer $\&$ du Capricorne.

Pourguoy Cortans de la Torride en plus de hathteur, l'on troune plus founent des

vents d'abas.

Chápitre VII.

V I voudra bié regarder de presce qui a efté dit, pourra auffi bien entendre, qu'en allant du Ponent à l'Orient, en hauteur plus outre que les Tropiques, 'on troulue des vents d'abas; d'autant que le mounement de l'Equinoxe eftant fi vifte, il eft caufe que l'air fe meut deffous luy, fuiuant fon mouuement, qui eft d'Orient au Ponent,attirant quant \& foy les vapeurs qui s'efleuent de la mer, de forte que les vapeurs \& exhalations qui s'elleuent des coftes de l'Equinoxe, ou Torride, venans à rencontrer le cours \& mouuernent de la Zone, font contraintes par la repercuffion de retourner quafi au contraire, d'où viennent les vents d'abas, \& Suroeft, communs $\&$ fi ordinaires en ces parties la. Tout ainfi que nous yoyons au cours des eauies, lefquelles fi el- 


\section{Hiffoire naturelle}

les font rencótrées d'aurres qui foient plus fortes, retournent quafi au contralre. Et femble qu'il en foit ainfi des vapeurs \& exhalations, d'où vient queles vents fe tournent \& fe fepazcnt d'vnepart à l'autre. Ces vents d'abas regnent le plus communemét en la moyéne hrauteur, qui eft de 27 aे 37. degrez! combien qu'ils ne foient pas fi certains \& fi i eguliers queles brifes le font en peu de hauteur. La raifon eft, pource que les vents d'abas ne font pascaufe de ce mounuement propre \& égal du Ciel, comme les brifes le font, eftans proches de la ligne. Mais comme i'ay dit, ils y font plus ordinaires, \& bien fouuent plus furieux, \& plus tempeftueux. Mais en allant en plus grande hauteur, comme de quarante degrez, il y a auffi peu d'affeurance és vents en la mer, comme en la terre, car tantoft les brifes, ou Norts y fouftlent, \& tantoft les vents d'abas, ou Ponents, d'où vient' que les nauigations y font plus incertaines \& plus dangereufes.

\section{Des exceptions quil y a en la regle fucdite, des vents of calmes quily a en la mer ó en la terre. \\ Chapitre VIII.}

E que nous auons dit des vents quit H 0 2 2 courét ordinairement dedans \& de. Tors la Torride, fe doit entendre en 4. Ja la haute mer \& aux gräds Golphes: car en la terre, ceft tout autrement, en laquellel'on trouue de toutes fortes de vents, a caufe de l'inegalité qu'il y a entrc les montagnes 


\section{des Fndes. Liure III.}

88

les vallées, le grand nóbre des rivieres \& des ics, \& les diueries frutuatiós des pays, d'où s'efle.. et les vapeurs groffes, \& efpaiffes, le fquelles sór imeués de l'vne, ou de l'autre part, felon la dier fité de leur origine \& commencement, qui ut ces vents diuers, fans quele mounement de air, caufé du Ciel, ayt tant de puiffance, que de s attirer \& mouuoir quant \& foy. Et cefte dierfité de vents ne fe troulue point feulement n la terre, mais auffi és coftes de la mer qui ont en la Torride, pource qu'il y a des vents orains qui viennent de la terre, \& marins, qui oufflent de la mer; lefquels vents de la mer font rdinairement plus fains, \&r plus gratieux, que on pas ceux de la terre, lefquels font au conraire ennuy cux \& mal făins, bien que ce foit la ifference des coftes qui caufe cefte diuerfité. Commanement les forains ou terriens foufcnt depuis la minuict, iufques au Soleil leuant, ziceux de la mer, depuis que le Soleil com: nence à s'efchauffer, iufques apres qu'il eft couhé. Dequoy la caufe ẹt parauanture que la erre, comme matiere plus grofle, fume dauanage alors que la flame du Soleil qne donne plus leffus, tout ainfi que le bois vert, ou mal fec, umedauantage en eftaignant la flame. Mais la ner comme elle eft compofée de parties plus ubtiles, n'engendre point de fumees, finó quăd on l'efchauffe; de mefne que la paille, ou le oing,eftant humide, $\&$ en petite quantité, enrendre de la fumée, quand on les brune; \& ors que la flame ceffe, la fumée deffaut tour ufis. toft. Quoy qu'il en foit, il eft certain que le 


\section{Hiftoire naturelle}

vent de la terre fouffle pluft oft la nuict, \& ce-

$\therefore$ luy de la mer au contraire durant le iour. Tellement que tout ainfi qu'il y a fouventesfors des vents contraires, violents, \& tempeftueux és coftes de la mer, ainfi y voit-onde tres-grands calmes. Quelques hommes fort experinentez racontent qu'ayans nauigé plufieurs grandes trauerfes de mer fous la ligne, ils n'y ont neantmoins iamais veu de calmes, mais que toujours peu ou beaucoupl'on y fair chemin, à caufe de l'air efmeu du mouuement celefre, qui fuffit à conduire la nauire donnant en pouppe, comme il fait. I'ay de fia dit, comme vne nauire de Lyma, allăr à Manilla, nauigea \& courut deux mil fept cens lieuës toufiours fous la ligne, à tout le moins n'en eftant efloigné que de douze degrez \& ce au mois de Feurier, \& de Mars, qui eft lors giue le Soleil y eft pour Zerit, \& en tout ceft efpace ne trouuerent aucuns calmes, mais toufiours vn vent frais, tellement qu'en deux mois ils frent ce grand voyage. Mais en la Torride, \& hors d'icelle, l'on a accouftumé de veoir de grands calmes és coftes où arriuent les vapeurs des Ifles, ou de la terre ferme. C'eft pourquoy les tourbillons \& tempeftes, \& les inefperees efmotions de l'air font plus certaines \& ordinaires aux coltes où arriuent les vapeurs de la terre, que non pas en la plaine mer. I'entens en la Torride, car hors d'icelle, \& en la haute mer, lon y trouue des calmes, $\&$ des tourbillons de vents. Toutesfois il ne laiffe pas d'y auoir quel. quesfois entre les deux Tropiques, voire en la anefmeligne, des grands vents \& des pluyes fubites, 


\section{des Indes. Liure. III.}

89

ires, encòr que ce foit bien au ant dans la mer: ar pource faire, les vapeurs \& exhalations de imer font affez fuffifantes, lefquelles s'efmouans aucunefois haftiuement en l'air, caufent es tonnerres \& tourbillons, mais cela eft plus rdinaire pres de la terre, \& deflus la terre. Quăd nauigeay du Peru en la neuue ESpagne, ie :marquay qu'en tout le temps que nous furies en la colte du Peru, noftre voyage fut (comce toufiours a accouftumé) fort doux \& facile caufe du vent de Sud qui y court , \& auec leuel l'on va vent en pouppe, retournant d' $E \int_{\mathrm{p} 2}$. ne \& de la neuue Efpagne. Comme nous traerfions le Golphe, \& allions toufiours auane ans la mer, prefque toufiours fous $l_{2}$ ligne ous trouuafmes in temps frais, paifible, \&graeux, vent en pouppe : mais artiuant comme roche de Nicaragua , \& $\&$ de toute cefte cofte ous eufmes des vents contraires, auec grande uantité de pluyes \& brouillars, qui quelques。 is bruyent horriblement. Toute cefte nauiga. on fut dans la Zone Torride; car de douze derez au Sud qu'eft Lyma, nous nauigeafmes ixfept, où gift Guatulco, port de la neuue Efagne, \& croy que ceux qui auront prins garde Ix nauigations quails ont faites dans la Torrie,trouueront à peu pres ce que i'en ay dit, qui iffira pour la raifon des vents qui regnent $p^{2}$ mer en la Zone Torride. 


\section{- Hifoire naturelle}

D'aucuns effects merueilleux des vents qu font en quelques endroicts des Indes.

Chapitre I X.

D E feroit chofe fort difficile de racon ter par le menu les effects admirable (17) que caufent aucuns vents en diuerfe 19 regions du monde, \& d'en donner raifon. Il y a des vents qui naturellement trou. blent l'eauë de la mer, \& la rendent verte-noire $\&$ d'autres quila rendent claire comme vn mi roir,les vns efgayent \& refiouyffent de foy, \& les autres apportent de l'ennuy \& de la trifteffe Ceux qui nourriffent des vers à foye ont grand foing de fermer les feneftres, lors que les vents d'abas foufflent, $8 x$ de les ouurir quand leurs contraires courent, ayans trouué par certaine experience que leurs vers fe meurent $\&$ diminuent par les vns, s'engraiffent $\&$ deuiennent meilleurs par le moyen des autres, \& qui y voudra prendre garde de pres, il pourra remarquer en foy-melme que les diuerfitez des vents caufent de notables impreffions \& changemens en la difpofition des corps, principalement aux parties dolentes \& indifporees, \& lors qu'elles

Exod.c. 10 ' font plus tendres \& debiles. L'Efcriture appelle E) I4. l'vn,vent bruflant, \& l'autre, vent de rofee \& 706170 Ioan. 4 . Ofee 13. Dar. 3 . plein de douceur. Et n'eft pas chofe efmerueit lable, que l'on apperçoiue de fi notables effects des vents és herbes, animaux, \& és hommes, 


\section{des Indes. Liure. III.}

wis que l'on en cognoift vifiblemét au fer mefo ne, qui eft le plus dur de tousles metaux. I'ay eu des grilles de fer en quelques endroits des ndes, de telle façon rnouluës \& confommees, ju'en les preffant entre les doigts, elles fe refoloient en poudre, comme fi c'eut eftédu foin, u de la paille feche. Ce qui procede tant feaement du vent, qui le corrompt du tout, \& fans a'on le puiffe empefcher. Mais laiffant à part lufieurs autres grands \& merueilleux effects, en veux feulement raconter deux, l'vn defjuels, encor qu'il caufe des douleurs plus gran les que la mefme mort, n’apporte point de mal, y d'in commodité dauantage; l'autre deftruit, ofte la vie fans le fentir. Le mal de la mer, lont ceux-ld font trauaillez quí commencent a rauiger, eft vne chofe fort ordinaire, \& neantnoins fi l'on ignoroit fon naturel, qui eft tant ogneu à tous les hommes, l'on penferoir que e fuft le mal de la mort, de la façon qu'il afflige z tourmente pendant le temps qu'il dure, par e vomiffement d'eftomach, douleurs de tefte $\&$. utres mil accidens fafcheux. Mais à la verité, ce nal fi commun \& fi ordinaire, vient apx hom. nes pour la nouueauté de l'air de la mer : car combien qu'il foit vray que le mouuement du auire y ayde beancoup, en ce qu'il s' efmeut pl" u moins, \& mefme linfection \& mauuaife deurr des chofes des nauires, neátmoins la prore \& naturelle caufe eft l'air \&z les vapeurs de la ner, lequel debilite \& trauaille tellemër le corps $x$ l'eftomach qui n'y font point accoultumez, y'ils en font merueilleufement efmeus \& chï. 


\section{Fiftoire naturelle}

gez: car lair eft l'element par lequel hous viuons \& refpirons, l'attirant dedans nos mefmes entrailles, lefquelles nous baignons \& arroufons d'iceluy : c'eft pourquoy il n'y a chofe qui altere fi toft $\&$ auec tant de force, que le changement de l'air que nous refpirons, comme l'on void en ceux qui meurent de pefte. C'eft chofe approuuee par plufieurs experiences, que l'air de la mer eft principal moteur de cefte eftrange indifpofition, l'vne eft, que quand il court de la mer vn air fort, nous voyons que ceux qui lont en terte, fe fentent du mal de la mer,comme il m'eft aduenu plufieurs fois. Vne autre, que tant plus auant l'on entre dans la mer, \& que l'on s'efloigne de terre, plus on eft atteint \& eftourdy de ce mal:vne autre, qu'allás le long de quelque Ine, \& venans par apres à emboufcher en la plaine mer, l'on y trouue en ceft endrot l'air plus fort. Encore que ie ne vueille pas nier que le mouuement $\&$ agitation ne puiffe caufer ce mal, puis que nous voyons des hommes qui en font épris, paffans des riuieres en des barques, $\&$ d'autres qui en font de mefme en allant dans des chariots ou caroffes, felon les diuerfes complexions d'eftomacs: comme au contraire y en 2 d'autres, qui pour groffe \& efmeuë que puiffe eftre la mer, ne s'en fentent iamais. Parquoy c'eft chofe certaine \& experimentée, que l'air de la mer caufe ordinairement ceft effect en ceux qui de nouueau entrent fur icelle. I'ay voulu dire tout cecy, pour declarer vn effeat eftrange qui aduient en certains endroits des Indes, où l'air \& le vent qui y court eftourdit 


\section{des Indes. Liure. III.}

es hommes, non pas moins, mais dauantage u'en la mer. Quelques-vns le tiennent pour able, d'autres difent que c'eft addition, de ma art, ie diray ce qui m'eft aduenu. Il y a au Peru ne montagne haute, qu'ils appellent Pariacaa, \& ayant ouy dire \& parler du changement u'elle caufoit, iallois preparé le mieux que ie ouuois, felon l'enfeignemeñt que donnent par lelà ceux qu'ils appellent Vaquianos, ou excerts: mais neantmoins toute ma preparation, quand ie vins à monter les efcalliers qu'ils apellent, qui eft le plus haut de cefte montagne, e fus fubitement atteint \& furprins d'vn mal fi nortel \& eftrange, que ie fus prefque fur le poinot de me laiffer choir de la monture en ter$e, \&$ encor que noua fuffions plufieurs de compagnie, chacun haftoir le pas fans attendre fon compagnon, pour fortir viftement de ce mausais paffage. Me trouuant donc feul auec un Indien, lequel ie priay de m'ayder $\grave{z}$ me tenir fur 2 monture, ie fus épris de telle douleur, de fanglots \& de vomiffemens, que ie penfay ietter \& rendre l'ame. D'autant qu'apres auoir vomy la viande, les phlegmes \& la colere, l'vne iaune \& l'autre verde, ie vins iufques à ietter le fang dë la violence que ie fentois en l'eftomach, ie dis en fin, que fi cela cuft duré, i'euffe péfé certainement eftre arriuéa la mort. Mais cela ne dura que comme trois ou quatre heures, iufques à ce que nous fuffions defcendus bien bas, \& que nous fuffions arriuez en vne remperature plus conuenable au naturel, où tous nos compagnós, qui eftoient quatorze ou quinze. eftoiens $M$ iij 


\section{Hiftoire naturelle}

fatiguez, quelques-vns cheminans demandoien: confeffion, penfans reallement mourir, lis autres mettoient pied à terrre, \& eftoient perdus de vomiffement, \& de force d'aller à la felle, \& me fut dit quautresfois quelquesvns y auoient perdu la vie de ceft accident. le veis vn homme qui fe defpitoit contre terre, s'efcriant de rage $\&$ douleur que luy auoit cauféle paflage de $\mathrm{Pa}$ riacaca. Mais ordinairement il ne fait point aucun dommage qui importe, autre que ceft ennuy $\&$ fafcheux defgouft qu'il donne pendant qu'il dure, \& n'eft pas feulement le pas de la montagne Pariacaca, qui a cefte proprieté, mais aufi toute cefte chaine de montagnes qui court plus de cinq céts, lieuës de lóg; \& tn quelque endroit que l'on la paffe, l'on fent cefte eftrange intemperature, combien que ce foit en quelques endroicts plus qu’és autres, \& plus ceux qui montent du cofté de la mer, quà ceux qui viennent du cofté des plaines. Iel'ay paffee melme outre de Pariacaca, par Lucanas \& Soras, \& en autre endroit par Colleguas, \& en autre par Cauanas, finalement par quatre lieux differens en diuerfes allees \& venuës, \& toufiours en cét endroit ay fenty lalteration \& eftourdiffement que i'ay dit, encor qu'en nul endroit, ce n'a efté tellement que la premiere fois en Pariacaca, ce qui a efté experimenté par tous ceux qui y ont paffé. Et n'y a point de doute, que la caufe de cefte intemperature \& fi eftrange alteratió, eft le vent, ou l'air qui y regne, pource que tout le remede ( $\&$ lo meilleur quils y trouuent) eft de fe bowfcher 


\section{des Fndes. Liure III.}

in que lon peut, le nez, les oreilles \& la bouhe, \& de fe coururird'habits, fpecialement l'eomach, d'autant que l'air eft fi fubtil \& peneant, qu'il va donner iufques aux entrailles: \& onfeulement les hommes fentent cefte alteation, mais auff les beftes, qui quelquesfois arreftent, deforte qu'il n'y a efperon quiles uiffe faire aduancer. De ma part, ie tiens que elieu eft vn des plus hauts endroits de la tere qui foit au monde : car l'on y monte vne eface démefuree, $8 \mathrm{r}$ me femble que la montaine Neuade d'Efpagne, les Pyrenees \& les Ales d'Italie, font comme maifons communes à endroit des hautes tours. Parquoy ie me peruade que l'element de l'air eft en celieu là fi ubtil \& fi delicat, qu'il ne fe proportionne oint à la refpiration humaine, laquelle le requiert plus gros \& plus temperé , \& croy que Eeft la caufe d'alterer fi fort l'eftomach, \& trouoler toute la difpofition. Les paffages des monagnes Neuades \& autres de l'Europe, que i’ay veuës, combien que l'air y foit froid, \& qu'il trauaille \& contraigne ceux qui y paffent, de fe veftir, neantmoins ce froid n'ofte pas l'appetic de manger, au contraire ille prouoque, ny ne caufe point de vomiffement en l'eftomach, mais feulement quelque douleur aux pieds, \& aux mains. Finalement leur operation eft exterieure, mais cil des Indes que ie dy, fans trauailler, ny les pieds, ny les mains, ny aucune partie exterieure, brouille toutes'les entrailles au dedans, \& ce-qui eft plus admirable, il aduient au mefméndroit que lc Soleil y eft chaud, qui $M$ iiij 


\section{Hiftoire naturelle}

me fait croire que le mal quel'on en reçait, vient de la qualité de l'air que l'on y refpire, d'autant qu'il eft tres-fubtil \& tres-delicat, \& que fon troid n'eft pas tant fenfible comme il eft penetrant. Toute cefte chaine de montagnes eft communement deferte, fans aucuns villages, ny habitations des hommes; de forte qu'a peinel'on y troulue des petiés maifons ou retraittes pour y loger les paffans de nuia.ll n'y a non plus d'animaux, ou bons, ou mautrase, fi ce n'eft quelques Vicunos, qui font des moutons du pays, l ef quels ont vne propriecé eftrange \&z merueilleule, comme ie diray en fon lieu. L herbe y eft fouuentesfois bruflee, \& toute noire de l'air que ie dis, \& ce defert dure comme vingteinq à trente lieuës de trauerfe, \& contient de longueur, commeiay dict, plus de cinq cens lieuës. Il y a d'autres deferts ou lieux inhabitez, qu'ils appellent au Peru, Punas (pour parler du fecond poinct que nous auons promis) où la qualité de l'air trenche les corps \& la vie des. hómes fans le fentir. Au tëps pafféles $E$ fpagnols cheminoient du Peru au Royaume de Chillé, par la montagne:auiourd'huy l'on va ordinairement par mei, \& quelquesfois le long de la coAte : \& combien que le chemin y foit ennuyeux \& fafcheux, il n'y a pas toutesfois tant de danger qu'en l'autre chemin de la montagne, où il y a des plaines, au paffage defquelles plufieurs hommes font morts $\&$ peris, \& d'autres en font efchappez par grande aduenture, dont les vns Font demeurez eftropiez. Il court en ceft endroit vn petit air qui n'eft pas trop fort, ny vio- 


\section{des Indes. Liure III.}

ent: mai il penetre de telle façon, que les homnes y tombèt morts quafi fans fe fentir, ou bien es doigts des pieds \& des mains y demeurent; equi pourra lembler chofe fabuleu e, \& rouefois c'eft chufe veritable. I'ay cogneu, \& long emps frequenté le General Hierofme Coftilla, ncien peupleur de Cufco, qui auoit perdu trois uquatre doigts des pieds, qui luy tomberent n pallant les deferts de Chillé, parce qu'ils uoien efté atteints \& penctrez de ce petit alr; $x$ quand il les vint à regarder, ils eftoient defia ous morts, \& tombernt d'eux-mefmes, fans uy faire aucune douleur, tout ainfi que tombe le l'arbre vne pomme gaftee. Ce Capitaine raontort que d'vne bonne armee qu' il auoit con. luite, \& paffee par ce lieu les annees preceden. es, depuis la defcounerte de ce Royaume faite ar Almagro, vne grande partie des hommes y lemeurerét morts, \& qu'ily vid les corps eftenlus parmy le defert, fans aucune mauuaife coruption \& odeur. Adjoultant dauantage vne hofe fort eftrange, quils y troutuerent vn ieule garçon viuant, lequel eftant enquis comme lauoit vefcu en ce lieu, dilt qu'il f'eftoit caché in vne petite cauerne, d'où il fortoit pour couer auec vn petit coufteau de la chair d"vn chetal mort, \& quill feeftoit ainfi fubftanté long emps, auec ne fçay combien de compagnons jui fe maintenoient de cefte façon: mais que lefia ils y eftoient tous demeurez, l'vn mourant tujourd'huy, \& demain l'autre, difant qu'il ne lefiroit autre chofe que de mourir là auecles ustres, veu quil ne fentoit defia plus en luy aus: 


\section{Hiftoire naturelle}

cune difpofition pour aller en vn autre endroit,' ny pour prendre gouft en aucune chole. I'zy entendu le mefme d'autres, \& particulierement d'vn qui eftoit de noftre Compagnie, lequel pour lors eftant feculier, auoit pallé par cesdeferts, \& eft vne chofe merueilleufe que la qualité de cét air froid, qui tuë, \& conferue aufi tout enfemble les corps morts fans corruption. Ie l'ay auffi entendu d'vn venerable Religieux de l'ordre de fainct Dominique, \& Prelat d'icel. le, quil'auoit veu paffant par ces deferts, \& qui pluseft, me conta qu'eftant contraint d'y paffer Ia nuict, pour fe deffendre \& remparer contre ce vent fi mortel qui court en celieu, ne trouuant autre chofe à propos, affembla vne grande quantité de ces corps morts qui eftoientlà, \& fift d'iceux comme vne muraille, \& cheuet de lict, de cefte façon il dormit, les mortsluy donnans la vie. Sans doute ceft vn genre de froid que ceftuy-là fi penetrant, qu'il efteint la chaleur vitale en coupant fon influe nce; $\&$ d'autant qu'il eft aufij tres-froid, il ne corrompt, ny donne putrefaction aux corps morts, parce que la putrefaction procede de chaleur $\&$ d'humidité. $Q$ uant à l'autre forte d'air que l'on oyt refonner fous la terre, \& qui caufe des tremblemens plus aux Indes qu'és autres regions, $j$ en parleray en eraittant des qualitez de la terre des Indes. Maintenant nous nous contenterons de ce qui eft dit des vents \& de l'air, \& paflerons à ce qui. fe prefente du fujet de l'eau. 


\section{Hiftoire naturelle}

rerre on a defcouuert depuis vne mer de l'autre cofté, laquelle ils ontappellee mer du Sud, d'au. tant qu'ils defcendirent, iufqu’à paffer la ligne, \& ayans perdu le Nort, ou Pole Arctique, quils appellerent Sud; pour cefte caufe l'on a appellé la mer du Sud tout cét Occean qui eft de l'autre cofté des Indes Occidentales, encores qu'vne grande partie d'icelle foit fituee au Nort, comme l'eft toute la colte de la neuue Efpagne, nua. ragna, Guatimala, \& Panama. L'on dit que le premier defcoureur decefte mer fut vn Blafconunes de Balboa, \& qu'il la defcouurit par l'endroict que nous appellons aujourd'huy Terre ferme, où la terre f'eftreffit, \& les deux mers fapprochent de fi pres l'vne de l'autre, qu'il n'y a que 7. lieües de diftance : car bien que l'on en chemine 18. de Noobre de Dios à Panama, neantmoins c'eft en tournoyant, pour chercher la có. modité du chemin : mais tirant par la droicte ligne, vne mer ne fe trouuera diftante de l'autre, de plus que jay dit. Quelques-vns ont difcouru $\&$ mis en auăt de rompre le chemin de 7. lieuies, afin de joindre vne mer auec l'autre, pour rendre le paffage du Peru plus cómode \& plus ay fé, parce que ces 18 . lieües de terre qu'il y a entre Nombre de Dios \& Panama, emportent plus de defpenfe \& de trauail, que deux mil trois cents qu'il y a de mer. Sur quoy toutefois quelquesvns ont voulu dire que ce feroit pour noyer la terre, difans qu'vne mer eft plus baffe que l'au-

Frerodos. tre. Comme au temps paffé l'on trouue par les 3 Trangas. hiftoires, que pour la mefme confideration l'on delailla l'entreprife de vouloir joindre 8 consi- 


\section{des Fndes. Liure III.}

auer la mer rouge auec le vil, du temps du roy efoftris, \& depuis de l'Empire d'Gthoman. Mais de tha part, ie tiens tel difcours \& propoition pour chofe vaine, encore que cér incontenient allegué n'y deuft point efcheoir, lequel uffi ie ne veux pas tenir pour certain, \& croy u'il n'y a puiffance humaine qui fuft fuffifante our rompre \& abattre ces tres-fortes \& impeietrables montagnes que Dieu a mifes entreles leux mers, \& les a faites de roches tres dures, in de fouftenir la furie des deux mers. Et quand ien ce feroit chofe poffible aux hommes, il me emble que l'on deuroit craindre le chaftiment lu ciel, en voulant corriger les œuures que le Createur par fa grande prouidence a ordonnees 2 difpolees en la fabrique de cét vniuers. L.aifant donc ce difcours d'ouurir la terre, $\&$ vnir es deux mers enfemble, il y en a vn autre moins emeraire, mais bien difficile \& dangereux de rechercher, fi ces deux grands abyfmes fe joignér in quelque partie du monde, qui fut l'entreprie de Fernăde magellan, gentilhóme Portugais, duquel la grande hardieffe \& conftance en la recherche de ce fujet, \& heureux fuccez qu'il euft en le trouuant, donna le nom d'eternelle memoire à ce deftroit que iuftement l'on appelle du nom de fon defcouureur, Magellan. Duquel deftroit nous traitterons quelque peu, comme d'vne des grandes merueilles du monde. Quelques-vns ont creu que ce deftroit que Magellan trouua en la mer du Sud, n'eftoit point, ou qu'il feftoit refferré, comme dom Alonfe d'Arfilla efcrit en fon Auracane, 8 aujourd'huy y en a qu? 


\section{Hiftoire naturelle}

difent qu'il n'y a point de tel deftroit, mais que ce font des Inles, entre la mer \& la terre, pource que la terre ferme prend fin en cét endroit, \& au bout d'icelle font toutes Ines, outre lefquelles vne mer fe joint plainement auec l'autre, ou pour mieux dire, eft toute vne mefme mer. Mais à la verité c'eft chofe certaine qu'il y a va deftroit, \& de la terre fort longue, \& forr eftenduë d'vn cofté \& d'autre, bien qu'on n'ayt encor peu cognoiftre iufques où fe peut eftendre cela qui eft de l'autre cofté du deftroit au Sud. A pres Magellan paffa le deftroit vn nauire de l'Euefque de Plaifance, Dom Guitieres Caruajal, de laquelle ils difent que le maft eft encores à Ly. ma, à l'entree du Palais, l'on alla depuis par le cofté du Sud pour defcouurir ce deftroit, par le commandement de Dom Guarcia de Mendoce, qui pour lors auoit le gouuernement de Chillé. Suiuant quoy le Capitaine Ladrillero le trouua \& le paffa I'ay leu le difcours \& la narratió qu'il en a faite, où il dit quil ne fe hazarda de defembarquer le deftroit, mais quayát defia recogneu la mer du Nort, il retourna arrier e pour l'afpreté du temps, \& que l'hyuer eftoit defia entré, ce qui cauloit que les vagues venans du Nort, elles cftoient groffes \& bondiffanter, \&: les mers toutes efcumantes de furie. De noftre temps François Drach Anglois, a paffé ce mefme deftroir. Depuis luy, le Capitaine Sarmiento le palfa par le cofté du Sud, \& tout dernierement, en l'an 1597. d'autres Anglois l'ont paffé par l'inftruction de Drach, lefquels de prefent rodent la colte du Peru, \& pource que le rapport qu'en a 


\section{des. Fndes. Liure III.}

96 fait le maiftre pilote qui le pafa, me femble no. cable, ie l'infereray icy.

Du deftroit de Magellan, ó comme ois le paffa du cofté du sud.

Chapitre XI.

Ci- $N$ l'an de noftre falut mil cing cents 1) 2 Soixante \& dix-neuf, ayant François 12 [es Drach paffé le déftroit de Magellan, \& couru la cofte de Chillé, \& de tout le Peru, \& prins le nauire de fainct Iean d'Anthona, où il y auoit grande quantité de barres d'argent, le Viceroy Dom François de Tollede. arma, \& enuoya deux bons nauires, pour recognoiftre le deftroit, allant pour Capitaine d'icelles, Pierre Sarmiente, homme docte en Aftrologie. Ils fortirent de Callao de Lyma, au commencement d'Octobre, \& pource qu'en cefte cofte il court vn vent contraire, qui fouftle roufiours du Sud; ils faduancerent bezúcoup en la mer, \& ayans nauigé vn peu plus de trente iours, auec vn temps fauorable, fe trouuerent en la hauteur du deftroit. Mais d'autant qu'il eft fort difficile de le recognoiftre, ils frapproche. rent de terre, où ils entrerent en vne grande Anfe, en laquelle il y a vn Archipelague d'tlles. Sarmiento f'obftinoit que là eftoir le deftroit, \& $\mathrm{tarda}$ plus d'vn mois d le chercher par diuers endroits, montant fur de tres-hautes montagnes en terre. Mais voyant quil ne le tronuoit point, à la requefte que ceux de l'armee luy fi= rent, retournerent en fin aे fortir en la mcr, ou if 


\section{Hiftoire naturelle}

sif largue. Le melme iour furuint vn têps affez rude, auec lequel ils coururent, \& au cōmencement de la nuid virent le feu de la Capitaine, qui auffi tolt difparut ; tellement que l'autre na. uire ne la vid iamais de puis. Le iour enfuiuant, durant toufiours la force du vent qui eftoit trauerlain, ceux de la Capitaine recogneurent v ne onuerture que faifoit la terre, \& trouuer ét bon de f'y retirerà l'abry, iufqu'à ce que la tempefte fuft appaifee. Ce quil leur fucceda de telle façon qu'ayans recogneu l'ouuerture, ils virent qu'ellealloit de plus en plus entrant dans la terré, \& foupçonnans que ce fult le deftroit qu'ils cherchoient, prindrent hauteur au foleil, où ils fe trouuerent en si. degré \& demy, qui eft la propre hauteur du deftroit; \& pour falfeurer dauátage, mirent le briguantin hors, lequel ayant couru plufieurs lieües dans ce bras de mer, fans en vorr la fin, recogneut que c'eftoit la le deAtroit. Et pource quils auoient ordre de le paffer, ils laifferent vne haute croix plantee là, \& des lettres au bas, afin que fil'antre nauire arriuoir là, elle euft nouuelles desla Capitaine, \& la fuiuift. Ils pafferent donc le deftroit en temps fauorable, \& fans difficulté, \& fortis en la mer du Nort, arriuerent en ie ne fçay quelles Ifles; où ils recueillirent de l'eau, \& fe rafraifchirent. De là prindrent leur roiıte au Cap de vert, d'où le pilote majeur retourna au Peru par la voye de Carthagene \& de Panama, \& apporta au Viceroy le difcours du deftroit $\&$ de tout le fuccez, dont il fut recompéfé felon le bon feruice qu'il augit fais. Mais le Capitaine Pierre Sarmiento, du Cap. 


\section{des Indes. Liure IIT.}

tu Cap de vert paffa en Seuille au mefme nauire u'il auoit paffé le deftroit, $\&$ fut à la Court, où Majefté-le recompenfa, \& à fon inftance firk ommandement de dreffer vre grofe armee, u'il enuoya fous la conduite de Diego Florez le Valdez, pour peupler \& fortifier ce deftroit. Toutefois cefte armee, apres diuers fuccez, filt eaucoup de defpenfe \& affez peu d'effer. Reueant donc à l'autre nauire Viçadmiralle, qui aloit en la compagnie de la Capitaine, l'ayất per. luë, auec le Temporal que j’ay dit, elle fe mit à rendre la mer le plus qu'elle peut : mais cóme e vent eftoit trauerfain \& tempeftueux, ils cuilerent certainemét perir, de forte qu'ils fe conefferent tous, fe preparans d la mort. La temefte leur continua trois iours fans f'appaifer, \& chaque heure ils penfoient deuoir donner en erre, mais il leur aduint bien au contraire: car Is f'alloient plus efloignans de la terre, iufqu'd a fin du troifiefme iour que la tempefte fappaia, \& lors prenans hauteur, ils fe trouuerent en 6. degrez : toutefois voyans qu'ils n'auoiene lonné au trauers, \& au contraire eftorent efloinez de la terre, fe trouuerét tous efmerueillez. oùils iugerent (comme Hernáde Lamero piote dudit nauire mele conta) que la terre qui it de l'autre cofté du deftroit, comme nous alons par la mer du Sud, ne couroit pas mefme umb que iufques audeftroit, mais qu'elle fe ournoit vers le Leuant: car autrement c'euft etté chofe impoffible qu'ils n'euffent abordé la erre, ayans couru tant de temps pouftez de ce. rauerfain: mais ils ne pafferent point plus ow:

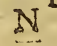




\section{Hiftoire naturelle}

tre, \& ne virent non plus fi la terre f'acheuoit li (cóme quelques-vns veuleńt dire) que c'eft vne Inle que la terre de l'autre cofté du deftroit, \& que là les deux mers de Nort \& Sud fe joignent enfemble, ou fi elle alloit courant vers l'Eft, juf qu'à fe ioindre auec la terre de Vifta, qu'ils appellent, qui refpond au Cap de bonne Efperance, comme c'eft'opinion d'autres. La verité de cecy n'eft encore aujourd'huy bien cogneite, \& ne fe trouue aucun qui ayt couru cefte terre. Le Viceroy dom Martin Henricque me dit qu'il te. noit pour inuention del'Anglois, le bruit qui auoit couru, de ce que ce deftroit faifoit incontinent vne Ifle, \& fe joignoient les deux mers; pource qu'eftant Viceroy de la neuue ESpagne, il auoit diligemment examiné le pilote Portugais que François Drach y laiffa, \& neantmoins n'auoit aucunement entendu telle chofe de luy. Mais c'ef oit vn vray deftroit \& terre ferme des deux coftez. Retournant doncladite Viçadmiralle, ils recogneur ent le deftroit, comme ledit Hernande Lamero me raconta, mais par vne au tre bouche ou entree qui eft en plus de hauteur, à caufe de certaine grande Inle qui eft à l'embou. cheure du deftroit qu'ils appellent la Cloche, pour la forme qu'ellea; \& comme il difoit, ille voulut paffer: mais le Capitaine $\&$ les foldats ne le voulurent point confentir, \& leur fembloit que le temps eftoit ja bien aduancé, \& qu'ils couroient grand danger; par ainfi ils re tournerent à Chillé , \& au Peru, fans l'auois pasfé. 


\section{des Indes. Liure III.}

Dudefroit que quelques -vns afferment oftre en la Floride.

\section{ChAPITRE XII.}

Madonse O V $\mathrm{T}$ ainfi que Magellan trouua 1. 0 ce deftroit qui eft au Sud, il y en 2 1. 1 eu d'autres qui ont pretendu def4 (3) counrir vnautre deftroit qu'ils difent eftre au Nort, \& l'imaginent en la Floride, dont la cofte court de telle façon, que l'on ne fçait la fin. L'Adelantade Pierre Me. endez, homme fçauant \& experimenté enla ner, afferme que c'eft chofe certaine qu'il y a la in deftroit, \& que le Ruy luy auoit commandé de le defcouturir, en quoy faire il monftroit vn res-grand defir. Il mettoit en auant ces raifons pour prouuer fon opinion, \& difoit quel'on uoit veu en la mer du Nort des reftes de nauires femblables à ceux dont vloient les Chinois, ce qui euft efté impoffible fil n'y euft eu paffage d'vne mer à l'autre; \& racontoit mefme qu'en certaine gră de baye qui eft en'la Floride, laquel. le entre trois cents lieies dans la terre, on y void des baleines en certain téps de l'annee, qui viennent de l'autre mer. Apportant outre ce, quelques autres indices, concluoit finalement que c’eftoit chofe côuenable à la fageffe du Creatcur \& au bel ordre de la nature, que cóme il y auoir communication \& paffage entre les deux mers, au Pole Antarctique, il y en euft aufi tout de $\mathrm{N}$ ij 


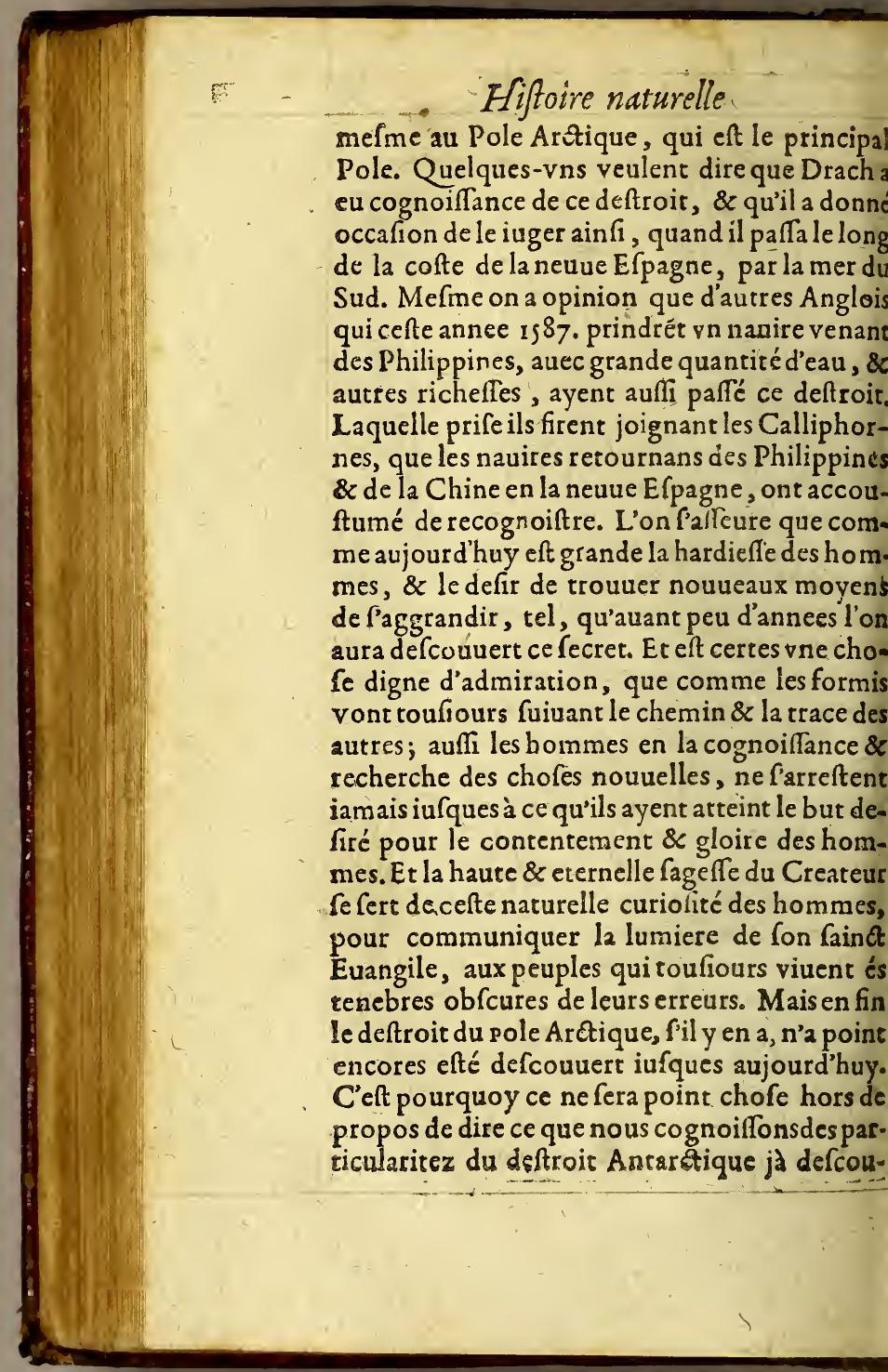




\section{des Indes. Liure 111.}

ert \& recogneu par le rapport de ceux qui ont veu \& remarqué oculairement.

Des proprietez du deftroit de viagellan.

Chapitra XiII.

E deftroit, comme jay dit, eft 2 so.

A 12 degrez iuftes au Sud, \& y a d'vne ( 2 (5) mer en l'autre, I efpace de quatre (15) vingts dix, ou cent lieies. Au plus
eftroit il eft d'vne lieuie, ou quelue peu moins, auquellieu ainfi eftroit ils preendoient que le Roy fift baftir vne fortereffe our deffendre le palfage. Le fond en quelques endroits eff fi profond, qu'on nele peut fonder, Be en d'autres l'on trouue fonds à 18 . voire à. is. braffees. De centlieuies qu'il contient de longueur d'vne mer à l'autre, l'on recognoift claire. ment que les vagues de la mer du Sud courent iufques à 30. ljeiies, \& les autres 70 . lieiies fone occupees des ondes \& des flots de la mer du Nort. Mais il y a cefte difference, queles trente lieiies du cofté du Sud courent entre des roches \&zmontagnes tres-hautes, les fommets defquelles font continuellement couuerts des neiges; tellemét qu'il femble (à caufe de leur grande hauteur) qajelles fe joignent les vnes auec les autres, ce qui rend l'entree du deftroit du colté du Sud, fi difficile à recognoiftre. En ces trente lieiies la mer y eft tres. profonde, fi bien qu'on n'y peur trouser fonds, toutefois l'on y peut amaser les nauires en terres, d'autant que le ris=? 


\section{Hiftoire naturelle}

uage yeft droir \& coupé : mais allx autres foi: xante \& dix lieiies qui viennent de la mer du Nort, l'on y trouue fonds, \& y a d'vn cofté $\&$ d'autre de grandes campagnes, qu'ils appelient: Camanas. Plufieurs grandes riuieres ' $d^{2} v$ ne eau belle \& claire, entrent dans ce deftroit, \& y a és enuirons d'iceluy de grandes \& merueilleufes forefts, oì l'on trouue quelques arbres d'vn bois exquis \& de bonne odeur, lefquels font in cogneuz par deçd, dont apporterent pour mon. Atre ceux qui y pafferent du Peru. Il y a de grandes prairies auant dedans la terre, \&y a plufieurs Ifles qui fe font au milieu du deftroit. Les Indiens qui habitent au cofté du Sud, font petits \& mefchans; ceux qui habitent du cofté du Nort font grands \& vaillans, ils en apporterent en Efpagne quel ques-vns qu'ils prindrent. Ilsy trounerent des morceaux de drap bleu, \& autres enfeignes, \& apparences que quelques hommes de l'Europe auoient paffé par là. Les Indiens faluierent les noftres, auecques le nom de I E S v s. Ils font bons archers; \& v ont veftus de peaux de beftes de chaffe, dont il y en 2 la grande abondance. Les eaux du deftroit croiflent $\&$ décroiffent, comme les marees; $\&$ voidon àl'œil que les marees d'vn cofté viennent de la mer du Nort, \& les autres de la mer du Sud. Au lieu où elles fe rencontrent, lequel comme j'ay dit, eft à trente lieuies du Sud, \& à foixante $\&$ dix du Nort, combien qu'il femble qu'il deuft y auoir plus de danger qu'en tout le refte, neantmoins quand le nauire du Capitaine Sarmiento, dont j'ay parlé cy deffus, la palfa, ils n'eurent 


\section{des Fndes. Liure 1 II.}

point de grande rourmente, au contraire ils y. tromuerent beaucoup rnoins de difficulté quioils ne penfoient, parce qu'alors le temps eftoit fort doux \& gracieux, \& dauantage, les vagues de la mer du Nort y venoient defia fort rompuës, à caufe du grand efpace de foixante \& dix lieües qu'ils chemiaent, \& les flots de la mer du Sud n'y font non plus furieux, à caufe de la profondeur qui eft en cét endroit, dedans laquelle profondeur ces mefmes flots fe rompent, \& fe noyent. Il eft bien vray qu'en temps d'hyuer le deftroit eft innauigable pour les tempeftes \& furies des mers qui y fontalors. C'ett pourquoy quelques nauires qui fe font ingerez de paffer ce deftroit au temps d'hyuer, fe font perdus. Vn feul nauire l'a paffé du cofté du Sud, qui eft la Capitaine que jay ditte, \& ay efté bien amplement informé de tout ce que jay dit, par le pilote diceluy, appellé Hernande Alonfe, \&zay veu la vraye defcription \& cofte du deftroit qu'ils firent \& tracerent en le paffant, de la. quelle ils apporterent la copie au Roy d'ESpa: gne, \& l'original a leur Viceroy au Peru.

Duflux \& reflux de la mer occeane és Indes.

CHADITRE XIV.

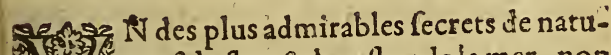
re eft le flux \& le reflux de la mer, non pas feulement pour cefte eftrange pro. prieté de croiftre \& décroiftre, mais encores beaucoup dauantage, pour la diffe$N$ iiij 


\section{Hiffoire naturelle}

rence qu'ily a en cela en diuerfesmers, voire en diuerfes coftes d'vne mefmemer. 11 y a des mers qui n'ont ny flux, ny reflux iournel, comme l'on void en la mediterranee interieure qui eft en la mer Thyrrene, \& tourefois il y a flux \& reflux par chacun iour en la mer Mediterra nee fuperieure, qui eft celle de Venife, qui donne occafion à bon droir de f'en efmerueiller en ce que toutes ces deux mers eftans Mediterranees, \& celle de Venife non plus grande que l'autre, fi eft-ce qu'elle a du flux \& reflux commel'Occean, \& cefte autre mer d'Italie n'en 2 point. Il fe trouue quelques mers Mediterranees qui manifeftement croiffent, $\&$ diminuent chaque mois, \& d'autres qui ne croiffent, ny au iour, ny au mois. Il y a d'autres mers comme l'Occean d'Efpagne, qui ont le flux \& reflux de chaque iour ; \& outre ceftuy-là, ils ont auffi celuy de chaque mois, qui vient.deux fois, aे f̧̧auoir à l'entree, \& au plein de la lune, \& l'appellent grande mer. Or de dire qu'il y ayt quelque mer qui aye le flux \& reflux de chaque iour, \& n’aye celuy du mois, ie n'en fçache point. C'eft chofe efmerueillable, que la diuerfité quel'ón void és Indes fur ce fubject: car ily a desendroits où la mer chaque,iour monte $\&$ diminuë deux lieïes, comme l'on void en Panama, \& au haut de l'eau elle montc beaucoup dauantage; il y en a d'autres où elle monte \& $\{$ 'ab. baiffe fi peu, qu'à peine en cognoift-on la difference. C'eft l'ordinaire de la mer Occeane d'auoir fon flux \& reflux iournel, \& ce reflux iournel ef deux fois au iour naturel, \& fraduan: 


\section{des Indes. Liure. III.}

IOI toufiours de trois quarts d'heure en vn ious luftoft qu'en l'autre, fuiuant le mounement de Lune. Par ainfi la maree n'eft iamais enfvne efmeheure d'vniour qu'elle eft en celle de autre. Quelques-vns ont voulu dire que ce ux \&z reflux procedoir du mouuement local e l'eaüe de la mer, de forte que l'eauë qui vient roiffant en vn cofté, va décroilfant en l'autre uiluy eft contraire, tellement qu'il teft plaine zer en vn endroict, lors que la mer eft baffe en partie oppofite, tour ainfi que l'on void en ne chaudiere pleine d'eauè que l'on remuë, uand elle panche d'vn cofté, l'eaué augmente, $z$ a l'autre colté elle diminué. Il y en a d'autres ui afferment quela mer en vn mefme temps roift en tous endroicts, \& en vn mefme temps lle y diminuë; tout ainfique le bouillon d'vn ot, fortant du centre, s'eftend à tous endroicts, $x$ quád il ceffe, il diminuë auffi de toutes parts. zefte feconde opinion eft vraye, $\&$ la peut-on enir, felon mon iugement, certaine \& experinentée, non pas tant pour les raifons que les. ?hilofophes en donnent en leurs Meteores, que pour l'experience certaine que l'on en a peu aire. Car pour me fatisfaire de ce point \& quetion, ie demanday fort particulierement au fufdit pilote, comment eftoient les marées qu'if trouua au deftroit, \& s'il eftoit ainfi que les marees de la mer du Sud defcroiffoient au temps que celles de la mer du Nort montoient. Et au contraire, pourquoy cefte demande eftant vericable, il aduenoit que le croifte de la mer en vn endroit, eftoit defcroiftre en l'autse, qui eft ce 


\section{Hiftoire naturelle}

que la premiere opinion afferme, il me refpon dit quill n'en eftoit pas ainfi, mais que l'o voyoit \& recognoiffoit appertemét que les m rées de la mer du Nort, \& celles de la mér d Sud, croifloient en mefme temps, tant quel vagues d'vne mer ferencontroient auec cell del'autre, \& qu'en vn mefme remps auffi cll commençoient à defcroiftre chacune en fa me difant que le monter $\&$ defcendre eftoit cho qu'ils voyoient chaque iour, \& que le coup le rencontre d'vn flux à l'autre f $\epsilon$ faifoit (comm) i’ay dit) aux foixante $\&$ dix lieuës de la mer Nort, \& aux trente de la mer du Sud; d'où l'o peut recueillir manifeftement que le flux \& r flux de l'Occean n'eft pur mouuement loca mais pluftoft vne alteration \& ferueur, par quelle reallement toutes les eaües montent croiffent tout en vn mefme temps, \& en aut elles s'abbaiffent \& diminuent, ainfi que boüillon du pat,dont iay parlé cy deffus. Il $\mathrm{f}$ roit impolfible de comprendre ce point par e perience, fi ce n'eftoit en ce deftroit où feioir tout l'Occean d'vne part \& d'autre, caril n'y que les Anges quile peuffent voir, \& recogno fre par les coltes oppofites, datitant que hommes n'ont point la veuë affe loingtain ny le pied affez vifte \& leger qu'il feroit de be foing, pour porter les yeux d'vn cofté à l'aut en fi peu de temps, qu'vne marée donne delo fir, qui font feulement fix heures. 


\section{des Indes. Liure. III.}

e diuers poiffons, \&o de la maniere de pefcher des Indiens.

ChapItre X V.

I y a en l'Occean des Indes vne innöbrable multitude de poiffons, les ef10.1.
Createux peut declarer.ll y en a plu-
ieurs qui font de mefme genre, que ceux que 1. peces \& proprietez delquels, le feul
Createux peut declarer.ll y en a plu-
ieurs qui font de mefme genre, que ceux que oyons en la met de l'Europe, comme font fain. es $\&$ allofes, qui montent de la mer aux riuiees, dorades, fardines, \& plufieurs autres. Ily n a d'autres, dont ie ne penfe point en auoir eu par-deçà de femblables, comme ceux qu'ils ippellent Cabrillas, qui reffemblent de quelque chole les truittes, \& les appellent en la neu. de Efpagne, bobos, \& montent de la mer aux iuieres.Ie n'ay point veu par delà de befugues, ny de truitres, encor qu'ils difent qu'on en trouue en Chillé. De Tonine il y en a en quelques endroits de la cofte du Peru, mais c'eft fort rarement, \& font d'opinion qu'à certain temps ils vont frayer au deftroit de Magellan, comme ils font en Efpagne, au deftroit de Gibaltar. Et pour cefte occafion l'on en trouue dauantage en la cofte de Chillé, combien que celle que i’ay veuë par delà, n'eft telle que celles d'E. pagne. Aux Inles quils appellent de Barlouente, qui font Cube, fainct Dominique, Port-riche \&lamaique, l'on trouue rn poifsó qu'ils ap. pellét Manati, eftráge efpece de poiffon, fi poiffonl'on doir appeller, vn animal qui engendre 


\section{Fiftoire naturelle}

fes petits viuants, \&a des mammelles \&du laic dont ill les nourrift, paiffant l'herbe aux champs.

mais en effect il habite ordinairemét en l'eau, \& pour cefte occafion ils le mangent comme poiffon, toutefois lors que i'en mangeay, qui fut à S. Dominique, vn iour de Vendredy, i'auois quelque fcrupule, non point tant pource qui en dit, comme parce qu'en couleur \& faueuri eftoit femblable à des morceaux de veau, \& auff eft-il grand, \& de la façon d'vne vache parla partie de derriere. Des Tiburons, \& de leur in. incroyable voracité, ie m'en ef me rueillay auec raifon, lors que ie veids que d'vn qu'ils auoient prins, (au port que i'ay dit) luy tirerent du petit ventre vn grand coufteau de boucher, vn grand haim défer, \& vn morceau de la tefte d'vne vache, auec fa corne entiere, encor ne fçay fi toutes deux y eftoient point. Ie veids en vne anfe que fait la mer, où l'on auoit pendu en vn pieu, pour paffetemps, vn quartier de cheual, qu'en vn moment vne compagnie de Tiburons vindrent à l'odeur, où à fin d'auoir plus de plaifir, la chair du cheual ne touchoit pas en l'eau, mais eftoit efleuee en l'air ie ne fçay combien de palmes, \& cefte bande de poiffons eftoient à l'entour, qui fautoient, \& d'vne atteinte en l'air couppoient chair \& os d'vne eftrange vifteffe, tellement qu'ils decoupoiét le mefme iarer du rouffin, comme fi c’euft efté vn tróç de laiauë, d'autant qu'ils ont les déts tréchantes cáme rafoirs. Il $y$ a des petits poiffons quails appellent rambos, qui s'attachent aे ces Tiburons, \& lefquels ils ne peuuent chaffer, \& fe nourrifent de ce qui 


\section{des Indes. Liure. III. $\mathrm{IO}_{3}$}

Chappe par les coftez à ces Tiburons : il y a autres petits poiffons, qu'ils appellent poifons volans, lefquels l'on trouue dans les Troiques, \& ne penfe point qu'il y en ayt ailleurs: sfont pourfuiuis par les Dorades, \& pour s'efhapper d'icelles, fautent de la mer, \& vont affez. ing en l'air, \& pour cefte caufe les appellent oiffons volans. Ils ont des aifles comme de oille, ou parchemin, qui les fouftiennent quelue temps en l'air. Au nauire où i'allois, en ola ou fauta vn que ie veids, \& remarquay $l_{2}$ açon que ie dy des aifles. Il eft fouuent fait méon és hiftoires des Indes, des lezards, ou caynans, quils appellent \& font de vray ceux que line,\& les anciens appellent crocodiles : on les rouue és coftes \& rivieres chaudes; cár aux cotes \& rivieres froides, il nes'en troutue point. Jeft pourquoy il n'y en a point en toute la cote du Peru, iufquésà Payra, mais de là en auant on en trouue ordinairement és riuieres. C'eft n animal tres-fier \& cruel, combien quil foir ort lent \&z pefant. Il fait fa chaffe, \& va cherher fa proye hors de l'eaü, \& ce qu'il y prend if,le va noyer en l'eau, toutesfois il ne le manre point que hors de l'eau, d'autant qu'il a le ofier de telle façon, que s'il y entroir de l'eau, I fe noyeroir facilement. C'eft vne chofe efnerueillable, que le combat d'vn caymant auec e tygre, dont il y en a de tres-cruels aux Indes. Vn Religieux desnoftres me raconta qu' il auoit reu ces beftes combatre cruellement l'vne conre l'autre au riuage de la mer. Le caymant, auec fa queuë donnoit de fort grands coups als 


\section{Hifoire naturelle}

iygre, \& talchoit par fa grande force de l'em. porter en l'eau, \& le tygre auec fes grriffes re. fiftoit au caymant, l'attirant à terre. En fin le ty. gre vainquit, \& ouurit le lezard, ce deuft eftre par le ventre qu'il a fort tendre, $\&$ fort delicat, car en autre partie il eft fi dur, qu'il n'y a lance, voire à peine arquebufe qui le puiffe percer. $\mathrm{La}$ viatoire qu'eut vn Indien d'vn autre caymant, fut encor plus excellente, le caymant luy auoit emporté vn fren petit fils, \& quant \& quant s'eftoit plongé en la mer, dont l'Indien efmeu \& courroucé, fe ietta incontinent apres, auec vn coufteau en la main, \& comme ils font excellens nageurs \& plongeurs, \& quele caymant nage toufiours à fleur d'eau, il le blelfa au ventre de relle façon, que le caymát fe fentant blef. $f e ́, f o r t i t$ hors au riuage, \& lafcha le petit enfant jà mort. Encor plus efmerueillable eft le combat que les Indiens ont auec les balaines, enquoy paroift la grandeur \& magnificence da Createur, de donner à vre nation fi baffe, comme font les Indiens, l'induffrie \& la hardieffe d'atraquer la plus fiere \& plus difforme befte qui foit en l'vniuers, \& non feulement de la cúbattre, mais aufi de la vaincre, \& d'en triompher fi gaillardement. Confiderant cela, ie me fuis foumenu plufieurs-fois du paffage du Pfalmifte, qui dit de la balaine: Draco ifte, quem formaftiadilludendum ei. Quelle plus grande moquerie peut-il eftre, que ce quivn Indien meine vne baleine auffi grande qu'vne montagne, vaincue $\&$ attachee auec vne corde? La façon \& maniege dont vfent les Indiens de la Floride , (felon 


\section{des Indes. Liure. III.}

104

1e m'ont raconté perfonnes expertes) pour endre ces balaines, defquelles y a grande quáé, elt qu'ilsfe mettent en voe canoë, ou bat1e, qui elt comme vne efcorle, \& en nageant approchent du cofté de la balaine, puis d'vne ande dexterité ils luy fautent \& montent fur col, \& là le tient commeà cheual, en attenunt fon point; puis à fa commodité met vin baon aigu \& fort, qu'il porte auec foy dansla neftre de la narine de la balaine, iappelle nane,le conduit, ou pertuis par où répirent les alaines. Incontinent le pouffe auant auec vn atre bafton bien fort, \& le fait entrer le plus rofondement qu'il peut. Cependant la balaie bat furieufement la mer, \& efleue des mongnes d'eau, s'enfonçant dedans d'vne grane violence, puis reffott incontinent, ne f̧̧ahant que faire de rage, l'Indien neantmoins emeure toufiours ferme \& affis , \& pour luy ayer l'amende de ce mal, luy fiche encor vn aure pieu femblable en l'autre narine, le faifant ntrer de telle façon qu'ill'eftou ppe du tout, $\&$ ay ofte la refpiration, \& alors il fe remet en $\mathrm{fa}_{2}$ anoë, qu'il tient attachee au cofté de la balaite, auec v ne corde, puis fe retire vers terre, ayắr remierement attaché fa corde à la balaine, lafuelle il va filant, \& lafchant fur la balaine, qui ependăt qu'elle trouue beaucoup d'eau, faule d'vn cofté \& d'autre, comme troublec de doueur, \& en fin s'approche de terre, où elle deneure incontinent à fec, pour la grande enornité de fon corps, fans qu'elle puife plus fe nounoir, ny fe manier, \& lors grand nombre 


\section{Hifoire naturelle.}

IIndiens viennent trouuer le vainqueur, potu cueillir fes defpoüilles, ils acheuent de la tuer, le decouppant, \& faifant des morceaux de fa chair qui eft alfez maunaife, lefquels ils fechent \& pi lent pour en faire de la poudre, dont ils vfent pour viande, qui leur dure long temps. Enquoy eft accóply ce qui eft dit en vn autre Pfalme de la mefine baleine: Dedistı eum efrä populis Ethiopü. L'Adelentade Pierre Médés, racótoit plufieurs fois ccfte pefcherie, de laquelle mefme fait men. tion Modardes en fon liure. Il y a vne autre pef cherie, dontvfent ordinairement les Indiens en la mer, laquelle, quioy qu'elle foir moindre, ne laiffe d'eftre digne de raconter. Ils font comme des fagots de iong, ou varig fec, bien liez, qu'ils appellent Balfas, \& les ayants portez fut leurs ef paules iufques à la mer, les y iettent, \& incontinent ils fe mettent deffus, \& ainfi affis, entrent bien auant en la mer, vogans auec de petites cannes d'vn cofté \& d'autre, ils von vne $\&$ deux lieuës en haute mer pour pefcher, portans fur ces fagots leurs cordes \& leurs rets, $\& z$ fe fouftenants fur iceux, ils iettent leurs rets, $\&$ font là pefchants la plus grande partie de la nuict, ou du io ur, iufques à ce qu'ils ayét emply leur mefure, auec laqquelle ils rètournent fort contens. Certes ce meftoit vne grande recreation, de les voir aller pefcher au Callao de Lyma, pource qu'ils eftoient grand nombre, \& ainfi chacun cheualier, out affis, couppant les ondes de la mer,à qui mieux mieux, lefquelles à l'endroit où ils pefchent, font grandes \& furieufes, reffembloient les Tritors, ou Neptunes, gृu'on 


\section{des Fndes. Liure III. IOS}

'on peint deflus l'eaüe, $\&$ eftás arriuez en tertirent leur barque de l'eaüe fur leur dos, larelle auffi to ft ils deffont \& cftédent fur le rige à fin que les herbes fe fechêr \& efgoutent. $\mathrm{y}$ auoit d'autres Indiens des vallees de $\mathrm{Yca}_{\mathrm{s}}$ ii auoient de couftume d'aller pefcher fur des iirs oú peaux de loups marins, enflez \& pleins vent, \& de fois à autre lis fouffloient cŏme lotes de venț, de peur qu'elles ne s'enfonfarnt. Au val de Canete, qu'anciennement ils apelloient le Guarco, il y auoit grand nombre pefcheurs Indiens, mais pource qu'ils refierent à l'Ingua, quand il fut conquefter cefte rre, il feignit faire paix auec eux : c'eft pourtoy à fin de luy faire fefte, ils ordonnerét vne iche folemnelle de plufieurs milliers d'Inens, quien leurs vaifleaux de ionc, entrerent la mer, \& au retour de l'Ingua, qui auoit apm areillé quelques foldats couuerts, fit d'eux vn uel carnage, \& de là demeura cefte terre tan fpeuplee, combien qu'elle foit fi abondante fertile. Ie vis vne autre façon de pefcher où e mena le Viceroy Dom François de Tolle: toutesfois ce n'eftoit point en la mer, mais 2 vne riuiere qủils appellent Gráde, en la pronce des Charcas, où des Indiens Chiraquanas plongeoient en l'eaüe, \& nageans auec vne imirable viftefle fuiuoient les poiffons, \& auec es dards ou harpós quills portoient en la main roite, nageans feuleinent auec la gauche, blefjient le poiffon, \& ainfi navré le tiroient en aut : reffemblans en cela eftre plus poiffons u'hommes de terre, Mais ores que nous foms 


\section{Hiftoire naturelle}

mes forties de la mer, venons à ces autres forte d'eauës qui reftent à dire.

\section{Des lacs of des eftangs que l'on troune és Indes.}

CEAPITRE XVI.

Y $V$ lieu de ce que la mer Mediter (2) (anee eft au vieil monde, le Crea teur a pourueu ce nounean $d$ plufieurs lacs, dót y en a quelque vns fi grands que l'on peut pro prement appeller mers:veu que l'E fcriture ap pelle ainfi celuy de Paleftine, qui n'eft pas fi gră que quelques vns de ceux-cy. Le plus renom mé eft celuy de Títicaca, qui eft au Peru enl Prouince de Collao, lequel, commei'ay dital liure precedent, contient prefque quatre vingt lieües de tour, \& y entrent dix ou douze grand fleuues. Il y a quelques tempsque l'on cómenç à le nauiger auec des barques \& des nauires, \& procederent fi mal, que le premier nauire qui entra s'ouurit d'vne tempefte qui s'efleua en c lac. L'eau n'eft pas totalement amere ny falle comme celle de la mer, mais elle eft fi efpaifi qu'on nele peut boire. Deux efpeces de poif fons s'engendrent en ce lac en fort gráde abon dance, l'vn defquels ils appellent Suches, qu eft grand \& favoureux, mais flegmatique \& mal fain:\& l'autre Bogas, qui eft plus fain, com bien qu'il foit petit $\&$ fort ef pineux. Il y a tres grand nombre de canards fauuages \& de cer. cereulles. Quand les Indiens veulent fairefe 


\section{des Indes. Liures IIİ.}

$\$ 06$

e ou dổner du paffetemps à quelque perfonage qui pafíe le long des deux riuages, quils ppellent Chucuyto \& Omafuyo, ils affemlent vine grand quantité de Canoës, \& vont ufant vn rond pourfuiuans \& enferrans les ca. ards iufques à en prendre auec les mains tant u'ils veulent, \& appellent cefte faęon de pefher, Chaco. En l'vn \& en l'autre riuge de ce ic font les meilleurés habitations du Peru. De on yffuë il naift \& procede vnautre lac plus etit, encore qu'il foit bien grand, qu'ils appelnt Paria, au riuage duquel y a grand nombre e beftial, fpecialement de porcs, qui s'engraifint extremement des herbiers qui croiffent en es riuages. Il y a beaucoup d'autres lacs aux eux hauts de la montagne d'où naiffent des uieres $\&$ des ruiffeaux, qui viennent de là en uant à eftre fort grands fleuues. Au chemin Arequippa a Collao, il y a au haut deux beaux cs d'vn cofté \& d'autre du chemin : de livn rtvn ruiffeau, qui depuis deuient fleuue, \& $\mathrm{fe}$ erd à la mer du Sud. De l'autre ils difent que fameufe riuiere d'A porima prend fon origie, de laquelle l'ont dit quela renommee riuie: des Amazones, autremét ditte de Maragnon, rocede auec fa grande quantité \& alfemblee eauës qui fe ioignent en ces montagnes. C'eft ne chofe quel'on peut fouuentesfois demaner, d'où viết quíli y a tant de lacs au haut de ces contagnes, efquels il n'entre aucune riuiere, uais au contraire plufieurs grands ruiffeaux en ortent, \& fi n'apperçoit-on point que ces lacs iminuent prefque en aucune faifon de l'ani 


\section{Hiftoire naturelle}

nee. De penfer que ces lacs s'engendrent des neiges fondues ou des pluyes du Ciel, cela ne fatisfait point du tout, car il y en a plufieurs de ceux-là qui n'ont cefte abondance de neiges ny tant de pluyes, \& fi l'on ne s'apperçoit poine qu'ils diminuent. Ce qui fait croire que ce font fources qui y naiffent \& fourdent naturellement, bien qu'il neioit pas mal à propos de croire que les neiges \& les pluyes y peuuent aider en quelques faifons. Ces lacs font fi communs aux plus hảuts fommets des montagnes, qu’à peine y a-il riuiere fameufe qui ne tire fon origine de quelqu'vn diceux. Leur eaüe eft fort nerte \& claire, \& fi engendre peu de poiffons, encor fi peu qu'il yen a, eft fort menu à causfe du froid qui y eft continuellement : combien qu'il y air routesfois quelques vns de ces lacs qui font veritablement chauds, qui eft vne autre merueille: Au bout de la vallee de Tarapaya proche de Potozi y a vn lac de forme róde rel quil femble auoir efté fair par compas, l'eauie duquel eft tres-chaude, combien que la terre en foit extremement froide. Ils ont accouftumé de s'y baigner pres du riuage, d'autant qu'vn peu auane l'on ne pourroit fouffrir la chaleur. Au milieu de celac y a vn boüillon de plus de vingt pieds en quarré, qui eft fa vraye fource: \& neärmoins quoy que cefte fource en foit ainfigrande, iamais on ne le void croiftre en aucune $f_{2}$ çon, \& femble quil s'exhale de foy-mefme, ou qu'il ait quelque iffuë cachee $\&$ incogneive. On nele void non plus diminuer', qui eft vne autre merueille, iaçoir quel'ó en air tiré vn gros ruif; 
eau courát pour faire moudre certains engins our le metal, veu que pour la grande quantiré l'eaüe qui en fort, par raifon 11 deuroir dimiuer. Or laiffant le Peru \& pafíanc à la neufue Efpagne, les lacs qui s'y trouuent ne font pas noins remarquables, fpecialemér ce tát fameux le Mexique, auquell'on trouve de deux fortes l'eaüe's, l'vne fallee $\&$ femblable à celle dela ner, \& l'autre claire $\&$ douce à caufe des riuices qui y entrent. Au milieu de ce lac y a vn ro. cher fort plaifant $\&$ delicieux où il a des baing $\$$ l'eaüe chaude qui y fourdent, lefquels ils efrimét beaucoup pour la fanté.1l y a desiardins au milieu de ce lac, fódez \& portez fur l'eaüe mé me où l'on void de parterres pleins de mille for. tes d'herbes \& do leuro, \& font de telle façon qu'on neles peut bien comprendre finon entes voyant. La Cité de Mexique eft fódee fur ce lac, encor que les Efpagnols ay ent remply de terre rout le lieu \& affiette d'icelle, laiffans feulement quelques courants d'eaiie, grands \& petits qui entrent $\&$ tournoyét dans la ville pour voiaturer ce qu'ils ont de befoin, comme bois, herbes, pierres, fruiots du pays, \& toutes autres chofes. Quand Cortes conquefta Mexique, il fit faire des brigantins, \& depuis luy fembla qu'il eftoit plus feur de nes'en feruir point. C'eft pourquoy ils vfent des Canoës, dont y a grande abondan-ce.Il y a en ce lac beaucoup de poiffon \& 2 de viuier, combien que ie n'y ay pas ven de poiffon de prix, toutesfois ils difent que le reuenu dece lac vaut tr ois cens mille ducats. Il y a plufieurs autres lacs non loing de là, d'où l'on porte beauO iij 


\section{Hiftoire naturelle}

coup de poiffon à Mexique. La Prouince deMe: chouacă eft ainfi appellèe, pource que c'eft vne Prouince abondante en poiffon.Il y a de tresbeaux \& grands lacs, efquels y a beaucoup do poifion, \& eft cefte terre faine $\&$ fraifche.ll y a plufieurs autres lacs, defquels il n'eft pas poffi. ble faire mention, ny les içauoir en particulier, feulement lont peut remarquer par ce qui en a efté difcouru auliure precedent, que fouz la Torride il y a plus grande abondance de lacs, qu'en autre partie du monde : \& ainfi parce que nous auons dit cy-deffus, \& le peu que nous dirons des riuieres \& fontaines, nous mettons fin à cefte mariere d'eaües.

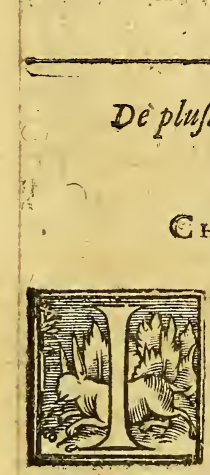

ChaPITRE XVII. dú vif argent, il y a vre fontaine qui ietre l'eaüe L y a és Indes comme és autros parties du monde grande diuey. fité de fources, fontaines \& ri. uieres, \& quelques vnes de proprietez eftranges. En Guancauelica du Peru où font les mines chaude, \& en coulant, fon eaüe fe conuertit en roche, de laquelle roche ou pierre l'on edifie quafi rouies les maisós du bourg. Cefte pierfe elt molle \& \&aifee à coupper, car auec vn fas 


\section{Hiftoire naturelle}

terre, relle eft lodeur qui fort continuellement de cefte fource. Aux baings, qu'ils appellent les baings de l'Ingua, y a vn canal d'vne eauie qui fort toute chaude \& boüillante, \& ioignát icel le y en a vne autre dont l'eau eft auffi froide que neige : L'Ingua auoit accouftumé de les mo. derer l'vne auec l'autre, $\&$ eft vne chofe remarquable, qu'il y ait des fources de qualitez fi contraires, qui font \& viennent fi pres l'vne de 1'autre. 11 y a vn nombre infini d'autres fources chaudes, fpecialement en la prouince des Charcas, en l'eau defquelles l'on ne peut endurer \& זenix la main l'efpace d'vn Aue Maria, comme iel'ay veu par gageure. Envne maitairie proche de Cufco fourd vne fontaine de fel, qui ainfi comme elle va courant, fe va conuertiffant en fel,qui eft blanc, \& bon à merueilles: que fi elle eftoit en autre contree, ce ne feroit petite richeffe, toutesfois ils'en font peu d'eftat, pour l'abondance du fel qu'il y a là. Les eaües qui courent en Guayaquil qui eft au Peru, prefque foubs la ligne Equinoxialle, font tenues pour falutaires, pourle mal Neapolitain, \& autres femblables. A raifon dequoy l'on y vient de plufieurs lieux fort efloignez pour y receuoir guarifon. Et difent que la caufe de cela eft, pour ce quil y a en cefte contree grande abondance de racines, qu'on appelle falcepareille, la vertu \& operation de laquelle eft fi cogneiie, \& qu’elle communique fa proprieté aux eaux où elle eft mife, de guarir cefte maladie. Bilcanota eft vne montagne, qui felon l'opinion dus commun, eft au plus haut lieu du Peru, le fom: 


\section{des Fndes. Liure III.}

109

net de laquelle eft tour couuert àe neige, \& en uelques endroits eft noir comme charbon. Il ort d'iceluy deux fources en lieux tout cótraies, qui deuiennent incontinent fort grands uilfeaux, \& peu à peu grands fleutues, l'vn defuels va à Collao dans ce grand lac Titicaca, \& autre va aux Landes, \& eft cel uy qu’’ils a ppel. entYucay, quife joignant auec vn autre, fort la mer duNort, ayant vn cours furieux $8 z$ mpetueux. Cefte fource quand elle fort de la oche Bilcanota que j’ay dit, eft de la mefme orte \& coulcur que l'eau de lexiue, ayant la ouleur cendree, \& jettant vne fumee, comme e chole bruflee, laquelle court ainfi vn long emps, iufques à ce que la multitude des eaux ui y entrent, luy efteignent ce feu \& fumee, u'elle tire de fon commencement. En la neiEfpagne j'ay veu vne fource, comme d'ancre uelque peu bleue, vne autre au Peru, de coueur rouge comme fang, d'où ils l'appellent la iuiere rouge.

\section{Des Rinieres.}

\section{CHATITR XVIII.}

FTRE toutes les riuieres non feulement des Indes, mais auffi de toutle eds monde vniuerfel, le Aleule Mara-
gnon, ou des Amazones, tient la
orincipauté, duquel nous auons parlé au liure eds monde vniuerfel, le Aleule Mara-
gnon, ou des Amazones, tient la
orincipauté, duquel nous auons parlé au liure orecedent. Les Efpagnols l'ont plufieurs fois nauigé, presendans defcouurir des terres, qui 


\section{Hiftoire naturelle}

felon le bruit commun, font fort riches, fpecialement celles qu'ils appellent de Dorado, \& Paytiti. L'Adelentade Iean de Sallines, fit vne entree memorable, encor qu'elle fut de peu d'effect.Il y a vn paffage qu'ils appellent le Pon go, qui doir eftre vn des plus dangereux pas de rout le monde: car la riuiere eftant relferree êr cét endroit, \& contraincte entre deux roche tres-hautes en precipice, vient à tomber droi aement du haut en bas, auec vne grande roi deur, où l'eaiie par la cheute qu'elle faict de haut, fait vn tel boüillon, qu'il femble impoffi ble de le paffer fans fe noyer. Neantmoins la hardieffe des hommes a bien ofé entreprendre de paffer ce paffage, pour le defir de ce Dorado tant renommé. Ils felaifferent couler du hau en bas, poulfez de la roideur \& du courant du fleuue, fe tenans-bien aux Canoes ou barques où ils eftoient, \& encor qu'elles fuffent renuer fees fans deffus deffoubs en tombant, \& eux \& leurs Canoes s'enfonçalfent en l'eau; neant. moins parleur force \& par leur induftrie ils fe remetroient \& retournoient toufiours en haut, $\&$ de cefte façon efchappa toute l'armee, excepté quelque peu qui fe noyerent. Et ce qui eft plus admirable, ils s'y comporterent fi dextrement quils ne perdirent pas mefme la munition \& la poudre gu'ils portoient. Au retour, (pource que apres auoir enduré beaucoup de trauaux, \& de dangers, ils furent cótraints en fin de retourner par ce mefmelieu) ils monterent par l'vne de ces roches tres-hautes auecleurs poignards qu'ils fichoient enla roche. Le Ca: 


\section{des Indes. Liure III. IIO}

itaine Pierre d'Orfua fit v ne autre entree par le iefme fleuue, lequel eftát mort fur ce voyage, les foldats s'eftans mutinez, d'autres Capitaies pourfuyuirent l'entreprinfe,par le bras qui ent ufques en la mer d' Nort. Vn Religieux e noftre Compagnie nous difoit, qu'eftant fealier, il fe trouna quafi en toute cefte entre. rinfe, \& que les marees montoient bien pres e cent lieuies à mont le fleuue, \& que à l'en. roit où il va fe ietrer dans la mer, qui eít quafi ubs la ligne, ou fort proche d'icelle, il a foiunte $8 x$ dix lieües d'emboucheure, chofe inoyable, \& qui excede la làrgeur de la mer lediterranee; encor quil y air quelques autres, ui en leurs defcriptions ne luy donnent que ingt cinq, ou trente lieuies d'embouchurc. pres cefte riuiere, tient le fecond lieu en l'viuers la riuiere de Plata, ou d'argent, qui s'apelle aurrement le Paraguey, laquelle court des 1ontagnes du Pera', \& fe va perdre en la ner, a la hauteur de trente cinq degrez au Sud. lle croif, comme ils difent, en la mefme cçón du Nil, mais beaucoup d'auantage fans ompairaifon, \& rend les champs qu'elle baine comme vne mer, par l'efpace de trois mois, pres retourne à fon cour's, où les nauires nontent beaucoup de lieuies àmont. Il y a pluieurs autres fleuues, qui ne font pas toutesois de telle grandeur, \& neantmoins efgallent, oire furpaffent les plus grands de l'Europe, omme celuy de la Magdaleine, proche de ainte Marthe, la riuiere grande, \& celuy d' Alsarado en la neuue Efpagne, \& va nombre 


\section{Hiftoire naturelle}

infiny d'autres. Du cofté du Sud aux monta gnes dur Peru, les fleuues communement $n$ font pas fi grands, pource qu'ils ont peu d'efpa ce de courir, \& ne peuuent affembler tan d'eaux, mais ils font fort roides, à caufe quil tombent de la montagne, \& ont des auallage. $\&$ des cruës fubites; à raifon dequoy ils fon fort dangereux, \& ont efté caufe que plufieur: hommes y font morts. En temps de chaleuril! croiffent, \& fe débordent le plus. I'ay trauerf vingt-fept riuieres en cefte cofte, dont ie n'er ay pas pafié vne feule à gué. Les Indieñs vín de mille artifices pour paffer les riuieres. Er quelques endroits ils ont vne longue corde qu trauterfe d'vn cofté à l'autre, \& en icelle penc vn panier, ou corbeille, dans laquelle fe mel celuy qui veut paffer, \& $\&$ alors ils le tirent du ri. uage auec vne autre corde, tellement qu'il par. fe dedans cefte corbeille. En d'autres endroit l'Indien paffe comme à cheual fur vin boteau de paille, \& derriere luy celuy qui veut paffer $\&$ voguant auec vn bout d'aix paffe de cefte fa. çon. En d'autres endroits lls ont vn radeau de courges, ou citroüilles, fur lefquelles ils met tent les hommes, ou hardes qu'ils doiuent paffer, \& les Indiens liez auec des cordes vont nageans, \& tirans apres eux ce radeau de citroüilles, comme des cheuaux rirent vn coche, ou caroffe; d'autres vont derriete pouffans les citroïilles pour leur ayder. Paffez qu'ils font, ils prennent fur leurs efpaules leur barque de citrciuilles, \& retournent à nage; ce quilils font en la riuiere de la Sàinte au Peru. Nous pafta- 


\section{des Indes. Liure III.}

es celuy d'Aluarado en la neuue Efpagne, I vne table que les Indiens porcoient fur urs efpaules, \& quand ils perdoient terre, ils geoient. Ces artifices $\&$ milautres, dont ils feruent pour paffer ainfi les riuieres, certaiment font auoir crainte en les regardant \& intemplant, en ce qu'ils $f^{\text {faydent de moyens } \mathrm{fi}}$ biles \& fragiles, mais neantmoins ils font rt affeurez. Ils n'vent point d'autres ponts, de de crins, ou de paille. Il y a defia en quelies riuieres des potits depierre, baftis par la ligence de quelques Gouuerneurs, mais eaucoup moins qual ne feroir de befoing en ne terre, où tant d'hommes fe noyent par faud'iceux, \& laquelle donne tant de deniers, equels non feulement l'Efpagne, mais auffi autres Royaumes eftranges baftiffent de fuerbes edifices. Les Indiens tirent $\&$ dériuent es fleuues qui coulent des montagnes aux vales \& és plaines, plufieurs \& grands ruiffeaux our arroufer la terre; ce quils ont accouftuté de faire d'vne telle induftrie, qu'il n'y en a as de meilleurs en Murcya, ny à Milan mefie : ce qui eft auffi la plus grande \& totale riheffe des plaines du Peru, \& de plufieurs au: es parties des Indes. 


\section{Hiftoire naturelle}

Dela qualité de la terre des Indes en general

Chapitre Xix.

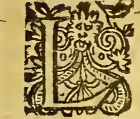

ON peu cognoiftre la qualité dela terre des Indes en la plus grande part, puis que c'eft le dernier des trois Elemens, defquels nous auós propofé de traitter en ce liure, par le difcours que nous auons fait au liure precedent de la Zone Torride, veu que la plus grande partie des Indes fe troulue fituce en icelle. $M$ ais pour ce faire enrédre plus particulieremết, j’ay remarqué trois fortes de terres, en ce que j'ay cheminé par ces regions, dont il y en a vne qui eft baffe, vne alstre tres-haute, \& l'autre qui tient le milieu de ces deux extremitez. La terre baffe eft celle qui eft en la cofte de la mer, dont il fen trouue par toutes les Indes, \& eft ordinairement fort chaude \& humide, qui caufe qu'elle n'eft pas fi faine, \& qu'à prefenr on la voit moins peuplee, combien quau temps paffé elle aye efté bien peuplee d'Indiens, comme il ar pert par les hiftoires de la neuue Efpagne \& du Peru, \& f'y conferuoient \& viuoient, entant que la region leur eftoit naturelle,comme ceúx qui y auoient efté engendrez. Ils y viuoient de la pefche de la mer, \& des femences qu'ils faifoient, tirans des ruiffeaux des riuieres, defquels ils fe feruoient faute de pluye, d'autắt qu'il y pleut fort peu, \&2 en quelques endroits n'y pleut point du tout: Cefte terre baffe a beaucoup de lieux inhabita 


\section{des Indes, Liure III.}

bles, tantà cáufe des fablons qui y font dangeeux; car il s'y trouule des montagnes entieres de ces fablons, qu'à caufe des marefcages qui "y font des eaux defcendants des montagnes, équelles ne trouuans point d'yfluë en ces teres plates \& baffes, les noyét du tout, \& les renlent inutiles. Et à la verité la plus grande partie le toure cefte cofte delamer eft de cefte forte s Indes, principalement du cofté dela mer du Sud: l'habitation defquelles coftes eft à preent fi diminuee \& mefprifee, que des trente arts du peuple qui y habitoit, les vingt-neufy lefaillent, \& à fon opinion, que le refte des Inliens finira auant peu de temps. Plufieurs felon eurs diuerfes opinions attribuent cela à diueres caufes, les vos aut trop grand trauail que l'on donné à ces Indiens, les autres au changemết $z$ diuerfité des viandes \& boire dont ils vfent, lepuis qu'ils cómuniquent auec les Efpagnols: es autres au trop grand excés de boire, \& aures vices qu'ils ont. Quant à moy, ie croy que e defordre eft la plus grande caufe deleur dininution, \& n'eft pas temps maintenant d'en lifcourir dauantage. En cefte terre baffe (que e dis generalement eftre mal faine \& peu contenable à l'habitation des hommes) il y a excetion en quelques endroits qui font téperez \& ertiles, comme la plus grande partie des plaires du Peru, où il y a des valós frais \& qui font ort fertiles. La plus grande partie de l'habitaion de la cofte entretient tout le commerce PEfpagne par mer, duquel dépend tout l'Eftat les Indes. En cefte cofte il y a quelques villes 


\section{Hiftoire naturelle}

affcz bien peu plees, comme Lyma \& Truxillo, au Peru, Panama \& Carthagene en la terre ferme, \& és Ifles S. Dominique Port-riche, \& 12 Hauane, \& plufieurs aurres villes qui font moindres que celle.cy, cóme eft la vraye Croix, en la neuue Efpagne, Yça, A ricgua, \& autres au Peru, \& metmes les ports font cómunement habitez, combien que ce foit alfez petitement. La feconde forte de terre eft au contraire fort haute, \& par confequent froide \& feiche, com. me toutes les montagnes le font ordinairemét. Cefte terre n'eft point fertile, ny plaifante, mais elle eft fort faine, qui la rend peuplee, \& habitee. Il y a des pafturages, \& en iceux beaucoup de beftial, ce qui fuftante en la plus grand" part la vie humaine, \& auec le beftial, ils fuppleent le deffaut qu'ils ont de bleds \& femences, par leurs trocs, \& efchanges. Mais ce qui rend encore dauantage ces terres habitees, \& quelques vnes fort peuplees, eft la richeffe des mines qui fe troutuent enicelles, pource que tout obeyt 2 l'argent \& à l'or. A caufe des mines il y a quelques habitations d'Efpagnols \& d'Indiens; qui fe font accreiles $\&$ augmentees, comme eft Po. rofi, \& Guancauelicqua au Peru, \& Cacatecas en la neuue Efpagne. Il y a aufi par toutes ces montagnes de grandes habitations d'Indiens, qui aujourd'huy (e maintiennét, voire veut-on dire quils vont en augmentăt, fínon que le trauail des mines en confume beaucoup, \& quel. ques maladies generalles en ont mefme deftuit vne grande partie, comme le Cocolifté en la neune Efpagne. Toutesfois l'on ne f'apperçoit 


\section{des Indes. Limie III.}

erçoit point qu'ils diminient beaucotip. En efte extremité de terre haute, froide, \&s feihe, il y a detix commoditez, que jay dites des afturages $\&$ des mines, quíl recompenfent bien es autres deux qui font és terres bafies de la ofte, à fçauoir le commerce dela mer, \& la ertilicé du vin, qui ne crơfl qu'en cesterres ort chaudes. Entre ces deux extremes il y a la erre de moyenne hauteur, laquiefle, combien u'elle foit en quelques endroits plus baffe, ou lus hatite l'vne que l'autre, ce nearitmo ins elle appreche ny de la chaleur de la colte, ny de intemperature des montagnes. En cefte forie e terreil croift beaucoup de femences, de froaent, d'orge, \& de mays, lefquelles ne fe trouent aucunement és terres hautes, mais bien ux baffes; il y a mefme abondance de pafturaes, de beftial, de fruicts, \& de forefts affez erdoyantes.' Cefte partie eft la meilleure habixtion des trois, pour la fantẻ, \& pour la recrea on; c'eft pourquoy aufi ce qui eft le plus peulé és Indes, eft de cefte qualité, ce que j'ay re.arqué fort curieufement en plufieurs cheuns $\&$ voyages que jay faids, \& ay troune our vray, queles Prouinces \& parties mietit euplees d'Indrens; font en cefte fituation. Que on regarde de pres en la neutue Efpagne (qua it fans doute la meilledure l'rouince que le Soil enuironne) par quelque endroit de la cofté ue l'on y entre, l'on y va touflours montant $\tau$ encores quapres auoir monté beaucoup, on commence à defcendre : toutesfois c'eft ortpeu, \& toufiours la terre y demeure beati. 


\section{Hifoire naturelle}

coup plus haute, que celie de la cofte. Tout? terroir de Mexique eft de cefte nature \& fitua tion, \& ce qui eft és enuirons du Vulcan, qu elt la meilleure terre des Indes, comme aufti font au Peru, Arequipa, Guamangua, \& $\mathrm{Cu}$ co, combien que ce foit l'vn plus quel'autre Mais en fon toat y eft terre haute, encores qu l'on y defcende à des vallees profondes, \& qu l'on monte de hautes montagnes, ils en difen autant de Quito, fainete Foy, \& du meilleu du nouneau Royanme. Pour refolution, ie cro que la fageffe \& prouidence du Createur a pour ueu en cecy, \& voulu pour le mieux, \& quel plus grande part de cefte terre des Indes fut haute, \& efleuee, à fin qu' elle fuft d'vnemeil leure temperature : car eftant baffe, elle eul efté fort chaude foubs la Zone Torride, prin cipalement eftant diftante \& efloignee de mer. Auffi toute la terre que i'ay veüe és Indes eft auoifince de montagnes d'vn cofté, ou d l'autre, \& quelquesfois de tontes parts. Telle ment que $i$ ay plufieurs fois dit par dela, quei defirois me voir en vn endroit, d'où l'horifol fe formaft \& finift par le Ciel, \& vne terre eften duc̈ \& v vie, comme l'on voit en Efpagne er mille campagnes : toutesfois ie n'ay point d fouuenance d'auoir iamais veu de telles veuie: aux Indes, fuft aux Ifles; ou en la terre ferme encores que iy aye cheminé plus de fept cent: lieies en longueur. Mais comme j'ay dit, le vei. finage des imontagnes eft fort à propos en ceft region, pour teniperer la chaleur du Solcil. Pal ainfi tour le plus habité des Indes, eft de la fa 


\section{Hiftoire naturelle}

tient en foy des proprietez fort eftranges, qui font qu'elle fert d'exception a la regle generale des Indes. La premiere eft qu'en toute la cofte il ne fouffle continuellement qu'vn feul vent, qui eft le Sud \& Suroeft, contraire à celuy qui a accouftumé de courir foubs la Torride. La leconde eft, qu'eftant ce vent de fa nature le plus violent, tempeftueux, \& maladif de tous, neantmoins il eft en cefte region merueilleufement gracieux, fain, \& aggreable, de telle $\mathrm{f}_{2}-$ çon que l'on luy doit attribuer l'habitation de celte cofte, laquelle fans doute feroit inhabitable, \& ennuyeufe, à caufe de fa chaleur, fi par fon foufflement ellen'eftoit addoucie. La troifiefme eft, que iamais il ne pleut, tonne, neige, ny grefle en toute cefte colte, qui eft vne chofe digne d'admiration. En quatriclme lieu, à peu de diftance de la cofte il pleut \& neige terriblement. En cinquiefme lieu, il y a deux chaines de montagnes, qui courent l'vne comme lautre, \& en vne mefme hauteur du Pole, neantmoins en l'vne y a de tres-grandes forefts, $\$$ y pleut la plus-part de l'annee, eftant fort chande. L'autre tout au contraire eft toste nuë, $\&<$ defcoviuerte, $\&$ fort froide ; de forte que l'hyver \& l'Efté forit departis en ces deux montaguties, \& les pluyes, \& la ferenité mefme. Or afin d'entendre mieux cecy; l'on doit confiderer que le Peru eft diuifé comme en trois parties, longues \& eftroittes, qu'ils appellent $L$ a. tios, Sierras, \& Andes. Les Lanos font la cofre de la tmer: la Sierra font toutes montagnes, \&i quelques vallees: \& les Andes font monta- 


\section{des Indes. Liure III.}

nes afpres \& rudes. Les Lanos, ou cofte de la ner, ont quelques dix lieues de large, en quelques endroits moins, \& en d'autres quelque peu dauantage. La Sierra contient comme vingt lieües en large, \& les Andes autant, tantoft plus, tantuft moins. Ils courent en leur ongueur Nort '\& sud, \&: en leur largeur, d'O-. rient au Ponant. C'eft doncques chofe merueileufe, qu'en fi peu de difance, comme font. cinquante lieiies efgalement efloignees de la ligne \& Pole, y aye vne fi grande diuerfité, qu'en vn lieu il y pleuue prefque toufiours, \& en l'antre il n'y pleuue quafiamais. Il ne pleur iamais en cefte colte ou Lanos, encores qu'ily tómbe quelquesfois vne eau menuë, qu'ils appellent Guarua, $8 \mathrm{en}$ Caftille, Mollina, laquelle quelquesfois s'efpaiffit en certaines gouttes d'eau qui tombe, toutesfois ce n'eft point chofe ennuyeufe, ny telle, qu'il foit befoing de fe couurir pour cela. Les couuertures y font de nates, auec vn peu de terre par deffus, \& leur eft chofe fuffifante. Aux Andes prefque durant toute lannee il y pleut, combien quil y ayt en vn' temps plus de ferenité qu'en l'autre. En la Sierra, qui gift au milieu des deux extremes, il pleut au melme tempsqu'en Efpagne, qui eft depuis Septembre, iufques en Auril: maist en l'autre faifon le tempsy eft plusferain, qui eft. quand le Soleil en eft plus efloigné, \& le contraire, quand il en eft plus proche, dequoy nous auons affez amplement traicté au liure precedent. Ce qu'ils appelient Andes, \& ce ce qu'ils appellent Sierra, font deux chaines de P iij 


\section{Hiftoire naturelie}

montagnes tres-hautes, qui doiuent couris plus de mille lieiies à veüe l'vne de l'autre, \& prefque efgalement. Il y a vn nombre infiny de vicugnes, qui naiffent \& f'engendrent aux Sierres, qui font proprement commechevres fauuages, fort viftes, \& fort agiles. Il y a mefmes de ces animaux, quils appellent Guanacos, \& Pacos, qui font des moutans, que l'on peut auffi bien dire, les afnes de ce pays, dequoy il fera traicté en fonlieu : \& aux Andes fe trouuent des finges fort gentils, \& plaifants, \& des perroquets en grande quantité. L'on y trouue auff l'herbe, ou arbre, qu'ils appellent Coca, qui eft tant eftimé des Indiens; \& la traicte quo lon en fait, y vaut beaucoup d'argent. Cello quils appellent Sierre, fait des vallees és endroicts où elle fouure, qui font les meilleures habitations du Peru, comme eft la vallee de Xauxa, \& d'Andaguaylas, \& de Yucay. En ces vallees il croift du froumenr, du mays, \& d'autres fortes de fruicts, toutesfois és vnes moins qu'aux autres. Plus outre que la Ciré de Cufco, (qui eftoir anciennement la Cour des Seigneurs de ces Royaumes) les deux chaines de montagnes queiay dires, fe resirent, \& fefloignent dauantage les vnes des autres, \& laiffent au milieu vne plaine \& large campagne, qu'ils appellent, la Prouince de Collao, où il y a grand nombre de riuieres, \& beaucoup d'herbages, \& pafturages fertiles, 8 là eft auffi le grand lac de 'Titicaca : mais encor que ce foit terre plaine, \& a la mefme hauteur $\&$ intemperature que la sier-

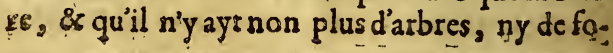




\section{des Fndes. Liure III.}

efts, tourefois le defaut qu'ils ont du pain, y eft ecompenfé par les racines qu'ils fement, lefuelles ils appellent Papas, \& croiffenrdedans a terre. Cefte racine eft le manger deś Indiens: ar les feichans \& nettoyans, ils en font ce qu'ils ppellêt Chugno, \& qui eft le pain \& nourritue de ces Prouinces. Il y a mérme d'aurres racires \& petites herbes qu'ils mangent. C'eft vne erre faine, \& la plus peuplee des Indes, \& Ia lus riche, pour l'abondance des beftiaux qui f'y hourriffent, tant de l'efpece mefme de ceux qui Cont en Europe, comme brebis, vaches, \& chevres; que de celles du pays quils appellent $\mathrm{Gua}$ nacos, \& Pacos, \& y a des perdrix alfez abondamment. Apres la Prouince de Collao vient celle de Charcas, ou il y a des vallees chaudes de grande fertilité, \& des roches tres-afpres, lefquelles font fort riches de mines; tellement qu'en nul endroit du monde il n'y en a point de meilleures, ny deplus belles.

Des caufes quils donnent pourguoy il ne plewt aux Lanos, ou coftes de la mer. Chapitre XXI.

'Autant que c'eft chofe rare \& extraordinaire qu'il y ait quelque terre où il ne pleuue iamais, ny tonne; les hommes defirent naturellemét fçauoir la caufe de telle nouveauté. La raifon que donnent quelques. $v$ ns qui ont resherché \& confideré cecy depres, eft quiil ne $P$ iiij 


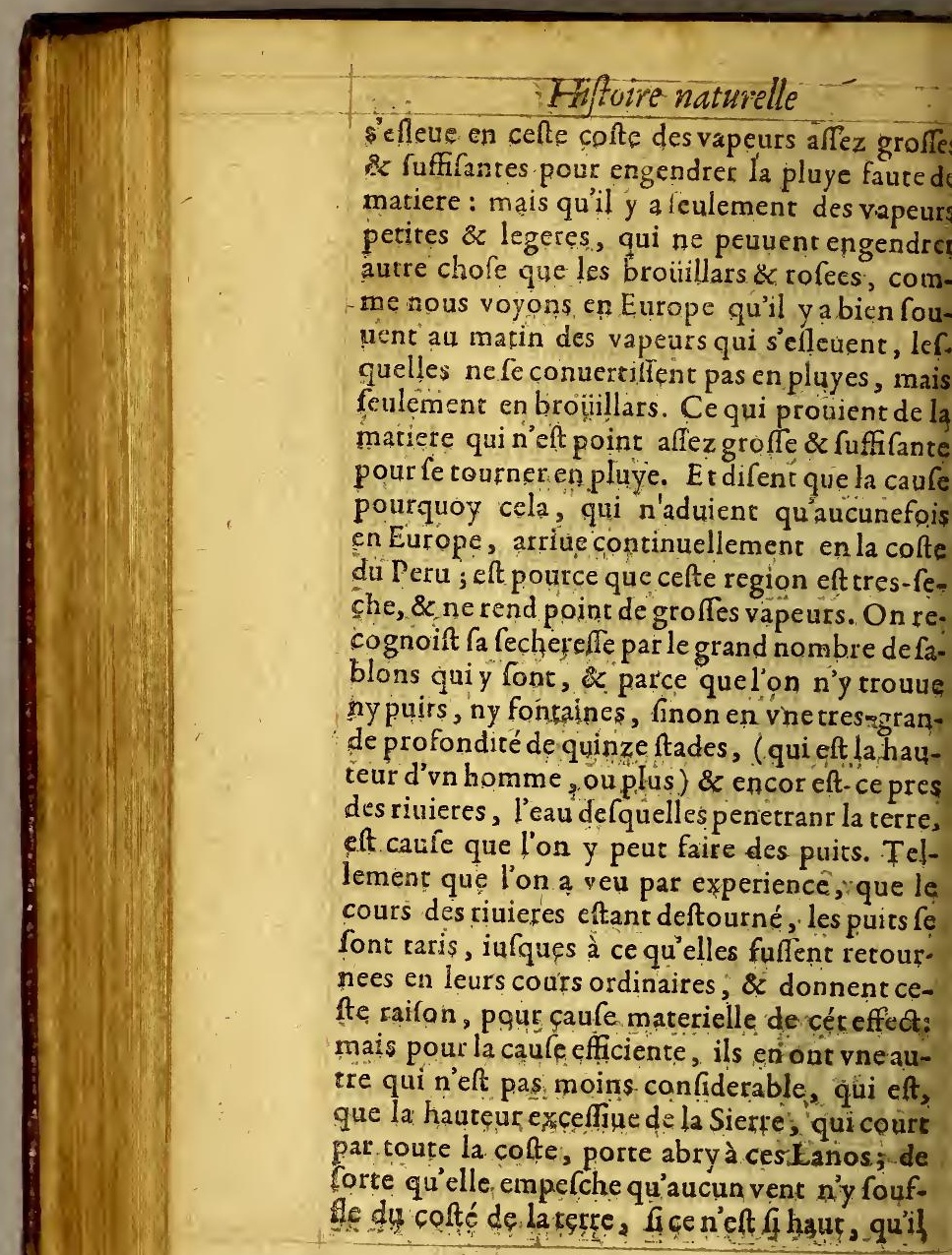




$$
\text { des Indes. Liure III. }
$$

it pardeffus les croupes de ces montagnes, moyen dequoy il n'y court qu'vn feul vent ui eit celuy de la mer, lequel ne trouuant point e contraire, ne prefle n'y exprime point les vaeurs qui s'efleuent pour engendrer la pluye, c maniere que l'abry de la Sierre empefche ue les vapeurs ne s'efpaiffiffent, \& fait qu'els fe conuertiffent touțes en bruines. Il y a uelques experiences quife rapportent à ce difours d'autant quil pleut en quelques collines e la cofte qui ont le mains d'abry, comme font es roches d'Atico \& d'Arequipa : mefmes quil a pleu en quelques annees queles Norts ou rifes y fouffloient, voire pendant tout le temps u'ils durcrent, comme fi arriua en foixante $8 z$ ixhuid aux Lanos de Trugillo, oil pleut bondamment; ce qu'ils n'auoient point veu lufieurs fiecles auparauant. Dauantage il pleut n la mefme cofte és lieux où les Brifes ou Jorts font ordinaires, comme en Guayaquil, $z$ és lieux ou la terre fe hauffe beaucoup \& fe eftourne de l'ombrage \&z abry des montagnes, omme en ceux qui font plus outre que Ariqua. Zuelques vns en difcourent de cefte façon, mais ue chacun en penfe ce qu'il voudra: ceft vne hofe certaine que defcendant de la Sierre $n$ ces Lanos l'on a accouttumé de voir comme eux Ciels, l'vn clair \&zerain par le haut, \& autre obfcur, \& comme vn voile gris tendia u deffoubs, qui counre toute la cofte; mais ncor quil n'y pleuue pas, cefte bruine y eft aerueilleufement profitable pour produire de terbe, \& pour efleuer , \& nourrir les femen: 


\section{Hifroire naturelle}

ces: car encor qu'ils ayent l'eaüe au pied tan qu'ils veulent quils tirent des eftrangs ou lacs toutesfois celtc humidité du Ciel a vne telle ver tu, que ceffant de tomber fur la terre, elle cauf vne grande incommodité \& diminution aus grains \& femences. Et ce qui ef plus digne d'ad. iniration, les fablons fecs \& $x$ fteriles par cefte ro. fee ou bruine, fe reueftent d'herbes $\&$ de fleur qui ef vne chofe plaifante \& agreable à voir $\&$ degrande vtilité pour les pafturages du beftial comme l'on void en la montagne, qu'ils appel lent de fablon, proche de la Cité des Roys.

De la proprieté de la neurue E/pagne, des Ifles o des autres terres.

Chapitre XXII.

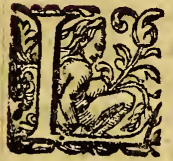

A neuue $E$ \{pagne furpaffe les autres Prouinces en pafturages, qui caufe qu'il y a vn nombre infiny de troupes de cheuaux, vaches, brebis $\&$ autres beftiaux. Elle eft fort abó. dante en fruicts, \& en toute forte de grain; en fomme c'eft la terre la mieux pourueiie, \& la plus accóplie qui foit és indes. Touresfois lepe ru la furpaffe en vne chole, qui eft a uvin, pource quil y en croit abondamment, \& de bon, \& de iour en iour les vignes y vont multipliant \& augmentant, lefquelles croiffent aux vallees fort chaudes où il y a arroufement d'eaües. Et combien qu'il y ait des vignes en la neuue Épagne, toutesfois le raifin n'y vieni point en fa maeurité 


\section{Des Indes. Liure III.}

I1 8 opre \& conuenable pour en faire du vin. La fe eft, pource qu'il pleur par delà en Iuiller Aouft, qui eft quand le raifin meurit : ceft urquoy il ne paruient à fa maturité. Que fi r curiofité l'on vouloit prendre la peine d'en re du vin, il feroir comme celuy du Geneis \& de Lombardie, qui eft fort petir \& fort re, ayant vn gout comme de verjus. Les es quils appellent de Barlouente, qui font Ppagnole, Cube, Port-riche, \& autres en ces uirons, font ornées de beaucoup de verdure, pafturages, \& font abondantes en beftial, uoir eft de vaches \& de porcs qui y font denus fauuages. La richeffe de ces ifles font, les gins de fucre, \& les cuirs. Il y a beaucoup caffe, fiftulle, \& de gingembre. Et eft chafe croyable de voir le grand nombre de ces archandifes, que l'on enleue en vne flotte, eftane quafi pas vray femblable, qu'en toure curope on en peuft tant gafter. Ils en enleuent efme du bois de qualiré \& de couleur excelnte, comme l'ebene \& autres qui feruent x edifices \& menuiferic. Il en y a beaucoup tils appellent, Ligram fanctum, ou Guayac opre pour guarir la verolle. 'Toutes ces Illes celles qui font en ces enuirons, qui font en es-grand nombre, ont vi tres beau \& treslaifant regard, pource que durant route l'an. ee elles font reueftuës d'herbes $\&$ d'arbres, tel:ment qu'ils ne peuuent difcerner, quand il eft utonne, ou Efté, pour lacontinuelle humidi. qui y eft ioinete auec la chaleur de la Torride, combier que cefto terrefoit de tres grande 


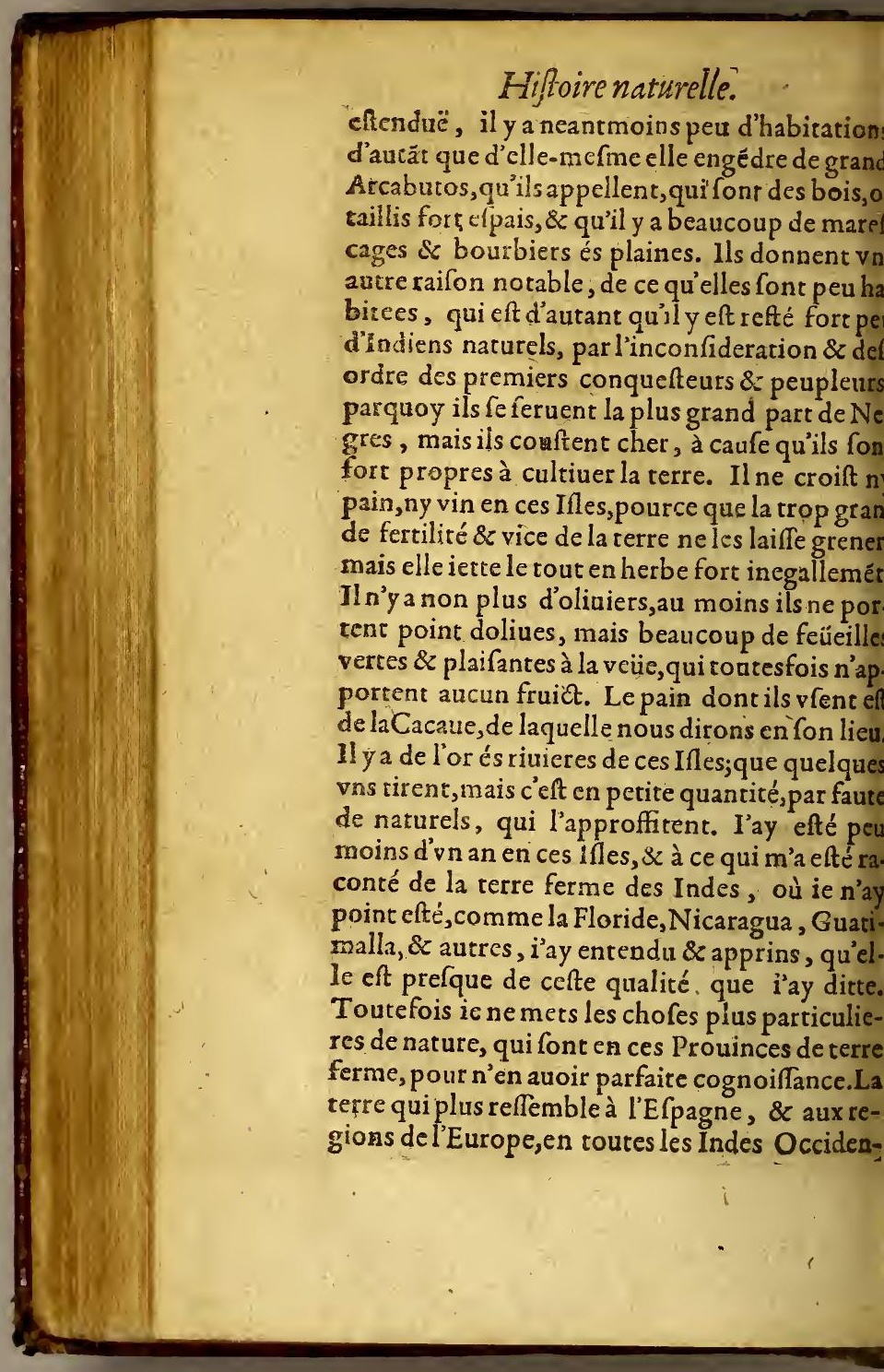


es, eft le Royaume de Chillé, qui eft hors de regle generalle de ces autres regions, d'autant il eft fitué hors la Torride \& le Tropique de apricorne. Cefte terre de foy eft frefche 85 tile, \& produit de toutes les efpeces de fruias ifont en Efpagne, \& rapporte auffi grande ondance de pain \& de vin, comme mef́me e abonde en pafturages $\&$ beftial. Le Ciely fain \& ferain, entre le chaud \& le froid. L'hyI \&z l'Efté y eft parfaitement, \& s'y trouue ande quantité d'or, qui eft rres-fin. Neantoins cefte terre eit pauure \& per peuplee, urlaguerre continuelle que les Auracanos, leurs alliez y font, d'autant que ce font des idiens robuftes, \& amis de leur liberté.

ela terre inīognuë, \&o de la diwerfitéd "wn iour entier, qui eft entre les orientaux ó occidentaux.

CHAP. XXIII.

17 L y a degrandes coniedures quícn la Eone Tempere, qui eft au Pole An1) tartique, il y air des terres grandes 8 2 fertiles, mais iufques auiourd hay elles e font defcouvertes, \& ne cognoift-on daurre rre en cefte Zone, que celle de Chillé \& quelie partie de la terre qui court d'Etiopie au ap de bonne Efperance, commeil a efté diat premier liure. On fçait aúfí peu, s'il y a haitation aux deux aurres Zones des Poles, \& 


\section{Hifoire naturelle}

fi la terre continue \& paruient iufques à cel du cofté de l'Antarctique ou Sud. L'on ne cr gnoift pas mefme la terre qui gilt paffé le d itroit de Magellan, d'autant quela plus granc hautcur que l'on a cognuë d'icelle, eft de cir quante fix degrés, ainfi qu'il eft dit cy-deuan $\Varangle$ du colté du Pole Arcticọue, ouNort, n'en fça on non plus iufques où va la terre, qui cou paffé le Cap de Mendoçin \& les Calliphorne: ny les boines \& fin de la Floride, \& iufqueso elle peut $s^{3}$ eftendre vers l'Occident. Il y a pe de temps que l'on a defcoumert vne nouuell terre, qu'ils appellent le nouueau Mexicque, 0 ils difent, qu'il y a beaucoup de peuples qui pai lent la langue des Mexicquains. Les Philippine \& les Ifles fuiuantes, comme racontent aucun quile f̧̧auent par experience, courent plus d neuf cens lieuies: mais de traitter de la Chine Cochinchine, \& Syam, \& autres regions qu font de l'Inde Orientale, ce feroit contre mos intention, qui elt feulement de traider des $\mathrm{Oc}$ cidentales. L'on ne cognoift pas mefme la plu grand part de l'Amerique quigift entre le Per $\&$ le Brefil, combien que de toutes parts l'on e cognoiffe les bornes. Surquoy il y a diuer opinions des vns \& des autres, qui difent, qu tout eft vne terre noyee, pleine de làcs \& de lieux aquatiques. D'autres afferment qu'ily de grands \& Heuriffans Royaumes, simaginan que là font le Paytiti, le Dorado, \& les Cæars où ils difent qu'il y a des chofes merueilleufes I'ay ouy dire à vn de noftre Compagnie, homme digne de foy, qu'il y auoit veu de grandes habj 


\section{des Indes. Liure III.}

ations, \& des chemins autant rompus \& batus comme font ceux de Salamanque à Vaillaolid, ce qu'il veid alors que Pierre d'Orfua, \&s epuis luy, ceux quiluy fuccederent firent l'cnree \& defcouuerte, par la grande rimitre des Imazones, lefquels croyans que le Dorado, u'ils cherchoient eftoit plus auant, ne fe foliierent de peupler là, \& apres demeurerent fans e Dorado quilils ne trouuerent point, \& fans efte grande Prouince qu'ils lailferent. De vray eft chofe iufques aniourd'huy cachee, que habitation de l'Amerique, excepté les extrenitez, qui font le Peru, le Brefil , \& l'endroit od a terre commence à s'eftreffir, qui eft en la riuiee d'argent, puis Tucuman, qui fair le toura Chillé, \& aux Charcas. Il y a fort peu de temps jue nous auons entendu par lettre des noftres jui cheminent en faincte Croix de la Sierre, jue l'on va defcoutrant de grandes Prouinces $x$ habitations, qui tombent en cefte partie, qui it entrele Brefil \& le Peru. Le temps les der:ouurira, car comme la diligence \& hardieffe les hommes eft auiourd'hny grande aे vouloir ircuir le monde d'vne part \& d'autre, nous pounons croire, que tout ainfi que l'on a defcounert rout ce qui eft cogneu iufques à prelent, l'on pourra de mefme defcoutrir ce qui re\{te, afin que le $S$. Euangile foit annoncé à l'vriuerfel monde, puifque defia les dewx Couronnes de Portugal, \& de Caftille, fe fontrencontrees par l'Orient \& par le Ponent, iufques a ioindre leurs defcouuertures enfemble, qui eft la veritó voe chofe remarquable, queles vas 


\section{Hifoire naturelle}

foient paruenus iufques en la Chine, \& Tappot par l'Orient, \& les autres aux Philippines qui font voifnes \& prefque contiguës à la Chine, parl'Oscident. Car de l'iffe de Lufion, qui eft Ia principalle des thilippines, où eft la ciré de Mammille, iulques à Macan, qui elt l'ifle de Cauton, il n'y a que quatre vingts ou cent lieües de mer entre deux , \& trouue chofe merueilletfe, qu'encore qu'il y air fi peu de diftance de l'vri à l'autre, il y a neantmoins, felon leur conte, vn jour entier de difference entre eux, de forte qu'il eft Dimanche à Macan, lors que à Mammille il eft Samedy, \& ainfi du refte. Ceux de Macan \& la Chine ont vn iour aduancé, \& ceux des Philippines en ont vn retardé. Il aduint au Pere Allonfé Sanchés, duquel il eft faict mention cy deuant, que partant des Philippines il arriua d Macan,le deuxiefme iour deMay felon fon conte, \& voulant dire l'office de faind Athanafe, trouia qua ils celcbroiêt la fefte de linuention faincte Croix, par ce qu'ils contoient là le troifiefme de May. Il luy en aduint tout autant, en vn autre voyage qu'il fit par delà. Quelques vns ont trouué cefte variation \& diuerfité eftrange, \& leúr femble, que cela procede de la faute des vns, ou desautres, ce qui n'eft pas toutesfois, mais eft vn conte vray \& bien obferué : car fuiuant la difference des chemins par où ont efté les vns \& les autres, il faut neceffairement dire, que quand l'on fe rencontre on doit auoir vn iour de difference. La raifon eft, pource que inauigeant d'Occident à l'Orient, l'on va toufiours gagnantleiour, \& troume l'on pluftoft le leueg 


\section{des'fndes. Liure. III.}

125 leuer du Soleil, \& au contraire ceux quínauk gent d'Orient au Ponent, vont toufiours perdant le iour, \& s'en retirent arriere, pource que le Soheil de plus en plus leur va leuât plus tard, \& cŏthe plus ils vont approchant du Leuant ou dú. Ponent, plus ils ont le iour toft ou tard.Au Peru, qui eft Occidental, au refpect de l'Efpagne, l'on y demeure de plus de fix heures arriere:de façot que quand il eft midy en Efpagne, il eft aube ou poinct du iour au Peru; \& quand l'aube du louts eft par deçà, la minuict fe trouve eitre par delà. I'ay fait preuue certaine de cela, par la compuation des Eclypfes du Solsil \& de la Lune. Maintenant done que les Portugais ont faiet leur nauigation d'Occident à l'Orient, \& les Caftillans d'Orient en Occident; quand its fe Ce font venus à ioindre \& rencontrer, quia eft aux Philipines \& Macan, les vins ont gaigné douze heures d'aduance, \& les autres en ont perdu tout autant. Par ainfi en vin mefme poind \& en vn mefme temps its troument la differen ce de vingt heures, qui eft vn iour entier. Atu moyer dequoy necellairement les vns font ait troifiefme de May quand les autres content le deuxiefme : \& quand les vns ieufnent le Samedy Sainct, les autres mangent de la chair pourile iour de la Refurrection. Que fi hous voulons feindre qu is paffaffent plus outre, tournoyans encor vne autre fois le monde, \& qu'ils vfaflent du mefme conte, quard ils tournoient à fe ioinidre, ils fe trouveroient aufsi bien par leur mefme conte en deuxiours de difference. Car comaie isy dit ceux gut ront au leuer du Splet

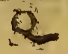




\section{If foire naturelle}

vontcontant le iour pluftoft, comme le Soleil leurva leuant pluftoft, \& ceux qui vont au couchant au contraire, vont contant le iour plu: tard, d'autant qu'il leur va fortant plus tard. Finalemét la diuerfité des midis fait les diuerscontes desiours. Et d'autant que ceux qui vót naui. geants du Leuant au Pönent, vont changeant: leurs midis fans le fentir, \& toufiours neantmoin pourfuiuent le mefme conte où ils fe trouuent quandils partent, il eft neceffaire qu'acheuants le circuit du monde ils trouuent faute à leur conte d'vn iour entier.

\section{DesKolcans, ou bauches de feir. CHAP. XXIIII.}

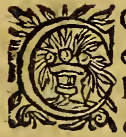

Ombien que l'on trouue en d'autres endroits des bouches de feu, comme le mont Atna Vvefuuio, quauiourd'huy ils appellent le mont de Soma, neantmoins c'eft chofe remarquable que ce qui fe trouue és Indes. Ordinairement ces Volcans font rochers ou pics de montagnes tres-hautes qui s'esleuent par deffus les fommets de toures les autres montagnes. Ils ont en leurs fommitez vne planure, \&rau milieu vne forfe, ou grande bouche qui defcend iufques au profond ou pied d'icelle, qui eft chofe efpouuentable à voir. De ces bouches il fort de la fumee, \& quelquesfois du feu. II y en a quelques-vnsqui iettent bien peu defumee, \& prefque n'ont aucune forme de Volcans, comme eft celuy d'Arequipa, qui 


\section{desIndes. Liure III.}

it d'vne hauteur démefuree, \& prefque du tout e fable qui ne fe peut monter en moins de deux urs, neantmoins on n'y a trouué aucune ap. aréce de feu, mais feulemët les veftiges de quelues facrifices que faifoient là les Indiens lors. u'ils eftoient Gentils. Et quelque peu de fumee u'il iette quelquesfóis.Le Volcan de Mexique, ui eft proche du bourg dés Anges, eft aufsi d' $v$ e hauteur admirable où l'on móte trente lieueuss tournoyant. De ce Volcan fort, non pas contiuellement, mais de fois â autre \& prefque chaue iour, vne groffe exhalation $\&$ tourbillon de imee qui fort droit en haut cồme vin trait d'aralefte, qui par a pres fe fait femblable à vh trer and plumage iứques à ce qu'il ceffe du tout \& ifsi toft fe-refoult en vne nuee noire \& obfcu- Plus communémét elle fort au matin apres le uer du Soleil, \& au foir quand il fe couche, en or que i'en ay veu fortir en autres heures. II rt aufsi quelquesfois apres cefte fumee beauoup de cẹndrès. De feu l'on n'en a encor veut ortir iufques a prefent, toutesfois l'on a crainte u'il ne forte \& brusle la terre qui eft a l'entour quelle êft la meilleure de tout le Royaume. Et ent-on pour certain qu'il y a quelques correfondance entre ce Volcan \& la Siérre de Tlaxala qui en eft affez proche, qui caufe les tonerres \& efclairs fi grands que l'on void \& oit rdinairement en ces parties. Quelques Efpanols ont monté en ce Volcan, lefquels ont raporté de la mine ou terre de foulfre pour faire e la poudre. Cortez raconte la diligence giu ita ite pour defcoururir ce quilil y auoir en ce Vol:-

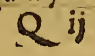




\section{Hifoire naturelle}

can. Les Volcans de Guatimalla font plusre nommez tant pour leur grădeur \& hauteur,qu les nauigeans en la mer du Sud defcouurent d fort loin, que pour l'ef pouuentement \& violén ce des feux quilsiettent de foy, Il arrivia au 2 : de Decembre de l'an paffé is 86 . que toute la $\mathrm{Ci}$ té de Guatimalla prefque tomba d'vn tremble ment de terre, oti demeurent mefme quelque perfonnes. Il y auoit defia fix mais que de iou \& de nuica le Volcan ne ceffoit de ietter par 1 haut \& cormme vomir vn fleuue de fẹu, la ma. tiere duquel tombant aux coftè du Volcan, $f_{1}$ conuertiflait en cendre cóme terre bruslee (çho fe qui furpaffe le iugement humain d'entendr comme il peut tirer de fon centre tant de matie re qu' il iettoit hors de foy durant çes, fix mois pource qu'il n'auoit accouftumé de iester qu de la fumee \& non pas toufiours, mais quel que fois de petites flammefches. Cela me fut effri eftant en Mexique par vn Secretaire de l'Au dience de Guatimalla, homme digne de foy ${ }_{2}$ voi re n'auoit pas encor aloris cefsé ce Volcan de jet. ter ces feux que ie dy. Ces ans paffez mę trou. uant en Quitto en la Cite des Roys; le Volcar qu'ils ont proche iettoit tant de cendre, qu'er beaucoup de lieux en circuit il plequt tant de cendre qu' elle obfcurciffoit la lueur du jour \& en tomba telle abondance en Quitto qu'il n' ftoit pofsible de cheminer par les ruës. L'ona veu d'autres Volcans qui ne iettent ny flamme ny fumee, ny cendre melme, maisl'on leswaid brusler au fonds d'vne viue flamme fans s'amortir:de telle façon eftoit celuy gu'en ngofre temp 


\section{des Indes. Liure III.}

Preftre cupide \& auaricieux fe perfuada quic qu'il voyoit bruslant, eftoient maffes d'or, iu ant en foy-mefme, que ce ne pouuoit eftre aue metal ny matiere, chofe qui depuis tant d'anzes ardoit fans fe confommer, \& eftant en cefte erfuafion, il fit de certaines chaudieres $\&$ chaiis, auec ne fçay quel inf̧trument pour cueillir retirer l'or de ce puits ou Volcan : mais le feu moqua de luy, pource que la chaine de fer $\&$. chaudiere n'approchoient pas pluftoft du feu, u'aufsi toft elles ne fe défiffent \& fuffent couees comme fi c'euft eftê des eftoupes. Ce neantloins on me dift que ce perfonnage s'obftinoit sufiours, \& alloit récherchant d'autresinuenós pour tirer \& puifer ceft or qu'il s's imaginoit.

Quelle eft la caufe pourguoy le feu or la fumee durentfilong tempsen ces $V$ olcans.

CHAPITRE XXV.

- 7 (c) I n'êt ja befoin de färe mention des autres Volcans, puifque par les deffufdicts lon peut entendre ce quien eft," toutésfois c'eft chofé digne dé recherher quelle eft la caufe qui fair durei le feu $\& 1 a$ umee en ces Volcans: pource qu il femble que e foit chofe prodigieufe, voire qui excedele ours naturel de ietter de leur eftomac tant de tammes comme ils en vomiffent. D'oú procede efte matiere quila leur dönne ou comme eftlle engendree là dedans? Quelquques-vns ont cu pinion que ces Volcans vont confommant la natiere interieure qu'ils ont de leur nature, \& 


\section{Ififtoire naturelle}

eroyent pour cefte caufe que naturellement if prendront fin quád ils auront confommé lẹ bois, par maniere de dire, qu'ils ont en eux. Suiuant cefte opinion, l'on void auiourd huy quelques montagnes ou rochers, d'ou l'on tire de la pierre bruslee, qui eft fort legere, mais fort dure, \& eft excellente à farre edifices $\&$ baftimens, comme celle que l'on apporte en Mexicque pour baftir. Et en effeçt il y.a des apparêces à ce qu'ọ dit, que ces montagnes ou rochers, ont eu autrefois vn feu naturel, qui s'eft efteint a pres la matiere confommee. Et par ainfi ces pierres font demeurees bruslees \& penetrees du feu, comme on les void. Quant eft de moy, ie ne veux pas contredire qu'il n'y ait eu autrefois du feu, ou qu'en ces lieux, au temps paffé il n'y ayt eu des Volcans. Maisce m'eft chofe difficile à croire, qu'il en foit ainfi de tousles Volcans, veu que la matiere qu'ils mettent hors, eft quafi infinie., \& qu'elle ne pourroit plus, eftant amaffee enfemble, eftre comprinfe dans cefte concauité mefme dont elle fort. Outre cela il y a des Volcans, qui en centaines, voire milliers d'annees, font toufiours d'vne mefme façon, iettans continuellement dela fumee, du feu, \& de la cendre. Plinehiftoriographe naturel(feló que refere l'autre Pline fon nẹpueu) recherchant ce fecret pour voir comme fe paffoit cefte affaire, \& s approchant de trop pres de l'exhalation du feu de l'vn de ces Yolcans, mourut \& penfant en venir à bout par fa diligence, vint à bout de fi vie. Pour moy fur cefte confideration, ie penfe, \& eft mon opinion, que comme il y a des lieux en la terre, qui ont la vertu d'atti- 


\section{desfndes: Liure III.}

rer à foy la matiere va poreufe, \& de la conuertir en eau, qui font les fontaines lefquelles toujours decoulent, \& toufiours ont dequoy decouler, entant qu'elles attirent à foy la matiere de l'eau: aufsi de mefme il y a des lieux qui ont la proprieté d'attirer à euxles exhalations chaudes, $\&$ de les conuertir en feu $\&$ en fumee, \& par leur force \& violence iettent mefme d'autres matieres ef paifies quife refuluent en cendre, en pierre de ponce, ou autre matiere femblable, \& qui eft vn argument fuffifant, qu'és Volcans cela foit ainfi, c'eft qu'ils iettent en certain temps de Ia fumee, non pas toufiours, \& en certain temps du feu, \& non toufiaurs, qui eft felon qu'ilsont peu attirer à foy $\&$ digerer, comme les fontaines en temps d'hyuer abondent, \& en efte diminuent, voire quelques-vnes fechent du tout, fe l'on la force \& vigueur qu'elles ont, \& felon la matiere qui fe prefente; ainfi eft-il de ce que ces Volcans en diuers tempsiettent du feu, plus ou moins. Les autres difent que c'eft le feu d'enfer, \& qu'il fort par là pour feruir d'aduertiffement, à fin de confiderer par là ce qui ent en l'autre vie: mais fil'enfer, comme tiennent les Theologiens, eft au centre de la terre, laquelle tient de diametre plus de deux mille lieuces, l'on ne peut pas iuger que ce feu foit du centre, d'autant plus que le feu d'enfer, felon que S. Bafile \& autres en-Bafo in p fal feignent, eft fort different de ceftuy que nous ${ }^{28}$. of in vayons, pource qu'il eft fans lumiere, $\&$ ard $\&$ brusle, fans comparaifon plus que le noltre.Ainfi ie conclus que ce quei ay diat me femble plus raifonnable.

Q iiij 


\title{
- in Hiftairenaturelle
}

Des tremblemens de terre.

\author{
CHAPITRE XXVI.
}

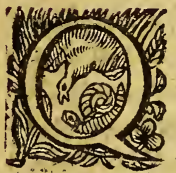

Velques-vns ont penfé,que de ces Volcãsquifont ésIndes, procedent es tremblemens de terre; affez frequens par delà: mais parce qu'ils font esioigne dennent ordinairemét és lieux qui eftre la ces Volcans, ce n'en peut pas taine forme \& fym. Il eft biè vray qu' ils ont cerpource que lẹs exhalationschaudes qui s'engendrent es intimes concauitez de la terre, femblent eftre principale matiere du feu deces Volcans, par lefquels mefme s'allume vne autre matiere plusgrofie, \& rend ces apparences de flamme \& fumee qui fortent. Et ces mefmes exhalations ne trouutans au dedans de la terre aucune fortie aifee, meuuent la terre pour fortir auec vne grande violence, d'où vient le bruit horrible qu'on entend au deffoubs de la terre, 8 mefrme le mouuement de la terre, eftant agitee de cefte bruslante exhalation. Tout ainfi comme la poudré á canon és mines \& artifices, eftant touchee du feu, rompt les roches \& les murailles: \& comme la chaftaigne mife au feu, faute $\&$ fe rompt en faifant bruit, lors qu' elle iette dehors l'air quieft enferme dedans fon efcorce, parla vigueur da feu: Aufsile plus ordinairemét ces tremblements de terre ont accouftumé d'aduenir aux endroits

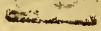




\section{des Indes. Liure. III.}

aritimes, qui font voifins de l'eau. Commel'on' oit en l'Europe, \& aux Indes, que les bourgs \& illes plus esloignees de la mer \& des eaux, fenent moins ce trauail, is au contraire ceux qui ont ès ports de mer, ès riuieres, ès coltes, \& ès eux qui en font voifins, endurent plus cefte alamite. Il eft aduenu au Peru vne chofe mereilleufe, \& digne de noter, f çauoir qu'il y a eu es tremblemens de terre qui ont couru deuis Chillé, iufques à Quitto, qui font plus de inq cens lieuës, ie dy des plus grandes dont $n$ ayt ouy parler, car les autres moindres y ont affez ordinaires. En la cofte de Chille' (il ne ne fouvient quelle annee) fut vn tremblement e terre fi terrible, qu'il renuerfa les montanes entieres, \& par ce moyen empefcha le ourant desfleuues, qu'il conuertit enlacs, if bbatit des villes, \& tua grand nombre d'homnes, faifant fortir la mer de fonlieu, quelques ieuës bien auant, de façon qu'elle laifla les natiresa fec, bien loing de la rade ordinaire, \& lufieurs autres chofes triftes \& efpouuentales. Et fi bien m'en fouvient, ils difent que le rouble \& efmotion que fit ce tremblement, ourut trois cens lieuès le long de la cofte. A seu de temps delà', quifut l'an de quatre vingts leux, vint le tremblement d'A requipa, qui abatit \& ruina prefque toute cefte ville là. Du lepuis en l'an quatre vingts fix, le neufief me de luillet, aduint vn autre tremblement en la Cité les Roys, lequel, felon qu'efcriuit le Viceroy, uoit couru le long de la cofte cent foixante $\&$ dix lieuës, \& de trauers dedans la Sierre cin- 


\section{Hiftoire naturelle}

quante lieües. La mifericorde du Seigneur fut grande en ce tremblement, de preuenir le peuple par vn grand bruit, qu'ils ouyrent quelques peu deuant le tremblement, \& comme aduertis

- par les experiences paffees, incontinent fe mi. rent en fauueté,fortant és ruës places \& iardins, finalement és lieıx defcouuerts, par ainfi encor qu elle ruina beaucoup ladite ville, \& que les principaux edifices d'icelle tomberent, ou furent à demy ruinez, neantmoins on dit qu'il n'y demeura que quinze ou vingt perfonnes feu-

- lement de tout le peuple. Il fit en la mer le mefme trouble \& mouuement qu'auoit faict celuy de Chillé, qui fut incontinent apresle tremblement de terre, fi que l'on veid la mer fortir furieufe $\&$ bondiffante de fes riuages, \& entrer au dedans de la terre prefque deux lieües auant: car elle monta plus de quatorze braffes, \& couurit toute cefte plage, tant que les digues \& - pieces de bois qui eftoient là , nageoient en I'eau, En apres l'an enfuiuant, il y eut encor vn autre tremblement de terre au Royaume \& Cité de Quitto, \& femble que tous ces notables tremblemens de terre en cefte colte, ayent fuccedé les vns aux autres par ordre, \& de faict elle eft fubiette à ces inconueniens. C'eft pourquay encor qu'en la cofte du Peru ils ne foient tourmentez du Ciel, des tonnerres \& foudres, ils ne laiffent pas toutesfois d'auoir de la crainte du cofté de la terre, \& ainfi chacun a deuant foy à veüe d'oil les herauts de la diuine Iuftice, à fin de craindre Dieu. Car, comme dit l'Efcriture, Eccles 3. Eecirbac vt timeatur. Retournant donc à noftre 
propos, ie dy que les lieux maritimes font plus ubiets à ces tremblemens, dont la caufe eft, comme il me femble, que l'eau bouche $\&$ eftoupe les conduits \& ounertures de la terre, par ou fẹ deurovent exhaler \& fortir les exhala. ions chaudes, qui s'engendrent en icelle. Et mefme que l'humidité efpaifsifant la fuperficie de la terre, fait que les fumees $\&$ exhalations chaudes fe referrent $\&$ fe rencontrent plus violemment là dedans, qui par apres vieninent à rompre en s'enflammant. Quelques- $r$ ns ont ob. ferué que tels tremblemens de terre ont accoutumé de s'efmouuoir, lors qu'il'vient vn temps pluuieux, apresquelques feches annees. D'où vient quel'on dit que les tremblemens de terre font plus rares és lieux où il y a grand nombre \& quantité de puits, ce qui eft approuué par lexperience. Ceux de la Cite de Mexicque ont opinion que le lac, fur lequel elle eft fituee, caufeles tremblemens de terre qui y furuiennent, encor qu' ilsn'y foient pas beaucoup violens, $\&$ c'eft chofe certaine, que les villes \& Prouinces fituees auant dedans les terres, \& quifont plus efloignees' de la mer, reçoiuent quelquesfois de grands dommages de ces tremblemens, comme la Cité de Chachapoyas aux Indes, $\&$ en Italie celle de Ferrare, encor que fur ce fubiect il fem ble que celle-cy, pour eftre voifine d'vne riuiere, \& n'eftre pasaufsi fort esloignee de la mer Adriatique, doiue pluftoft eltre mife au nombres des villes maritimes. En l'an mil cinq cens quatre vingts \& vn,en Chuguiano, Cite du Pefu, autrement appellee la Paix, arriua va 


\section{Hiftoire naturelle}

cas fort eftrange fur ce propos, c'eft qu'vn bourg, appelle Angoango, auquel habitoient plufieurs Indiens, enchanteurs \& idolatres, tomba inopinément en ruine, de forte qu'vne grande partie de ce bourg fut enleuee $\&$ emportee, dont plufieurs de ces Indiens furent eftoufez, \& ce quifemble incroyable (neantmoins atteftepar perfonnages dignes de foy) la terre qui fe ruina \& qui s'abbatit ainfi, courut $\&$ coula fur le pays leếpace d'vne lieuë \& demie, comme fic'euft efté del'eau ou de la cire fonduë;de façon qu'elle toucha \& remplit vn lac, \& demeura ainfi eftenduë parmy toute cefte contree.

Conime la terre o la noer s'embraf]ent l'vne lautre.

\section{CHAPITRE XXVIT.}

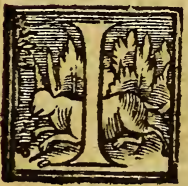

-Acheveray par cét element de la terre, le ioignant auec le precedent dél'eau, l'ordre \& èmbraffement defquels eft de foy certainement admirable. Ces deux elemens ont vne mefme fphere departie entr'eux, \& fe vont émbraflans \& accollans en mille façós \& maniéres. Par quel. ques endroits l'eau combat furieufement la terre, comme fon ennemie, \& en autres, elle la vient enceindre d'vne façon fort douce \& a miable. It y a des lieux ou la mer vient entrer dedans la ter re bien auant, comme venant la vifitel', \& d'atttres efquels la terre fe recompenfe, iettant en la 


\section{des Indes. Liure. III.}

mer'fescaps, pointes, \& languesauancees, qui vont penetrant iufques aux entrailles. En quelquesendroits vn element s'acheue, \& l'autre fe commence, fe donnant place peu à peu l'vna l'autre. Aux autres, chacuns d'eux (lors qu'ils fe ioignent) ont vne tref-grande profondeur, \& esleuation, comme il fe troliue des Isles en la mer du Sud, \& mefme en la mer du Nort, defquelles lesnauires s'approchent tout contre. Et quoy qu'ils y iettent la fonde en forxante \& dix, \& qua tre-vingts braffees, fi eft-ce qu'ils n'y trounent point de fonds; qui faict iuger que ce font com. me des pics ou pointés de terre, quimontent du profond, \& s'esleuent en haut, chofe digne de grande admiration. A ce propos me dit vn Pilote fort experimente', que les Isles, quil's appellent des loups, \& d'autres qui font fur le commencement de la cofte de la neuue Efpagne, quills appellent des: Cocos, eftoient de cefte merme façon. Daunantage, il fe trouue vn endroit at milieu du grand Ocean, hors de la veuë de terre, \& esloigne d'icelle de plufieurs lieuës, auquel l'on voit comme deux tours, ou pics, d'vne roche fort hault esleuez, qui fortent du milieu de la mer, \& neantmoins foignät icelles l'on ne peut trouuer ny fonds, ny terre. I'on ne peut encor certainement comprëdre, ny recognoiftre quelle eft la forme entiere \& parfaite de la terre des Indes, pourn'auoir efté les extremitez d'icelle du tout defcouuertes iufqu'à prefent. Neantmoins nous pouuoos dire comme à trauers, qu' $e$ le peut eftre comme vn cœur, auec les poulmons. Le plus large de ce cour, eft du Brefilau 


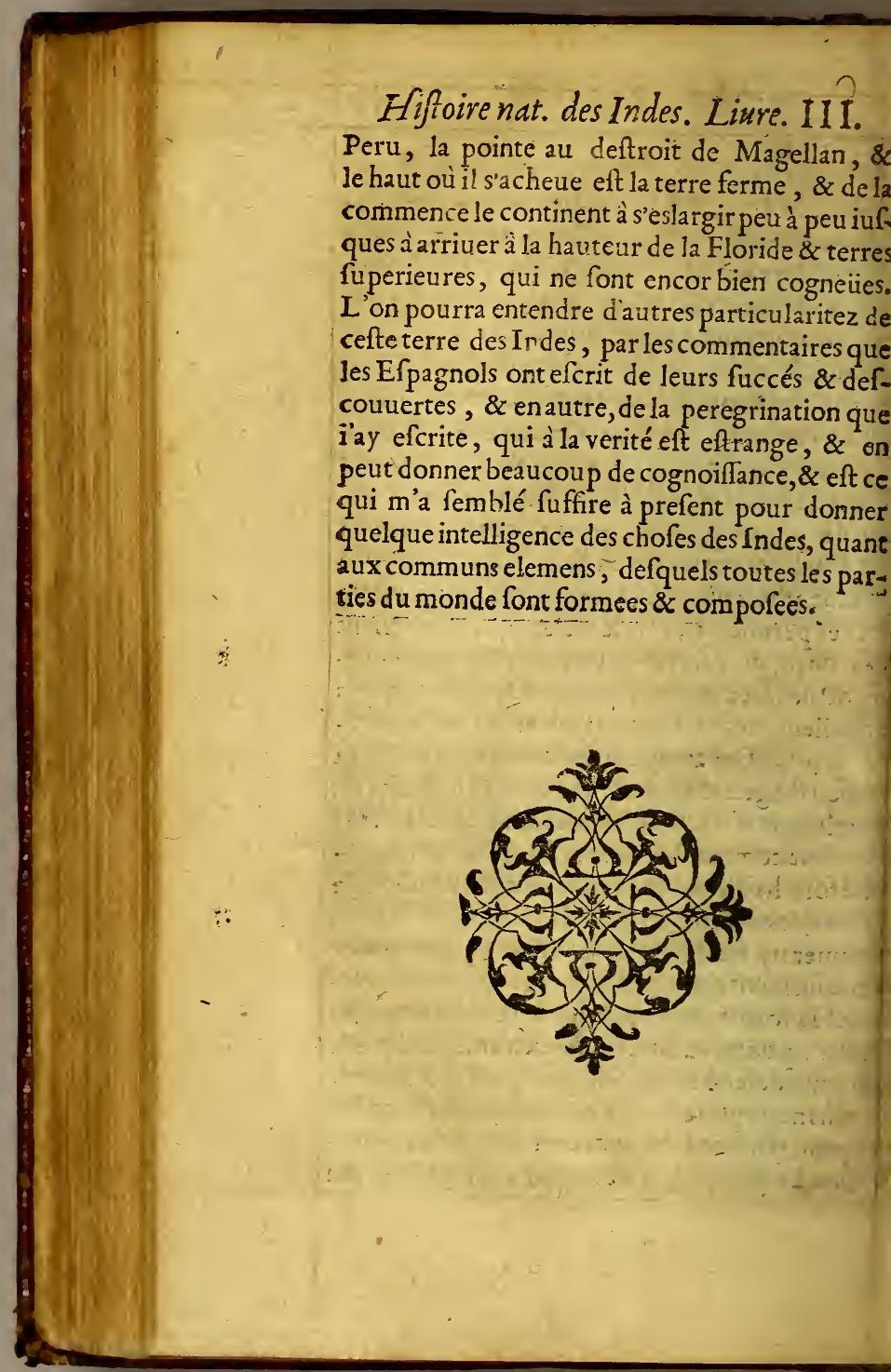




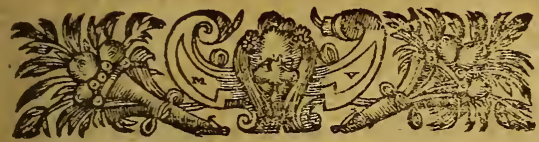

IVRE QVATRIESME

DE L'HISTOIRE NATV= RELIE ET MORALE DES Indes.

\section{CHAPITRE I.}

Des trois gerres de mixtes, ou compolez, dont ie dois traitter en cefte biffoire.

(2) Y A T traittéau liure precedent 1 Oy de ce qui touche les elemens, \& A les fimples des Indes, nous parle2. rons en ce prefent liure, des mix24. tes \& descompofez, entant qu'il ious femblera conuenable au fubject, dont nous youlons traitter. Et combié qu'il y ait beaucoup l'autres genres diuers, nousreduirons toutesfois cefte matiere entrois, qui feront les metaux, les lantes \& les animaux. Or les metaux font cóme les plätes couuertes \& cachees dedās les entrailes de la-terre, qui ont quelque reffemblance :ntr'eux, en la forme \& maniere de leur production : d'autant que l'on voit, \& recognoift mefme entre eux des rameaux \& comme vn tronc, duquel ils naifent \& proce. dent, qui font les groffes veines \& les moindres, 


\section{Hiftoire naturelle}

tellement qu'ilsont entree eux vne liaifon, tell qu'il femble proprement, que ces minerau croiffent à la façon des plantes. Non pas 'qu'i. ayent vne vraye vie vegetatiue interieure, $c a$ c'eft chofe qui eft feulement propre aux vraye plantes, maisils $\mathrm{fe}$ produifent aux entrailles $d$ Ia terre, par la vertu, $\&$ la force du Soleil, \& de , autres planetes, \&x dans vine longue ef pace $d$ temps fe vont augmentant; \& prefque multi pliant, à la façon des plantes. Et tout ainfi com me les metaux, font des plantes cachees en ter te, ainfi pouuons nous dire que les mefmes plan tes font desanimaux fixes $\&$ arreftez en vnlieu la vie defquelles s'entretient par l'aliment qu nature leur va fourniffant, dés leur propre naif fance. Mais les animaux fur paffent les plantes. en ce qu'ils ont vr eftre plus parfait, \& delo aufsi ont-ils befoin d'vn aliment \& norriture plus parfaite. Pour lequel chercher nature leus a donné vn mouuement $\&$ vn fentiment, afir de le defcouurir \& cognoiftre. De forte que la terre rude \& fterille, \& comme la matieré, \& aliment des metaux, \& celle qui eft fertic \& mieux affaifonnee, la nourriture des plantes. Lesmefmes plantes feruent d'aliment aux animaux, \& les plantes \& animaux tous enfemble font l'aliment des hommes, feruant toufiours la nature inferiture à l'entretien \& fuftentation dela fuperieure, \& la moins parfaictefe fubmettant à la plus parfaicte. D'où l'on peut voir combien il s'en faut, que l'or , l'argent, \& leș autres chofes que les hommes eftiment tant par leur auarice, foient lz firi $\alpha$ le buit de l'homme súg que 


\section{des Fndes. Liure IV.}

uquel il doiue tendre, puis quils font tant de egrez plus bas en qualité que l'hornme, lequel efté creé \& ordōné, pour efte fuject de feruir eulement au Createur vniuerfel de toutes choes, cốme à fa propre fin, \& fon parfaict repos: $\checkmark$ auquel homme, toutes les autres chofes de ce aöde n'ant efté propofees, ou delaiffees, finon our s'en feruir à gagner cefte derniere fin. Qui oudra cófiderer les chofes creées \& en difcouir felon cefte' Philofophie; poúrra certes tirer uelque fruit de leur cognoilfance \& confidera. ion fe feruant d'icelles, pour cognoiftre \& glö ifier leur Aútheur. Mâis qui fe voudra aduãcér lus outre d la cognoiffance de leurs proprietez ¿ vriliter, \& voudra fe endre curieux de les rehercher, cêlny-là trouuera finallemeñe en cês reatures, ce que le Sage dit, ourils font whx pieds Sap ta? es fols $\sigma$ ignoirans, fçauloir des lacs, $\&$ des pleges ù ils fe precipitent, \& fe perdent iournelletinêt. cefte intention donc, \& affin que le Createur oit glorifié è fes creatures, ie pretens dire en e liure quelques-vnes des chiofes dont ily a reaucoup's Indes, dignes d'hiftoire, 8 d'ente acontees, touchant les metatix? plantes \& 2 aninaux, qui font propres, \& particuliers en ces arties. Nais d'autant que cé ferólt vrie eaure ref-grande, que de traicter ceecy exacterient; $x$ qui requetroit plus grand fçatioir \& cogñơî ance, voire beaucoup plus de loiftr, que ie n'ay as, ie dis, quefeulement mon intention eft de raidtè fuccintement quelques chofes quie îay omprinfes, \& remarquees tant par éxperfience, jue par le rapport degens dignes de foy tow? 


\section{Hiftoire naturelle}

chant ces trois chofes que i'ay propolees, laif fánt aux autres plus curieux $\&$ diligens, de pou uoir traicter plus amplement de ces matieres.

Del labondance of grande quantité des metaus ino quifont és Indes Occidentalles.

Chapitre II.

i $1,3,90$,

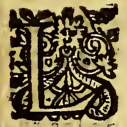

A fageffe de Dieu a creé les metaux pour medecine $\&$ pour deffence,pous ornement, \& pour inftrument des operations de lhomme. Defquelles quatres chofes lon peut facilement donnes exemple, mais la principale fin des metaux, \& la derniere d'icelles, eft pour-ce que la vie humaine n'a pas befoin feulement de fe fuftanter, comme celle des animaux, mais aufli de trauailler, \& ouurer felon la raifon, \& capacité que luy a donnéle Createur: $\&$ ainfi cóme l'entendement humain s'applique à diuers arts \& facultez, ainfi le mefme autheur a donné ordre qu'il y euft matiere \& fubject à diuers artifices pourla confetuation, reparation, feureté, ornement, \& exaltation de fes œuures. Doncques la diuerfité des metaux que le Createur a enferrez és armaires, \& concauitez de la terre, eft telle \& fi grande, que la vie humaine tire profit \& commodité de chacun d'iceux. Des vns elle fe fert en la guarifon des maladies, des autres pour Les armeures, \& pour defferfes contre les enne; 


\section{des Indes. Liure IV.}

is; les vasfont pour lornement \& parute de is perfonnes, \& de nos maifons, \& les aútres nt propres a faire des vaiffeaux, \& ferremens; ecles diuerfes façons dinftrumens que lin. frrie humaine a inuenté \& mis en vlage. Mais tous les vfages des inetaux, qui font fimples naturels; la communication des hommes en a uué vn, qui ent lv rage de la mốnoye, laquelle ariff.s. me dit le Philo fophe, eft la mefure de toutes Ethico.s. ores, Et cơbien que de foy \& naturellement, e ne foir qu vne feule chofe, neantmoins en eur \& eftimation, l'on peut dire qu' elle eft ités chores. La moonoye nous elt cómé vianveftement, maifon, cheuauchúre, \& generalent tout ce que les hómes ont de befoin. Pat moyen tout obeift a la monnoye, \& comme le Sage, pour faire rne inuention, qu'vne Erci. 200 ofe fuft toưtes, les hómes guidez ou poufrés. $n$ inftinct naturel, efleurenit 1 chofe plus dule, \& plus manialile, qui ent te metail, \& ences metaux voulurent que ceux-1a euffentla éminenceen cefte inuention de monoye, qui leur naturel eftoiet plus durables, \& incorrubles, à f fauoir largent \& lor. Eefquels non lement on efté en eftime; entre les Heelix, Alfyriens, Grecs, Romains, \& autres na. ns de leurope \& d'Afie, thas aufi entre les is efloignees \& barbarés nations de l'vniuers mine font les trdiens tant Orientaux; comOccidentaux, ou lor \& 1 argent eft tenu en í grand pris \& eftime, lemployans en l'ouge deleurs Temples \& Palais, \& aux veftens, \& accouftremens des Roys s \& des grands R ij 


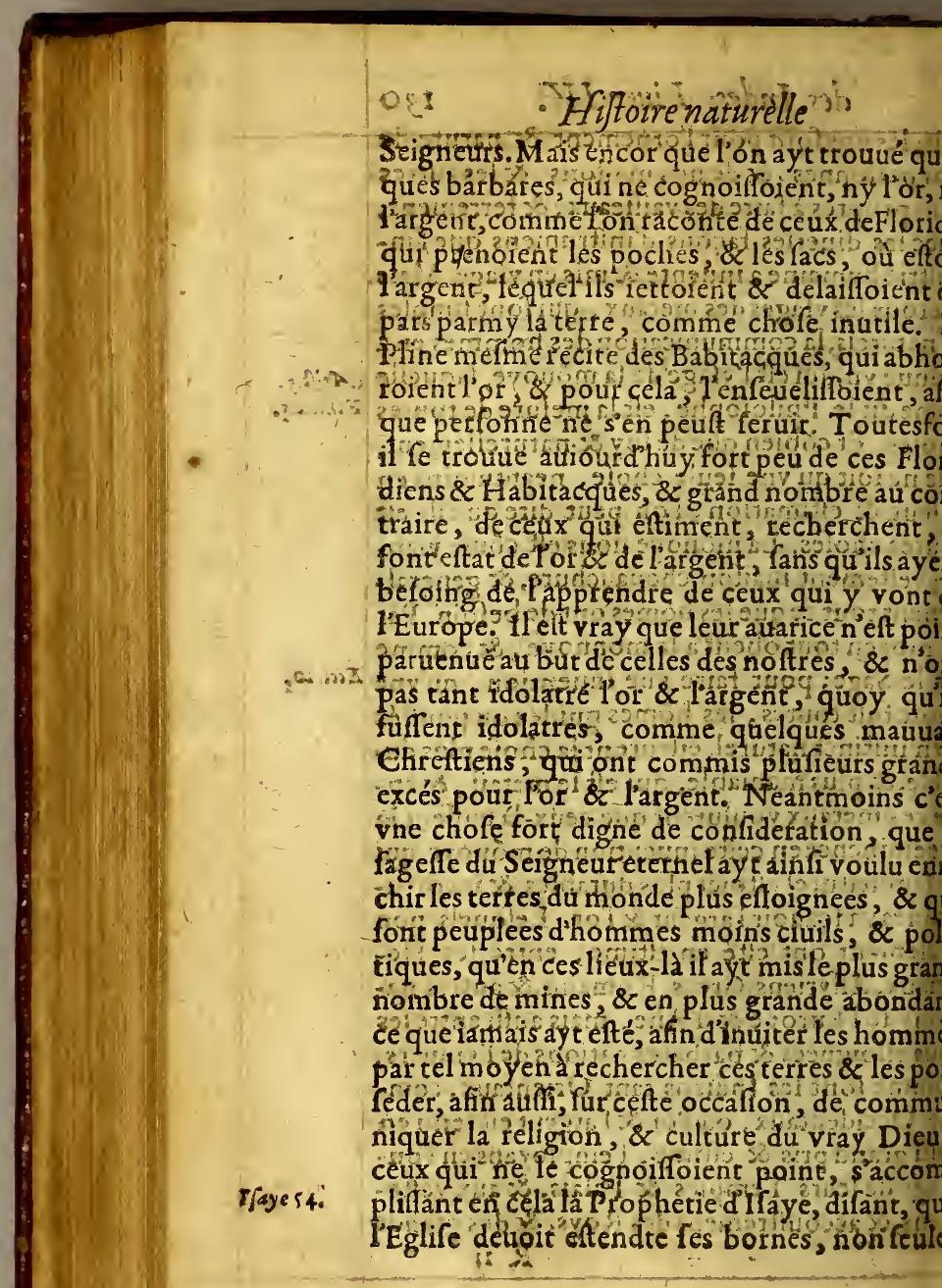




\section{Ififoire naturelle}

voire femble que raute la terre elt femee de

metaux plus quaucune autre terre qui no

1.1.r.m at:- fon fort a prefent cogneue au monde, ou de quelle les autheurs anciens ayent faict mentio

parlepalre.

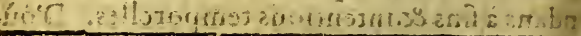

De la qualite or in mo - uentiles metaux, ca gue tous ces metaux

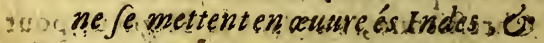
comoles Indiensfofersionent ant

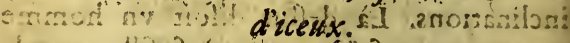
C CHAPR RE IHF

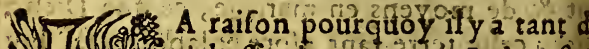
1) richeffes de metaù $x$ es Indes,, $\mathrm{p}$ 1) cialement aux Óccidentales du y ru, eft commeíay da la vólon Lo té du Createur, quia departy le dons comme il luy a pleu. Márs vétiantà la ral fon naturelle \& Philo fop hique, celt chofe bie

Philolib.5. de Genef. mund.

vraye ce qu'en a efcrit Philon homme fage di Tant, quelor, largent \& metaux naiffent natu rellementaux terres plus feriles $\&$ infructueu foc. De vray hous voyons qua sux terres de bion netemperature, \& qui font fertiles d'herbes 8 de fruiats, rariment ou iamais on ny trout des mines, pource quela nature fe contented de prapar. leur donner vigueur, pour por fuire les fruia Enang.e.s. plus neceffaires a la conferuation $\alpha$ entreties de la vie des animaux \& des hammes. Ais con traire, an terres qui font fort afpres feiches, 


\section{desfndes. Liure IV.}

teriles, comme en dés montagnes tref-haütes; \& $x$ en des roches qui font afpres, \& d'vne temperature fort rude, l'on y trourue les mines d'ar gent, de vif-argent, \& dcl'or, \& toutes ces richelfes (qui font venuës en Efpagne, depuis quo les Indes Occidentales ont efté defcounertes) ont efté tirees de lieux comme cela, qui font afpres, penibles, defcouuerts \& fteriles. Toutesfois le gouft de cefte monnoye rend ces lieux. doux \& agreables voire habitez de grand nom bre de peuple. Or combien qu'il y ay r aux. Indes (comme iay dict) plufieurs veines \& 2 mines de toutes fortes de meraux, toutesfois ils n'en tirent, ny fe feruent point d'autres; quédes mines d'or \& d'argent, \& mefme de vif-argent, d'autant qu'il eit neceffaire, pour tirer \& affiner l'or \& l'argent. Ils y portent le fer d'Efpagne, \& de la Chine. Quant au cuiure, les Indiens en ont tiré \& mis en aure quelquesfois pour ce que leurs ferreméns \& armes ñeftoient point ordinairement de fer, mais de cuiure. Depuis que les Efpagnols tiennent les, Indes; lon en a tiré fort peu, \& ne prennent pointla peine d'en rechercher les mines, encor qu'ily en ayt plufieurs, pour ce qu'ils s'arreftent 2 la recherche des meraux plus riches \& precieux, \& y employent leur temps \& leur trauail. 11 s fo feruent des autres metaux decuiure \& fer, tant feulement de ce qu'on leus en enuoye d'Efpagnie), ou bien de ce quir refte de l' affinement de Fos \& l'argent. L'on ne trouue point queles Indiens vfaffent cy-deuant d'or, ny d'argent, ny. d'autre raietail pour monnoye, \& pour prix des $\mathbf{R}$ iiij 
slin.lib.33. shape 3 .

i: $:$ I

\section{Hiftoire naturelle}

chofes' mais feulement s'en feruoient pour of nement, comme il a efté dit, \& ainfi il y en auoi grandefomme \& quanticé áux Temples, Palais \&: fepultures, auec miligenres de vafes d'or \& d'argent qu'ils auoient. Ils ne fe feruoiét poin d'ot ny d'argent sour traficquer \& acheter maischiangeoient \& troquoient des chofes au autres, comme Homere \& Pline sacontent de! anciéns. Ils auoient quelques autres chofes de plus grande eftime, quii couroit entr'eux pou prix, au lieu de momnoye, \& iufques auiourdhuy dure celte couftume entre les Indiens comme aux Prouincesde Mexicque, ils vfens aulieu de monnoye du Cacao (qui eft vn peti fruia) \&\& auec iceluy acheptent ce quils veutert A A Peru ils fe feruent du Coca, pour cefte mefmęfin, qui eft wne feüille queles Indiens eftinent beaucoup, conme zu Paraguey ïlson des coings de ferpour monnoye, \& du cofton riffi en faincte Croix de la Sierre. Finalement la maniere de traficquer des Indiés, \& leuracheter \&ovendre, eftoit efchanger \& bailler chofés pour ohofes s \& bien quili y euft de grands matchéz, \& des foires fort celebres; fi eft-ce qu'ils n'ónt eu befoing; ny neceffité de monnoye, ny mefme de courratiers, pource que tou's eftoiét for biẻn apprins, à fcauoir cöbien il eltoit befoing de doner d'vne forte de marchandife poir vne, tant d'vne autre. Depuis que les Efpagnols y font entrez, les Indiens fe font mefmes feruis de lor \& de l'argent pour acheter, \& a u commencement n'y auoit aucune mónnoye, majs largent au poids eftoit deur pris \& leur mon: 


\section{des Fndes. Liure $1 V$.}

noye, comme l'on raconte des anciens Ro- plin. li.330 mains. Du depuis pour la plus grande commo- $6 x p_{0} .4$. lité, l'on forgea de la monnoye en Mexique, \& u Peru : toutefois iufqu'à prefert, en ces Indes Dccióentales l'on n'a battu aucune monnoye le cuiure, ou autre metal, mais feulement d'aryent \& d'or, pource que la richeffe d'icelle teren'a admis, ny receu la monnoye qu'ils appelent de billon, ny autres genres d'alloy dont ils fent en Italie, \& aux autres Prouinces de l'Euope; bien quil foit vray qu'en quelques Ifles lés Indes, comme fainct Dominique, \& Portiche, ils vfent de monnoyede cuiure, qui font , is st. les quarts, lefquels ont cours feulement en ces hes, pource qu'il y a peu d'argent $\&$ d'or. Ic dis eu, encorequ'il y en ayt beaucoup, toutefo is Ln'y a perfonne qui le rire, ou affine. Mais pare que la richelfe des Indes, \& livfage de trauailer aux mines, confifte en or, argent, vif-argent, ediray quel que chofe de ceș troịs metaux, laif-

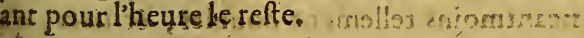

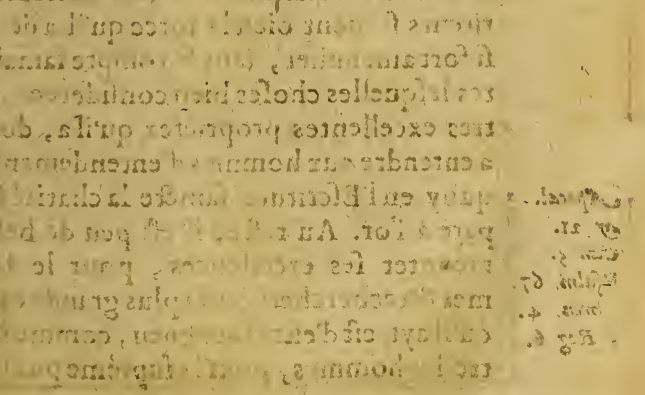




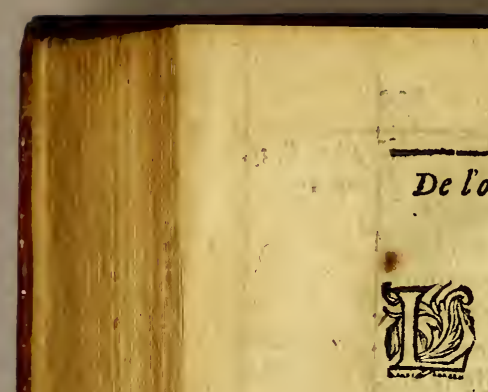

\section{Hiftoire naturelle}

De lor que lion tive, \&u affine és Indes.

CHAPITRE IV.

'OR entre tous les metaux a efté tou frours eftimé pour le plus excellent, 8 auecques bonne raifon, d'autant qu'i eft le plus durable, \& incerruptibled rous : carle feu, qui confume, $\&$ diminue tou les autres, l'amende, \& le rend en fa perfe otion. L'or qui a palfé plufieurs fois par le feu demeure en fa couleur, tres-fin, \& tres-pur, le.

Plin lib. 33. quel proprement fappelle (felon que Pline rap rap-3. - porte) Obrifo, dequoy fait tant de mention l'Ef criture, \& lvfage qui confomme tous les au. tres metaux (comme dit lemefme Pline) n'a moindrit aucunement l'or, \& n'y faid aucu dommage, mefme il ne fe mange, ny ne f'en. uieillit. Er encores que fa matiere \& fon corp: foit fi ferme, \& fi folide qu'il ent; il fe laifi neantmoins tellement doubler, \& tirer, qu c'eft chofe merueilleufe. Les batteurs d'or \& tireurs fçauent bien la force qu'il a de felaiffel fi fort amenuifer, fans fe rompre iamais. Tollres lefquelles chofes bien confiderees, auec au. tres excellentes proprietez qu'il a, donneron à entendre aux hommes d'entendement, pour.

ipocal. 3. quoy en l'Efcriture fainde la charité f'accomCo 2r. pare à l'or. Au refte, il eft peu de befoing de

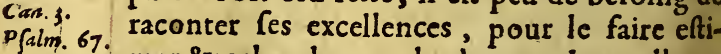
bren. 4. mer \&rechercher: car la plus grande excellence 3. Reg 6. qu'il ayt, eft d'eftre ià cogneu, comme il l'eft entre les hommes, pour la lupréme puiffance, \& 


\section{des Indes. Liure IV".}

134

grandeur du monde. Venăr doncà noftre fujet, il y a a Indes grande abondance de ce metal, \&r rçait-on par les hiftoires cerraines, que les Inguas du Peru nefe contentoient pas d'auoir de grads \& petirs vafes d'or, des cruches, des coup pes, des taffes, \& des flacós, voire des tinnes, ou gtands vaifecaux; mais aufi en auoient-ils des cháires, des brăcars, ou litriéres rout d’or maffif; \& en leurs Temples anoient mis plufieurs fta tues \& images d'or maffif, defquelles on en trou? ue encore en Mexique quelqu vnes, mais non pas en tellequantité, que quand les premiers Conquefteurs arriuerent en lon \& en l'autre Royaume qui y trolueerent de grandes richef? fes, \& en fút encor fans comparailon caché dans terre beaucoup dauantage par les Indiens. $\mathrm{Ce}$ feroit chófe qui fembleroit fabuleufe de raconrer qu ils ayent fait des fers a cheuaux dargent, fáute de fer, \& qu'ils ayent payé trois cents ef cus d'yne boureille de vin, \& autres chofes êtranges; \& toutefois en verité elles font adwenuês, voire $\&$ des chofes encores plus gtandes. 'L'on tire Por de cesparties en trois façon's \& manieres, ou à tout le moins iłay veu ver de cestrois: car il fe trouue de l'or én paille, ou pepin, del ar en poudre, \& de lor en pierre. Ils appellent l'or en pepin, de petits morceaux d'or qui fe trouuent ainfi entiers, \& fans mellange d'autre meral, lequel n'a befoing d'eftre fondu, ay affiné parle feu; \& les appellent pepins, pour ce qu'ordinairement ce font de petits motceaux comme pepins, ou femence de mellons \& cirrouiltes, \& celuy dont parie Iob quand il dit:

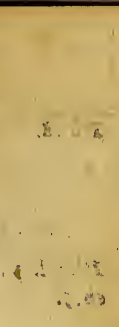




\section{Hifoirenaturelle}

20b 18. Ieueillins aurum Combien qu'il arriue quel quefois, quily en a de plus grands, \& de tels que ien ay veu qui peroient plufieurs liures cient Lexcellence \&la grandeys de ce meralfeul $\mathrm{re}$ plin. li.3. lon que pline afferme de te trouuer ainf pur ab.s. \&parfaic , chore ui naduient point a tous a tres metaux, lefquels ont toufiours de lefcime '\&du terreftre, 2 ont de befoin qu'on les afine auecle feu. l'ay yeu mefme de largent naturel, 1. enfacom mefmeil ena tautre que les Indiens appeller Papas, $\&$ quelques fois il fen trouue des morceaux detout pur \& fin, en facon de Betites racines, rondes: ce qui eft rare toutefois en cemetal, mas afley ordinaire en lior. It fe trouuc peu de cet or en pepin au refpeg des autres efpeces cerf or en pierre eft vne vene d or glu naift \& fengendre dans la mefme pierre ou caillou, comme ilay veu apx mines de Caruma augoumernement de SAllines des pierres fort grandes toutes penetres

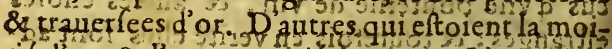
tied or \& Pautremoitic de pierre. $L^{\prime}$ or $q 41$ i f de cefe facon fe tripune en des puits on des mines, qui ontleurs veines fommed argent, mais ils font rres-difficiles du turer. Agatarchides es critauliure cinquiefmede Ia mer Erythree, ou

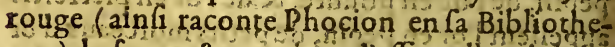
qued la façon \& maniere d'affiner or tite des pierres, de laquelle ont vfé anciennementes Roys d'Egypte, \& eft yne chofe admirable de veoir comme ce qưli en efcrit, refremble \& fe rapporte proprement a la façon dont on vis encore maintenant a raffiner ces metaux of or 


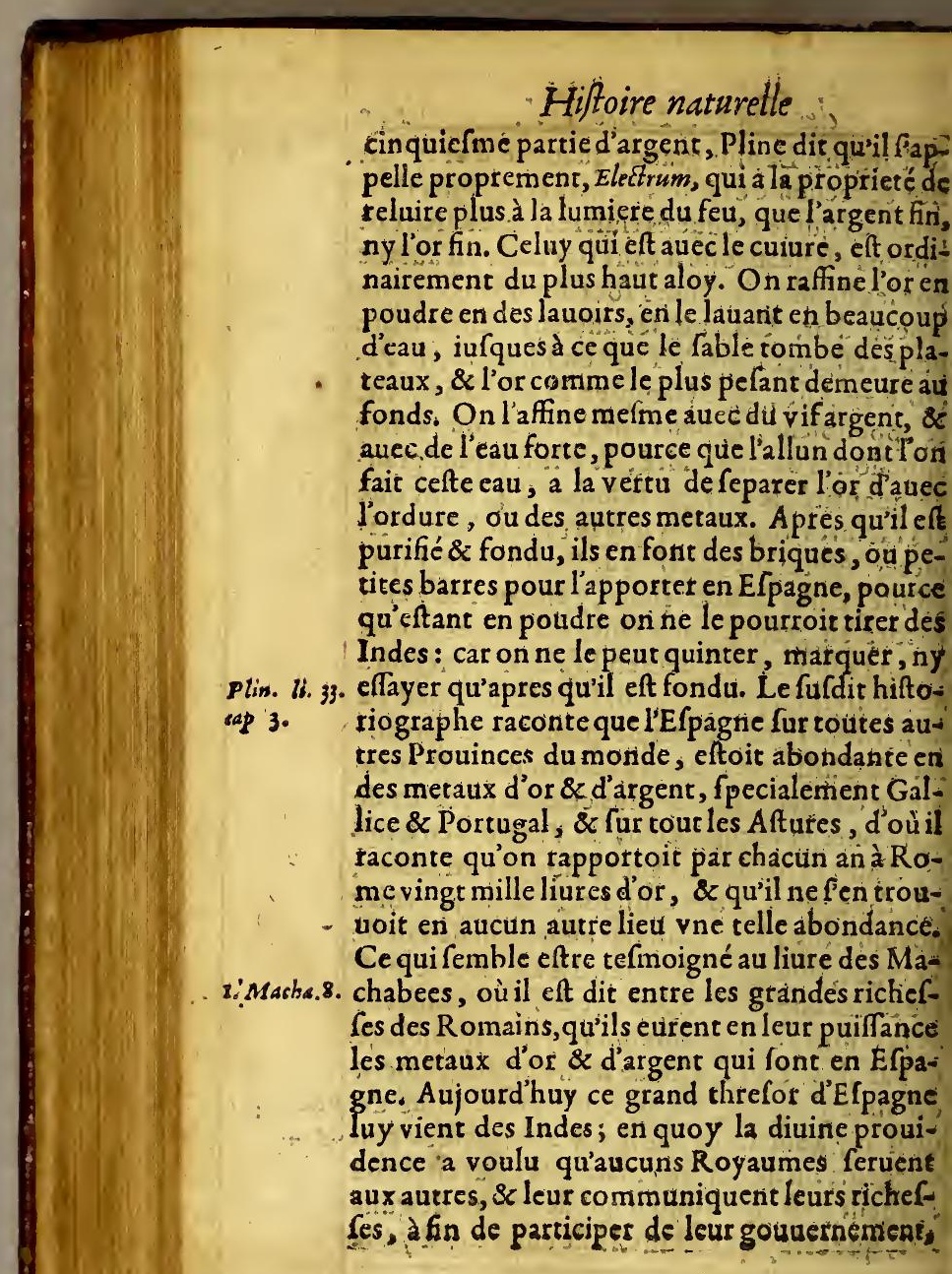




\section{des Indes. Liure $1 \mathrm{~V}$.}

our lebien des vns \& desautres, en fe comunniquant reciproquement les biens \& graces ont ils iouylfent. On ne peut bien apprecier, y eftimer le nombre \& quantité d'or que lon. pporte des Indes: mais l'on peut bien affermer ue c'eft beaucoup dauantage que ce que Pline conte qu'on apportoit chaque an d'Efpagne come. En la flotte où ie vins, qui fut l'an is 87. declaration de la terre ferme fut de douze cafons d'or, defquels chaque caffon pour le moins efoit quatre arobes, qui font cent liures peant, \& mil cinquante-fix marcs de la neute EFagne, qui eftoit tant feulement pour le Roy, ans ee qui vint pour les marchands \& particuers, eltant enregiftré, \& ce qui vint non enreifté, commel'on en apporte beaucoup. Cela uffit en ce qui touche lor des Indes : del larent nous en dirons maintenant.

\section{De l'argent des Indes.}

CHATITRE V.

2. Ors lifons au liure de Iob ces paroles: L'argent a certains cossmencemers $\sigma$ ra- $10 b$ 28:

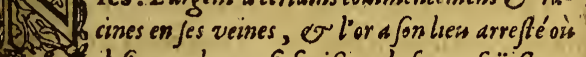
il sengendre 0 fospaißzt, le fer en foüijßant, tire de la terre, of la pierre fondue parla chaleur, $f e$ urine en cuiure. Par cela il declare en peu de paoles fort lagement, les proprietez de ces meaux, largent, l'or, le fer \& le cuiure. Nous auós it quelque chofe des lieux où l'or $f^{\prime}$ engendre, s fe congels, qui font des fufdites pierses au 


\section{Hiftoire naturelle}

profond des montagnes\& és entrailles de la rere re, ou de l'arene des rinieres; \& és lieux par où les torrents ont paffé, ou bien aux tres-hautes montagnes; lefquelles poudres d'or defcendent $\&$ f'efcoulent auec l'eau, qui eft la plus commure opinion que l'on tient és Indes. D'où vient que plufieurs du vulgaire croyent que le deluge ayant noyé toute la terre iufques aux plus hautes montagnes, a efté caufe qu'à prefent lon trouue cét or és riuieres, \& en des lieux fi élloignez. Nous dirons maintenant commel'on defcouure lcs mines d'argent, de leurs veines, racines $\&$ commencemens, dont parle Iob. Et diray en premier lieu, que la caufe pour laquelle l'on donne le fecond lieu à l'argent entre les metaux, eft pource quil approche de l'or plus que nul autre d'iceux, en ce qu'il eft plus durable, \&̇fe fent moins endommagé du feu, fe laif fant auffi manier, \& mettre en cuure plus faci.. lement que les autres, voire il furpaffe l'or en fa clarté \& rplendeur, \& au fon quili a plus clair, \& plus agreable: car fa couleur eft plus conforme, \& reflemblante la lumiere, \& fon fon eft plus penetrant, plus vif \& plus delicat. Auffi y a-il certains lieux efquels ils eftiment l'argét dauantage que non pas l'or. Toutefois c'eft vn argument \& firne, pour iuger que l'or eft pluṣ precieux de tous les metaux, en ce quil fe trouue plus raremét $\&$ que la nature fe monftre plus efcharfe à le produire, que non pas les autres, encore qu'il y ayt des terres (cómélon dit de la Chine) efquelles t'on trouue plus facilement del'or, que de l'argent mefrme. Toutefois c'eft (1) 


\section{des 7 ndes. Liure IV.}

hole plus cómune \& ordinaire, que l'on troue plus facilement, \& en plus grande abondane de l'argent, que del'or. Le Createur a poureu les Indes Occidentales d'rne fi grande rihelle d'argent, que tout ce que l'on void és hioires anciennes, \& tout ce que l'on dit des arenteries, \& minieres d'Efpagne, \& des autres rouinces, eft beaucoup moins que ce que l'on oid en ces parties. là. Les mines d'argent fe couvent communement és montagnes, \& rohes tres-hautes, \& du tout defertes, encores u’autrefois on en ayt trouué és plaines $\&$ cam. agnes. Il y en a de deux fortes differentes, les nes qu'ils appellent efgarees, \& les autres fixes $z$ arreftees, Les efgarees font des morceaux de netal qui fe trouuent amaffez en quelques enroits, lefquels eltans tirez \& leuez, l'on n'en rouue point apres dauantage. Mais les veines xes font celles qui en profondeur \& longueur nt vne fuite continuë en façon de grädes branhes \& rameaux d'vn arbre, \& quand lon en a rouué vne d'icelles, l'on en trouue ordinaireent plufieurs autres au mefmelieu. La façon e purger \& d'affiner l'argent, de laquelle ont féles Indiens, eftoit parfondure, en fondant faifant refoudre cefte maffe de metal par le eu qui iette le terreltre d'vn cofté, \& par fa orce fepare l'argent d'auecle plób, l'c ftain d'aecle cuiure, \&r les autres metaux qui fe trouent meflez. A cefte finils faifoient, \& baftifoient des petits fourneaux en lieux où le vent ouffloit le plus communement, \& auec du bois du charbon qu'ils y mettoient, faifoient leur. 


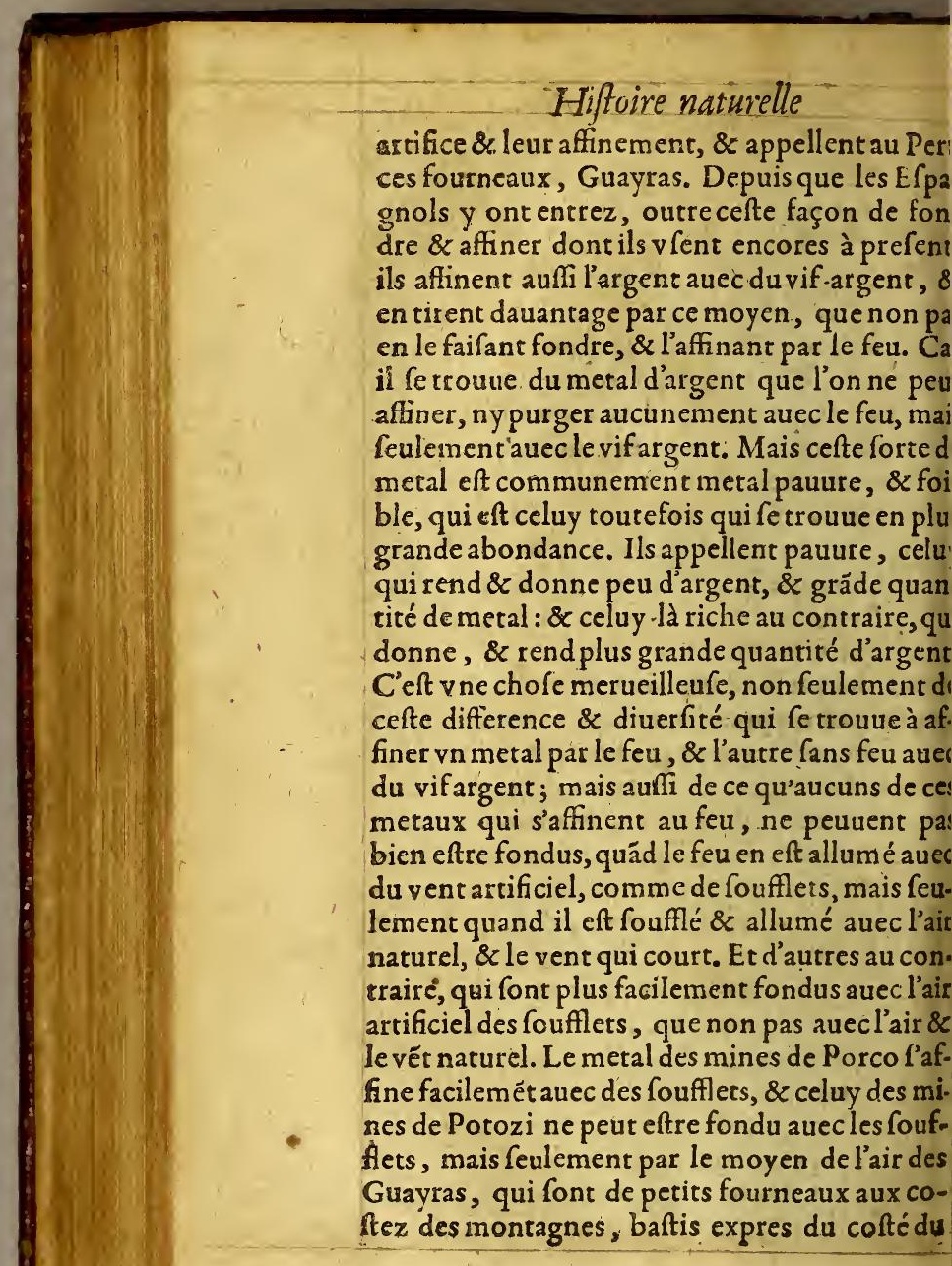




\section{des Fndes. Liure IV.}

ent, au dedans defqueis ils fondent ce metal, $x$ combien que ce foir chofe difficile de donner aifon à cefte diuerfité, toutefois elle eft toute ertaine \& approuuee par la longue experiene. Tellement que l'auaricieux defir de ce metal ant eftimé des hommes, leur a fait rechercher nille inuentions \& gentils artifices, d'aucuns lefquels naus ferons mention cy apres. Les rincipaux lieux des Indes où l'on tire l'argent, ont la neuue Efpagne, \& le Peru : mais les mies du Peru furpaffent de beaucoup les autres, $x$ entre toutes les autres du monde, celles de 'otozi, defquelles nous traicterons vn peu a oifir, pource que ce font des choles plus celeres \& plus remarquables qui foient és Indes.

De la montagne, ou colline de Potozi, \&s de $\int a$ defconnerture.

ChAPITRE VI

A montagne ou colline de Potó zi tant renotnmee, eft fituee en la Prouince de Charcas, au Royaume da Peru, diftant de l'Equinoxe vers le cofté du Sud, ou Pole Antarctiq ue, de 21. degrez 2. tiers; de forte qu'elle rombe fous le Tropique aux confins de la Zone rorride, \& toutefois cefteregion eft fort froide, voire plus que n'elt pas Caftille la vieille au roy: aume d'Efpagne, \& plus encores que la Flandre mefme, combien que par raifon elle deuft eftre chaude, ou temperee, eu efgard 2 la hauteur, \& 


\section{Hiftoire naturelle}

efleuation du pole où elle eft frtuee.' La raifon de celte fi froide temperature eft que cefte mon tagne eft fort eflenee, \& qu'elle eft agiree, \&: hantee de vents qui font fort froids, \& intermperez, Ipecialement de celuy qu'ils appellent, Thomahaui, qui eft imperueux \& tres-froid. I) regne ordinairement és mois de Iuin, Iuillet, \& Aouft. Le fonds \& terre de cefte montagne eft fec, froid \& fort mal agreable, voire du tout fte rile, qui n'engendre, ny produit aucun fruict: ny herbe, ny grain, auffi eft-il naturellement in habitable pour l'intemperature du ciel, \& la fte rilité de la terre. Mais la force de l'argent qui at. rire à foy l'auarice \& le defir des autres chofes, a peuplé cefte montagne plus qu'aucun autre lieu qui foit en tous ces Royaumes, la rendant fi abondante de toutes fortes de viandes, qu'on ine peut defirer chofe qui ne $f y$ trouue, voire en grande abondance; \& combien qu'il n'y ayt rien que ce que l'on y apporte par voiature, neantmoins les places $y$ font $f 1$ pleines de fruits, conferues, vins exquis, foyes, \& toutes autres delices, qu'il ne f'en troutue en autre endroit da. uantage. Cefte muntagne eft de couleur tirant fur le roux \& obfcur, \& eft fa façon d'vne affez agreable rencontre d la veiie, reffemblant parfaitement la forme d'vn pauillon rond, ou bien d'vn pain de fucre. Elle f'elleue, \& furpaffe toutes les autres montagnes \& collines qui font $\frac{1}{2}$ lénuiron. Le chemin par lequel on y monte, eft fort alpre, \& for roide, encor qu'on y aille tout aे cheual. Elle finit par le haut en pointe de forme ronde, \&s a en fon pied vne lieiie de circuit, 


\section{des Fndes. Liure IV.}

Ile contient depuis le fommet iufques au pied. nil fix cents vingt-quatre verges communes; efquelles reduites à la mefure des lieiies d'ECagne, font vn quart de lieiie. A u pied de cefte nontagne l'on void vne autre petite colline fui naift d'icelle, en laquelle anciennementily eu quelques mines de ces metaux efpartis, 86 ans fuitte, qui fe trouloient là comme en des ourfes, \& non pas en des veines fixes, \& coninuës, \& neantmoins elles eftoient fort riches, encores qu'elles fuffent en petit nombre. Ce petit roc eftoit appellé des Indiens, Guayna Potozi, qui veut dire, le ieune Potozi ; au pied duquel commence l'habitation des Efpagnols \& Indiens, qui font venus à la richeffe, \& à l'œuture de Potozi ; laquelle habitation peut contenir quelques deux lieües de circuit, $8 z$ toute la plus grande traitte \& commerce qu'il y ayten aucun lieu du Peru, fe faict en cefte habitation. Les mines de cefte montagne n'ont point efté foüies, ny defcouuertes du temps des Inguas, qui eftoient les Seigneurs du Peru, auparauant que les Efpagnols y entraffent, combien quils ayent foüy, \& ouuert les mines de Porco, affez proches de Potozi, n'en eftant diftantes que de fix lieiies tant feulement. La caufe en pouuoit eftre, faute d'en auoir eu la cognoiflance, combien quaucuns racontent ie ne fçay quelle fable, que comme on voulat quelques-fois ouurir ces mines, vne voix fut entenduë, qui difoit aux Indiens qu'ils n'y touchaffent pas, \& que cefte montage eftoit referuee pour d'autres. Devray, l'on n'euft als. 


\section{Hiftoire naturelle}

eune cognoiffance de Potozi, ny de fa richeffe, que iufques à douze ans apres l'entree des Ef pagnols au Peru, duquel la defcouuerture f'en fift en cefte façon. Vn Indien appellé Gualpa, de la nation de Chumbibilca, qui eft vne Prouince de Cufco, allant vn iour à la chaffe \& pourfuite de quelque venaifon, \& cheminant vers la part du Ponent, où la befte feretiroit, commença de courir à mont le roc = qui pour lors eftoit couuert, \& planté pour la plus-part de certains arbres gu'ils appellent, $Q$ uinua , \& de buiffons fort efpais, \& comme il f'elleuoir pour monter en vn paffage quelque peu alpre $\&$ difficile, fut contraint mettre la main en vnebranche qui fortoit de celte veine d'vne mine d'argent (à laquelle depuis ils ont donné le nom de riche) qu'il arracha, \& apperceut en la foffe \& racine d'icelle, le metal qu'il recogneut eftre fort bon;, par l'experience qu'il auoit de ceux de Porco; puis ayant trouué en terre, ioignant cefte veine, quelques morceaux de metal qui f'eftoientrompus \& departis d'icelle, fans tourefois qu'on les peuft bien cognoiltre à caufe que leur couleur eftoir changee, \& gaftee du foleil $\&$ de leau, il les porta à Porco effayer par Guayras (qui eft efprouuer le metal par le feu) \& ayant recogneu par là fa grande richelfé, \& heureufe fortune, fouyffoit, \& tiroit fecrettement cefte veine, fans le communiquer, ou en parler à perfonne, iufques à ce qu'vn Indien, nommé Guáca, natif de la vallee de Xaura, qui eft aux limites de la Cité des Roys, lequel dereurant au lien de Porco, proche voifin de ce 


$$
\text { des Indes. Liure IV. } \quad{ }_{140}
$$

alpa, Chumbibilqua fapperceut vn iour qư'it foit quelque affinement, \& qu'il faifoir de us grands fomons \& briques, que celles qu'on ifoit ordinairement en ces lieux, pource mefe qu'il augmentoit en defpenfe d'habits, ayant fques alors vefcu affez pauurement. Pour cee occafion, \& que ce metal que fon voifin affioit \& mettoit en œuure, eftoir different de cey de Porco; il penfa de defcouurir ce fecret, \& It tant, que combien que l'autre tinft fon affaifecrette autant qu'il luy eftoit poffible, neantoins par importunité fut contraint de le meer au roc de Potozi, ayant defia paffé 2. mois $n$ la iouyffance de ce riche threfor. Et lors l'Inien Gualpa dit à Guanca qu'il print pour fa part ne veine qu'il anoit defcouuerte, laquelle eftoit roche de la veine riche, \& eft celle que l'on ap: elle aujourd'huy, la veine de. Diego Centeno, ui n'eftoir pas moins riche, mais feulemét plius lure à foüir, \& plus difficile à tirer. Par ainfi out d'vn accord partirét entr'eux le rocle plus iche du monde. Il aduint du d'epuis que l'Intien Guanca trouuant quelque difficulté à foüir \& cauer fa mine qui eftoit tres dure, \& l'autre Gualpa ne luy voulant faire part de la fienne, eurent debat enfemble, \& pour cefte caufele Guanca de Xaura irrité de cela, \& de quelque autre thofe, alla defcounrir cefte affaire à fon maitre qui fappelloit Vuillaroel, Efpagnol, qui lors refidoit aे Porco. Ce Vuillaroel en vouslant cognoiftre la verité, alla en Potofi, \& trouuant la richeffe que fon Yanacona, ou feruiteur luy auoir dir, fift enregiftrer l'Indien Guancas. $S$ iiij 


\section{Hiftoire naturelle}

feftaquant auec luy à la fufdite veine, qui fu dite Centeno; ils appellent cela eftaquer, qu vaut autant que fignaler, \& remarquer pou foy la mine, \& autant d'elpace que la loy conce de \& permet à ceux-là qui trouuent yne mine ou bien à ceux qui la fouylfent; au moyen de. quoy apres l'auoir monftree $\&$ defcouuerte à luftice, ils demeurerent Seigneurs de la mine, pour la fouiir, \& en tirer l'argent, comme de leur propre, en payant feulement au Roy fon droict de cinquiefme. De forte que le premies enregiftrement \& declaration que l'on fift des mines de Potozi, fut le vingt-vniefme iour du mois d'Auril, de l'an 1545 . au territoire de Porco, par lefdits Villaroel Efpagnol, \& Guanca Indien. Incontinent apres lon defcouturit vne autre veine, qu'ils appellent veine d'eftain, qui a efté tres-riche, quoy que rude \& laborieufe à y trauailler, pour eftre fon metal auffi dur que le caillou. Du depuis le trentiefme iour d'A ouft, au mefme an de quarante-cinq, $I_{2}$ veine appellee Mendiet3, fut enregiftree, qui font les quatre principales veines de Potozi. Ils difent de la veine riche, la premiere qui fut defcouuerte, que fon metal eftoir hors terre la hauteur d'vne lance en façon de tochers, foufleuant la fuperficie de la terre, comme vne crefte de trois cents pieds de longueur, \& de treze delarge, \&z que cela demeura defcouuert $\&$ defcharné par le deluge, ayant cefte veine, comme la partie la plus dure, refifté à la force $\&$ impetuofité des caux. Son metal eftoit fi riche, quill y auoit la moitié d'argent, \& continua cefte veine en fa richeffe 


\section{des Indes. Liure IV.}

fques à cinquante \& foixante ftades, à la hauur d'vn homme de profondeur, où elle vint defaillir. De cefte façon furent defcouuertes $s$ mines de Potozi par la prouidence diuine, quelle a voulu pour la feliciré d'Efpagne, que plus grande richefle qu'on fçache, \& qui izais ayt efté au monde, fuft cachee pour vn mps, pour la defcouurir au temps que l'Emereur Charles le Quint, de glorieufe meinoi, tenoir l'Empire, Ies Royaumes d'Efpagne, Ia feigneurie des Indes. Incontinent apres ue la defcounerture de Potozi fut cognuë aux oyaumes du Peru, plufieurs Efpagnols, \& refque la plus-part des bourgeois de la Cité Argent, qui eft à dixhuict lieuës de Potozi, indrent pour y prendre des mines, mefmes y indrent plufieurs Indiens de diuerfes Prouines, \& fpecialement les Guayzadores de Porco, qu'en bref temps ce fut la meilleure \& plus rande habitation de tout le Royaume.

e la richefJe que l'on a tirée \&o tire chacun iour du roc ou montagne de Potozi.

Chapitre VII.

17y efté plufieurs fois en doute s'il fe 20 trouuoit aux hiftoires des anciens vne 2 L fi grande richeffe de mines, comme e celles que nous auons veuës de noftre empsau Peru. S'il ya eu iamais au monde des aines riches \& renommees pour cét effect, ce 


\section{Hiftoirènaturelle}

ont efté colles d'Efpagne, dont les Carthaginoi ont ioüy, \& $\mathrm{c}$ du depuis les Romains : lefquelles comme iay dit, ne font pas feulement eftimee: \& renommees par les liures profanes, mais auf fi parles Efcrirures fainctes. Celuy qui plus par ticulierement faict mention de ces mines, at moins que iaye veu, eft Pline, qui efcrit ainfi er PEin.i3.33. Con hiftoir e naturelle: Il fe trourue del'argent prefqu en toutes Prouinses, mais celuy d'Efpagne eft le meilleun de tous, lequel croift $\sigma$ s'engendre en vne terre ferile, aux mantagnes $\mathcal{O}$ rochers, $\mathcal{O}$ est chofe cerraine $\mathcal{O}$ infaillible qu'és lieux air l'on a vne fois defcourcert aucunes de ces vernes, il $y$ en a d'autres qui n'en font gueres efloigrees: cequife troure anß $\beta$ i. prefque en tous autres metaux, $\sim$ pour cela les Grecs (a mon aduis) les appellerent metaux. C'est vne chofe eftrange, que les prits ou trous de ces mines d'E Epagne, lefquels on commença d fouyr du temps de Hannibal, Se vigyent encor à prefent, $\mathcal{O}$ retiennent encor les mefmes noms de ceux qui les defcousurivent. Entre ces mines, celle que defcoururit Bebel lo, qui en retient le nom encor awiourd'buy, fut fort re*ormmee, o dit-on qu'elle donnott or rapportoit fi grande richeffe à fon maistre Hannibal, que chaque iour low recuetloit trois cens liures d'argent, $\mathcal{F}$ iufques à maintcnant on toufrours continué de trauailler à ceste mire, de telle forte qu'elle eft à prefent de mil cinq cens pas de profondeur caure en la montagne. Defquels puirs neantmoins cefte grande profondeur, les Gajcons qui y trausillent tirent leau quils $y$ trounent pour les affeGenebravdus in Chronographia. cher, or y cauer mieux à leur aife, tout durant le temps que les chandelles of la lumiere leur durent, en telle abondance gri'il femble que ce qu'ils en inttent foit une riusiere. Iufques icy font les paroles de Pline, que iay 


\section{des Indes. Liure IV.}

142

uluicy reciter de mot à mot, pour contendauantage ceux qui entendent que c'eft de ines, voyant que la mefme chofe qu'ils expenentent auiourd'huy, a efté excercee parles ciens. Et certainement la richeffe de cefte ne d'Hannibal aux monts Pyrenees, eftoit ande \& bien remarquable, laquelleles Roins poffederent, y ayans continué fon ouuraiufques au temps de Pline, qui fut comme is cens ans. La profondité de cefte mine oit de mil cinq cens pas, qui eft vn mil \& de, \& fut fi riche au commencement, qu'elle loit à fon maiftre par chäcun iour trois cens res, de douze onces la liure. Mais combien e cefte richeffe ayt efté grande, elle n'approe neantmoins à celle qui de noftre temps It retrouuee en Potozi. Car comme il appert les regiftres de la maifon de la contractan de cefte Prouince, \& comme plufieurs mmes anciens dignes de foy l'atteftent, au nps que le Licentié Pollo gouuernoit cefte ouince, qui fut plufieurs annees apres la defuuerte de cefte montagne, l'on enregiftroit tiroit pour la cinquiefine, chacun Samedy, at cinquante \& deux cens mil pezes, dont le quielme reuenoit a trente $\&$ quarante mil es, \& pour chacun an vin million \& dem ys peu moins. Tellement que fuiuant ce con'on tiroit chaque iour de cefte mine, comtrente mil pezes, dont il reuenoir an Roy ur la cinquiefme, fix mil pezes pariour. Il y a cor vne chofe à metre en auant, pour moner la richeffe de Potozi, que le conte quia 


\section{Hiftoire naturelle}

efté faiot, n'eft feulement que de l'argent qui marquoit \& quintoit, \& eft chofe cognuë: Peru, quel'on a vfélong temps en ces Koyar mes d'argent qu'ils appelloient, courant, lequ n'eftoit marqué ny quinté. Et tiennent pol certain ceux qui cognoiffent ces mines, qu'c ce temps, la plus grande partie de l'argent qu lon tiroit de Potozi, ne fe quintoit point, ? eitoit celuy qui auoit cours entre les Indien. \& beaucoup entre les Efpagnols, comme l'ay veu continuer iufques à mon temps. $\mathrm{P}_{\text {i }}$ cela l'on peut bien croire, quele tiers de lar. cheffe de Potozi, voire la moitié ne fe manife ftoit, ny ne fe quintoit point. Il y a encor vn autre confideration plus remarquable, en $c$ que Pline met quel'on auoir fouy mil cinq cer pas en cefte mine de Babello, \& que toufiour Ion trouuoir de l'eau, qui eft-ce qui donnel plus grand empefchement qui foit à tirer ] metal des mincs. Mais en celle de Potozi, en cor que l'on y ayt fouy \& caué plus de deu cens ftades ou hauteurs d'vn homme en pro fondeur, iamais on n'y a trouué d'eau, qui el le plus grand heur de cefte montagne. Mai quoy? les mines de Porco, dont le metal e trefbon \& tref-riche, font auiourd'huy delail fees pour l'incommodité de l'eau qu'ils y on rencontree en y fouyffant. Pour ce que ce fon deux trauaux infupportables en recherchant 1 metal, de cauer $\& z$ rompre les roches, $\&$ d'e tirer l'eau tout enfemble. Le premier defquels à fçauoir de caüer la roche, donne affez de pei ne, voire eft trop dur \& trop exceffif. Finale 


\section{des Indes. Liure IV.}

ent auiourd'huy fa Majefté reçoit pour fon int par chacun an, l'vn portant 'lautre, vn milin de l'argent des mines de Potozi, fans l'aue richeffe, qui luy vient de vif-argent, $8 \mathrm{z}$ at es droicts Royaux, qui eft vn grand threfor. uelques hommes experts ayans fupputé les intes, difent, que ce que loon a apporté à quinr en la cafre, ou douiane de Potozi, iufques en in mil cinq cens quatre vingts cinq, fe monse cent millions de pezes d'effay, dont chaque ze vaut treize reaux \& vn quart, fans conrer irgent que l'on a peu tirer fans quinter, \& qpi efté quinté és autres caffés Royalles, \& Cans argent courắt que lon a mis en œuure aui päis, ain'eft point quinté, qui eft vne chofe innomrable, combien que les premiers regiftes des aints nefoient pas fi clairement, ouintelliblement efcrits, que font ceux d'autiourd'huy: our ce quaux commencemens, \& premiees defconuertes, l'on faifoit la recepre par Roaines, tant eftoit grande l'abondance quility n auoit. Mais par les memoires \& recherches uefifte Viçeroy Dom Francifgue de Tollee, en lannee mil cinq cens roixante \& qusorze, fe trouua qu'il y auoit foixante $\&$ feize nillions, iufqu'en ladite annee, \& depuis leit an iufques à celuy de quatre vingts cinç inlufiuement, il apperr par les regiftres Royaux u'il s'ef quinté iufques à trenze cinq̨ millions. Con enuoya au Viçeroy ce conte de Potozi, I'an que i'ay dit, lors que i’eftois au Peru, \&r lu depuis la richelfe qui eft venuë aux flotes dus eru, eft monree a beaucoup dauantage. En la 


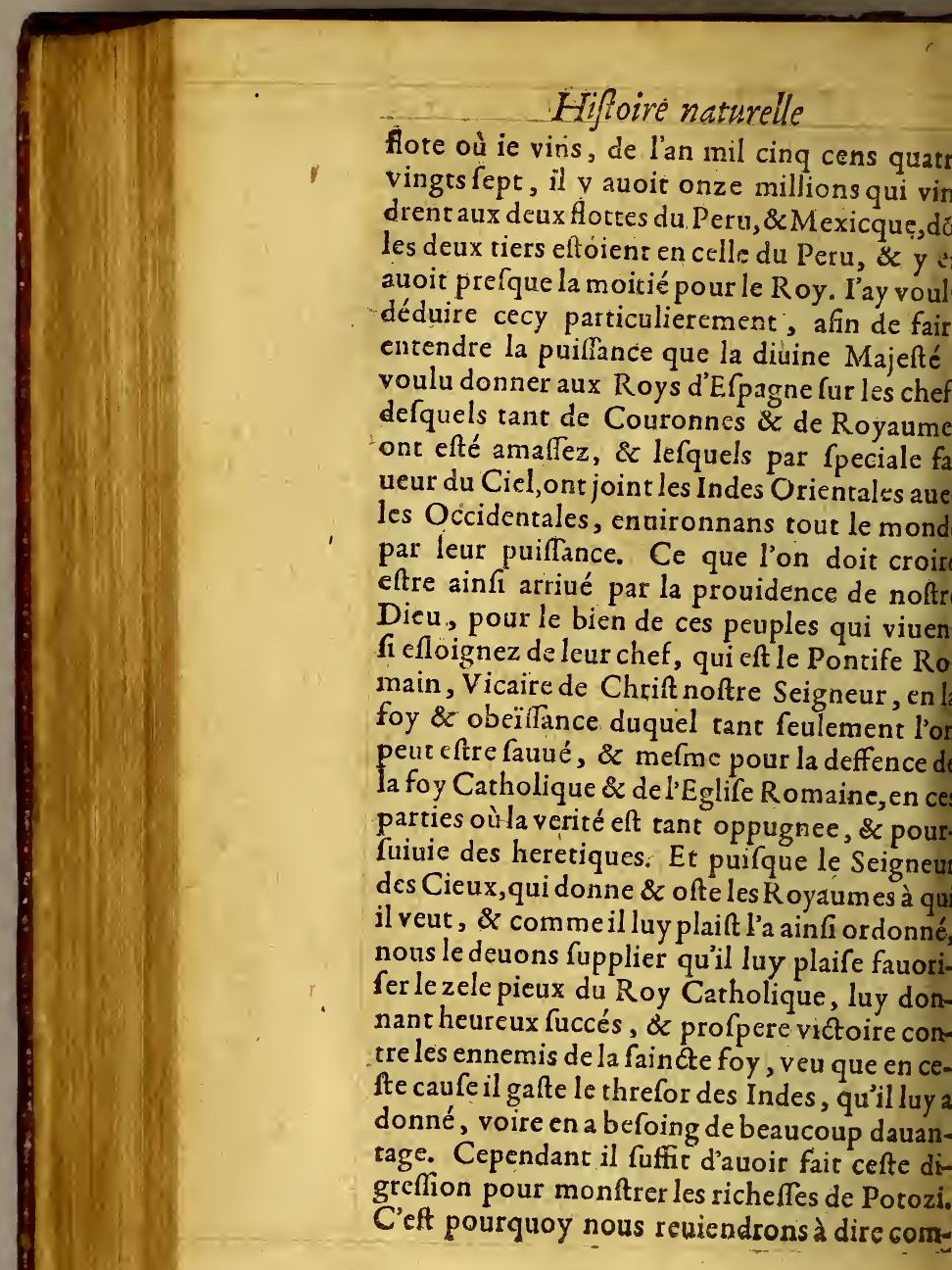




\section{des Indes. Liure IV. $\quad 144$}

e lon rrauaille és mines, \&z.comme l'on affine metaux que Ton en tire.

Comme l'on trauaille és mizzes de Patozi.

\section{Chap. VIII.} Oëce fe plaignant du premier inuen- Boütass de Hens primus, quis furt alle, Auri ponders tefi.

Gemmá gque, latere volentes, Preciofa pericula fodit? consfolass. ec raifon, il les appelle precieux dáger, pour grand trauail \& peril auec lequell'on tire les etaux, que les hommes eftiment tant. Pline qu'en Italie il y a plufieurs metaux, mais que Plin. $236.33^{\circ}$ sap. 4 . anciens ne youlurent pas permettre d'y trailler, afin de conferuer le peuple. Ils apporient ces metaux d'Efpagne \& faifoient crailler les Efpagnols aux mines, comme rribuires. L'Efpagne en fait auiourd'huy tout de efme aux Indes, ence que y ayant \& reftane ns doute en Efpagne plufieurs minesde meux, neantmoins ils ne les veulent pas cherer, ny permettre qu' on y trauailie, à caufe des cóueniens, que l'on y voit chacun iour : mais les font apporter des Indes, ou on les tirs ec beaucoup de trauail, \& rifque. Ce roc de tozi contient en foy, comme i'ay dit, quatre 


\section{Hiftoire naturelle.}

veines principales, qui font la veine riche, cel le de Centeno, celle d'E.ttain, \& celle de Men dieta. Toutes ces veines font en la partie Orien tale de la montagthe, comme regardans le leue du Soleil : car en l'Occidentale il ne s'en trou ue aucune; Lefdictes veines courent Nort \& Sud, qui eft de Pole en Pole. Elles ont à l'en. droit le plus large fix pieds, \& au plus eftroi: vne paulme. Il y en a d'autres de diuerfe façor qui fortent d'icelles veines, comme les grand: rameanx des arbres, ont de couftume d'en pro. duire de petits. Chaque veine a diuerfes mine: qui font parties ou portions d'elle-mefme, di. ftinctes, \& feparees entre diuers maifres, des noms defquels elles font ordinairement appel. lees. La grande mine contient quatre vingts verges, \& ne peut contenir dauantage par l'or donnance, \& la moindre en contient quatre. Toutes ces mines font auiourd'huy forr profondes. L'on conte en la veine riche foixante $\&$ dixhuict mines, qui font profondes de quatre virgts \& cent ftades, ou hauteurs, d'hommes, voire en quelques endroizts iufques à deux cens. L'on conte en la veine de Centeno vingt quatre mines, dont quelques vnes s'aduancent iufques à feptante ou quatre vingts ftades, de profond, \& ainfi des autres veines de cefte montagne. L'on inuenta pour remede a cefte grande profondité,des mines qu'ils appellent focca. bones, qui font caues ou mines faictes au pied de la montagne, lefquelles vont trauerfant iufques à rencontrer les veines. Carl'on doit entendre, que coobien que les veines courentNort, 


\section{des Indes. Liure IVt.}

Sud, comme il a efté dit, neantmoinis c'eft en bailfant depuis le fommet iufques au pied \&c is de la montagne, qui fera felon qu'on croit ar coniecture, plus de douze cens ftades. Et à conte encor que les miness'eftendent'en telprofondeur, il refte neantmoirs encore plus fix fois autant d'efpace, iufquesà leur fonds racine, laquelle, felon qu ils difent, doit eft te es-riche \& abondante, comme le tronc \& la urce de toutes les veines. Combien que iufiauiourd huy nous ayons veu le contraire par zperience, car tant plus haute $\&$ esleuee êft la ine da fuperficie de la terre, tant plus fe trouriché;plus aufsi qu'elle va en profondeur, l'on ouue fon metal plus pauure, \& moindre d'aly. Cependant ils inuenterent les Soccabons, ir lefquels on entre \& fort aifement, pour trailler aux mines, auec moins de couft, de peine de danger. Ils ont huict pieds de largeur $\&$. e fade de hauteur, \& les ferment auec des ortes; L'on tire par iceux lés metaux fort faciment, en payant au proprietaire du Soccabon, cinquiefme de touit le metal que l'on zire par eluy. Il y en a defia neuf de faicts: $\&$ autres que in a commencéa faire. L'on fut vingt neuf ans faire vn Soccabon, qu'ils appellent, du venin; i va fe rendre $\&$ donner à la veine riche, ayant té commencé en l'an mil cinq cent cinquañte, inziefme annee de la defcounerte; \& acheué en n mil cinq cèns quatre vints cinq, l'vnfiefme auri!; Ce Soccabon rencontra la veine riche, $i$ ente cinq ftades pres de la fource ou racine, \&z uoit de là où il rencontra la veine iufques at

$$
\text { r }
$$




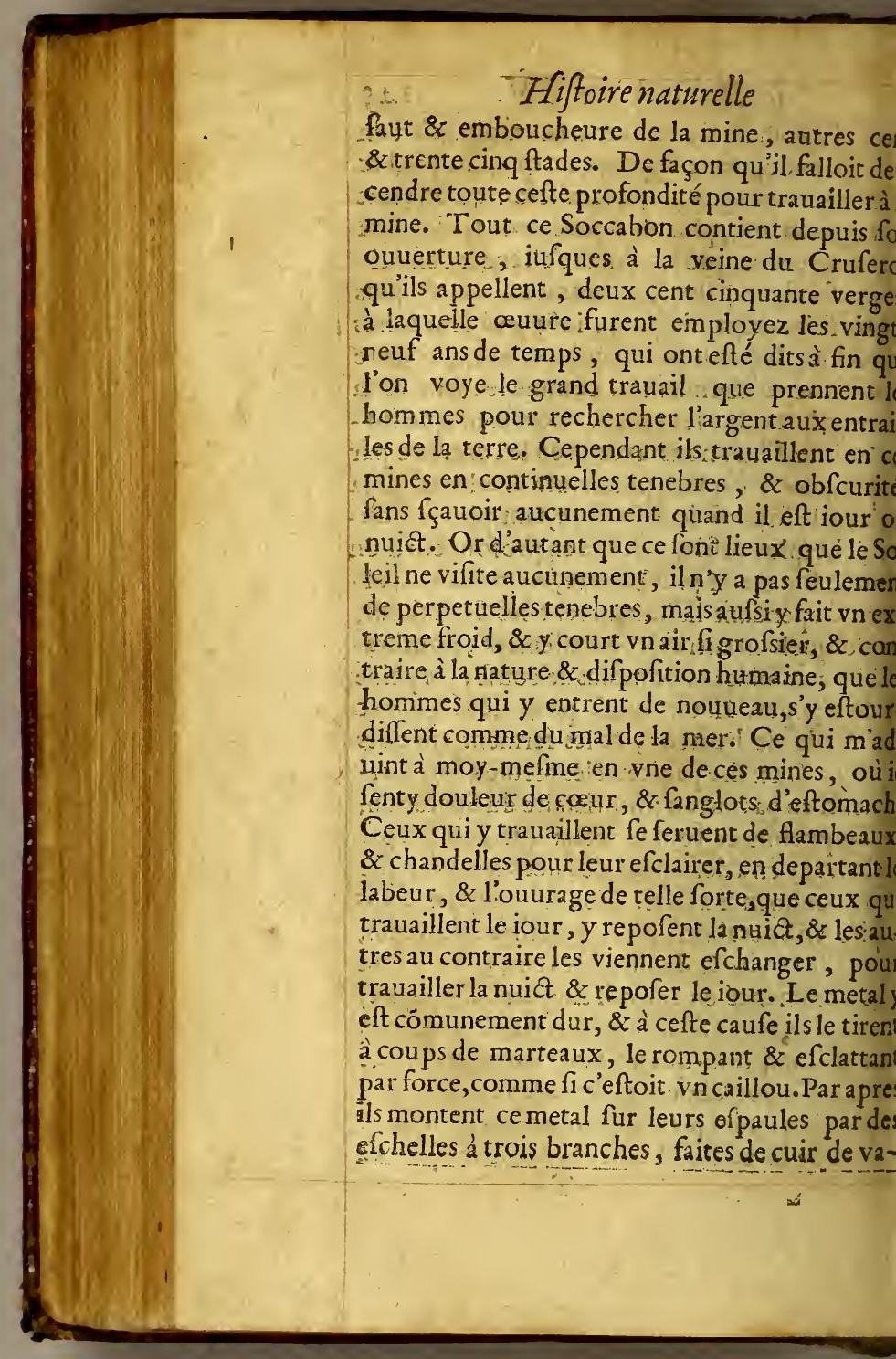




\section{desfndes. Liure IV.}

I 46

he retors, comme pieces de bois, qui font traerfees d'efchellons de bois : de forte qu'en chaune de ces efchelles, l'on y peut monter \& defendre tout enfemble. Ces efchelles font lonues de dix ftades, \& à la fin d'icelles en recomaéce vne autre de la mefme longueur, commenant of \& finiflant chaque efchelle à des eitalies \& , plattes formes de bois, où il y a desifie es, \& lieux pour fe repofer, comme galleries; autaht qu'il y a plufieurs de ces ef chelles a nonter, bout à bout. Vn homme y porte ordiairement, fur fesefpaules, le poids de deuxarobes de metal, auec vne toille attachee, en açon d'vne hotte, \& y montent troisà trois. $\mathrm{Ce}$ uy qui va deuant, porte vne chandelle attachee fon poulce: car comme il eft dit, il n'y a nulle umiere du Ciel, \& vont fe tenansà l'efchelle es deux mains pour monter fi grande efpace de auteur, qui furpaffe communement cent ciriuante ftades de hauteur, chofe effroyable, $\&$ ui donne l'efpouuente feulement à y penfer ant eft grand le defir d'argent, pour la recherhe duquel les hommes endurent tant de traail. Et certes ce n'eft point fans raifon que line traittant de cefte matiere, s'exclame \& dit infi: Nous entrons infques aw $x$ éntrailles de la terre, $\mathscr{O}$ llons pourfuiuant les richeffes infanes aux lieux descon- Plin. in amne 7. Et par apres au mefime line, il dit protm.l. 32 i:Ceux qui recherchent les metaux, font les ceusuresplus ue de geants, faifans des trous, $O$ ruettes an proind dela terre, perceans les montagnes fi auant, $\sigma$ iprofondement, à la luewr des chandelles, oì leiour I ij cap. 6 . 


\title{
Hifoire naiurelle
}

- la nuidt font sëblables, of en plufieurs mois ne voyen awiour, d'oi bren founent il adurient, que les parois de mines fondent $\sigma$ tombent, accablans deffoubs plufseur des miniers quily trawaillent. Et en aptes il adioufte Ils entament la roche dure, auec des marteaux de fer,pe. fants cent cinquante lusres, $\mathcal{O}$ tirent les metaux fur leur: e paulles, trausaillans de iour $\sigma$ de nuilt, les vns de fquel. baillent leur charge aux autres, o tout cela eft en obfow. rité, puifque les derniers feulement voyent la lumiere. Aisec des coings de fer, $\sigma$ des marteaux ils rompent les caillous, tant durs, o forts qu'ils foient, pource gue ha faim de l'argent eft encor plus a jpre, o plus forte. Cela eft de Pline, qui encor qu'il parle comme hiftoriographe d'alors, neantmoins femble prophete d'auiourd'huy. Et n'eft moindre ce que Phocion d'Agatharchides raconte du grand trauail qu'enduroient ceux, qu'ils appelloient Chryfios à tirerl'or, pource que comme le fufdit autheur dit, l'or \& l'argent donnent autant de trauail à le tirer \& rechercher, comme il apporte de contentement eftant poffedé.

\section{Comme l'on affine le metal d'argent}

\author{
CHA PITRE IX.
}

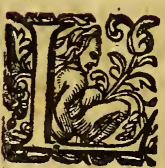

Es veinesquei'ay dit, où l'on troüue l'argent, courent ordinairement entre deux rochersqu'ils appellent la chaffe, dontl'vn d'iceux a accouftumè d'eftre tres-dur comme cailEceles 3. lou, \& l'autre mol \& plus facile à rompre. Tout 


\section{des, Indes. Liure. IV.}

metal ne fe trouue pas toufiours efgal \& d've mefme valeur. Car il y en a vne mefme veine, 'vne forte fort riche,qu'ils appellent Cacilla, ou 'acana, d'où l'ó tire beaucoup d'argét , \& l'aue eft pauure, duquel l'on tire peu d'argent. Le etalle plusriche de cefte montagne eft de cou. ur d'ambre, \& apres celuy qui tire le plusfur noir. Il y en a d'autre, qui eft comme roux, autre femblable à la couleur de cendre: en omme de plufieurs \& diuers couleurs, \& femleà ceux qui ne les cognoiffent point que ce bient des pierres de nulle valeur. Mais les miiers cognoiffent incontinent fa qualité \& fa per Etion, par certains fignes \& petites veines, qu'ils voyent. On porte tout le metal que l'ontire es mines, fur des mottons du Peru, qui feruent 'afnes à porter aux moulins. Le metal le plus rihes'affine en le fondant dedans ces pétits foureaux que i'ay dit, qu'ils appellent Guayras: car eftuy eft le plus plombeux, pour raifon dequoy len eft plus facile à fondre, aufsi pour le mieux ondre; les Indiens y iettent ce qu'ils appelent Soroche, qui eft vn metal fort plombeux, \& e metal eftant en ces fourneaux, l'ordure \& le erreftre, par la force du feu, demeure en bas , \& e plomb, \& largent fe fondent de telle faon, que l'argent eft porténageant fur le plomb, ufques à ce qu'il foit purifie, puis a pres ils raftient encor plufieurs fois ceft argent par cefte naniere de fondeure. L'on a accouftume de tid'vn quintal de metal, trente, quarante; voire cinquante pezes d'argent, \& toutesfo's i'ent ay veu d'vne forte quel'on me monitsa parexI iij 


\section{Hiftoire naturelle}

cellence, duquel l'on tiroit en le faifant fondre de cefte façon, deux cens, voire deux cens cinquante pezes d'argent du quintal, richeffe vrayement rare \& prefque incroyable, fi par le feu nousn'en auionsveu l'experience, mais tels metaux font fort rares. Le pauure metal eft celuy qui d'vn quintal rend deux ou trois, cinq ou fix pezes, ou peu dauantage. Ce metal ordinairement n'eft point plombeux, mais eft fec: c'eft pourquoy l'on ne le peut affiner par le feu. Et pour cefte raifonil y auoit en Potozi vne grande quantité de ces pauures metaux, defquelsl'on ne faifoir pas grand eftat, \& eftoient deiettez comme la paille \& comme l'efcume des bons metaux, iuf quesà ce que l'on mit en auant le moyen d'affiner auec le vifargent, paf le moyen duquel cefte efcume qu'ils appelloient. Oquiache, fut de grand profit. Car le vif argent par vne eftrange \& merueilleufe proprieté purifie l'argent, \& eft propre pour ces metaux qui font fecs \& pauures, efquels toutesfois il fe confume moins de vif årgent, que non pas és riches : car tant plus ils font riches, plus ils ont befoin de vifargent. Auiourd'buy la fáçon d'affiner, qui eft la plus commune \& plus exercee en Potozi, eft, celle qui fe fait par le vif argent, comme aufsi és mines de Cacatecas \& autres de la neuue Efpagne. Il y auoit anciennement aux flancs \& aux fommets de Potozi plus de fix mil Guayras, quifont ces petits fourneaux où l'on fond le metal, lefquels eftoient pofez en façon de luminaires, tellea ment que c'eftoit vn plaifant fpectacle de les yoir de nuict, \& iettoiết la lumiere fi loin, qu'ils 


\section{desIndes. Liure. IV. I 48} mbloient n'eftre "qu'vn brafier ou flamme de u. Mais auiourd'huy pour le plusqu'on y en: ouue, c'eft deux mil, d'autant que comme i'ay at,ils vfent peu de la fonte, mais affinent auec vifargent qui eft de plus'gräd profit. Et pour. que les proprietez du vifargent font admirales, \& que cefte maniere d'affiner l'argent eft irt remarquable, ie traitteray du vif argent, e fes mines $\&$ ouurage, \& ce qui femblera conenable à ce fujęt.

DesproprieteZ merueilleuses du vif argent.

CHAPITRE, X.

39 9 Evif argent ainfi appellé par lés 1 Latins, pour-ce qu'il coule \& 10 $\mathrm{fe}^{2}$ gliffe viftement d'vn lieu en (N) autre,entre tous les metaux a de grandes \& merueilleufes pro-" prietez. La premiere, que combien que ce Coit vn vray metal, fi eft ce toutes-fois qu'il 'eft pas dur, \& fi n'a point de forme arreftee, ny de confiftance comme les autres metaux, mais il eft liquide \& coulant, non pas. comme l'or \& l'argent fondu, ains de fa propre nature; combien qu'il foit vne liqueur, il eft neantmoins plus pefant qu"aucun autre metal: cieft pourquoy tous lesautres nagent deffus $\&$. ne vont point au fond, d'autant qu'ils font plus legers. I'ay veu mettre en vn baril de vif argent doux liures de fer, lefquelles nageoient deflus

$$
\text { I iiij }
$$




\section{Hiftoire naturelle}

plin. tib. 33. comme fair du bois ou du liege fur l'eau. Plin f.:P.6. met vne exception à cela, difant que l'or tan feulement s'y enfonce \& ne nage pas deffus : it n'en ay pas veu l'experience, mais parauentur cela procede de ce que le vif argent naturellement circuit l'or \& le cache dedansfoy, qui ef vne des plus importantes proprietez qu'il ait Car il s'attache a l'or d'vne façon merueilleufe, le cherche \& le va trouuer là où il le fent, \& ce non feulement, mais aufsi il l'enuironne \& le ioint de telle façon, qu'ille defpoüille \& fepare dequelconque metal \& autre corps où il foit mesle. Pour cefte raifon ceux-lá prennent de l'or qui fe veulent preferuer du dommage \& des incommoditez du vifargent. L'on s'eft feruy pour donner remede à ceux, ès oreilles defqueis on auroit mis du vif argent pour les faire mou riir feçretement, de certaines petites platines d'or qu'on leur mettoit és oreilles, à caufe de la vertư qu'a l'or d'attirer le mercure. Et par apres ils tiroient les platines toutes blanches du vif argent quis'y eftoit attache'. Eftant vn iour a $\mathrm{Ma}_{2}$ dril allé voir les ourages exquis que Iacomo de Treço, excellent ouurier Milannois faifoit pour fainct Laurens le Royal, il aduint que ie m'y trouuay le iour qu'ils doroient quelques pieces d'vn contre-table qui eftojent la bronze, ce qui fe fait auec vif argent. Et d'autant quela fumeo du vif argent eft mortelle, il me dift que les ouuriers fe preferuoient de ce venin en prenant va doublon d'or roullé qu'ils aualloient, lequel eftant en l'eftomac attiroit à foy tout le vif argent quileur entroit en fumee par les yeux, par 


\section{des Indes. Liure. IV.}

s oreilles, par les narrines \& par la bouche, $8 e$ ar ce moyen fe garantiffoient du dommage duif argent que l'or attiroit ainfi en l'eftomac, iettoient en apres le tout auec les excremens, hofe certes digne d'admiration. A pres quele firgent a purifiél'or, \& qu'il l’a nettoyé \& urgé des autres metaux, \& de tout meslange, eft feparé luy-mefme d'aueclor fon amy par chaleur du feu,lequel le laiffe du tout purifié fans vif-argent. Pline dit que par certain art inuention l'on feparoit l'or d'auecle vifarent, toutesfoisiene voy point qu'auiourd'huy on vfe de tel art, \& me femble que les anciens ont point fceu \& entendu que l'argent fe euft affiner auec du vif argent, qui eft ausurd'huy le plus grand vfage \& principal pro$t$ du vif argent, pour ce qu'il dir expreffément ue le vif argent ne fe ioint à aucun autre metal 'u'à l'or, \& lors qu'il fait mention d'affiner l'arent il ne parle feulement que de la maniere de ondre, d'où l'on peut inferer que lesanciens iont point cogneu ce fecret. A la verité iaçoit u'entre l'or \& le vif argent il y ayt vne amitié fympathie, neantmoins là où le vif argent ne rouue point d'or, il fe va rendre a l' argent $\&$ e ioint auec luy, bien que ce ne foit pas de telle açon qu'il fait auec l'or. Mais en fin ille netoye, ille fepare d'auec la terre, le cuiure \& le plomb, parmy lefquels s'engendre l'argent, fans quil foit befoin de feu pourle raffiner par fondure, encor quil fe faille feruir du feu pourle Teparer d'auec l'argent, comme ie diray cy dh pres. Le vif argent ne tient conte des autres 


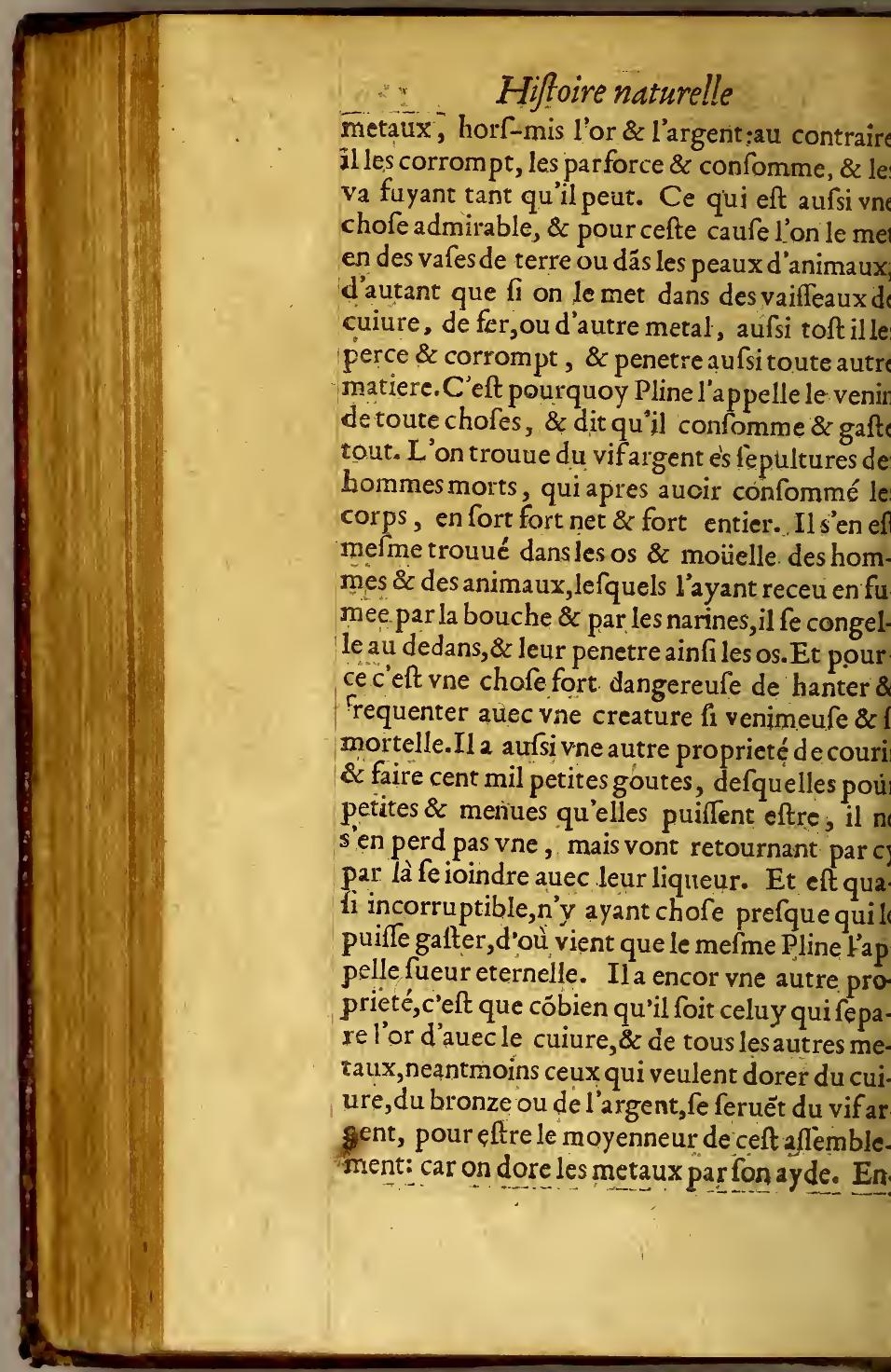




\section{des Indes. Liure. IV.}

toutes les merueilles de ceite eftráge liqueur, lle qui m'a femblé plus digne d'eftre remaree, eft que combien qu'il foit la chofe la plus fante du monde, neantmoins il fe tourne totanent en la chofe pluslegere du monde, qui eft. fumee par laquelle il monte en haut ayant efté nuerty en icelle, aufsi toft la mefme fumee, qui tvne chofe fi legere, ferezourne du tout en ie chofe fi pefante, comme eft la propre lileur du vif argét: enquoy il fe refout:car cefte mee venant à rencontrer en haut le metal qui t vn corps dur, ou bien venant à vne region oide, aufsitontil s'efpaifsit \& fe tourne en vif gent; que fil'on luy donne vne autre fois feu, tout de melme il fe retourne en fuee pour fe refoudre encor en vif argét? Tranfutation v rayement eftrange d'vne chofe fi pente en chofe fi legere, \& d'vne fil lege en vne pefante, ce que l'on peut tenir pour chofe raen nature. Et pour ce l'Autheur de la nature t'digne d'eftre glorifié en toutes ces $\$$ autres Ztranges proprietez de ce metal, puifque toute hofe engendree obeyt promptement à fes loix achees $\&$ incogneuës.

ulien ou lon troune le vif-argent, of cornm? l'an defcousurit ces tres -riches mines en Guancarilica.

Chapitre XI. 19. Evifargent fe trouue en vne maniere aufsi tout enfemble ce vermeillon que es anciens appellerent Minium, \& encor au- 


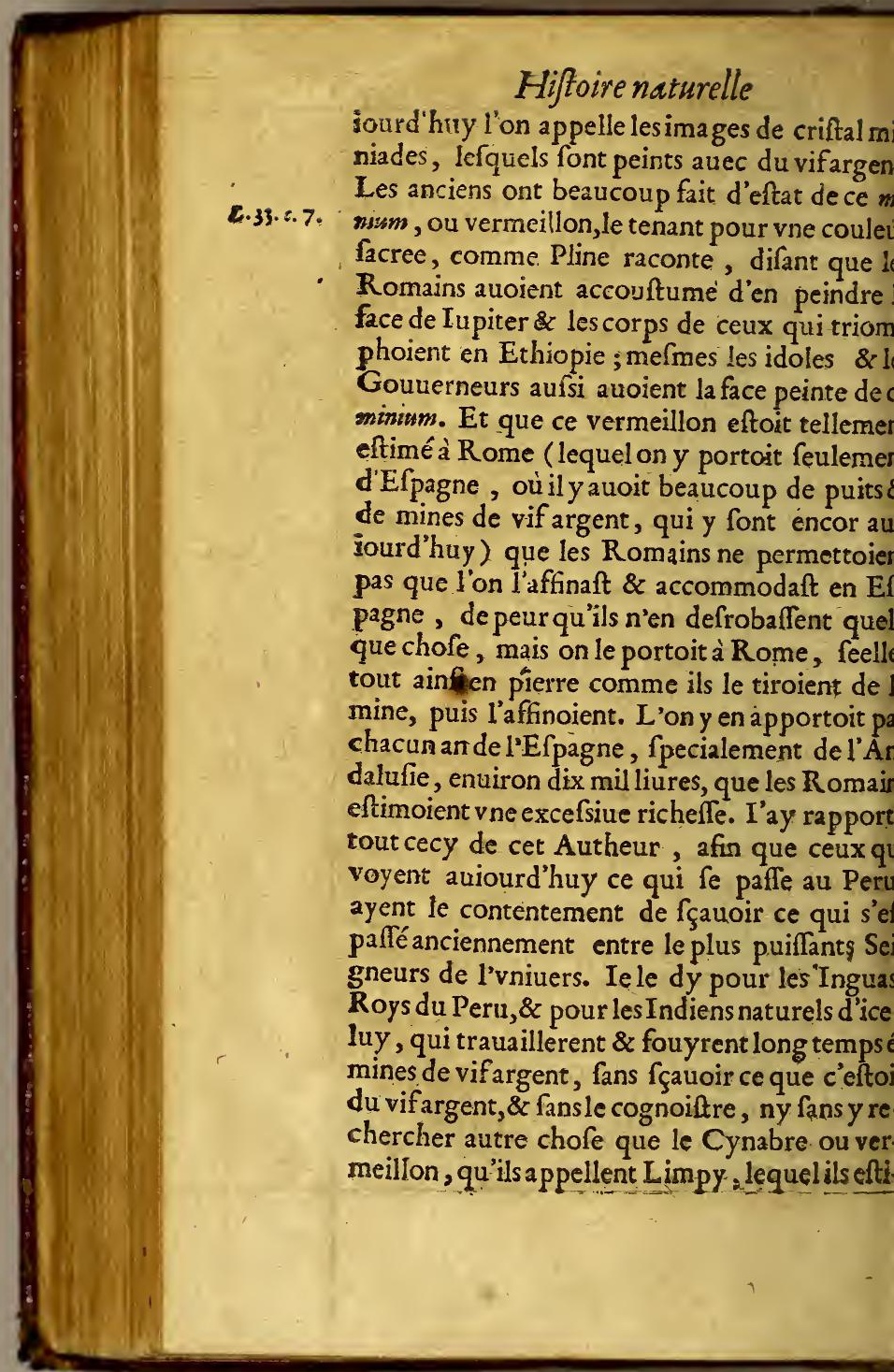




\section{des Indes. Liure. IV.}

int beaucoup, pour ce mefme effect que Plie a raconté des Romains, \& des Ethiopiens, qui it pour fe peindre \& teindre la face \& le corps 'eux \& leurs idoles;ce qui a efte beaucoup praqué par ies Indiens, pecialement quand ils aljient à la guerre, \& en vfent encor auiourd huy uand ils font quelques dances \& feltes, \& apellết cela fe barbouiller, pour ce qu'ill leur femJoit que les faces \& vifages ainli barboülliez fpounentoient beaucoup, \& auiourd'huy le iennent pour vn ornement $\&$ mignardife. Pour efte caufe il y a eu d'eftranges ouurages de mies, aux montagnes de Guancauilca, qui font au 'eru, proches de la Cité de Guamangua, der|uelles ilstiroient ce metal, \& eft de la façon, que iauiourd'huy l'on entre par les caues \& foccaons, que des Indiens firent de ce tempsla, les 1ommes s'y pérdent, \& ne troutent point de hemin pour en fortir: maisils ne fe foucioient oint du vif-argent, qui naturellement eft en la nefme matiere, ou metal de vermeillon, ny ne ognoiffoient point qu'il y euft au monde deelle matiere.Les Indiensn'ont pas efté feuls qui yent efté long temps fansauoir cognoiffance de efte richeffe, mais aufsiles Efpagnols ont eftè le mefme, iufquesà ce que en l'an mil cinq cens oixante fix, \& foixante fept, que le Licentié Catro gouternoit au Peru, l'on defcouurit les mines de vif argét, ce qui aduint de cefte façon. Vn hóme d'entendemêt , appelle'Henricque Guarces, Portugais de nation, ayant vn morceau de ce metal colore',que i'ay dit que les Indiens a ppellent Limpy, auec lequel ils le peignent le vifage, 


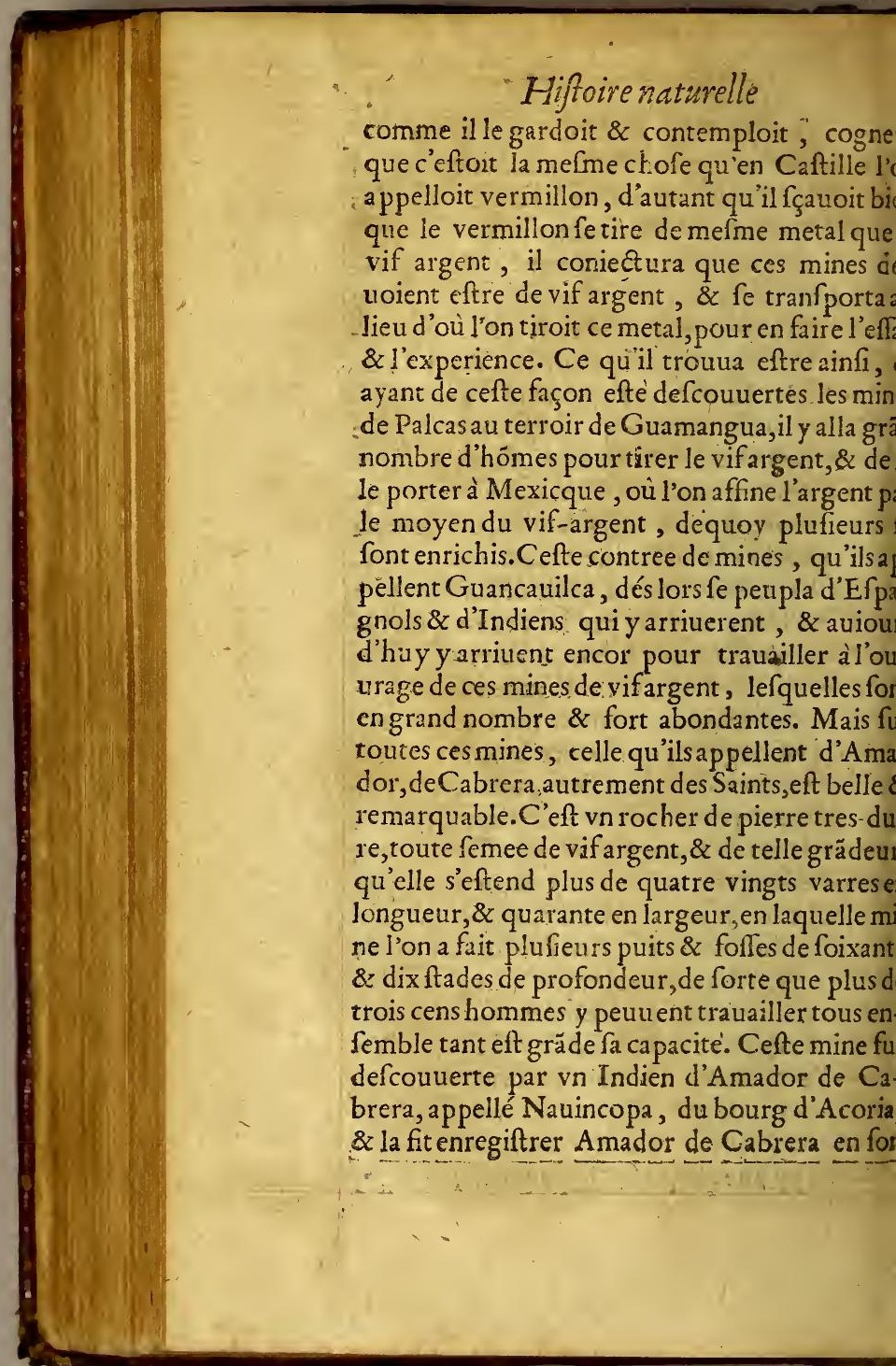




\section{des Indes. Liure IV.}

om. Il en fut en procez contre le Procureur fcal, mais par arreft l'vfufruict luy en fut adıgé, comme ayant eftè le defcouureur. Dư epuisil vendit fon droict'a vn autre, pour le rix de deux cens cinquante mil ducats, \& par pres ayant opinionqu'il auoit efté trompé en efte vente, mit enaction l'acheteur, pour ce u'ils difent qu'elle vaut plus de cinq cens mil ucats, voire quelques-yns tiennent qu'elle aut bien vn millionid'or: chofe rare, quil y it vne mine de telle valeur \& richeffe! Lors jue Dom Francifque de Tollede gouuernoit u Peru, il y eut vn homme qui auoir efté en Mexicque, \& remarqué comme l'on affinoit 'argent; auec le mercure, appellé Pero Fernanles de Vielafco, qui s'offrit \& s'ingera d'afiner $x$ de tirer l'argent de Potozi auecle mercure, $x$ en ayant fait preutie en l'an mil cinq censfoi. cante $\&$ onze, en vint a fon honneur, \& lors on ommença en Potozi à affiner l'argent auec le if-argent que l'on y portoit de Guancarelicjua, qui fut vn beau remede pour les mines: car ar le moyen de ce vif-argent, l'on tira vn nom. re infiny d'argent de ces metaux, dont ils ne aifoient point d'eftat, lefquels ils appelloient acleures. Car comme il a eftè dit, le vif-argent purifie l'argent encor qu'ilfoit fec, panure, \& le peu d'alloy, cequel'on ne peut faire en le faifant fondre par le feu. Le. Roy Catholique ire de l'ouurage des mines du vif-argent, fans couft ny rifque aucune, frefque quatre cens mil pezes de mine, quifont de quatorze reaux chacun, ou peu moins, outre le droir quiluy $r$ : 


\section{Hiftoire naturelle}

uient en Potozi, où il eft employé, qui eft vir autre grä́de richeffe. L'on tire chicun an, t'v portantl'autre, de ces mines de Guancauilca, mil quintaux de vifargent, \& voire dauantag,

Delafacon de tirer le vif argent, comme one affinel'argent.

\section{CHAPITRE XII.}

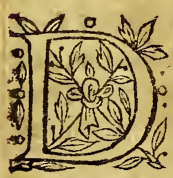

Ifons maintenant comme l'on tir le vifargent, \& cŏme auec luy l'o affine l'argent. L'ó prend la pierr ou metal, où fe trouue le vif argêt s laquelle ils mettent au fcu dedar des pots de terre, bien bouchez, a pres qu ils l'c premierement pillee \& moulliie, de forte que $c$ metal ou pierre, venant à fe fondre par la cha leur du feu,le vifargent s'en fe pare, $\&$ en fort e. exhalation, \& quelquefois melme auec la fume de mefme feu, iufques à ce qu'il rencontre quel que corps, où il s'arrefte \& fecongelle: que s' paffe outre en haut fans rencontrer a ucun corp dur, il va à mont iufques à ce qu'il foit refroidy \& lors eftant congellé il retombe en bas, Quan Ja fondure eft acheuee, ils deftoupent les pot $\&$ en tirent le metal, attendants toutesfois : ce faire, qu'ilfoit bien refroidy, car sil y reftoi encor quelque fumee ou vapeur, quirencontraft les perfonnes qui les deftoupent, ce feroi pour les faire mourir, ou demeurer preclus, ou a tout le moins pour en perdre les dents. E d'autant que l'on vfe \& def pend vn nombre in 


\section{des Indes. Liurê.It.}

ny de bois, pour entretenir le fúcu à fondre les etaux. V n menfnier nom mé Rodrigo de Tor$s$, trouua vne inuention tres-vtile, qui fut a cueillir d'vne certaino paille qui croift par utes ces montagnes du Peru, laquelle ilsapellent Ycho, \& eft comme vne efpece de ionc. ur auec quoy ils font dufeu. Geft chofe mereilleure, que da force que cefte paille a pour indre ces metaux, ce qui eft, comme Pline dit, Li.33ri.4? u'il y a de l'or que l'on fónd plus facilement uec la flàmé de la paille, que non pas auecivin ros brafier, quoy qrili foit bien ardent \& cnämé. Ils metcent levif-arg cut ainfr fondu dans es peaux, d'autant quil fe gardem fort bient as du cuir, \& $\&$ de cefte façon 1 i on le met aux ma afins du Roy, d'où lon le tire pour le porter ar merà Áricqua, puis à Potozi par terre, furch es moutons dupays: Il fe confume ordinairenent cbaque an en Potozi, pour l'affinemente les metavix; enuiron fix ou fept mil quintaux de if-argent; fans ce que l'on tire des lames, (qui it le terseftre, \& ordure des premiers lauoirs les métaux, qui fe font en des chaudieres.) Lefquelles lames.ils bruftêt \& mettent en des fourneaux pour en tirer le vifargent qui demeure en icelles. Et $y$ a plus de cinquante de ces fourneaux en lá ville de Potozi, \& en Tarpaya. La quantité des metaux que l'on affine (commee quelques hommes experimentez en ont fait le conte, $)$ fe peut monter à plus de trois cens, mil quintaux par an,des lames \& terreftres defquels refonduës \& rafinees, l'on peut tirer plus de deux mil quintaux de vif.argent. Or l'on doif 


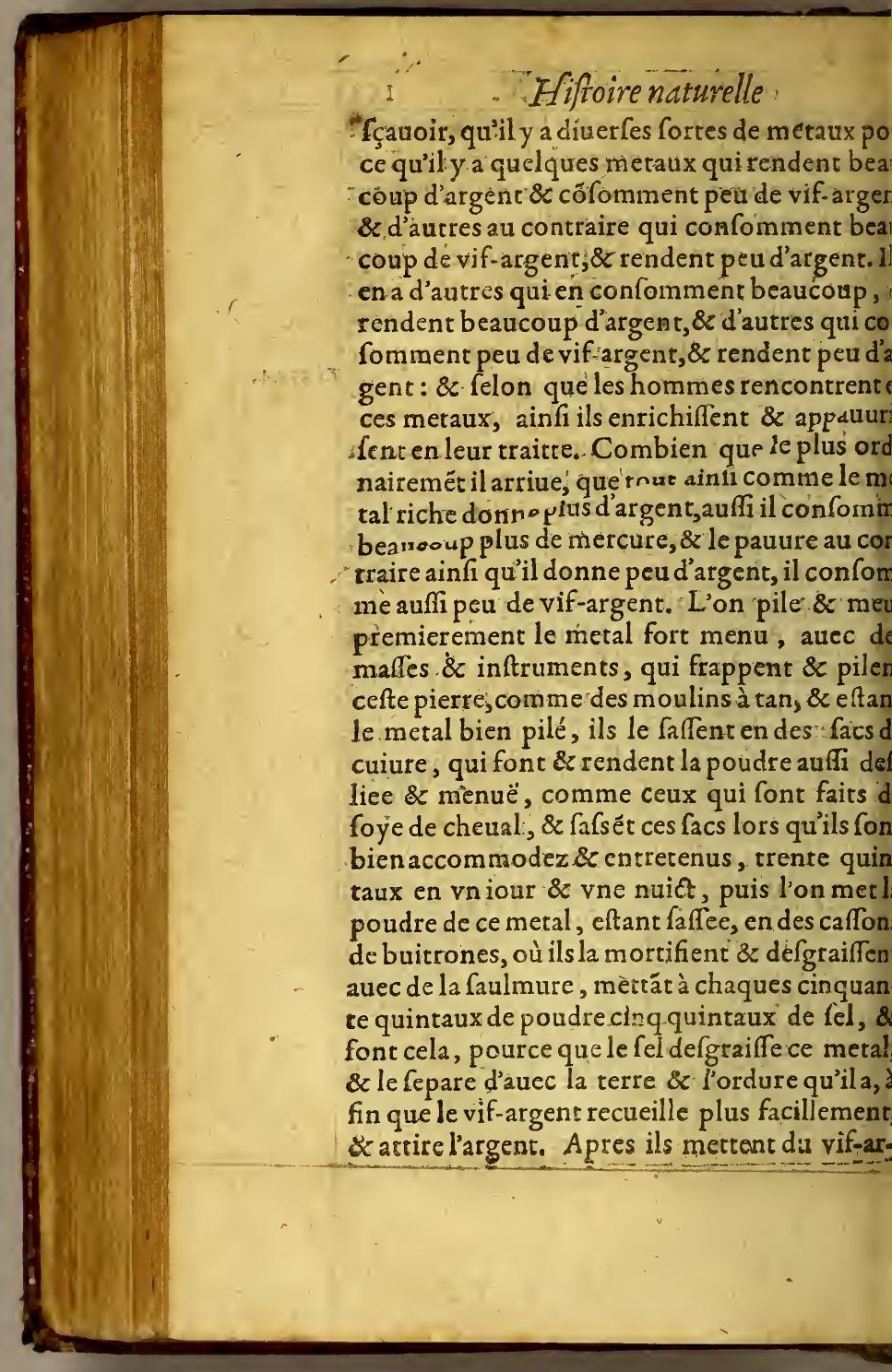




\section{Hiftoire naturelle}

pleins d'eau, pu, auec des moulinets ou rolies vont tournant tout à l'entour le metal, comme qui feroit de la mouftarde, \& lors va fortant 1 . terre \& ordure du metal, auec l' eau qui court; \& l'argent \& vif-argent, comme plus pefas: demeurent au fond de ta chaudiere, \& le meta qui demeure eft comme du fable : de là ils le ti rent \& portent lauer vne autre fois auec di grands plats de bois en des cuues pleines d'eau \& là ils acheuent de faire tomber la terre, laif fant l'argent \& vif argent feuls. Toutesfois i nelaire pas de couler quelquefois- vn peu-d'ar gent \& vif argent auec la terre \& ordure, \& el ce quils appellent relaué, lequel ils ap prouf tent par apres, \& en tirentce quill refte. Apre donc que largent $\&$, vif argent font nets, $\&$

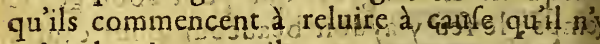
refte plus de terre, ils prennent tout ce meta lequel entant mis dans yn linge, ils le parer (fents \& expriment tres-forr, \& par ce mgyen, (ate tou Ie vit-argent qui n'eft point incoxporé aude l'ar gent, \& demeure le refte fait comme vn pài d'argent, \& vif -argent, ainfi que demewre marc des amandes quand lelles font preflee pour faire de l'huyle, \& eftantajn fibien preffó le marc qui demeure contient en foy feulerent la fixierme partie d'argent, \&lescinqautrés de mercure; tellement que sil refts yn marc de folxante liures, les dix font d'argent, \& tes cinquantc de vif-argen Deces marcs ils font des pines qu'ils appellent, ou pommes de pin, en la façon de pains de fucre, creufes par dedans, lef. quelles ils font ordinairement de cent liures 


\section{des Indes. "Liure IV.}

Ifs.

efant, puis pour feparer l'argent d'auec le vifrgent, les metrent au feu violent, où ils les courent d'vn vafe de terre, à la façon d'vn moule faire les pains de fucre qui font comme capuhons, \& les couurant de charbon, leur donent le feu, par lequel le vif-argent s'exhale n fumee, $2 x^{\prime}$ rencontrant ce capuchon de tere, la s'efpaffit \& diftille ainfi que fait la fumee a pot au couuercle, \& par vn canal en façón allembicq, l'on reçoit tout le vif-argent qui ediftlle, demeurant l'argent feul, lequel ne fe hange en la forme $\&$ figure, mais aux poids il liminuë de cinqparts moins qua auparauant, \& lemeure crefpu \& fpongieux, qui eft vne chofe ligne de voir. De deux de ces pines l'on fair ne barre diargent, du poids de foixante cinq u foixante fix marcs, $\&$ de cefte façon ils la por: ent effayer, quinter $\&$ marquer. L'argent tiré uec le mercure eft fi fin, que iamais il n'abaiffe le deux mil trois cens quatre vingts d'alloy, 8 if fi excellent que pourle mettre en cuire les Orfeuies ont beroing de l'abaiffer d'alloy, en metrant de la foulde, ou meflange, cóme aufi on fait és maifons de la monnoye, où l'argent e met en ceuure fous le coing. $L^{2}$ argent endure tous ces tourmens \& martyrs. (s'il taut dire ain i) pour eftre affiné : que fil'on confidere bien, c'eft vn amas tout formé, où l'on meut, l'on s'atre, l'on paiftrit, l'on fait le leuain, \& l'on cui l'argent:autre tout cela, l'on le laue, relaue, cuit, \&c recuit, paffant par les pillons, facs, auges, buytrones, chandieres, batoirs preffoirs, fours; \& finablement par l'eau \&e par le feu. Ie dis cecy 


\section{Hiffoire naturelle}

pour-ce que voyant cét artifice en Potozi, ic confiderois ce que ditl'Efcriture des iuftes, que:

'Math.3. Colabut eos, OT.purgabit quaji argentum, \& ce qu'el Ecclef.2. Sfal. II. le dit en autre part; sicut argentum purgatum terra purgatum feptuplum. Tellement que pour purifict l'argent, l'affiner \& le nettoyer de la terre \& pierre où il s'engendre, l'on le purge 2 purifie fept fois : car en effect ils le tourmentent $\&$ pal. fent par les mains fept fois, voire dauantage, iufques à ce qu'il demeure pur $\&$ fin, ce qui eft de mefme en la doctrine du Seigneur, \& doiuent eftre telles, \& ainfi purifiees les ames, qui doiuent participer \& ioiiyr de fa pureté diuine.

\section{Des engins à moudre les metaux, \& de leefay de l'argent.}

Chatitre XIII.

DD Our conclure cefte matiere \& fuject (1) $\$$ de l'argent \& des metaux, il nous refte o deux choles à dire, l'vne defquelles eft de traitter des engins \& moulins, \& l'autre des effais. I'ay defia dit comme l'on meut le metal pour receuoir le vif-argent, laquelle moulure fe fait auec diuers inftrumens \& engins, les vns auec des cheuaux comme des moulins à bras, \& les autres comme moulins à eau, defquelles deux fortes y a vne grande quantité. Mais d'autant que l'eau qu'ils ont là communement, n'eft que de la pluye, il n'y en a pas fuffifamment en Potozi; qu'en trois ou quatre mois, qui font en Decembre, Ianuier, Feurier: 


\section{des Indes. Liure IV. Is}

ur cefte occafion ils ont fait des lacs \& angs qui contiennent de circuit, comme, 1 \& fix cens verges, \& de profondeur trois ides, il y en a fept auecleurs efclufes, telleent que quand il eft befoin d'eau, l'on-leue. ie efclufe d'où fort vn ruiffeau d'eau, "lequel referrent aux fertes. Et quand les lacs \& tangs fe rempliffent, \& que lannée eft abonnte en pluyes, le moudre y dure fix ou fept ois, de façon que mefme pour l'argét les homes defirent $\&$. demandent vne bonne annee eau en Potozi, comme l'on fait aux autres adroits pour le pain. Il y a d'autres engins en arapaya, qui eft vne vallee diftante trois ou uatre lienës de Potozi, oùil court vne riuiere, omme mefme en d'autres endroits. La diuerfiqui eft entre ces engins, eft que les vns font de $x$ pilons, les autres de douze, \& les autres de uatorze. L'on meut \& pile le metal endes tortiers où iour \& nuiłt ils trauaillent, \& delà on porte ce qui eft moulu pour faffer. Il y a au iuage du ruifleau de Potozi quarante huia inrumens $\&$ engins à eau, de huid, dix \& douze ilons, \& quatre autres del'autre colté, quils ppellent Tanacognugno. En la vallee de Taraaya, y en a vingt deux tous à eau, outre lefquels en a trente à cheual en Potozi, \& plufieursaures en d'autres endroits, tant a efté grand $\& x$ eft encor le defir \& induftrie de tirer l'argent. Lequel finalemét eft effayé \& efprouué par les maitres à ce deputés par léRoy. Pour dóner l'alloy a chaque piece l'on porte les barres d'argent à 'eflayeur, qui met aे chacune fon numero, pour

$\mathrm{V}$ iiij 


\section{Hiftoire naturelle}

ce que lon luy en porte plufieurs à la foís, coupe de chacune vripetit morceau, lequel poile iuftement, \& le met en vn creufer, qui et vn petit vale fait de cendres d'os bruflez \& bat tus puis il pofe tous ces creufers chacun en for ordre au fourneau, leur donnant le feu violeni lorsile metal fe fond, \& ce qui eft plomb fe re fout en fumee, \& le cuiure \& eftain fe diffoul uent, demeuranc largent tres-fin de couleur di feu: \& eft vne chofe merueilleufe, que quan, il eft ainfi raftiné, encor qu'il foit liquide \& fondu, il ne s'efpand point, quoy que l'on ren. ueife le creufet la bouche en bas, maisil demeu. rè roufiours fixe, \& fans en tomber vne gou. te. L'effayeur recognoint en la couleur $\&$ at tres fignes quandi il eft affiné, \& lors il tire les creufers du feu \& repefe delicatement chalque morceau, regarde ce quil eft diminué, do fon poids, pour-ce quue celuy qui eft de haute loy, diminuè peu, \& celuy qui eft de baffe loy, beaucoup, \& ainfi felon qu'il elt diminué il voit l'alloy quill tient, fuiuant quoy il marque punextuellement chaque barre. Le poids \& ballance font $f$ delicats $\&$ les grains fit menus, que P'on ne les peut prendre auec la main, mais feulement auec des pincettes, \& fair l'on cét effay à la lumiere de la chandelle, afin qu'il n'y ayt aucun air qui face mounoir les balances: car de ce peu dérpend le prix \& valeur de toute $l_{a}$ pal.6g. barre. C'eft à la verité vne chofe delicate, \& proon.17.27. qui requiert vne grande dexterité, dequoy mefme sayde la faincte Efcriture en diuers endroicss a partie pour declarer de quelle façon 


\section{des Indes. Liure IV.}

liei efproune les fiens, \& four noter, \& relarquer les differences des merites $\&$ valeur es ames, où au Prophere Hieremie Dieu don- Hierem. ele tiltre d'effay eur, afin quill cognoiffe $\&$ delare la valeur Ipirituelle deshommes, \& de fes :uures; qui eft vn propre negoce de l'efprit de ieu, eftant celuy qui pefel'elprit des hom mes. lous-nous contenterons de ce qui eft dit fur le bjet de l'argent, metaux \& mines, \& paffeins aux deux autres mixtes propofez, qui font splantes \& animaux.

\section{Des Efmeraudes. \\ Chatitre Xiv.}

L ne fera pas hors defujet de dire 5 (5) quelque chofe des efmeraudes,

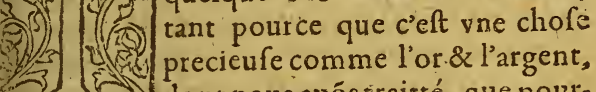
(n) dont nous auós traitté, que pourequ'ils viennent, \& prénent leur origine mef-
e des mines $\&$ des metaux, ainfi que raconte line. L'efmeraude a efté anciennemét en gran- Plin. 1i.37\% eftime, comme le mefmeautheur efcrit, \& cap. 5 . yy donnoit-on le troifiefme lieu entre les oyaux \& pierres precieufes, fçauoir apres le iamant \& la perle. Aujourd'huy l'on n'eftime lus tant l'efmeraude, ny la perle, pour la graneabondance qu'on a apportee des Indes de ces leux fortes de pierres, \& n'y a que le diamant. eul quiretienne \& demeure en fa principauté, 


\section{Hiftoire naturelle}

laquelle on ne luy peut ofter A pres viennent er eftime les rubis fins \& les autres.pierres, qu'or tient plus precieufes que-les efmeraudes. Les hommes font tant amis des fingularitez, \& de: chofes rares, que ce qu'ils voyent eftre cómun ils ne l'eftiment plus. On raconte d'vn ESpagno. qui au cúmencement de la defcouuerte des In. des fut en Italie, \& monttra à vn lapidairè vne efmeraude; auquel demandant le prix d'icelle: apres que le lapidaire l'eut regardee de pres, \& bien confideree cóme elle eftoit d'vne excellente qual ité \& figure, refpódit qu'elle valloit cen ducats. Illuy en monftra vne autre plus grande, que le lapidaire eftima trois cens ducats. L'ESpagnol eftant enyuré de ces propos, le mena en fon logis, \& luy en móftra vn caffion tout plein lors l'Italien voyant vn figrand nombre de ces émeraudes, dift, Monfieur, celles-là vaudront bien vn efcu la piece. Il en eft aduenu autant és Indes \& en $E$ fpagne, que ces pierres ont perdu leur valeur, pour la grande richelfe $\&$ abondan-

Plin. $l: 37$. app. S. ce d'icelles qui fy en eft trouuee. Pline raconte plufieurs excellences des efmeraudes, entre lef. quelles il dit qu'il n'y a chofe plus agreable, ny plus faluble à la veiie, en quoy il a raifon: mais Ion authorité importe peu, pendant qu'il y en aura telle abondance. Lalia Romaine, de laPlim. l. 9. quelle il raconte qu'en vn fcoffion \& veftement eap. 35 . brodé de perles \& efmeraudes, elle employa la valeur de quatre cens mille ducats; pourroit aujourd'huy auec moins de quarante mil en faire deux paires tels que celuy-là. Il fen eft trouué en diuerfes parties des Indes, \& les Rois de Mes 


\section{des Fndes. Liure IV.}

que les eftimoient beaucoup, voire auoient couftumé quelqu'vns de fe percer les narines, d'y mettre vne excellente efmeraude. Ils les ettoient aux vifages de leurrsidoles; mais le u où l'on en a trouué, \& fien troutue encor auurd'huy plus grande abondance, eft au nouau Royaume de Grenade, \& au Peru, proché Manta \& Port vieil. 11 y a vers ce lieu vn terir qu'ils appellér, Terre des efmeraudes, pour cognoiffance que l'on a qu'il y en a beatcoup, cores que: iufques aujourd'huy l'on n'a point. nquefté cefte rerre. Les efineraudes naiffent des pierres, en forme de cryftaux, \& les ay ües en la mefme pierre, qu'ils vont comme y rmant vne veine, \& comme il femble, fe vont ù à peu efpaiffifant \& affinant. Pource que $n$ vids quelques-vnes qui eftoiét moitié blanes $\&$ moitié vertes, d'autres toutes blanches, d'autres jà toutes vertes, \& parfaites du tout. an ay yeu quelques- vnes de la grandeur d'vne jix, \& fen trouue de plus grandes: mais ie ay point fceu qu'en noftre temps l'on en aye ouué de la grandeur \& figure du plat ou ioyau 'ils ont à Gennes, qu'ils eftiment auec raifon our ioyaux de grand prix, \& non pas pour reque, puis qu'il n'apparoift point que ce foit ie relique, mais eft le contraire. Neantmoins ns comparaifon, ce que Theophrafte raconte l'efmeraude, que le Roy de Babylone prefen. Pliz li. 37 . ca. I. au Roy d'Egypte, furpafte celle de Gennes. r elle auoit quatre couldees de long, \& trois elarge, \& dit qu’au Téple de Iupiter il y auoit ne elguille, ou pyramide, faite de quatre pier- 


\section{Hiftoire naturelle}

res d'efmeraudes, de quarante coudees delon, \& en quelques endroits, de quatre coudees d latge, \&r de deux en d'autres endroits, \& que $d$ fon temps il y auoit à Tyr, au Templed'Herct les, vin pillier d'efmeraude. Il eftoit parauentr re, comme dit Pline, de pierre verte, qui tiro: fur l'efmeraude, \&tl'appelloiêt, efmeraude faul fe: commé quelques-vns veulent dire que ces tains pilliers qui font en l'Eglife Cathedrale d Cordoiie, font de pierre d'efmeraude, \& y for depuis le temps qu'elle fut méquitte des Ro: Miramamolins Mores, qui regnerent en icelli En la flotte de rs 87. en laquelle ie vins des Ir des, ils apporterent deux caflons d'efmeraude: dont chacun pefoit pour le moins quatre arre bes, d'où l'on peut voir l'abondance quil y en: Exod.29. L'Efcriture faincte celebre les efmeraudes corr 30. me ioyaux fort precieux; on la met entre li pierres precieufes que le grand Pontife porto: en fon Ephod, ou Pectoral, comme celles qi ornoient les murs de la celefte hierufalem.

\section{Des Perles.}

\section{CHAPITRE XV.}

7 A I N TENA N T que nous traiton 14 de la principale richeffe que l'o 12V apporte des Indes, il n'eft pas rai 1) fonnable d'oublier les perles, qu 1 L les anciens appelloiènt marguari

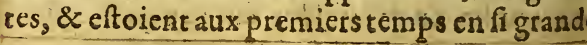




\section{des Indes. Liuîre $I V$.}

ime; qu'il n'appartenoit quaux perfonnes yales d'en porter; mais aujourd huy il y en a telle abondance, que les Negreffes mérmes portent des chaines. Elles fengendrent és nches ou huiftres de la mer auec leur chair, \& eft arriué, mangeant des huiftres, d'y trouuer s.perles au milieu. Ces huiftres:font par dedás ne couleur commede ciel, fort viue, \& en elques endroits lon en fait des cucillieres iils appellét de riacre. Les perles font de tresfferentes formes en la grandeur, figure, cou* ar \& polifure, comme aufi en leur prix elles fferent beaucoup. Ils appellent les vnes Auearias, pour eftre commeles petits grains du appelet; les aurres Patenóftres, parce qu'elles. nit grofles: Peu fouuent l'on en trouue deux a foient tout d'vne grandeur, forme, \& cotrur. Pour cefte occafion les Romains, felon iefcrit. Pline, les appelloient V nions. Quand aduient que l'on en trouue deux qui fe reffemlent dub tout, ils hauffent beaucoup de prix, ecialement pour des pendants d'oreille. l'enr yeu quetquesipaires quils eftimoientà milers de ducats, encore qu'elles ne fuffent pas de valeur des deux perles de Cleopatra, defquel - Ibidem? s Pline raconte que chacune valoit cent milie ucats, auec lefquelles cefte folle Royne gagaia gageure quelle anoit faite contre Mare Anaine, de gafter, \& defpenfer en vn fouper plus e cent mille ducats, d'autant que fur le deffert lle mit vne de ces perles en de fort vinaigré: uis apres la perle eftant diffoure aueclevinaire, elle la beut ainfi. Ils difent qu lue l'autre per- 


\section{Ffifoire naturelle}

le fut coupee en deux, \& mife au Pantheonci Rome; aux pendants d'oreille de la fatue Venus. Efope raconite de Clouis fils du baft leur ou comedien, qu'en vn banquet il fit pri f́nter aux conuiez, entre les autres mets, à chi: cun vne perle riche, diffoute en vinaigre, afind rendre la ferte plus.magnifique. Ce font efté de folies de ces temps là, mais celles d'aujourd'hu ne font pas moindres, attendu que nous voyor non feulement les chapeaux \& les cordós, ina auffi les bottines, \& lespattins des femmesd baffe condition, eftre tout femez de broderied perles: On pefche des perles en diuers endroir des Indes: mais, la plus grande abordance efte la merdu Sud, proche du Panama, où font le Ifles qu'ils appellent pour cefte occafion, te Ifles des perles. Mais l'on en tire aujourd'hu en la mer du Nort en plus grande quantité, $: 8$ de meilleures, qui eft proche de la riuiere quil appellent, de la hache. Ie vis là comme l'on es faifoir la pefche, qui fe fait auec affez de couft $\&$ de tranail des pauures efclaues, lefquels $f$ plongér fix; neuf, voire douze braffés en la mer à chercher les huiftres, lefquelles ordinairemen font attachees aux rochers \& graviier de la iner Ils les arrachent de là ; \& f'en chargent pour re uenir furl'eau, \& les metrre en leur's canoes, oi ils les ouurét apres pour en tirer le threfor qu'il. ont dedans. L'eau de la mer eft en cét endroi tres-froide, mais encore ce leur eft beuaucoup plus grand trauail de retenir leur haleine quel. quefois vn grand quarr d'heure, voire demie heure, en faifant leur pefche. Et afin que ces 
des Fndes. Liure $I V . \quad 760$ uuures efclaues puiffent mieux retenir leur haine, ils leur font manger des viandes feiches, encore en petite quantité; tellement que l'a. arice leur fait faire ces abftinences \& contiences contre leur volonté. L'on met des perles neuure en diuerfes façons, \& les perce-ton our faire des chaines, \& y ena jà grande abon- . unce en quelque lieu que ce loit. En l'an is $8 \%$. vids au memoire de ce qui venoit des Indes ur le Roy, quil y auoit dix-huict mares de erles, \& encores trois caffons dauantage, Et our les particnliers il y en auoit mil deux céns ixante \& quatre marcs, \& outre tout cela, pt fachets qui n'eftoient point pef $\mathrm{cz}$, ce qu'on ift tenu en autre temps pour fable.

Dupain des Indes, of du mays. CHARITRE XVI.

A INTENANT pour traitter des plantes nous commencerons a celles qui font propres \& partictilieres és Indes; \& puis apres de celles qui font communes aux Indes, \& à l'Europe. Et pource que les plans ont efté creées principalement pour l'cntreen de thomme; \& que la principale dont il end nourriture, eft le pain, il fera bon de dite sel pain il y a aux Indes, \& dequoy ils ventz ute d'iceluy. Ils ont comme nous auons icy, nom propre, par lequel ils defignent \& fi- 


\section{Hiftoire naturelle}

gnifient le pain, quilis difent au Peru, Tanta, 8 en d'autres lieux d'vne autre façon. Mais la qua lité \& fub?tance du pain dont ils voient aux In des, eft chofe fort differente du noftre, pourc qu'il ne fe trouue quil y euft aucun genre $d$ froment, ny orge, ny mil, ny de ces autres grain dont on fe fert en Europe a faire du pain, au lie de cela ils vfoient d'autres fortes de grains \& ra cines, entre lefquels le mays tient le premie lieu, \& auec raifon le grain qu'ils appellêtmays quel'on appelle en Caftille, bledd'Inde, \& e Italie, grain de Turquie. Et ainfi comme le fro ment eit le plus commun grain pourl'vfage de hommes, és regions de l'ancien monde, qu font Europe, A fie \& Afrique; ainfi aux endroit du nouteau mondele grain de mays eft le plu commun, \& qui prefque f'eft trouué en tousle Royaumes des Indes Occidentales, conme à Peru, en la neuue Épagne, au nonueau Royau me, en Guatimalla, en Chillé, en toute la ter re ferme. Ie ne trouue point qu'anciennemen és Ifles de Barloguente, qui font Cuba, fainé Dominique, Iamaycque, \& faind I ean, ils vfal fent du mays, aujourd'huy ils vfent heaucou de la Yuca, \& Caçaui, dequoy nous traicteron incontinent. Ie nepenfe point que le grain d mays foit inferieur au froment en force, ny e: fubftance, maisileft plus chaud; \& plus groffel \&.engendre beaucoup de fang, d'où vient qu ceux qui n'y font point accouftumez s'ils e mangent trop, ils deuiennent enflez \& ro gneux. Il croift en des cannes, ou rof eaux , cha cun defquels porte vne ou deux grappes, aul quelle is, 


\section{des fndes. Liure $I V$.}

I6r

uelles le grain eft attaché; \& combien que le rain en foir affez gros, fi eft-ce qu'il f'y en trouc en grande quantité ; tellemét qu'en quel ques rappes j’ay conté fept cens grains. Ille faut feier à la main vn à vn, \& non pas efpars. Il veut terre chaude $\&$ humide, \& en croitt en plu-. eurs lieux des Indes en fort grande abondance, n'eft point chofe rare en ces pays de recueillir ois cens fanegues ou mefures d'vne feule de mence. Il y a de la difference entre le mays, smme il y en a entre le froment; l'vn eft gros, fort nourriflant; \& l'autre petit \& fec, qu'ils pellent moroche. Les feiiilles \& la canne verdu mays eft vn manger fort propre pour les ules \& pour les chenaux, \& leur fert auffide tille quad elle eft feiche; le grain en eft de plus fubftance \& nourriture pour les cheuaux, 1e n'eft pas l'orge. C'eft pourquoy ils ont acuftumé en ces pays de faire boire les beftes lant que leur donner à manger : car fi elles uuoient apres, ce feroit pour les faire enfler, mme elles feroient ayant mangé du froment. E mays eft le pain des Indes, \& le mangent mmunemét boüilly ainfi en grain tout chaud, lappellent mote, comme les Chinois \& Iap. ons mefmes mangent le ris cuit auec fon eain aude, quelquefois le mangent rofty. Il y a du ays rond \& gros comme celuy de Lucanas, de les $E$ fpagnols mangent rofty comme viande licieufe, \& a meilleure faveur que les guarinfes, ou pois roftis. Il y a vne autre façon de manger plus delicieufe, qui eft de mouldre le ays, \& en ayant amaffé la tleur, en faire de pes 


\section{Hiftoire naturelle}

tits tourteaux qu'ils mettent au feu, qu'on a a couftumé de prefenter tous chauds à la tabl En quelques endroits ils les appelient Arepa Ils font mefme de cefte pafte des boulles ros des, \& les accouftrent d'vne façon qu'ils durcı $\&$ fe conferuent long temps, les mangeant cor me vn mets delicieux. Ils ont inuenté aux Ind (pour friandife $\&$ delices) vne certaine façonc paftez qu'ils font de cefte pafte $\&$ fleur auecc fucre, lefquels ils appellent bifcuits, \& melli dres. Le mays ne fert pas feulement aux Indie: de pain, mais auffil il fert de vin: car ils en fos leur boiffon, de laquelle ils f'enyurent pluftol que de vin de raifins. Ils font ce vin de mays diuerfes façons, l'appellans au Peru, Acua, pour le nom le plus commun és Indes, Chich Le plus fort fe fait en façondeceruoife, me tant rremper premierement le grain de ma: iufques à ce qu'il fe creue; par apres ils le cuife d'rne telle façon, \& deuient fi fort, qu'il en fal peu pour abbatre fon homme. Ils appellent $c$ ftuy ià au Peru, Sora, \& eft vn breuuage de fendu par la loy, à caufe des grands inconueni qui en prouiennent, enyurant les hommes. $\mathrm{M}_{2}$ cefte loy y eft mal obferuee, d'autant qu'il's : laiffent point d'en vfer, ains paffent les nuik \& les iours entiers à en boire en dançans \& ba Plin. ii. s4. lans. Pline raconte que cefte façon de breuu xap. 22. ge, qui eftoit de grain trempé, \& cuit par apre aueclequel on fenyuroit, eftoit anciennemes en vfage en France, . en Efpagne, \& en d'autr! Prouinces, comme aujourd'huy en Flandresi vfent de la ceruoife faite de grain d'orge. 11 y 


\section{des Indes. Livire $I V$.}

$\pi 62$

e autre façon de l'A cua, ou Chicha, qui eft de afcher le mays, \& faire du leuain de ce qui a éainfi máché, apres le faire boüillir, voire l'opinion des Indiens, que pour faire de bon uain il doit eftre marché par des vieilles pours, ce qui fait mal au cour à l'ouyr feulement, utefois ils ne laiffent pas de le boire. La façon plus nette, la plus faine, \& qui fait moins de mmage, eft de roftir ce mays, qui eft celle nt vfent les Indiens les plus ciuilifez, \& queles Efpagnols, mefme pour medecine : car en ect ils trouuent que c'eft vne fort falubre iffon pout les teins, d'où rient qu'és Indes à ine fe trouue il aucan qui fe plaigne de ce mal reins, à caufe de ce qu'ils boiuent de ce Chia. Les Efpagnols \& Indiens mangent pour andifes ce mays boüilly, ou rofty, quand il tendre en fa grappe comme laict, ils le mei: nt aupot, \& en font des faulfes, qui eft vin n manger. Les rejettons dumays font fort as, \& feruent au lieu de beurre \& d'huille; llement que le mays és Indes fert aux homes \& aux beftes de pain, de vin, \& d'huille. our cefte raifon le Viceroy Dom Francifque Tollede difoit que le Perruanoit deux chofes ches, \& de grande nourriture, qui eftoient le ays \& le beftial du pays. A la verité il auoie ifon, d'autant que ces deux chofes y feruent mil. Ie demanderay pluftoft que ie ne refondray, d'où a efté porté le premier mays aux ides, \& pourquoy ils appellent en Italie ce ain tant profitable, grain de Turquie : car à la trité ie ne trouue point que les anciens fafferit: 


\section{Hiftoire naturelle}

mention de ce grain, combien que le mil ( q) Pline efcrit eftre venu de l'Inde en Italie, y auc dix ans lors qu'il efcriuoit) ayt quelque reffen blance auec le mays, en ce qu'il dit que c'eft ? grain qui naift en rofeau, \& fe couure de feúllle, ayant le coóneau comme des cheueu \& en ce qu'il eft fertile. Toutes lefquelles chi fes nefe rapportent pasaumil. En fin le Cre teur a departy \& donné à chaque region ce q luy eftoit neceffaire. A ce continent il a dont le froment, qui eft le principal entretenemes des hommes $; \&$ au continent des Indes il a do néle mays, qui tient le fecond lieu aptes le frı ment, pour l'entretenement des hommes \& $\mathrm{d}$ animaux.

Des 2 ucas, Caçaui, Papas, Chunes \& du Ri CHAPITRE XVII.

[I] $N$ quelques endroits des Indes l'on v] II d'vn genre de pain qu'ils appellentC

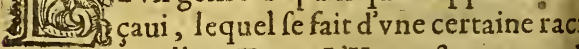
ne qu'ils appellent Yuca. I'Yuca eft vne grand \& groffe racine qu'ils coupent en petits mo ceaux, la rápent, puis la mettans comme en vr preffe, il l'efpreignent pour en faire vne tourt deflice \& grande, de la forme prefque d'vne tar gue ou bouclier de More, puis apres ils la fon feicher, \& eft le pain qu'ils mangent. C'eft vn chofe fans gouft, mais qui eft faine, \& de bonn nourriture.'Pour cefte raifon nous difions, eftä 'à S. Dominique, que c'eftoit le propre mange des gourmands; carl'on en peut manger beau coup, fans craindre que l'excez en faffe mal. I 


\section{des Indes. Liure IV.}

$t$ befoin d'humecter la Caçaue pour la maner, d'autant qu'elle eft afpre, \& f humedte faciment auec dẹ l'eau, ou du potage, où elle eft or bonne, pource qu'elle f'entle beaucoup; \& 8 nfi ils en font des capirotades. Mais elle fe trôe malaifément en du laic, ny en du miel de unes, ny en du vin, parce que ces liqueurs ne peuuent penetrer, comme ils font le pain de oment. Il y a de cefte Caçauel'vne plus delicaque l'autre, qui eft celle qu'on fair de la fleur u'ils appellent Xauxau, laquelle ils eftiment eaucoup en ces parties la quár a moy, i'eftime. jis dauấtage van morceau de pain, quelque dur r noir qu'il peuft eftre. C'eft chofe merueilleuque lefuc ou eau qui fort de cefte racine lors. u'ils l'efpreigaent ainfi, \& quils font la Caçae, eft vir venin mortel, \& fi on en boit il occit: ais le marc quigen refte eft vn pain \& nourriure fort faine, comme nous auons dit. Il y a vn utre genre d'Yuca qưils appellér doux, qui n'a as ce venin en fon fuc; ceftuy la fe mange en iraine, bouiilly, ou rofty, \& eft vn bon manger.La Caçaue fe conferue long téps, aufí la porte. on Ir mer en lieu de bifcuit, Le lieu où l'on vfe da. antage de ce pain, eft aux Ifles quils appellent e Barlouente, lefquelles font, comme nous uons dit, S. Dominique, Cuba, Port-riche, amayque, \& quelques autres de ces enuirons, caufe que la terre de ces. Ifles ne rapporte pas le froment, ny de mays: car lors qu' on y feme lu froment, il $y$ vient bien, \& naift quant \& quant en fort belle verdure: mais c'eft fi inégaement, qu'on ne peut le recueillir, pource que $\mathrm{X}$ iij 


\section{Hiftoire naturelle}

d'vne mefme femence $\&$ en vn mefme téps l'v eft en tuyau, \& lautre en efpic, \& l'autre qui n fait que germer; l'rn eft grand, \& l'autre peti lynn'eft que del'herbe, scl'autre eft defia e grain; \& combien qu'on y ayt mené des labou reurs pour voir fils y pourroient vfer de lagei culture du bled, freftoce qu'ils n'y ont trouu aucun moyen de ce faire, pour la qualité del terce. On y apporte de la farine de la neuue $E$ pagne, ou des Canaties, laquelle eft fi humidi quà peine en peut on faire du pain qui foit pro fitable, \& de bon gouft. Les hofties quand nou difions la Meffe, fe plioient comme fi c'eufe eft du papier mouillé, ce qui eft caúfé par l'extre me humidité \& chaleur qu'il y a tout enfembl en cefte terre. 11 y a vn autre extreme; \& con traire à ceftuy.cy, qui eft quen quelques en droits des Indes il n'y croift de mays, ny de fro ment, comme eft le haut de la Sierre du Peru 8 les Prouinces quils appellent de Collao, qui el la plus grande partie de ce Royaume, où la tem perature eft fi froide \& fi feiche, qu'elle ne peu endurer qu'il y croiffe du froment, ny du mays à lieu déquóy les Indiés vfent d'v $\mathrm{n}$ autre gen re de racines qu'ils appellent Papas, lefquelle: font de la façon de turmes de terres, qui fon petites racines, $\&$ iettent bien peu de feíilles Ils cueillent ces Papas, \& les laiffent bien feche $2 u$ foleil, puis les pilans, en font ce qu'ils appel. lent Chuṇo, qui fe cóferue ainfi plufieurs iours, \& leur fert de pain. Il y a en ce Royaume for grande traitte de ce Chuno pour porter aux mi. hea de Potozi; on mange mefme ces Papas aina 


\section{des Indes. Liure $I V$.}

164 aifches, boiiillies, ou rofties, \& des efpeces icelles y en a de plus douce, \& qui croift és eux chauds, dont ils font certaines fauffes \& achis qu'ils appellent Locro. En fin ces racines one tout le pain de cefte terre; tellement que. uand l'annee en eft bonne, ils f'en refiouy ffent ort, pource quafrez fouuét elles fe gellent deansla terre, tant eft grand le froid \& intempeature de cefte region. Ils apportét les mays des allees, \& de la cofte, ou riue de la mer, \& les fpagnols qui font friands, font apporter des nefnes lieux de la farine de bléd, laquelle fe cóerue bien, \& f'en fair de bon pain, à caufe que a terre eft feche. En d'autres endroits des Indes comme és Ifles Philippines, ils fe feruent de ris u lieu de pain, dont il y en croift de fort exquis, sen grande abondance en toute cefte terre;: \& en la Chine, où il eft de bonne nourriture, ils le cuifent en des pourcellaines; \& apres le meflète tout chaud auec fon eau parmy les autres viandes: ils font mefme de ce ris en beaucoup d'en-? droits leur vin \& breutiage, le faifant trêper, \& puis boüillir cómel'on fait la biere en Flandres ou l'Acua au Peru. Le ris eft vne viande qui n'eft gueres moins commune, \& vniuerflle en tout le mande que le fromét \&zlemays, \& parauenture encore l'eft-il dauantageacar outre ce qu' ils en vfent en la Chine, an Iapon, és Philippines? $\&$ en la plus grande partie del'Inde Orientale; cett le grain qui eft le plus commun en Afrique \& en Ethiopie. Le ris demande beaucoup d'hu. midité, \& prefque vne terretoute réplie d'eari; comme vne prairie. En Europe; au Peru, \& ea

$X$ iiij 


\section{des Fndes. Liure IV.}

par deçà, le fquelles ont cela de plus, qu'elles rofitent \& fructifient dauantage que ne font les plantes des Indes, quand elles font aprree's en Europe: la caufe en eít cóme ie croy utant que par delà il y a plus de diuerfitez de nperature que non pas par deça, pour raifon quoy il eft aifé d'elleuer, \& nourrir les plantes ces regions, \& de les accómoder a la tempeure quelles requierent. Et mefme les racines les plantes qui y croiffent, fans y auoir efté rtees, y font meilleures que par deçà ; carles gnons, les aulx, \& les paftenades, ne font pas les en Efpagne, qu'elles font au Peru: pour naueaux, ils y font en fi grande abondance, 'ils ont augmenté en quelques endrorts de le façon, que l'on m'a affermé qu' ilsn'y pouient efpuifer l'abondance, \& force des naaux, qui y pulluloient ainfi pour y femer du ed. Nous auós yeu affez de fois des raues plus offes que le bras d'vn homme, fort rendres 8 bon gouft, \& de ces racines que i'ay dites, 1elques vnes feruêt pour viande, \& manger ornaire, cóme les camotes, lefquelles eftant roies, feruet de fruir, ou de legumes. Il y en a d'au. es qui leur feruent de delices, cóme le cochu10, qui eft vne petite racine douce, que quelues vns cófiffent pour plus grande delicateffe. y a d'autres racines qui font propres pour raaifchir, comme la xiquima qui eft d'vne qualifort froide $\&$ humide, \& en temps d'Eftéraaichit, \&c eftanche la foif; mais les Papas \& les ças font les principales pour la nourriture, \& bftance. Les Indiens êftiment l'ail fur toures 
Hifioirenaturelle

de de grande efficace. En quoy ils n'ont pas fat de raifon, pource qu'il leur conforte \& efchau l'eftomach, à caufe qu'ils le mangent d'vn apf tit, \& ainfi crud, cornme il fort de la terre.

De plufaerurs fortes de verdures, \& legumes, de ceux quils appellent concombres, pines ou pormmes de pin, petits fruits de Chillé, \& des prunes. ChAPITRE XIX. Dana (9) moindres plantes, ie pourray touch -3 verdures, \& les porees, \& ce quel Latins appellét $\mathcal{A}$ ibufta, fans toucher encor ri des arbres. Il y a quelques genres de ces arbrj feaux ou verdures aux Indes, qui font de fo bon gouft. Les premiers Efpagnolsnommere. beaucoup de chofes des Indes des noms d'Efp gne prins des chofes à quoy ils reffembloient plus, comme les pines, concóbres $\&$ les prune combien que ce fuffent à la verité des fruits $d$ uers \& fort differens, fans comparaifon, de cet d'Efpagne, qui s'appellent ainfi. Les pines $c$ pommes de Pin, font de la mefme façon \& fig re exterieure, que celles de Caftille: mais aud dans elles differét du tout, pource qu'elles n'o: point de pignós, ny d'efcailles, mais le tout y e vne chair, que l'ó peut manger quádl'efcorce e eft dehors, \& eft vn fruit qui a l'o deur fort exce 


\section{des Indes. Liure IV. $\quad 166$}

ite, \& eft fort favoureux \& delicieux au gouft. ent plein de fuc, \& a la faueur d'aigre-doux, ils nangent l'ayant couppé en morceaux, \& laiftremper quelques temps en de l'eau \& du fel. elques-vns difent quil engendre la cholere, que l'vfagen'en eft pas trop fain. Mais ie n'en point veu aucune experience qui le puiffe faicroire. Flles naiffent vne à vne, comme vne nne ou tige qui fort d'entre plufieurs feiilles, mme le lys, combien qu' elle foit vn peu plus ande, \& plus groffe. Le haut \& couppeau de aque canne ef la pomme, elle croift en terres audes \& humides, \& les meilleures font cel$s$ des Ifles de Barlouente. Il n'en croilt point I Peru, maisl'on y en apporte des Andes, lefrelles toutesfois ne font ny bonnes, ny bien eures. L'on prefenta vne de ces pines à l' $' E . m-$ zreur Charles, qui deuoit auoir donné beauup de peine \& de foucy à l'apporter des Ines, ainfi auec fa plante, car on nel'euft pest auement apporter: toutesfois il n'en voulut pas prouuer le gouf. I'ay veu en la neuue Épagne e la conferue de ces pines, qui eftoir fort bóne. eux qu'ils appellent concombres, ne font point tbres non plus, mais feulemét des arbriffeaux, arce qu'ils n'ót qu'vn an de duree. Ils luy donerent ce nom, pource que quelques -vns de ces ruits, \& la plus part font en lọgueur \& en roneur femblables aux concöbres d'Efpagne, mais u refte ils font beaucoup differéts, parce quils iont pas la couleur verde, mais violette, ou iau2 , ou blanche, \& ne font point épineux, ny fcareux,mais fort vnis \& polis,ayans le gouft tręs 


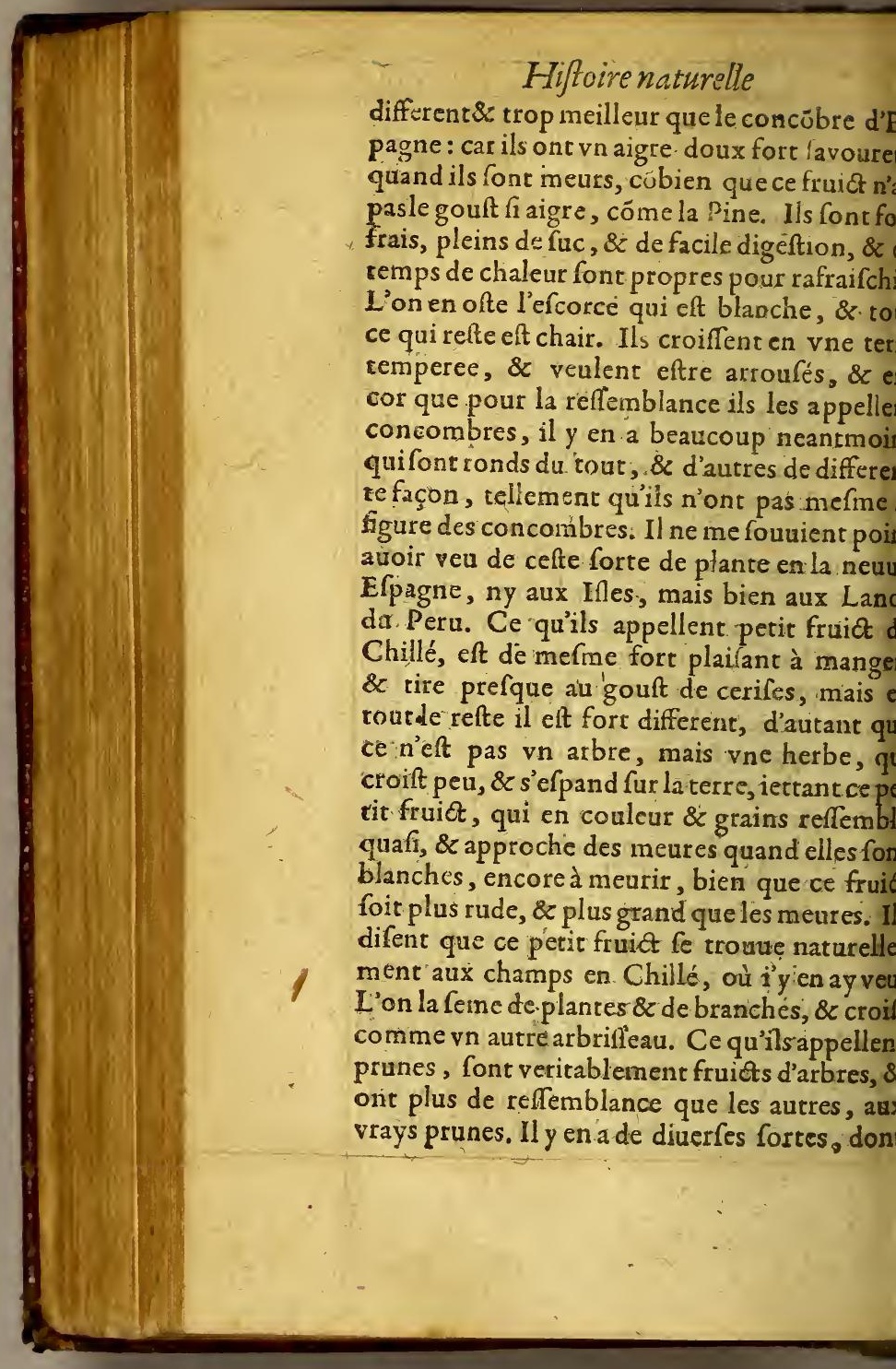




\section{des Indes. Liure IV. $\quad 167$}

appellent les vnes prunes de nicaragua, qui ne fort rouges \& petites, \& ont fort peude air au deflus du noyau,mais le peu quils tiennt, eft d'vn gouft exquis, \& d'vn aigret auffi n ou meilleur que celuy des cerifes. L'on eltie ce fruiot eftre fort fain, qui caufe que l'onle nne aux malades, fpecialement pour prouoer l'appetit Il y en a d'autres grandes $8 z$ de uleur obfcure, qui ont beaucuup de chair, ais c'eft vn manger grofier, \& de peu de gouft, i font comme Chauacanas, lefquels ont chaa'vn deux ou trois petits noyaux. Or pour wenir aux verdures \& porees, ie ne troune oint que les Indiens euffent des iardins de dierfes plantes \& porees, mais qu'ils cultiuoient terre; en quelques endroirs feulement, pour slegumes, dontils vfent, comme ceux qua' ils pellent Frifolles \& Pallares, qui leur fert omme icy de guarbences, febves, ou lentils, \& n'ay point recogneu que ceux-cy, ny aues genres de legumes d'Europe, s'y foient outez auant que les Efpagnols y entraffent, fquels y ont porté des plantes \& legumes d'ECagne, qui y croiffent 2 multiplient fort bien, oire en quelques endroits, ils excedent beauoup la fertilité de par deçà. Comme fi nous arlions des mellons, qui croilfent en la vallee e Yuca au Peru, defquels la racine fe fait tige, ui dure plufieurs annees, portant chacune des nellons, \& l'accommodent comme fi c'eftoit narbre, chofe que ie né fçache point qui foit in nulle partie d'Efpagne. Mais c'eft vne autre nonftruofité que les callabalfes ou citroúilles 


\section{Hiftoire naturelle}

des Indes en la grandeur qu'elles ont, comr elles croiffent fpecialement celles qui font pri pres \& particulieres du pays, qu'ils appeller Capallos, lefquelles ils mangent le plus for uent en Carefme, boüillies ou accommodees e vne autre fauffe. Il y a mil differences de gent de callabaffes : car quelques-vnes font tant dit formes pour leur grandeur, qu'ils font de let efcorce, eftant coupee parle milieu \& nettoyer comme des paniers où ils mettent toute la vian de poư vn difner. Des autres petites ils en for des vafes pour manger, ou boire dedans, \&le accommodent fort proprement, pour plufieur \& ditiers vfages. I'ay dit cecy des petites plan tes, nous dirons maintenant des grandes, 0 nous parlerons de l'Axi, qui neantmoins ef encor des petites.

\section{De l'Axi,ou Poivre d'Inde.}

\section{Chafitra XX.}

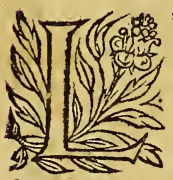

'On ría point trouué és Indes $\mathrm{O} c$. cidentales aucune efpicerie qu leur fut propre, \& particuliere cöme Poivre, Clou, Canelle, Muf. cade, ou Gingembre : iaçoit qu'vr frere de noftre Cópagnie, qui a voyagé en beaucoup \& diuers endroits, nous ayt recité qu'en des deferts de l'ine Iamaycque, il auoit trouué des arbres, où croiffoit du Poivre. Mais l'on n'eft point encor certain que f'en foit, \& n'y a 


\section{des Indes. Liure IV.}

nt mefme de traitte de ces efpiceries aux In- Le Gingembre fut porté de l'Inde à l'Épalle, \& y a multipliéde telle façon, que lon nè aroit auiourd'buy que faire du grand nóbre: il y en a. En la flotte de l'annee mil cinq cens trre vingts fept, l'an apporta vingt deux mil ginte trois quintaux de Gingembre à Seuilmais l'efpicerie naturelle que Dieu a donné Indes Occidentales, eftce que nous appelis en Caftille, Poivre des Indes, \& aux Indes $i$, par vn mot general, prins de la premiere re des Ifles, quils conquefterent. Uleit diten gue de Cufco Vchu, \&r cn celle de Mexicque, ili. Cefte plante eft defia fort cognü̈, paroy ien diray peu de chofe, feulemert l'on doit tendre quanciennement entre les Indiens, e eftoit fort eftimee, \& en portoient aux enoits où elle ne croilfoit point, cóme vne matandife de confequence. Elle ne croift pas és rres froides, comme en la Sierre du Peru, mais xvallès chaudes, où elle eft foutuent arroufee. y a de cét Axi de diuerfes couleurs, l'vn eft ord, I'vn rouge, \&l'autre de couleur iatlne, \& y a d'vne forte de fort cauftique, qui ils appeliết aribe, qui eft extremement afpre \& poignant, d'autre qui n'a point cefte afpreré, mais au Straire eft fi doux que l'on le peut manger feul, ome vn autre fruit. Il y en a qui eft fort menu, odoriferant en la bouche, quafi cóme d'odeur e mufc, \& eft trefbon. Ce qui eft afpre \& poinant en cét Axi, font les vcines \& la graine feuement: car le refte ne l'eft point, attendu qu'on e máge verd \& $\int e c_{2}$ entier \& broyé.au pot, \& ex 


\section{Hiftoire naturelle}

des fauffes, carc'eft la principale fauffe, \& tc re l'efpicerie des Indes. Quand cét Axi eft pr: moderément, il ayde \& conforte l'eftoma pour la digeftion: mais fil'on en prend trop a de maunais effets, pour-ce que de foy il eft $f_{c}$ chaud, fort fumeux, \& fort penetratif, di vient que l'vfage en eft preiudiciable à la fan des ieunes gens, principalement de lame, d'a tant qu'il prouoque à la fenfualité, \& eft v. chofe eftrange, que cöbien que le feu \& la ch leur qui eft en luy, foit affés cogneuë par l'exp rience que tous en font, veu que chacun dit qu brufle en la bouche $\&$ en l'eftomach, neátmoi quelques-vns voire plufieurs veulent mainten que le poivre d'Inde n'eft pas chaud, mais qu eft froid \& bien temperé. Mais ie leur pou rois dire, qu'il en feroit tout autant du poivr encor qu'ils m'amenaffent toutes les experies ces qu'ils voudroient de l'vn \& de l'autre. Tor tesfois c'eft vne mocquerie de dire quil n'e point chaud, veu qu'il l'eft extremement. L'o vfe duiel pout temperer l'axi, d'autant qu'il grande force de le corriger, \& fe moderent ain l'vn l'autre par la contrarieté qui eft entr'eus Ils vfent auffi de Tomates qui sút froids \& bie fains. C'eft vn gếre de grain qui eft gros, \& plei de fuc, lequel dóne bon gouft àla fauffe, \& fon bons auffia manger. Il fe trouue de ce poivr d'Inde vniuerfellemét en toutesles Indes, \& II les, neuue Efpagne, Peru, \& en tout le refte qu eft defcouuert, tellemét que cóme le mays eft ll grain le plus general pour le pain, ainfi l'axi ef efpicerie la plus commune pour les faufics. 


\section{des Indes. Liure. IV.}

\section{Du Plane.}

\section{ChaPITRE XXI.}

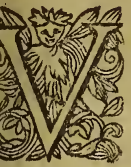

Enant aux grandes plantes, ou aux arbres; le premier des Indes duquel il eft conuenable parler, eft le plane ol platane, comme le vulgaire l'appelle. I'ay efté quelque sen doute, fl le plane, que les anciens ont cere, \& celuy des Indes, eftoit vne mefme efpe: ceftuy-cy bien confideré, \& ce qu'ils efcrint del'autre, il n'y a point de doute qu'ils ne ent en diuerfes efpeces. La caufe pourquoy Ef pagnols l'ont a ppelle' plane (car les natu$s$ nauoieht point de tel nom ) a efte corme utres arbres, pour autant qu'ils ont trotue elque reffembläce de l'vn à l'autre, en la meffaçon qu'ils ont appellé prunes, pines, aman, \& concombres, deschofes fi differentes à les qui en Cartille font appellees de ces noms. chofe enquoy il me femble qu'ils trouverent is de reffemblance entre ces planes des Indes, les planes qu'ont celebrè les anciens, a efté ens grandeur des feüilles : pour ce que ces planes ont tres-grandes \& tres-fraifches, \& lesaninsles ont tant eftimez aufsi pour cefte granur, \& cefte fraifcheur de leurs feuilles. C'eft si vné plãte qui a befoing de beaucoup d'cau, prefque continuellement, ce qui s'accorde ec l'Efcriture, qui dit: Comme le plane aupres des

$$
\text { X. }
$$




\section{Hifoire naturelle}

Ecl. 24. 'enux. Mais à la verité il n'y a non plus de com raifon ny de reflemblance de l'vne à l'autre, $n$ plus qu'il y a,comme dit le prouerbe, de l'œu la chaftaigne. Car premicrement le plane: cien ne porte point de fruict, au moinsils n faifoient point d'eftat, mais la principalle occ fion pourquoy ils l'eftimoient, eftoit à caufe fon ombrage, parce qu'il n'y auoit non plus Soleil deffous vn plane, qu'il y a deffous vne cc uerture.A u contraire, la raifon pourquoy! le doit eftimer en quelque chofe és Indes, $v$ re en faire beaucoup d'eftat, eft à caufe del fruict, qui eft tres-bon, car dombrage ilsn ont aucunement. Dauantage le plane anc auoit le tronc figrand, \& les rameaux fi efpa pline lib. 2. que Pline raconte d'vn Licinius, Capitaine $R$ cap. .x. main, lequel accomppagné de dix huict de compagnons, print fa refection fort à l'aife, $d$ le creuxd'vn de ces planes. Et de l'Emper Caius Caligula, qui s'afsit luy \& vnze conu fur le haut des rameaux d'vn autre plane 8 leur fit vn fuperbe banquet. Les planes des des, n'öt point de tels creux, troncs, ny rameal II dit dauantage que les anciens planes cro foient en Italie, \& en Ef pagne, combien qu yeuffent efté apportez premierement de G ce, \& auparauant de l'Aiie : mais les planes Indes ne croiffent point ny en Italie, ny en I pagne. Ie dy qu'ilsn'y croiffent point, car en que l'on en ait veu quelques vns à Seuille au din du Roy, ilsn'y croiffent, \& ny vallent ri Finalement la chofe enquoy ils trouuent di reflemblance entre d'vn \& l'autre eft fort dis 


\section{desfndes. Liure IV.}

te. Car iaçoit que la feüille de ces planes anns fuft grande, toutesfois elle n'eftoit pas telny femblable à ceux qui font és Indes veu que nel'accompare à la feüille d'vne vigne, ou de plinelib sà? uier. Les feüilles du plane des Indes font d'v - cap. ${ }^{26 .}$ merueilleufe grandeur, \& font prefque fufintes pour couurir vn homme des pieds iur. es à la tefte, tellement qu'aucun ne peut meten doute, qu'il n'y ait grande difference entre. n \& l'autre. Mais pofé le cas, que ce plane Indes foit different de l'ancien, pour cela il in merite pas moindre loủange, mais peut eftre cor dauantage, à caufe des proprietez tant les, \& profitables qu'ila enluy. C'eft vre ante qui fait vn ceps dedans la terre, duquel rtent plufieurs reiettons diuers \& feparez, fans re ioints enfemble. Ces reiettons croiffent groifsiffent, faifant prefque chacun vn ariffeau à part, \& en croiffant ils jettent ces iillesqui lont d'vn vert fin , \& liffé, \& de la andeur que i'ay dit. Quand il eft creu, com* e de la hauteur d'vne ftade \& demie, ou de ux, il iettevn feul rameau ou grappe de fruict, quel il y a quelquesfois grand nombre de ce aict, \& quelquesfois moins. I'en ay conté quelques vns de ces rameaux, trois cens, dont acun auoit vne paulme de long, plus ou oins, \& eftoit gros comme de deux ou trois oigts, bien qu'il y ait beaucoup de difference cela, encre les vns \& les autres. L'on en ofte coque, ou efcorce, tout le refte eft vne chair, u noyau ferme, \& tendre, qui eft bon a langer, fain \& de bonne norriture. Ce fruias 


\section{Hiftoire naturelle}

incline vn peu plusà froideur qu'à chaleur. ont accouftumé de cueillir les rameaux, c grappes, que i'ay dit, eftants verds, \& les mett en des vaiffeaux où elles fe meuriffent, eftal bien couuertes, fpecialement quand il y a d'vr certaine herbe, qui fert à cét effect:fi l'on les lai fe meurir en l'arbre, ils ont meileur gouft, ; vne odeur tres-bonne, comme de camoiffes, 0 pommes douces. Ils durent prefque tout long de l'annee, à caufe qu'il y a toufiours di reiettons, qui naiffent de ce ceps, tellement qu quand l'vn acheue, l'autre commence à donne fruict, I'vn eft à demy parcreu , \& l'autre com mence.à iettonner de notıueau, de façon que le vns fuccedent aux autres, \& ainfi y a toufrous du fruict toutel'annee durant. En cueillant 1 grappe ils couppent le reietton, d'autant qu' s'en iette point plus d'vne, ny plus d'vne fois mais comme i’ay dit, le ceps demeure \& reiett continuellement de nouueaux reietttons, iuf ques à ce qu'il fe laffe, \& vieilliffe du tout. $C_{1}$ plane dure quelques annees, \& demande beau. coup d'humidite, \& vne terre fort chayde. Il luy mettent de la cendre au pied pour le mieur entretenir, \& en font des bocqueteaux fortefpais, quileur font de grand profit \& reuenu. pour ce que c'eft le fruict dont l'on vfe le plu es Indes, \& y eft prefque vniuerfellement commun en tous endroits, iaçoit qu'ils difent que fon origine foit venuë de l'Ethiopie. Et à la verité les Negresen vjent beaucoup, \& en quelquesendroits s'en feruent au lieu de pain, voire en font du vin. L'on mange se fruict de plane 


\section{des Indes. Liure. IV.}

ut cru comme unautre fruict, l'on le roftit efme, \& en fait-on plufieurs fortes de pota$s$, voire des conferues, \& en toutes ces chofes accommode fort birn. Il y a d'vne efpece de tits planesblancs $\&$ fort delicats, lefquels ils pellent en l'Efpagnol, Dominique. Il y en a autres qui font plus forts \& plus gros, \& d'vne uleur rouge. II n'en croift point en la terre du ru, $m$ ąis l'on les y apporte des Indes, comme à exique de Cuernauaca, \& des autres vallees. la terre ferme \& en quelques Isles y a de ands planares, quifont comme boqueteaux rt ef pais. Si la plante eftoit propre pour brufr, c'eut efté la plus vtile de toutes, mais elle. y eft aucunement propre: car fa focille, ny fes meaux ne peuuét brusler, \&encor moins feruil - mefrain, à caufe que c'eft vn bois moüelleux, qui n'a point de force. Neantmoins Dom Alnfe Darzilla(comme il dit) fe feruit des feüil sfeches de cèt arbre pour efcrire vne partie de Auracane, \& à la verité à faute de papier on s'en ourroit feruir, veu que $f_{a}$ feüille eft de la larcur d'vne feuille de papier, ou peu moins \& ingue de quatre fois autant.

\section{Du Cacao \& de la Coca.}

\section{ChapITRE XXII.} Thoit que le plane foit le plus profiLI eftimé en Mexique, \& la Coca au Pe$u_{2}$ efquels deux arbresils ont beaucoup de fir- 


\section{Hiftoire naturelle}

perftition. Le Cacao eft vn fruict vn peu moir drequ'amendes, \& toutesfois plus gras, 'lequ eftant rofty n'a pas mauuaife faveur. Il eft ta eftimé entre les Indiês, voire entre les $\mathrm{E}$ [pagno? que c'eft vn des plus riches, voire plus gran commerces de la neuue $E$ p pagne. Car comm c'eft vn fruict fec \& qui fe garde long tem] fansfe corrompre, ils en ameinent desnauir chargez de la Prouince de Guatimalla. En l'a paffé vn corfaire Anglois brusla au port de Gu: tulco en la neuue Efpagne plus de cent $m$ charges de Cacao. L'on s'en fert mefme com me de monnoye, d'autant qu'auec cinq Cacac ils acheptent vne chofe, auef trente vne autr $\&$ auec cent vine autre, fans quil y aye contra dittion, $\&$ ont accouftumé de les donner pou aumofne aux pauures qui leur demandent. I principal vfage de ce Cacao eft en yn breuuag qu'ils appellent Chocholaté, dont ils font gran casence pays, follement \& fans raifon, \& fai mal au cour à ceux qui n'y font point accouftu męz, d'autant qu'il y a vne efcume $\&$ vn boüil lon au haut qui eft fort mal agreable pour et vfer, fil'on n'y a bexucoup dopinion. Toutes fois c'eft vne boilfon fort eftimee entre les In diens, de laquelle ils traittent, \& feftoyent le Seigneurs qui viennent ou paffent par leur ter. re. Les $E f_{p}$ tgnols qui font ja accouftumez al pays, font extrememét friands de ce Chochola té. Ils difent qu'ils font ce Chocholaté en diuer. fes façons \& qualitez, fçauoir I'vn chaud, l'autre froid, \& l'autre temperé, \& y mettent desefnices beaucoup de ce chilio Mefmes its en font 


\section{des Indes. Liure. IV.}

paftes, qu'ils difent eftre propres pour l'efto. $c h, \&$ contre le catarrhe. Quoy qu'il ne foit, ix qui n'y ont point efté nourris n'en font pas. ucoup curieux. L'arbre où croift ce fruict d'vne moyenne grandeur \& d'vne belle fa $n$,il eft $f i$ delicat que pour garder que le Soleil le brusle ils plantent aupres de luy vn autre and arbre qui luy fert feulement d'ombrage, l'appellent la mere du Cacao. Il y a des lieux ils font ainfi que les vignes \& les oliuiers font Efpagne. La Prouince qui en a plus grande ondance, pour le commerce \& la marchandieft celle de Guatimalla.II n'en croift point au eru, mais ily croift de la Coca, qui eft vne atre chofe oì ils ont encor vne autre plus granefuperftition qui femble eftre chofe fabuleu2. A la verite la traitte de la Coca en Potozi fe nonte à plus de demy million de pezes par chaun an, dautant qu'on y en vfe quelques quatre ingts dix ou quatre vingts-quinze mille coreilles par an. En l'an mil cinq cës quatre vingts $2 x$ trois on y en confomma cens mil. Vne corbeille de Coca en Cufco vaut deux pezes \& $\mathrm{de}$ my, \& trois, \& en Potozi elle vaut tout contant quatre pezes \& cinq tomines, \& cinq pezes effayez. C'eft l'efpece de marchandife à l'oscafion de laquelle prefque fe font tous les marchez $\&$ foires, parce que c'eft vne marchandife dont il y a grande expedition. La Coca done qu'ils eftiment tant, eft vne petite feüille verde qui naif en des arbriffeaux qui font comme d'vne brafle de haut, elle croift en des terres fort shaudes \&s humides, \& iette ceft arbre de qua: 


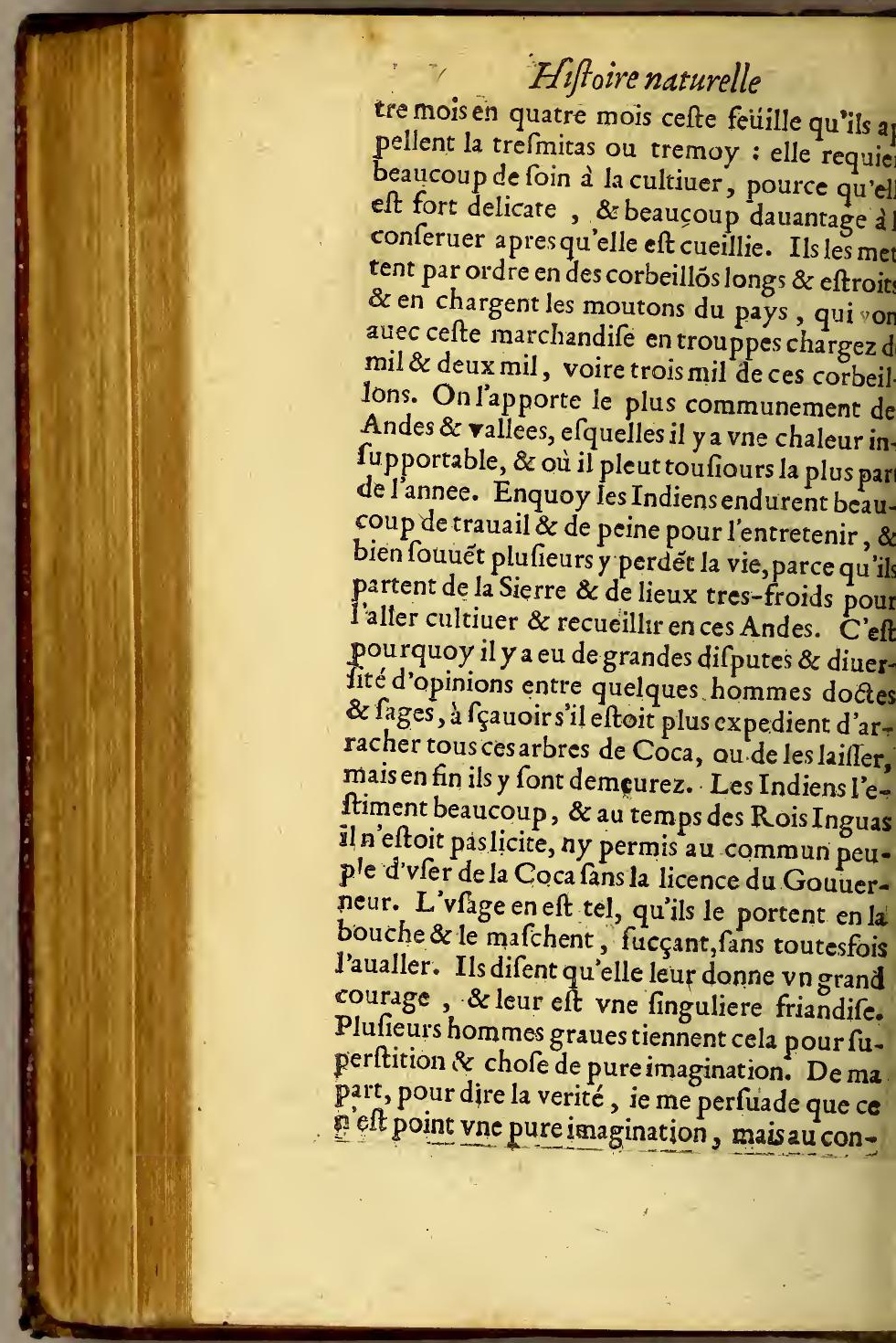


ire i'entends qu'elle opere \& donne force \& urage aux Indiens : carl'on en voit des effects i ne peuvent eftre attribuez à imagination, ne de cheminer quelques iournees fans man$r$ auec vne poignee de $\mathrm{Coca}, \&$ autres effeets nblables. La faulfe auec laquelle ils mangent Coca leur eft affez conuenable, pource que ay goufte', \& a comme le gouft de Sumacq. $s$ Indiens la broyent auec de la cendre d'os uslez \& mis en poudre, ou bien auec de la ax, comme d'autres difent, ce quileur femble 't appetiffant $\&$ de bon gouft, \& difent qu' il Ir fait vn grand profit. Il y employent libreint leur argent, \& s'en feruent en mefmevfage e de la monnoye. Encor toutes ceschofes ne oient point mal à propos, n'eftoit le hazard rifque qu'il y a en fon commerce, \& àl'apofiter, en quoy tant ces gens font occupez. s Seigneurs Inguas vfoient du Coca comme chofe royale \& friande, \& eftoit la chofe 'ils offroient le plus en leurs facrifices, le brufit en l'honneur de leursidoles.

Du Maguey, du Tunal, de la Cochenille, de lanir ó du cotton.

Chapitre XXIII.

Don $E$ maguey eft l'arbre des merueilI 1 les, duquelles Nouneaux ou Cha700 Indes ) ont accouftumé d'efcrire des mira- 


\section{Hiftoire naturelle}

cles,ence qu'il donne de l'eau, du vin, de l'hu le, du vinaigre, du miel, du firop, du fil, dese guilles, \& mil autres chofes. C'eft vnarbreq les Indiens eftimét beaucoup en la neuue Efp gne, \& en ont ordinairemét en leurs habițatio quelqu'vn pour entretenir leur vie. Il croift Je cultiuent aux champs, \& a les feüilles lar \& grofsieres, au bout defquelles il y a vne poir forte $\&$ aigüe, qui fert pour attacher comme efplingues, ou pour coudre comme vne efgu le, \& tirent aufsi de cefte feüille comme vnce tain fil, dont ils fe feruent. Ils coupent le tro qui eft gros quand il eft encore tendre, \& meure vne grande concauité, par laquelle mo te la fubftance de la racine, \& eft vne lique quel'on boit comme del'eau qui eft frefche douce. Cefte mefme liqueur eftant cuitte tourne comme vin, lequel deuient vinaigre le laiflant aigrir, \& en le faifant boliillir d'aua tage il deuient comme du miel ; \& le cuifan demy il leur fert de firop, qui eft affez fain \& bonne faveur, voire me remble meilleur que firop de raifins. Voyla comme ils font cuire fe feruent de cefte liqueur en diuerfes façons, laquelle ils tirent bonne quantité, d'autant qu' certaine faifon ilstirent par chaque iour que ques pots de cefte liqueur. Il y a mefme dec arbres au Peru, mais ils ne les rendent poin profitables comme en la neuue Efpagne. I bois de ceft arbre eft creux $\& \mathrm{~mol}$, \& fert po conferuer le feu, pource qu'il le retient comn vne mefche d'arquebuze, \& s'y garde long tế! dont iay veu que les Indiens s'en feruojent à ca 


\section{des Indes. Liure IV. $\quad 174$}

ct. Le tunal eft vn autre arbre fameux en la tue Efpagne, fi arbre nous deuons appelvn morçeau de feüilles amaffees les vnes fur autres, lequel eft de la plus eftrange façon rbre, qui foit. Pource qu'il fort de terre preerement vne feüille, \& d'icelle vne autre, \&t celte.cy vne autre, \& ainfi va croifsät iufques perfection, finon que comme fesfeuilles nt fortant en haut $\&$ aux coftez, celles d'em$s$ 'engrofsiffent, \& viennent prefque à perdre igure de feüilles, en faifant vn tronc \& des neaux qui font afpres, ef pineux \& difformes, ù vient qu'en quelques endroits ils l'appelt chardon. Il y a des chardons, ou Tunaux unages qui ne portent point de fruict, ou bien it fort efpineux, \& fans aucun profit. Il y a efme des Tunaux domeftiques, qui donnent fruict fort eftimé entre les Indiens, qu' ils apllent $T$ unas, \& font de beaucoup plus gransque les prunes de frere, \& ainfi longues. Ils ouurent la cocque, qui elt graffe, $\&$ au dedans a le la chair, \& des petits grains femblables $a$ ux des figues, qui font fort doux , $\&$ ont vin on gouf, fpeciallement les blanches, lefquels at vne certaine odeur fort agreable, mais les ouges ne font ptsordinairement $f \mathrm{~b}$ bons. Il y a ne autre forte de Tunaux, lefqueis ils eftiment eaucoup dauantage, encor qu'ils ne donnent oint de fiuict, \& lescultiuent auec vn grand ing \& diligence: $\&$ iaçoit qu'ils n'en recueilint point de ce fruict, neantmoins ils rapporent vne autre commodité $\&$ profit qui elt de graine, d'autant que certains petits vers naif 


\section{Hifoire naturelle}

fent aux feuiiles de cet arbre, quand il eft bi cultiué, \& y font attachez, conuerts d'vne ce taine petite toile déliee, lefquels on circuit de. catement, \& eft la cochenille des I I des tant $r$ nommee, de laquelle l'on teint en graine. Ils laiffent fecher, \& ainfi fecs, ils les apportent Efpagne, qui eft vne groffe, \& riche marchand fe. L'arrobe de cefte cochenille, ou graine, val plufieurs ducats. On en apporta en la flotte 'an mil cinq cens quatre-vingts fept, cinq $m$ fix cens foixante dix-fept arrobes, qui montoier ì deux cens quatre vingts trois mil, fept cer \& cinquante pezes, \& ordinairement il e vient tous les ans vne femblable richẹfe. C Tunaux croiffent és terres temperees, qui decli nent à froideur. Au Peru il n'y en croift poin encor iufques à prefent. I'en ay veu quelque plantes en Efpagne, quine meritent pastoutes fois d'en faire aucun eftat.Ie diray aufsi quelqu। chofe de l'Anir, combien qu'il ne vient pas d'vs arbre, mais d'vn herbe, parce qu'il fert à la tein ture des draps, \& que c'eft vne marchandife qu s'accommode auec la graine, \& mefme qu'i croift en grande quantité, en la neuue $\mathrm{E}$ f pagne d'où il en vint en la flotte que i'ay dit, cinq mi deux cens foixante $\&$ trois arrobes, ou enuiron, qui montent autant de pezes. Le cotton mefme croift en des petits arbriffeaux, \& en des grands arbres qui portent comme des pommettes, lefquels s'ourrent \& donnent cefte filafle, \& apres l'auoir cueillie, la fillent, \& la tirent pour en faire des eftoffes. C'eft vne des chofes qui fait ès Indes de plus grand profit, \& de plus d'vfage, car 


\section{des Indes. Liure IV.}

eur fert de lin, \& delaine pour faire des hac s. Il croift en terre chaude, \& y en a vne granquantité és vallees \& cofte du Peru, en la neuEfpagne, ès F hilippines, \& en la Chine. Tou fois il y en a beaucoup dauantage, qu'en au: n lieu que ie fache, en la Prouince de Tuciin, en celle de faincte Croix de la Sierre, \& au raguey, \& leur eft le cotton le principal reue- L'on apporte en Efpagne du cotton des Ifde S. Dominique, \& en vint l'annee que i'ay foixante \& quatre arrobes. Aux endroits des des où croift le cotton ils en font de la toile int les hommes \& les femmes vfent le plus mmunement, mefmes en font leurs feruicttes tables, voir des voiles de nauire. Il y en a de. os, \& d'autre qui eft fin \& delicat. Il le teient en diverfes couleurs, comme nous faifons draps de laine en Europe.

\section{Des Mameyes, Grayanos, \& Paltos.}

\section{CHAPITRE XXIV。}

12ara Es plantes dont nous auons parlé, font at les plantes les plus profitables des In (2) des, \& celles qui font les plus necerfaires pour le viure : toutesfois il y en beaucoup d'autresqui font bonnes ìmanger, atre lefquelles les mameyes font eftimees tans de la façon des groffes pefches, voire lus groffes. Ils ont vn ou deux noyaux dedans, a chair quelque peu dure. Il y en a quifont 


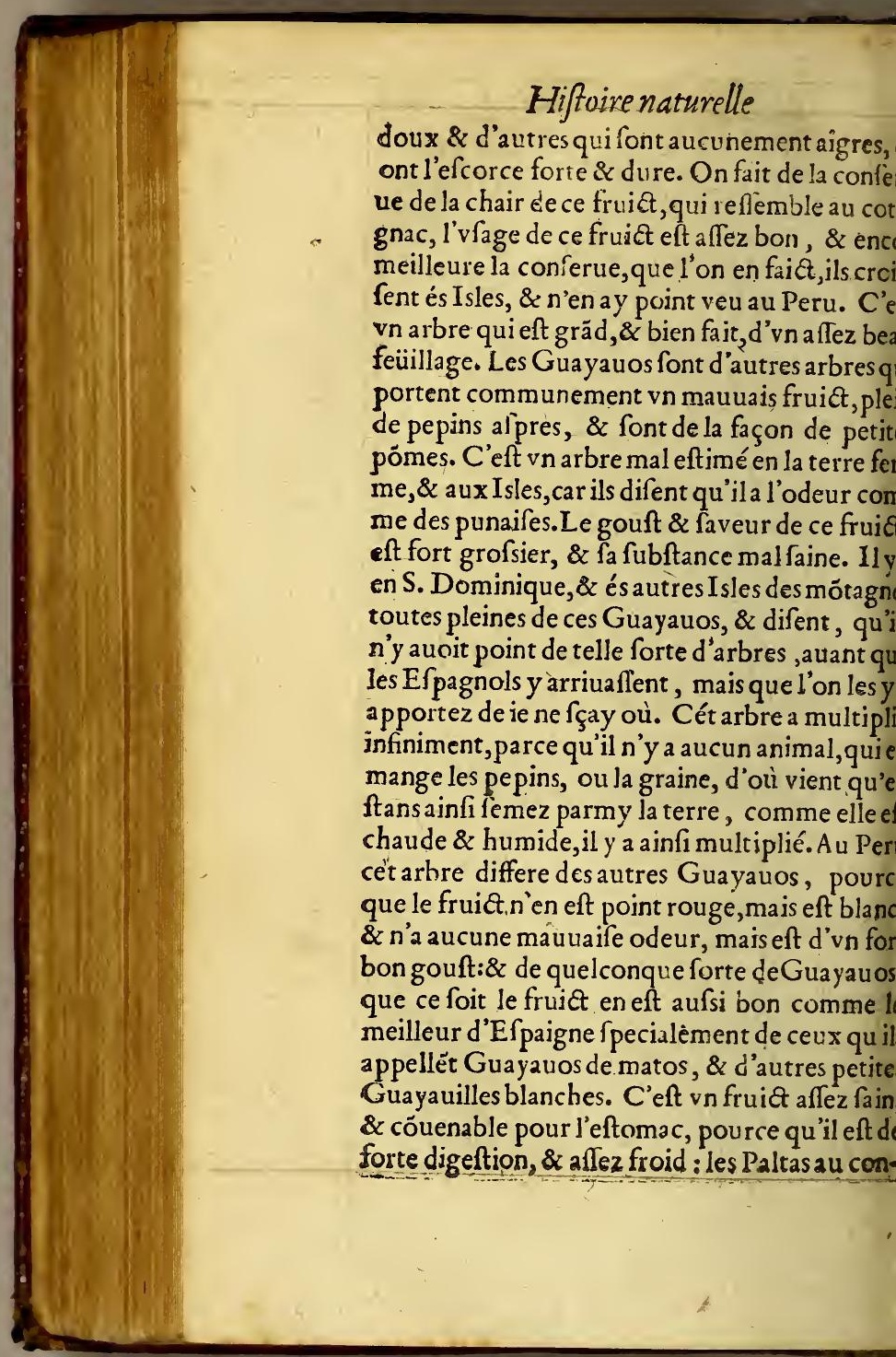




\section{des Indes. Liure. IV.}

aîre font chaudes \& delicates. Le Palto eft va bre grand $\&$ de beau feüillage, qui a le fruict, omme des groffes poires, il a dedans vn gros oyau, \& tout lo refte eft vne chair molle, telleent que quand ils font bië meurs, ils font com. e du beurre, $\&$ ont le gouft delicat. Les Paltas ont grands au Peru, \& ont vne efcaille fort du, quel'on peut ofter toute entiere. Ce fruict eft Mexique, pour la plus part fort, ayant l'efcore deliee, qui fe pelle comme des pómes. Ilsles ennent pour vne viăde faine, \& comme iay dit, ui decline quelque peu à chaleur.Ces mamayes suayauos, \& Paltos, font les pefches, les pomnes, \& les poires des Indes, encor que ie choifiois pluftoft celles de l'Europe. Maisquelques utres par l'vfage, ou peut eftre, par affection, ourront eftimer dauantage ceux-cy des Indes. ene doute point, que ceux qui n'ont point ver, y goufté, de ces fruict, prend rŏ́t peu de plailir a ire cecy, voire fe lafferót de l'oü yr, \& moy mefne ie m'en laffe, qui caufe que i'abregeray en raótant quelques autres fortes de fruit. Car ce feoit chofe imporsible de pounoir traiter de tous.

Du Chicocapote, des Annonas \& des Capollyes. ChAPITRE。 XXV.

Velques vns qui ont voulu augmenter les chofes des Indes, ont mis en auant qu'il y auoit vn fruict, qui eftoit femblableau cotignac, \& l'autre qui eftoit comme dublanc manger : pource que la 


\section{Hiftoire naturelle}

faveur leur fembla digne de ces tioms. Le cot gnac ou mermelade(fi ie ne me trompe)eftoit c qu'il's appelloient, ça potes, ou chicoça potes, qu font divn gouft fort doux, \& approchant à couleur de cotignac. Quelques Crollos, (quie) !e nom dont ils appellent les Ef pagnols nais au Indes)difent que ce fruict furpaffe en excellens tous les fruicts d'Efpagne. Toutesfois ce n'e mon opirion, maisils difent qu'au gouft prin cipalement il furpaffe tous les autres fruicts, o ie ne me veux pasarrefter neátmoins, parce qu cela ne le merite pas. Ceschicoça potes ou ça po tes, entre lefquels il y a peu de difference, croif fent és lieux chauds de la neuue $\mathrm{E}$ pagne, \& n'a point cognoiffance, qu'il y ait de tel fruict en terre ferme du Puru.Pour le blanc manger, c'ef l'Annone, ou guanauana, quicroift en terre ferme. l'Annona eft de la façon d'vne poire, \& ainfi quelque peu aigue $\&$ ouuerte, tout le dedăs eft tédre \& mol comme beurre, \& eft blanc, doux \& d'vngouft fort favoureux. Ce n'eft pas manger blanc, encor qu'il foit blanc manger, mais à la verité c'eft beaucoup augmente de luy donner tel nom, bien qu'il foit delicat $\&$ d'vn gou it fav oureux, \& quoy que felon le iugemét d'aucuns, il foit tenu pourle meilleur fruict des Indes, il a en foy vne quantité de pepins noirs, \& les meilleurs que i’ay reu, a $\in$ fté en la neute $E f$ pagne, cù les ca polyes croifsēt aufsi, qui font cóme des cerifes, \& vn nor au, bië que quelque peu plus gros. Mais la forme \& figure eft comme de cerifes, de bóne faveur, ayāt un doux-aigret:mais ien'ay point veu de capollyes en autre contree. 


\section{des Indes. Liure IV.}

plufieurs fortesdefruitiers, des cocos, des Amendes, des Andes, Oo des Amendes de Chachapayas.

CHAPITRE XXVI.

7 L ne feroit pas pofible de racôter tous L les fruits \& arbre des Indes, attendi. 21 queie ne m'en refoutiens pas de plu* fieurs, \& qu'il y en a encor beaucoup tantage defquels ie n'ay pas cognoiffance, \& femble chofe ennuyeufe de parler de toutes, at il me fouvient. Ilfe trouue donc d'autres ares de fruitiers \& de fruits plus groffiers, nme ceux qu'ils appellent lucumes, du fruit quels ils difent, par prouerbe, que c'eft vn $x$ diffimu'é, comme les guauas, pacayes, les oos, \& les noix qu'ils appellét emprifonnees, quels fruits femblent à plufieurs eftre des ix de la mefme efpece que font celles d'Efpa$\therefore$ Voire ils difent, que fil l'on les träfplantoit uent d'vn lieu en autre, qu'ils rapporteroiét noix toutes femblables à celles d'Efpagne $\&$ quils donnent ainfi vn fruit fauuage, \& fi $\mathrm{mal}$ ifant, eft à caufe qu'ils font fauuages. En fin a doit bien cófiderer la prouidence \& richeflu Createur, lequel a departy à tant de diuerparties du monde, telle varieté d'arbres fruirs, le tout pour le feruice des hommes qui haent la terre, \& eft vne chofe admirable de oir tant de differ entes formes, gouft, \& effets tout incognus, \& dont on n'auoit iamais oüy 


\section{Hiftoire naturelle}

parler au monde, auparauant la defcouue des Indes. Et defquelles mefme Pline, Di coride \& Theophrafte, voire les plus curie n'ont eu aucune cognoiffance, neantmo toute leur recherche \& diligence. Il s'eft tr ué des hommes curieux de noftre temps quic efcrit quelques traittez de ces plantes des des, des herbes, \& riuieres, \& des operatic qu'ils ont en l'vfage de medecine, aurquels l' pourra recourir, qui en voudra auoir plus a ple cognoiflance, parce que ie pretends trait feulement en peu de mots \& fuperficieilem ce qui me viendra en la memoire, touchant fubiect. Neantmoins il ne me femble pasb paffer foubs filence les cocos, ou palmes Indes, à caufe d'vne proprieté qu'ils ont, qui fort notable, \& remarquable. Ie les appelle p. mes, non pas proprement, ny quily ait des di tes, mais d'autant que ce font arbres femb. bles aux autres palmes. Ils font hauts \& for \& plus ils montent en haut, plus vont. ils ietta des rameaux grands \& fort eftendus. Ces $p$ mes ou cocos donnent vn fruit qu'ils appelle aufficocos, dequoy ils ont accoultumé fai des vafes pour boire, \& difent qu'il y en a que ques vns qui ont vne vertu, $\&$ proprieté cont le poifon, \& pour guerir le mal de cofté. I noyau \& la chair diceux (quand il eft efpoiffi fec)eft bon à manger \& approche quelque pe du gouft de chaftaignes verdes. Quand le co eft en l'arbre encor tendre, tout ce qui eft ded' eft comme vn laict qu'ils boiuent par delice \& pour rafraifchir en temps de chaleur. I' 


\section{des fndes. Liure IV.}

de ces arbres en fainct Iean de port riche autres endroicts des Indes, \& m'en dirent vne ofe remarquable, que chaque mois ou Lune arbre iette vn nouneau ranseau de ces co5, tellement qu'il donne du fruit douze fois ran, comme ce qui eft efcrit en l'A pocaly pfe, à la verité il me feinble que ce fuft de melme, urce que tous les rameaux font d'aages fort ferens, les vns commencent, les autres font lia meurs, \& les autres le font à demy. Ces cosque ie dy font ordinairement de la figu\& groffeur d'un petit mellon': 11 y en a d'vne tre forte qu'ils appellent coquillos, qui eft fruit meilleur, dont il y en a en Chillé. Ils nt quelque peu plus petits que noix, mais vn u plus ronds. 11 y a v ne autre efpece de cocos i ne donnent point ce noyau ainfi efpoiff, aisils ont dedans vne quantité de petits fruits mme Amendes, à la façon des grains de grede. Ces amendes font trois fois auffi grandes e celles de Caftille, \& leur reffemblent au uft, encor qu'elles foient vn peu plus afpres font au ffi humides \& huilleufes. C'eft vn afzbon manger, auffi ils s'en feruent en deli$s$, faulte d'amendes, pour faire des maffeins, \& autres telles chofes. Ils les appellent nendes des Andes, pour ce que ces cocos oiffent abondamment és Andes du Peru, font $f i$ forts \& durs, que pour les ouurir, il eft foing de les frapper rudemét auec vne groffe erre. Quand ils tombent del'arbre, sils renintroient la tefte de quelqu'vn, il n'auroit ia Loing d'aller plus loing. Et femble vne chofs $\mathrm{Z}$ ij 


\section{Hiftoire naturelle}

incroyable, que dedans le creux de ces co qui ne font pas plus grands que les autres, gueres dauantage, il y a neantmoins vne mulcitude \& quantité de ces amendes. M en ce qui concerneles amendes, \& tous les tres fiuits femblables, tous les arbres doiu ceder aux amendes de Chachapoyas, lefqu les ie ne peux autrement appeller. C'eft le in le plus delicat, friand, \& plus fain de tous, $t$ que i'aye veu és Indes. Voire vn docte Mede affermoit qu'entre tous les fruits qui font és des, ou en Efpagne, nul n'approchoit de l'ex lence de ces amendes. Il y en a de plus gräde: de plus petites que celles que $i$ ay dit des And mais toutes font plus graffes que celles de $\mathrm{Caf}$ le. Elles font fort tendresà manger, ont be coup de fuc, \& de fubftance, \& côme onctueu \& fort agreables, elles croiffent en des arb tres-hauts, \& de grand feuilllage. Et com c'eft vne chofe precieufe, nature auffil leur a di né vne bonne couverture \& deffenf'; veu qu' les font en vne efcorce quelque peu plus gra de \& plus poignante, que celle des chaftaign toutesfois quand cefte efcorce eft fe:he, 1 en tire facilement le grain. Ils racontent $q$ les finges, qui font fort friands de ce fruit, defquels il y a vn grand nombre en Chach poyas du Peru, (qui eft la contree de tout où ie fçache qu'il $y$ ayt de ces arbres) pour fe picquer en l'efcorce, \& en tirer l'amenc les iettent rudement du haut de l'arbre fur pierres, \& les ayans ainfi rompuës, les ach uent d'ouurir pour les manger à leur plaifr. 
plufeurs \& dinerfes fleurs, o de quelques arbres qui donnent feulewaent de la feur, oc commeles Indiens en vent.

CHAPITRE XXVII.

Eng Indiens font fort amis des fleurs, 6ren la neuue Efpagneplus qu'en autre partie du monde, parquoy ils ont accouftumé de faire plufieurs fortes. boucquets, qu'ils appellent là fuchilles, auec e telle varieté \& gentil artifice, que l'on n'y ut rien defirer dauantage. Ils ont vne couftue entre eux que les principaux offrent par honur leurs fuchilles, ou bouquets aux feigneurs? à leurs hoftes, \& nous en donnoient en telle. ondance, quand nous cheminions par cefte rouince, que nous ne fçauions qu'en faire, ien qu'ils fe feruént auiour d'huy $\mathrm{z}$ cet effet, es principales fleurs de Caftille, pour-ce u' elles croiffent là mieux qu'icy, conme fone es cillets, rofes, iafmins, violettes, fleurs d'oanges, \& les autres-fortes de fleurs, quils y ont ortees d'Efpagne, y profitent merueilleufeaent. Les rofiers en quelques endroits y croifoient trop, tellemert quils ne donnoižr point le rofes. 11 arriua vn iour qu'vn rofier fut brué, \& les reiettons \& fcyons qui ietterent inontinent, porterent des rofes en abondance, $x$ de là ils apprindrent à les efmonder, \& er ofter le bois fuperflu, tellement quauiousa

$$
Z \text { iij }
$$




\section{Hiftoire naturelle}

d'huy ils doninent des rofes fuffifammer Mais ourre ces fortes de fleurs que l'on y portées d'icy, il y en a beaucoup d'autres, I noms defquelles ie ne peux pas dire: qui fo rouges, iaunes, bleües, violettes, \& blanch. auec mil differences, lefquelles.les Indie ont accouftumé de porter en leurs tefte comme vn plumage pour ornement. Il vray que plufieurs de ces fleurs n'ont que veiie, pource que l'odeur n'en eft point bo ne, ou elle eft groffiere, ou elles n'en os point du tour, encor qu'il y en ait quelqu vnes d'excellente odeur. Comme celles $q$ croiffent en vn arbre quills appellent floripō dio, ou porte-fleur, qui ne donne aucun fru mais porte feulement de ces fleurs, lefquell font plus grandes que fleurs delys, \& font qu: fi en forme de clochettes, toutes blanches, i ont au dedans des petits filets comme l'on vo au lys : il ne ceffe toure l'année de produir ces fleurs, l'odeur defquelles eft merueilleufe ment douce \& agreable fpecialement en 1 frailcheur du matin. Le Viceroy Dom Fran cifco de Tollede enuoya de ces arbres au Ro Dom Philippes, comme vne chofe dign d'eftre plantée auxiardins Royaux. En la neu ue Efpagne les Indiens eftiment beaucout la fleur qu'ils appellent yolofuchil, qui fignifi fleur de caur, pource qu'elle eft dela mefm forme d'vn cœur, \& n'êt pas gueres moindre Il y a mefme vn autre grand arbre, qui porte de cefte forte de fleurs, fans porter d'autre fruit elle ane vdeur qui ett forte, \& comme if me 


\section{desfndes. Liure IV. $\quad 280^{\circ}$}

mble, trop violente, à d'autres elle leur pourfembler aggreable. C'eft vne chofe affez coieie que la fleur qu'ils appellent fleur du Soi, a la figure du Soleil , \&z fe zourne felon le ouuement d'iceluy. Il y en a d'autres qu'ils pellent aillets d'Inde, lefquels refiemblent vn fin velours orangé $\&$ violet, celles-là n'one cune fenteur qui foit d'eftime, mais feulemét int belles à la veiie. Il y a d'autres fléurs, qui atre la beauté de la veïe, combien qu'elles ayent aucune odeur, ont vne faveur comme lles qui reffemblent à celle du creffon alleois: que fi l'on les mangeoir fans les voir, l'on e iugeroit point que ce fuft autre chole. $\mathrm{La}$ eur de granadille eft tenuë pour chofe rearquable, \& difent qu'elle a en foy les marues \& enfeignes de la paffion, \& que l'on y emarque les clouds, la coulomne, les fouëts, couronne d'efpines, \& les playes, enquoy $s$ ne font pas du tout efloignez de raifon, çoit que pour y trouuer \& remarquer toues ces chofes, il foir befoing de quelque pie, qui aydeà en faire croire vne partie, mais lle eft fort exquife, \& tresbelle à la veïe, enor qu'elle n'aye point d'odeur. Le fruit qu'ils ppellent aufi granadille, fe mange, fe boit, tu pour mieux dire, fe fucce, pour rafraifchir: e fruit eft doux, \& felon l'opinion de queljues-vns, il l'eft par trop. Les Indiens ont iccouftumé en leurs feftes, \& dances de porter les fleurs en leurs mains, \& les Roys, \& Seizneurs en portent pour la magnificence. Pour

$$
Z \text { iiii }
$$




\section{Hifoire naturelle}

celte occafion lon void des peintures de lei anciens ordinairement auec des fleurs en main, comme l'on void icy auec des gan Il mefemble en auoir affez dit fur ce qui co cerneles fleurs. L'on vfe auffi à ceft effect bazilic, encor que ce ne foit point vne flet mais feulement vne herbe, \& ont accouft mé d'en auoir en leurs iardins, \& de la bi cultiuer, mais maintenant ils en ont fi peu foing, qu'il n'eft plus auiourd'huy bazili mais s'eft vne herbe qui croif autour d eftangs.

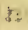

\section{Du Baulme.}

Chapitre XXVIIT.

71, $E$ founerain Createur n'a pas feule - L d ment formé les plantes pour feru - de viande, mais anfi pour la recrea tion \& pour la medecine $\&$ guarifo del'homme. I'ay dit quelque peu de celles qu feruent pout la nourriture, qui eft le principal Et mefme quelque peu de celles qui feruent $d$ recreation. Il refte donc maintenant de traitte de celles qui font propres à la medecine, don ie diray auffi quelque peu de chofe. Et enco que toutes les plantes foient medecinales quác elles font bien cogneiies \& bien appliquées routesfois il y a quelques chofes particuliere. ment, que l'on void notoirement auoir efté ordónées du Createur pour la medecine, \& pour 
des Fndes. inure $1 \mathrm{~V}$. I8I Canté des hommes, comme font les liqueurs,
ulles, gommes \& rezines qui prouiennent de iuerfes plantes \& herbes, \& qui facilemét deonftrent à l'experience à quoy elles font prores. Sur toutes ces chofes le baufme antec rạion eft renommé pour fon éxcellente odeur, \& 2 , eaucoup dauantage pour l'ex quis offect quil a ecurer les playes \& autres diuers remedes que on experimente en luy fur la guarifon des madies. Le baufme qui vient des Indes Occidenales n'eft pas de la mefme elpece que le vray aufine qu'on apporte d'Alexädrie, ou du Caie, \& qui anciennemét eftoit en ludee, laquelie udee, felon que Pline efcrit, polfedoit feule au Plin.l. rs: onde cefte grandeur, iufquesà ce que l'Empe- cap. 15 . eur Vefpafian l'apporta à Rome \& en Italie. equi me donne occafion de direque l'vne liueur \& l'autre nefont point d'vne mefme efece, c'eft à caufe que les arbres d'oì elles forent font entr'eux fort differentes: car l'arbre du. aufme de Paleftine eftoit petit, \& à la façon de igne, comme raconre Pline pour l'auoir veu; \& ceux d'aujourd'huy' qui l'ont veu en Orient; n difent autant. Comme auffi la fain हte Efcriure appelle le lieu où grofir le baufme, vigne cart. to 'Enguaddi, pourla reffemblance qu'il a aucc. es vignes. I'ay veu l'arbre d'où fe tire le baufme les Indes, qui eft auffi grand com are vn grena-, lier, voire àprochát quel que peu de fa façon, i iay bonne memoire, n'ayant rien de cómun. uec la vigne; combien que Strabon efcriue que Strab.l 1 tro arbre ancien du baufme eftoit de la grandeur Grograph des grenadiers. Mais aux accidens \& operations $s_{2}$ 


\section{Hiftoire naturelle}

ce font liqueurs fort femblables, comme ell le font en leur odeur admirable, \& en la cure guarifon des playes, en la couleur, \& en la fu ftance; veu qu'ils racontent de l'autre baufm qu'il y en a de blanc, de vermeil, de verd, \& noir; ce quel'on void auffi en ceux des Indes. tout ainfí qu'ils tiroient l'ancien en coupant, incifant l'efcorce, pour en faire diftiller cefte queur; ainfi en font-ils de mefme en celuyd plin. lib. in. Indes, encore qu'il diftille en plus grande qua eap. 15.1 tité. Et comme en cét ancien il y en a d'vne fo te qui eft tout pur, lequel ils appellent Opoba famo, qui eft la propre larme qui diftil! e; \& v autre qui n'eft pas fi exquis, lequel on tire boisde l'efcorce \& des feüilles efpreintes\& $\mathrm{cu}$ tes au feu, lequel ils appellent Xyloballami. D mefme auffi entre le baufme des Indes il y en vin pur qui fort ainfi de l'arbre, \& d'autres qu les Indiens tirent en cuifant \& efpreignant $l 6$ feiilles \& le bois, mefmes ils le fophiftiquen $\&$ augmentent auec d'autres liqueurs, afin qu' y en ayt dauantage. Et n'eft pas fans raifon qu'i. l'appellent baufme: car il l'eft veritablemen encores quil ne foit pas de la mefme efpeced l'ancien, \& eft beaucoup eftimé, \& le feroit da uantage, fi ce qui eft auiourd' huy és efmeraude \& perles n'y eftoit, à (çauoir d'eftre à prefent es grande quantité. Ce qui importe dauantage eft l'vfage auquel il eft employé de feruir d chrefme qui eft fi neceffaire en la faincte Eglife \& de telle veneration, ayant declaré le Sieg. A poftolique, qu'on faffe le chrefine aux Inde. auec le baufme, \& qu'on en vfe au Sacremét d 


\section{des Indes. Liure IV.}

282 onfirmation, \& aux autres Sacremens, dont iglife vfe. On apporte le baufme en Efpagne la neuue Efpagne, de la Prouince de Guarialla, de Chiappa, \& d'autres lieux où il abon¿dauantage, encore que le plus eftimé foit cey qui vient de l'Ine de Tollu, qui eft en la terferme, non pas loing de Cartagene. Ce baufe eft blane, \& cómunement ils tiennent pour lus parfaict le blane que le rouge, encore que line donne le premier lieu au vermenl, le fecód ablanc, le troifiefmeau verd, \& le dernier au oir. Mais il femble que Strabon eftime dauangele baufine blanc, commeles noftres l'eftiplim.l. x:"' ient. Monardes traitte amplement du baufme es Indes en la premiere \& leconde partie, fpeialement de celuy de Caftagene \& de Tollu, ui eft tout vn. Ie n'ay point trouué que les Iniens anciennement eftimalfent beaucoup le Strab.libs: Geograph: aufme, ny mefmes l'employaffent en viage importance, encores que Monardes dife que indiens curoient auec iceluy leurs playes, \& ue de là l'apprindrent les $E$ fpagnols.

cap. 25.

el ambre, of des autres huilles, gommes, of drogues que l'on apporte des Indes.

Chapitre XXIX,

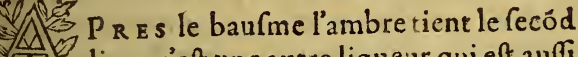
lieu; c'elt vne autre liqueur qui eft auffi odoriferente \& medicinale, mais plus Ppaiffe de foy, qui fe tourne \& l'efpaiffic en vne afte de complexion chaude, \& de bon parfum, 
Hiftoire naturelle

lequel ils appliquent aux playes, bleffures, autres necefitez. Surquoy ie me rapporte a Medecins, fpecialement au Docteur Monard qui à la premiere partie a efcrit de cefte liqueu $\&$ de beáucoup d'autres medicinales qui vie nent des Indes. Cét ambre vient mefrne de neuue Efpagne, laquelle a cét aduantage fur 1 autres Prouinces, en ces gommes, liqueurs, fucs d'arbres; qui caufe qu'ils on tlà abondan de marieres pour le parfum, \& pour la medec ne, comme eft l'Animé qui y vient en gran quantité, le Copal, ou Suchicopal, qui eft autre genre, comme de Storax \& Encens, qu mefme d'excellentes operations, \& eft d'vt tres-bonne odeur, propre pour les fuffumig tions. Mefme la T tamahaca, \& la Carani qui font auff fort medicinales. On apporte cefte Prouince de l'huille d'a(pic, de laquelle ${ }_{1}$ Medecins \& Peintres fe feruent affez; les un pour leurs emplaftres, \& les autres pour vern leurs peintures. L'on apporte mefme pour ls Medecins la caffe fiftule, laquelle croift abor damment en fainct Dominique. C'eft vn gran arbre qui porte fes cannes comme fon fruiह $L$ Lon apporta en la flotte où ie vinsde fainct $D c$ minique, quarante-huict quintaux de caffe fi ftule. La falćepareille n'eft pas moins cogneüi pour mille remedes à quoy on l'employe; il e: vint en cefte flotte cinquante quintaux de 1 mefme Inle. Il y a beaucoup de celte falcepareil le au Peru, \& de fort excellente en la Prouin de Guay aquil, qui eft foubs la ligne. Plufieur fevont faire guarir en cefte Prouince, \& eft l'o 


\section{des Fndes. Liure IIT.}

nion de quelques-vns, que les feules eaux mples qu'ils boiuent, leur donnët fanté à cauquelles palfent par racines, comme nous ions dit cy deffus, d'où elle tire fa vertu; telleent que pour fuer en cefte terre, il n'eft point efoing dc beaucoup de couverture, ny d'haits. Le bois de guayac, quils appillent autreent, bois fainct, ou bois des Indes, croift en bondance aux mefmes lfles, \& eft aulfi pefant wele fer; tellement qu'il l'enfonfle incontinent $n$ l'eau. De ceftuy l'on en apporta en cefte flottrois cens cinquante quintaux, \& en eutt- on eu apporter vingt, voire cent mil, fil y auoit iftribution de ce bois. Il vint auffi en la meime otte \& de la mefme Ine, cent trente quintaux e bois de brefil, qui eft fi rouge, enflambé, \& cogneu, \& dont on vfe tant pour les teintues \& autres chofes. Il y a és Indes vne infinité 'autres bois aromat:ques, gommes, huilles \& rogues; de forte qu'il n'eft pas polfible deles ouuoir tous raconter, \& eft chofe aulf depeu limportance à prefent. Ie diray feulement que u temps des Rois Inguas de $\mathrm{Cufco}$ \& des $\mathrm{Ro}$ is Mexiquains, il y eut beaucoup de grands per onnages experts à curer \& medeciner auecles imples, \& faifoient de fort belles cures, d'auant qu'ils auoient cognoiffance de plufieurs ertus $\&$ propriete $z$ des herbes, racines, bois, $x$ des plantes qui croiffent pardelà, \& dont es anciens d'Europe r'ont eu aucune cognoifance. Il y a mille de ces fimples qui font propres pour purger, comme les racines de $\mathrm{Me}$ choaçan, les pignons de la Punna, la conferue 


\section{Hiftoire naturelle}

de Guanucquo, l'huille de figuier, \& plufiet autres chofes, Ic fquelles eftans bien applique $\&$ en temps, ne font pas (comme lls tienne de moindre efficace que les drogues qui vie nent d'Orient. Ce qui fe peut voir en lifant difcours qu'en fait Monardes en la premiere feconde partie où il traitte amplement du $\mathrm{T}$ baco, ou petun, duquell'on a fait de notabl expetiences contre le venin. Le Tabaco eft arbrifieau, ou plante affez commune, qui a foy neantmoins des rares vertus, comme ent autres de feruir de contrepoifon, ainfi que pl ficurs \& diuerfes plantes; parce que l' Authe de toutes chofes a departy fes vertus comme luy a pleu, \& n'a point voulu qu'aucune cho nafquift au monde ocieufe. Mais ceft vn aut don fouuerain à l'homme de les cognoiftre, en çauoir vfer comme il conuient, ce que mefme Createur concede à qui illuy plaift. I Decteur François Hernande a fait vn bel œuu de cefte matiere, des plantes des Indes, liqueu $\&$ autres chofes medicinales, par l'expres com mandement \& commiffió de fa Majefté, faifar peindre \& pourtaire au naturel toutes les plar tes des Indes; lefquelles, commeils difent, for en nombre de plus de mille deux cens, \& difen que cét cuure a coufté plus de foixante mill ducats; duquel cuure le Docteur Nardus An tonius medecin Italien, a fait vn extrait curieux \& renuoye aufdits liures celuy qui voudra pluz exactement cognoiftre des plantes des Indes principalement pour la medecine. 
des Fndes. Liure IV.

184

es grandes forefts des Indes, des Cedres, des Ceiuas, fr autres grands arbres qui y /ont.

Chapitre XXX.

Açoit que dés le commencement du monde la terre a produit des plantes \& des arbres par le commandement du Seigneur, neansmoins elle n'a laiffé d'en produire en quelques lieux plus qu'es au-

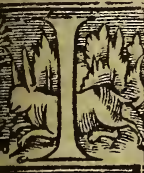
es; - \& outre les plantes \& les arbres, qui par
induftrie des hommes ont efté tranfplantees, : apportees d'vn lieu en autre, il y en a encore eaucoup que nature a produits de foy-mefne. croy que de cefte forte il y en a dauantage au ouneau monde que nous appellons Indes, foir nombre, ou en diuerfitez, que non pas au ieil monde, \& rerres de l'Europe, de l'Afie, \& ffrique. La railon eft, pource que les Indes ont d'vne temperature chaude \& humide, omme nous auons montré au fecond liure, ontre l'opinion des anciens; qui caufe que la erre produit en grande abondance vne infinide plantes fauuages \& naturelles, d'où vient ue prefque la plus grande partie des Indes eft ahabitable, \& qu'on n'y peut cheminer pour es bois \& efpaiffes forefts qui y font, aufquelsl'on trauaille continuellement pourle; abatre. Il a efté befoing \& neceffaire, pour cheainer par quelques endroits des Indes, princialement aux nouuelles entrees, de fairele che. 


\section{Hiftoire naturelle}

min, en courant les arbres, \& effartant les bu fons: de forte que comme nous l'ććcrivét que ques Religieux quil'ont efprouué, il a efté to le fois quils nont peu cheminer en vn io plus d'vne lieüe. Vn de nos freres, hommed gne defoy, nous contoit que f'eftant efgaté perdu dans les montagnes, fans fçauoir quel part, ny par où il deuoit aller, il fe trouuad dans des buiffons fi efpais, quil fut contrain de cheminer fur iccux fans mettre les pieds terre, par l'efpace de quinze iours entiers, que pour y voir le foleil, \& pour remarqu quelque chemin en cefte foreft fi efpaiffe pleine de bois, ilauoit befoing de monter: coupeau des plus grands arbres, pour de là de coutrir le chemin. Quilira le difcours traitta de fon voyage, \& combien de fois il f'eft per \& efgaré, \& les chemins qu'il a cheminez, 1 eftranges aduentures qui luy font aduenuës, que jay efcrit fuccinctement, pour me fembl chole digne d'eftre feeite; \& qui aura quelqu peu cheminé parles montagnes des Indes, et core que ce ne foient que les dix-huict lieï quil y a de Nom de Dieu à Panama, pourra bie penfer de quelle grandeur font ces forefts de Indes; de forte que n'ayant a ucun hyuer en ci parties là qui faffe fentir le froid, \& que l'hum dité du cicl \& de la terre y eft fi grande, que lo montagnes produifent vnc infinité de foreft \& la campagne quils appellent Sauanas, vne ir finitéd'herbe. Iln'y a point faute d'herbe por les pafturages, de mefrain pour les edifices, $n$ de bois à faire du feu. C'cft vne chole impont 


\section{des Indes. Liure. IV.}

ede pouuoir raconter les differences \& figu-i sde tant d'arbres fauuages; d'autant que de la us part l'on n'en fçait pas les noms. Lescedres ftimez anciennement, font li fort communs, ur les edifices \& pour les nuuires, \& y en a de ierfes façons, les vns blancs, \& d'autres roux, ifont fort odoriferãs.Il y a vne grande quande lauriers d'vn plaifant regard aux Andes Peru. Aux montagnes de la terre ferme, aux es, en Nicaragua, \& en la neuue Erpagne. mme aufsi il y a vne infinité de palmes, \& de uas, dequoy les Indiens font leurs canoes, qui It des bafteaux faits tout d'vne piece. L'on aprte en Efpagne du mefrain de bois fort exquis la Hauane, en l'Isle de Cube, où il y a vne inté de femblables arbres, comme font l'Ebene Zaouana, Ia Grenadille, les Cedres, \& autres eces que ie ne cognois point. Il y a mefme de nds Pins en la neuue Efpagne, encor qu'ils ne ent pas fi forts que font ceux d'Ef pagne. IIs ne tent point de pignons, mais pommes vuiLes Chefnes qu' ils appellent de Guayaquil, vn bois exquis, \& odoriferant, quand on le le, mefme il y a des cannes $\&$ rofeaux tres. its, des rameaux \& petites cannies, defquels iis $t$ des bouteilles \& cruches pour puifer de u , \& s'en feruent mefmes en leurs baftimens. a aufsi le bois de mansle, dequoy ils font des res \& mafts de nauires, \& les eftiment aufsi ts comme fi c'eftoit du fer. Le Molle eft vn re de beaucoup de vertus, lequel iette des its rameaux, dont les Indiens font du vin, ils pellent en Mexique, arbre du Peru, pour ce 


\section{Hiftoire naturelle}

qu'il eft venu de là, mais il en croift aufsien neuue Efpagne, \& de meilleur que celuy Peru. Il y a mil autres fortes d'arbres dont cef roit vn tranail fuperflu d'en traitter. Quelqu $\mathbf{v} n s$ de ces arbres font d'vne enorme grandeur, parleray feulement d'vn qui eft en Tlaco $\mathrm{Ch}$ uoya, trois lieües de Guayaca, en la neüue $E f_{p}$ gne. Cét arbre eftant mefuré, fe trouua feul ment en vn creux aucir par dedans neuf graç \& par dehorsioignant la racine, feize, \& $\mathrm{pl}$ haut douze. Cét arbre fut frappé de foudre $d$ puis le haut iufques en bas, au droit du cœur, $q$ fit ce creux, qui y eft. Ils difent que au paraua que le tonnerre fuft tombé deffus, il eftoit fuf fant pour ombrager mil hommes. C'eft pou quoy il s'y affembloient pour faire-leurs danc bals \& fuperftitions;neantmoins il refte encor prefent des rameaux \& de la verdure, maisn pas beaucoup. Ils ne fçauent quelle ef pece d': bre c'eft, finon qu'ils difent que c'eft vne efpe de Cedre. Ceux quitrouueront cecy eftrang lifent ce que Pline raconte du plane de Lydie, Pline lib.12. creux duquel cótenoit quatre vingts \& vn pic capp.s.

$\&$ reflembloit pluftort vne cabane ou maif que non pas creux d'arbre, fon branchage bois entier, l'óbrage duquel couuroit vne gra de partie de la campagne Par ce qui efcrit de arbre, l'on n'aura point tant d'occafion de s'i merueiller du Tyfleran quiauoit $f a$ maifon meftier dans le creux d'vn Chaftaignier. Et d' autre Chaftaignier , fice n'eftoit ceftuy-là me me, dedans le creex duquel entroient hu hommes à cheual, \& en reffortoient fans s'inco 


\section{Hiftoire naturelle}

deçà de domeftique, \& de profit : de forte qui ceux qui y ont fait voyage, ont efté curieux d' porter des femences de toutes fortes, \& le tout; a.beaucoup fructifié encor que ç'ait efté diuer femét, fçauoir aux vns mieux, aux autres moins $Q$ uant aux arbes, ccux qui plus generallement \& plus abondamment y ont fructifié, ontêté le oranges, lymonniers, citronniers, $\&$ autresfruict de cefte forte. Il y a defia en quelques endroits. comme des bois, \& des forefts d'orangers. $C_{i}$ que trouuant eftrange, ie demanday qui auoil remply ces champs de tant d'orangers, l'on me refpondit, que cela eftoit aduenu fortuitement, d'autant que les oranges eftans tombees à terre, \& pourries, leur femence auoit germé, \& de cel les que les eaux auoient emporté en diuers endroits, venoient à naiftre ces bois ainfi efpais. Ce qui me fembla vne bonne raifon. I'ay dit que c'eftoit le fruict, qui generalleméts'eft plus aug. menté és Indes, pour ce que ie n'ay efté en nu. endroit où il n'y ait desoranges, d'autant que toutes les Indes font v ne terre chaude \& humide , qui eft ce requiert cét arbre. Ilsne croiffent point en la Sierre,maisl'on les y apporte des vallees, ou cofte de la mer. La conferue d'oranges clofes qu'ils font és Isles, eft la meilleure que íay veüe par deçà, ny par dela mefme. Les pefches, les prefles, \& abricos, y ont fort multiplié, \& en la neuue Efpagne plus qu'en autre endroit. If croift au Peru fort peu de ces fortes de fruicts, outre les pefches, \& encor moins és Isles. Ily croift des pommes \& des poires, mais c'eft affez moyennement, il y a des prunes rarement, mais 


\section{des Indes. Liure. IV.}

187

des figues en abondance, principalement au Peru. Ii fe trouue des coings en toutes les contrees des Indes, \& en la neuue Efpagne, en telle abondance, qu' ils nous en donnojent cinquante à choifir pour demie realle. Il y a affez de grenades aufsi, bien qu'elles foient toutes douces, car les aigres n'y font point bien venuës. Il y a detresbons mellons en quelques endroits du Peru. Les cerifes \& Ies guignes iufques auiourd'huy n'ont point encor bie fructifié és Indes, \& croy que ce $n$ 'eft pas faute de temperature, pource qu'il y en a de toutes fortes, mais peut-eftre faute de foing, ou par ce que l'on n'a pas bien rencontré fa temperature. En fin ie ne trouue point que par dela ils ayent faute d'aucun fruict delicieux. Quant aux fruicts grofsiers, ils n'ont point de beillottes, ny de chaftaignes, \& n'ay point de cognoiffance, que iufques auiourd'huy il y en ait creu. Les amendes y croiffent, maisc'eft fort peu. L'on y porte d'E $\mathrm{f}$ pagne pour les friands, des amenides, de noix, desauellaines, \& n'ay point entendu qu'il y ait des nefles, ny des cormes; ce qui importe peu. Me femble que cecy doit fuffire pour faire entendre qu'il n'y manque aucune delice de fruids. Maintenant difons quelque chofe des plantes de profit, que l'on y a portees d'Efpagne, \& acheuerons ce traitté des plantes, qui eft defiz ennuyeux.

A 2 iij 


\section{Hiftoire naturelle}

Desraifins, vignes, oliues, meures, \& des cannes du Jucre.

\section{Chapitre XXXII.}

Hefe 'Entens par les plantes profitables cel les qui outre ce que l'on en mange at (2) $(0)$ logis, apportent de l'argent à leu: maiftre. La principale defquelles ef la vigne, de laquelle vient le vin, le vin-aigre, $k$ raifin vert $\&$ fec,le verjus \& le firop. Mais le vir eft celuy qui vaut le mieux. Il ne croift point d vin ny raitin és Isles, ny terre ferme, mais en l: neuue Efpagne il y a quelques vignes qui por tent du raifin, toutesfuis l'on n'en fait point de vin. La caufe en doit eftre pource que le raifir ne fe meurit pasbien, à caufe des pluyes qui j viemnent aux mois de Iuillet $\&$ Aouft, qui le empefchent de meurir : ilss'en feruent tant feulement pour manger. L'on y porte le vin d'Ef pagne $\&$ des Canaries, comme en tout le reft des Indes, referué au Peru \& au Royaume d, Chillé, où il y a des vignes qui rapportent de tres-bon vin, lefquelles vont chaque iour croif fant en quantité à caufe que $c^{\prime}$ eft vne grande ri cheffe en ce pays; $8 x$ en bonté, parçe quaue le temps ils deuiennent plus experimentez vi gnerons. Les vignes du Peru font communesé vallees chaudes, où il y a des eaües, \& les arrou. fent auec la main, parce qu il n'y tombe point de pluyes du Ciel; \& aux Lanos, \& en la Sierre clle 


\section{des Fndes. Liure IV.}

y vient point à temps. Il y a des endroits où les ones ne font point arrofees ny du Ciel, ny de la 're, \& toutesfois elle ne laiffent de fructifier en ande abondance, comme en la vallee d'Yca, \& $\mathrm{x}$ foffes qu'ils appellent de Villacuri, efquxels ux il fe troutue des folfez, ou terre enforcees irmy les morts fablons, lefquels font toute l'ane d'vne incroyable fraifcheur, fans qu'il y euve aucunement en quelque faifon que ce it, ny qu'il y ait des eaües pour les arrofer arficiellement. La caufe eft parce que le terroir t efpongieux, \& qu'il fucce l'eaúe des rivieres ui viennent de la Sierre, qui humectent cesfalons, ou bien c'eft l'humidité de la mer (comme autres penfent) laquelle paffart au trauers de e fable, caufe que l'eaüe n'en eft pasfterile,ny nutile, ainfi que le Philofophe l'enfeigne. Les ignes y ont tant multiplié, qu'à cefte occafion es difmes des Eglifes y font augmentez de cinq fix fois au double depuis vingt ans. Lesvalees plus fertilles de vignes font Victor, prohe d'Arequipa, Yca, au terroir de Lyma \& Caraguato, au terroir de Chuquiauo. Ils parent ce vin à Potozi, Cufco \& en diuers enAroits, ce qui eft vn grand reuenu : Carauee oute l'abondance qu'il y en a, vne bouteille ou arrobe $y$ vaut cinq ou fix ducats; que fi c'eft vin d'Efpagne, comme on y en porte communement aux flottes, il en vaut dix ou douze. L'on fait du vin comme celuy d'Erpagne au Royaume de Chillé, pourçe que c'elt le mefme climat, mais il fe gafte quand l'on l'apporte au Peru.Ils mangent des railins, ou l'on ne pout Aa iiij 


\section{Hiffoire naturelle}

boire de vin, \& eft chofe admirable, quel', trouue en la Cité de Cufco des raifins fro tout le long de l'annee, qui vient (comme: me dirent) de ce que les vallees produifent $d$ fruict en diuers mois de l'an, foit qu'ils entel les vignes en diuerfes faifons, ou que cefte v: rieté vienne de la qualité de la terre : quoy qu en foit, c'eft vne chofe certaine qu'il y a quel ques vallees qui portent du fruict tout le lon de l'annee. Si quelqu'vn s'efnerueille de cecy, fe pourra efmerueiller dauantage de ce que diray, \& peut eftre ne le croira pas. Il y a di arbres au Peru, defquels l'vne moitié donne d fruict fix mois durant, \& l'autre moitié en don ne les autres fix mois. En Malla, qui eft treiz lieuies diftante de la Cité des Roys, y a vn $f$ guier, duquel la moitié, qui eft au cofté $d$ Sud, eft verte, \& donne du fruizt vne faifon l'annee, fçauoir quand il eft Efté en la Sierre , 8 l'autre moitie qui eft versles Lanos du cofté d la mer, eft verte, \& donne fon fruict en l'autr faifon contraire, quand il eft Efté aux Lanos. $C_{1}$ qui prouient de la varieté de la temperature \& del'air qui vient d'vne part ou d'autre. Le reuenu du vin qui y eft, n'elt pas petit, maisiln fort point de la Prouince. Mais la foye quife fait en la neuue Efpagne, fe tranfporte és autre Royaumes, comme au Peru. Iln'y en auoi point au tempsdes Indiens, mais l'on y a porte des meuriers d'Efpagne, \& y viennent bien, principalement en la Prouince qu'ils appellent Miftecqua, ou il y a des vers à foye, \& metten en guure la foye qu'ils en recuiellent, dont ils , 


\section{des Indes. Liure. IV.}

int de tref-bon tafetas. Toutesfois ils n'en ont oint fait iufques à prefent de damas, de fans, ny de velours. Le fucre eft ine autre reues. plus grand, veu que non feulement on en onfomme és Indes, mais aufsi l'on en apporte eaucoup en Efpagne, car les cannes croifint fort bien en diuerfes parties des Indes. Ils nt bafty leurs engins aux Isles, en Mexique, Peru $\&$ en d'autres endroits quileur apporint vn fort grand reuenu. L'on me dift que engin à fucre de Nafca fouloit valoir de reueu, plus de trente mil pezes par chacun an. eluy de Chicama, ioignant Truxillo, eftoit iefme d'vn grand reuenu, \& ceux de la neuue fpagne aufsi ne le font pas moins : 'car c'eft ne chofe eftrange que ce que l'on gafte \& conomme de fucre és Indes. L'on apporta de l'Ifde fainct Dominique, en la flotte où ie vins, uizt censquatre vingts \& dixhuict caffons de acre, lefquels eftans comme ie les vids charer en Port-riche, chaque caffe deuoit eftre à ton opinion, de huict arrobes pefant, qui font eux cens. Le fucre eft le principal reuenu de es Isles, tant fe font addonnez les hommes à l'apetit des chofes douces. Il y a mefmes des olies \& oliuiers aux Indes, ie dy en Mexique \& u Peru : toutesfois il n'y a point eu encor iufues auiourd'huy aucun moulin à huille, \& ne en fait point, parce qn'ils confomment toues les oliues à manger, \& les accommodent fore ien: ils trouuent que pour faire l'huille, le gouft eft plus grand quele profit. C'eft pourquoy on' y porte toute l'huille qu'il ya d'Ef pagne. 


\section{Hiftoire naturelle}

En ceft endroitiacheueray la matiere des plar tes, \& venons aux animaux des Indes.

\section{Dubeftialportant laine, d des vaches. ChaPITRE XXXIII.}

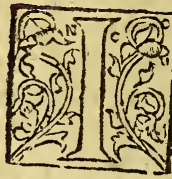

Etrouve qu'il y a trois fortes d' nimaux és Indes, dont les vns ont efté portez d'E $E$ pagne, lesa tres font de la mefme efpece. ceux que nous auons en Europ \& toutefois n'y ont point efté portez par les $E$ pagnols, \& les autres font animaux propres Indes, \& defquelsl'on ne trouue point en $\mathrm{Ef}$ : gne. De la premiere forte lont les brebis, vache chevres, porcs, cheuaux, afnes, chiens, chats, autres telsanimaux : car il y'en a és Indes de to tes ces efpeces. Le menu beftial y a beaucor multiplie, que fi l'on y pouuoit approfiterl laines pour les enuoyer en Europe, ce feroit vi des plus grandes richeffes qu'ils euffent és Inde pource que les troupeaux de brebis ont là grand nombre de pafturages, fans quel'herbe diminuë en beaucoup d'endroits. Il y a au Pes vne telle abondance de ces pafturages \& herb: ges, que perfonne n'en poflede en propre, ma chacun fait paiftre fes troupeaux ou il veu Pour cefte raifon il y a communement granc abondance de chairs, lefquelles font à fort bc marché, mefme les autres chofes qui procede des brebis, comme le laict \& le fromage. Ils $f$ rent vn tempsqu'ils laiflerent perdre toutes 


\section{desIndes. Liure. IV. $\quad 190$}

ies, iufques à ce que quelques vns fe mirent à mefnager \& en faire des draps \& couuertu, quia efté vngrand fecours pour le comin peuple de cefte terre: d'autant que le p de Caftille y eft fort cher. Il y a plufieurs ipiers drapans au Peru, \& beaucoup dauane en la neuue Efpagne, encorque lesdraps e l'on y porte d'Efpagne foient beaucoup illeurs, foit que la laine en foit plus fine, ou e les ouuriers foient plus experts. Autres$s$ fe font trouuez des hommes qui polfeient foixante \& dix,\& cent mil teftes de bre, encor qu'à prefent n'y en ait gueres moins. ue fi c'eftoit en Europe ce feroit vne tresande richefle , mais en ces pays-là ce n'eft 'vne moy enne richeffe. En plufieurs endroits s Indes, \& croy que c'eft en la plus grand rt, le menu beftial ne fructifie, \& n'y profite is bien à caufe que l'herbe eft haute, \&.la terfi vicieufe, qu'il n'y peut pas bien paiftre comê le grand beftial. C'eft pourquoy il y a vne numerable multitude de vaches, defquelles y de deux fortes. Les vnes font domeftiques, \&t ui vont en trouppeaux, comme en la terre de harca, \& en autres Prouinces du Peru comiemefme en toute la neuuie Efpagne. De ces aches domettiques ils s'en feruent \& en tirent e la commodité, tout ainfi qu'en Efpagne, auoir la chair, le beurre, les veaux, \& les œufs pour labourer la terre. L'autre forte de aches funt fautuages quife tiennent és montanes \& forefts:c'eft pourquoy on ne les dompte oint, \& n'ont aucun maiftre à qui elles foient en 


\section{Hiftoire naturelle}

propre, tant pour l'afpreté \& efpeffeur de refts, que pour la grande multitude qu'il $2: \&$ celuy quile premier les tuë, en eft le $n$ ftre comme d'vne'befte de chaffe. Ces vac fauuages ont tellement multiplié en S. Dom que, $\&$ en autres endroits des enuirons, qu'e vont à milliers par les campagnes $\&$ bois, n'ay zucun maiftre à qui elles a ppartiennent. L'on la chaffe à ces beftes, pour leur cuir tant feu ment, \& fortent en la campagne des negres des blancs à cheual, auec leurs coupe-iare qui courent les toreaux \& vaches, \& quand les ont frappez, \& arreftez, ils leurs appartie nent. Ils les efcorchent, \& en portent la pe en leur maifon, laiffant la chair perduè, qu'il y ait perfonne qui la prenne ou empor à caufe de labondance quil y en a. Telleme qu'ils m'ont attefté en cefte Isle, qu'en qu ques endroits l'air s'y eftoit corrompu, po l'abondance de ces chairs empuanties. Le $\mathrm{Cl}$ que l'on apporte en Efpagne, eft vndes me leurs reuenus des Isles, \& de la neuue Efpagn En la flotte de quatre vingts \& fept, il vint de Dominique le nombre de trente-cinq mil quat cens quarante quatre cuirs de vaches, \& de neuue $E$ p pagne foixante-quatre mil trois ce cinquante, qu'ils eftimerent à quatre vingts $\mathrm{fe}_{\mathrm{e}}$ ze mil cinq censtrente deux pezes. Deforte qu quand l'on defcharge vne de ces flottes, c'e chofe admirable, de voir la riuiere de Seuille cét arcenal où fe defchargent tant de cuirs \& $d$ marchandife. Il y a aufsi des chevres en gran nombre, le principal profit defquelles eft 


\section{des Indes. Liure IV.}

,outre les cabrits, le laict, \& autres commoz qu'on en tire: d'autant que les riches, \& auures fe feruent de ce fuif pour leur cfclaicar comme il y en a grande quantité, aufsi v il à fort bon conte, \& plusque l'huille merIl eft vray que tout le fuif dont ils fe fer$t$, n'eft pas feulement de celuy des masles. Ils ccommodent les marroquins pour la chauf, toutesfois ie n'ay point opinion qu'ils nt $f$ bons comme ceux que l'on y porte de tille. Les cheuaux y ont multiplié, \& y font uis en beaucoup d'endroits, voire en la plus : s'y en trouue des races d'aufsi bons, comles meilleurs d'Efpagne, tant pour courir carriere \& pour parade, que pourle trauail, our faire chemin. C'eft pourquoy ils fe fert pour beftes de loüage, \& pourvoyager le ordinairement des cheuaux, combien qu'il it pas fauté de mulles, car il yen a beaucoup, iallement és lieux où fe font les voitures par e, comme en la terre ferme. Il n'y a pas vn fi ad nombre d'afnes, aufsi ils ne s'en feruent res à cét vfage, ny pour le trauail \& feruiDes chameaux il y en a quelque peu, \& en eu au Peru qui y auoient efté portez des $\mathrm{C}_{2}$ ies, \& qui y auoient multiplié, mais affez pement. En S. Dominique les chiens $y$ ont Itiplié en nombre, \& en grandeur d'vne telle on, que c'eft auiourd'buy la playe , \& l'aftiin de cefte Isle. Car ils mangent les brebis, tc it en trouppes par les champs. Caux qui les. nt y ont vn tel falaire, que ceux quituent les psen Ef pagne:de vrays chiens, il n' y en auoit 


\section{Hiffoire naturelle}

point prèmierement és Indes, mais quelques a maux femblables à des petits chiens, lefquels Indiens appellent Alco ; c'eft pourquoyils pellent du mefme nom d'Alco, les chiens I'on y a portez d'Ef pagne, à caufe de la reffe blance qui eft entr'e ux, \& font les Indien amis de ces petitschiens, qu'ils efpargneröt l manger pour leur donner: tellement que qua ils vont par pais, ils les portent auec eux fur le efpaulles, ou en leur fein, \& quand ils font ma desils tiennent ces petits chiens auec eux, fan feruir d'eux en autre chofe que pour l'a mitic compagnie.

De quelgues animaux de l' Europe que les EJ nols trounerent és Indes, of comment ils peunent yauoirpa/sé.

\section{ChapItre XXXIV. -}

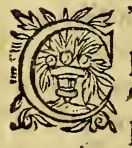

'Eft vne chofe certaine, que l'ol porté d'Epagne tous ces anima sont iay parlé, \& qu'il n'y en au point és.Indes, quand elles fur premierement defcouvertes, il n'y a pas a ans : car outre que c'eft vne chofe qui peut ef approuuee pardes tefmoings qui viuent en res, c'en eft vne preuue fufthante, de voir $q$ les Indiensn'ont en leur langue aucun mot pi pre pour fignifer ces animaux, mais ils fef uent dermefmes noms $\mathrm{E} f$ pagnols, combien qu foient corrompus. Pour autant que ne cogno 


\section{Hiftoire naturelle}

chaffer les lyós, \& font comme vn circuit ' qu'i appellent chaco, dont ils les enuironnent, pu les tuent à cou ps de pierres, de baftons, \& d'au tres inftrumens; Ces lyons mefmes ont accou ftumé de grimper aux arbres, où eftans monte lesIndiens les tuent auec des lances, ou arbal leftres, \& plus facilement auec des arquebuze Les tygres y font plus furieux, \& plus cruel: $\&$ ont la rencontre plus dangereufe, à cauf qu'ils s'eflancent \& affaillent en trahifon. I] font tachetez, \& de la mefme façon queles hi ftoriographes les peignent. I'ay ouy quelques fois conter que cestygres eftoient animez con tre les Indiens, \& qu'ils n’affailloient point le Efpagnols, ou bien peu, \& qu'ils alloient pren dre \& choifir vn Indié au milieu des $E$ fpagnols \& qu'ils l'emportoient. Les ours qu'ils appel lent en langue de $\mathrm{Cufco}$, otoioncos, font de melme efpece que ceuxd'icy, \& fe terriffent. $L$ 'on y void peu de ruches, pource que les ray. de miel qui font és Indes, fe trouuent aux arbre: $\&$ defioubsla terre, \& non pas aux ruches, com. me en Caftille. Les rays de miel que i'ay veusen la Prouince de Charcas, que là ils appellent le chiguanas, font d'vne couleur grife, ayant peu de fuc, \& reffemblent plus à vne paille douce, qu'à des rays de miel. Ils difent que lesabeilles font petites comme mouches, \& qu'elles iettent leur effain deffous la terre. Le mielen eft afpre, \& noir, toutesfois en quelques endroits il y en a de meilleur, \& des rayons mieux formez, comme en la Prouince de. Tucuman en Chillé, \& en Cartagene.le n'ay point veu ny ouy parler 


\section{des Indes. Liure IV.}

"il y ayt des fangliers, mais des regnards \& aues animaux qui mangent les beftes, \& la volle, il y en a pl tus que les pafteurs ne voudroiét utre ces animaux qui font furieux \& dommaables, il y en a d'autres profitables, qui n'y ont int efté portez par les $E$ fpanols, comme font cerfs $\&$ autres, dont y en a grande abondance toutes les forefts. Mais la plus grande partie yne venaifon fans cornes, à tout le moinsie en ay pointveu d'autress, ny oúy parler qu'on $n$ ayt veu, \& tous font fans cornes cóme cors. Il ne me femble pas difficile de croire, mais prefque certain que tous ces animaux par urlegereté, \& pour eftre naturellement fauges, ayent paffé d'vn móde à l'autre par quele endroit cù ils fe ioignent, puis qu aux granInles \& enloignees de la terre ferme, ie n'ay int de cognoiflance qu'il s'y en trouue, quoy e i'aye fait recherche de le defcouurir.

s oy eau.x de par deçà qui fontés Indes, to comment ils peuuent y auoir paßsé.

\section{Chabitre XXXV.}

'On pourra plus facilemét croire qu'il en foit ainfí des oyfeaux, \& qu'il y en de la mefme efpece de ceux de par deçà, comme font les perdrix , les tour, pigeons, ramiers, cailles \& plufieurs \& dires fortes de faucons, lef quels l'on enuoye de acuu Efpagne \& du Peru, aux feigneurs d'Ef ib 


\section{Hiftoire naturelle}

pagne, d'autant qu'on en fait grande eftime. y a mefme des Herons, \& des Ạigles de diuerf fortes, \& n'y a point de doute que ces efpec: d'oyfeaux \& autres $f(m b l a b l e s$, n'y ayent $p a f$ bien pluftoft que les lyons, les tigres, \& $l_{1}$ cerfs. Il fe trouue aufi és Indes vn grand non bre de Perroquets, Ipeciallement aux Andr du Peru, \& és Ines de Port-riche,\& S. Domin que, où ils vont par bandes, comme fontle pigeons par deçà. En fin les oyfeaux auec leu! ailles, vont où ils veulent, \& certainement plt Plin. lib.10. fieurs efpeces d'iceux pourront bien paffer

Golphe, puis que c'eft chole certaine, comm Pline l'afferme, qu'il y en a beaucoup qui pa fent la mer, \& vont en des regions fort eftrar ges, combien que ie n'aye point leu qu'aucur oyfeaux paffent au vol vn fi grād Golphe, corr me eft celuy de la mer Occeane des Indes. Tor tesfuis nele tiens-ie pas pour du tour impoffi ble, puis que l'opinion commune des mariniel eft,qu'il s'en trouue deuxcens lieuës, voire beal coup dauantage loin de la terre. Et que mefme Arift. lib.3. cöme Ariftote l'enfeigne, les oy feaux enduren de part !ani-facilement eftre dans l'eau, d'autant qu'ils on mal. cap.6. peu de refpiration, cóme noụs voyons aux oy feaux maritimes, lefquels fe plongent \& font v1 long-temps dedansl'eaul. Ainfi pourra-on dire que les oyfeaux qui fe trouuent à prefent enl terre ferme, \& és lifies des Indes, ont peu paffe la mer, fe délaflans en des iflectes $\&$ en en des ter - res qu'ils recognoiffent par vn inftinct nature! Plin.lib.10. (comme Pline raconte de quelques vns) ou par ap.250 aduanture fe laifians tomber en l'eau, quand 


\section{des Fndes Liure. IV.}

it fatiguez de voller, \& apres reprenás le vol ind ils fe font repofez quelque peu. Quant oyfeaux que l'on void és Inles, efquelles il a point d'animaux terreftres, ie tiés fans douquils y ont paffé par vne des façons fufdites. is pour les autres oyfeaux qui fe trouuent en arre ferme, principalement cewx qui ont vn it vol, il eft plus aifé de croire qu'ils y ayent comme des animaux de la terre, qui font de efme efpece de ceux d'Europe. Car il y a aux es de grands oyfeaux fort pefans, commeles truches, dont il y en a fort au Peru, lefquelont accouftumé d'efpouuanter quelque fois noutōs du pays qui vont chargez. Mais laifces oyleaux qui fe gouuernent d'eux mef, fans que les hömes en ayent le foing, fi ce pour la chaffe, parlons des oy feaux domeues. Ie mefmerueille des poulles, attendu y en auoit aux Indes, auant que les EfpaIs y arrinaffent, ce qui eft aflez prouué, paru'elles ont vn : om propre du pays, \& appella poulle Gualpa, \& leur œuf Ponro, \& ont fage le mefme Prouerbe que nous auösicy, peller poulle vn homme coiiard. Ceux qui nt à la defcouuerte des intes deSalomon, ratent qu'ils y ont veu dis poulles femblables noftres. L'on peut entendre quela poulle at vn oyfeau fi domeftique, \& fi profitable e elle eft, les húmes les y ont peu porter auec quand ils pafferent d'vn lieu en autre, cóme s voyós encor auiourd huy, \& que les Indiès oyageant portoient leur poulle, ou porillet a charge qu'ils portent fur leurs efpaulles, $\mathrm{Bb}$ ij 


\section{Hifoire naturelle}

$\&$ mefmes les portent facilement en leurs por liers, \& cages de ionc, ou de bois. Finaleme il y a és Indes beaucoup d'efpeces d'animaux, d'oyfeaux de ceux de l'Europe, que i'ay dittes, d'autres fortes que d'autres pourront raconts

Comme il eft poßsible quil y ayt és Indes que ques fortes d' animaux, dont il riy ayt point ailleurs.

Chapitre XXXVI.

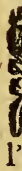
l'efpece defquels nous n'auons point en ce co tinent. Car fi le Createur les a produits en parties, il ne faut point alleguex, ny auoir $r$ cours à l'Arche de Noé, \&z n'eftoit point deb foin de fauuer alors toutes les efpeces d'oyfea $\&$ animaux , fi d'autres deuoient eftre creées nouueau : d'autre part on ne pourroit pas dit que le monde euft efté fait \& acheué és fix iot de la creation, s'il y euft eu encor d'autres no uelles efpeces à former, \& principalement d animaux parfaits, \& non moins excellens, q ceux qui nous font cogneus. Si nous difo donc que toutes les efpeces d'animaux fure conferuees en l'arche de Noé, il s'enfuit que. animaux, de l'efpece defquels il ne s'en trou en d'autres endroits qu'ćs Indes, $y$ ayent $p a$ 


\section{des Fndes. Liure $I V$.}

ce continent, tout ainfi comme nous auons des autres animaux qui nous font cogneus. la fuppofé, ie demande comme il eft poffiqu'il n'en foit tefté par deçà aucun de leur ece, \& comme il s'en trourue feulement par aे, où ils font comme voyagers \& eftrangers. ft à la verité vne queftion qui $\mathrm{m}^{2} a$ long téps u en perplexité. Ie dy pour exemple, fi les utons du Peru, \& ceux qu'ils appellent $\mathrm{Pa}$ , \& Guanacos, ne fe trouuent point en d'aus regions du monde, qui les a portez au $\mathrm{Pe}$ ou comment y ont ils efté, veu qu'il n'eft deuré aucune apparence, ny refte d'iceux en tt ce monde? Que fi ils n'y ont point paffé ne autre region, comment fe font ils formés produits par delà ? Par aduanture Dieu a-il vne autre nouuelle creation d'animaux? que ie dy de ces Pacos, \& Guanacos, ie le de mil autres differentes efpeces d'oyfeaux d'animaux de forefts, qui iamais n'ont efté coeus, ny de figure, ny de nom, \& defcyuelsil it fait aucune mention, foit entreles Latins, t entre les Grecs, ou quel ques autres nations cemonde. Il faut donc dire, que combien e tous les animaux foient fortis de l'Arche, antmoins par vn inftinct naturcl, \& prouince'du Ciel, diuers genres d'iccux s'eŕpartitt en diuerfes regions, en aucunes defquelles fe trouuerent fibien, qu'ils n'en voulurent int partir; au s'ils en fortirent, ne fe conferrent, ou bien en finde temps ils perirent toement, comme l'on void arriuer en beatsup decholes: car fi l'on y veur regarder de bb iij 


\section{Hiftoire naturelle}

pres, on trouuera que ce n'eft pas tant feul ment vne chofe propre \& particuliere és $I_{2}$ des, mais auffi generalle en beaucoup d'autr regions \& Prouinces de l'Afie, d'Europe, d'Affrique, efquelles l'on dit qu'ily a de certa nes efpeces d'animaux, qui ne fe trouuent pois en d'autres.regions, au moins s'il s'en trouu ailleurs, l'on recognoift qu'ils y ont efté porte de là. Puis donc que ces animaux font fortis o l'arche, comme pour exemple, les Elephar. que l'on trouue feulement en l'Inde Orientali $\&$ de là fe font communiquez en d'autres it gions, nous en pourtons dire autant de ces an maux du Peru, \& des autres des Indes quine trouuent en autre partie du monde. L'on pet bien auffi confiderer fur ce fubjet, fi tels an maux different en efpece, \& effentiellement d tous les autres, ou fi cefte leur difference eft ac cidentalle, laquelle peut y auoir efté caufée pa diuers accidens, comme nous voyons au ligna ge des hommes, que les vns font blancs, \& le autres font noirs; les vns geans, les autres nains \& en l'efpece des finges, les vns n'ont point d queiie, \& les autres en ont : entre les moutons les vns font ras, \& les autres vellus; les vns grăd $\&$ forts, qui ont lé col fort long, comme ceu: du Peru, \& les autres foibles \& petits, ayans 1 col court comme ceux de Caftille. Mais pou en parler plus fainement, qui voudra par ce dif cours, en mettant feulement ces differences ac cidentalles, conferuer la propagation des ani. maux és Indes, \& les reduire à ceux d'Europe. prendra vne charge de laquelle il pourra malais 
Des Indes. Liure IV. $190^{\circ}$ nent fortir à fon honneur. Car fi nous dens iuger les efpeces d'animaux par leurs proietez, ceux des Indes font fi differens, que At appeller l'cuf chaftaigne, deles vouloir reire aux efpeces cogneués de l'Etrope.

Des oyjeaux qui font propres és

Indes.

Chapitre XXXVII.

L y a aux Indes de plufieurs fortes 1'oyfeaux remarquables, foit quils 2 foient de la mefme efpece de ceux d'ila $\mathrm{cy}$, ou autres differens. 1ls apportent plume. Ils ne saffient point en terre, mais fe pendent aux rameaux par des filets, ou umes quils ont, \& ainfi fe repofent comme es mouches, \& chofes aëriennes. Au Peruily des oyfeaux quils appellent Tomineios, fi pets, que beaucoup de fois iay douté, les voyant oler, fi c'eftoient abeilles, ou papillons: mais à verité, ce font oyfeaux. Au contraire ceux uils appellent condores, y font d'vne extreme randeur, sod'vne telle force, que non feuleentils ouurent $\&$ defpecent vn monton, \& le nangent, mais auffi vn veau tout entier. Ceux uilsappellent Auras, \& les autres.poullazes, efquelles ie croy quant a moy eftre du genre

Bb iiij 
Hiftoire naturelle

des corbeaux) font d'vne eftrange legereté, ont la veuë fort aiguë, eftans fort propres por nettoyer les Citez, d'autant qu'ils n'y laiffer aucunes charongnes, ny chofes mortes. Ils pa fent la nuiet fur les arbres, ou fur les rochers, \& au matin viennent aux Citez fe mettans fur 1 fommet des plus hauts edifices, d'où ils efpier $\&$ attendent leur prife. Leurs petits ont le plu mage blanc, comme l'on raconte des corbeaux \& changent le poil en noir. Les guacamayac font oyfeaux plus grands que perroquets, 8 leur reffemblent en quelque chofe, ils font efti mez pour la diuerfe couleur de leur plunage qui eft fort beau, \& fort aggrcable En la neuu Efpagne ily a abondance d' oyfeaux, d'vn excel lét plumage, de forte quil ne s'en troulue poin en Europe,qui en approchent:comme l'on peu voir par lesimages de plumes, qu'ils apporten de là, lefquels auec beaucoup de raifon, font pri rés \& eftimés, donnans occafion de s'efimer. ueiller que l'on punfe faire auec des plumes d'oifeaux, vne cuure fi delicate, \& fi parfaictement efgale, quils femblent proprement eftre de'vrayes couleurs de peinture, $\&$ ont vn ceil, $\&$ vn regard fi gay, fi vif, \& fi agreable, quie le peintre n'en peut pas faire de fi beaux anec fon pinceau, \& fes couleurs. Quelques Indiens, bons ouuriers \& experts en cet art, pourtrayent de ces plumes, \& reprefentent prafaictement ce quils voyent peint auecle pinceau, de telle façon que les peintres d'Efpagne n'ont en ce point aucun aduantage fur eux. Le precepteur du Prince d'EC pagne Dom Phillippe, luy donna 


\section{des Instes. Liure IV.}

ois eftampes; ou pourtraits faicts de plume, mme pour mearre en vn Breuiaire; lefquelles n Alreffe monftra au Roy Dom Philippes oftre freur Con pere; lefquels fa Ma; efté conmplant, \& regardant de pres, dift qu'il n'auoir mais veu en cuare fi perite vne chofe de fi ande perfection \& excellence. Commel'on ift va iour prefenté à la Saincteté de Sixte V. a autre quarre plus grand où eftoit pourtrait inct François, \& qu'on luy euft dit que les In. ens faifoient cela de plume; il le voulut efouuer, touchant des doigts le tableau, pour oir fi c'eftoir plume, d'autant que cela luy fem. ott chofe merueilleufe d'eftre fi proprement reancé, que la veüe ne pouuoit iuger, \& difiner fi c'eftoient couleurs naturelles de plu$e$, ou fi elles eftoient artificielles, de pinceau. eft vne chiofe fort belle, que les rais \& regard ee ietre vn verd, vn orengé, comme doré, \&\&. itres couleurs fines, \& vne chofe digne de rearquer, que les regardans d'vne autre façon, les void comme couleurs mortes. Ils font les eilleures \& plus belles images de plume, en la ronince de Mechouacan, \& au bourg de PafIro. La façon eft qu’auec de petites pinces delites ils arrachent les plumes des mefmes oyaux morts, \& auec vne colle defliee quilits ont, s vont attachant legerement \& poliement. Ils rennent ces plumes fidelicates \& petites de es oyfeaux qu'ils appellent au Peru, Tominos, ou d'autres femblables, qui ont de tres. arfaictes couleurs en leurs plumes. Les Iniens, outre ces images, fe feruoient des plumes 


\section{Hiffoire naturelle}

on beaucoup d'autres ouurages fort precieux fpecialement pour l'ornement des Roys \& Sei gneurs, de leurs temples $\&$ idoles: car il y auffi d'autres grands oyfeaux qui ont des plu mes excellentes \& tres.fines, dequoy ils fai foient des pennaches $\&$ plumages bigarre $z$, fpe ciallement quand ils alloient en guerre, les en richiffant d'or \& d'argent, fort artificiellement qui eftoit vne chofe de grand prix. Les mefme oyfeaux y font encores aujourd'huy, mais il n'en font pas tant curieux, \& n'en font plu tant de pennaches, ny de gentilleffes, comm ils fouloient. Il y a aux Indes d'autres oy feaur du tout contraires à ceux-cy, de fi riche pluma. ge, lefquels outre ce qu'ils font laids, ne feruen d'autre chofe que de faire de la fiente, \& neant moins ne font ils pas, peut eftre, de moindre profit. l'ay confideré cela, m'efmerueillant de la prouidence du Createur qui a ainfi ordonne que les autres creatures feruent aux hommes. En quelques Iftes ou Phares, qui font ioignan la cofte du Peru, l'on void le loing des pics, 2 montagnes toutes blanches, \& diroit-on a les voir, que ce feroit de la neige, ou que tout y eft vne terre blanche: mais ce font des monceaux de la fiente de ces oyfeaux marins qui vont la continuellement fienter, \& y en a fi granide abondance, qu'elle fe hauffe plufieurs aulnes, voire plufieurs lances en haut, ce qui femble chofe fabuleufe. Ils vont auec des bafteaux a ces Ifles, feulement pour charger cefte fiente, pource qu'il n'y a autre fruict, grand, ny petie enicelles; \& eft cefte fiente fi commode, \& fi 


\section{des Indes. Liure IV.}

ofitable, que la terre qui en eft fumee, raprtedu fruiet en fort gräde abondance. Ils ap. llent cefte fie te, guano, d'où a pris le nom la llee, qu'ils difent de limaguana, és vallees du ru, où ils fe feruent de celte fiente, \& eft la us fertile de ce terroir. Les coings, grenades, autres fuicts y excedent en grandeur $\&$ bontous les autres, \& difent que c'eft pource te l'eau auec laquelle ils les arroufent, paffe I dela terre fumee de celte fiente, qui caufe beauté de cefruiat. Tellement que ces oyaux n'ont pas feulement la chair pour feruir viande, le chant pour ta recreation, la plume ur l'ornement \& gaillardife; mais auffi leur nte fert pour engraiffer la terre. Ce qui a efté nfi ordonné par le Createur fouuerain, pour feruice de l'homme, à fin qu'il fe reffouniende recognoiftre, \& eftre loyal à celuy duquel ut fon bien procede.

\section{- Des beftes de chaffe.}

\section{Chapitre XXXVIII.}

Confo V T R les anim aux de chaffe dont (0) (a) nous auons parlé, qui font communs és Indes \& à l'Europe, il y en a d'autres qui fe trouuent par delà, dont ie ne fçache point qu'il en ayt par deça, finon que parauenture ils y yent efté apportez de ces parties la: Ils appelnt Sainos, des animaux qui font faits comme etits porcs, qui ont cefte chole eftrange d'a- 


\section{Hiftoire naturelle}

uoir le nombril fur l'efchine du dos. Ceux.l vont par les bois en trouppe, ils font cruels fan eftre aucunement craintifs, au contraire ils al Gailkent, \& ont des crocs comme razoirs, aue lefquels ils font de dangereufes bleffures $\&$ in cifions, fi ceux qui les chaffent ne fe mettent lieu de fauueté. Ceux qui les chaffent, pourle tuer plus feurement montent en des arbses, o incontinent les Sainos ou porcs accourent, 8 arriuent en trouppe à mordre l'arbre quand il ne peuuent nuire al lhomme, \& alors du hau auec vne lance ils bleffent \& $z$ tuent ceux quil veulent. lls font tres-bons à manger: mais eft befoing auffi toft leur ofter $\&$ coupper rond qu'ils ont au nombril de l'efpine, car au. trement dans vn iour ils fe corromproient. Il s a vne autre race de petits animaux qui reffem blent à des cochons de laict, \& les appellent Guadatinaias. Ie doute fil y auoit aux Indes, auant que les Efpagnols y vinffent, des porcs de la mefme efpece de ceux d'Europe, d'autant qu'en la defcouuerte des Ifles de Salomon, il eft dit qu'ils y troutuerent des poulles $\&$ des porcs d'Efpagne. Mais quoy que ce foit, c'eft vne cho. fe certaine que ce beftial a multiplié prefque en toutes les parties des Indes fort abondammét. Ils en mangent la chair fraifche, la tiennent aufi faine \& bonne, comme fic'eftoit du mouton; comme en Carthagene en quelques endroits ils font deuenus fauuages \& cruels, \& leur fait-on la chaffe comme à des fangliers, ainfi que l'or void en fain ct Dominique, \& és autres Ifles où le beftial s'eft habitué aux forefts. En quelques 


\section{des Fndes. Liure IV.}

adroits ils les nourriffent auec le grain de iays, \& ils s'engraiftent merueilleufement afin en auoir le fain, dont ils vfent aे faute d'huille. $n$ aucuns lieux l'on en fait des iambons, comie en Tolluca de la neuue Efpagne, \& en Paria u Peru. Retournant donc à ces animaux de par ela , tout ainfi comme les Sainos font femblales aux porcs, quoy qu'ils foient plus petits; infi les dantes reffemblent aux petites vaches, ombien qu'ils reffemblent mieux à des mulles, our nauoir point de cornes. Le cuir de ces anijaux eft fort eftimé pour des collets \& autres ouvertures, \& font fi dars, qu'ils refiftent à uelque coup que ce foir. Et commeles dantes ont deffendus par la force $\&$ dureté de leur uir, ceux qu'ils appellent armadillos, le fone uffi par la multitude des efcailles qu'ils ont, efquels s'ouurent, \& fe ferrent comme ils veuent en façon de cuiraffe. Ce font des petits aninaux qui vont par les bois, lefquels ils appelent armadillos, a caufe de la deffenfe qu'ils ont e mettans dans leurs coquilles, \& les defcou. urant quànd ils veulent. I'en ay mangé, \& ne ne femble pas chofe de grande valeur: mais la hair des y quanas eft vn meilleur manger, comjien qu'ils foient hideux \& horribles à la veiie; car ils reffemblent aux vrais lezards d'Efpagne, ancores qu'ils foient d'vn genre ambigu \& douceux, d'autant qu'ils vont en l'eau, \& fortans en terre, montent aux arbres du riuage, \& comme is fe ietrent des arbres en l'eau, les batteaux fe mettent deffous qui les recueillent. Les chinchilles eft vo autre genre de petits animaux, 


\section{Fiffoire naturelle}

comme efcurieux; ils ont vn poil meraeilleufe. ment doux \& liffé, \& porte t'on leurs peaus comme vne chofe exquife \& falutaire pour ef chauffer l'eftomach, \& les parties qui ont be foing de chaleur moderee. Ils font des couver. tures \& des caftellongnes du poil de ces chin. chilles, \& fe trouuent en la Sierre du Pera, où il y a mefmevn petit animal forr commun qu'ils appellent cuyes, que les Indiens eftument pour vn tres bon manger, \& ont accouftumé d'offrir founent en leurs facrifices ces cuyes. Ils font comme petits connins, \& ont leurs creux $\&$ tanieres dans la terre, \& en quelques lieux ont miné toute la terre; les vns font gris, les autresblancs, \& les autres meflez. Il y a d'autres petits animaux qu'ils appellent vifcachas, qui font cormme des lievres, combien qu'ils foient plus grands, aufquels ils font la chaffe, \& les mangenr. Des vrais lievres il y en a afrez grand nombre pour la chaffe en quelques endroiets. I'on trouue auffi des connins au Royaume de Quitto, maisles bons y font venus dEf pagne. C'eft vn autre animal eftrange que celuy, lequel pour fon exceffiue pefanteur $\&$ tardiucté a fo mouuoir, ils appellent Perico-legero, ou petit Fierre le leger: il a trois ongles à chaque main, \& meut fes pieds \& fes mains comme par compas, \& fort pefamment, \& reffemble de face 2 vne guenon il a vn cry hautain, il monte aux arbres, \& mange des four mis. 
des Fndes. Liare IIP.

200

Des Micos, ou guenons des Indes.

Chatitre XXXIX.

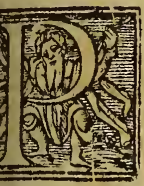

A $\mathrm{R}$ toutes les monragnes de ces Ines de la terre ferme, \& des Andes, il y a vn nombre infiny de micos, ou guenons, qui font de la race des linges, mais differents en ce qu'ils ont vne queüe, voire $t$ longue. Ety en a entr'cux quelques races i font 3. fois plus grands, voire 4. que les oraires; les vns font du to ut noirs, les autres ys, les autres gris, \& les autres tachetez, \& :nez. Leur legereté \& leur façon de faire êt mirable, pource qu'il femble qu'ils ay earat de raifon \& du difcours à cheminer par les ares, en ce qu'ils veulent prefque imiter les oyux. En allant de Nom de Dieu en Panama, ie Is en Capira qu'vne de ces guenons fauta d'va ore en l'autre qui eftoit de l'autre collé de la iere, ce qui me fift beaucoup ef merueiller. lls utent où ils veulent, f'entortillans la queäe en ebranche pour fefbranler; \& quand its veait fauter en vn lieu éloigné, \& qu'ils ne peunt d'vn faut $y$ atreindre, ils vfent alors d'vne ntillefaçon, qui eft qu'ils f́artachér à la queüe vns des autres, \& font par ce moyen comme e chaine de plufieurs, puis apres ils fiélancent fe iettent auant, \& le premier eftant aydéde force des autres, atteint où il veut, \& fattache vn rameau, puis il ayde \& fouftienctour le 


\section{Hiffoire naturelle}

refte, iufqu'à ce qu'ils foiét tous paruenus atta chez, comme j'ay dit, à la queuie ics vns des aư tres. Ce ferost chofe longue à raconter quelle folies, embufehes, \& trauerles \& lesieux, 8 gaillardifes quils font quand on les drelie; lel quelles ne femblenr pas enir d'animaux bru taux, mais d'vn entendement humain. I'en vid vn en Carthagene en la, mai fon du Gouuerneu tellement dreffé, que les chofes qu' 1 faifoit fem bloient incroyablics. Ils l'enuoyoient à la taues - ne pou auoir du vin, \& luy mettoient en vn main de l'argent, \& le pot en l'autre, n'eftoi pas poffible de luy tirer l'argene de la main, iuf qu'à ce qu'on luy euft donné le por plein de vin Si les enfans le rencontroient par la rae \& quil le vinffent agaffer, ou luy iet er des pierres, mettoir bas le pot d'vn colté \& fur les pierres ruant de fa part contre les enfans, iufques à c qu'il euft affeuré le chemin; puis retournoit porter fon por, \& qui plus eft, cncores qu'll fat bon beuueur de vin (come plufieurs fois ie lu en ay veu boire, lors que fon maiftre luy en iet toit d'enhaut) neantmoins il n'y euft iamais tou ché qu’on ne luy en euft donné congé. Ils m dirent mefmeque s'il voyoit des femmes far dees, il fe iettoit fur elles, \& leur tiroit la coiffu re, les des-accommodát, \& les voulant mordre Cecy pourra eftre addition pource que ie l'ay point veu: mais ie ne penfe point qu'ily ay animal qui phus approche de ta cóverfation ha maine, que cefte race de guenons. Ils en racon tent tant de chofes, que de peur qu'on ne penf que j'adjoufte foy 2 des fables, ou qu'on nele 
des Indes. Liure IV. $20 \dot{P}$ enne pour telles, ie trouue meilleur de laiffer lubiect \& conclure celte matiere, en benifat l'autheur de toutes creatures de ce qu'il a oulu creer vne efpece d'animaux feulementur la recreation \& le plaifir des hommes. uelques vns ont efcrit que l'on apportoit ces cos ou guenons à Salomon de l'inde Occintale, mais ie croy de ma part que c'eftoit de rientale.

\section{Des vicugnè of tarugues du Peru.}

Chapitre XL.

N N T E les chofes remarquables des 1. 3 , Indes du Peru, font les vicugnes \& (E) moutons du pays quils appellent, qui font des animaux traistables \& de ucoup de profit. Les vicugnes font fauuages es moutons eft yn beftial domeftique. Quel. es vns ont penfé que les vicugnes font ce que iftote, Pline, $\&$ autres autheurs traittent, ind ils efcriuent de ce qu'ils appellent Capres, Ariff. ti. so font chevres fauuages, \& leur portent cer-animal cafo.

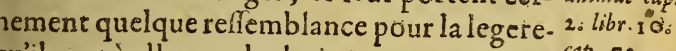
u'ils ont à aller par les bc is \& montagnes, \& cap. 72. ar reffembler auffi en quel que chofe aux che$s$, mais en effet elles ne font point d'vne mef. efpece, car les vicugnes nont point de cor, mais celles là en ont, comme Arifote ra* te. Ce ne font point non plus les chevres de de Orientale, do l'efpece defquels ils tirens $\mathrm{C}_{G}$ 


\section{Hiftoire naturelle}

les pierres de bezaar : car s'ils font de ce genr ce leroit vne efpece diuerfe, comme en la tac des chiensl'efpece du maftin eft autre que cell du levrier. Les vicugnes du Pera ne font poin auffi les animaux qui portent la pierre de bezaa en la Prouince de la neuue Efpagne, lefquels i appellent là bezaars, d'autant que ceux-là for de l'elpece des cerfs \& venaifon. Neantmoins ne f̧ache autre partie du monde où il y ayed cesanimaux, finon au Peru, \& en Chillé, q font Prouinces joignantes l'vne de l'autre. Le vicugnes font plus grandes que les chevres, plus petites que les veaux. Ils ont le poil tiran à couleur de rofe feche, quelque peu plus cla re. Ils n'ont point de cornes comme les cerfse capreas. Ils paiffent, $8 z$ fe recirent és endroirs le plus hautains des montagnes, qu'ils appellen Pugnas. La neige, ny la gelee ne les offenfe pas au contraire il femble quelle les recrée.Ils von en trouppe, \& courent tres-legerement. Quä ils rencontrent des voyageurs, ou quelques be ftes, ils f'enfuyent comme beftes fort timides $\&$ en fuy ant ils chaffent deuant eux leurs petit: On ne f'apperçoit point qu'ils multiplient beau coup. C'elt pourquoy les Rois Inguas auoien deffendu la chalfe des vicugnes, fi ce n'efto pour leurs feftes, \& par leur commandemen Quelques.vns fe plaignent que depuis quele Elpagnols y font entrez, on a donné tro $p$ de li cence à̀la chaffe des vicugnes, \& qu'ils font dì minuez pour cefte oscafion. La maniere d chaffer dont les Indiens vfent, eft de ce chaco qui eft qu'ils famaffent plufieurs hommes en 
iemble, quelquefois iufques à mil, ou trois mil, voire dauartage, \& entourant vn grand elpace de bois, vont chaffant la venaifon, iufques à ce qu'ils fe foient ioincts de tous coftez par ce noyen ils fe prennent d'ordinaire de 3 . à 4 . cens ou enuiron, \& lorsils prennét ce quils veulent, aiflans aller le refte, fpecialement les femelles our la multiplication. Ils ont accouftumé de ondre ces animaux, \& de faire de leur laine des ouuertures \& caftellongnes de grand prix, pare que cefte laine eft comme vne foye blanche, ui dure long temps; \& cöme la couleur eft naurelle, \& non point de teinture, elle eft perpeuelle. Les eftoffes faites de cefte laine, font fort raifches, \& fort bonnes pour le temps de chaeurs, \& tiennent qu'elles font profitables pour inflámation des reins \& autres parties, tempeans la chaleur exceffitie. La mefme vertu a cefte aine, quand elle eft mife en des mattelas. C'eft ourquoy quelques vns en vfent à céte fin pour experience quils en ont. lls difent dauantage, une cefte laine, ou couuerture faite d'icelle, eft aedicinale pourd'autres indifpofitions, comme our la goutte, toutefois 1e n'ay pas cognoilfane qu'on en ayt fait aucune experience certaine. chair de ces vicugnes n'eft pas bonne, encom e que les Indiens la mangent, \& qu'ils en font ela cecine, ou chair fechee, pour les effeats de medecine. Ie diray ce que j'ay veu cheminant ar la Sierre du Peru, $j$ arriuay en vn tambo, ou oftellerie vn foir, eftant affligé d'vne terrible louleur des yeux, tellement quil me fembloir u'ils vouloient fortir dehors ( qui eft va acciC. $\mathrm{G}$ ij 


\section{Hiftoire naturelle}

dent lequel ordinairement aduient en ces parties-là, d'autant qu'on paffe des lieux couverts de neige, qui caufe cét accidét en les regardant.) Eftant donc couché auec telle douleur que ie perdois prefque patience, arriua vne Indienne qui me dift, Pere, mets-toy cela aux yeux, \& tu feras guary; c'eftoir vn morceau de chair de vicugne tuee nouuellement, \& encore toute fanglante. I'vfay de cefte medecine, \& incontinent cefte douleur s'appaifa, \& peu de temps apres me quitta du tout. Outre les chacos que jay dit, qui eft la façon generalle, \& plus commune de chaffer és Indes, ils ont accouftumé d'en vfer d'vne autre particuliere pour les prendre, qui eft qu'en approchant affez pres, ils iettent des cordeaux auec certains plombs, qui prennent, $\&$ fe meflent entre leurs pieds, \& les empefchent qu'ils ne peuuent coutir, par ce moyen ils prennent la vicugne. $\mathrm{L}$ a principale raifon pourquoy cét animal eft eflimé, eft à caufe des pierres de bezaar qui fe trouuent enluy, defquelles nous traitterons cy apres. $11 \mathrm{y}$ a vn autre genre d'animaux qu'ils appellent taruguas, lefquels auffi font fauuages, \& font plus legers que les vicugnes. Ils font plus grands de corps, \& ont vne chaleur plus feche. Ils ont les oreilles molles \& pendantes, \& nemarchent point en trouppe comme les vicugnes, aे tout le moins ie n'en ay point veu que defeules, \& communement en des lieux tres-hauts. On tire mefme des pierres de bezaar de ces tarugues, lefquelles font plus grandes, \& ont plus d'operation, \& de vertu. 
des Fndes. Liure IV.

Des Pacos, Guanacos, Ǵ moutons du Perr.

Chapitre XLI.

L n’y a chofe au Perude plus grã. 1) du pays, que les noftres appellér moutős des Indes, \& les Indiens en langue generalle l'appellét lama: car tout bien confideré, $c^{\prime}$ eft ianimal du plus grand profit, \& de la moindie tefpenfe de tous ceux qu'on cognoiffe. Ils tirent de ce beftial la viande \& le veftement, comme ils font des brebis en Efpagne. Dauantage ils en tirent la commodiré de la charge $\&$ de la voitute de tout ce qu'ils ont befoin, attédu qu'il leur fert à porter leurs charges, \&d'autre cofté, il n'eft point de befoin de defpendre à les ferrer, ny en lelles, ou en bafts, \& non plusen auoine: mais 1 fert fes maiftres gratuitement, fe contentant de l'herbe quill trouue parmy les champs; de maniere que Dieu les a pourueus de brebis $\&$ de iuments en vn mefme animal. Et comme ceft vne nation pauure, il a voulu auffi les exempter en ce poinct, de couft \& de def penfe, pource qu'il y a beaucoup de pafurages $\&$ herbages en la Sierre, \& ce beftial n'a point befoin d'autre couft. Il y a deux efpeces de ces moutons ou lamas, les vns defquels ils appellent pacos, ou moutons porte laine, \& les autres font raz, $\&$ de peu de laine; auffi font-ils meilleurs pour la charge. Ils font plus grands que des grands moutons, \& moindres que des veaux, \& ont lo Cc iij 


\section{Hifoire naturelle}

col fort long, à la fembiance d'vn chameau, dont ils ont bien befoing: car eftans hauts $\&$ efleuez de corps, ils ont befoing d'vn col ainft long, pour ne fembler point difformes. Ils font de diueríes couleurs, les vns tous blancs, les autres noirs, les autres gris, \& les autres meflez, quids appellent Moromoro. Les Indiens auoient de grandes fuperftitions a choifir ces animaux, pour les facrifices, de quclle couleur ils deuoient eftre, felon la diuer fité des faifons, $\&$ des $\Upsilon_{a}$ crifices. La chair en eft bonne, encores qu'elle foit dure: mais, celle de leurs agneaux eft la meilleure, \& la plus delicate que l'on fçauroit manger, toutefois l'on n'en conformme pas beaucoup à manger, pource que le principal fruict \& profit qu'ils rapportent, eft la laine pour faire desdraps, \& leferuice quils font porter charge. Les Indiens mettent la laine en ouure, \& font des eftoffes, dont ils fe veftent, l'v ne qui eft groffiere \& commune qu'ils appellent hanafca, \& l'autre fine $\&$ delicate, qu'ils appellent cumbi. De ce cumbi ils font des tapis de table, des counertures, \& autres ouurages exquis, qui font de longue duree, \& ont vn affez beau luftre, approchant comme du mifoye; $\&$ ce qu'ils ont de fingulier, eft leur façon de tiftre la laine', d'autant qu'ils font à deux faces tous les ouurages qu'ils veulent, fans que l'on voye aucune fin, ny bout en toute vne piece. L'Ingua Roy du Peru auoit de grands maiftres ouuriers à faire cefte matiere de cumbi, \& les principaux refidoient au quartier de Capachica, joignant le grand lac de Titicaca. Ils teignent cefte 


\section{des Fndes. Liure IV. 204}

ine de diuerfes couleurs tres-fines, auec pluurs fortes d'herbes, de laquelle ils font beauup de differents ourag $₫ s$, de grofliers, ou mmuns, \& de fins. Tous ies Indiens \& Inennes y trauaillent en la Sierre, \& ont leurs eftiers en leur maifon, fans quiils ayent befoin acheter, ny faire faire les eftoffes qu'ils vfent ez eux. Ilsfont dela chair de ce beftial, du achargui, ou chair fechee, qui leur dure long imps \& en font grăde eftime. Ils on t accouftu. ie de conduire des bandes de ces moutons, hargez comme voituriers, \& vút en vne banede trois cens, ou cinq cens, voire mil mouons, lefquels portent du vin, du mays, du coca, u chuno, du vif argent, \& toute aurre forte de archandife, \& qui plus eft, de l'argent la meileure de toutes: car on porte les barres d'argent lepuis Potozi iufqu'en Ariqua, où il a foixante x dix lieues, \& auoient autrefois accouftumé le les porter à Arequipa, qui font cent cinquane lieues. Te me fuis beaucoup de fois efmerzeillé de voir ces trouppes de moutons chargez de mil \& deux mil barres d'argent, \& beaucoup dauantage, quifont plus de troiscent mil ducars, fans autre garde, ny efcorte, que queiques Indiens, qui feruent feulement pour guider les moutons, \& les charger, \& defcharger, ou. pour le plus quelques Efpagnols; \& dorment ainfi toures les nuids au milieudes champs fans autre garde que cela. Et neantmoins en $v \mathrm{n}$ fi long chemin, \& auec fi peu de garde, lon ne trouue iamais qu'il y ayt faute, ou perte d'aucune chofe fur va fi grand nombre d'argent, tant

C c iiij 


\section{Hiftoire naturelie}

eft grande la feureté, deffoubs laquelle on che mine au Peru. La charge que porte ordinair ment vnde ces moutons, eft comme de quatr ou fix arrobe; ; quand le voyage eft long, ils n cheminent par iour que deux, ou trois lieuies ou quatre pour le plus. Les moutonniers qu'il appellet, qui font ceux qui códuifent les troup pes \& bandes, ontleurs giftes, \& repaires or dinaires, qu'ils cognoiffent où il y a de l'eau $\&$ des pafturages, \& là ils defchargent, \& fon leurs tentes, y faufans du feu, \& accommodan leur manger, \& ne font pas trop mal, encore que ce foit vne façon de cheminer affez flcgma tique \& tardiue. Quand il n'y a point plus d'v né iournee de chemin à faire, v n de ces moutó porte bien huict arrobes pefant, \& dauantage \& chemine auec fa charge vne iournee entier de huiat, oudixlicües, ainfi qu'en ont vfé de pauures foldats qui cheminorent par le Peru. Tout ce beftial e plaift en vn air froid, \& pous cefte occafion il fe troune bien en la Sierre, \& meurt aux Lanos à caufe de la chaleur. Il arriue parfois que ce beftial eft tout couuert de glace $\&$ de gellee \& neantmoins demeure fain, \& 2 fe porte fort bien. Les moutons ras font plaifans à regardcr, pource qu'ils f'arreftent au chemin, $\&$ hauffent le col, regardans les perfonnes fort attentiuement, \& demeurent là ainfi v ne longue efpace de remps fans fe mouuoir, ny faire femblant de crainte, ny de contentement; ce qui donne occafion de rire, les voyant ainfiarreftez, encores que quel quefois ils f'efpouuentent tubitement, \& fen courent auec la charge 


\section{des Indes. Liure IV.}

iques aux plus hauts rochers. De façon que les pouuans atteindre, on eft contraint de les er, \& tirer à l'arquebuze, de peur de perdie $s$ barres d'argent, qu'ils portent quelquefois. es Pacos fe fafchent \& sobftinent contre la arge, fe couchans auecicelle, fans qu'on les aiffe faire releuer, mais pluftoft fe laiffer ont ils supper en mil pieces que de fe mounooir, quand defpit leur vient, d'où eft veatule prouerbe aijs ont au Peru, de dire que quelqu'vn s'eft npacqué, pour fignifier quil s'eft obftiné, autant que quand ces animaux fe fafchent, eft auec excés. Le remede que les Indiens one ors, eft de s'arrefter, \& $s^{3}$ alfeoir aupres du $\mathrm{Pa}$ , \& luy faire beaucoup de carcffes, iufqu'à ce ail ofte la fafcherie, \& qu'il fe releue \& auient uelquesfois, qu'ils font contraints d'attendre eux ou trois heures, iufqu'à ce qu'il foir deferm. acqué \& defennuyé. Il leur vient vn'mal come de la galle, qu'ils appellent carache, quiles it mourir ordinairement. Les anciens auoient ce vn remede, d'enterrer toure vifue celle ui auoit le carache, de peur qu'elle n'en infeaft le refte : pour-ce que c'eft vn mal fort congieux, \& qui va de l'vnà l'autre. Vn Indien uiaura vn ou deux de ces moutons, n'eft pas puté pauure: car vn de ces moutons de la tervaut lix \& fept pezes effayés, \& dauantage Lonle temps \& les lieux. 


\section{Fiftoire naturelie}

\section{Des pierres Bezaars. \\ Chapitre XLII.}

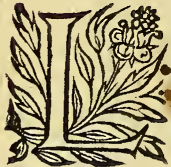

A pierre Bezaar fe troutue en ton es animaux, que nous auons d. y deflus eitre propres \& particu liers du Peru, de laquelle quelque utheurs de noftre temps oat el crit desliures entiers, que pourront voir ceu qui en voudrót auoir plus particuliere cognoil fance. Pour le fubiect prefent, il fuffira de dir que cefte pierre qu'ils appellêt bezaar, fe trouu en l'eftomach \& ventie de ces animaux, que quefois vne feule, \& quelquefois deux, \& troi: $\&$ quatre. Elles font beaucoup differentes entr elles, en la forme, en la grădeur, \& en lacouleu d'autăt que les vnes font petites, cóme auelines \& encormoindres, les autres font comme de noix, les autres comme des cuf de pigeons, 8 quelquesvnes auffi grádes cómevn ouf de pou le, \& on ay veu d'aucunes de la grandeur d'vn orange: en la forme, lesvnes font de forme rỏde les autres d'oualle, les autres de façon de lentil le, \& de plufieurs aurres formes. Pour leur cou leur, il y en a de noires, de blanches, de grifes de verd-brunes, d'autres qui font cóme dorees Ce n'eft pas vne regle certaine, que de regarde Ia couleur, ny la figure, pour iuger quelles fon les meilleures, ou les plus fines. Toutes ces pier res font formees $\&$ compofees de diuerfes tuni 


\section{des Fndes. Liure IV. $\quad 206$}

$s$, ou pellicules \& les vnes fur les autres. En 'rouince de Xaura, \& en d'autres Protinces Peru, l'on trouue de ces pierres en diuerfes tes d'animaux, fiers $\&$ domeftiques, comme suanacos, és Pacos, és Vicunes, \& és Tar us, d'auties y adiouftét vne autre efpece, qu'ils int eftre chevres fautages, \& font celles que Indiens appellent Cypris. Ces autres fortes nimaux font fort cogneuës au Peru, \& en ns defia traitté cy deffus. Les Guanacos ou utons du pays, \& les Pacos, ont communent les pierres plus petites, \& noirettes, \& font pas tant eftimees, ny approuuees pour age de la medecine. On tire les plus grofpierres de bezaar, des Vicunes, \& font gri, ou blanches, ou de verd obfcur, lefquelles it tenuës pour les meilleures. L'on eftime e celles des. Tarugues font les plus excellen , dont il y en a quelques-vnes bien grolies, es font communement blanches, tirans fur ris, \& ont leurs tuniques \& pellicules, cominement plus groffes $\approx$ efpaiffes que les aus. L'on trouue la pierre bezaar efgalement ant aux manles, quaux femelles. Tous les imaux qui l'engendrét, ruminent, \& ordinainent paiffent parmy les neiges, \& les roes. Les Indiens racontent de tradition \& engnement de leurs peres $\&$ anciens, que en la ouince de Xaura, \& en d'autres Prouinces du ru, il y a plufieurs herbes \& animaux venieux , lefquels empoifonnent l'eau, \& les parages où ils boiuent \& mangent, \& où ils urent. Defquelles herbes venimeufes il y en 


\section{Hiffoire naturelle}

a vne qui eft fort cogneuë de la vicugne par inftinct naturel, \& des autres animaux qui gendrent la pierre bezaar, lefquels mangent ite herbe, \& par le moyen d'icelle ils fe pref uent du poifon des eaux \& des pafturages, ainfir difent-ils que de cefte herbe fe forme leur eftomach cefte pierre, d'où elle tire tol la vertu qu'elle a contre le poifon, \& fes aut operations merueilleufes. C'ett l'opinion tradition des Indiens, defcouuerte par desp fonnes fort experimentés au Royaume du I ria, ce qui s'accorde auecla raifon, \& auec plin.lib.ro, que Pline raconte des chevres montagner cap. 72. lefquelles fe nourriffent, \& paiffent de poif fans qu'il leur fafte mal. Les Indiensinterrog pourquoyles moutons, les vaches, chevres veaux, del'efpece de ceux de Caftille, n'ont la pierre de bezaar, veu qu'ils paiffent és mefr roches que font les autres; refpondent qu ne croyent pas que ces fufdits animaux de $C$ ftille, mangent cefte herbe, $8 z$ qu'ils ont mef trouué la pierre bezaar en des Cerfs, \& Daims. Cela femble faccorder auec ce que no fçauons, qu'en la neuue Efpagne il fe trouue pierres de bezaar, combien qu'il n'y ayt poi de vicugnes. de Pacos, de Tarugues, ny de Gu nacos, mais feulement des Cerfs, en quelqu vn defquels l'on trouue cefte pierre. Le pri cipal effet de la pierre bezaar, eft contrelev nin \& maladies venimeufes, encor qu'il y a fur ce diuerfes opinions, \& qualques-vns tie nent cela pour mocquerie, \& les autres en fo des miracles. Comment ques'en foit, c'ett v 


\section{des Indes. Liure IV.}

fe certaine, qu'elle eft de grande operation, nd elle eft appliquee à temps, d'vne façon enable, ainfi que les herbes, $\&$ à des perfoncapables \& diffofees. Car il n'eft pas de meine, qui guarifle infalliblement roufiours. Efpagne, \& en Italic, l'on a veu d'admirables ats de cefte pierre contre la Tauerdette, qui rne efpece de pefte, mais non pas tát auPeru. n l'applique pilee\&mife en quelque liqueur, fe puiffe accommoder pour la guerifon de elancholie, mal caduc, fiebvres peftilentieu\& pour plufieurs fortes de maladies. Les vns rennent auec du vin, les autres auec du vin$c$, auec eau dazahac, de langue de bouf, de urraches, \& d'autres fortes, que diront les decins \& Apoticaires. La pierre de bezaar aucune faveur propre, comme mefmele dir is Arabe: L'on en a veu quelques experienremarquables, \& n'y a point de doute que theur de tout cét vniuers, n'air dóné de granvertus à cefte pierre. Les pierres de bezaar, viennent de l'Inde Orientale, ont le premier I'eftime entre ces pierres, lefquelles font ouleur oliuaftre, le fecond celles du Peru, \&z oifiefme celles de la neuue E pagne. Depuis l'on a cómencé de faire eftat deces pierres, difent queles Indiens en ont fophiftiqué, \& d'artificielles; \& plufieurs quand lis voyent ces pierres plus grandes que les ordinaires, yent que ce font pierres faulfes, \& v ve tromie: neantmoinsil y en a de grandes fort fines, de petites quifont contrefaites. L'efpreuue xperience, eft le meilleur maiftre de les co- 


\section{Fiftoire naturelle}

gnoiftre. Vne chofe eft digne d'admirer, qu naiffent $\&$ fe forment fur des chofes fort eft ges, cúme fur un fer d'efguillette fur vne efp. gue, ou fur vne buchetre, que l'on trouue centre dela pierre, \& pour cela ne tienner. pas, qu'elle foit faufe, pour-ce qu'il arriue l'animal peut auoir auallé cela, \& que la pi fe caille \& s'épaiffit là deffus, qui va croiffant coquille l'vne fur l'autre, \& ainfi s'augmente veids au Peru deux pierres fondees \& form fur des pignons de Caftille, ce qui nous fit $t$ beaucoup efmerueiller, pour-ce qu'en tou Peru nous n'auions point veu de pignes, ny pignons de Caftille, s'ils n'eftoient appor d'Efpagne, ce qui me femble chofe fort extra dinaire. Ce peu fuffife, touchant les pierres zaars. On apporte des Indes $d$ autres pierres decinalles, cóme la pierre d'Hyiada, ou de 1 te, la pierre de fang, de laikt, \& de mer : Ce quils appellent Cornerinas, pour le cœurd quelles il n'eft point de befoing de parler, n'auoir rien de cómun à la matiere des anim dont nous auó traitté. Ce qui eft dit, foit pi faire entendre comme le grand Maittre \& theur tout puiffant de l'vniuers, a departy dons, \& fecrets inerueilleux à toutes les par du monde, pour lefquels il doit eftre ador glorifié par tous les fiecles des fiecles. Amen 


\section{8}

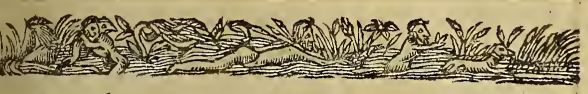

\section{Prologue des Liures fuiuans.}

(G) Yant traicté ce qui concerne l'hi(1.2. (9) foire naturelle des Indes, ie traitMre teray cy apres de l'biftoire morale, (1) Indiens. Car apres le Ciel, la temperature, la uation, \& les qualitez du nouneau monde, res les elements, \& les mixtes, ie veux dire metaux, plantes, $\&$ animanx, dequoy nous ons parlé aux liures precedens, ce qui s'eft preté: L'ordre \&o raifon nous inuite à pouy Juinre entreprendre le traitté des hormmes qui bacnt au nouneau monde. C'eft pourquoy is preus dire aux liures fuiuans, ce qui me fembledigne d'eftre recité fur ce friet. Et pource que ntention de cefte biftoire nieft pas feulement ur donner cognoiffance de ce qui Je paffe aux des, mais aussi pour acheminer cefte cognoifsace, an fruict que l'an pers tiver dicelle, guice f iider à ce peuple à faire leur falut, \& glorifier Createur o Redempteur qui les a tirez des zebres tref-obfcures de leur infidelité, \&o leur ommuniqué l'admirable lumiere de fon Euan:1e. Partant premierement ie dirag en ces lies fuimans, Ce gui touche lewr religion, OH /Ba- 
perftition, leurs conftumes, leurs idolatries, leurs acrifices,puis apresce quieft de beur poli \& gounernement, de leurs loix, couftumes of leursfaicts. Et pource que la memorre s'eft cor feruee entre la nation Mexiquaine, de leu. commencemens, fucceßions, guerres, \& autr chojes dignes de raconter, ouire ce quilera tra. té au liwre fixiejme, ie feray un propre \& part. culier dij cours au liure leptiefrine, iulqu' a mon. ftrer la dippofition of augures que ces nation eurent du nouneau Royaume de Chrift, nofts Seigneur,guife denoit ftendre en ces terres, les fubiuguer à Joy, comme il a fait en tout le re fte dumonde. Qui à la veritéeft vne chofe di gre de grande confideration, de voir comme l diuine prouidence a ordonné, que la lumiere a Japarole troutaft entree aux dernieres fins e bornes de la terre. Ce rieft point chofe qui for de mon proiet defcrire maintenant ce gue le E/pagnols ont faiten cesparties la, car iiy a al jez de liures efcrits fur cefte matiere, \& no plusce que les ferwiteurs du seigreur y ont tra suillé $O$ fruct ifié, d'autant que cela requier wne autre nounelie divigence. Ie me contentera feulemert de mettre cifte biftoire, ourelation aux portcs de l Euangile, pisis qu' elle eft defis toute acheminee à faire cognoiftre les chofe jaturelles o moralles des briaes, a fin que Buntuel 
irituel, or le Chreftianifmey Joit planté \& igmenté; comme ileft amplement expliqué ix liures que nous auăs efcrit, de procurầda idiorum faluce. 'Quejiquelqu'vn s'efmerille d'aucunes façons, \& couftumes des Inens, \& les veut me prijer comme idiots, ou les oir en borreur, conume gens inhumains or aboligues; quil prenne garde o fe fourienne elesme/meschofes, voire depires, ont efté wës entreles Grécs of les Romains, quiont nman dé à tout le monde, comme i on pourrie ilement entendre non' Jeulement denos $A$ us. urs, Eujebe de Ciefaree, Clemiet Alexandrin, codoret, $O$ autres; mais au si des leurs mefs, comme Pline, Denys Halycarnaffe, ó Plum que. Car le Prince des tenebres eftant le $f$ de toute infidelité, cen'eft pas chofe nom. de drouner entre les infideles des cruauter immondices, or des follies, propres or conrables à vn telmaiftre. Et iacoit que les anns Gentils ayent de beascousp (surpaffeceusdu nouneau monde, en valeurs ¿d fience urelle; neantmoins peut-oik renarguer en plufieurs choles dignes de memoire. $M$ ais in le plus qu'ily a, eft comme de gens barba le quels priuez de la lumiere Jupexnaturelnt eu au/si defaut de la philofophie do denenaturelle. 


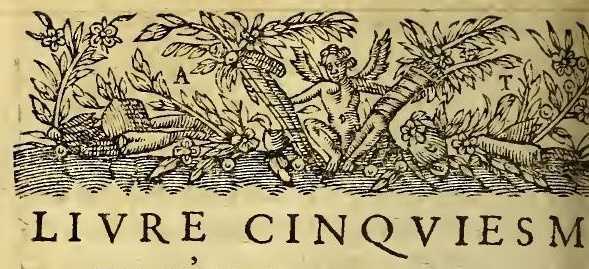

DE LHISTOIRE NATV. relle \& morale des Indes.

2ue l'orgueil ó l'enuiedu diable a cftéla casye de l'idolatrie

CHAPITRE PREMIER.

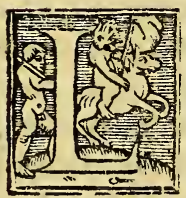

'ORGVEIL \& la prefompti du diable eft figrande \& fi obf nee, que toufioursil appette s'efforce de fe faire bono pour Dieu, \& tout ce qu'il pe defrober \& s'approprier de qui appartient au tres-haut Dieu, ilne ceffe le faire aux nations aueugles du monde, lefqu les la lumiere \& refplendeur du fain\&t Euang yob.4?. n'a point encor éfclaircies. Nous lifons en I de cét orgueilleux tyran, qu'il met fesyeux plus haut, \& qu'entre tous les fils de l'orgue eft le Roy. Les divines Efcritures nous ent gnët fort clairement fes mauuaifes intentions fa trahifon fi outrecuidee, par laquelle il a tendu efgaller fon throfne à celuy de Dir 


\section{Hiftoire naturelle}

uer entr'eux la fauffe $\&$ menfongere diuinité, laquelle le fils de Dieu luy auoit oftee en fon Eglife, l'enchaifnant \& enfermant commeen vne cage, ou prifon, ainfi qu'vne befte furieufe à

\$ob.40. fa grande confufion, \& refiou yffance desferuiteurs de Dieu, comme il le fignifie en Iob. Mais en fin ores que l'idolatrie a efté extirpee de la meilleure, \& plus notable partie du monde, il s'eft retiré au plus esloigné, \& a regné en cefte autre partie du monde, laquelle combien qu'elle foit beaucoup inferieure en noblefte, ne l'eft pas toutesfois en grandeur \& largeur. Il y a deux caufes \& motifs principaux, pour lefquels le diable s'eft tant eftudié i planter l'idolatrie \& toute infidelité , de telle façon qu'à peine l'on trouiu aucune nation, où il n'y ait quelque idolatrie. $L$ 'vne,eft fa grande prefomption \& orgueil, qui eft telle, que qui voudra confiderer comme il a Matth. 4. 'bien olé s'attaquer au mefme Fils de Dieu \& vray Dieu, en luy difant effrontément qu'il fe profternaft deuant luy, \& qu'ill'adoraft, ce qu'il faifoit, combien qu'il ne fceuft pas affeurément que c'eftoit le mefme Dieu, mais pour le moins ayant quelque opinion qu'il fuft le Fils de Dieu. Cruel \& efpou uantable orgueil, d'ofer ainfin indign ement attaquer fon Dieu ! certainement celuy-là ne trouuera pas beaucoup eftrange, quil fe faffe adorer cóme Dieu, par des nations igno . rantes, puis qu'il s'eft voulu faire adorer par Dieu mefme, en fe difant Dieu, bien qu'il foir sne fi a bominable\& deteftable creature. L'autre caufe \& motif de l'idolatrie, eft la hayne morselle, \& inimitić qu ila conceüe pour iamais con 


\section{des Indes. Liure. V.}

res les hommes. Car commé dit le Sauueur, dés e commencement il a efté homicide, \& retient cela comme vne condition \& proprieté infepa:able de fa mefchanceté. Et pource qu'il- fçair que le plus grand mal'heur del'homme, eft d'alorer la creature, comme Dieu;' à cefte occafion Ine ceffe d'inuenter toutes fortes d'idolatries, our deftruire les hommes \& les rendre ennemis le Dieu. Il y a deux mainx que le diable fait en 'idolatrie, l'vn qu'il nie fon Dieu, fuiuant ce affage, Tu as delarfe le Dieu quit'a creé: Et l'autre, Dent. 32.' u'il s'affubietit à vne chofe plus baffe que luy, ource que toutes les creatures font inferieures la raifonnable, \&'le diable, encor qu'il foit fuerieur de l'homme en nature, neantmoins en ftat il eft beaucoup inferieur, puis que l'homme n cefte vie eft capable de la diuinité $\&$ eternité. ar ce moyen Dieu eft des-honoré, \& l'homme erdu en tous endroits par l'idolatrie, dequoy le iable fuperbe $\&$ orgueilleux eft fort content.

Depluferurs fortes d'idclatrie, defquellesles Indiens ont veé.

Chapitre II.

10 'Idolatrie, dit le fainct Efprit parle Sap I4。 Sage, eft la caufe, le commencement, $\&$ la fin de tous maux, pour cefte occafion l'ennemy des hommes a mulplié tant de fortes \& diuerfitez d'idolatrie, que Dd iij 


\section{Hiftoire naturelle}

ee feroit chofe infinie de lesconter toutes parle menu ; Toutesfois on pourra reduire toute l'idoladrie en deux chefs, I'vn qui eft fur les chofes naturelles, \& l'autre fur celles qui font imaginees, \& compofees par inuention humaine. La premiere d'icelles eft divifee en deux, car ou la chofe quel'on adore eft generalle, comme le Soleil, la Lune, le feu, la terre, \& les Elemens: ou elle eft particuliere, comme vne certaine riuiere, vne fontaine, vn arbre, \& vne foreft, quand ces chofes ne font point adorees generalement en l'efpece dont elles font, mais qu'elles font tant feulement adorees en leur particularité. Dece premier genie d'idolatrie, ils ont excefsiuement vfé au Peru, \& l'appellent proprement guaca. Lefecond genre d'idolatrie qui defpend d'vne inuention ou fiction humaine, fe peut mefme diuifer en deux fortes. L'vne qui regarde le pur art \& inuention humaine, comme d'adorer les idoles, ou les ftatues d'or, de bois, ou de pierre, de Mercure, ou de Pallas, quine font, ny n'ont iamais efté riẹn autre chofe que la peinture: \& l'autre quiconcerne ce qui reallement a efté, \& eft veritablement quelque chofe, mais non pas telle, que ce que l'idolatrie quil l'adore en feint, comme les morts, ou les chofes qui leur font propres, que les hommes adorent par vanité, $8 c$ flatterie. De forte que nousles reduifons toutes en quatre fortes d'idolatrie, dont vfent les infidelles, de toutes lefquelles il nous conuiendra dire quelque, chofe. 
des Indes. Liure. V.

Queles Indiens ont quelque cognoiffance de Dieu.

CHAPITRE. III.

aens 3 premier lieu, iaçoit que les tenebres de 1 infidelitétiennent l'entendement de ces nations obfcurcy; toutesfois en beaucoup de chofes, la lumiere de la verité, \& de la ifon ne laife pas d'operer quelque peu en eux. 'eft pourquoy communement ils tiennent, \& cognoiffent vn fupréme Seigneur, \& Autheur toutes chofes, lequel ceux du Peru appel. ient, Viracocha, \& luy donnoient des noms de ande excellence, l'appellans Pachacamac, ou achayachachic, qui eft Createur du Ciel \& de terre, \& Vfapu, qui eft admirable, \& autres oms femblables. C'eft celuy qu'ilsa doroient, toit le plus grand de tous, lequel ils honoroient regardant au Ciel. On en peut voir autant en e ceux de Mexique, \& auiourd'huy entre les hinois, \& en tous autres infidelles. Ce quife apporte fort bienà ce que raconte le liure des ates des A poftres, que fainit. Paul fe trouua n Athenes, où il veit vnautel intitulé, Ignoio 00, au Dieu incogneu, d'où l'A pottre print ACE. $1 \%$ ccafion de les prefcher leur difant, Celng que ous autres adore' 2 Sans le cognoiftre, ef celuy que ie prefbe. De mefme ceux qui prefchent au:ourd'huy Euangile aux Indiens, ne trouuent pas beauoup de difficulté à leur perfuader qu'il y a yn Dieu fupréme, \& Seigneur de toutes chofes, Dd iiij 


\section{Hifoire naturelle}

\& que ceftuy-là eft le Dieu des Chreftiens, \& I vray Dieu, combien que c'eft vne chofe qui $m$ beaucoup fait efmerueiller, que iaçoit qu' ils eu! fent bien cefte cognoiffance, ilsn'auoient poin neantmoins de nö propre, pour nommer Dieu car fi nous voulons rechercher en langue des In diens vn mot qui refpondeà ce nom de Dieu comme le latin, Deus, le grec, Theos, l'Hebreu, El I'A rabic, Alla, l'on n'en trouvera aucun en langue de Cufco, ny en langue de Mexicque. D'ot vient que ceux qui prefchent, ou efcriuent aus Indiens, vfent de noftre mefme nom Efpagnol Dios, s'accommodans à l'accent \& prononciation propre des langues Indiennes, qui font for differentes. D'où il appert le peu de cognoiffan ce qu'ils auoient de Dieu, puis qu'ils ne le peuuent pas mefmes nommer, fi cé n'eft par noftr mefme mot. Toutesfois à la verité, ils ne laif foient pas d'en auoir vne cognoifiance telle quelle. C'eft pourquoy ils luy firent au Peru vn tres-riche temple, qu'ils a ppelloient la $\mathrm{Pachaca}$ mac, qui eltoit le principal Sanctuaire de ce royaume. Et commeil a efté dit, ce mot de Pachacamac, vaut autant que Createur, combien qu'en ce temple ils excerceaffent aufsi leurs idolatries, adorant le diable, $\&$ les figures. Ils faifoient mefme des facrifices, $\&$ offrandes au viracocha , qui tenoit le fuprefme lieu entre les adoratoires que les Roys Inguas ont eu. Delà vint qu'ils appelloient les F. Pagnols, viracochas, parce qu'ils auoient opinion qu'ils eftoient fils du Ciel, \& diuins, de mefme que les autres attribuerent vne deäté à Paul, \& à Barnabé,appellans l'vn It- 
ter, \& l'autre Mercure; ainfi ils vouloient leur frir des facrifices, comme à des dieux, \& tout mefme que les Barbares de Melite ( qui eft althei) voyansque la vipere ne faifoit point de làl'A poftre, l'appelloient Dieu.Dóc comme $\mathbf{\Lambda} t .18$ : ififoit que c'eft vne verité conforme 'a toute nne raifon; quil y ait vn foumerain Seigneur Roy du Ciel, lequel les gentils auec toutes irsidolatries \& infidelité, n'ont pas nié, ainfí e l'on voit en la Philofophie du Timee de ton, en la Methaphyfique d'Ariftote, \& en Efculape de Trifmegifte, comme mefme és vltimo. éfies d'Homere, \& Virgile. Delà vient que les Methap. edicateurs Euangeliques n'ont pas beaucoup difficulté à planter, \& perfuader cefte verité nfupréme Dieu, quelques barbares \& beTrimeg: alles que foient les nations, aufquellesils prefent. Mais il eft tres difficile de leur defraciner l'entendement qu'il n'y ait nul autre Diell;ny tre deité qu'vne feule, \& que toutes lesautres ofes de foy n'ont point de puiffance ny d'e$e$, ny d'operation quileur foit propre, finon que le tres grand, feul Dieu, \& feul Seigneur Ir donne, \& leur cómunique. En fin il eft neTaire de leur perfuader cela par tousmoyens, reprouuant leurs erreurs, tant en ce qu'ils llent vniuerfellement, d'adorer plus d'vn eu, qu'en particulier (qui eft beaucoup dantage) de tenir pour dieux , \& de demander de, \& faueur, des autres chofes qui ne font int dieux, \& n'ont aucun pouuoir, que celuy. le le vrayDieu, leurSeigneur, \& Createur leur incede. 


\section{Hifoire naturelle}

Du premier genre delidolatrie far les chofe naturelles, \&uninerfelles.

Chapitre IV.

PresleVirachocha, ou le fupr
me Dieu (le plus fouuent \& com
munement entre tous les infidel
les) ce qu ilsont adoré, $\&$ adoren
eft le Soleil, \& apres les autr chofes qui font les plus remarquables en natu re celefte ou elementaire, comme la Lune les Eftoilles, la mer, \& la terre. Les guacas, o adorataires que les Inguas Seigneurs du Peru auoient en plusgrande reuerence, a presle vir: cocha,\& le Soleil, eftoit le tonnerre, qu'ils appe loient par trois diuers noms, Chuquilla, Catuil 1a, \& Intiillapa; fimaginans que c'eft vn homm qui eft au Ciel,auec vne fonde, $\&$ vne maffuë, $\varepsilon$ qu' il eft en fa puiffance de faire pleuuoir, gref ler, tonner,\& tout le refte qui a ppartient à la re gion de l'air, ou fe creent lesnuages. C'eftoit vn guaca(ainfi appelloient-ils leurs adoratoires)ge neralle à tous les Indiens du Peru, \& luy of froient diuers facrifices, $\&$ en Cufco, qui eftoit 1 Cour \& ville Metropolitaine, ils luy facrifioien mefme des enfans, comme au Soleil. Ils adoroiê cestrois, Viracocha, le Soleil, \& le tonnerre, d'v ne autre façon que tout le refte, ainfi que Pol. lo efcript l'auoir experimenté, qui eftoit quil 

des fndes. Liure. V. 214
$\quad 214$
oient, comme vn gantelet, ou bien vn en leurs mains, quand ils les hauifoient les adorer. Ils adoroient mefme la terre, elle ils appelloient, Pachamama, à la faque les anciens celebroient la deeffe Tel\& la mer aufsi, qu'ilsappellent Mamaco, comme les anciens adoroient Thetis, ou tune. Dauantage ils adoroient l'are du 1, \& eftoient les armes \& blarons de l'In, auec deux couleuures eftenduës aux co- Entre les Eftoilles communement tous roient celle qu'ils appellent Colça, que is appellons par deça les Cabrilles. Ils atuoient à diuerfes Eftoilles divers offices, \& $x$ qui auoient befoing de leur faueur, les roient comme les Pafteưrs adoroient, \& $\mathrm{fa}_{2}$ ioient à vne Eftoille qu'ils appelloient, $\mathrm{V}$ iillay, qu'ils difent eftre vn mouton de pluirs couleurs, ayantle foing de la conferuandu beftial, \& tient l'on que c'eft celle que Aftrologues appellent Tyra. Ces Pafteurs fme adorent deux autres Eftoilles qui vont cheminent proches dicelles, lefquelles ils mment, Catuchillay \& Vicuchillay, \& feient que c'eft vne brebis \& vn agneau. D'auis adoroient vne Eftoille qu"ils appellent $\mathrm{Ma}$ acuay, à laquelle ils attribuent la charge \& iffance fur les ferpens \& couleuures, pour ipefcher qu'ils ne leur fiffent mal. Ils attriloient la puiffance d'vne autre Eftoille, qu'ils pelloient Chuquinchinchay, qui vaut autant ie tigre fur les tigres, les ours \& les lyons, ont creu generalement que de tous les ani- 


\section{. \\ Hiftoire naturelle}

maux qui font en la terre, il y en a vn feu. Ciel qui leur eft femblable, lequel a la cha $\&$ le loin de leur procreation \& augmentat Et ainfi ils remarquoient \& adoroient plufie $\&$ diuerfes eftoilles, comme, celles qu'ils pelloient Chacana, Topatarca, Mamana, $M$ co, Miquiquiray, \& plufieurs autres. T ellern qu'il femble qu'ils approchoient aucunem des propofitions des Idees de Platon. Les $M$ xiquains prefque de la mefme façon, apres fu préme Dieu adoroient le Soleil. C'eft pol quoy ils appelloient Hernando Cortez (co me il l'efcrit en vne lettre enuoyee à l'Em reur Charles le Quint) fils du Soleil, pour fa ligence \& courage à circuir la terre. Mais faifoient la plus grande adoration à lidole a pellee Vitzilipuztli, lequel en toute cefte r gion ils appelloient le Tout-puiffant \& $S_{s}$ gneur de toutes chofes. Pour cefte caufe Mexiquains luy baftirent vn temple le $p$ l grand, le plus haut, le plus beau, se le pl magnifique \& fomptueux de tous. La fituati \& forterereffe duquel fe peut coniecturer $p$ les ruines qui en font demeurees au milieu de Cité de Mexique. Mais en ceft endroit l'idol. trie des Mexiquains a efté plus pernicieufe. dommageable, que celle des Inguas, comn l'on verra mieux cy apres, d'autant que la pli grăde partie de leur adoration \& idolatrie, $s^{3}$ or cupoit auxidoles, \& non pas aux mefmes cho fes naturelles, combien quills attribuoient $k$ effects natiurels auxidoles, comme des pluye: de la multiplication du beftial, de la guerre, d 


\section{des Indes. Liure $V$.}

neration, ainfi que les Grecs \& les Latins fe forgez des idoles de Phcebus, de Mercure piter, de Minerue, \& de Mars. En fin qui Ira bien confiderer cecy de pres, trouuera la façon \& maniere dont le diable a vféa iper les Indiens, eft la mefme auec laquelle ompé \& deceu les Grecs \& Romains, \& les es anciens Gentiis, leur faifant entendre que reatures remarquables, le Solsil, la Lune, les illes \& les Elemens, auoient d'eux mefmes opre pouvoir \& authorité de faire du bien, u mal aux hommes: Et combien que Dieu ree toutes ces chofes pour le feruice de nme, reantmoîns il s'eft tant oublié qu il voulu esleuer contre luy. Et d'autre part il ogneu \& s'eft affubjetty aux creaturesqui ont mefme inferieures, en adorant $\&$ inuoit fes propres œuures, \& laiffant d'adorer $\& 2$ quer le Createur, comme le propofe fort le Sage par ces paroles: Tous les bonmes font o abufe'z, Eq quels la cognoifsance de Dien ne ee trous$n$, veu quils noont pas pew cograiffre celuy qui eft, chofes mefmes qui leur femblorent eftre bonnes. Et quills consemplajent fes cuunres, ils n'ont pas tostes traint iusques a la cognoisfance del authearr o ous d'icelles:mais ils ont cren que le ferw, le verst, l'air agz-

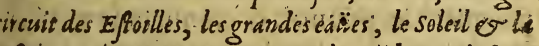
effoient Dieux $\sigma$ goumerneurs du móde, or-'seftant is amoureux de la beauté de telles chofes, il leur fentqu'bls le deuoient eftimer comme Dieux. C'eft raid its confiderent de combien plus bean eft leur Creapuis que c'eft celuy qui donne les beaute 7,0 qui s megmes chafes. D'antre part s' uls ont en en adnis: 


\section{Hiftoire naturelle}

ration la puiffance $\mathcal{O}$ les effects de ces chofes, par me fmesils dotuent enterdre de combien dout eftre plus fant qu'ellestoutes, celuy qui leur a donné ceft eftreq les ont, pource quel'on peut coniecturer par la beaul grandeur qu'ont les creatures, quel doit eftre le Create toutes ceschofes. Iufques icy font les paroles d ure de Sapience, defquelles l'on peut tire bon \& fort argument, pour conuaincre la g: de tromperie des idolatres infidelles, qui i lent pluftoft feruir \&<reuerer la creaturc q Rom.1. Createur: comme iuftement l'A poftre les prend. Mais d'autant que cecy n'eft poin prefent fubiect, \& qu'il eft fuffifamment porté aux Sermons que l'on a efcrits contr erreurs des Indiens, il fuffit quant à prefer dire qu'ils adoroient-le grand Dieu , \& 1 Dieux vains \& menfongers tout d'vne me façon: pource que la façon de faire oraifo Viracocha, au Soleil, aux Eftoilles, \& au des Guacas ou idoles, eftoit d'ouurir les $m$ \& faire certain fon auec les levres, comm perfonnes qui baifent; \& de demander ce chacun defiroit, en leur offrant facrifices. C bien qu'il y euft grande differ roles dont ils vfoient pour parler auec le gr Ticciuiracocha, auquel ils attribuoient pri palement le pouuoir $\&$ commandemét fur tes chofes, \& celles dont ils vfoient à parler autres, lefquels ils n'adoroient feulement chacun en fa maifon comme Dieux ou Seign particulièrs, \& difoient qu'ils eftoient leur terceffeurs enuers le grand Ticciuiracocha. fte façon d'adorer ouurant les mains, \& con 
des Indes: Liure. V. baifant, a quelque chofe de femblable à celle te Iob auoit en horreur, comme chofe propre tob.33. sidolatres, difant: si $i$ ay baif' mes mains aurc ma uche regardant le soleil quand il reluit, ou la Lwane and elle eft claire : ce quieft vne tres-grands siniquite? - eft neer le tres. grand Diem.

De lidolatrie dont les Indiens verent fur les chofesparticulieres.

C.HAPITRE V.

7 I E diable ne s'eft pas cŏtenté de faire que 21) - les aueugles Indiens a doraffent le Soleil, la Lune, les Eftoilles, la terre, \& la mer plufieurs autres chofes generales en la nature; lais il a paffé plus outre en leur donnant pour ieu, \& les affubiectiffans à deschofes balles \& etites, \& la plus grãd'part,ordes \& infames. L' $\phi$ es'ef pouuentera point de ceft aueuglemët des arbares, qui fe voudra fouuenir de ce que l'A - Rom. .. oftre dit des Sages \& des Philofophes, qu'ayans ogneu Dieu, ils ne le glorifierêt point, ny ne luy endirent graces comme à leur Dieu, mais qu'ils e perdirent en leurs opinions \& penfees, \& leur œur a efté endurcy en leur follie, \& ont changé gloire \& deïté de l'eternel Dieu à des femlances \& figures des chofes caduques \& coruptibles, côme d'hommes, d'oyfeaux, de beftes $x$ de ferpens. L'on fçait affez que les Egyptiens doroient le chien d'Ofiris, la vache d'Ífis, \& le nouton d'Ammon: les Romajns adorojent la 


\section{Hiftoire naturelle}

deeffe Februa, des fieures, \& l'oye Tarpeï ne, \& qu'Athenes la fage adoroit le $\mathrm{Coq} \&$ Corbeau, \& femblables autres vanitez \& m queries, dont les hiftoires des anciens Gent font toutes remplies. Et font tombez les hon mesen vn fi grand mallheur, pourn'auoir vou s'affujettir à la loy de leur vray Dieu \& Cre teur, comme fainct Athanafe le traicte doct ment, efcriuant contre les idolatres. Maisc' vne chofe merueilleufement eftrange, que desbordement \& perdition qui a efté en ce entreles Indiens, Specialement du Peru : car adoroient les rivieres, les fontaines, les em boucheures des riuieres, les entrees des mon tagnes, les roches ou grandes pierres, les co lines, les fommets des montagnes qu'ils appe lent Apachitas,' \& les tiennent pour chofe d grande deuotion. En fin ils adoroient tout chofe en nature, quil. ur fembloit remarquabl \& differente du refte, comme y recognoiffan quelque particuliere deitè. L'on me monftra e Caxamalca de la Nafca vne colline, ou grand terre de fable qui fut le principal adoratoire ou Guaca desanciens. Ie leur demandois quell diuinite ils y trouuoient, \& ils me refpondi rent quails l'adoroient à caufe de cefte merueille qu'il au oit d'eftre vne terre de fable tref haute au milieu des montagnes de pierre qu eftoient tref-efpaifles. Nous eufmes befoing et la Cité des Roys, d'vn grand nombre de gro. bois, pour fondre vne cloche, \& pource l'on coupa vn grand arbre difforme, qui pour fa grandeur \& fonantiquité auoirefté lon ptemp 


\section{des Indes. Liure $V$.}

oratoire, \& Guacades Indiens. Er leur femoit qu'il y auoit quelque divinité en tout ce i auoit quelque chofe d'extraordinaire \& d"eange en fon genre, iufqu'à en attribuer auit tux petites pierres 86 metaux, voire aux ines \& aux fruicts de la cerre, comme aux raies qu'ils appelloient Papas. Il y en a d'vne te eftrange qu'ils appelloient Lallahuas, lefelies ils baifoient \& les adoroient. Ils adot auffi les Ours, les Lyons, les Tigres \& les uleuures, afin qu'ils neleur fafsét aucun mal, tels que font leurs Dieux, telles \& aufi plaiites font les chofes quils leur offrent en les rant. Ils ont accouftumé quand ils vont par min d'y ietter óu aux carrefours, aux colli, \& principalement aux fommets, qu'ils aplent A pachittas, des vieux fouliers, des plus, du Coca mafché, qui eft vne herbe dont ils nt beaucoup. Et quand ils nont rien dauan$e$, leur iettent vne pierre, le tout en offrande, quils les laifent paffer, \& qu'ils leur donat bönes forces, lefquelles ils difent leur augnter par ce moyen, comme il eft rapporté én Cócile Prouincial du Peru. C'eft pourquoy menfif, 2.p. a trourue en ces chemins de grands monceaux 2 cap.99. ces pierres offertes, \& des autres chofes fules. De femblable folie vfoient les anciens, quels il eft dit aux Prouerbes; Comme celuy qui Prouerb. 57 ; edes pierres au möcean de Mercure, ainfi que celuy qui orelesfols: Qui eft à dire, quel'on ne tire non is de fruit ny d'vitité du fecond, que du preer : pource que le Mercure de picrre ne recooit point l'offrande, ny le fol ne peut recos 


\section{Hifoire naturelle}

gnoiftre l'honneur que l'on luy fait. Ils vfoie d'vne autre offrande, non moins plaifante \& - dicule, qui eft d'arracher le poil des fourcils, les offrir au Soleil \& aux collines, aux Apacl tas, aux véts, ou aux chofes qu'ils craignerr. I eft le mal heur auquel plufieurs Indiens ont $v$ cu \& viuent encor auiourd'huy, aufquels led ble fait entendre ce qu'il veut commeà dese fans, quelque grande folie que ce foit. Ai fainet Chryfoftome en vne Homelie, accomp re les Gentils, mais les feruiteurs de Dieu, 9 trauaillent en leur enfeignement \& faluatio ne doiuent pas mefprifer ces folies \& enfanc puis qu'elles fuffifent à enlacer ces pauures ab fez à vne eternelle perdition, ains les doiue auec bónes \& claires raifons, tirer d'vne fi gra de ignorance : Car à la verité c'eft chofe con derable, comme ils s'affubiettiffent à ceux $q$ leur enfeignent le vray chemin de raifon. Il $n^{3}$ chofe entre les creatures plus illuftre que le $S$ leil, \& eft celuy lequel tous les Gentils comm nement adoroient. Vn capitaine difcret $\&$ bc Chreftien me contoit, qu'auec vne böne raif il auoit perfuadé aux Indiens que le Soleil n" ftoit pas Dieu, mais feulement vne creature Dieu,\& fut ainfi. Il demanda au Cacique \& $\mathrm{fe}$ gneur principal qu'slluy donnaft vn Indien 1 ger, pour porter vne lettre, il luy en donna v \& le capitaine demanda au Cacique,dy moy $q$ eft le Seigneur \& le principal, où cét Indien q porte la lettre fi legerement, ou toy quil'es uoyes porter? Le Cacique refpondit, c'eft mo fans doute, pource que ceftuy-là ne fait auts 


\section{Des Indes. Liure $V$.}

ofe que ce que ie luy commande. Ainfi replia le capitaine, en eft-il du Soleil que nous yons, \& du Createur de toutes choles, d'auit que le Soleil n'eft point dauantage qu'vn llet de ce tres-haut Seigneur, qui par fon mandement chemine auec telle legereté fans laffer, portant la lumiere à toutes les nations. nfi tu vois comme c'eft contre raifon de reneau Soleil l'honneur qui eft deu au Createur feigneur de tout. La raifon du capitaine les nitenta tous, \& dit le Cacique $\&$ les Indiens i eftoient auec luy, que c'eftoit grande verité, qu'ils s'eftoient beaucoup refiouys de l'auoir tenduë. L'on raconte d'vn des Roys Inguas, mme de fort fubtil d'entendement, lequel yant comme tous fes predecefleurs adoroient Soleil, dift qu'il ne luy fembloit point que le leil fuft Dieu, ny ne le pouuoir eftre; pource e Dieu eft vn grand Seigneur, qui auec vn and loifir \& repos fait fes auures, \& quele leil ne ceffe iamais de cheminer, difant qu'vchofe qui trāuailloit tăé, ne luy poutuoit femer eftre Dieu, en quoy il dift verité. Ainfi lors el'on vient à declarer aux Indiens leurs erars \& aueuglement par des raifons douces \& ees à comprendre, ils font incontinent conincus, \& le rengent admirablementà la veé. 


\section{Hiftoire naturelle}

D'vn genre d' I dolatrie fur les deffuncts. ChAPITRE VI.

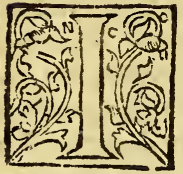

L y a vn autre genre d'idolat fort different des fufdits, dont Gentils ont vré à l'occafion leurs deffuncts, qu'ils aymoie \& eftimoient, \& femble que Sage vueille donner à entendre que le comme cement de lidolatrie foit procedé de là, difa ainfi; Le commencement de fornication fut par la putation desidoles, $\sigma$ cefte inuention eft une totale

Sayis. ruptron de la vie, car au commencement dus monde $2 n^{n}$. point eu d'idoles, ny en la fin n'y en aura pour tourfoum aumais. Mais la vanuté $\sigma$ orfineté des hommes a appo sefte inuention au monde, vorre pour cefte occafion dur Si peu leurs vires, pource qu'al arriua que le pere portã an rement la mort de fon fils miferable, fit pour sa confolat: wn pourtrait du deffunct, $\mathcal{O}$ cömença à l honorer $\mathcal{O}$ a rer comme Dieu, lequel pew auparausant auoit achené sours comme bomme mortel, $\sigma$ pour cefte fin ordonnat entre fes fesuiteurs, qu'en fa memoire l' on fift des denotiu O facrifices. Du depuis apresplufieurs iours paffez, ce maudice couf:sume ayant efte authorifee, demeura cét erre canonife pour loy, $\mathcal{O}$ ainfi par le commandement des $R_{1}$ $\mathcal{O}$ tyrans, les pourtrats $\mathcal{\sigma}$ les idoles eforent adore $Z$. là vint au $\beta$ q que l'on commença à en faire autans aux a fens, $\mathcal{O}$ cenx que l'on ne posiuot adorer en prefence, po eftre eloignés, ils les adoroient de cefte façor, o fajour apporter les pourtrates des Roys quids vouloient honor suppleane par cefte muentson l'abjence de coux gu ils vo 


\section{des Fndes. Liure $V$.}

ut adorer. La currojité des excellens ousuriers angmenta anuention d'idolatrie, te llement que par leur art ces ues furent $\sqrt{2}$ elegantes, que ceux qui ne fyaroient ce ceffort, eftorent prossoquez à les adorer, d'autans par l'excellence de leur art, prerendans contenter celuy leur basllott a faire, ils trroient des pourtraits on tures beaucoup plus excellentes, o le vinlgarre conduie apparence $\mathbb{O}$ grace de lousurage, vins à tenir of eftspour Deeu celuy qui peu auparassant awoit efté bonoimme homme. Et cela fut lerreur mifer able des hom, quis saccomodansores à leur affection o fentiment, àla flatterie de leurs Roys, vindrent à impofer aux resle nom incommunicable de Dieu, les adorans pour $u x$. Tout cecy eft au liure de Sapience, qui digne d'eftre notté , \& trouueront au pied la re ceux qui feront curieux rechercheurs de atiquité, que l'origine de lidolatrie ont efté pourtrairs \& ftatuës des deffunts, ie dy de l'ilatrie, qui eft proprement d'adorer des idoles mages: car il n'eft pas certain que cefte autre latrie d'adorer les crearures, cosme le Soleil, la milice du Ciel, ou le nombre des planertes eftoilles; dequoyil eft fait mention aux Proetes, ayt efté depuis l'idolatrie \& les ftatuës: Hieremiso. mbien que fans doutel'on ayt fait des ftatuës Soph.x. idoles en l'honneur du Soleil, de la Lune $\&$ de erre. Venant à nos Indiens, ils vindrent au nmet de l'idolatrie par les mefmes voyes que móftre l'Efcriture. Premierement ils auoient ng de conferuer les corps de leurs Roys \&e igneurs, \& demeuroient entiers fans aucune tuuaife odeur, \& fe corrompre plus de deux as ans. De cefte façon eltoient les Roys InEe iij 


\section{Hiftoire naturelle}

guas au Cufco, chacun en fa chappelle \& ado ratoire, dont le Viceroy Marquis de Canett pour extirper l'idolatrie, fit tirer \& porter en Cité des Roys trois ou quatre Dieux, qui cau grande admiration de voir ces corps morts de puis tant d'annees fi beaux $\&$ fi entiers qui $i$ cftoient. Chacun de ces Roys Inguas laiffo tous fes threfors, moyens \& reuenu pour entr tenir fon adoratoire où l'on mettoit fon corp $\&$ yauoit beaucoup de miniftres, auec toure famille, qui eftoient dediez à fon feruice. $\mathrm{C}$ nul, Roy fucceffeur n'vfurpoit les threfors vaiffelle de fon predeceffeur, mais il en affen bloit tout de nouneau pour luy \& pour fon $P$ lais. Ils ne fe contenterent point de cefte idol trie enuers les corps des deffuncts, mais auffi $\mathrm{i}$ faifoient leurs ftatuës \& reprefentations, \& ch que Roy duránt fa vie faifoit faire vneidole 0 il eftoir reprefenté, laquelle ils appelloient $\mathrm{Gu}$ oigui, qui fignifie frere. Pource que l'on deuo faire à cefte ftatuë durăt la vie \& la mort de l'I gua, autant d'hóneur \& de veneration quà lus mefme. Et portoient cefte ftatuë en la guerre en proceffion, pour auoir de la pluye \& du bo temps, \& leur farfoient diuerfes feftes, \& facr fices. Il y a eu beaucoup de ces idoles au Cufc $\&$ en fon territoire : toutesfois l'on dit à prefet que cefte fuperftition d' adorer les pierres y a ce fé du tout, ou en la plus grande partie. Apr qu'on les euft defcounertes, parla diligenced Licencié Pollo, \& fut la premiere celle d'Ingu Rocha, chef de la partialité ou race principal de Hanam Cufco, \& trouue l'on de cefte façor 


\section{des fndes. Liure $V$. $\quad-220$}

entre les autres nationsils auoient en grande ime, \& reueroient les corps de leurspredecef1rs, \& adoroient auffil leursftatuës.

Des fuperftitions dont ils voient allec les morts.

Chapitre Vit.

Es Indiens du Peru ont creu com-

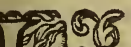
Es Indicns du Peru ontcreucomvinapres cefte vie, \& que les bons eftoient en la gloire, \& les mauuais en la peine: tellement qu'il y a peu difficulté, à leur perfuader tels articles. Mais ne sót pas parnenus iufquau point de co gnoire que les corps deuoient refufciter auec les nes. C'eft pourquoy ils employoient vne exflue diligence, cốme il a efté dir, à conferuer s corps lefquels ils honoroient apres la mort; à ite fin leurs fucceffeurs leur bailloient des roes, \& leur faifoient des facrifices, Cpecialement $s$ Roys Inguas en leurs enterremens deuoient tre accompagnez de grand nombre de feruiurs \& femmes pour fon feruice en l'autre vie. arquoy le iour qu'il decedoit, l'on mettoit à ort les femmes qu'il auoit le plus aymees, fes eruiteurs \& officiers, afin qu'ils l'allaffent ferir en l'autre vie. Quand Guanacapa mourut, ui fut pere d'A tagualpa, au téps duquel entreent les Efpagnols, l'on mit à mort mil \& 2 tant e perfonnes, de tous aages, \& conditions, pour on feruice, \& pour l'accópagner en l'aurre,vie. Ee iiij 


\section{Fiftoire naturelle}

Iis les tuoient apres plufieurs chäfons, \& yur gneries, \& ces deftinez à la mort fe tenoiêt bic heureux. Ils leur facrifioient plufieurs chofe fpecialement des petits enfans, \& deleur far faifoient vne raye au vifage du deffunat d'vi oreille en l'aurre; Cefte mefme fuperftition, inhumanité de tuer des hommes, \& des femm pour accompagner $\& z$ feruir le deffunat en 'al tre vie, a efté fuiuie d'autres, \& eft encor à pri fent vifitee parmy d'autres nations barbare voire comme efcrit Pollo, elle a efté prefqu generale en toutes les Indes. Levenerable Bed mefme racóte, que les Anglois auparauant qu fe conuertir a l'Euangile, auoient cefte mefm couftume de tuer des hommes, pour accompa gner \& feruir les deffuncts. L'on raconte d'v Portugais, qu'eftant captif entre les barbares auoit receu vn coup de flefche, dont il perdit $v$, xil, \& comme ils le voulurent facrifier, vn iou pour accompagner vn Seigneur deffunat, il ref pondit que ceux qui demeuroient en l'autre vie feroient peu d'eftat du deffunct, fi on luy don noit pour cópagnon vn homme borgne, \& qu’i eftoit meilleur luy en dóner vn qui euft fes deus yeux, \& cefte raifon eftant trouuee bonne pat les barbares, fuft caufe qu'ils le laifierent. Ou. rre cefte fuperftition de facrifier les hómes aux deffiunts, dont l'on n'vfe qu'à l'endroit des gräds reigneurs, il y en a eu vne autre beaucoup plus commune \& generale en toutes les Indes, qui eft de metrre à boire, \& à manger fur les fepulrures des deffunats, croyans qu'ils fe nourriffoient de cela, qui a melme efté vn erseur entre 


\section{des Fndes. Liure. $V$.}

sanciens, comme efcript faint Auguftin. Et our ceft effect, de leur donner à manger $\&$ à ire. Aujourd'huy plufieurs Indiens infidel$s$, tirent de terre fecrettement leurs deffuncts s cimetieres, \& les enterrent en des collines, 1 en des palfages desmontagnes, oubien en urs propres maifons. Ils ont mefme accouimé de leur mettre de l'argent, \& de l'or en la ouche, aux mains \& aufein, \& de les reueftir robes neuues, \& du rables, doublees, \& iees, par deffous le lict mortuaire. Ils croyene ie les ames des deffuncts vont vagabondes, \& idurent le froid, la foif, la faim, \& le trauail; par cefte occafion, ils font leurs anniuerfai$s$, en leur portant des habits, à manger \& a ire. A raifon dequoy les Prelats en leurs Sydes aduertiffent fur tout que les Preftres don ent à entendre aux Indiens que les offrandes ie l'on met aux. Eglifes fur les fepultures, ne nt pas le manger, ny boire des deffunets, mais our les pauures, \& pour les miniftres, \& que ieu eft feul qui fultante les ames en l'autre vie, is qu'ils ne mangent, ny ne boiuent aucune rofe corporelle, \& importe beaucoup qu'ils achent bien cela, afin qu'ils ne conuertiffent trfage religieux en fuperftition gentile, com: éle font plufieurs. 


\section{Hiffoire naturelle}

De la façon d'inbumer les deffuncts entre h Mexiquains \& autres nations.

Chabitre ViII.

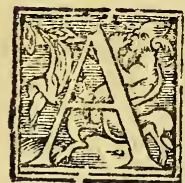

Y A N T raconté ce que plufieu nations du Peru ont fait aueck deffuncts, il ne fera mal à prc pos de faire mention particulic re des Mexiquains en cét er droit, les mortuaires defquel eftoient fort folemnifez, \&: pleins de grands folies. C'eftoir l'office des Preftres \& Religieu en Mexique ( car il yen auoit qui viuoient e vne eftrange obferuance, commeil fera ditc apres) d'enterrer les morts, \& faire leurs obfe ques. Les lieux où ils les enterroient, eftoien en lieuxiardins, \& aux courts de leurs maifon propres; les autres les portoient és lieux des fa crifices qui fe faifoient és montagnes. Les au tres les brufloient, \& apres enterroient les cen dres en leurs temples, \& les enterroient tous auec tout ce qu'ils auoient d'habits, de pierres \& de ioyaux. Ils mettoient les cendres de ceu qu'ils brufloient, en des pors, \& auecicelles, le ioyaux, pierres \& affiquets des deffuncts, quel ques riches \& precieux qu'ils fuffent. Ils chan toient les offices funebres, comme refponfes \& leuoient les corps des deffuncts beaucoup d fois, faifans plufieurs ceremonies. En ces mor tuaires ils mangeoient \& beuuoient; \& fic ce ftoient perfonnes de qualité, on luy donnoit de 


\section{des Indes. Linre $V$.}

bits à tous ceux qui eftoient venus à l'enternent. Quand quelqu'vn mouroit, ils le metient eftendu en vne chambre, iufqu'd ce que rous coftez les parens $\&$ amis fuffent venus, quels apportoient des prefens au mort, \& le uoient, comme f'il euft efté en vie. Et fíc'eit vn Roy, ou Seigneur de quelque ville, ils y offroient des efclaues pour eftre mis à mote ec luy, afin de l'aller feruir en l'autre monde. ; faifoient mourir aufi le Preftre ou Chappelin qu'il auoit (car tous les Seigneurs auoient Preftre qui dans leur maifon adminiftroit les remonies) \& le tuoient alors, afin qu'il allaft Iminiftrer fon office au mort. Ils tuoient le iifinier, le fommellier, les nains \& les bolfus, Equels ils fe feruoient bsaucoup, \& ne parinnoient pas mefmes aux freres du deffunct, ai l'aubient le plus feruy : car c'eftoit vne grancur entre les Seigneurs de fe feruir de leurs fre$s, \&$ des deffufdits. Finallement, ils tuoient us ceux de fon train pour aller entretenir fa taifon en l'autre monde; $\&$ de peur que la paureté ne les vinft accueillir, ils enterroient auce ux plufieurs richeffes d'or, d'argent, de pierreies, de courtines d'vn ourage exquis, de braelets d'or, \& d'autres riches pieces. Que fils rufloient le deffunct, ils en faifoient autant de ous fesferuiteurs \& ornements qu'ils luy bailoient pour l'autre monde; puis ils prenoient oute cefte cendre, laquelle ils enterroient auec ne grande folemnité. Les obleques duroient ix iours, auec des chants de pleurs, \& de lanentation, \& les Preftres emportoient les def- 


\section{Hiftoire naturelle}

funds auec tant de ceremonies (felon qu'onk en requeroit) \& en fi grand nombre, qu'on n les pourroit conter. Ils mettoient aux Capita nes \& Seigneurs leurs marques d'honneur, leurstrophees, felon leurs entreprifes \& lava leur qu'ils auoient employee aux guerres, \& gouuernements. Car pour cét effect ils auoier des blafons \& armes particulier es. Ils portoien ces marques $\&$ blafons au lieu où ils defiroien eftre enterrez, ou bruflez, marchant deuant I corps, \& l'accompagnant comme en procel fion, où les Preftres \& dignitez du templeal loient auec diuers ornements \& appareils; le vns encenfans, les autres chantans, \& les au tres fonnants de fluftes triftes, $\&$ de tambours ce qui augmentoit beaucoup les pleurs desval faux \& parents. Le Preftre qui faifoit l'office eftoit orné des marques de l'idole que le Sei gneur auoit reprefenté : car tous les Seigneur reprefentoient les idoles, \& en prenoient nom de quelqu'vn , \& à cefte occafion eftoien eltimez \& honorez. L'ordre de Cheualerie por toit ordinairement ces marques deffufdites. $\mathrm{Ce}$ Juy qu'ils deuoient brufler, eftant apporté at lieu à ce deftiné, ils l'enuironnoient de bois de pin, \& tout ce qui eftoit de fon bagage, puis y mettoient le feu, commej'ay dit cy deflus, l'aug mentant toufiours auec du bois gommeux; iuf ques à ce que le tout fuft conuerty en cendre. Incontinent fortoit vn Preftre, en habit \& ornement de diable, ayant des bouches à toutes les iointures, \& plufieurs yeux de miroir, \& tenoit un grand bafton, auec lequel il meflois 


\section{des Indes. Liure V.}

utes les cendres fort audacieufement, \& auec gufte, \& vne reprefentation fi terrible, qu'il ponuentoit tousles affiftans. Quelquefois ce iniftre auoit d'autres habits differents, felon eftoit la qualité du mort. l'ay fair cefte dieffion des obfeques $\&$ funerailles, fur l'idolae \& fuperftition qu'ils auoient aux deffunds; aintenant il eft raifonnable de retourner aे ntention principale, \& d'acheuer cefte mare.

"quatriefme of dernier genve d'idolatrie,

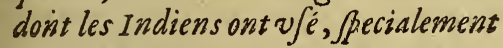

- les Mexiquains, enuers les images \& fatuës.

CGAPITRE IX.

FT3 O M B I N que veritablement Dieu 2) foit grandement offenfé en ces ido(2) latries furdires, où l'on adoroir les 1 creatures, fieft-ce que le fainct E[at reprouue, \& condamne encores dauantage 1 autre genre d'idolatrie, qui eft de ceux qui lorent feulement les images \& figures $f_{d i} i$ tes la main des hommes, lefquelles n'ont autre rofe en elles, que d'eftre un bois, ou pierre, ou etal, \& la figure que Dieu leur a voulu doner. C'eft pourquoy le Sage parle ainfi de telles

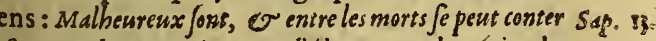
Perance de ceux quiont appelléles aurues des míains des

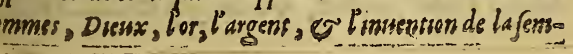




\section{Hifoire naturelle}

blance d' animanx, ou vne pierre inutile, qui n'a rien a uantage que deftre vne antiquaille. Et pourfuit dut nement ces propos à l'encontre de cét erreur

EFa. 44 .

Hierem.io.

Barke. 6.

Pfalm.113.

folie dis Gentils. Cóme auffi le Prophete Efa Je Prophete Hieremie, le Prophete Baruc, \& fainct Roy Dauid, en traitrent amplement. eft neceffaire, \& conuenable que le miniftre Iefus-Chrit, qui reprouue les erreurs de l'id latrie, aye bonneveüe, \& qu'il confidere bi cespaffages, \& les raifons que le fainct Efp touche fi viuement en iceux, \& comme tout

Ojea 8 . fe reduifent en vne brieue fentence que mets auant le Prophete Ofee: Celuy quil'a fatt, a efte' oururier; parguoy al ñeft point Dieu: le vean donc de Sam nee feruura arsx coulles d' araggnees. Reuenăt donc à nı It te propos, il y a eu aux Indes vne grande ct riofité de faire des idoles \& peinturcs de diue fes formes, $\&$ de diuerfes matieres, lefquell ils adoroient pour dieux, \& les appelloient a Peru, Guacas, eftans ordinairement des bef laides \& difformes, au moins celles que ipa veiies eftoient toutes ainfi. Ie croy certain ment que le diable, en 1 honneur duquel on $\mathrm{fa}$ foit ces idoles, prenoit plaifir de fe faire ador en ces difformitez. Et à la verité il fe trouvo auffi que le diable parloit \& refpondoit $e$ beaucoup de ces Guacas, ou idoles ; \& fes Pre ftres \& minift res venoient à cesoracles du pe re de menfonge; \& quel il eft, tels eftoient fe confeils, aduis \& propheties. C'a efté és Pro uinces de la neuue Efpagne, en Mexique, Tet cuco, Tlafcalla, Cholula, \& aux parties voif nes de ce Royaume, où ce génre d'idolatrie 


$$
\text { des Fndes. Liure } r \text {. }
$$

té le plus practiqué qu'en Royaume du mone. Et eft vne chofe prodigieufe d'oüir conter s fuperftitions qu'ils ont eies en ce point; tousfo:s il ne fera pas mal plaifant d'en raconter selque chofe. Le principal idole de Mexique toit, comme i’ay dit, Vitzilipuztli.. C'efloi: re ftatuë de bois, taillee en femblance d'vn omme affis en vn efcabeau de couleur d'azur ofé fur vn branquard, de chaque coin duquel rtoit vn bois, ayant la forme d'vne tefte de rpent : l'efcabeau denoroit qu'il eftoit affis au el; cér idole auoit tout le front azuré, \& eftoir é par deflus le nez d'vne bande de couleur d'aIr, qui prenoit d'vne oreille à l'autre; il auoit rla tefte vn riche plumage, en façon d'vn bee petit oyfeau, qui eftoit counert par le baut va or bien bruny; il auoit en la main gauche e rondelle blanche auec cinq formes de pones de pin faites de plumes blanches, qui y toient pofees en croix, \& du haut fortoir va illarder d'or, ayant aux coftez quatre fagets, lefquelles, au dire des Mexiquains, anoierit té enuoyees du ciel, pour faire les actes \& oiielfes qui fe diront en fonlieu. Il auoir en main dextre vn bafton azuré, qui eftoir taillés façon d'vne couleuure ondoyante. Tout cé nement, \& le refte qu'ilauoir, portoit fon $n s$, ainfi que le declaroient les Mexiquains. enom de vitzilipuztli, main gauche de plume luifante. Ie diray cy apres du temple fuperbe, es facrifices, feftes, \& ceremonies de ce grand ole, qui font chofes remarquables. Mais a refent il fera feulement dit que cér idole veftus 


\section{Hiffoire naturelle}

\& orné richement, eftoit mis en vn autel fo haut, en vne petite piece, ou encaftillemen fort couverte de linceux, de io yaux, de plum $\&$ d'ornemens d'or, auec beaucoup de rond les de plumes les plus belles \& plus gentill quils pounoient recouurer, \& auoit toufiou deuant foy vne courtine, pour plus grandev neration. Ioignant la chambre ou chappelle cét idole, il y auoit vne piece qui eftoit de moj dre ouurage, \& non pas fi bien ornee, où i auoit vn autre idole qu'ils appelloient Thalc Ces deux idoles eftoient toufiours enfembl pource qu'ils les reputoicnt côpagnons, \& d' ne efgale puiffance. 11 y auoit vn autre idole Mexique, fort eft tmé, qui eftoir le dieu de pc nitence, \& des iubilez \& pardons des pechez. appelloient cét idole Tezcallipuca, \& eftoit f d'vne pierre fort reluifante \& noire, comn iayel, eftant veftu de quelques gentils affiquer à leur mode. Il auoit des pendants d'oreill d'or \& d'argent, \& en la levre d'embas vn pet canon de cryftal, de la longueur d'vn xeme, c demy pied, dans lequel ils mertoient quelqu fois vne plume verte, \& quelquefois vne azure qui le faifoit reffembler tantoft vne efmeraud tantoft vne turquoile; il auoit les cheueux cein $\&$ bandez auec vn lifer d'or bruny, au bout du quel pendoit vne oreille d'or, auec deux brar dons de fumees peintes en icelle, qui fignifio les prieres des affligez, \& pechez quil oyoi quand ils fe recommandoient à luy. Entre lo deux oreilles pendoient vn nombre de peti herons. Il auoit $v$ nioyau pendu au col fi grand 


\section{des Indes. Liure V.}

illuy couuroitl'eftomach. Aux deux bras des celets d'or, au nombril vne riche pierre ver\& en la main gauche vn efuentail de plumes cieufes, vertes, azurees, \& jaulnes, qui for. ent d'vn chafton d'or reluifant, \& fort brutellement qu'il fembloit que ce fuft vn mi, qui fignifioit que dedăs ce miroir il voyoit t ce qui fe faifoit au monde. Ils appelloient niroir, ou chafton d'or, Itlacheaya, qui veut , fon regardoir. Il tenoit en la main dextre tre fagettes, qui fignifioient le chaftiment 1 donnoir aux maunais pour les pechez. It la raifon pour laquelle ils craignoient le scét idole, de peur quil ne defcouurift leurs res. Il y auoir pardon de pechez en fa fefte, re faifoir de quatre en 4 . ans, commeil feit cy apres..lls tenoient ce mefme idole Tezipuca, pour le Dieu de la fechereffe, de la fae, fterilité, \& de la peftilence; parquoy ils le noient auffi en vne autre forme, affauoir, nt affis auec beaucoup de niajefté fur vn ef. eau, entouré d'vne courtine rouge, peinte, labouree de teftes \& os de morts. En la main che il auoit vne rondelle auec cinq pines ou nes de pommes de pin, faites de cotton; \& a droi Ate vne dardille, comme d'vn gefte affant, \& ayant le bras eftendu, comme qui oudroit jetter, \& de la rondelle fortoient tre fagettes. 11 auoit le vifage \& apparence ourroucé, \& de choleré, le corps oinct tout oir, \& la tefte pleine de plumes de cailles. vfoient de grandes fuperititions enters cét e, pour la grande crainte qu'ils auoient de F $\underline{E}$ 


\section{Hiftoire naturelle}

luy. En Cholula, qui eftoit v ne Republiqu Mexique, ils adoroient vn fameux idole, eftoit le pieu des marchandifes, pource eftoient grands marchands, \& encores auj d'huy font-ils fort addonnez au commerce l’appelloient Quetzaalcoalts. Cét idole el en vne grande place, en vn temple fort hai auoit autour de luy de l'or, de l'argent, ioyaux, des plumes fort riches, $\&$ des habir dinerfes couleurs. Il auoit le corps en fo d'homme, mais le vifage d'vn petit oyfeau : vn bec rouge, \& au deffus vne crefte plein verruës, ayant des rangs de dents, \& la lan qui luy fortoit dehors. Il portoit furla tefte mittre pointuë de papier peint, vne faulx e main, \& beaucoup d'affi quets d'or aux iam $\&$ mil autres folles inuentions, qui to auoient leur fignification, \& l'adorois parce qu'il faifoit riche ceux quil v loit, comme Memnon \& Plutus. Et à la rité ce nom que les Choluanos donnoier leur Dieu, eftort bien à propos, encore qu'il l'entendiffent pas. Ils l'appelloient Quetz coalt, qui fignifie couleuure de plume riche tel eft le diable de l'auarice. Ces barbares n contentoient point d'auoir des Dieux, mais a ils auoient des deefles, comme les fables Poëtes les introduirent, \& l'aueugle genti des Grecs \& des Romains, les ont venerees. principale des deeffes qu'ils adoroient, ef appellee Tozi, qui veut dire, noftre ayeule, quelle, comme racontent les hiftoires de $\mathrm{Mc}$ que, fur fille du Roy de Culguacan, qui fu 


\section{des Fndes. Liure $V^{*}$}

miere qu'ils efcorcherent par le commandene de Vitzilipuzth, laquelle ils confacrerent :efte façon pour eftre fa four, \& dés lors ils nemencerentà efcorcher les hommes en leurs :ifices, \& de veftir les viuans des peaux des :ifiez, ayans apprins que leur dieu fe plaifoir cela, comme mefme d'arracher le cœur de $x$ qu'ils facrifioient; ce qu'ils apprindrent de r Dieu, lequel tira \& arracha le cœur de ceux il chaftia en Tulla, commeil fera dit en fon 1. L'vne de ces deeffes qu'ils adoroient eut vn grand chaffeur, que ceux de Tlafcalla depuis adrent pour dieu, \& ceux-là eftoient le parcontraire des Mexiquains, auec l'aide def.o is les Efpagnols gagnerent le Mexique. La uince de Tlafcalla eft fort propre pour la ffe, \& le peuple fort addonné à icelle. C'eft Irquoy ils faifoient vne grande fefte à cét le, lequel ils peignoient d'vne telle forme, Il n'eft jà befoing de perdre le temps à la defe. Mais la fefte qu'ils luy faifoient eftoit plaite, \& en cefte façon. Ils fonnoient vne tromfur laube du iour, au fon de laquelle ils farbloient tous auecleurs arcs, flefches, filets, autres inftruments de chaffe, \& alloient auec r idole en proceffion, fuiuis d'vn grand nomde peuple à vne Sierre haute, au fommet de uelle ils auoient dreflé \& accommodé vne illee, \& au milieu vn autel tres - richemene. té, où ils mettoient l'idole. Ils alloient chenans auec v n grand bruit de trompettes, de nets, de fluftes, 8 de tambours, \& paruenus lieu, ils circuiffoient $\&$ enuir on roient toss Ff ij 


\section{Hiftoire naturelle}

les coftez de cefte Sierre, ou montagne, oi mettoient le feu par tous les endroits, au mo dequoy fortoient plufieurs \& diuers anima comme cerfs, connins, lievres, renards \& lor lefquels alloient vers le fommet fuyants le Ces chaffeurs couroient apres, auec de gra cris \& bruits de diuers inftruments, les chaff iufques au fommet deuant l'idole, où arriv vn tel nombre de beftes de chaffe, en fi gra. preffe, qu'elles lautoient les $v$ nes fur les aut fur le peuple, \& fur l'autel mefme; en quo prenoient vn grand plaifir, \& refiouylfar Alors ils prenoient vn grand nombre de ces ftes, \& facrifioient deuant l'idole les cerfs, grands animaux, leur arrachant le caur, aue mefme ceremonie dont ils vfoient au facri des hommes; ce qu'eftant acheué, ils prenoi toute cefte chaffe fur leurs efpaules, \& fer roient auecleur idole de la mefme façon q y eftoient venus, \& entroient en la cité char de toutes ces chofes, fort refiouys, auec gr nombre de mufique, debuccines, \& de bours, iufques à arriuer au temple, où ils $n$ toient leur idole auec grande reuerence, \& lemnité. Ils alloient tous incontinent acce moder les chairs de cefte chalfe, dequoy ils foient vn banquet à tout le peuple, \& a pres ner faifoient leurs farces, reprefentations dances deuăt l'idole. Ils auoient vn autre gr nombre d'idoles, de dieux $\&$ deeffes : mais principales eftoient en la nation Mexiqua B aux peuples voifins, ainfi qu'il a efté dit. 
des Fndes. Liure V.

une eftrange façon d'idolatrie, practiquee entre les Mexiquains.

\section{Chatitre X.}

O M M nous auons dir que les Rois Inguas du Peru firent faire à leur femblance de certaines ftatuës, qu'ils appelloient leurs Guaoiquies, ou freres; \& leur faient porter autant d'honneur, qu'à eux-mefs. Ainfien ont faict les Mexiquains de leurs ux : mais ils ont paffé plus outre, pource e des hommes vifs ils failoient des dieux, qui oit en cefte maniere. Ils prenoient vn captif, $s$ qu'ils aduifoient bon eftre, \& auparauant ie de le facrifier à leurs idoles, luy donnoient mefme nom de l'idole auquel il deuoit eftre crifié, \& le veftoient \& ornoient des mefmés nements que leur idole, difans qu'il reprefenit le mefme idole. Et pendant tout le temps ie duroit cefte reprefentation ( qui eftoit d'vn i en certaines feftes, en d'autres de fix mois, \& 1 d'autres moins) ils l'adoroient \& veneroient la mefme façon que le propreidole; cepenunt il mangeoit, beuuoit, \& ferefiouyffoit. Iuand il alloit par les ruës, le peuṕle fortoit our l'adorer, \& tous luy offroient beaucoup aumofnes, \& luy portoient les enfans, \& lés talades, afin qu'il les guarif \& benift, \& luy iffoient en tout faire fa volonté , fauf qu'il

$$
\text { Ff iij }
$$




\section{Hiftoire naturelle}

eftoit toufiours accompagné de dix ou dot hommes, de peur qu'il ne f'enfuyft. Et luy a que l'on luy fift reuerence par où il paffoit, fo noit de fois à autre d'vne petite flufte, afin le peuple f'appreftaft pour l'adorer. La fe eftant venuë, \& luy eftant bien gras, ils tuoient, l'ouuroient, \& le mangeoient, faif va folemnel facrifice de luy. A la verité c vne chofe pitoyable de confiderer la façon laquelle Satan tenoit ces gens en fa puiffan $\& 2$ tient encores aujourd'huy plufieurs qui fo de femblables cruaurez $\&$ abominations, a defpens des triftes ames, \& des miferab corps de ceux qu'ils luy offrent; \& luy fe mo que $\&$ rit de la bourde \& mocquerie qu'il fa aux pauures mal-heureux, lefquels merite bien par leurs pechez que le tres-haut Dieu delaiffe en la puiffance de leur ennemy, qu ont choifi pour Dieu, \& pour fouftien. M puis que j'ay dit ce qui fuffit de l'idolatrie Indiens, il f'enfuit que nous traittions dele religion, ou pour mieux dire, fuperftition, laquelle ils vfent en leurs facrifices, temples, çeremonies, \&r ce qui touchéle refte. 


\section{des Indes. Liure $V$.}

nme le diable s'eft effurcé de s'égaler à Diew, in de luy reffembler aux façons de facrifices, religion, \& Jacrements.

\section{Chatitre XI.}

W A. doit confiderer vne chofe, qui eft figne de regarder de pres, qui eft, que comme le diable par fon oril a prins party, \& f'eft rendu contraire a ed; ce que Dieu par fa fageffe ordonne pour 1 honneur \& feruice, \& pour le bien \& falut l'homme; le diable fefforce de limiter, \& le cuertir, pour eftre honoré, \& faire que omme en foit condamné. Car comme nous yons que le grand Dieu a des facrifices, des eftres, des Sacrements, des Religieux, des opheties, $8 r$ des gens dediez à fon feruice dia, \& fainctes ceremonies; ainfi le diable a fes crifices, Preftres, fes façons de facremens, $f a$ nt dedice, fes reclus \& fainctetez faintes, auec il fortes de faux Prophetes; rout ce qui fera aifant d'entendre, eftăt declaré en particulier, non point de petit fruiat, pour celuy quife uuiendra commele diable eft le pere de men. nge, ainfi que la verité le dit en l'Euangile; urquoy il procure vfurper pour foy la gloire $10 a n$. S. - Dieu, \& contrefaire la lumiere par fes reneies. Les enchanteurs d'Egypte, enfeignez de ur maittre Satanas, f'efforçoient de faire d'aues merueilles, femblables à celles de Moyfe, Exod. Ff iiij 


\title{
Hiftoire naturelle
}

\&z d'Aaron, pour f'efgaler à eux. Nous lifons

Ind. 18. liure des Iuges, de ce Micas Preftre du vain id le, qui fe feruoit mefme des ornemens dont l', vfoit au Tabernacle du vray Dieu, comme l'Ephod du Seraphin, \& des autres chofes. Sc que ce foit, à peine ya-il chofe inftituee par I fus. Chrif noftre Seigneur, en $\Gamma_{2}$ loy Euange que, que le diable ne l'aye fophiftiquee en qu que façon, \& portee à fa gentilité, commel'c pourra voir en iifant ce que nous tenons po certain, par le rapport de gens dignes de fo des couftumes \& ceremonies des Indiens, de quelles nous traicterons en ce liure.

\section{Des Temples qui fe font trowuez és Indes.}

\section{Chapitre XII.}

\begin{abstract}
O M M N ÇANT donc par les Ten 6 Ples, tout ainfi que le grand Dieu (4) voulu qu'on luy dediaft vne maifo (1) où fon fainct Nom fuft honoré, qu'elle tuft particulierement voüee à fon feru ce; ainfile diable par fes mefchantes intentio perfuada aux infidelles qu'ils luy físér de fupe bes tempes, \& des particuliers adoratoires, fanctuaires. En chaque Prouince du Peru il auoit vn principal guaca ou maifond'adoration \& outre icelle, il y en auoit vne vniuer felle pa rous les Royaumes des Inguas, entre lefquelle il y en a eu deux fignallees $\&$ remarquees; l'vn qqu'ils a ppelloiêt de Pachacama, qui eft à quatr
\end{abstract}




\section{des Indes. Liure V.}

euës de Lyma, où l'on voit encor auiourd'huy s ruines d'y tres-ancien, \& grand edifice, duuel François Pizarre \& les fiens tirerent cefte cheffe infinie des vafes, \& des cruches d'or \& 'argent, qu'ils apporterent quand ils prindrét Ingua Altagualpa. Il y a certains memoires \& ifcours qui difent, que le diable en ce Temple, arloit vifiblement, \& donnoit refponfes par in oracle, \& que quel quefois ils voyoient vne ouleuure tachetee; 2 eft vne chofe fort comune \& approuuee és Indes, que le diable parit, \& refpondoit en ces faux fanctuaires, en - ompant les miferables. Mais là où l'Euangile It entré, \& là où l’on a éfleué le figne de la iroix, le pere de menfonge y eft deuenu muet, infi que Plutarque efcrit de fon temps. Curcefuerit Pychyas fondere oracula. Et fainct Iuftin mar- Pluta. lib.de

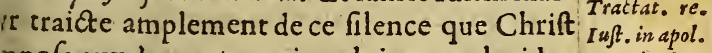
npofa aux demons, qui parloient par les ido- pro Chriftia. s, comme il auoit efté beaucoup auparauant rophetilé en la diuine Efcriture. La façon u'auoient les miniftres infidelles \& enchaneurs, de confulter leurs dieux, eftoit comme le iable les enfeignoit. C'eftoir ordinairement e nuict, \& pour le faire, entroient, les efpaules ournees versl'idole, marchans en arriere, $2 e$ lians les coips en inclinans la tefte, \& fe metoient en vne laide pofture, \& ainfílis les con ultoient; La refponfe quils faifoient ordiairement eftoit en maniere d'vn fifflement efouuentable, ou comme vn grinffement, qui eur faifoit horreur, \& tout ce dont il les adueriffoit, \& leur commandoit, eftoit vn achemi- 


\section{Hiftoire naturelle}

nement à leur deception \& perdition. Mainte. sant l'on trouue peu de ces oracles, par la mifericorde de Dieu, \& grande puiffance de Iefus. Chrift: Il y a eu au Peru vn autre temple, \& ora. toire plus eftimé, qui fut en la Cité de Cufco, où eft auiourd'huy le monaftere de fainet $\mathrm{Do}$. minique. Et l'on peut voir que ç'a efté vne cus. ure fort belle \& magnifique par le paué \& pierres de l'edifice, qui reftent encor auiourd'huy. Ce temple eftoit commele Pantheon des Ro. mains, en ce qu'il eftoir la maifon $\&$ demeur de tous les Dieux: Car les Roys Inguas miren en iceluy les Dieux de toutes les natiós, \& Pro. uinces qu ils conqueftoient, ayant chaque idole fon lieu particulier, où ceux de leur Prouince Ites venoient adorer, anec vne defpenfe exceffuc de choles que l'on apportoit pour fon minifte. re. Et par cela ils auoient opinion de retenir feurement, \& en deuoir, les Prouinces qu'il: auoient conqueftes, tenans leurs Dieux comme en oftage. En cefte mefme maifon eftoir le Pinchao, qui eftoit vne idole du Soleil, de tresfin or, ouuré d'vne grande richeffe de pierreries, lequel eltoit pofé vers l'Orient, auec vn tel artifice, que le Soleil à fon leuer iettoit fes rayon fur luy, \& comme il eftoit de tres-fin metal, les rayons reuerberoient auec telle clarté, qu'il reffembloit vn autre Soleil. Les Inguas adoroient ceftuy-là pourłeur Dieu, \& le Pachayacha, qui fignifie le Createur du Ciel; ils difent qu'aux defpoïilles de ce temple fi riche, vn foldat eut pour fa part cefte trefbelle planche d'or du SoLeil. Et comme le jeu eftoir lors de faifon, ill 


\section{des Indes. Liure $V$.}

erdit vne nuict en iouiant, d'où vint le prouer= equi eft au Peru, pour les grands ioüeurs, diant qu'ils ioüent le Soleil auant qu'il naiffe.

Des Juperbes Temples de Mexique.

\section{Chapitre Xili。}

A fuperfition des Mexiquains a efté fans comparaifon plus grande que celle de ceux-cy, tant en leurs ceremonies, comme en la grandeur de leurs emples, lefquels anciennement les $E$ fpagnols ppelloiêt de ce mot $\mathrm{Cu}$, lequel mot peut auoir fté prins des infulaires de fainct Dominique, ude Cuba, comme beaucoup d'autres mots ui font en vfage, lefquels ne font ny d'ESpame, ny d'autre langue dont l'on $v$ fe auiourd'huy Indes, comme font Mays, Chico, Vaquiano, Chapeton, \& autres femblables. Il y auoit dóc in Mexique le $\mathrm{Cu}$, fi fameux temple de Virzilisuztli, qui auoir vn tour \& circuit. fort grand, $x$ faifoit au dedans de foy vne belle court. Il :ftoit tout bafty de grandes pierres en façon de :ouleuures, attachees les vnes aux autres, \& pour cela le circuir eftoir appellé Coatepantli, qui veut dire circuit de couleuures. Sur chacun des coupeaux des chambres \& oratoires où eftoient les idoles, y auoit vn perron fortioly, ouuragé des petites pierres menuës, noire comme du geais, arrangees d'vn bel ordre, auec le champ tout releué de blanc \& de rouge, qui 


\section{Hiftoire naturelle}

rendoit à le voir d'embas vne grande clarté. El au deffus du perron il y auoit des carneaux for mignonnement faits, ouuragez comme en limaçons, \& auoit pour pied \& appuy deux Indiens de pierrre affis, tenans des chandeliers en leurs mains, \& d'iceux fortoient cóme des croifons reueltus auec les bouts enrichis de plume iaunes \& vertes, \& des franges longues de mef. me. Au dedăs du circuit de cefte court il y auoi plufieurs chambres de Religieux, \& d'autre qui eftoient au deffus pour les Preftres $\&$ Papes car ainfi ils appelloient les fouuerains Preftre: qui feruoient à lidole. Cefte court eft fi grande \& fi fpatieufe, que huiot ou dix mil perfonnes dançoient en rond fort à laife, s'entretenans le mains les vns des autres, qui eftoir vne couftu. me dont ils vfoient en ce R oyaume; ce qui fem ble chofe incroyable. Il y auoit quatre porte ou entrees à l'Otient, au Ponent, au Nort, \& au Midy. De chacune de ces portes fortoit \& commençoit vne chauffee fort belle de deux : trois lieuës de long. Parquoy il y auoit au mi lieu du lac où eftoit fondeela Cité de Mexiqu quatre chauffees en croix fort larges, quil'em belliffoient beaucoup. Sur chacun portail of entree il y auoit vn Dieu ou idole, ayant le vifa ge tourné du cofté des chauffees vis à vis de li portede ce téple de Vitzilipuztli. Il y auoit tren re degrez de trente braffes de long, \& eftoien reparez de ce circuit de la court par vne ruë qu eftoit entr'eux. Au haut de ces degrez il y auoi vn pourmenoir de trente pieds de large tout en duit de chaux, au milieu duquel pourmenoir ? 


\section{des Indés. Liure $V$.}

oyoit vne palliffade trefbien faite d'arbres fort lauts plantez de rang, à vne broffel'vn de l'aure. Ces arbres eftoient fort gros, \& tous percés le petits trous, depuis le pied iufqu'au coupeau, $x y$ atooit des verges trauerlans d'va arbre à autre, aufquelles eftoient trauerfees \& enchaifiees plufieurs teftes de morts par les tamples. En :hafque verge il y auoit vingt teftes, \& ces răgs le teftes cótinuoient depuis le bas iufqu'au haut les arbres. Cefte palliffade eftoit $f i$ pleine de ces eftes de morts depuis vn bout iufqu'à l'autre, jue c'eftoit vne chofe merueilleufement trifte $\&$ pleine d'horreur. Les teftes eftoient de ceux qu'ils auoient facrifiez; car apres qu'ils eftoient morts, \& que l'on en auoit mangé la chair, la tefte en eftoit apportee \& baillee aux miniftres du temple, qui les enchaifnoit ainfi iufqu’à ce que elles tóbaffent par morceaux, \& auoient lefoing de remplaccr celles qui tomboient, par d'autres qu'ils mettoient en leurs places. Au fommet du temple il y auoit deux pierres on chappelles, \& en icelles eftoient les deux idoles que iay dites de Vitzilipuztli, \& fon compagnon Tlalot. Ces chappelles eftoient taillees 2 cifellees fort artificieufement, \& $f$ h hautes elleuees, que pour $y$ monter il y auoir vn efcallier de pierre de fix vingts degrez. Au deuant de ces chambres ou chappelles il $y$ auoit vne court de quarante pieds en quarré, au milieu de laquelle il y auoit vne pierre haute de cinq paumes, qui eftoit verte \& pointuë en façon de pyramaide, \&eftoit là pofee pour les facritices des homraes guel'on y faifoit: Car vn homme eftant couché 


\section{Hiftoire naturelle}

deffus à la renuerfe, elleluy faifoit ployer 1 corps, \& ainfi ils l'ouuroient, \& luy tiroient cour, comme ie diray cy apres. Il y auoit en! Cité de Mexique 8. ou 9. autres temples cóm celuy que i'ay dit, lefquels eftoient attachez \& continuez les vns aux autres dans vn grand cir cuit, \& auoient leurs degrez particuliers, leu court, leurs chambres \& leurs dortois. Les en trées des vns eftoient au Ponient, des autres al Leuant, des autres au Sud, \& celles des autre au Nort. 'Tous ces temples eftoient ingenieufe ment elaborez, \& enceints de diuetfes façon de creneaux \& peintures, auec beaucoup $d$ figures de pierres, eftans accompagnez \& forti fiez de grands \& larges efperons. Ils eftoien dediez à diuers Dieux, mais apres le temple di Vitzilipuztli, fuiuoit celuy de Tezcalipuca,qu eftoir le Dieu de pænitence $\&$ des chaftimens fort efleué,haut, \& fort bien bafty. Il y auoir quatre vingts degrez pour $y$ monter, au haul defquels fe faifoit vne planure ou table de fix vingts pieds de large, \& ioignant icelle, vne falle tapiffee de courtines de diuerfes couleurs \& ouurages. La porte d'icelle eftant baffe \& large, toufiours counerte d'v n voile, \& n'y auoit que les preftres feulement qui y pouuoient entrer. Tout ce temple eftoit elabouré de diuerfes tailles \& effigies auec vne grande curiofité, d'alltant que ces deux temples eftoient comme les Eglifes Cathedrales, \& le refte à leur refpeo comme Paroiffes \& Hermitages; \& eftoient fit fpacieux \& de tant de chambres qu'il y auoit en iceux les minifteres, les colleges, les efcholes \& 


\section{des. Fndes. Liure $V$.}

es maifons des preftres, dont ie parleray cy pres. Ce qui eft dit peut fuffire pour entendre 'orgueil du diable, $\&$ le malheur de cefte mifeable nation, qui auec fi grande defpenfe de eurs biens, de leur trauail, \& de leurs vies, fertoient ainfi leur propre ennemy, qui ne preten. loit d'eux autre chofe, que de deftruire leurs mes, \& confommer les corps, Neantmoins its 'en contentoient fort, ayansopinion en leur $\mathrm{f}$ rrande erreur, que c'eftoient de grands \& puifans Dieux que ceux aufquels ils faifoient ces eruices.

Des Preftres \& de leurs offices.

CHAPITRE XIV.

T tions du monde, des hommes paraticulierement dediés au feruice du
our deciarer au peuple ce que leurs Dieux leur aticulierement dediés au feruice du
our deciarer au peuple ce que leurs Dieux leur aticulierement dediés au feruice du
our deciarer au peuple ce que leurs Dieux leur ommandent. Il y a eu au Mexique fur ce point ne eftrange curiofité. Et le diablevoulant conrefaire l'vfage de l'Eglife de Dieu, en mis a l'orIre de ces Preftres de plus grands ou Superieurs, $\forall$ de moindres, les vns comme Acolytes, \& les utres comme Leuites. Et ce qui m'a plus faict fmerueiller, c'elt que le diable a voulu vfurper our foy le feruice de Chrift, iufquà fe feruir du nefme nom: Carles Mexiquains appelloiens 


\section{Hiffoire naturelle}

leurs grands Preftres en leur ancienne langue Papas, comme pour fignifier fouverains Pont fes, ainfi qu'il a ppert à prefent par leurs hiftoire Les Preftres de Vitzilipuztli fuccedoient $p_{a}$ lignages de certains quartiers de la ville, depute à cét effet; \& ccux des autres idoles y venoien par eflection, ou pour auoir efté offerts au tem ple dés leur enfance. Le continuel exercice de Preftres eftoir d'encenfer les idoles, ce quil faifoient quatre fois durant le iour naturel. $L$ premiere à l'aube du iour, la feconde à midy, 1 troifiefme au Soleil couchant, \& la quatriefm à minuict. A cefte heure de minuiat fe leuoien toutes les dignitez du temple, \& au lieu de clo chesils fonnoient des buccines $\&$ de grăds cor nets, \& les autres des fluftes, \& fonnoient long temps vn fon trifte, \& apres auoir ceffé le fon forroit le femainier, veftu d'vne robbe blanch en façon de Dalmatique, auec l'encenfoir en le main plein de brafier qu'il prenoit au foyer bruflant cótinuellement deuant l'autel; en l'autre main vne bourfe pleine d'encens, lequel iettoit en l'encenfoir, \& comme il entroitau lieu où eftoit l'idole, il encenfoit auec beaucoup de reuerence;apres il prenoit vn linge, duquel 1 nettoyoit l'autel \& les courtines. Cela acheué ils s'en alloiêt tous enfemble en vne chappelle, \& Jà faifoéit certain genre de penitence fort ri-

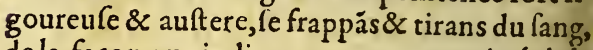
de la façon que ie diray cy-apres au traitté dela penitence, que le diable à enfeignee aux fiens \& ne failloient iamais à ces matines de minuict. A tocuns autres cue les Preftres ne pouuoient fe 


\section{Hiftoire naturelle}

en auoit vn en chaque Prouince. Ily auoit ces Monafteres deux fortes de femmes, les vn anciennes, qu'ils appelloient Mamacomas, po l'inftruction \& enfeignement desieunes ; \& 1 autres eftoient de ieunes filles deftinees là po vn certain temps', puis a pres l'on lestiroit de pour leurs Dieuxou pour l'Ingua. Ils appe loient cefte maifon ou Monaftere,Acllaguas qui eft à dire, maifon de choifies. Chaque $M$ naftere auoit fon vicaire ou gouuerneur, non mé A ppopanaca, lequel auoit la puilfance \& berté de choifir tontes celles qu'il vouloit, quelque qualité qu'elles fuffent, eftans au de foubs de huict ans, fi elles leur fembloient bonne taille $\&$ difpofition. Ces filles ainfi enfe rees dans ces Monafteres, eftoient endoctrine par les Mamacomas en diuerfes chofes neceffa res pour la vie humaine, $\&$ aux couftumes $\& \mathrm{c}$ remonies de leurs Dieux, \& par a presils lest roient de là eftans au deffus de quatorze ans, lesenuoyent en la court auec bonne garde, vi partie defquelles eftoient deputees pour fert aux Guacas \& fanctuaires, conferuans perp tuellement leur virginité, vne partie pour facrifices ordinaires qu'ils faifoient de pucelle $\&$ autres facrifices extraordinaires qui fe fa foient pour le falut, la mort, ou les guerres l'Ingua, \& vne partie mefme pour feruir de fen mes \& de concubines à l'Ingua, \& à d'autres fie parens \& Ca pitaines aufquels ill les donnoit, $q$ leur eftoit vne grande \& honorable recomper fe: \& ce departement fe faifoit par chacun a Ces Monafteres auoient \& polfedoient en pro 
des Indes. Liure. V. des heritages, rentes\& reuenus pour l'entien, nourriture \& fuftentation de ces vier; qui eftoient en grand nombre. Il n'eftoit int licite à vn pere de faire refus de bailler fes es lors que l'Appopacana les demandoit pour enferrer \& mettre en ces Monafteres, voire ifieurs offroient leurs filles de leur bonne voité,leur femblant que c'eftoit vn grand meripour elles deftre facrifiees pour l'Ingua. Si $n$ trouuoit que quelques-vns de ces Mamamas ou Acllas euft failly contre fon honneur, ftoit vn inćuitable chaftiment de les enterrer utes viues, ou de les faire mourir par vnaugenre de cruel fupplice, Le diable a eu mefen Mexique $\mathrm{fa}$ façon \& maniere de religieu, encor que leur profefsion ne furt de plus in an entier, \& eftoit en cefte forte. Au dedans ce grand circuit que nous auons dit cy-defs, qui eftoit au téple principal, il y auoit deux iifons comme clauftrales, visà vis 'v'vne de l'au, I'vne d'hommes \& l'autre de femmes. En lie de femmesily yuoit feulement des pucelide douze à treize ans, lefquelles ils appelient, les filles de penitence. Elles eftoientaunt comme les hommes, viuoient en chafteté $8 x$ gle comme pucelles, dediees au feruice de leur ieu. L'exercice qu'elles auoient eftoit de netyer \& ballier le temple, \& apprefter chaie matin à manger à l'idole \&̀ à fes miniftres l'aumofne que recueilloient les religieux. a viande qu'ils appreftoient à lidole eftoit spetits pains en figure de mains $\&$ de pieds, mme du maffe pain, \& appreftoient auecce $\mathrm{Gg}$ ig 


\section{Fiffoire naturelle}

pain de certaines faulces qu'ils mettoient cha que iour au deuant de l'idole, \& fes preftres

Danitl. mangeoient comme ceux de Baal, que cont

Danitel. Ces filles auoient les cheueux roupez \& les laiffoient croiftre par apres iufqu’à quel. que temps: elles fe leuoient a minuict aux mati nes de l'idole, qu'ils celebroient tous les iours faifans les mefmes exercices que les religieux Ils auoient leurs A bbaiffes qui les occupoient faire des toiles de diuerfes façons pour l'orne. ment de leursidoles \& des temples. Leur habi ordinaire eftoit tout blanc fans aucun ouurage ny couleur. Elles faifoient aufsi leurs peniten cesà minuict, fe facrifians en fe bleftans elles. mefmes, \& fe perçansle bout d'enhaut des oreil. les, \& mettans en leurs iouës le fang qu'elles er tiroient, \& parapres fe lauoient pour ofter fang en vn petit eftang qui eftoit dedans leur monaftere. Elles viuoient en grande honnefteté \& difcretion: \& s'il fe trouuoit que quelqu'vne euft failly, quoy que ce fuft legerement, incontinent elle eftoit mife à mort fans remiffion, difants qu'elle auoit violé la maifon de leut Dieu. Ils tenoient pour vn augure $\&$ aduertifiemết que quelqu'vn de ces religieux ou religieltfes auoient fait faute, quand ils voyoient pafter: quelque rat ou fouris, ou chauue-fouris en la chappelle de leuridole, ou qu'ils auoient rongé quelques voiles: pource qu'ils difoient quele rat ou chauue-fouris ne fe fuft point hazardé faire vne telle indignite', fi quelque delict n'euft procedé, \& $\dot{x}$ deslors commençoient à faire inquifition \& recherche du fait, puisayant defcou: 


\section{des Indes. Liure. V. $\quad 235$}

ext le delinquant ou delinquante, de quelque salité qu'il fuft, incontinent le faifoient mour. En ce Monaftere n'eftoient receües que les les de l'vn des fix quartiers qui eftoient nomez pour ceft effcct, \& duroit cefte profefsion, imme il a efté dit,l'efpace d'vn an entier, penint lequel leurs peres où elles atroient fait vou : feruir l'idole en cefte façon, \& de là elles forient pour fe marier.Ces pucelles de Mexique, encor plus celles du Peru, auoient quelques flemblance auec les vierges Veftales de Roe, comme racontent les hiftoires, à fin que l'on itende comme le diable a eu le defir d'eftre fery de gens qui gardent virginité ; non pas que la atteté luy agree, car de foy il eft ef prit immun, mais pour le defir qu'il a d'ofter au grand ieu, felon fon pouuoir, cefte gloire de fe ferruir enetteté \& integrité.

ies Monafteres de Religieux que le diable a inuentez pour la /uperfitition.

\section{CHAPITRE, XVI。}

'On cognoift affez par les lettres des Peres de noftre Cópagnie ef. crites du Iappon, le nombre \& la multitude des Religieux qu'ily a en ces Prouinces, lefquels ils apellent Boncos, \& mefme leurs couftumes, fiierfition, \& menfonges, Quelques Peres qua $\mathrm{Gg}$ iij 


\section{Hiftoire naturelle}

ont efté en ces pays, racontent de ces boncos, \& religieux de la C.hine, difans, qu'il y en a de plu fieurs ordres; \& de diuerfes fortes, que les vns is vindrent voir veftus d'vn habit blanc, portar des bonnets, \& les autres, d'vn habit noir , far cheueux \& fansbonnet, \& que ces religie ux or dinairement funt peu eftimez, \& les Mandarin ou miniftes de iuftice les foüettent comme i font le refte du peuple. Ils font profefsion den manger de chair, ny de poiflon, ny de chofe au cune ayant vie, ains feulement du ris, \& d herbes, maisen fecret ils mangent de tout, ? font pires que le commun peuple. Ils difent qu les religieux qui font en la court, qui eft en $\mathrm{Pa}$ quin, font fort eftimez. Les Mandarins vont or dinairement fe recreer aux Narelles, ou Mona fteres de cesmoines, \& en retournent prefqu toufiours yures. Ces Monafteres font ordinai rement hors des villes, \& ont dedans leur enclc des temples. Toutesfois ils font peu curieu en la Chine des idoles, ou des temples : car le Mandarins font peu d'eftat des idoles, \& le tiennent pour vne chofe vaine, \& de rifee, voir ne croyent pas qu'il y ait autre vie, ny autre $\mathrm{Pa}$ radis, que d'eftre en office de Mandarin, d'autre enfer, que les prifons qu'ils donnent au, delinquans. Quant au vulgaire, ils difent qu' eft neceffaire de l'entretenir par l'idolatrie,com me mefme le Philofophe l'enfeigne à fes gou "Arift.12: Metap. Exod.3I. uerneurs. Et a efté en l'Efcriture vne excufe,qu donna Aaron, de l'idole du veau qu'il auoit faic faire. Neantmoins les $C$ hinois ont accouftum de porter aux pouppes de leurs nauires, en 


\section{des Indes. Liure. V.}

tites chappeles vne pucelle en bofle afsife en chaire auec deux Chinois au deuant d'elle. enoüillez en façon d'Anges, \& y a de la luiere ardente de iour \& de nuict. Et quand ils iuent faire voile, ils luy font plufieurs facrifi$s$, \& ceremonies, auec vn grand bruit de tamJurs, \& de cloches, iettans des papiers bruslans ur la pouppe.Venăs donc aux Religieux, ie ne ache point qu'au Peru il y ait eu maifon prore d'hommes retirez outre leurs Preftres, \& rciers, dont y en a vne infinité. Maisça efté en Iexique, où il femble que le diable ait mis vne ropre obferuance : Car il y auoit au circuit du rand temple deux Monafteres, comme i'ay dit y-deffus, ívn de pucelles, dequoy i'ay traicté, \& autre de ieunes hommes reclus de dix-huift à ingt ans, lefquelsils appelloient Religieux. Ils ortoient vne couronne en la tefte comme les reres de par deçà,les cheueux vn peu plus longs juileur tomboient iufquesà moytié de l'oreile, excepté qu'au derriere de la tefte ils les laifoient croiftre quatre doigts de longs qui leur lefcendoient fur lesefpaulles, \& lestrouffoient 3. accommodoient partreffes. Ces ieunes gens qui feruoient au temple de Vitzilipuztli, viuoient en pauureté, $\&$ chafteté, $\&$ faifoient l'office de Leuites, adminiftrans aux Preftres, \& dignitez du temple, l'encenfoir, le luminaire, \& les veftemens. Ils ballioyent, \& nettoyoient !es lieux facrez apportans du bois, afin qu'il bruflaft toufiours, au brafier, ou fouyer du Dieu, qui eftoit comme vne lampe qui ardoit continuellement deuant l'autel del'idolę. Outrẹ ces s.

$\mathrm{Gg}$ iiij 


\section{Hiftoire naturelle}

cunes hommes, il y auoit d'autres petits gar çons, qui eftoient comme nouices, qui feruoien aux chofes manuelles, comme eftoit d'accom moder le temple de rameaux, rofes, \& ioncs donner l'eaiie à lauer aux Preftres, bailler les ra zoirs pour facrifier, \& aller auec ceux qui de mandoéit l'aumofne pour la porter. T ous ceux cy auoient leurs fuperieurs, qui a uoient la char ge \& commandement fur eux; \& viuoient aue vne telle honnefteté, que quand ils fortoient er public, où il y auoit des femmes, ils alloient tou jours lesteftes fort baiffees, les yeux en terre fans les ofer hauffer pour les regarder. Ils auoiël póur veftement des linceux de red, \& leur eftoil permis de fortir par la Cité quatre à quatre, \& fix à fix pour aller demander l'aumofne aux quartiers. Et quand l'on ne leur la donnoit, il auoient licence d'aller aux grains des champs, \& cueilfir les efpics de pain, ou grapettes de mays, qu if sáuoient de beföing, fans que le maitre en ofaft parler, ny les empefcher. Ils auoient cefte licence, pource qu'ils viuoient pauurement, 8 n'auoient autre reuenu que l'aumofne. Ils ne pounoient eftre plus de cinquante, \& s'exerçoient en penitence, fe leuans à minuit à fonner des cornets \& buccines, pour efueiller le peuple. Ils faifoient chacun leiurquart à veiller lidole, de peurquele feu deuant l'Autel nes'êftaignifr. Ils adminiftroiêt en l'encénfoir, a uec lequel les Preftres encenfoient l'idole à minüit, au mat in, â midy, \& aủ foir. Ils eftoient fort fubjects \& obeyflansàl leurs fuperieurs \& n'outrepaffoient pas d'vn point ce qu'ils leur commandoient. Et 

res qu'à minuit les Preftres auoient acheué encêfer, ceux-cys'en alloient en vn lieu fecret, efcarté, \& facrifioient, fe tirans du fang des ollets auec des pointes dures \& aiguës. Et de fang qu'ils tiroient ainfi,ils s'en frottoient les mples,iufque au deffous l'oreille, \& ayăs ache. 'ces facrifices, ils s'en alloient incontinent $\mathrm{fe} \mathrm{la}_{2}$ $r$ en vn petit eftang, deftiné à cét effet. Ces ines gens ne fe oignoient point d'aucun be$\mathrm{m}$, par la tefte, ny par le corps, comme faiient les Preftres, \& leurs veftemens eftoient me toile, qu'ils font là fort rude, \& blanche. ét exercice $\& r$ afpreté de penitences leur du. it vnan entier, auquelils viuoient auec beauup d'aufterité, \& folitude.C'eft à la verité vne ofe eftrange, que la fauffeo opinion de religion ant de force à l'endroit de cesieanes hommes filles de Mexique, qu'ils vont feruans le diable ec tant de rigueur \& d'aufterité : ce que pluurs de nous autres ne faifons pas au feruice du s- haut Dieu, qui eft vne grand'honte \& confion pour ceux d'entre les noftres quife glorient d'auoir fait vn bien peu de penitence, comen que l'exercice de ces Mexiquains n'eft pas rpetuel, maisd'vn an feulement, ce qui leut toit plustolerable, 


\section{Hiftoire naturelle}

\section{Des peritences, \&o de l'aufterité dont les I diens ont $v \int e ́$, à la perfuafion du diable. \\ ChaPITRE XVII.}

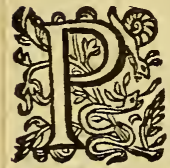

Vifque nous fommes venus à point, il fera bon, tant pour de couurir le maudit orgueil de $S$ : tan, comme pour confondre, refueillerquelque peu noftre $l_{a}$ cheté \& froideur au feruice du grand Dieu, $q$ nous difions quelque chofe des rigueurs \& per tences eftranges que cefte miferable gent faif 3. Reg.18. par la perfuafion du diable,comme les faux $\operatorname{Pr}$ phetes de Baal, qui fe bleffoient, \& frappoien auec des lancettes, \& fe tiroient du fang, \& con me ceux qui facrifioient leurs fils $\&$ filles au $f_{a}$ Belphegor, \& les paffoient par le feu, felon qu p faim.ros. tefmoignent les diuines lettres. Car Satan a to 4. Keg.2I. jours defiré d'eftre feruy, au grand dommage, defpens des hommes. Il a efté defia dit, comr les Preftres \& Religieux de Mexique fe leuoi à minuit, \& ayans encenfé deuant l'idole, cor me dignitez du temple, ils s'en alloient en vn lie affez large où il y auoit beaucoup de cierges, là s'affeoient, \& prenans chacun vne pointec manguey, qui eft comme vne alefne, ou poinço aiguë, auec lefquelles, ou auec autres fortesc lancettes, ou rafoirs, ils fe peignoient \& pe çoient le mollet des iambes, ioignant l'os, fet räs beaucoup de fang, auec lequel ils s'oignoier par les temples, \& mettoient tremper ces poin 


\section{des Indes. Liure. V.}

;, ou lancettes, dedans le refte du fang, puis ires les mettoient aux creneaux dela court, fiiez en des globes, ou boulles de paille,à fin que us veiffent $\&$ cogneuffent la penitence qu'ils ifoient pour le peuple. Ils fe lauent, \& netyent ce fang, en vn lac deputé pour cét effet, iils appellent Ezapañgué,quieft'à dire, eau de ng ; Et y auoit au Temple vn grand nombre : ces pointes \& lancettes, parce qu ilsne pouoient faire feruir vne deux fois. Outre cela ces reftres \& Religieux faifoient de grands ieufes, comme de ieufner cinq \& dix iours fuiants, deuant quelqu'vne de leurs grandes fees, \& leur eftoient ces iours comme noz quatre emps:ils gardoient fi eftroittement la continen$e$, que quelques vns d'eux pour ne tomber en uelque fenfualité, fe fendoient les membres viilz par le milieu, \& faifoient mil choles, pour fe endre impuiffans, à fin ue n' noffenfer point leurs Jieux. Ils ne beuwoient point de vin, \& dornoiêt fort peu, pource que la plus part de leurs xercices eftoient de nuiet, \& commettoient fur ux-mefmes, de grande cruautez, fe martyrifais our le diable, le tout a fin qu' ils fuffent reputez rrands ieufneurs \& penitens. Ils auoient accoutumé de fe difcipliner auec descordes pleines le noeuds, \& non pas eux feulemét, mais encore e peuple faifoit cefte maceration \& fuftigation, en la procefsion \& fefte quils faifoient a lidole Tezcalipuca, que i’ay dit cy-deffus eftre le Dieu de penitence. Car alors ils portoient tous á leurs mains des cordes neuues de fil de mäguey, d'vne braife do long, auec vn noud au bout, 


\section{Hiftoire naturelle}

\& d'icelles ils fe furtigeoient, s'en donnant grands coups par les efpaules. Les Preftresie noient cing iours fuy yans, auant cefte fefte, $m$ a geans vne feule fois le iour, \& fe tenoient fep rez de leurs femmes, fans fortir du temple, pe dant ces cinq iours fe foil ettans rigoureufeme auec les ordres furdits. Les lettres des Peres Ia Compagnie de I E sv s, qu'ils ont efcrites Indes, traittent amplement des penitences, \& e cefsiues rigueurs dont vfent les Boncos, enc que le tout y ait efté fophiftiqué, \& qu'il y plus d'apparence que de verité. Au Peru po folemnifer la fefte de l'Yta, qui eftoit grand tout le peuple ieufnoit deux iours, durant le quels ils ne touchoient point à leurs femmes, ne mangeoient aucune viande auec du $\mathrm{fel}$, d'ail,ny ne beuuoient point de Chica.Ils voie beaucoup de cefte façon de ieufner, pour ce tains pechez, \& faifoient penitence en fe foüe tansauec des orties fort afpres. Et tantoft s'er trefrappans plufieurs coups par les ef paules d' ne certaine pierre en quelques endroits. Cef gent aueuglee par la perfuafion du diable, tranfportoit en des Sierres, ou montagnes fo afpres, où quelques fois ils fe facrifioient eux mefmes, fe precipitans du haut en bas de que que haut rocher, qui font toutes embufches tromperies de celuy qui ne defire rien tant, qu le dommage \& perdition des hommes. 
des Indes, Liure. V.

:s facrifices que les Indiensfairfoient audia: ble, \& de quelleschofes.

CHAPITRE XVIII.

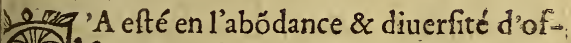
- 20 frandes \& facrifices, enfeignez aux in2. Sidelles pour leur idolatrie, que l'cnnemy de Dieu \& des hommesa plus monftré fon aftuce \& fa mefchanceté. Et mme c'eft vne chofe conuenable, \& propre la religion, de confommer la fuftance des eatures au feruice \& à l'honneur du Creaur, qui eft le facrifice : ainfi le pere de menfona inuenté de fe faire offrir \& facrifier les creares de Dieu, comme à l'autheur \& feigneur icelles. Le premier genre de facrifices, duquel hommes ont vfé, a efté fort fimple : car Cä̈n frit des fruicts de la terre, \& Abel du meilleur fon beftail, ce que firent aufsi depuis Noé, Gene. zs: braham, \& les autres Patriarches, iufq̨uesà ce Le ceft ample ceremonial du Leuitique ait effé onné par Moyfe, auquel il y a tant de fortes \& ferences de facrifices, pour diuers affiaires, de. uerfes chofes, \& auec diuerfes ceremonies. De mefme façon il s'eft contenté, entre quelques tions, de leur enfeigner qu ils luy facrifiallent ce qu'ils auoient : mais enuers d'autres il a Ifré fi outre, en leur donnant vne mulcitude couftumes, \& de ceremonies, fur les facrices, \& tant d'obferuances, qu'elles font efmerillables. Et femble clairement, que par ls is 


\section{Hifoire naturelle}

vüeillez debattre, \& s'efgaller à la loy ancienr \& en beaucoup de chofes vfurper fes propr ceremonies. Nous pouuons reduire en trois ge res de facrifices tous ceux dont vfent les infide les, les vnes des chofes infenfibles, les autr d'animaux, \& les autres d'hommes. Ils auoye accouftuméau Peru de facrifier du Coca, $q$ eft vne herbe qu'ils eftiment beaucoup, \& mays, qui eft letirbled, des plumes de couleu $\&$ du Chaquira, qu'ils appellent autremes Mollo, des conches ou huiftres de mer, \& que ques fois de l'or \& de l'argent, qui eftoit auct nes fois en figures des petits animaux. Mefmer la fine eftophe de Cumbi, du bois taillé, odoriferant, \& le pius ordinairement du fu bruslé. Ils faifoient ces offrandes ou facrifice pour obtenir des vents propices, \& vn bc temps, ou pour la fanté $\&$ deliurance de que ques dangers, ou mal-heurs. Au fecond ger re , leur ordinaire facrifice eftoit des Cuyes, q font des petits animaux, comme petits connil que les Indiens mangent ordinairement. Et e chofes d'importance, ou quand c'eftoient que ques perfonnes riches, ils offroient des Pacos ou moutons du pays, ras ou veilus, \& pre noient garde fort curieufement au nombre aux couleurs, \& au temps. La façon de tue quelconque victime, grande ou petite, dor vfoient les Indiens felon leurs ceremonies an ciennes, eft la mefme de laquelle vfent auiour d'huy les Mores, qu'ils a ppellent Alquiblé, qu eft de prendre la befte fur le bras droit, \& luy tourner les yeux vers le Soleil, difant certaine 
des Fndes. Liure. V.

zroles, felon la qualité de la vißame que l'on ï. Car fi elle eftoit de couleur, les paroles addreffoient au Chuquilla, \& tonnerre, à fin dil n'y euft difette d'eaux : fi elle eftoit blanie \& rafe, ils l'offroient au Soleil auec certaies paroles, fi elle eftoit veluë, ils l'offroient ifsi auec d'autres, à fin qu'il donnaft fa lúiere, \& fuft propice à la generation: fr c'eftoit n Guanaco, qui eft de couleur grife, ils addrefjient le facrifice au Viracocha. Au Cufco l'on 1oit \& facrifioit chacun an, auec cefte ceresonie, vn mouton ras au Soleil, \& le brufjient veftu d'vne chemifolle rouge, \& lors u'il brusloient, ils iettoient au feu certains peits panniers de Coca, qu'ils a ppelloient Vilcaonca, pour lequel facrifice ilsauoient des homnes deputez \& du beftail, quine feruoit à aure chofe. Ils facrifioient mefme des petits oyeaux, encor que cela ne fuft pas fi frequent au Peru, comme en Mexique, ou les facrifices des :ailles eftoit fort ordinaire. Ceux du Peru facriioient des oyfeaux de la Puna, (ainfi a ppellent is le defert (quand ils deuoient allerà la guere pour faire diminuer les forces des Guacas de leurs contraires. Ils appelloient ces facrifices Cuzcouicça, ou Conteuicça, ou Haullauicça, ou Sopauicça, \& le faifoient en cefte forme. Ils prenoient plufieurs fortes de petits oyfeaux du defert, \& affembloient beaucoup d'vn bois ef pineux, qu'ils appellent Yanlli, lequel eftant allumé, alfembloient ces petits oy feaux. Cét affemblement eftoit appellé Quico, puis lesietsoient au feu, a tu tour duquel alloient les offi. 


\section{Hiftoire naturelle}

ciers du facrifice, auec certaines pierres ro des $\&$ cottellees, où eftoient peintes plufiet couleuures, lyons, crapaux, \& tigres, pro rans ce mot V fachum, qui fignifie, la victo nous foit donnee, \& autres paroles. Enqu ils difoient que les forces des Guacas de let ennemis fe perdoient, \& tiroient certains mo tons noirs, qui eftoient en prifon, quelqu iours fans manger, lefquels ils appelloient $\mathrm{V}$ ca, \& en les tuans, difoient ces paroles, cor me les cours de ces animaux font affoibl ainfi foient affoiblis nós contraires: que ? voyoient en ces moutons, qu'vne certai chair qui eftoit derriere le cœur, ne fe fu point confommee par les ieufnes \& prifo paffees, ils les tenoient pour vn mauuais a gure. Ils amenoient certains chiens noirs, qu' a ppelloient Appuros, \& les tuoient, les-ie tans en vne pleine auec certaines ceremonie faifans manger cefte chair à quelques fort d'hommes, lefquels facrifices ils faifoient, peur que l'Ingua ne fuft offenfé auec du po fon, \& pour cét effet ils ieufnoient depuis matin iufques au leuer des eftoilles; \& lo als fe faoulloient, \& fe honniffoient à la faço des Mores. Ce facrifice leur eftoir le plus cor uenable, pour foppofer aux Dieux de leu contraires, \& combien que pour le iourd hu vne grand' partie de ces couftumes ayent ceff les guerres ayans prins fin, toutesfois il en demeuré encor quelques reftes, pour l'oce: fion des difputes particulieres ou communes de Indiens, ou des Caciques, ou d'entre les ville 
des Indes. Liure $V$.

24

is facrifioient $\&$ oftroient aufsi des conchè le la mer, qu' ils a ppellent Mollo, \& les offroiêtr ux fontainies \& fources, difans que les conheseftoiët filles de la mer, mere de toutes les aux. Ils donnent à ces conches des noms diferens, felon la couleur, \& s'en feruent aufsi à liuerfes fins. Ils en vfent prefque en toutes fores de facrifices, \& encor auiourd'huy quelques ns mettent des conches pilees dedans leur Shica, par fuperftition. Finalement il leur embloit conuenable d'offrir facrificès de tout e qu'ils femoient \& esleuoient. Il y auoit des ndiens deputez pour faire ces tacrifices aux ontaines, fources, \& ruiffeaux qui paffoient ar les villes, ou parleurs Chacras, qui font ours meftairies, \& les faifoient, a pres auoir cheué leurs femailles, afin quilis ne ceffaffent e courir, \& qu'ils arroufaffent toufiours leurs teritages. Les forciers iettoient leur fort pour: ognoiftre le temps auquel les facrifices $\mathrm{fe} d \mathrm{de}$. oient faire, lefquels eftans acheuez, l'on afembloit de la contribution du peuple, ce que on deuoit facrifier, \& les bailloit-on à ceux: uiauoient la charge de faire cesfacrifices. Ils es faifoient au commencement de l'Hyuer, uieft lors que les fontaines, fources, \& riuieescroiffent pour l'humidité du temps, \& eux attribuoient à leurs facrifices: Ils ne facriv oient point aux fontaines \& fources des de -1 erts. Aujourd'huy demeure encor entr'cuxle efpect qu'ils auoient aux fontaines, fources ftangs, ruiffeaux, ou riuieres quii paffent pas les illes, \& Chacrassmefmes aufsiaux fontaines \& H

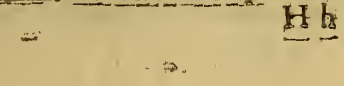




\section{Hiftoire naturelle}

riaieres des deferts. Ils font particuliere reu rence $\&$ veneration à la rencontre de deux r uieres, \& là fe lauent pour la fanté, s’oigna: premierement auec de la farine de mays, $c$ auec autres chofes, en y adiouftant diuerfes $c$. remonies, ce qu'ils font mefme enleurs baing

\section{Des facrifices d'bommes quils faifoient. \\ CHAPITRE XIX.}

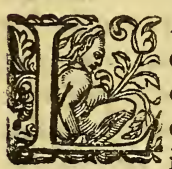

A plus pitoyable mefauanture ce pauure peuple, eft le vaffella: quils payoient au diable, luy crifiant des hommes, quifont 1 images de Dieu, \& ont efté creé pour iouyr de Dicu. En beaucoup de nations auoient accouftumé de tuer, pour accomp: gner les deffunets, comme a efté dit cy deffus, 1 perfonnes quileur eftoient les plus aggreable $\&$ de qui ils imaginoient qu'ils fe pourroie mieux feruir en l'autre monde. Outre cefte or cafion,ilsauoient accouftumé au Peru, de facs fier des enfans de quatre ou fix ans, iufques a di: \& la plus part de ces facrifices, eftoient pour 1 affaires qui importoient à l'Ingua, comme c fes maladies, pour luy enuoyer fanté, mefr quand il alloit en guerre, pour la victoire, quand ils donnoient au nouueau Ingua bourrelet, qui eft l'enfeigne du Roy, comn font icy le fceptre \& la couronne. En cefte fo lemnité, ils facrifioient le nombre de deu cents enfans de quatre à dix ans, qui eftoit $v$ 
des 7 ndes. Liure $V$. $24^{2}$ uel \& inhumain fpectacle. La façon de les $\Upsilon_{a}$ fier eftoit de les noyer \& enterrer aucć cernes reprefentations $\&$ ceremonies, tantoft leur couppoient la tefte, $-\&$ s'ojgnoient auec ir fang d'vne oreille en l'autre. Ils facrifioient frme des filles, du nombre de celles qu'on tenoit à l'Ingua des Monafteres, dont i'ay itté cy-deffus. 11 y auoit en ce cas vn abus r grand $\&$ fort general, qui eftoit que fi quele Indien qualifié, ou du vulgaire, eftoit ma$e, \&$ le deuin luy difoit que pour certain il soir mourir, ils facrifioient au Soleil, ou au acocha fon fils, le prians de fe contenter d'iuy, \& qu'il ne vouluft ofter la vie au pere. if vne femblable cruauté à celle que rapporEfcriture, dont víale Roy de Moab, en fafiant fon fils premier né fur la muraille, à la $4 . R \mathrm{eg} \mathrm{g}^{3} \mathrm{~s}$ ië de tous ceux d'lfraël, aufquels cét e fembla fi trifte, quisls ne voulurent pas le ffer dauantage, \&zainfi s'en retournerent en rs maifons. L'Efcriture raconte auffi le mefgenre defacrifice auoir efté en vfage entre natiós barbares des Cananeans $8 r$ Iebureans, es autres dont efcrit le liure de Sapience: $I l_{s}$ Sapq.i2,6.r4 Llent paix, de viure en $j \hat{i}$ grands maux, $\mathcal{O}^{-}{ }_{i}$ griefs me de facrifier leurs propres fils, ou de faire d' awires facescacho 7 , ou de veiller touce la nuict, faifaris altes de , o ainfials ne gardent point nettetéen leur vie, ny enz s mariages, mais l'un par enuie ofte la vie à l'autre, tre luy ofte fa femme fon contentement, or tout $y$ ? n confufion, le fang, lhomidide, le larcin, la tromperie, rruption, l'infidelite, les feditions, les pariurements, les merces, loubliance de Dieus la cötamination des ames 0

Hh if 


\section{Hiftoire naturelle}

lechangement de fexe, $\sigma$ de naifance, lincor/fance masiages, le defordre de l'adultere, or ordure. Carl' latrie eft vn abyfme de tous maux. Le fage dit çel ces peuples; defquels Dauid fe plaint que c d'Ifraël apprindrent telles couftumes, iufo facrifier leurs fils \& filles au diable. Ce que mais Dieu n'a voulu, \& ne luy a point efté greable. Car commeil a efté autheur dela \& quil a fait toutes ces autres chofes pou commoditéde l'hóme, il ne fe plaift point les hommes s'oftent la vie les vns aux aut Bien que le Seigneur ayt approuué $\&$ accept volonté du fidele Patriarche Abraham, il confentit pas pourtant au fait, qui eftoit dè c per la tefte à fon fils. Enquoy l'on voit la ma \& tyrannie du diable, qui a voulu en cela paffer Dieu, prenant plaifir d'eltre adoré a effufion de fang humain, \& procurant pa moyen la perdition des ames \& des corps femble, pour la haine enragee quil por l'hornme, comme fon cruel aduerfaire.

Des horribles Jacrifices d'hormmes, dont $v$ o les Mexiquains.

\section{Chatitre XX.}

7 A çoit que ceux du Peru ayent furp 12 5 cux de Mexique en l'oçcifion \& fa 20 0 ice de leurs enfans, (car ie n'ay p 22 leu, ny enrendu, queles Mexiqu. vfaffent de tels, ou pareils facrifices) resfois ceux de Mexique les ont furpaffés v 


\section{Des Indes. Liure V. $\quad 243$}

utes les nations du monde, au grand nom :e d'hommes qu'ils lacrifioient, \& en la façon orrible quils le faiforent. Et afin que l'on voye grand mal-heur enquoy le diable tenoit ce zuple aueuglé, ie raconteray par le menul'vge \& façon inhumaine quils auoient en cela. remierement les hommes qu'ils facrifioient, toient prins en guerre. Et ne faifoient point s folemnels facrifices, fi ce n"eftoient de capfs, de forte qu'il femble qu'en cela ils ont fuiy le ftile des anciens. Car felon que veulent ire certains Autheurs, pour cefte occafion ils spelloient le facrifice, victima, d'autant que c'eoit de chofe vaincuë: comme mefme ils l'apelloient, Hoftia, quafi ab hofte, pource que c'eftoir ne offrande faite deleurs ennemis, combien ue l'on ayt accommodé ce motà toutes fors de facrifices. A la verité les Mexiquains ne tcrifioient point à leurs idoles que leurs capfs, \& n'eftoient les ordinaires guerres qu'ils tifoient, que pour auoir des captifs pour les icrifices. C'eft pourquoy quand les vns \& les utres fe battoient, ils tafchoient de prendre ifs leurs contraires, \& de ne les tuer point pour ouyr de leurs facrifices. Er cefte fut la raifon ue donna Motecuma au Marquis du Val, uand il luy demanda, pourquoy eftant $f i$ puifant, \& ayant conquefté tant de Royaumes, Inauoit pas fubiugué la Prouince de Tafcala, qui eftoit fi proche: Motecuma refponit a cela, que pour deux caufes, il n'auoir is conquefté cefte Prouince, combien qu'il uy euft efté fr facile s'il l'euft voulu entreprenth th iij 


\section{Hiftoire naiturelle}

dre : l'vne pour auoir enquoy exercer $l_{a}$ ie neffe Mexiquaine, de peur qu'elle ne fe not rift en oyfiueté \& delicateffé : l'autre \& pr. cipalt, qu'il auoit referué celte Prouince po auoir d'où tirer des captifs pour facrifier leurs Dieux. La façon dont ils vfoient ces facrifices, eftoir quils affembloienten ce: pallifiade de teftes de morts, qui a efté ditre

- deffus, ceux quideuoient eltre facrifiez, \& f foit l'on auec eux au pied de cefte palliffade $\mathrm{v}$. ceremonie, qui eftoit quils les metroient to ztrangez au pied de cefte palliffade auec bea eoup d'hommes de garde qui les entouroier Incontinent fortuit va Preftre veftu d'vne a be courte pleine de flocquons, ou houpett par le bas, \& defcendoit du haut du temp auec vne idole farcte de pafte de bled, \& ma: amaffé auec du miel, qui auoit les yeux: grains de voirre vert, \& les dents de grains، mays, \& defcendoit auec toute la vifeffe qu pounoir les degrez du temple en bas, \& mo1 toit par deffus vne grande pierre qui eftoit 1 chee en vne fort haure terraffe au milieu de court. Cefte pierre s'appelloit Quauxicalli, q1 veut dire, la pierre de l'Aigle, \& y montoit. Preftre par vn petit efcailler qui eftoit au di uant de la terraffe, $\&$ defcendoit par vn aut qui eftoit en l'autre cofté, toufiours embraffar fon idole: puis móroit au lieu où eftoient ceu que l'on deuoit facrifier, \& depuis vn bor ìufqu’à l'autre alloit monitrant celte idole à v chacun d'eux en particulisr, leur difant, ceftu eft voftre Dieu. Et en acheuant de monftrer, de 
:endoit par l'autre cofté des degrez, \& cous eux quideuoient mourir s'en alloient en proeffion jufqu'au lieu ou ils deuoient eftre farifiez, \& là trouuoient appreftés les miniftres jui les deuoient facrifier. La façon ordinaire de facrifier, eftoit d'ouurir l'eftomach à celuy qu'ils facrifioient: apres tuy auorr tiré le cœur encor à demy-vif, ils iettoient lhomme \& le faifoient rouler par les degrez du temple, lefquels eftoient tous baignez $\&$ foüillez de ce (ang. Et afin de le faire entendre plus particulierement, fix Sacrificateurs conftitués en cethe digniré, fortoient aulieu du facrifice, quatre pour tenir les mains \& les pieds de celuy que l'on deuoit facrifier: l'autre pour tenir la tefte, \& l'autre pour ouurir l'eftomach, \& tirer le cœur du facrifié. Ils appelloient ceux-là Chachalmua, qui en noftre langage vaut autant que miniftre de chofe facree. C'eltoit vne dignité fupréme \& beaucoup éftimee entr'eux, ou l'on heritoit \& fuccedoit comme en vne chole de Mayorafque ou fief. Le miniftre qui auoit l'office de tuer, qui eftoitle fixiefme d'iceux, eftoit eftimé \& honoré comme fouuerain Preitre $\&$ Pontife, le nom duquel eftoir different, felon la difference des temps \& folemnitez. Tout de mefme eftoient leurs habits differens quand ils fortoient à excercer leur office, felon la diuerfité de temps. Le nom de leur dignité eftoit Papa \& Topilzin, leur habit \& robbe eftoit vne courtine rouge en façon de Dalmatique auec des houpes au bas, vne couronne de riches plumes verdes, blanches \& iaulnes fur la tefte, \&

$\mathrm{Hh}$ iiij 


\section{Hifloire naturelle}

aux oreilles comme dés pendans d'or, aufquel $y$ auoit des pierres vertes enchaffees, \& au del fous de la levre ioignant le milieu de la barbe auoit vne piece comme vn petit canon d'vn pierre azuree. Ces fix Sacrificateurs venoien les vifages \& les mains ointes d'vn noir for luifant. Les cinq autres auoient vne cheuelu refort crefpuë \& entortillee auec des lifets d cuir, defquels ils font ceints par le milieu de tefte, \& portans au front de petites rondel. les de papier, peintes de diuerfes couleurs, \& eftoient veftus d'vne Dalmatique blanche ou uree de noir. Ils reprefentoient auec ceft or nemene, la mefme figure du diable : de fort que cela donnoit crainte \& tremeur à tout $k$ peuple de les voir fortir auec vne fi horrible reprefentation. Le fouuerain Preftre portoi en la main vn grand coufteau d'vn caillou for large \& aigu, vn autre Preftre portoir vn col lier de bois, ouuré en façon d’vne coulcuure Tous fix fe mettoient en ordre ioignant cefte pierre pyramidalle, de laquelle iay parlé cy deuant, eftant vis à vis de la porte de la chap. pelle de lidole. Cefte pierre eftoit fi pointué, que l'homme qui deuoit eftre facrifié, eftani couché deffus à la renuerfe, fe plioit de telle façon, qu'en luy laiffant feulement tomber le coufteau fur l'eftomach, fort facilement il s'ouuroit par le milieu. Apres que ces facrificateurs eftoient mis en ordre, l'on tiroit tous ceux qui auoient efté prins és guerres, lefquels depoient eftre facrifiez en cefte fefte. Et eftan's fore accompagnez d'hommes pour la garde \& 


\section{des Fndes. Liure $V$.}

us nuds, on les faifoit monter de rang ces lars degrez, au licu où eftoient appareillez les iniftres; \& comme chacun d'eux venoit en $n$ ordre, les fix Sacrificateurș le prenoient l'vn ir vn pied, l'autre par.vn autre, l'vn par vne ain, \& l'autre par l'autre, \& le ietroient à la nuerfe fur cefte pierre poinctuë, où le cintiefme de ces miniftres luy mettoir le collier - bois aucol, \& le grand Preftre luy outuroit iftomach aucc le coufteau, d'vne eftrange romptitude \& legereté, luy arrachant le cœur tec les mains, \& le monfroit ainfi fumant au oleil, à qui il offroir cefte chaleur \& fumee de cur, \& incontinent fe tournoit vers l'idole, ? luy iertoit au vifage, puis ils iettoient le orps du facrifié, le roulant par les degrez du emple fort facilement, pource que la pierre ftoit mife fi proche des degrez, qu'il n'y auoit as deux pieds d'efpace entre la pierre \& le pre nier degré; de forte que d'un feul coup de pied Is iertoient les corps du haut en bas. De celte açon ils facrifioient vn à vn tous ceux qui y ftoient deftinez, \& apres qu'ils eftoient morts, $x$ quel'on auoit ietté les corps en bas, leurs naiftres, ou ceux quiles aucient prins, lesaloient releuer, \& les emportoient, puis apres es ayans departis entr' eux, ils les mangeoienr, :elebrans leur fefte \& folemnité.ll y âoit touiours pour le moins quarante, ou cinquante de :esfacrifiez, pource qu'il y auoit des hommes ort addroits a les prendre. Les nations circonuolfines en faifoient autant, imitans les Mexiquains en leurs couftumes $\&$ ccremonies fur le 


\section{Hiftoire naturelle}

\section{D'one autre forte de facrifices d'bommes, do}

voient les Mexiguains.

\section{Chapitre XXI.}

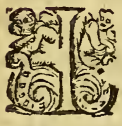

L y auoit vne autre forte de facrifi qui ils faifoient en diuerfes feftes, 1 , quels ils appelloient Racaxipe Veli: $\mathrm{li}$, qui eft autant qu'efcorchement perfonnes. On l'appelle ainfi, pource qu'en c taines feftes ils prenoient vn, ou plufieurs efc ues, felon le nombre qu'ils vouloient, \& aps l'auoir efcorché, en reueftoient de la peau homme qui eftoit deputé à cét effect. Ceftuy fien alloit par toutes les maifons \& marchez la Cité, dançant \& ballant, \& luy deuoient to offirir quelque chofe; \& fi quelqu'vn ne luy o froit rien, il le frappoit d'vn coin de la peau: vifage, le foüillant de ce fang figé qui y efto. Cefte inuention duroit iufques à ce que le cu fe corrompift, pendant lequel temps ceux $q$ alloient ainfi, affembloient beaucoup d'aumo nes qu'ils employoient aux chofes neceffair pour le feruice de leurs vieux. En beaucoup ces feftes ils faifoient vn deffy entre celuy $q$ facrifioit, \& celuy qui deuoit eftre facrifié, cefte forme. Ils attachoient l'efclaue par v pied à vne grande roüe de pierre, \& luy bai loient vne efpee \& vne rondelle a ux mains, af quil fe deffendif; \& fortoit incontinent celu qui le deuoit facrifier, armé d'vne autre efpe 


\section{des Indes. Liure $V$.}

$x$ rondelle; que fi celuy qui deuoit eftre facriié, fe deffendoit vaillamment contre l'autre, $x$ l'empefchoit, il demeuroit exempt \& deliuré du facrifice, acquerant le nom de Capitaine ameux; \& comme tel, eftoit du depuis entenlu: mais fil eftoit vaincu, ils le facrifioient en a mefme pierre où il eftoit attaché. C'eftoit vn utre genre de facrifice, quand ils dedioiene quelque efclaue pour eftre la reprefentation de idole, \& difoient que c'eftoit la reffemblance. Ils donnoient aux Preftres par chacun an vn efo. claue, afin qu'il n'y euft iamais faute de la femblance viue de l'idole; $8 z$ incontinent qu'il entroit en l'office, apres qua il eftoit bien laué, ilsle veftoient de tous les habits \& ornemens de liidole, luy donnans fon mefme nom. Il eftoit coute l'annee reueré \& honoré comme le mefme idole, \& auoit toufiours auec luy douze hommes de garde, de peur qu'il ne f'enfuift, auec laquelle garde on le laiffoit alter librement où 11 voúloit; \& fi d'auenture il Penfuyoir, le chef de la garde eftoit mis en fon lieu, pour reprefenter l'idole, \& apress eftre facrifié. Cét Indien auoir le plus honorable logis de tout le temple, où il mangeoit \& beuuoir, \& où tous les principaux le venoient feruir $\&$ honoret, luy apportans à manger auecl'ordre \& appareil que l'on fait aux grands. Quandil fortoit parmy les ruës de la Cité, il alloit fort accompagné de Seigneurs, \& portoit vne petite flufte en la main, qu'il touchoit de fois à autre, pour faire entendre qu'il paffoit. Et incontinent les femmes fortoient auec leurs petits enfans en leurs 


\section{Hiftoire naturelle}

bras, \&cles luy prefentoient, le falüans comm Dieu; tout le refte du peuple en faifoit autan Ils le metroient de nuict en vne forte prifor ou cage, de peur qu'il ne f'en allaft, iufques à c qu'arriuant la fefte ils le facrifioient, comm jay dit cy deffus. Par ces façons, \& beaucou d'autres, le diable abufoit, \& entretenoit ce pauures miferables, \& eftoit tellela multitud de ceux qui eftoient facrifiez par cefte infernal cruauté, qu'il femble que ce foit chofe incroya ble: car ils afferment quily en auoit quelque fois plus de cinq mil; \& que tel iour f'eft pall quils en ont facrifié plus de vingt mil en diuer endroits, Le diable vfoit, pour entretenir ceft tuerie d'hommes, d'vne plaifante \& eftrange in uention, qui eftoit, que quand il plaifoit au. Preftres de Satan, ils alloient aux Rois, \& leu declaroient comme leurs dieux fe mouroient d faim, \& qu'ils euffent memoire d'eux. Inconti nent les Rois f'appareilloient, \& aduertiffoien les vns les autres que les dieux demandoient manger, partant qu'ils commandaffent au peu ple de fe tenir preft à venir à la guerre; $\&$ ain le peuple affemblé, \& les compagnies ordon nees, ils fortoient aux champs, où ils affem bloient leur armee, \& toute leur difpute \& combat eftoit de fe prendre les vns lesautre pour facrifier, tafchans de fe faire paroiftre tan d'vn cofté que d'autre, en amenant le plus de ca ptifs pour le facrifice; tellement qu'en ces ba railles ils tafchoient plus à f'entre-prendre, qu'? f'entre:tuer, pource que tout leur but eftoit d'a mener des hommes vifs pour donner à mange 


\section{des Indes. Liure $V$.}

à leurs idoles, qui eftoit la façon par laquelle ils apportoient les victimes à leurs dieux. Et doicon fçauoir que iamais Roy n'eftoit couronné, quau prealable il n'euft fubiugué quelque Prouince, de laqualle il amenaft vn grand nombre de captifs pour les facrifices de leurs dieux, \& ainfi par tous moyens ceftoit chofe infinie que le fang humain que l'on efpandoit en l'honneur de Satan.

Comme defia les Indiens eftoient laffez, on ne pounoient plus fouffrir la cruauté de leurs dieux.

\section{Chatitre XXII.}

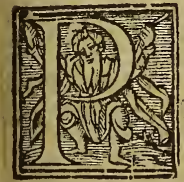

Lvsievrs de ces barbares eftoient defia laffez \& ennuyez d'vne fi exceffrue cruauté à efpandre tant defang d'hommes, \& dutribut fi ennuyeux d'eftre toufiours en peine de gagner des captifs pour la hourriture de leurs dieux, lear femblant vne chofe infupportable; \& neantmoins ils ne laiffoient de fuiure, \& executer leurs rigoureufes boix, pour la grande crainte que les miniftres des idoles leur donnoient de leur cofté, \& par les rufes auec lefquelles ils tenoient ce peuple en erreur: mais en l'interieur ils defiroient affez de fe voir libres d'vne fi pefante charge. Er fut vne grande prouidence de Dieu, que les premiers qui leur donnerent la 


\section{Hiftoire naturelle}

cognoiffance de la loy de Iefus-Chrif, les itor ualfent en cefte difpofition, pource que $f_{a n}$ doute celeur fembla vne bonneloy, \& vn bo Dieu, qui vouloit eftre feruy de cefte façon. Su ce propos me contoit vn Religieux graue en I: neuue Efpagne, que quand il fut en ce Royau me il auoit demandé à vn ancien Indien, hom me de qualité, comment les Indiens auoien fi toft receu la loy de lefus-Chrift, \& laiffé leur, fans faire dauantage de preuue, d'effay, ny de difpute fur icelle: car il lembloit qu'lls fe ftoient changez fans y auoir efté ef́meus par rai. fon fuffifante. L'Indien refpondit: Ne crois point, Pere, que nous prenions fi inconfiderément la loy de Iefus-Chrift, comme tu dis, pource que ie t'apprends que nous eftions defia Iaffez, \& mefcontents des chofes que lesidoles nous commandoient, \& que nous auions defra parlé de les laiffer, \& de prendre vne autre loy; Et comme nous trouuafmes que celle que vous nous prefchiez, n'auoit point de cruauté, \& qu'elle nous eftoit fort conuenable, iufte, \& bonne; nous entendifmes, \& creufmes que c'eftoit la vraye loy, \& ainfi nous la receufmes fort volontairement. La refponfe de cér Indien f'accorde bien auec ce qu'on lit aux premiers difcours qu'Hernãde Cortez enuoya à l'Empereur Charles le quint, où il raconte qu'apres auoir conquefté la Cité de Mexique, eftant en Guyoacan, luy vindrent des A mbaffadeurs de ia Republique \& Prouince de Mechoacan, demandans qu'il leur enuoyaft faloy, \& quilla leur apprift \& filt entendre, pour autant qu'ils pre: 


\section{des 7 ndes. Liure 7 .}

2,8

doient de laiffer la leur, qui ne leur fembloir $s$ bonne; ce que leur accorda Cortez, \& aurd'huy font les meilleurs Indiens, \& plus ais Chreftiens qui foient en la neure Efpae. Les Efpagnols qui virent ces cruels facrifis d'hommes, fe determinerent d'employer ute leur puiffance à deftruire vn fi deteftable maudit carnage d'hommes; \& d'autant plus ils virent vn loir deuant leurs yeux facrifier ixante, ou foixante \& dix foldats Efpagnols, ii auoient efté prins en vne bataille, qua re unna fur la conquefte de Mexique, \& vne aue fois trouuerent efcrit de charbon, es vne lambre en Tezcufco, ces mots: Icy fuft prifarser vn tel malheureux, awec fes compagnons, que cewa TeZcufco facrifierent. Il aduint melme à ce proos, vn cas fort eftrange, \& neantmoins veritale, ayant efté rapporté par perfonnes dignes foy, \& fut que les Ef pagnols regardans vo ectacle de ces facrifices, \& comme ils auoient uuert \& tiré le cour à vnieune homme fore ifpos, l'ayant ietré, \& fait rouler du haut en as des degrez, comme eftoit leur coufume uand il vint en bas, dift aux Efpagnols en $f^{\prime}$ ingue, Cheualiers, ils mont tué; ce qui efheut grandement les noftres d'horreur, \& de itié. Et n'eft point chole incroyable que ceuy-là ayant le cour arraché, ayt peu parler, at:ndu que Galien raconte qu'll eft arriué plu- Gál.li.2. de eurs fois aux facrifices des animaux, apres leur Hippoc. of uoir tiré le cœur, \& ietté fur l'autel, que les ani- Platon, pla saux refpiroient, voire bramoient \& crioient cit.cap. 4. autement, mefme couroient quelque temps. 


\section{Hiftoire naturelle}

Laiffans maintenant cefte queftion, comm foit poffible que cela puiffe eftre par nature, pourfuiuray mon intention, qui eft de faire combien ces barbares abhorroient defia ce infupportable feruitude qu'ils auoient à l'hor cide infernal, \& combien grande a eftéla mi ricorde que le Seigneur leur a faite, en le communiquant fa loy douce, \& du tout agri ble.

Comme te diable feft efforcéd'en/uiure, o contrefaire les facrements de la

$$
\text { faincte Eglife. }
$$

Chapitre XXV.

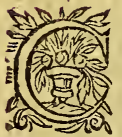

Equi eft le plus efmerueillable de l'e uie \& prefomption de Satan, eft, qu ayt contrefait non feulement en l'id latrie \& facrifices, mais auffi en cert: nes ceremonies nọs $S a c r e m e n t s$, que Iefus-C noftre Seigneur a inftituez, \& defquels vfe fainote Eglife, ayant fpecialement preten imiter en quelque façon le facrement de Cor munion, qui eft le plus haut, \& le plus diuin tous, pour le grand erreur des infidelles, qui procedoient en céte maniere. Aqu premier mo quau Peru ils appellent Raymé, \& refpond noftre Decembre, fe faifoit vne tres folemnel fefte, appellee Capacrayme, \& en icelle fe fa foient beaucoup de facrifices \& ceremonie qui duroient plufieursiours, pendant lefque nul forair \& ettranger ne fe pouuoit trous 


\section{des Indes. Liure IV.}

$\mathrm{l}_{\mathrm{a}}$ Cour, qui eftoit en Cufco. Ces iours eftăs ffez, ils donnoient congé $\&$ licéce aux eftranis d'entrer, afin qu'ils participaífent à la fefte aux facrifices, leur communiant en cefte fore. Les Mamacomas du Soleil, qui eftoien imme Religieufes du Soleil, faifoient de petits ins de farine de mays, teinte, \& paiftrie auec fang des moutons blancs qu'ils facrifioient ce urlà, incontinent ils commádoient que tous $s$ forains des Prouinces entraffent, lefquels fe ettoient en ordre, \& les Preftres qui eftoient̂́ certain lignage, defcendans de Liiquiyupaniy, donnoientà chacun yn morceau de ces peis pains, leur difans quids leur donnoient ces orceaux, afin qu'ils fuffent confederez \& v vis tec l'Ingua, \& qu'ils les aduifoient qu'ils ne fient, ny penfaffent mal contre l'Ingua : mais iilsluy portaffent toufiours bonne affection; jurce que ee morceau feroit tefmoin de leur tention, \& volonté, que f'ils nie faifoient cé ails deuoient, illes defcouiriroit, \& feroit ontre eux. L'on portoir ces petits pains en de tanàs plats d'or, \& d'argent, qui eftoient deftir ez pour cet effet, \& tous receuoient, \& manzoient ces morceaux remercians infiniment le oleil d'vne fi grande grace qu'il leur faifoit, dins des paroles, \& faifans des fighes d'vn grăd ontentement \& deuotion : proteftans qu'en ur vie ilsneferơient, ny penferoiént chole ontre le Soleil, ny contre l'Ingua, \& qu'auec efte condition ils receuoient ce manger du Soil, \& que ce manger demeureroit en leurs orps pour tefmoignage de la fidelité qu'ils gats: 


\section{Hiftoire naturelle}

doient aiu Soleil, \& à l'Ingua leur Roy. Cefte çon de communier diaboliquement fe faif mefme au dixiefme mois appellé Coyarayn qui eft oir Seprébre, en la fefte folemnelle qu appellent Cytua, faifant la mefme ceremon $\&$ outre cefte communion ( $\mathfrak{F}$ il eft permis d'v de ce mot en chofe diabolique) qu'ils faifoier tous ceux qui venoient de dehors;ils entroyo auffi de ces pains en tous les guacas, fanctuair ou idoles de tout le Royaume, \& tout en mefme temps fy trouuoient des perfonnes tous coftez, qui venoient expres pour les re uoir, aufquels ils difoient en leur baillant, $c$ le Soleil leur enuoyoir 'cela en figne qu'il vo loit que tous le veneraffent \& honoraffent, en enuoyoient mefme par honneur aux Ca ques. Quelqu'vn parauenture tiendra cecy pc fable \& inuention : mais pourtant c'eft vne $\mathrm{cl}$ fe tres-veritable, que depuis Ingua Yupan ( qui eft celuy qui a fait plus de loix, de couf mes, \& ceremonies, comme Numa à Ron dura cefte mantiere de communion, iufques à que l'Euangile de noftre Seigneur lefus-Chi mift hors toutes ces fuperftitions, leur donna le vray manger de vie, qui conferue \& vnift ames auec Dieu. Qui voudra s'en fatisfaire $p$ amplement, life la relation que le Licencié $\mathrm{P}$ lo efcriuit à l'Archeuefque des Rois, Dom H ronymo de Loayfa, où il trouuera cecy, \& be: coup d'autres chofes qu'il a defcouuertes \& prouuees par fa grande diligence. 
des fndes. Liure V.

e la façon que le diable s'eft efforcé de contrefaire en Mexique la fefte du Jainct sacre ment \& Communion, dont vfe la faindte Eglife.

Chapitre XXIV.

E lera chofe encor plus efmerucilla: ble d'ouyr parler de la fefte \& folemnité de la Communion, quele 1 1 mefme diable, Prince d'orgueil, ornna en'Mexique, laquelle, bien qu'elle foit a peu longue, il ne fera mal à propos de racon. $r$, felon qu'elle eft efcrite par perionnes dignes foy. Les Mexiquains faifoient au mois de lay leur principale fefte de leur dieu Vitziliuztli, \& deuxiours auparauant cefte fefte, ces les dont i'ay parlé cy deffus, qui eftoientreufes au mefme temple, \& eftoient comme regieufes, moulloient vne quantité de femence eblettes, auec du mays rofty, \& apres qu'il tọit moulu, le paifrifforér, \& amaffoient auec u miel, \& faifoient decefte pafte vnidole de mefme grandeur qu'eftoit celuy de bois, luy ettans aulieu des yeux, des grains de voirres erds, azurez, ou blancs; \& au lieu de dents, des rains de mays, affis auec tout l'ornementr $\&$ ppareil que i’ay dit cy deffus. Apres qu'il eftoit ì tout acheué, tous les Seigneurs venoient, \& y apportoient vn veftement exquis, \& riches our femblable à seluy de lidole, duquel ils le eltoient. Et apres l'auoir ainfi veltu \& orné, ils affeoient en vn efcabeau azuré, \& fur va brara.

Iij ij 


\section{Hiftuire naturelle}

card, pour le porter furles elpaules. Le mat de la fefte venu, vne heure auant le iour fo toient toutes ces filles veftuës de blanc, auec d ornemens tousneufs, lefquelles eftoient appe lees ce iour là, Scurs du bieu Vitzilipuztli. E les venoient couronnees de guirlandes de ma: rofty, \& creuaffé, reffemblant azaar, ou flei d'orenge, \& portoient en leur col de groff chaines de mefme, qui leur paffoient en e charpe par deffous le bras gauche. Elles eftoier colorees de vermillon par lesioües, \& auoier lesbras, depuisles couldes infques aux poing counerts de plumes rouges de perroquers, i ainfi ornees, elles prenoient l'idole fur leurse paules, le tirans, \& portans en la court o eftoient defia tous les ieunes hommes veft d'habits faits d'vn red artificieux, eftans coror nez de la mefme façon que les femmes. Alo que ces filles fortoient auecl'idole, les ieunt hommes s'approchoient auec beaucoup de re uerence, \& prenoient la littiere, ou brancar où eftoit l'idole, fur leurs efṕaules, la portar au pied des degrez du Temple, où tout le per ples'humilioir, \& prenant de la terre de l'air fela mettoit fur la tefte, qui eftoit vne ceremo nie ordinaire qu'ils obferuoient entreux, au principales feftes de leurs sieux. Celte cere monie faite, tout le peuple fortoit en proces fion, auec toute la diligence \& legereté quileu eftoit poffible, \& alloient à vne montagne qu eftoit à vne lieue de la Cité de Mexique, appel lee Chapultepec, \& là faifoient vne ftation, \& des facrifices. Incontinent ils partoient de 1 


\section{des Fndes. Liure $V$. 257}

uec la mefme diligence, pour aller en vn lieus ui eftoit proche de là, quils appelloient Atlauyauaya, où ils faifoient la feconde ftation, \& u partir de là, alloient en vn autre bourg, vne ielie plus outre, qui fe homme Cuyoaquan, 'où ils partoient, retournans en la Cité de Meique, fans faire aucune autre ftation. Ils faioient ce chemin de plus de quatre lieües, en rois, ou quatre heures, \& appelloient cefte roceffion, Y payna Vitzilipuztli, qui veut die$e$, le vifte \& diligent chemin de Vitzilipuztli. trriuez quils eftoient au pied des degrez, ils nettoient en bas le brancard de lidole, \& preioient de groffes cordes, lefquelles ils attahoient aux bras d'vn brancard, puis apres auec eaucoup de difcretion \& de reuerence, ils nontoient la littiere auec lidole, au fommet lutemple, les vns tirans d'enhaut, \& les autres eur aydant d'embas, cependant l'on n'entendoit retentir que le fon des fluftes, des buccines, tes cornets, \& des tambours qui fonnoient. Ils e montoient de cefte façon, d'autant que les degrés du temple eftoient fort roides \& eftroits, \& lefcallier fort large; ; tellement quilis n'y pouuoient monter cefte littiere fur leurs efpaules. Pendant qu'ils montoient cefte idole, tour le peuple eft oit en la court, auec beaucoup de reuerence \& de crainte. Apres qu'il eft oit monté iufques au haut, \& qu'on lauoir mis en vne petite loge de rofe, laquelle ils luy tenoient appreftee, incontinent venoient les ieures hommes, lefquels femoient, \& refpandoient vne grande quantité de fleurs de diuerfes couleurs,

Ii iij 


\section{Hiftoire naturelle}

dont ils rempliffoient tout le temple doda \&e dehors. Cela fait, toutes les filles fortoie auecques l'ornement que nous auons dit deffus, \& apportoient de leur Conuent $d$ tronçons, ou morceaux de pafte, compofee blettes, \& de mays rofty, qui eftoit de la mo me pafte de laquelle l'idole eftoit fait \& cor pofé, \& eftoient en forme de grands os. lls! b́ailloient aux ieunes hommes, lefquels les po toient en haut, les mettans aux pieds de l'id le, dont ils rempliffoient tout lelieu, iufqu à ce qu'il n'y en peuft entrer dauantage. lls a] pelloient les tronçons de pafte, les os \& cha de Vitzilipuztli. Et ayans ainfi eftendu ceso quffi toft venoient tousles anciens du Templ Preftres, Leuites, \& tout le refte des miniftre felon leurs dignitez, \& leurs antiquitez : car i auoit entr'eux fur ce point, vne belle regle, ordonnance, \& venoient les vns apresles al tres auec leurs voiles de red, de diuerfes col leurs, \& ouurages, felon la dignité, \& offi d'vn chacun, ayans des guirlandes en leurs t ftes, \& deschaines defleurs penduës au co Apres eux venoient les dieux \& deeffes, qu'i adoroient en diuerfes figures, veftus de la me meliuree, puis fe metrans en ordre au tourd ces tronçons \& morceaux de pafte, faifoier certaine ceremonie, en chantant, \& ballant fu iceux. Au moyen dequoy ils' demeuroient be nits \& confacrez pour la chair $\&$ os de cét ido le. La ceremonie \& benedietion de ces tron cons de pafte, par laquelle ils eiltoient tenus 8 efimez pour os \& chair de l'idole, eftant ache 


\section{des. Indes. Liure $V$.}

252 ils honoroient ces morceaux de la mefime aniere que leur dieu. Puis fortoient les Sacriateurs qui commençoient le facrifice d'homes en la façon qu'il a efit dit cy deffius, \& en crifioit on ceiour la vn plus grand nombre 'en nulautre, pour autant que c'eftoit la fela plus folemnelle qu'ils euffent. Les facrices eftans acheuez, fortoient tout auffi tolt us les ieunes hommes \&z filles du temple, orez comme il a efté dic, \& apres s'eftre mis en rdre, \& f'eftre rangez les vns vis a vis des au:es, ils balloient, \& dançoient au fon du tamour qu'on leur fonnoit en louiange de la foemnité \& de l'idole qu'ils celebroient. Auquel hant tous les Seigneurs anciens, \& les plus orables leur refpondoient, ballans à l'entour iceux, \& faifans un grand cercle, commeils nt de couftume, demeurans toufiours les ieuieshommes \& filles au milieu. A ce beau \{petacle venoit toute la Cité, \& y auoit vn commandement fort diligemment obferué en cefte terre, que le iour de l'idole Vitzilipuztli, l'on ne deuoit manger aurre viande que celte palte emmiellee, dequoy l'idole eftoit fait. Er cefte viande fe deuoit manger incontinent au poind du iour, \& ne deuoit-on boire d'eau, nyaucune autre chofe apres, iufques apres midy, \& re.. noient que c'eftoit vn mauuais augure, voire facrilege, que de faire le contraire: mais apres les ceremonies acheuees, il leur eftoit permis de manger toute autre chofe. Pendant le temps de cefte ceremonie ils cachoient l'eau aux pesits enfans, aduertiffans tous ceux qui auosent 


\section{Hiftoire naturelle}

l'vfage de raifon, de ne boire point d'eau ; qu Pils le faifoient, lire de Dieu viendroit fur eux \& mourroient; ce quils obferuoient fort dil gemment, \& rigouredfement. Les ceremonies bal, \& facrifices acheuez, ils fien alloient tou defpoüillet, \& les Preftres \& dignitez du tem ple prenoient lidole de pafte, lequel ils def pouiilloient de ces ornements qu'il auoit, 8 faifoient plufieurs morceaux, tant de cét ido le mefme, que de ces tronçons qui eftoien confacrez, puis apres ils les departoient au peu ple en forme de Communion, commençan aux plus grands, \& continuans au refte, tan hommes, femmes, que petirs enfans, lefquel les receuoient auec tant de pleurs, de crainte $\&$ de reuerence, que c'eftoit vne chole du tou admitable, difans qu'ils mangeoient la chair \& les os de Dieu, dequoy ils fe tenoient indi gnes. Ceux qui auoient des malades, en de mandoient pour eux, \& leur portoient aued beaucoup de reuerence, \& veneration. Tous ceux qui communioient, demeuroient obligez de donner le difme de cefte femence, ou grain, dequoy eftoit faict l'idole. La folemnité de la Communion eftant acheuee, vn vieillard de beaucoup d'authorité montoit fur vn lieu eminent, \& d vne voix fort haute, prefchoit leur loy, \& leurs ceremonies. Qui nef'efmerueilleI2 doncques que le diable ayt efté fi curieux de fe faire adorer \& receuoir en la façon que Iefus-Chrift noftre Dieu a ordonné, \& enfeigné, \& comme la faincte Eglife a accuuftumé? Par cela cettes, l'on yoid clairement verifić ce 


$$
\text { des.Indes. Liure } V \text {. }
$$

dia efté proporé au commencement, que $\mathrm{S}_{\mathrm{a}}$ $n$ tafche $\&$ s'efforce tant qu'il peut d'vfuror \& de defrober pour foy l'honneur\& feruice ui eft deu à Dieu feul, encor qu'il y mefle tousurs fes cruautés $\&$ ordures, pource que c'eft nefprit d'homicide \& d'immondicité, \& pere emenfonge.

\section{Des Canfeffersrs, \&o de la Confeßion dant} voient les Indiens.

Chapitre XXV.

vate E pere de menfonge a voulu mefme contre-faire le fácrement de Confefsion, \& en fes idolatries fe faire honorer auec des ceremonies fort mblables à l'vfage des fideles. Au Peru ils uoient opinion que toutes les maladies \& duerfitez leur venoient pour les pechez qu'ils uoient faits, \& pour remede ils vfoient de farifices, \& outre cela, fe confeffoient mefme erbalement prefque en toutes les Prouinces, $x$ auoient des Confeffeurs deputez pour ceft ffect, des fuperieurs, \& d'autres qui leur ftoient inferieurs: $\&$ y auoit des pechez referdez au fuperieur. Ils receuoient des penitences, voire quelques fois tres-rigoureufes : \& prinipalement quand le pecheur eftoit quelque Jauure homme, quin' auoit que donner auConeffeur, \& eftoit ceft office de Confeffeur merne exercé par les femmes. L'vfage de ces Confeffeurs forciers, quils appellent Ychuiri ous 


\section{Hiftoire naturelle}

Ychuri, à efté le plus vniuerfel és Prouince de Collafuio. Ils ont vne opinion que c'eft $v s$ enorme peché d'en celer en la Confersion quel qu'vn qu'ils ayent commis. Et les Ychuris ot Confeffeurs defcouuroient fi l'on leur en ce loit, par desforts, ou par le regard de la courroye de quelque animal, $\&$ les chaftioient es leur donnant vn nombre de coups d'vne pierre fur les efpaules, iufques à ce qu'ils euffen tout defcouuert, puis apres luy donnoient vn penitence, \& faifoient le facrifice. Ils fe feruent mefme de cefte Confefsion, quand leur enfans, Jeurs femmes, leurs maris ou leurs $\mathrm{C}_{2}$ eiques font malades, ou qu'ils font en quel. ques grands trauaux. Et quand l'Ingua eftoi malade, toutes les Prouinces fe confeffoient principalement ceux de la Prouince de Col. lao. Les Confeffeurs eftoient obligez de teni fecrettes les confefsions quils receuoient finon en certains cas limitez. Les pechez def quels principalement ils fe confeffoient, eftoi le premier de tuer l'vn l'autre hors la guer. re : en a pres de defrober, de prendre la femm d'autruy, de donner du poifon ou forcelleri pourfaire mal, \& tenoient pour vu grief pe ché, de s'oublier à la reuerence de leurs Gua cas ou chappelles, de ne garder point les fe Ites, de dire mal de l'Ingua, de ne luy obey point. Ils ne s'accufoient point d'actes \& peche interieurs, mais felon le rapport de quelque Preftres, depuis que les Chreftiens vindrenter ce pays, ils s'accuferent aufsi à leurs Ychuris \& confelfeurs de leurs penfees. L'Ingua ne con 


\section{des 7 ndes. Liure $V . \quad 254$}

foit fes pechez à nul homme, maisfeulement ${ }_{1}$ Soleil, afin quili les dift au Viracocha, \&c u'il les luy pardonnaft. A pres que l'Ingua s'eoit confeflé, il failoit vn certain bain pour theuer de fe nettoyer en vne riuiere couran$\therefore$ difant ces paroles: I'ay dit mes pechez au oleil, toy riuiere reçoy les, \& les porte à la er, où iamais ils ne puiffent paroiftre. Les aures qui fe confeffoient vfoient mefmement eces bains, auec certaines ceremonies fort emblables à celles dont les Mores vfent au surd'huy, qu'ils appellent Guadoy, \& les In* iens les appellent $O$ pacuna. Et quand il arrioit à quelque homme que fes enfans luy nouroient, il eftoit tenu pour vn grand peheur, \& luy difoient que ceftoit pour ' fes pehez que le fils eftoit mort premier que le pere. Z'eft pourquoy ceux à qui cela arriuoit, apres u' 'ils s'eftoient confelfez, ils eftoient baignez en e bain appellé O pacuna, comme il a efté dit :y deffus : $\mathrm{p}$ 'is quelque Indien monftrueux, zomme boffu \& contrefait de nature, les venoit fouëtter auec certaines orties. Si les Sorciers ou enchanteurs par leurs forts ou augures, afformoient que quelque malade devoit mourir, le malade ne faifoit point de difficulté de tuer fon proprefils, encor qu'il n'en euft point d'autres, efperant par ce moyen fe fauuer de la mort, \& difant quau lieu de luy il offroit fon fils en facrifice. Et depuis qu'il y a des Chreftiensen cefte terre, cefte cruauté a efté encor exercee en quelques endroits. C'eft à la verité vne chofe eftrange, que cefte couftumę de con- 


\section{Hiftoire naturelle}

feffer les pechez fecrets, foit demeuree fi lor temps, \& de faire de fi rigoureufes penitenc qu'ils faifoient, comme de ieufner, de donn des habits, del'or, de l'argent, de demeurer au montagnes, \& de receuoir de grands coups $\mathrm{ft}$ leserpaulles. Les noftres difent, qu'en la Pro uince de. Chiquito, ils rencontrent encor au iourd'huy cefte pefte de confeffeurs, ou Y $\mathrm{ch}$ ris, \& que beaucoup de malades fe retire verseux: mais def-ja par la grace de Dieu, peuple va du tout s'efclairfiflant, \& recognoil fent l'effect \& le grand benefice de noftre con fefsion. facramentale, à laquelle ils vienner auec vne grande deuotion. Et en partie cét vfa ge paffé leur a efté permis par la prouidence d Seigneur, afin que la confefsion neleur fem blaft difficile. Parce moyen le Seigneur eft e tout glorifié, \& le Diable mocqueur, demeur mocqué. Or d'autant que c'eft vne chofe qu touche à ce propos, ie raconteray icy l'ufag d'vne eftrange confefsion que le diable auo introduite au Iappon, comme il appert par vn lettre venuë de là , qui dit ainfi. Il y a en Ocac des roches tres grandes, \& fi hautes, qu'ily des picsen icelles, de plus de deux cens braffe de haut. Entre ces grands rochers, il y a vnd ces pics, ou pointes qui s'elleue fi terriblemen haut, que quand les Xamabuzis ( qui font le pelerins) le regardent feulement, les membre leur en tremblent, \& les cheueux s'en herifon ment, tant eft ce lieu terrible \& efpounenta ble. Il y a au fommet de cefte pointe vne gran de verge de fer de trois braffes de long, qui 


\section{des Indes. Liure $V . \quad \overline{2} 55$}

: pofee par vn eftrange artifice. Au bout de fte verge eft attachee vne balance, dont les efilles font fi grandes, qu'en vne d'icelles fe peut Coir vn hóme, \& les Goquis, (qui font des diaes en figure humaine). commandent qu'vn de s.pelerins y entrent les vns apres les autres, nsquil en refte vn feul, puis auec vn engin $8:$ ftrument qui fe remuë, moyennant vne rouie, font que cefte verge de fer, en laquelle la bance cft penduë, forre dehors, \& demeure toufurpenduë en l'air, eftant affis l'vn des Xamaxisen l'vn des plateaux de cefte ballance. Et imme l'efcaille où eft affis l'homme, n'a point : contrepois de l'autre cofté, incontinent elle ind en bas, \& l'autre s'efleue iufqu'à ce qu'elle ncontre \& touche à la vẻrge. Alors les Gouis leur difent du rocher, quilis fe confeffent, dient tous les pechez qu'ils auront commis, ont ils fe fouviendront, \& ce à haute voix, afin ue tous les autres qui font là le puiffent ouyr. continent il cómenceà fe confeffer, pendant woy quelques-vns des affiftans fe rient des peaez qu ils oyent, \& les autres en geniffent. Et chaque peché qu'ils difent, l'autre efcaille de la allance baiffe vn peu, iufquà ce que finaleient ay ant dit tous ces pechez la vuide demen- efgale à l'autre, où eft le trifte penitent, puis s Goquis refont tourner la roüe, \& retireñt ers cux la verge \& ballance d'ou fort le pelein, \& apres y en entre vn autre, iufqu'à ce que ous y ayent paffé. Vn Iapponnois contoit cela presquill fuft Chreftien, difant qu'il auoit efté a ce pelerinage,\& entré en la bal lance fept fois 


\section{Hiftoire naturelle}

où publiqquement il s'eftoit conferfé. Il difo melme, que fi dauanture quelqu'vn de ceux q font mis en celieu, ne raconte le peché comm il eft paffé, ou qu'il en cele quelqu'vn, l'efcaill! de la ballance vuide ne s'abbaiffe point, \& $s^{\prime}$ s'obftine apres qu'on luy a fait inftance de confeffer, \& ne vueille defcouurir tous ces pe chez, les Boquis le iettent \& font choir du hat en bas, où en vn mómentil eft rompu $\&$ bril en mille pieces. Neantmoins ceChreftien nor mé lean, nous difoit qu'ordinairement la crair te \& tremeur de ce lieu eft figrande à tous ceu qui s'y mettent, \& le danger que chacun voit l'œil, de tomber de la ballance, \& eftre defrom pu \& briféen bas, quili aduient fort peu for uent quil y en aye qui ne defcouurent tov lcurs pechez. Ce lieu eft appellé d'vn autre nor Sangenotocoro, qui veut dire, lieu de cốfeffior L'on voit bien clairement par ce difcours, com me le diable a pretendu vfurper pour foy le fer uice diuin, en faifant de la confeffion des peché (laquelle le Sauueur a inftituee pour le remed des hommes) vne fuperftition diabolique, pou leur grand dommage \& perdition. Et ne l'a pa fait moins à l'endroit de la gentilité du Iappon qu'à l'endroit de celle des Prouinces de Collar au Peru. 


\section{des Indes. Liure V. $\quad$ 25G}

De l'atominable onetion dont vfoient les Pres. fres Mexiguains of autres nations, of de leur fortileges.

\section{ChasITRE XXVI.}

aranam Ieu ordonna en la Loy ancienne, ân la façon comme l'on deuoit confa1)

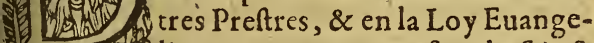
烈 Chrefme, \& onction, dequoy l'on vfe quand l'on nous facre Preftres de Chrift. Il y auoit mef. me en la Loy ancienne, vne certaine cúpofition odoriferante, que Dieu deffendoit d'employer en autre chofe qu'au feruice diuin. Le diable a voulu contrefaire toutes ces chofes à fa façon, cóme il a accouftumé, ayant inuenté à cefte fin des chofes fiordes, \& fi fales, qu’ellesmonftrent affez quel en eft l'Autheur. Les Preftres des idoles en Mexique, s'oignoient en cefte maniere. Ils s'oignoient le corps depuis les pieds iufqu'd la tefte, \& tous les cheueux aufi, lefquels leur demeuroient en forme de treffes reffemblans à des crins de cheual, à caufe qu'ils y appliquoient cefte onction humide \& moüillee. Les cheueux leur croiffoient tellement auec le temps, qu'ils leur tomboient iufqu'aux iarets, fi pefans, quils leur donnoient beaucoup de peine à les porter, car ils ne les coupoient, ny tondoient point, jufqual ce qu'ils mouruffent, ou quason les en difpenfaft pour leus 


\section{Hiftoire naturelle}

grande vieilleffe, ou bien qu'on les employa: aux gouuernements \& autres offices honora bles en la Republique. Ils portoient leurs che uellures treffees; de fix doigts de long, \& 1 noirciffoient \& teignoient auec de la fumee d bois de pin, ou railine, pource que de tout antiquiré entr'eux, ç'a efté toufiours vne of frande qu'ils faifờent à leursidoles. Ex pour ce fte occafion elle eftoit fort eftimee \& reuerce Ils eftoient toufiours noircis de cefte teinture deptis les piedsiufquàla tefte, tellement qưil reffembloientà des Negres fort reluifants, \& celle-łà eftoir leur ordinaire onction. Toutes fois quand ils alloient facrifier \& encenfer de dans les montagnes, ou aux fommets d'icel les, \& aux cauernés obfcures \& tenebreufes où eftoient leurs idoies, ils vfoient d'vne autre onction fort differente, faifont de certai nes ceremonies pour leur ofter la crainte, \& augmenter le courage. Cefte onction le fai. fort auec diuerfes beftiolles venimeufes, com. me d'araignees, de fcorpions, de cloportes, do fallemandres \& de viperes, lefquelles les garçons des Colleges prenoient \& amaffoient, quoy ils eftoient fi adroits, qu'ils en eftoien toufiours garnis, quand les Preftres leur en de. mandoient. Le principal foing \& foucy deces garçons, eftoit d'aller à la chaffe de ces beftiolles: quesilsalloient autre-part, \& que dauanture ils rencontraffent quelqu'vne de ces beftiolles, ils s'arreftoient à la prendre, auec autant de peine, comme fi leur propre vie euft defpendu de cela. A raifon dequoy les Indiens 


\section{des Indes. Liure. V.}

lè craisnoient point ordinairement ces betiolles venimeufes, n'en faifans non plus d'etat, que fi elles ne l'euffent point efté, d'autant ju'ils auoient tous efté nourris en cót exercie. Pour faire cét vnguent de ces beftiolles, ils es prenoient toutes enfemble, \& les bruf-s oient au foyer dú temple, qui eftoit deuant 'aut $\in 1$, iufques à ce qu'elles fuflent reduittes en endre, puis les mettoient en des mortiers auec seaucoup de $T$ auaco, ou betũ (qui eft vne bere, dont cefte nation vfe pour endormir la chair, \& pour ne fentir point le trauail) auec lequel Is mesloient ces cendres, quileur faifoit perdre a force.Ils mettoient mefme auec cefte cendre, quelques fcorpions, araignes \& cloportes viies, meslans \& amaflans le tout enfemble, puis ls y mettoient d'vne femence toute moulliie, qu'ils appelloient Ololuchqui, dequoy les Inliens font vn breuuage, pour voirles voifins, l'autant que l'effect derefte herbe eft d'ofter, priuer l'homme du fens. Ils moulloient mefne auec ces cendres, des vers noirs \& velus, defquels le poil feulement eft venimeux, \& amaíloient tout cela enfemble auec du noir, ou fumee de rezine, le mettans en des perits pots, lefquels ils pofoient deuant leur Dieu, difans que c'eftoit là leur viande. C'eft pourquoy ils appelloient cela, manger diúin. Par le moyen de cét oignement ils deuenoient forciers, \& voy oient, \& parloiét aux diables. Les Preftres eftans barboüillez de cefte pafte, pexd oiét toute crainte, prenans en eux vn ef prit de cruauté. A rain. fon d squoy ils tueient les hommes aux factifi: 


\section{Hifoire naturelle}

ces fort hardiment, \& alloient de nuict to feuls aux montagnes $\&$ dedans les cauernes ot fcures, mefprifans les beftes fieres, \& tenas pour certain \& approuve, que les lyons, tigre ferpens, \& autres beftes furieufes qui s'enger drent aux montagnes \& forefts, fenfuyroies d'eux, par la vertú de ce betum de leur Dieu. à la verité, fi ce betum ne les pouuoit faire fuy: c'eftoit chofe fuffifante pour ce faire, que pourtraict du diable enquoy ils eftoient tran formez. Ce betum feruoit mefme pour guar. les malades \& les enfans, parquoy tous l'appe loient, la medecine diuine, \&ainfi de toutes par venoient-ils par deuers les dignitez \& Preftre: -comme vers leurs Sauucurs, à fin qu'ilsteur ap plicaffent la medecine diuine, \& Tes oignoier d'icelle, par les parties deullantes. Ils affermer qu'ils fentoient par ce moyen vn notable allege ment, ce quideuoit eftre à caufe que le Taua co,\& Ololuch qui, ont d'eux mefmes cefte pro prieté d'endormir la chair, eftans appliquez e façon d'emplaftre, ce qu'ils doiuentoperer, plus forte raifon, eftans meslez auec tels poifon Et pource quil leur amortiffoit , \& appaifoit douleur, il leur fembloit que ce fuft vn effect $d$ fanté, \& de vertu diuine. C'eft pourquoyi accouroient à ces Preftres, comme à des hom mes faints, lefqucls entretenoient en cét erreu \& esblouyffement les ignorans, leur perfuadar ce qu'ils vouloient, \& les:faifans venir à leu medecines; \& ceremonies diaboliques, pare qu'ils auoient telle authorité, qu'il fuffifo güils le diffent, pour. lo faire tenir, eomme ar 
des Indes. Liure. V. tricle de foy. Et ainfils faifoient parmy le vulgaire mille fuperftitions, en la façon d'offrir lencens, en la façon de leur couper les cheueux, enaattachant de petites buchettes au $\mathrm{col}_{\text {, }}$ $\&$ des filets auec des petits os de couleuures, leur commandant qu ils fe baignaffent à certaine heure, qu'ils veillaffent de nuict au fouyer, de peur que le feu ne s'eftaignift, qu'ils ne mangeaffent point d'autre pain que celuy qui auoit efté offertà leur Dieu, qu'ils fe retiraffent en leur befoing incontinent par deuers les forciers, lefquels auec certains grains iettoient les forts $\&$ deuinoient, regardans en des cuues, \& poölles pleines d'eau. Les forciers \& miniftres du diable auoient accouftumé mefme d'embadurnofer beeaucoup. Et eft vne chofe infinie de la grande multitude quil y a eüe de ces deuins, fortilleges, enchanteurs, deuineurs $8 x$ autres fortes de faux prophetes. Auiourd' huy il refte encor de cefte peftilence, quoy qu'ils. fe, tiennent fecrets \& couuerts; ' n' ofans ouuerte ment exercer leurs facrileges, \& diaboliques ceremonies, \& fuperftitions, mais leurs abus \& malefices font defcounuerts plus au long, \& particulierement aux confefsionnaires faits par les Prelats du Peru. Il y a vn genre de forciers entre les Indiens permis par les Roys Inguas, qui font comme deuins, lefquels prennent vne telle forme \& figure qu'ils veulent, allans \& faifans par l'air beaucoup de chemin en fort peu de temps, \& voyent ce qui fe paffe. Ils, parlent auec le diable, lequel leur refoond en de certaines pierres, ou autre $\mathrm{Kk}$ if 


\section{Hiftoire naturelle}

chofes qu'ils vencrent beaucoup. Ils fe feruét de deuins, \& pour dire ce qui fe paffe en des licux les plus esloignez, auant que la nouuelle en vienne ou puiffe venir. Comme mefme il eft encor arriué depuis que les Efpagnols y font, qu'en diftance de plus de deux ou trois cens lieies, lion a fceu les mutineries, les batailles, les rebellions, les morts, tant des tyrans, comme de ceux qui eftoient du cofté du Roy, \& des perfonnes particulieres, ce que l'on a f̧̧eu du mefme iour que les chofes arriuerent, ou bien le iour enfuy yant, qui eftoit chofe impofsible, felon le cours de nature. Pour faire cefte diuination, ils fe mettent en vne maifon fermee pardedans, \& s'enyurent iufques à perdre le iugement, pirs vn iourapres ils refpondent à ce que l'onleur de mande. Quelques vns afferment qu'ilsvfent de certaines onctions. Les Indiens difent que les vieilles exercent ordinairement cét office de fortileges, \& particulierement celles d'vne Prouince, qu'ils appellent Coaillo, d'vne autre ville, a ppellee Manchey, \& de la Prouince de Guarochiri. Ils enfeignent mefme où font les chofes perduës \& defrobees. De toutes ces fortes de forciers, il y en a eu en tous endroits, vers lefquels viennent ordinairement les Anaconas, \& Cyuas, quif feruent aux $E$ fpagnols quand ils ont perdu quelque chofe de leur maiftre, ou qu'ils defirent f̧auoir quelque fuccez des chofes paffees, ou aduenir. Comme quand ils defcendene \& vont aux Citez des Efpagnols pour leurs affaires particulieres, ou pour tes publiques, ils leurs deriandent fi le ur voyage fe portersbien, 


\section{des Indes. Liure $V$.}

fils feront malades, s'ils mourront, ou retourneront Fains's'sils obtiendront ce qu'ils pretendent; $\&$ les forciers, ou deuineurs rel pondent, ouy, ou non, ayans premierement parlé auec le diable, en vn lieu obfcur, de maniere que ces Anaconas oyent bien le fon de la voix, mais ils ne vvoyent pasà qui les deuins parlent, ny n'entendent pas ce qu'ils difent. Ils font mil ceremonies \& facrifices pour cét effect, auec lefquels ils inuoquent le diable, \& fenyurent brauement. Et pour ce faire, ils vfent particulierement d'vne herbe, appellee Villea, le fuc de laquelle ils mettent dedansle Chica, ou le prënent d'autre façon. L'on peutvoir en cecy,combien eft grand le mal' heur de ceux qui ont pour maiftres, les miniftres de. celuy-là, duquell'office eft de tromper. Et eft vne chofe approuuee, qu'il n'y a rien qui em pefche tant les Indiens de receuoir la foy du $S$. Euangile, \& de perfeuerer en icelle, que la communication de ces forciers qui ont efté, \& y font encor en tref-grand nombre, bien que parla grace du Seigneur \& diligence des Prelats, \& des Preftres, ils vont diminuant, \& ne font plus. fi preiudiciables. Quelques.vns d'iceux fe font conuertis \& ont prefché publiquement, defcouurans, \& blafmans eux-mefmes leurs erreurs \& tromperies, \& declaransleurs finefles 8 menteries, dequoy on a veu fortir des grands fruitts, comme mefme nous f çauons par lettres du Iappon, qu'il eft arriué de mefme en ces parties, le tout à la gloire $\&$ honneur de noftre Dieu \& Seigneur.

$\mathrm{K} k \mathrm{iij}$ 


\section{Hiftoire naturelle}

\section{Des autres ceremonies \& couftumes des Indiens, qui font femblables aux noftres.}

\section{Chapitre XXVII.}

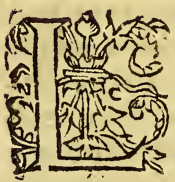

Es Indiens ont eu vn nombre infiny d'autres ceremonies \& couftumes, plufieurs defquelles re. fembloient à la loy ancienne de Moyfe, les autres à celle dont vfent les Mores, \& les autres a pprochoient de la loy Euangelique, comme les baings, ou Opacuna, qu'ilis appellent, qui eftoit qu' ils fe lauoient enl'eau, pour fe nettoyer de leurs pechez. Les Mexiquains auoient aufsi entr'eux quelque forte de baptefme, qu'ils faifoient auec ceremonie, qui eftoit qu' ils incifoient les oreilles \& le membre viril aux petits enfans noulueaux nez, contrefaifans aucunement la Circoncifion des Ituifs. Cefte ceremonie fe faifoit principalemét a l'endroit des fils de Roys, \& des Seigneurs. Incontinent a pres leut naiffance les Preftres les lauoiět, \& leur mettoiêt vne petito efpee à la main droitte, \& à la gauche vnerondelle, \& aux enfans du commun \& vulgaire, ils leur mettoyent les marques de leurs offices, \& aux filles des iniftrumens à filer, à tiltre, \& à trauailler. Et duroit cefte ceremonie quatre iours, quife faifoit deuant quelque idole. Ils contractoient leurs mariages à 


\section{des Indes. Liure V. 260}

eur mode, dont le Licêcié Polo a efcrit vn traité tout entier, \& en diray cy a pres quelque chofe. En autres chofes, mefmes leurs ceremanies \& couftumes auoient quelque apparence de raifon. Les Mexiquains fe marioient parla main de leurs Preftres en cefte façon. L'elpoux \& efpoufe fe mettoient enfemble deuant le Preftre, lequel les prenoit par les mains, \& leur demandoit s'ils fe vouloient marier, puis ayant entendu la volonté de tous deux, il prenoit vn coing du voile, dont la femme auoit la tefte couverte, \& vn autre coing dela robe de lhomme, lefquels il attachoit enfemble, faifant vn nœud, \& les menoit ainfi attachez à la maifon de l'éfpoufe, où il y auoit vn fouyer allumé, \& lorsil faifoit faire à la femme fept tours à l'entour de ce fouyer, puis les mariez fe feoient enfemble, \& par ce moyen eftoit contra\&téleur mariage. Les Mexiquains eftoient tref-ialoux de l'integrité de leurs femmes \& efpoufes, tellement que s'ils s'apperceuoient qu'elles ne furfent tellesqu'elles deuoient eftre (ce qu'ils recognoiffoient par fignes, ou par paroles eshontees)ils le faifoient incontinent entendre aux peres \& parens de ces femmes, à leur granće honte \& deshonneur: parce qu' ils n'auoient pas bien prins garde fur elles. Mais ils honoroiènt \& eftimoient beaucoup celles qui conferuoient leur honnefteté, leur faifans des grandes feftes, $\&$ donnoient plufieurs prefents à elle $\&$ à fes parens. Ils faifoient pour cefte occafion des grandes offrandes à leurs Dicux, \& vn banquet folemnel en la maifon de la fermme, \& 1 in $\mathrm{kK} \cdot$ iiij 


\section{Hiftoire naturelle}

autre en la maifon de l'homme. Quand on le menoit en leur maifon, ils mettoient par m: moire tout ce que l'homme $\&$ la femme apportoient enfemble de prouifions de maifon, de terre, de ioyaux \& d'órnements, lequel me. moire chaque pere d'iceux gardoit par deuer: luy, pource que fi d'auenture ils venoient à fai. re diuorce (comme il eltoit ordinaire entr'eux) ne fe trouuans bien l'rnauec l'autre, ils partoient leursbiens, felon que chacun d'eux en auoit apporté, ayant chacun d'eux liberté en tel cas, de fe remarier auec qui bon luy fem. bleroit, \& bailloient les fillesà la femme, "\& à l'homme les fils. Ils leur deffendoient expreffëment, fur peine de mort, de fe remarier enfemble, cequils obferuoient fort rigoureufe. ment. Et iz̧̧oit qu'il femble que plufieurs de leursceremonies s'accordent auec los noftres, neantmoins elles font fort differentes, pour le grand meslange d'abamination qui y eft touriours. C'eft vne chole commune \& generale en icelles, qu'il y a ordinairement vne de ces trois chofes, ou de la cruauté, ou de l'ordure, ou dala pareffe : car toutes leurs ceremonies eftoient cruelles \& dommageables, comme de tuer les hommes, \& de refpandre le fang : ou elles eltoient ordes \& fales, comme de boire \& de manger au nom de leurs idoles, \& d'vriner mefme en leur honneur, les portans fur leurs efpaulles, de s'oindre \& barboüiller fi laidement, \& de faire mille autres fortes de vile. nies, qu eftoient pour le moins vaines, ou ridi. cules \& oyfeufes, \& qui reffembloient plus au: 


\section{des Indes. Liure. V. 261}

res d'enfans, que d'hommes. La caufe deceเ,eft la propre condition de l'efprit malin, duuel lintention eft toufiours dreffee à faire ial, prouoquant les hommes à des homicides $z$ ordures, ou pour le moins à des vanitez $\&$ iccupations inutiles. Ce qu'vn chacun peut afez bien cognoiftre, en confiderant attentiuenent les actions \& comportemens du diable l'endroit de ceux qu'il va deceuant. Car en outes fesillufions l'on y trouue toufiours mefeeș toutes, ou quelqu'vne des cestrois chofes. ies Indiens merme depuis qu'ils ont la lumiee de noftre Foy, fe rient, \& fe moquent des olies $\&$ inepties, efquelles leurs Dieux leste roient occupez, \& aufquels ils feruoient beausoup plus, de crainte qu'ils auoient d'eux qu'ils ne leur fiffent du mal,' en ne lsur obeyffant point en toutescholes, que non pas pour lamour qu'ils leur portoient. Combien que quelques-vns, voire en grand nombre, vefquifient trompez \& deceus de vaines efperances des biens temporels : car d'eternels ils n'en auoient point cognoiflance. Et certainement lì ò̀ la puiffance temporelle s'elt plus agrandie, là s'eft plus accreii: \& augmentee la fuperftition. Comme l'on void aux Royaumes de Mexique \& de Cufco, où c'eft vne chofe incroyable que le nombre des adoratoires qu'il y auoit : veu que dans l'enclos de la Cité de Me. xique il y en auoit plus de trois cents. MangoIngua Yupanguy, entre les Roys du Cufco, a efté celuy qui a le plus augmenté le feruice de leus idoles, inuentant mille diuerfitez de fa: 
Hiftoires naturelle

crifices, feftes \& ceremonies. Autant en fit e Mexique le Roy If coalt, qui fut le quatriefn Roy. Il y auoit aufsi grand nombre de fuper ftitions \& facrifices en ces autres nations d'Ir diens, comme en la Prouince de Guatimalla, at Inles, au nouueau Royaume, en la Prouince Chillé, \& autres qui eltoient comme Republ ques \& C.ommunautez.Mais ce n'eftoit rien a refpect deMexique, \& de $\mathrm{Cufco}$,où fatan efto comme en fa Rome, \& en fa Hierufalem, iu: ques à ceq u'il ait efté ietté dehors contre fa vc lonté, \& ait efté pofee \& colloquee en fon lie la faincte Croix, \& que le Royaume de I E sv: C н R I t noftre Dieu ait occupé celuy que! tyranauoit vfurpé.

De quelques feftes.celebreespar ceux de Cuf o6 of comment le diable a voulu me/me imiter le myftere de la tres-faincte Trinitế.

ChaPITRE XXVIII.

00 Our conclure ce qui touche la Reli (1) gion, il refte de dire quelque chol So des fertes \& folemnitez que celebroien Ies Indiens, lefquelles pource quelles fon diuerfes, \& en grand nombre, ne pourron pas eftre toutes racontees. Les Inguas Seigneur du Peru auoiët deux fortes de feftes, les vnes qu eftoient ordinaires \& qui efcheoient en certain mois de l'annee, \& d'autros extraordinaires, qu 


\section{des Indes. Liure. V.}

aifoient pour caufes occurrentes $\&$ d'impor ice, comme quandl'on couronnoit quelque umeau Roy, quãd l'on commençoit quelque erre dimportance, quand il y auoit quelque ande necefsité d'eaüe, ou de fechereife, ou utres chofes femblables. Pour les feftes ordiires, l'on doit entendre que chaque mois de $n$, ils faifoient des feftes \& facrifices differents, encor que tous euffent cela de femblable, que in y offroit cens moutons, toutesfois en la couir, \& en la forme les moutons deuoient eftre It differents, Au premier moisqu' ils a ppellent ayme, qui eft le mois de Decembre, ils faiient la premiere fefte qui eftoit la principale toutes, \& pour cefte occafion ils l'appelloient apacrayme, qui eft à dire, fefte riche ou prinpale. En cefte fefte l'on offroit vn grand nome de moutons \& d'agneaux en facrifice, \& $s$ brusloit-on auec du bois taillé \& odorifent, puis ils faifoient apporter de l'or \& de l'ar nt deffus certains moutons, \& mettoient les oisftatuës du Soleil , \& les trois du tonnerre, pere, le fils, \& le frere. En ces feftes l'on deioit les enfans Inguas, en leur mettant les Guais ou enfeignes, \& leurs perçoient les oreil. s, puis quelque vieillard les fouëttoit auec des indes, \& leur oignoit le vifage auec du fang, : tout en figne quils deuoient eftre Cheualiers yaux de l'Ingua. Nul eftranger ne pouuoir tre en $\mathrm{Cufco}$, durát ce mois \& cefte felte, mais ir la fin ils y entroient, \& leur donnoit on alors e ces morceaux de mays, auec du fang du facrice, quills mạngeoient en figne de cófederation 


\section{Fiftoire naturelle}

auec l'Ingua, comme il a efté dit cy-deffus.C yne chofe eftrange que le di je felon fa mc ait mefme introduit, en l'idolatrie, vne Trini carlestrois fatuës du Soleil, eftoient appell A pomti, Churiinty, \& Intiquaoquy, qui fig. fie le pere \& Seigneur Soleil, le fils Soleil, \& frere Soleil, de la mefme façon ils nommoic lestrois ftatuës de Chuquilla, qui eft le $\mathrm{Di}$ qui prefide en la region de l'air,où il tóne, ple \& neige.Il me fouuient qu'eftant en Chuquif ca, vn Preftre honorable me monftra vne formation, que i'euz affez long temps en mesmains, où il eftoit prouué qu'il y auoit certain Guaca, ou oratoire, où les Indiens ad roient vn idole, nommé Tangatangã, laque. ils difoient eftre vne en trois, \& trois en vr Et comme ce Preftre eftoit emerueillé dece ie luy dy que le diable, par fon infernal $\&$ obl né orgueil, par lequel il pretend toufiours faire Dieu, defroboit tout ce qu'il pounoit la verité, pour l'employer à fes menfonges, tromperies. Reuenans donc aux feftes du ft cond mois, qu'ils appellent Camey, outre ! facrifices qu'ils faifoient, ils iettoient les cendr aual vn ruiffeau, allans cinq, ou fix lieuies apre auec des bourdons, ou baftons, le priant qu les portaft iufques à la męr, pour autant que Viracocha y deuoit receuoir ce prefent. A troifiefme, quatriefme, \& cinquiefme mois, offroient cent moutons noirs meslez, \& gri auec beaucoup d'autres chofes, que ie laife, peur d'eltre ennuyeux. Le fixiefme mois s'ap pelle Hatuncuzquy A ymorey, qui refpond 


\section{des Indes. Liure. V. $\quad{ }_{2} 6_{3}$}

ay, auquel l'og facrifioit cent autres moutós toutes couleurs, en cefte Lune, \& mois , qui quand l'on apporte le Mays des champs en naifon, lon faifoit la fefte qui eft encor auurd'huy fort en vfage entre les Indiens \&t ppellent Aymorey. Cefte feftefe fait en veit depuis la Chacra, ou metairie iufques à la ifon, difans certaines chanfons, où ils prient e le Mays puife durer long temps, \& l'appelIt, Mamacora. Ils prennent certaine portion plus fecond Mays, du creu de leurs metais,lequelils mettent en vn petit grenier qu'ils pellent Pirua, auec certaines "ceremonies, illants tiois nuizts, \& mettent ce Mays dans plus riches habits qu'ils ayent, $\&$ dés qu'il ainfi enueloppé \& accummodé, ilsadorent fte Pirua, \& l'ont en grande veneration, dints que c'elt la mere du Mays de leurs heritas, \& que par ce moyenle Mays augmente, \& conferue. En ce moisils font vn facrifice parculier, \& les forciers demandent à la Pirua,fi le a de la force affez pour durer iufques : In à venir, $\&$ fi elle ref pond, que non, ils pornt le mays brusler à la metairie, d'où ils l'ont 'porté, felon la puiffance d'vn chacun, apres ; font vne autre l'irua, auecles mefmes cereonies, difans quils la renouuellent, afin que femence du Mays ne periffe, \& fi elle refpond u'elle a de la force affez, pour durer d'auange, ils la laiffent iufqueș a l'autre année. Cefte tte vanité dure iufques auiburd'huy , $\&$ ' eft rrt commune entre les Indiens, d'auoir ces iruas, \& faire lä fefte d'A ymorey. Le feptieime 


\section{Hiftoire naturelle}

mois refpond à Iuin, \& s'appelle Aucaycuzic Intiraymy. En iceluy ils faifoient la fefte app lee Intiraymy, oú l'on facrifioit cent moutc guanacos, \& difoient que c'eftoit la fefte du : leil : en ce mois ils faifoient vn grand nom de ftatuës de bois de quinua taillé, toutes ftuës de precieux habits, \& fe faifoit le qu'ils appelloient Cayo. Encefte feftel'on pandoit beaucoup de fleurs par le chemin, y. venoient les Indiens, fort barboüillez, les Seigneurs y eftoient ornez auec des pet: platines d'or à la barbe, \& chantoient to $\&$ doit-on fçauoir que cefte fefte tombe qi fi au mefme temps, que nous autres Chreft: faifons la folemnité au fainet Sacrement, luy reffemble en quelque chofe, comme a dances, chants \& reprefentations: Et pour fte raifon, il y a eu, \& a encor entre les I diens ( lefquels celebroient vne fefte aucur ment femblable à celle que nous celebions fainct Sacrement ) beaucoup de fuperftitic a celebrer cefte fefte ancienne de l'Intiraym Le huictiefme mois eft appellé, Chahưa, $\mathrm{Hu}$ quy, auquel ils brusloient cent autres moutor tous gris, de couleur de Vizcacha, felon l'ord fufdit, lequel mois ref pond à noftre Iuillet: ] neufiefme mois sappelloit Yapaguis, auqu l'on brusloit cent autres moutons, de coule de chaftaigne, \& couppoit - on la gorge, $\&$ br loit-on aufsi mil Cuyes, afin que la gellee, 1 l'eau, ny l'air, ny le Soleil ne fiffent aucun m aux metairies, \& refpond ce mois à l'A ouft. I dixifme mois s'appelloit Coyaraymy, auqu 


\section{des Indes. Liure. V.}

on brusloit cent autres moutons blancs, qui toient vellus. En ce mois, qui refpond à Sepmbre, l'on faifoit la fefte appellee Situa, en : Ate forme. Ilss'affembloient le premier iour - la Lune, auant qu' elle leuaft, \& en la voyant ss'efcrioient hautemét, portans en leurs mains es flambeaux de feu, difans, que le mal s'en ille dehors, en s'entre frappans les vinsles aues, auec ces Hambeaux. Ceux qui faifoient ceis'appelloient Panconcos. Et a pres auoir ache és'en alloient en baing general, aux ruifleaux $\tau$ aux fontaines, chacun en fon propre eftang. fe mettoient à boire quatre iours durahs. En e mois les Mamacomas du Soleil faifoient rande quantité de petits pains, faits auec le ang des facrifices, \& en donnoient vn morceau chacun des eftrangers, \& forains, mefme ils en nuoyoient aux Guacas, eftrangers, de tout le oyaume, \& à plufieurs Curacas, en fịne de onfederation, \& loyauté,au Soleil \& à l'Ingua, omme il a efté jà dit. Les baings, yurogneries; $x$ quelque reftes de cefte fefte Situa, demeurent incor auiourd'huy en quelques endroits, auec lesceremonies quelque peu differentes, ce qui if fecretement toutesfois, parce que ces fetes principalles, \& publicquies ont ceffé. L'vniefme mois, Homaraymy Punchaiquis, auquel

ils. facrifioient cent autre moutons. Et s'ils auoient faute d'eaüe pour vn remede, \& à fin de faire pleuuoir, ils mettoient vn mouton tout noir, attaché au milieu d'rne plaine efpandant beaucoup de Chica tout au tour de luy, \& ne luy donnoient point ì manger, iufques à ce qu'il 


\section{Hiftoire naturelle}

pleuft, ce qui eft encor praticqué aujourd he en plufieurs endroits, en ce mefme temps $q$ eft Octobre. Le douziefme, \& dernier me s'appelloit Aymara, auquel l'on facrifioit ce: autres moutons, \& faifoient la fefte appell Raymicantara Rayquis. En ce mois qui ree $p e$ à Nouembre, l'on a ppareilloit ce qui eftoit nn ceffaire pour les enfans qui fe deuoient faire $n$ uices le mois enfuiuant, \& les enfans auec! vieillards faifoient vne certaine monftre aut quelques tours, \& cefte fefte eftoit a ppellée It raymi, laquelle fe fait ordinairement quand pleut trop, ou trop peu, ou qu'il y a de la peft lence. Entre jes feftes extraordinaires, qui eftoient aufsi en grand nombre, la plus fame fe eftoit celle quils a ppelloient Ytu. Cefte $f_{0}$ fte Ytu n'auoit point de temps, ny de faifon a reftée, autrement, que en temps de necefsit Pour fe preparer à icelle, tout le peuple jeu noit deux iours durants, aufquels ils ne tor choient point à leurs femmes;ny ne mangeoier point de viande auec le fel, ny ail, \& ne beuuoie point de Chica. Tous s'affembloient en yn place, où iln'y auoit aucun eftranger, ny aucu animal, \& auoient de certains habits \& orne ments, qui feulement feruoient pour cefte fe fte. Ils marchoient en procefsion fort douce ment, lesteftes couuertes de leurs voiles, bat tans des tambours fans parler l'vn à l'autre. Cel. duroit vn iour \& vne nuiet, puisle iour enfui uant, ils danfoient, \& faifoient bonne chere, pa deux iours \& deux nuits continuellement, di fans que leur oraifon auoit efté acceptée. E 


\section{des Indes. Liure V. $\quad 265$}

ncor que cefte felte ne fe faffe auiourd'huy uec toute cefte ceremonie ancienne, fi eft-ce ue cổmunement ils en font vne autre, qui eft ort femblable, laquelle ils appellent Ayma; uec des veftemens qui feruent feulement à cét ffect, \& font cefte maniere de proceffion auec eurs tambours, ayans auparauant ieufné, puis pres fe mettent à faire bonne chere; ce quils int de couftume de faire en leurs vrgentes neeffire $z_{\text {E }}$ Er combien queles Indiens ayent deaiffé en public de facrifier des beftes, \&z autres hofes qui nefe peuuent cacher des Efpagnols, teantmoinsils fe feruent toufiours de plufieurs eremonies qui ont leur origine de ces feftes $\& t$ uperftitions anciennes. Car ils font encor auourd'huy counertemét cefte fefte de l'Y tu aux lances de la fefte du Sacrement, en faifans les lances de Lyamallama, \& de Guacon, \& d'aures felon leur ceremonie anciếne, à quoy l'or loit bien regarder de pres. L'on a fait des traitez plus amples de ce qui concerne cefte matie. e, pour les lieux où il eft receffaire rèmarquer es abus \& fuperftitions qu'auoient les Indiens ors de leur gentilité, afin que les Preftres \& Curez y prennent garde. Suffife donc à prefent t'auoir traitté de l'exercice,auquel le diable ocupoit fes deuots, afin que contre fá volonté 'onvoye la differencequ'il y a de la lumiere aux enebres, \& de la verité Chreftienne, au menonge gentil, quoy que liennemy de Dieu \& des hómes ayt tafché auec tous les artifices de zontrefaire les chofes de Dieu. 


\section{Hiftoire naturelle}

\section{De la fefte du Iubilé que celebroient les Mexiquains.}

Chapitre XXIX.

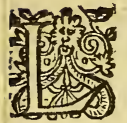

Es Mexiquains n'ont efté moíns cu rieux en leurs feftes \& folemnitez, le: quelles eftoient de peu de defpent de biens, mais d'vin gräd couft de fan humain. Nous auonscy deffus parlé de la fert principale de Vitzilipuztli, apres laquelle la fe fte de Tezcalipuca eftoit la plus folemnifee Cefte felte tóboic enMay, \& en leur Kalendrie ils l'appelloient Toxcolt, elle efcheoit de qua tre ans en quatre ans auecla fefte de penitence où il y auoit planiere indulgence $\&$ pardon de pechez. En ce iour ils facrifioient.vn captif, qu auoir la femblance de l'idole Tezcalipuca, qu eftoit le 19. de May. En la veille de cefte felte les feigneurs venoient au téple, \& apportoien vnveftement neuf, femblable à celuy de l'idole lequel les Preftresluy veftoient, luy ayans pre mierement ofté les autres habits, lefquels il gardoient auec autãt ou plus de reuerence qu nous faifons les ornemens. Il y auoit aux coffre de l'idole plufieurs ornemés, ioyaux, affi quets $\&$ autresricheffes, de bracelets, de plumes pre cieufes, qui ne feruoient d'autre chofe que d'e. Atre là, \& adoroient tout cela comme le mefme Dieu. Outre le veftement, auec lequel ils adoroient l'idole ce iour-lat, ils luy mettoient do 
Des Indes. Liure V. 266

zertaines enfeignes de plume, des garde. Folells; des ombrages, \& autres chofes: l'ayans ainfif reueftu $\&$ orné, ils oftoient la courtine ou voile de la porte, afin qu'il fuft veu de tous; \& alors Cortoit vne des dignitez du Temple, veftu de la mefme façon que lidole, portant des fieurs en la main, \& vne petite fufte de terre, ayant vn fon fort aigu, \& re tournant du cofté de l'Orient, il la touchoit, puis rctourné vérs l'Occident, le Nort \& le Sud, il faifoit le feminblable: Et apres auoir ainfi fonné vers les quatre parties du monde (denotant que les prefens \& ab(ens l'oyoient) il mettoit le doigt en l'aire, \& cueillant de la terre d'icelle, la mettoit en fa bouche, \& la mangeoit en ligne d'adoration. Autant en faifoient tous ceux qui y eftoient prefens, \& en pleurans fe profternoient, inuoquans l'obfcurité de la nuict \& les vents, les prians qu'ils ne les delaiffaffent, ny oubliaffent point, ou bien qu'ils leur oftaffent la vie, pour donner fin à tant de trauaux quils enduroient en icelle. Les larrons, les fornicateurs, les homicides, \& tous les autres delinquans auoient grande crainte \& trifteffe en cux peridant que cefte flufte fonnoit : tellement que quelques uns ne pouuoient diffimuler, ny cacher leurs delicts. Par ce moyen tous ceux-là ne demandoient autre chofe à leur Dieu, finon que leurs delicts ne fuffent point manifeftez, ef́pandans beaucoup de larmes, \& a tiec vne grande repentance \& regret, offroient quantité dénéns pour appaifer leurs Dieux. Les hommes colntageux \& vaillans, \& tous les vieux foldat 


\section{Fiftoire naturelle}

gui fuiuoient l'art militaire, en oyant cefte fli:fte demandoient auec vne grande deuotion a Dieu le Createur, au Seigneur pour lequel nous viuons au Soleil, \& à d'autryes leurs Dieux, qu'ils leus donnaffent victoire contre leurs ennemis, \& des forces pour prendre beaucoup de captifs, afin d'honorer leurs facrifices. La ceremonie fufdite fe faifoit dix iours auparauant la fefte, pendant lefquels dix iours le Preftre fonnoit cefte flufte, afin que tous fiffent cefte adoration de manger de la terre, \& de demander à leur idole ce quils voudroient, \& faifoient chaque iour oraifon, les yeux hauffez au Ciel, auec des foulpirs \& gemiffemens, comme perfonnes qui fe contriftoient de leurs fautes \& pechez. Iaçoir que cefte contrition ne fuft que par crainte de la peine corporelle que l'on leur donnoit, \& non pas pour crainte de l'eternelle, parce qu'ils crøyoient pour certain qu'il n'y auoit point de peine fi eftroitte en l'autre vie. C'elt pourquoy ils s'offroient à la mort volontairement, ayans opinion que c'eftoit à tous vn repos affeuré. Le premier iour de la fefte de cét idole Tezcalipuca eftant venu, tous ceux de la Cité s'affembloient en vne court pour celebrer auffi la fefte duKalendrier, dont nous auons parlé, qui s'appelloit Toxcoalth, qui fignifie chofe feche : laquelle fefte ne fe faifoit à autre fin, que pour demander de leau en la façon que nous autres folemnifons les Rogations: \& ainfi cefte fefte eftoit toufiours en May, qui eft le temps que l'on a plus faute d'eau en ce pays-là. L'on commençoit aे 


\section{des Indes. Liure $V$.}

la celebrer le neufiefme de May, finiffant le dixneufiefme. Le dernier iour de la fefte au ma. tin, les Preftres tiroient vn branquart ou littiere, fort bien ornee de courtines, \& de fandos de diuerfes.façons. Ce branquart auoit autant de bras \& tenons, quilil y auoit de miniftres qui le deuoient porter. Tous lefquels fortoient barboüillez de noir, les cheueux longs, treffez par la moitié auec des lizets blancs, \& veftus de la liuree de lidole. Deffus ce branquart ils mettoient le perfonnage de lidole, depuré pour cefte fefte, quils appelloient, femblance du Dieu Tezcalipuca, \& le prenans fur leurs efpaules, le riroient en public au pied des degrez, \& incontinent fortoient les ieunes hommes, \& les filles reclufes. de ce temple, portans vne groffe corde torfe de chaifnes de mays rofty, auec laquelle ils enuironnoient le branquart, \& mettoient ats col de lidole vne chaifne de mefme, \& en la tefte vne guirlande. Ils appellent la corde Toxcalt, denotant la fechereffe, \& fterilité du temps. Les ieunes hommes fortoient entourez auec des courtines de red, des guirlandes, \& des chaifnes de mays rofty. Les filles eftoient veftuës d'habits \& ornemens tous. neufs, portans au col des chaifnes de mays rofty, \& en leurs teftes des Tyares faittes de vergettes toutes couvertes de mays. Ils auoient les pieds couverts de plumes, \& les bras \& ioués colorees de fard. Ils apportoient auffis beaucoup dece mays rofty, \& les principaux fe les mettoient à la tefte \& au col, prenans Ll 1 iij 


\section{Hifioire naturelle}

des fleurs en leurs mains. Apres que lidole eftoit mis en fon branquart \& littiere, ilsfe: moient par tout au tour grande quantité de tameaux de manguey, les feüilles duquel font larges \& efpineufes. Ce branquart mis fur les efpaules des deffurdits Religieux, ils le portoient en proceffion par dedans le circuit de la court, $\&$ deux Preftres marchoient deuant auec des brafiers ou encenfoirs, encenfans fort fouuent lidole, \& chaque fois qu'ilis mettoient l'encens, ils hauffoiens le bras/le plus haut qui ils poutuoient vers lidole \& vers le Soleil, leur difans quils efleuaffent leurs oraifons au Ciel, comme cefte fumee s'efleuoit en haut. Alors tout le peuple qui eftoit en la court, alloit \& $\mathrm{fe}$ rournọit en rond vers le lieu où alloir l'idole, portans tous en leurs mains des cordes neuues de fil de manguey, d'vne braffé de lóg, ayans vn neud au bout, \& auec icelles fe difciplinoient s'en donnans de grands coups fur les efpaules, de la façon que l'on fe difćipline en Efpagne le Ieudy faint. Toute la muraille de la court $\&$ les creneaux eftoiết pleins de rameaux\& de fleurs, fi bien ornez, \& auec telle fraifcheur, qu'ils donnoient vn grand contentement. Cefte proceffion eftant acheuee, ils rapportoient lidole au lieu où il auoit accouftumé d'eftre: puis apres venoit vne grande multitude de peuple auec des fleurs'accômodees de diverfes façons, dont ills rempliffoient le téple \& toute la court, de forte quill fembloit ornement d'oratoire. Tout cela eftoit accommodé \& mis en ordre partes mains des Preftres, les ieunes hommes pat 


\section{des Indes. Liure V.}

268

in Temple leur baillant, \& feruant ces chofes te dehors. La chapelle ou chambre de l'idole temeuroir ce iour là defcounerte fans y mettre levoile. Cela fait chacun venoit offrir des courrines, des fandaux, des pierres precieufes, des ioyaux, del'encens, du bois gommeux, des grapes, ou efpics de mays, descailles, \& finalement tout ce quils auoient accouftumé d'offrir en telles folemnitez. Quand ils offroient ces cailles, (qui eftoil l'offrande des pauures) ils faifoient cefte ceremonie, qu'ils les bailloient aux Preftres, lefquels les prenans, leur arrachoient la tefte, \& auffi toft les ietroient aux pieds de l'autel, où ils perdoient leur fang, \& autant en faifoient-ils des autres quils offroient. Chacun offroit felon fon poutuoir, d'autres viandes, \&x fruits lefquels eftoient aux pieds de l'Autel des miniftres du Temple, \& eftoient ceux quiles recueilloient, \& les portoient en leurs chambres. Cefte folemnelle offrande faite, le peuples'en alloit difner chacun en fon bourg \& en fa maifon, laiffans ainfi la fefte fufpenduë, iufqu'apres difner. Pendant ce temps les ieunes hómes \& filles du Temple, auecles ornements - fufdits s'occupoient à feruir l'idole de tout ce qui luy eftoit dedié pour fon manger. Laquelle viande eft oit appreftee par d'autres femnes qui auoient fait vœu de s'occuper ce iour-la à faire le manger de lidole, \& d'y feruir tout le iour. C'elt pourquoy toutes celles qui auoient fait le vœu,venoiết au point du iour, soffrans aux deputez du Temple, a fin qu' ils leur cómandaffene ce qu'elles deuoient faire, \& l'accompliffoien

II iij 


\section{Hiftoire naturelle}

fort diligenment. Elles faifoient \& appreftoiế tant de diuerfités \& inuentions de viandes, que $c^{\prime} \in$ ftoit vne chofe admirable. Cefte viande eftă accómodee, \& l'heure du difner venuë, toute: ces filles fortoient du Temple en proceffion, chacune vn petir panier de pain en la main,\& en l'autre vn plat de ces viandes, \& marchoir deuant elles vn vieillard qui feruait de maifte d'hoftel, auec va habit affez plaifant; il eftoit veftu d'vin furplis blanc, qui luy venoit iufqu'au mollet des iambes, fur vn pourpoint fans manches, de cuir rouge, à la façon d'vne tunique. Il portoir des aifles, au lieu de manches, d'où fortoient des lifets larges, aufquels pendoit fur le milieu des efpaules, vne moyenne callabaffe ou citroüille, qui eftoit toute remplie, \& couuerte de fleurs, par des petits trous qui y eftoiêt, \& au dedans y auoit plufieurs chofes de fuperftition. Ce vieillard marchoir ainfi accommodé deuant l'appareil, fort humble, \& trifte, ayant la tefte bailfee, \& en approchant du lieu qui eftoit au pied des degrés, il faifoit vne gran. de humiliation \&z reuerence, puis fe retirant d'vn cofté, les filles s'approchoient auec la viande, \& l'alloient prefenter de rang , \& par ordre les vnes apres les autres, auec beaucoup de reuerence. Puis ayans prefenté toutes ces viandes, le vieillard s'en retournoit comme deuant, $\&$ remenoir les filles en keur Conuent. Cela fait, les ieunes hommes \& miniftres de ce Temple fortoient, \& recueillaient cefte viande, la quelle ils portoient aux chambres des dignitez 8. Prẹtres du Temple defquels auoient ieufné 
des Fndes. Liure $V$. irl'efpace de cinq iours, mangeans feulemene ze fois le iour, \& f'eftoient abltenus de leurs mmes, fans fortir du temple, durant ces cinq urs, pendant lefquels ils fe foittoient rigouufement auec descordes, \& mangeoient de efte viande diuine (ainfi l'appelloient-ils) tout : qu'ils pouuoient, \& n'eftoit licite à aucun 'en manger, finond deux. Tout le peuple ayant cheué de difner, fe r'affembloit à la court pour elebrer \& voir la fin de la fefte, où ils faifoient enir vn captif, qui parl'efpace d'vn an auoit eprefenté l'idole, eftant veftu; orné, \& honoré omme le mefme idole, \&luy faifans tous reterence, le mettoient entre les mains des facriicateurs, lefquels fe prefentoient au mefme emps, \& l'alloient faifir par les pieds \& mains. .ePapa luy fendoit \& ouuroit l'eftomach, luy irrachant le coeur, puis hauffoit la main tane ju'il poutoit, le montrant au Soleil, \& à l'ido. e, comme il a efté dit cy deuant. A yans ainfi farrifié celuy qui reprefentoit l'idole, ils f'en aloient en vn lieu confacté, \& deputé pour cé offet, où arriuoient les ieunes hommes, \& filles du temple, avecles ornements fufdits, lefquels eftans mis en ordre, dançoient, \& chantoient Pentour des tambours, \& autres inftruments, dont les dignitez du temple ioüoient, \& fonnoient. Puis venoient tous les Seigneurs, ayans les mefmes enfeignes \& ornemens que les ieunes hommes, lefquels dançoient en rond aurour d'iceux. On né tuoit point ordinairement en ce iour d'autres hommes que le facrifié, toutefois de quatre en quatre ans feulement on en 


\section{Hifoire naturelle}

atroit d'autres auecluy, qui eftoit en l'an du I bilé \& indulgence pleniere. Apres le Soleil co ché, chacun eftant content de fonner, de mas ger $\&$ de boire, les filles f'en alloient toutes leur Conuent, \& prenoient de grands plats terre, pleins de pain paiftry de miel, qui eftoi couverts de perits paniers ouurez, \& façonn de teftes \& os de mort, \& portoient la collatic à l'idole, montansiufques à la court qui efto deuant la porte de l'oratoire, \& l'ayans polee $\epsilon$ ce lieu, elles defcendoient auec le mefme ord: qu'elles y auoient monté, le maifte d'hoftel a lant toufiours deuant. Incontinent fortoies rous les ieunes hommes en ordre, auec descar nes, ou rofeaux és mains, qui commençoient courir au haut des degrez du temple, à l'enu l'vn de l'autre, pour arriuer les premiers au plats de la collation. Cependant les dignitez $r$ marquoient celuy qui arriuoit le premier, $f$ cond, troifiefme \& quatriefme, fans faire eft du refte. Cefte collation eftoit auffi toft enleue par ces ieunes hommes, laquelle ils emportoie comme grandes reliques. Cela fait, les quatr qui premiers eltoient arriuez, eftoient mis a milieu des dignitez \& anciens du temple, auec beaucoup d'honneur les mettoient e leurs chambres, les loüans, \& leur donnans bons ornemens, \& delà en auant eftoient reue rez \& honorez comme hommes fignalez. L prinfe de cefte collation eftant acheuee, \& la fe ite celebree auec beau coup de refiouy ffance, \& de crierie, ils donnent congé à tous cesieune: hommes \& filles qui auoient feruy l'idole; at 


\section{des Findes. Liure $V$.}

syen dequoy ils fen alloient les vns apres les tres, au temps qu'elles fortoient. Tous les pesenfans des colleges \& efcholes eftoient à la rte de la court, auec des pelottes de ionc, \& ierbes aux mains, lefquelles ils leur iettoiene mocquans \& rians d'elles, comme de perfon$s$ qui fe retiroient du feruice de lädole, ils rto:ent auec liberté de difpofer de foy à leur lonté, \&z auec cela prenoit fin la felte.

De la fefte des marchands yue celebroient ceux de Cholutecas.

\section{Chapitre XXX.}

OM B IEN que jayeaffez cy def. A] 1 Gus parlé du feruice queles Mexi. quains faifoient à leurs dieux, fi eft-ce que ie diray encore quelque chofe de la fefte de celiry quils ap. elloient $Q$ uetzacoaalt , qui eftoit le dieu des ches, laquelle fe folemnifoit en cefte forme. Luarante iours auparauăt les marchands acheJient vn efclaue, bien fait, fans aucun vice, ny ache, tant de maladie, comme de bleffure, leuel ils veftoient des ornements de lidole, afin u'uil le reprefentaft quarante iours. Auant que le le veftir ils le purifioient, le lauant deux fois n vn lac quils appelloient, lac des dieux, \& presquilil eftoit purifié, ils le veftoient de melne que l'idole eftoit veftu. Il eftoit fort reueré, lurant quarante iours, à caufe de ce qu'il repreentoit. Ils l'emprifonnoient de nuifr, comme 


\section{Hiftoire naturille}

il a efté dir cy deffus, de peur qu'il ne f'enfury \& le matin le tiroient de la prifon, le mette en vn lieu eminent où ils le feruooient, en $l$ donnant d’manger des viandes exquiles. Ap qu'il au oit mangé, ils luy mettoient des chaif.t defleurs au col, \& beaucoup de bouquets a mains. 11 auoit fa garde fort accomplie, au beaucoup de peuple qui laccompagnoit, \& loit auec luy par la Cité.Il alloit chantát \& da çant par toutes les ruës, a fin d'eftre cogneu po Ia femblance de leur dieu, \& lors quil cos mençoit à chanter, les fermmes \& petits enfa fortoient de leurs maifons pour le falüer, 81 faire leùrs offrandes comme à leur dieu. De vieillards d'entre les dignitez du temple, v noient par deners luy neuf iours auparauant ferte, lefquels f'humilians deuant luy, luy foient d'vne voix fort humble \& baffe, $S$, gneur, tu dois fçauoir que d'icy à neufiours ? cheue le trauail de danfer \& de chanter : car lo tu dois mourir, \& il deuoit refpondre, que fuft à la bonne heure. Ils appelloient cefte cer monie Neyolo Maxiltleztli, quíveut dire l'a uertiffement ; \& quand ils l'aduertiffoient, prenoient garde fort attentiuement $f$ il fecos triftoit point, \& fil dançoit aúffi ioyeufeme que de couftume; que fil ne le faifoit auec v relle gayeré qu'ils defiroient, ils faifoient vr fotte fuperftition en cefte maniere. Ils f'en a loient incontinent prendre les razoirs des facr fices, lefquelsils lauoient, \& mettoient du fan humain qui y reftoit des facrifices paffez. Et $d$ ces laueures luy faifoient vn breauage men 


\section{des Indes. Liure $V^{5}$.}

:c vne autre liqueur faice de Cacao, \& luy nnoient à boire, \& difoient que ce breuuage jit telle operation en luy, quill lay feroit per: la memoire de tout ce qu'on luy auoir dit, que cela le rendroit prefque infenfible, \& re. urneroit aे fon chant \& gayeté ordinaire. Ils ent datrantage, quil fooffoit allegrement à ourir, eftant enchanté de ce breuuage. La caupourquoy ils tafchoient de luy ofter celte triine, eftoit, pour autant qu'ils tenoient cela ur vn mauuais augure, \& pour vn pronoltic quelque grand mal. Le iour de la fefte eftan: :nu, apres luy anoir fait beaucoup d'honneur, ianté la mufique, \& luy aroir prefenté l'enns, les Sacrificateurs fur la minuiat le preoient \& le facrifioient à la façon fufdite, fains offrande de fon cour a la Lune, lequel its troient apres contre lidole, laifant tomber le orps au bas des degrez du temple, où ceux qui auoient offert le releuoient, qui eftoient les sarchands defquels eftoit la fefte; puis l'ayant orté en la maifon du plus notable d'entr'eux, : faifoient apprefter en diuerfes faulfes, pour elebrer à l'aube du iour le banquet \& difné de a fefte, ay ans premierement donné le bon iour lidole, auec vn petit bal qu'ils faifoient penlant que l'aube fortoit, \& qu'on accommodoir e facrifié. En apres tous les marchands s'affemloient à ce banquet, fpecialement ceux qui aifoient le commerce de vendre \& acherer des efclaues, qui auoient en charge d'o ffrir par chacun an vn efclaue pour la ferablance de leur dieu. Cét idole eftoit yn des plus honorez de ce- 


\section{Fiffoire naturelle}

fte terte, comme iay dit, c'eft pourquoy le te: ple où il eftoit, eftoit de beaucoup d'authorit Il y auoit foixante degrez pour y monter, \& deffus d'iceux y auoit vne court de moyennel: geur, fort proprene ét accommodee \& plaftre au milieu de laquelle il y auoir vne grande pie ronde; en la façon de four, ayant fon entr baffe \& eftroite, tellement que pour y entrer falloit fe baiffet bien fort. Ce temple auoit $f$ chambres, ou chappelles comme les autres, 0 il y auoit des Conuents de Preftres, de ieun hommes, de filles \& d'enfans, comme il a eft dit, \& toutesfois il n'y auoit qu'vn feul P'reft qui refidoit continuellement là, \& eftoit com me fomainier : car combien qu'il y euft en cha cun de ces temples trois ou quatre Curez \& di gnitez, chacun y feruoit fa lemaine fans en for tur. L'office du femainier du temple (apres auoj endoetriné les enfans) eftoit de battre vn gran. tambour tous lesiours à heure que fe couchoi le Soleil, pour la mefme fin que nous auons ac couftumé de fonner l'oraifon. Ce tambou. eftoit tel, qu'on en entendoit le fon enroié d. toutes les parts de la Cité, alors vn chacun fer. roit fa marchandife, \& fe retiroit en fa maifon $\&$ y atioit vn fi grand filence, quill fembloit qu'sl n'y euft homm viuant dans la ville. Au matin, lors que l'aube du iour commençoit à fortir, il recommençoit à battre ce tambour, qui eftoit le figne que leiour commençoit, au moyen dequoy les voyagers \& forains s'arreftoient à ce fignal pour commencer leurs voyages, pource qu' il n'eftoit point permis iufques aे 
des Indes. Liure V.

272

: temps de fortir de la Ciré. Il y avoit en ce mple vne court de moyenne grandeur, en lauelle on faifoit de grandes dances \& refrouyfnces, auce des farces, ou entremets, le iour e la fefte de l'idole. Pour lequel effeet il y doit au milieu de cefte court vn petit theatre e trente pieds en quarré, fort propremét agen. , lequel ils accommodoient de feiillages pour iour, auec tout l'artifice \& $z$ gentillelfe qu'il thoit poffible, eftant tout enuironné d'arcades e dinerfes fleurs \& plumages, \& y tenoient at achez en quelques endroits beaucoup de perits yfeaux, connils, \& autres animaux paifibles. upres difner tout le peuple f'affembloit ence eu, \& les bafteleurs fe prefentoient, \& ioüoiét es farces; les vns contrefaifoient les fourds \& is enrumez, les autres les boiteux, les aueugles z les manchots, lefquels venoient demander uarifon à lidole. Les fourds refpondoient du oq a l'afne, les enrumez touffoient, les boieux clochoient, racontans leurs mifercs \& enuis, dequoy ils faifoient beaucou p rire le peule; les autres fortoient en forme de beftioles, es vns eftans veftus comme efcargots, les asres comme crapaux, \& d'autres coume lezards, uis fentre-rencontrans racontoient leurs off:es, \& fe retirans chacun de fon cofté, ils touhoient de periees fluftes, qui eftoir chofe plaiante à ouyr. Ils contrefaifoient mefme des $\mathrm{pa}$ jillons, \& des petits oyfeaux de diterfes coueurs, \& eftoient les enfans datemple quireprefentoient ces formes; puis ils montoient en vne petite foreft qui eftoit là plantee expres, ol 


\section{Hiftoire naturelle}

les Pieftres du temple les tiroient auee des fa bacanes. Er cependant ils fe difoient plufieu plaifans propos, les vins en attąquant, \& les a: tres en deffendant, dequoy les affiftans eftoier ioyeufement entretenus. Cela acheué, ils fa foient v $\mathrm{n}$ bal, ou mommerie auec tous ces pel forfnages, \& par ce moyen s'acheuoit la feft Ce qu'ils auoient accouftumé de faire aux plt principales feftes.

2 uel profit l'on peut tirer. du traicté des fuperfitions des Indes.

\section{Chapitre XXXI.}

QDus E qui a efté dit, fuffife pour entendr le foing \& la peine que les Indier employoient aे feruir \& honorer leu (1doles, \& pour mieux dire, le diabl car ce feroit vne chofe infinie, \& de peu de pro fit, de vouloir raconter entierement ce quis paffe; veu mefme qu'il pourra femblęr à que ques-vns qu'il n'eftoit point de befoing d'en d - re tant comme jay fait; \& que c'eft perdre ! temps, comme on fait, en lifant les contes qu feignent les Romans de Cheualerie. Mais ceux qui ont celte opinion, y veulent regarde de pres, ils trouueront qu'il y a grande differen ce entrel'vn \& l'autre, \& recognoiftront qu ce peut eftre vne chofe vtile, pour plufieur confiderations d'auoir la cognoiffance des cou ftumes \& ceremonies dont vfoient les Indiens 


\section{des fndes. Liure $\dot{V}$.}

273

'remierement cefte cognoiffance n'eft pas feuement vtile, mais auffi neceffaire aux terres ou Is ont vfé de ces fuperftitions, afin que les Chre. tiens, \& maiftres de la loy de léius Chrift, fçatent les erreurs \& fuperititions des anciens, lou: voir fi les Indiens en vfent point encores àjourd'huy ouuertement, ou couucrtement. 'our cefte occafion plufieurs doctes \& fignalez erfonnages ont efcrit des difcours affez amles de ce qui s'en eft trouué, voireles Concies Prouinciaux, ont commandéqu'on les efcriie \& imprime, comme on a fait en Lima, où vri lifcoursa efté fait plusample, que ce qui en eft cy traitté. C'eft pourquoy c'eft chofe imporante pour le bien des Indiens, que les Efpanols eitans en ces parties des Indes, ayent la ognoiffance de toutes ces chofes. Cefte narra ion mefme peut feruir aux Efpagnols de delà, ì tous autres, en quelque endroit quilis oient, pour remercier Dieu noftre Seigneur, luy rendre graces infinies d'vn fi grand bien jue celuy que nous a departy, \& va donnant $f_{a}$ aincte loy, laquelle eft toute iufte, toute nette, $x$ toute profitable. Ce qu'on peut cognoiftre n la comparant auec les loix de Satan, où tant e malheureux ont vefcu fi miferables. Elle eut mefme feruir pour defcouurir l'orgueil, 'enuie, les ttromperies, \& les embufches du liable, qu'il exerce contre ceux qu'il tient capifs; veu que d'vn coftéil veutimiter Dié, \& aire comparaifon auec luy \& fa faincte loy; \& iautre cofté il entremefle en fes actes tant de anitez , d'ordures, \& de cruautez, cormme se$M$ 


\section{Hiftoire naturelle}

luy qui n'a point d'autre exercice que de foph ftiquer, \& corrompre tout ce qui eft bon. Fin: lement qui verra les tenebres $\&$ l'aueuglemet auquel tant de grandes Prouinces \& Royaume ont vefcu filong temps, \& que beaucoupd peuples, voire vne grande partie du monde, $v$ : uent encores deceus de femblables tromperie: ne pourra (fil a le cœur Chreftien) qu'il ne ren de graces au tres-haut Dieu, pour ceux quil ap pelle de fi grandes tenebres, à l'admirable lu miere de fon Euangile, fuppliant limmenf charité du Createur qu'il les conferue, \& aug mente en fa cognoiffance, \& en fon obeyflance $\&$ que de mefme aufiil fe contrifte pour ceu qui toufiours fuinent le chemin de perdition $\&$ qu'en fin il fupplie le Pere de mifericord quil leur defcoumre les threfors \& richeffes d Iefus-Chrift, lequel auec le Pere \& le fainct Et prit regne par tous les fiecles, Amen. 


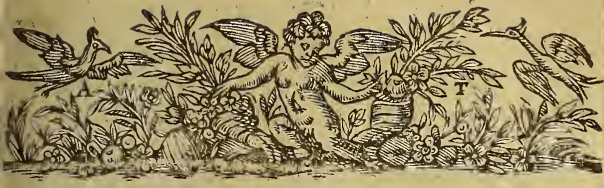

LIVRE SIXIESME, DE

L'HISTOIRE NATVRELLE

\& morale des Indes.

Que lopinion de ceux-là eft faufe, qui tiens, neat que les Indiens ont faute d'enteridement.

CHAPITRE PREMIE⿺辶⿸

P Y Y T traitté cy deuant de la ré(2)(1) ligion dont v foient les Indiens, ie pretens efcriré en ce liure de leurs 18 1 couftumes, police \& gouuerne18 1 couftumes, police \& gouuernel'ofter la fauffe opinion que l'on a commune. nent d'eux, qu'ils font hommes grofliers, \& trataux, ou quils ont fi peu d'entendement; ưà peine meritent-ils que l'on die qu'ils en yent. D'où vient quel'on leur fait plufieurs ex́ez \& outrages, en fe feruane d'eux prefque en 3 mefmefaçon que fi c'eftoient beftes brutes, $x$ les reputans indignes d'aucun refpect, qui eft' n fi vulgaire \& fi pernicieux erreur(ainfi que le çauent fort bien ceux qui auec quelque zele \& pnfideration, ont cheminé parmy eux, \& qus $M \mathrm{mij}$ 


\section{Hiftoire naturelle}

ont veu \& cogneu leurs fecrets \& confcils: ) 8 d'autre part, le peu de cas que font de ces In diens plufieurs qui penfent lçauoir beaucoup \& neantmoins qui font ordinairement les plu ignorans, \& plus prefomptueux, que ie ne vo: point de plus beau moyen pour confondre ce fte pernicieufe opinion, qu'en leur deduifan lordre $\&$ façon de faire quils auoient au temp quils viuoient encore fous leur loy, en laquell combien qu'ils euffent beaucoup de choles bar bares, \& fans fondement, neantmoins ils et auoient beaucoup d'autres, dignes de grand admiration, par lefquelles l'on peut entendr qu'ils ont le naturel capable de receuoir tout bonne inftruction, \& de fait ils furpaffent er quelques chofes, plufieurs de nos Republiques Et n'êt point chole de merueille quil y ayt et entr'eux de fi grandes \& filourdesfautes, ver qu'il y en a eu auffi entre les plus fameux Legif lateurs \& Philofophes, voire fans excepter Ly curgue, ny Platon. Et entre les plus fages Re publiques, comme ont efté la Romaine, \& l'A thenienne, où l'on peut recognoiltre des cho fes fi pleines d'ignorance, \& fi dignes de rifee qu’à la verité files Republ. des Mexiquains \& Inguas euffent efté cogneuies en ce temps de Romains \& des Grecs, leurs loix \& gouuerne mens euffent efté beaucoup eftimez d'eux. Mai nous autres à prefent ne confiderans rien de ce la, y entrons parl'efpee, fansles ouyr, ny en tendre, nous perfuadans que les chofes des In diens ne meritent qu'on en falfe autre eftime gue comme l'on fait d'vne venaifon prife enl. 


\section{des Indes. Liure VI. 275}

oreft, qui ayt efté amenee pour noftre feruice so paffetemps. Les hom tres plus profonds, \& plus diligents, qui ont penetré \& arteintiufques à la cognoiffance de leurs fecrets, couftumes \& gouuernement ancien, en ont bien autre opinion, \& f'efmerueillent de l'ordre, \& dı difcours qui a efté entr'eux; du nombre defquels eft Polo Ondeguardo; lequel ie fris communement an difcours des chofes du Peru; \& pour celles de Mexique, Iean de Toiiar, qui auøit eu vne prebende en l'Eglife de Mexique, \& aujourd'huy eft Religieux de noftre Compagnie de lefus, lequel par le commandement du Viceroy Dom Martin Enrriques, a fait vn diligent, \& ample recueil des hiftoires de cefte nation, \& plufieurs autres graues $\&$ notables per. fonnages, lelquels tant par parole, que par eferit, mont fuffifamment informé de toures ces chofes que ie raconte icy. L'autre fin \& intention, \& le bien qui fe peut enfuiure par la cognoiffance de ces loix, couftumes \& police des Indiens, eft afin de leur ayder, \& les regir par les mefmes loix \& couftumes, attendu qu'ils doitrent eftre gouuernez felon leurs couftumes \& privileges, entant qu'ils ne contreuiennent à da loy de Iefus-Chrift, \& de fa faincte Eglife, quon leur doit conferuer \& entretenir comme leurs loix principales: car lignorance des loix \& couftumes a efté caufe qu'on y a commis plu fieurs fautes de grandeimportance, parce que les Iuges \& Gouuerneurs ne f̧̧auent pas bien comment ils doiurent donner iugement, \& y regir leurs fujets. Er qu'outre ce que c'eft leur fai-

$$
\mathrm{M} \text { m iij }
$$




\section{Hiffoire naturelle}

ge vn grand tort, \& aller contre raifon, ce wous en chofe prejudiciable $\&$ dommageable, parce que de là ils prennent occafion de nous abhorrer, comme gens qui en rout, foit au bien, ou au mal, leur auons efté, \& fommes toufiours contraires.

Dela Jupputation des temps, \& du Kalendrier? duquelvfoient les Mexiquains.

\section{CHAPITRII.}

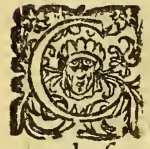

O M MENÇA N T donc par la diuifion \& fapputation des temps que les Indiens taifoient (en quoy certes

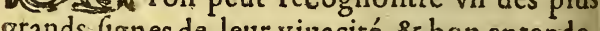
grands fignes de leur viuacité \& bon entendement) ie diray premierement de quelle maniere les Mexiquains contoient, \& diuifoient leur annee, de leurs mois, de leur Kalendrier, de leurs contes, des fiecles, \& des aages. Ils diuifoient l'an en dix -huict mois, à chacun defquels ils attribuoient vingt iours, en quoy les trois cents foixante iours font accomplis, fans comprendre en aucun de ces mois, lescing iours qui reftent du furplus, faifant l'accompliffemét del'an entier: maisils les contoient à part, \& les appelloient, les iours de rien, durant lerquels le peu ple ne faifoit aucune chofe, \& n'alloient pas mefmes en leurs temples; magis ils soccupoient feulement à fe vifiter les vnsles autres, perdans ainfile temps, \& les SacrificaEeurs du temple ceffoient auffi de facrifies, 


\section{des Fndes. Liure VI. $\quad 276$}

Ipres ces cinq iours paffez, ils recommençoiét zur conte de lan, duquel le premier mois \& le ommencement eftoit en Mars, quäd les feuilis commençoient aे reuerdir, encores quijils rinffent 3. iours da mois de Feurier: car leur remier iour del'an eftoit comme le 26 . de Fe. irier, ainfi qu'il appert par leur Kalendrier, delans lequel mefme le noftre eft comprins, \& :mployé d'vn fort ingenieux artifice, \& fut fait arlesanciens Indiens, qui cogneurent les preniers Efpagnols. I'ay veu ce Kalendrier, \& l'ay :ncores en ma puiffance, qui merite bien d'eftre reu, pour entendre le difcours, \& l'induftrie qu’auoientles Indiens Mexiquains. Chacun de ces dix-huict mois auoit fon propre nom, \& fa propre peinture, qu'il prenoit communement de la principale fefte qui fe faifoit en ce mois, ou de la diuerfité du temps que l'an caufe en iceux. Ils auoiét en ce Kalendrier certains iours marquez \& deftinez pour leurs feftes, \& contoient les fepmaines de treize iours, en y remar. quant les iours par vn zero, qu'ils mulriplioient iufqu’à treize, \& incontinent recommençoient à conter, vn, deux, \&c. Ils remarquoient auffi les annees de ces roiles, par quatre fignes, ou figures, attribuans à chacun an va figne; dont l'vn eftoit d'vne maifon, l'aurre d'v n connin, le troifiefme d'vn rofeau, \& le quatriefme d'vn caillou. Ils les peignoient de cefte façon, deno= tans par icelles figures l'an qui couroit, difans à tant de mairons, ou à rant de caillowx de telle roije fucceda telle chofe : car l'on doit fçauoir que leur roiie, qui eftoit conitne vn fiecle, con $\mathrm{M} m$ iiij 


\section{Hiftoire naturelle}

renoit quatre fepmaines d'annees, eftantcha. cune fepmaine de treize ans qui accomplitioiêt en tout, cinquante- deux ans. Ils peignoient au milieu de cefte roue vn Soleil, d'où fortoiens en croix quatre bras, ou lignes iufques à la circonference de la roüe, \& faifoient leur tour en telle façon que la circonference eftoit diuifee en quatre parties efgales, chacune defquelles auec fon bras, ou ligne, auoit vne coulcur particuliere, \& differente des autres, \& eftoient les quatre couleurs, verd, azuré, rouge \& iaune. Chaque portion de ces quatre, auoit treize feparations, qui auoient toutes leurs fignes, ou figures particulieres, de maifon, ou de connin, ou de rozeau, ou de caillous, fignifiant par chaque figne vne annee, \& en tefte de ce figne, ils peignoient ce qui eftoit arriué celt an là. C'eft pour quoy ie veids au Calendrier, que i’ay dit, l'annee, en laquelle les Efpagnols entrerent en Mexique, marquee par vne peinture d'vn homme veftu de rouge, à noftre mode, car tel eftoit l'habit du premier Efpagnol, qu'enuoya Fernand Cortez, au bout de cinquante deux ans, que le fermoit, \& accompliffoit la roüe. Ils $v$ foient d'vne plaifante ceremonie, qui eftoit que la derniere nuict ils rompoient tous les vafes \& vtenfiles qu'ils auoient, \& efteignoient tout le feu, $\&$ toutes les lumieres, difans que le monde deuoit prendre fin à l'accompliffement d'v̀ne de ces roües', \& que d'auenture ce pourroit eftre celle où ils fe trouuoient : car (difoient-ils) puis que le monde doit alors finir, qu'elt-il plus de befoing d'apprefter de viande, ny de manger? 


\section{des Indes. Liure VI.}

"eft pourquoy ils n'auoient plus que faire de afes, ny de feu. Sur cefte opinion ils palfoient oute la nuict en grande crainte, difans que vent eftre 1 ne viendroit plus de iour, \& veiloient tous fort atteutiuement pour voir quăd e iour viendroir: mais voyans que l'aube comnençoit à poindre, incontinent ils battoient lufieurs tambours, \& fonnoient des bucci ies, les futtes, $8 z$ autres inftrumens de refioyffan: $\&$ allegrelfe, difans que defia Dieuleur al. ongeoit le temps'd'vn autre fiecle, qui eftoient inquante deux ans. Et alors ils recómençoient tne autre roüe. Ils prenoiêt en ce premier iour, $x$ com nencement du fiecle du feu nousueau, \& ichetoient des vafes \& vtenfiles neufs pour aprefter la viande; \& alloient tous querir ce feu zouueau chez le grand Preftre, ayans fait au Jaraunt vne folemnelle proceffion d'action le graces pour la venuë duiour, \& prolongaion d'vn autre fiecle. Telle eftoit leur façon, s maniere de conter les annees, les mois les lepmaines, \& les frecles.

Comment les Roys Inguas contoientles ans Oo les mois.

\section{CHATITRE III.}

Yemg Ombien que cefte fupputation des Al emps practiquee entre les Mexic-
(2) juains, foit affés ingenieufe \& certaie pour des hommes qui nauoient atcuies settres, toutesfois il me femble qu'ils 


\section{Hiftoire naturelle}

ont eu faute de difcours \& de confideration n'ayans point fondé leur conte furle cours di la Lune,ny diftribué leurs mois felon icelle; er quoy certainement ceux du Peru les ont fur. paffés, pource qu'ils partoient leur an en autan de iours parfaictement aćcomplis, cóme nou: faifonsicy, \& le diuifoient en douze mois, or Lunes, efquels ils employoient \& confom. moient les vnze iours, qui reftent de la Lune ainfi que l'efcrit Polo. Pour faire leur conte de l'an feur \& certain, ils vfoient de cefte indu. ftrie, qu'aux montagnes qui eftoient au tour do la Cité de Cufco(ou fe tenoir la court des Roy: Inguas, \& le plus grand fanctuaire des Royau. mes, comme fi nous difions vne autre Rome il yauoit douze coulomnes afifes par ordre en telle diftance l'vne de l'autre, que chaqui mois vne de ces coulónes remarquoit le leuel \& coucher du Soleil. Ils les appelloient Suc. canga, \& par le moyen d'icelles ils enfeignoiem $\&$ annonçoient les feftes, \& les faifons propre: aे femer, à recueillir \& à faire autres chofes. Il faifoient de certains facrifices à es pilliers $\mathrm{d} v$ Soleil, fuiuant leur fuperftition. Chaque mois auoit fon nom propre, \& fes feftes particulie. res. Ils commençoient l'an par Ianuier, com. me nous autres, mais depuis vn Roy Ingua. appellé Pachacuto, qui fignifie reformateur $d x$ Temple, fit commencer leur an par Decembre: à caufe (comme ie coniecture) qu'alors le So. leil commence à retourner du dernier point de Capricorne, qui eft le Tropique pluspto. che d'eux. Ie ne f̧cay point queles vns, ny les 


\section{des Fndes. Liure VI.}

278

utres, ayent remarqué aucun Bifexte, comien que quelques-vns difent le contraire. Les emaines que contoient les Mexiquains n'etoient pas proprement femaines, puis qu'elesn'eftoient pas de fept iours, auffiles Inguas 'en firent aucune mention, ce qui n'eft pas de nerueille, actendu que le conte de la femaine ieft pas fondé fur le cours du Soleil, comme eluy de l'an, ny fur le cours de la Lune comme eluy des mois, mais bien entre les Hebrieux. it fondé furla creation du monde, que rapsorte Moyfe, \&z entre les Grecs, \& les Latins, ur le nombre des fept planetes, du nom def juelles mefmeles iours de la femaine ont prins eur nom. Neantmoins c'eftoir beaucoup à ces indiens, eftans hommes fans liures, \& fans letfes ${ }^{+}$comme ils font, qu'ils euffent vn an des aifons \& des feftes fi bien ordonnees comme il eft dit cy-delfus.

Quelonn'a point trouné aucune nation d' Indiens quivfaft de lettres.

Chapitre IV.

Eve lettres furent inuentees pour :cP prefenter \& fignifier propremene les paroles que nous prononçons, ainfi que les paroles mefmes (felon le Philo(ophe) fontles fignes \& marques propres des conceptions \& penfees des hommes. Et l'vn \& l'autre (ie dy les lettres \& les mors) ont efté ordonnez pour faire entendre les cho: 


\section{Ffiftoire naturelle}

fes. $L_{2}$ voix pour ceux qui font prefens, \& le lettres pour les ablens, \& pour ceux qui font venir. Les fignes \& marques qui ne font $p$ a propres pour fignifier kes paroles, mais les che res, ne peuuent eftre appellés, ny ne font poir à la verité des lettres, encor quilils foient efcrit Car l'on ne peut dire qu'vne image du Sole peint, foit vne efcriture du Soleil, mais feule ment vne peinture, autant en eft-il des autre fignes \& characteres qui n'ont aucane reffem blance à la chofe, mais qui feruent tant feule ment de memoire. Car celuy quiles inuenta ne les ordonna point pour fignifier des paro les: mais feulement pour denoter vne chofe On n'appelle point aufin ces characteres let tres ny efcritures, comme de fair ils ne le fon pas, mais pluftoft des chiffres ou memoires ainfi que font ceux dont vfent les Spheriftes 8 Aftrologues, pour fignifier diuers fignes où pla nettes de Mars, de Venas, de Inpiter, \&c. Tel characteres font chiffres, \& non pas lettres pourautant que quelque nom que Mars puiff auoir en Italien, François, en Efpagnol, touf iours ce charactere le fignifie; ce qui ne fe trou ue point és lettres : Car iaçoit qu'elles deno rent les chofes, c'eft par le mayen des paroles D'où vient que ceux qui n'en fçauét la langue, ne les entendent pas, comme pour exemple le Grec, ny l'Hebrieu, ne pourra pas compren. dre ce que fignifie ce mot sol, iaçoit qu'ils voyent efcrit, pource qu'ils ignorent le mo Latin. Tellement que lefcriture \& les lettre: font feulement praetiquees parceux qui auec 


\section{des fndes. Liure VI. 2 \%}

celles fignifient des mots, car fi imnediatenent elles fignifient les chofes, elles ne font lus lettres ny efcritures, mais des chiffres $2 Z$ des ,eintures, dequoy l'on tire deux chofes bien 10 tables. L'vne que la memoire des hifoires \& intiquirés peut demeurer aux hómes par l'vne le ces trois manieres, ou par les lettres \& efcri:ures, cóme il a efté practiqué entre les Latins es Grecs, les Hebrieux, \& beaucoup d’autres ations, ou par peinture, cómel'on a véé prefque en tout le monde : car il eft dit au Concile de Nice fecôd. La penture eft vn liure pour les idiờs qui ne Şauent lire, ou par chiffres $\&$ characteres, comme le chiffre fignifie le nombre de cent, de mil \& autres, fans fignifiter celte parole de cent, ou de mil. L'autre chofe notable que l'on en peut tirer, eft celle qui s'eft propofee en ce chapitre, à f̧̧auoir que nulle nation des Indes defcouuertes de noftre temps, n'a vfé de lettres, ny d'efcriture, mais de deux autres manieres, qui en font images \& figures. Ce que i'entends dire non feulement des Indes, du Peru $\&$ de la neuue ECpagne, mais auffi du Iappon \& de la Chine. Et bien que ce que ie dis parauanturé pourra fembler à quelques-vns eftre faux, veu qu'il eft rapporté par les difcours qui en font efcrits, qu'il y a de fi grandes Librairies \& Vniuerfitez en la Chine \& au Iappon, \& qu'il eft fait mention de leurs. Chapas, lettres \& expeditions, toutesfois ce que ie dy eft chofe veritable, ainf qu'on pourra eatendre par le difcours fuiuant. 


\section{Hiftoire naturelle}

De la faģon des lettres ou des liures dont voient les Chinois.

CHAPITRE V.

-T 1 L y en a plufieurs qui penfent, \& ef 20 Dien la plus commune opinion, qu 13 - lis efcritures dont vfent les Chinois 2. Cont lettres, comme celles dont nou: vfons en Europe, \& que par icelles l'on puiff, efcrire les paroles \& difcours, \& que feule. ment ils different de nos lettres \& efcritures et la diuerfité des characteres, comme les Grecs different des Latins, \& les Hebreux des Chaldeans. Mais il n'en eft pas ainfi, pource qu'ils n'ont point d'Alphabet, ny n'efcriuent point de lettres, mais toute leur efcriture n'eft autro chofe que peindre $\&$ chiffrer, \& lcurs lettres ne fignifient point des parties de diations; comme font les noftres, mais font des figures \& reprefentations des chofes, cóme du Soleil, du feu, d'vn homme, de la mer, \& des autres chofes. Ce qui appert euidemment, par ce que lcurs efcritures \& Chapas font entëduës d'eux tous, combien que les langues dont patlent les Chinois; roient en grand nöbre, $\&$ fort differentes entre elles, en la mefme façon que nos nombres de chiffre font entendus efgalement en Fräçois; en Ef pagnol, \&z en Arabic. Car cefte figure huicts où que ce foit fignifie huid, encor que le François appelle ce nóbred'vne façon, \& l'Efpagnol 


\section{des Indes. Liure VI.}

îne autre. D'où vient que les chofes eftans de oy innumerables, les lettres auffi ou figures dót fent les Chinois, pour les denoter font prefjue infinies: tellemêt que celuy qui doit lire ou fcrire à la Chine (comme font les Mandarins) oit fçauoir \& retenir pour le moins quatre ingts cinq mil characteres ou lettres, 8 zeux ui font parfaits en cefte leouure, en fçauét plus efix vingts mil. Chofe prodigieufe \& eftrăge, oire qui feroit incroy able, fi elle n'eltoit attetee par des perfonnes dignes de foy, cóme les 'eres de noftre Cópagnie, qui font là cótinuel. -ment apprenans leur langue \& efcriture, \& y plus de dix arrs que de nuict \& de iour ils s'e:udientà cecy, auec vn perpetuel trauail. Car la harité de IefusChrift, \& le defir de la faluation es ames, furmóte en eux tout ce trauail \& dificulté, qui eft la raifon pour laquelle les homaes lettrez font tant eftimés en la Chine, à catte de la difficulté qu'il y a à les comprendre, \& eux-là feulement ont les offices de Mandàins, Gouuerneurs, Iuges \& Capitaines. Pour efte occafion les peres prennent beaucoup de eine de faire apprendre à leurs enfans à lire $8 *$ [crire. Il y a grand nombre de ces efcholes ù les enfans font inftruits, \& où les maiftes es font eftudier de iour, \& le pere de nuict nla maifon. Tellement qu'ils leur endommaent beaucoup lesyeux, \& les foüettent fort outuent auec des rofeaux, bien que ce ne foit as de ces rigoureux, defquels ils foüettent les nal-faicteurs; ils appellent cola la langue $M$ arilarine, qui a befoin de l'âge d'vn homme pour 


\section{Hiftoire naturelle}

eftre comprinfe: \& doit-on fçauoir qu'enco que la langue de laquelle parlent les $M$ andarir foit particuliere \& differente des vulgaires, lel quelles font en grand nombre, \& qu'on eftudi cóme l'on fait par deçà en Latin \& en Grec, que les lettrez qui Cont pàr toute la Chinel fçauent \& entendent tant feulement : fi eft- $c$ toutefois que tout ce qui eft efcrit en icelle, et entendu en toutes les langues, \& iảçoit que le Prouinces ne s'entr'entendent point de parol les vnés les autres, toutefois par elcritils s'en tr'entendent l'vn l'autre, car il n'y a qu'vne for te de figures ou carackeres pour toutes, qui fi gnifie vne mefme chofe, mais non pas vn mel me mor, ny prolation veu que comme iay dit ils font feulement pour dentoter les chofes, 8 non pas les paroles, cóme l'on peut facilemen entendre par l'exemple des nombres de chif fre. C'eft pourquoy ceux du lappon \& les $\mathrm{Ch}$. nois lifent \& entendent fort bisn les efcriture les vns des autres, combien que ce foient de nations \& des langues fort differentes. Qu s'ils parloient ce quils lifent, ou efcriuent, 1 : ne le pourroient pas entendre. Telles font don leslettres, \& les liures dont vfent les Chinoi fi renommez au monde. Pour farre leurs im preffions ils grauent vne planche, des fig ure qu' ils v eulent imprimer. Puis en eftampent au rant de feüilles de papier qu'ils veulent, del: mefme façon quel'on fait icy les peintures, qu font grauees en du cuiure, ou du bois. Mai quelque homme d'entendement pourra de. mander, comment ils peuuent fignifier leur: conception: 
des Fndes. Liure. VI. $28 \mathrm{I}$ onceptions par des figuresquiapprochent, ous affemblent à la chofe qu'ils veulent reprefen:r, comme de dire que le Soleil efchauffe, or u'il a regardé le Soleil, ou que le iour eft du So:il.Finalement, comment illeur eft pofsible de enoter par de mefmes figures, les cas, les coninetions,\& les articles qui font en plufieurs lanues \& efcritures. Te refponds à cela, qu'ils diinguent, \&r fignifient cefte varieté par certains oincts rayez, \& difpofitions de la figure. Mais il it difficile d'entendre comment ils peuuent efrire en leur langue des noms propres, fpecialerent d'eftrangers, veu que ce font chofes que iarais ilsn'ont veües, \& qu'ilsne peuuent inuenar des figures qui leur foient propres. I'en ay oulu faire l'experience me trouuant en Mexiue auec des Chinois, \& leur dy qu'ils efcriuifent en leur langue cefte propofition. Iofeph 'Acofta eft venu du Peru, \& autres femblables, urquoy le Chinois fut va long temps penfif, aais en fin il l'efcriuit. Ce que d'autres Chinois surent apres, bien qu' ils variaffent vn peu en la rononciation du nom propre. Car ils vent de eft artifice pour efcrire le nom propre, qu'ils herchent quelque chofe en leur langue quiaye effemblance à ce nom, \& mettent la figure de efte chofe. Et comme il eft difficile entre tant le noms propres, de leur trouuer des chofes qui eur portent reffemblance en la prolation: aufsi estr eft-ce chofe fort difficile \& fort laborieufe l'efcrire tels noms.Sur ce propos le Pere AlloneSanchez nous contoit que lors qu'il eftoit ers Chine, \& que l'onle menoit en diuers Tribu- 


\section{Hifoire naturelle}

naux, de Mandarin en Madarin, ils eftoient fol long temps à mettre fon nom par efcrit en leus Chapas, toutesfois ils l'efcriuoient en fin, le nom mans en leur façon, \& tellement ridicule, qu' peine-approchóient-ils le nom, qui eft la faço des lettres \& efcritures dont vfoient les $C$ hinoi Celle des I a p ponnois en a pprochoit beaucoup encor qu'ils afferment que les Seigneurs Iappon nois qui vindrent en Europe, efcriuoient facile ment toutes chofes en leur langue, quoy que $c$ fuffent des noms propres d'icy, mefme l'on m' montré quelques efcritures d'eux : parquoy femble qu'ils doiuent auoir quelque forte $d$ lettres, encor que la plus part de leurs efcriture foient par characteres \& tigures, comme il a eft dit des C.hinois.

\section{Desefcholes \&u uniuerfitez de la Chine.}

\section{ChaPITRE VI.}

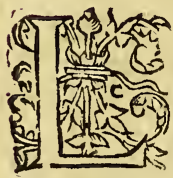

Es Peres de la Compagnie difen qu'ils n'ont point veu en la $\mathrm{Chi}$ ne de grandes efcholes \& Vni. verfitez de Philofophie, \& autre fciences naturelles, \& croyét qu'i n'y en a point, mais que toute leur eftude eft er la langue Mandarine, qui eft tref-ample: \& tref. difficile, comme i'ay dit, \& que ce qu'ils eftu. dient font chofes qui font efcrites en cefte langue, qui font des hiftoires des fectes \& opinions des loix ciuiles, des prouerbes moraux 


\section{des Indes. Liure. VI.}

des fables, \& plufieurs autres telles cópofitions, \& ce quien defpend. Des fciences diuines ils n'en ont aucune cognoiffance, ny n'ót autre chofe des naturelles que quelques petits reftes qu'ils ont en des propofitions efgarees, fansart \& fans methode, felon l'entendement \& eftude d'vn chacun. Pour les Mathematiques, ils ont experience des mouuemens celeftes, \& des eftoiies; \& pour la Medecine, ils ont cognoiffance des herbes, par le moyen defquelles ils guariffent plufieurs maladies, \& en vfent beaucoup. Ifs efcriuent auec des pinceaux, \& ont plufieurs liures efcrits à la main, \& d'autres imprimez qui font tous d'affez mauuais ordre. Ils font grands ioüeurs de Comedies: ce qu'ils font auec vn grand appareil de theatres, veftemens, cloches, tambours, \& de voix, felon qu'il eft conuenable. Quelques Peres racontent y auoir veu des Comedies qui duroient dix \& douze iours auec leurs nuicts, fans qu'il y euft faute de ioüeursfur le theatre, ny de fpectateurs pour les regarder. Ils font plufieurs Scenes differentes, \& pendant que les vris reprefentent, les autres dorment ou repaiffent. Ilstraittent ordinairement en ces Comedies des chofes, morales $\&$ de bon exemple, quifone neantmoins entremeslees de chofes gayes $8 x$ plaifantes. Voila en fomme ce que les noftres racontent des lettres \& exercices de ceux de la Chine, où l'on ne peut nier qu'il n'y ait beaucoup d'entendement, \& d'induftrie. Mais tout cela eft de peu de fubftance, pour ce qu'en effect toute la fcience des Chinois tend feulement à fçauoir efcrire \& lire, \& non poing Nn ij 


\section{Hifoire naturelle}

dauantage : carils ne paruiennent point és fciences plushautes, \& leur efcrire $\&$ lire n'eft point proprement efcrire \& lire, puifque leurs lettres ne font point lettres, qui puillent reprefenter les paroles, mais font figures de chofes innumerables, lefquelles ne fe peuuent apprendre que par vn bien long temps, \& auec vn trauail infiny. Mais en fin auec toute leur fcience, vn Indien du Peru, ou Mexique qui a a pprinsà lire \& efcrire, fçait plus que le plus fage Mandarin d'entr'eux, veu que l'Indien auec vingt quatre lettres qu' il fçait, efcrira \& lira tous les mots \& paroles qui font au monde, \& le Mandarin auec fes cent mil lettres aura beaucoup de peine pour efcrire quelque nom propre de Martin, ou Allonfe, \& a plus forte raifon ne pourra-il pas efcrire les noms deschofes qu'il ne cognoift point. Car en fin l'efcrire de la Chine n'eft autre chofe qu'vne façon de peindre, ou chiffrer.

Di la façon des lettres ó efcritures dont ont $v e^{\prime}$ 'les Mexiquains.

\section{Chapitre VII.}

Uy. On trouue qu'il y a entre-les nations L $\mathrm{L}$, de la neuue Efpagne vne grande coa gnoiffance, \& memoire de l'antiqui7. quelle façon les In fiens auoient conferué leurs hiftoires, \& tant de particularitez, i’apprisque encorqu'ilsne fuffent point fifubtils, ny ficts- 


\section{des Indes. Liure. VI.}

rieux comme font les Chinois \& les Iapponnois, fi eft-ce qu'ils auoient entr'eux quelque forte de lettres \& de liures, par lefquels ils conferuoient à leur mode les chofes de leurs predeceffeurs. En la Prouince de Yu-latan, où eft l'Euerché, qu'ils appellent de Honduras, il y auoit des liures de feúilles d'arbresà leur mode ployez \& efquarris, efquels les fages Indiens tenoient comprinfes \& def́duitesla diftribution de leurstéps, la cognoiffance des planettes, des animaux \& des autres chofes naturelles, auec.leurs antiquitez: chofe pleine de grande curiofité \& diligence. Il fembla à quelque Pedant que tout cela eftoit vn enchantement $\&$ art de magie, $\&$ fouftint obftinément que l'on les deuoit brusler; de forte qu'ils furent mis au feu. Ce que depuis non feulement les Indiens recogneurent auoir efté mal fait, mais aufsi les Efpagnols curieux quidefiroient cognoiftre les fecrets du pays. H en eft arriué autant és autres chofes, car les noftres pen. fans que le tout fuft fuperftition, ont perdu plu fieurs memoires des chofes anciennes \& facrees, qui pounoient beaucoup profiter. Cela procede d'vn zele fol \& ignorant, qui fans fçauoir, ny. vouloir entendre les chofes des Indiens, difent (comme à charge clofe) que ce font toutes forcelleries, \& que tous les Indiens ñe font que des yurongnes, qui font inca pables de fçauoir, ny d'apprendre aucune chofe. Car ceux quife font voulu diligemment informer d'eux, y ont trouué beaucoup de chofes dignes de confideration. Vn de noftre Compagnie de IEsvs, homme fort accort \& experimenté, aflembla en la Pro$\mathrm{Nn}$ iij 


\section{Hifoires naturelle}

uince de Mexique les anciens de Tefcuco, de Tulla , \& dé Mexique, \& confera fort amplement auec eux, lefquels luy monftrerent leurs liures, hiloires, \& Calendriers, qui eftoient chofes fort dignes de voir, pource qu'ils auoient leursfigures, \& hieroglyficques, par lefquelles ils reprefentoient les chofes en cefte maniere. Cellesqui auoient forme, ou figure, eftoient reprefentees par leurs propresimages, \& celles qui n'en auoient point, eftoient reprefentees pardes chara cteres quiles fignifioient, \& par ce moyen ils figuroient, \& efcriuoient ce qu'ils vouloient. Et pour remarquer le temps auquel quelque chofe arriuoit, ils auoient ces roies peintes, car chacune d'icelles contenoit vn fiecle, qui eftoit cinquante-deux ans, comme a efté dit cy-deffus, $\&$ au colté de ces roties, ils peignoient auec ces figures $\&$ characteres, à l'end roit de l'annee, les chofes memorables qui aduenoient en icelle. Comme ils remarquerent l'annee, que les Efpagnols entrerent en leur pays, en peignant vn homme auec vn chapeau, \& vne iuppe rouge, au figne du rofeau, qui couroitalors. Et ainfi des utres accidens. Mais pource que leurs efcritures \& characteresn'eftoient pas fi fuffifans, comme nos lettres \& efcritures, ils ne pouuoient exprimer de fi prés les paroles, ains feulement la fubftance des conceptions. Et d'autant qu'ils auoient accouftumé de raconter par cœur des difcours, \& dialogues compofez par leurs Orateurs, \& R hetoriciens anciens, \& beaucoup de Chapas dreffez par leurs Poëtes (ce qui eftoit imporsible d'apprendre par les hieroglyphi: 


\section{des Indes. Liure VI.}

jues, \& characteres) les Mexiquains eftoient ort curieux, que leurs enfans a p priffent par menoire ces dia logues \& compolitions. A raifon Jequoy ils auoient des efcholes \& comme des colleges, ou feminaires, où les anciens enfeignoient aux enfans ces oraifons, \& beaucoup d'autres chofes, qui fe conferuoient entr'eux par la tradition des vns aux autres aufsi entierement, comme fi elles euffent efté couchees par efcrit. Specialement les nations plus renommees auoient foing que leurs enfans (qui auoient inclination pour eftre Rhetoriciens \& exercer l'office d'orateurs) apprinflent de mot à mot ces harangues. Tellement que quand les Efpagnols vindrent en leur pays, \& qu'ils leur eurent enfeigné à lire \& efcrire noftre lettre, plufieursde ces Indiens efcriuirent alors ces harangues, ainfique le tefmoignent quelques hommes graues qui les leurent. Ce qui eft dit pource que ceux qui liront en l'hiftoire Mexiquaine de tels difcours longs \& elegans, croiront facilement quilis font inuentez des Efpagnols, \& non pas reallement prins, \& rapportez des Indiens. Mais en ayant cogneu la verité certaine, ilsne laifferont pas d'adioufter foy, comme c'elt la raifon, à leurs hiftoires. Ils efcriuoient anfsices mefmes difcours à leur mode, par des images \& characteres, \& ay veu, pour me fatisfaire en: cét endroit, les oraifons du Pater nofter, \& Aue Marra, Symbole, \& confefsion generalle, efcrites en cefte façon d'Indiens. Et à la verité quiconque les verra, s'en efmerueillera. Car pour fignifier ces paroles, Moy pecheur me confeffe $-\mathrm{N} n$ iiij 


\section{Hifoire naturelle}

ils peignoient vn Indien à genoux aux pieds d'v Religieux, comme qui fe confefle, \& puis pous celle -cy, à Dreutout-priffant, ils peignoient troi: vifages auec leurs couronnes, en façon de ta Trinité, o à laglorremfe vierge Marie, ils peignoient vin vifage de noftre Dame, \& vn demy corps de petit enfant, $\sigma$ à faind Pierre $\sigma$ fanct Paul,desteftes auec des couronnes, \& $\mathrm{v}$ ve clef,' $\&$ vne efpee, $\&$ où les images leur deffailloient, il mettoient des characteres, comme, enquoy iay peché, ov. D'où l'on peut cognoiftre la viuacitế de l'enten. dement de ces Indiens, puifque cefte façon d'er: crire nos oraifons, \& chofes de la foy, ne leur a pas efté enfeignee par les Ef pagnols, ny ne l'euffent peu faire, s'ilsn'euffent eu particuliore coneeption de ce qu'on leur enfeignoit .l'ay veu au Peru la confersion de tous les pechez qu'vn Indien apportoit pour fe confeifer, efcrite de la mefme forte, de peintures, \& de characteres, en peignant chacun des dix commandements d'vne certaine façon, où il y auoit certaines marques comme chiffres, qui eftoient les pechez qu'il auoit faits contre ce commandement. Ie ne doute point que fi beaucoup des plus habiles Efpagnols eftoient employez à faire des memoires de chofes femblables par leursimages \& marqués, qu'en vn an ils n'y pourroient paruewir, non pas en dix. 


\section{des Indes. Liure VI.}

es regiffres, Eo façon de conter, dont vfoient les Indiens dic Peru.

CHAPITRE VIII.

V parauant queles Ef pagnols vinfent ésIndes, ceux du Peru n'auoient aucune forte d'efcriture, fuft par letr tres, par characteres, chiffres, ou figu. s, come ceux de la Chine \& de Mexique: tousfoisils ne laifferent pas de conferuer la meoire de leurs antiquitez, ny de retenirl'ordre e toutes leurs affaires, de paix, de guerre, \& de olice, pource qu'ils ont efté forts diligens en la adition des vns aux autres, \& lesieunesgens pprenoient \& gardoient, comme chofe facree, que leurs fuperieurs leur racontoient, \& l'enignoient auec le mefme foing à leurs fuccerurs. Outre cefte diligence, ils fuppleoient la ute d'efcritures $\&$ des letrres, en partie par la einture, comme ceux de Mexiqué(combiễ que sux duPeru y fuffent fort grofsiers \&lourds) $\& x$ 1 partie, \& le plus cómmunement par des quip. os. Ces quippos font des memoriaux, ou regi. res, quifont faicts de rameaux, efquels ily a diers nœuds \& diuerfes couleurs, qui fignifient iuerfes chofes: \& eft vne chofe eftrange, que ce u'ils ont exprimé \& reprefenté par ce nioyen. ar lesquipposleur vallent autant, que les lires d'hiftoires, deloix, de ceremonies, \& des ontes de leursaffaires. Il y auoit des officiers de: utez pour garder ces quippos(qu'auiourd'huy 


\section{Hiftoire naturelle}

ils appellent Quipócamayos ) lefquels eftoien obligéz de tenir $\&$ rédre conte de chaque chof comme les Tabellions par deçà. C'eft pourquo en tout l'o leur adiouftoit entiere foy, \& crean ce, car felon diuerfes fortes d'affaires, comme $d$ guerre, de police, de tributs, de ceremonies, \& d rerres, il y auoit diuersquippos, ou rameaux, e chacun defquels il y auoit tant de nœuds peti \& grands, \& de filletsattachez, les vnsrouges, ls autres verts, les autres azurez, \& les autres blä́c: $\&$ finalement tant de diuerfitez; que tout ain que nous autres tirons vne infinité de mots $d$ vingt-quatre lettres, en les accommodansen di uerfes façons, ainfi ils tiroient des fignificatior innumerables de leurs nouds \& diuerfes cou

- leurs. Ce qu'ils font d'vne telle façon, qu'il arri ue auiourd'huy au Peru, que quand au bout $d$ deux ou trois ans, vn Cómiffaire va informer d la vie de quelque officier, que les Indiens vien nent auec leurs menus contes \& approuuez,d fans, qu'en tel bourg ils luy ont baillé tăt d'œu lefquels ils n'a point payez, en vne telle maifo vne poulle, en vne autre deux faix d'herbes por fes cheuaux, \& qu'il n'a payé que tant d'argen $\&$ demeure en refte de tant. La preuue eftas faite fur le champ, auec cefte quantité $c$ noulds \& de poignees de cordes, cela demeus pour tefmoignage, $\&$ efcriture certaine. Te vi vne poignee de ces filets aufquels vne Indienr portoit efcrite la confefsion generalle dẹ tou favie, \& par iceux fe confeffoit comme i'euf peu faire $\in$ n du papier efcrit, \& luy demanday que c'eftoit, que quelques filez qui me fembl 
des Indes. Liure. VI. :quelque peu differens, elle me diff que c'eent certaines circonttances que le peché reroit pour eftre entierement confeffé. Outre quippos de fil, ils ont vne autre comme maie defcrire auec de petites pierres, par le yen defquelles ils apprennent panctuelleat les paroles qu il ils veulết fçauoir par cœur. oft vne chofe plaifante de voir les vieillards \& ucs, auec vne roüe faite de petites pierres, ap - ndre le Pater noffer, auec vne autre P'A Aue Ma-1 \& auec vne autre le Credo, \& de retenir quelierre eft, qui fut congeunduS. Efprit, \& laquelle, Frit foubs Ponce Pllate. C"eft aufsi vne chole plaite, de les voir corriger quand ils faillent, car tte la correction ne gift qu'à contempler rs petites pierres, \& feroit vne de ces roües fifante pour mefaire oublier tout ce que ie y par cour. Il y a vn grand nombre de ces ies aux cimetieres des Eglifes, pour cét eft. Mais c'eft chofe qui femble enchante:nt de voir vne autre forte de quippos qu'ils it de grains de mays. Car pour faire vn condifficile, auquel vn bon Arithmeticien feroit en empefché auec la plume, \& pour faire vne rtition, à fin de voir combien vn chacun it contribuer, ils tirent tant de grains d'vn fté, \& en adiouftent tant de l'autre, auec il autres inuentions. Ces Indiens prendront urs grains, \& en mettront cinq d'vn cofté, jis d'vn autre, \& huict en vn autre, \& changent vn grain d'vn cofté, $\&$ trois d 'vn autre. Telnent qu'il fortent auec leur conte certain, ns faillir d'vn point. Et fe mettent pluftoft à 


\section{Fiffoire naturelle}

la raifon par ces quippos, fur ce qu'vn chac doit payer, que nous ne pourrions faire nousa tres auec la plume. Par cela l'on peut iugers' ont l'entendement, \& fices hommes font beft De ma part ie tiens pour certain qu'ils nous fu paffent és chofes où ils s'appliquent.

\section{De l'ordre que les Indiens tenoient en beurs efcritures.}

Chapitre. IX.

175 fera bon d'adioufter icy ce que no - auons remarqué touchant les efcrit Q 2 res des Indiens: carleur façon n'eft L pas d'efcrire auec vne ligne fuiu: mais du haut è bas, ou en rond. Les Latins Grecs ef criuoient du colté gauche au droit, $q$ eft la commune, $\&$ vulgaire façon dont no $v$ fons. Les. Hebrieux au contraire comme. çoient de la droite à la gauche, c'eft pourque leurs liures commencent où les noft res finififer. Les Chinois n'efcriuent paś, ny cóme les Grec ny camme les Hebrieux mais de haut en b. car comme ce ne font pas dés lettres, mais d dictions entieres, \& que chaque figure, charactere fignifie vne chofe, ils n'ont poi de befoing d'affembler les parties des vnesau les autres, \& ainfi peuuent-ils bien efcrire haut en bas. Ceux de Mexique pour la mefn raifon n'efcriuoient pas en ligne, d'vn cofté lautre, mais au rebours des Chinois commel 
des Indes. Liure. VI.

287

sen bas, montoient toufiours en haut. Ils fe toient de cefte façon d'efcrire au conte des $r s, \&$ du refte des chofes qu'ils remarquoient. bien que quand ils efcriuoient en leurs roües, fignes, ils commençoient du milieu où ils peijient le Soleil, \& de là alloient montans par rs annees iufques au tour, \& circonference de oile: Finalement ils fe trouue quatre diffetes fortes d'efcrire, les vns efcriuans de la itte à la gauche, les autres de la gauche à la jitte, les vns de haut en bas, \& les autres du. en haut, enquoy l'on voit la diuerfité desendement humains.

mme les Indiës enroyoient leurs ineffagers.

Chapitre $\mathrm{X}$.

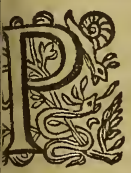

Our acheuer la façon qu'ils auoiét d'efcrire, quelqu'vn pourra douter auec raifon, comment les Roys de Mexique \& du Peru avoient cognoiffance de to us leurs royau: $q$ qui eftoient fi grands, ou de quelle façonils uuoient defpefcher les affaires qui fe prefenient en leur Cour, veu qu'ils n'auoient l'vfage zucunes lettres, ny d'efcrire mifsiues. Surquoy in peut eftre fatisfait de cedoute, quand on aura que par paroles, par peintures, ou par ces emoriaux, ils eftoient fort foutent aduertis de ut ce qui fe paffoit. Pour cét effect il y auoit s hommes fort viftes, \& difpos, qui feruoient 


\section{Hiftoire naturelle}

de courriers, pour aller $\&$ venir, lefquels nourriffoient en cet exercice de courir dés le enfance, \& prenoiết peine qu'ils fuffent de $k$ gue haleine, afin qu' ils peufient monter en co rant vne montagne fort haute, fans le laff C'eft pourquoy en Mexique ils donnoient prix aux trois \& quatriefmes premiers, montoient ces grands degrez du temple, cor me il a efté dit au liure precedent. Et en Cuf, lors que fe faifoit leur folemnelle fefte de $\mathrm{C}$ pacrayme, les nouices montoient à qui mie mieux le roc de Vanacauri, \& generaleme lexercice de la courfé a efté \& eft encor fort vfage entre les Indiens. Quand il fe prefents rne affaire d'importance, ils enuoyoient peinte aux feigreurs de Mexique la chofe do ils les vouloient informer, ainfi qu'ils fires alors que les premiers nauires $\mathrm{E} \int_{\text {pagnols par }}$ rent à leur veüe, \& lors qu ils prindrent Top chan. Ils eftoient au Peru fort curieux des cou riers, \& l'Ingua en auoit par tout fon Roya me, cŏme des poftes ordinaires, appellez Cha quis, defquels fera traitté en fon lieu.

De la façon de gounernement, \& des Roj quiont eu les Indiens.

ChAPITRE XI.

MTy Left affez expérimenté que la cho en quoy les Barbares monftrent pl D. 20 leur barbarifme, eft en leur goune nement, \& façon de commander, pour ce qu tant plus les hommes approchent de la 


\section{des Indes. Liure. VI.}

on, tant plus leur gouuernement eft humain, t moins infolent, \& les Roys \& feigneurs ont plus traittables, \& saccommodent mieux uec leur valfaux, en recognoiffants qu'ils sur font efgaux en nature, \& toutesfois inerieurs en l'obligation d'auoir foing de la Republiq ie. Mais entre les Barbares, tout y cft ontraire, d'autant que leur gouuernement eft yrannique, \& traittent leurs fubjets comme ieftes, \& de leur part veulent eftre traittez omme Dieux. Pour cefte occafion plufieurs euples \& nations des Indes, n'ont point foufert de Roys, ny de feigneurs abfolus, \& fou erains, mais viuent en communauté, \& creent $z$ ordonnent des Capitaines, \& Princes pour ertaines occafions feulement, aufquels ils beyffent durant le temps de leur charge, \& pres ils retournent à leurs premiers offices. a plus grande partie de ce nouueau monde, ù il n'y a point de Royaumes fondez, ny de iepubliques eftablies, ny Princes, ou Roys erpetuels, fe gouuernent de cefte façon; iaçoit u'il y ait quelques feigneurs \& principaux ommes, qui font esleuez entre le vulgaire. infi eft gouuernée toute la terre de Chillé, en quelle les A uracanes, ceux de Teuca pel, \& au. 'es, ont par tant d'années refifté contre les Eragnols. Et de mefme aufsi tout le nouneau oyaume de Grenade, celuy de Guatimall a, les iles, toute la Floride, le Brefil, Luffon, \& d'au'es terres de grande eftenduie, 'excepté qu'en lufieurs de ces lieux ils y font encore plus arbares, veu qu'à peine y recognoiffent ils de 


\section{Hiftoire naturelle}

chef, mais tous commandent; \& gouvernente commun, n'y ayant autte chofe que de la volon té, de la violence, de l'induftrie, \& du defordre tellement que celuy qui peut dauantage, com mande, \& y a le deffus. Il y a en l'Inde Oriental de grands Royaumes, bien fondez, \& \& bien or donnez, comme eft celuy de Sian, celuy de Bif naga, \& autres, qui peuuent affembler \& mettr cn campagne quand ils veulent, iufques à cent \& deux cens mil hommes. Comme aufsi le R oyau me de la Chine, lequelen grancieur \& puiffanc furpafle tous les autres, \& dont les Roys, felo: qu'ils racontent, ont duré plus de deux mil ans pourle belordre \& gouvernement qu'ils ont Mais en l'Inde Occidentale, l'on y a feulemen troutué deux Royaumes, ou Empires fondez qui eftoient celuy des Mexiquains en la neuu. Efpagne, \& celuy des Inguas au Peru. Et $n$ pourrois pas dire facilement lequeldes deux efté le plus puillant Royaume, d'autant qu Motecuma fur paffoit ceux du Peru en edifices $\& \in n$ la grandeur de fa court. Mais les Ingua aufsi furpaffoient les Mexiquains en threfors richeffies, \& en grandeur des Prouinces. Pour 1 , regard del'antiquité, leroyaume desInguas l'ef dauantage, bien que ce ne foit pas de beaucoup $\&$ me femble quils ont efté efgaux en faits d'ar mes, \& en vićtoires. C'eft vne chofe certaine que ces deux Royaumes ont de beaucoup exce dé tout le refte des Seigneuries des Indiens def. couvertes en ce nouueau monde, tant en bon or dre \& police,qu'en pounoir \& richeffe, \& beau. coup dauantage en fuperftition \& foruice de 


\section{des Indes. Liure VI.}

urs idoles, ayans plufieurs chofes femblables svnes aux autres. Mais en vne chofe ils eft toiét ien differens, car entre les Mexiquains la fucefion du Royaume eftoir parefleation, comie l'Empire Romain, \& entre ceux du Peru eleftoit hereditaire, \& fuiuoir l'ordre du fang omme les Royaumes de France \& d'Efpagne. : traicteray donc cy-apres de ces deux gouernements, (comme de la chofe principale \&\& lus cogneuë d'entre les Indiens, ) en tant qu'il jefemblera eftre propre à ce fubiect, laiffane lufieurs chofes menuẹs \& prolixes, qui ne unt pas d'importance.

Du gounernement des Roys \&o Inguas
du Perw.

\section{Chapitie Xit.}

त्रु 'Ingua qui regnoit au Peru eftát mort; 1) fon fils legitime luy fuccedoit, \& teo 7, zónoient pour tel celuy qui eftoir né de la principale femme de l'Ingua, lauelle ils appelloient Coya. Ce quils.ont toufouts obferué depuis le remps d'vn Ingua, apellé Yupangui, qui efpoufa fa foeur. Car ces Loys reputoient pour hóneur d'efpoufer leurs cours. Et bien quilils euffent d'autres femmes un concubines, toutesfois la fuccelfion dus Royaume appartenoir au fils dela Coya. Il eft ray que quand le Roy auoit vri frere legitimie 1 fuccedoit au deuant du fils, \& apres luy fort 


\section{Hiftoire naturelle}

nepueu, \& fils du premier. Les Curacas \& Sei gneurs gardoient le mefme ordre de fuccet fion en leurs biens \& offices. Et faifoient leur mode des ceremonics, \& obfeques excel fiues au deffunct. Ils obferuoient vne couftu me, veritablement gräde \& magnifique, qu'v Roy qui entroit au Royaume de nouueau, n'he ritoit point d'aucune chole des meubles, vten files \& thrcfors de fon predeceffeur, mais il de uoir eftablir fa maifon de nouueau, \& affem bler de l'or \& de l'argent, \& les autres choft quiluy eftoient necellaires, fáns toucher à ce luy du deffunct, qui eftoit totaiement dedi pour fon adoratoire, ou Guaca, \& pour l'entre tien de la famille qu'il laiffoit, laquelle auec fucceffion s'occupoit continuellement aux fa crifices, ceremonies \&: feruice du Roymor Car aufi-toft qu'il eftoit mort, ils le tenoien pour vieu, \& auoit fes facrifices, ftatuës \& au tres choles femblables. Pour cefte occalion y auoit au Peru vn threlor infiny, carvncha cun des Inguas s'eftoit efforcé de faire que fó oratoire $\&$ threfor furpaliaft celuy defes pre deceffeurs. La marque óu enfeigne par la quelle il prenoit la poffeftion du Royaume eftoit vn bourrelet rouge, d'vne laine plus fin que foye, lequel luy pendoit au milieu du frôt n'y ayant que l'Ingua feul quile pouuoit por ter, pour autant que c'eftoit comme la couror ne, \& diadême Royal. Toutesfois l'on pou uoit bien porter vn bourrelet pendu au cofte proche de l'oreille,comme quel ques Seigneu: en portoient, maisl'Ingua feulle pouuoit pot 


\section{Des Indes. Liure VI.}

ter au milicu du front. Au temps quils prenoicnt ce bourrelet, ils faifoient des feftes fort folemnelles, \& plutieurs facrifices auec grande quantité de vales d'or $\&$ d'argent, grand nombre de petites formes, ou images de brebis, faites d'or \& d'argent, grande abondance d'eftoffes de Cumby, bien eflabourees de fine \& de moyenne, plufieurs conches de mer de toures forres, beaucoup de plumes riches, $8 \mathrm{mil}$ mou. tons qui deuoient eftre de diuerfes couleurs. Puisle grand Prettre prenoit vn enfant entre ${ }^{\circ}$ fes mains de l'aage de fix à huict ans, \& prononçoir ces paroles auecles autres miniftres, parlant à la ftatuë du Viracocha, seigneur; noovis $t^{2}$ effroins cela, afin que tu noustitennes en repos, $\mathcal{O}$ nosis aydes en nos guerres, conferue noftre seigneur linguab en fagrandewr of eft at, qui il aille touf fours augmertant, $\mathcal{O}$ luy donne beaucoup de f̧̧auoir afin quilinous goisuerne. Il fe trounoit des hommes de tout lè Royaume, \& detousles Guacas, \& fanctuaires à cefte ceremonie \& ferment. Et fans dotste l'affection \& reuerence que ce pcuple portoit aux Roys Inguas, eftoit fort grande ; car il ne fe trouue point que iamais aucin des fiens's luyaye fait trahifon: pour autant quils procedoient en leur gouuernement non feulement auec vne puiffance abfoluë, mais aufi auec on bon ordre \& iuftice, ne permettant pas qu'aucun y fuft foulé. L'îngua pofoit fes goutuerneurs en diuerfes Prouinces, entrelefquels les vns eftoient fuperieurs, \&z qui ne recognoiffoient autre que luy, d'autres qui eftoiét moindres, \& d'autres plus particuliets auec vo fibel 


\section{Hifoire naturelle}

ordre \& vne telle grauité quils ne s'enhardiffoient pas de s'enyurer, ny de prendre vn efpic de mays de leur voifin. Ces Inguas tenoient pour maxime qu'il conuenoit toufiours entretenir les Indiens en occupation, de là vient que nous voyons encor auiourd'huy des chaufees des chemins, \& des auures d'vn fort grand trauail, lefquels ils difent auoir efté faites pour exercer les Indiens, de peur quils ne denzeuraffent oyfifs. Quand il conqueftoit vne Prouince de nouueau, il auoit accouftumé d'enuoyer incontinent la plus grande part \& les principaux des naturels de ce pays, en d'autres Prouinces, ou bien en fa court, \& les appellent auiourd'huyau Peru, Mitimas. Puis au lieu d'iceux il enuoyoit d'autres de la nation de Cuf$\mathrm{co}$, fpecialement les Oreiones, qui eftoiét com. meles Cheualiers d'ancienne maifon. Ils chaftioient rigoureufement les crimes \& delicts, c'eft pourquoy ceux qui ont cogneu quelque chofe de cela, font bien d'opinion quil n'ypeut auoir de meslleur gouuernement pour les Indiens, ny plus affeuré, que celuy des Inguas. 


\section{des Fndes. Liure VI.}

291

De la diftribution que les Inguas faifoient de leurs vaffaux.

\section{ChAFITRE XIII.}

mananes Our particularifer dauantage ce que (19) i’ay dit cy-dellus, l'on doit fçauoir que la diftribution que faifoient les Inguas de leurs vaflaux, eftoir fi exacte \& particuliere, quil les pouuoit tous gouuerner fort facilement, combien que fon Royaume fuft de mil lieuës d'eftenduë; car ayant conquefté vne Prouince, il reduifoit incontinent les Indiens en villes \& communautez, lefquels il diuifoit en band̨es. Sur çhacune dixaine d'Indiensil en cómettoit vn pour en auoir la charge, fur chaque centaine vn autre, fur chaque millier vn autre, \& $\&$ fur dix mil hommesvn autre, lequel ils appelloient Humo, qui eftoit vne des grädes charges, \& par deffus tous ceuxlà encor, en chaque Prouince il y auoit vngouuerneur de la maifon des Inguas, auquel tous les àutres obeyffoient, \& luy rendoient conte tous les ans par le menu, de tout ce qui eftoit arrịué, à fçauoir de ceux qui eft oient nez, de ceux qui eftoient morts, des trouppeaux \& des femences. Les gouuerneurs fortoient par chacun an de Cufco, où eftoit la court, \& y retournoiér pour la graude fefte du Rayme, en laquelleils apportoient tout le tribut du Koyaume à la court, \& n'y poúuoient r'entrer qu'à cefte condition. Tour le Royaume eftoir diuifé en quz-

Oo iij 


\section{Hiftoire naturelle}

ire parties, quils appelloient Tahuantinfuya, fçauoir Chinchafuyo, Collafuyo, Andefuyo \& Condefuyo, fuiuant les quatre chemins qui forroient de Cufco où refidoit la court, \& fe faifoient les affemblees generales du Royaume. Ces chemins \& Prouinces correfpondantes aे iceux, eftoient vers les quatre coings du móde, Collafuyo au Sud, Chinchafuyo au Nort, Condefuyo au Ponent, \& Andefuyo au Leuant. En roures les villes $\&$ bourgades il y auoir deux fortes de peuple, qui eftoient de Hananfaya $\& e$ Vrinfaya, qui eft comme dire, ceux d'enhaut $\& x$ ceux d'embas. Quand l'on cómandoit de faire quelque œuure, ou de fournir quelque chofe dे I'Ingua, les officiers fçauoient auffi toft de combien chaque Prouince, ville \& partialité y deuoit cótribuer, dót le departement ne fe faifoir point par parts efgales, mais par cottifation, $\mathrm{fe}$ Ion la qualité \& moyens du pays. Tellement que s'il falloit cueillir par maniere de dire, cent mil fanegues de mays, l'on fçauoir auffit toft cóbien il falloit que chaque Prouince en baillaft, fuft la dixiefme partie, la feptiefme, ou la cinquiefme. Autant en eftoit des villes \& bourgades, \& Aillos, ou lignages. Les Quipoca mayos, qui eftoient les officiers \& intendans, renoient le conte de tout auec leurs filetz \& neuds, fans y faillir aucunement, rapportans ce quel'on auoit payé, iufqu'à vne poulle \& vne charge de bois, \& en vn moment voyoit-on par leurs regiftres ce que chacun deuoit payer. 
des fndes. Liure VI.

292

Desedifices \& façon de baftir des: Inguas.

CHAPITRE, XIV.

\% Es edifices \& baftimens que les 25. Inguas ont faits en temples \& for2.7. S (1) ont efté en grand nombre \& d'vn xceffif trauail, comme l'on peut voir encor auourd'huy par les ruines \& veftiges qui en retent, tant en Culco,qu'en Tyaguanaco, Tamo \& en autres endroits, où il ya des piertes l'vne grädeur démefuree : de forte que l'on ne eut penfer cóme elles furent couppees, amesees \& affifes au lieu où elles.eft oilent. Il venoit ngrand nombre de peuple de toutes les Pro: inces pour trauailler à ces edifices $\&$ forterefes que l'Ingua faifoit faire en Cufco, ou en l'autres parties de fon Royaume: d'autant que :els ourages eftoient eftranges, \& pour efpouaenter ceux qui les contemploient: Ils 'n'vSoient point de mortier ou ciment, \& n'atoient point de fer, ny d'acier pout couper \& mettre en œuure les piertes. lls natoient nois plus de machines, ny d'aitres inftruments pour les apporter: \& toutesfois elles eftoient li proprement mifes en @uure, qu'cn beaucoup d'endroicts à peine voyoit-on la iointure des. vnes auec les aurres; \& y a plufieurs de ces pierres fi grandes, comme il eft clict, que ce feroit vne chofe incroyable fi on ne les voyoit. Ie mefuray aे Tyaguanaco vne pierre de trente Oo iiij 


\section{Hiftoire naturelle}

huict pied's de long, de dix. huict de large, \& fir d'efpais. Et en la muraille de la fortereffe di Cufco, qui eft de Moallon, il y a beaucoup ds pierres qui font encor d'vne plus eftrange gran deur, $8 x$ ce qui eft plus efmerueillable, eft qus ces pierres n'eftans point taillees, ny efquarries pour les accommoder, mais au contraire for inegales les vnes aux autres en la forme \& gran. deur, neantmoins ils les ioignoient \& enchaf. foient les vnes auec les autres, fans ciment, d'vne façon incroyable. Tout cela fe faifoit à for. ce de peuple, \& auec vne grande patience a y trauailler. Car pour enchaffer vne pierre auec laurre, felon qu'elles eftoient adiuftees, il eftoit befoing de les effayer, \& manier plufieurs fois la plus-part d'icelles, n'eftans pas efgales, ny vnies. L'Ingua ordonnoit par chacun an le nombre du peuple qui deuoir venir pour trauailler aux pierres $\&$ edifices, \& en faifoient les Indiens le departement entr'eux cóme des autres chofes, fans quaucun fuft toulé. Neantmoins encor que ces edifices fuffent grands, ils eftoient communement mal ordonnez \& incommodes, \& prefque comme les Mofquittes, ou edifices des barbares. Ils n'ont fceu faire d'arcades en leurs edifices ny de ciment pour les baftir. Quand ils virent dreffet des arcs de bois en la riuiere de Xaura, \& apres quele pont fut acheué qu'ils virent rompre le bois, tous commencerent à fuyr, penfans que le pont qui eftoir de pierre de taille deuft tomber à l'inftant; \& comme ils 'eurent veu qu'il demeuroir ferme, \& que les Efpagnols mar: 


\section{des Fndes. Liure Vì.}

oient deffus, le Cacique dift a fes compagnós: eft bien raifon que nous ferrions à ceux $x$-cy qui femblent en efireà la verriéfils du soletl. Les ponts qu'ils faiient eftoient de ioncs tiffus, qu'ils attachoient 1 riuage auec de forts pieux, d'autant qu'ils ne ounoient faire aucuns ponts de pierres, ny de ois. Le pont qui eft aujourd'huy au cours de eau du grand lac de Chiquitro en Collao, eft Imirable: car ce bras d'eau eft fi prófond, que on n'y peut affeoir aucun fondement ; \& fi lare, qu'il n'eft pas poffible d'y faire vne arche qui trauerfe; tellement qu'il eftoit du tout imporble d'y faire aucun pont, fuft de pierre, ou de ois. Mais l'entendement \& induftrie des Iniens inuenta le moyen d'y faire vn pont affez urme \& a afeuré, eftant fair feulement de paille; thofe qui femble fabuleufe, \& toutefois qui eft eritable: car comme nous auons dit cy deffus, $s$ amiaffent \& attachent enfemble certaines ottes de joncs $\&$ d'herbiers qui fiengendrent a lac qu'ils appellent Totora; \& comme ceett ne matiere fort legere, \& qui ne fenfonce pas n'eau, ils iettent deffus vne grande quantité eioncs, puis ayans arrefté \& attaché ces bots d'herbiers d'vn'cofté \& d'autre de la riuiere, s hommes \& les beftes chargez palfent par def. as fort à l'aife. Ie me fuis quelquefois efmerueilen paffant ce pont, de l'artifice des Indiens, eu que d'vne chofe fi facile \& fi communeils ont vn pont meilleur, \& plus affeuré que n'eft as le pont de batteaux de Seuille à Triane. I'ay zefurélalongueur de ce pont, \& fi bien m'en uuient, il eftoit de plus de trois cents pieds, 


\section{Hiftoire naturelle}

\& difent que la profondité de ce courant eff tres-grande, \& femble par deffus que l'eau n': aucun mouuement, toutefois ils difent qu'ai fonds il a vn cours furieux $\&$ violent. Cecy fuf fife pour les edifices.

Du reuenu de l' Ingua, \& de lordre des tribut. gu'il impofoit aux Indiens.

\section{Chattre XV.}

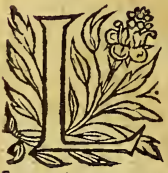

A richeffe des Inguas eftoit in comparable : car bien qu'aucus Roy n'heritaft point des moyen \& threfors de fon predeceffeur neantmoins ils auoient à leur vo lonté toutes les richeffes qui eftoient en leur Royaumes, tant d'argent $\&$ d'or, comme d'e ftoffe, de cumbi $\&$ beftiaux, en quoy ils eftoien tres-abondans; \& la plus gräde richeffe de tou tes eftoit linnumerable multitude de vaffaus qui eftoient tous occupez \& attentifs à ce qu plaifoit au Roy. Ils apportoient de chaque Pro. nince ce qu'il auoit choifi pour fon tribut. Le: Chichas luy enuoyoient du bo is odoriferant \& riche, les Lucanas des bracards pour porter $f_{2}$ litriere, les Chumbilbicas des danceurs; \& ainf rout le refte des Prouinces luy enuoyoit de ce quils auoient en abondance, \& ce outre le tri. bur gerreral auquel tous contribuoient. Les In diens qui eftoient nommez pour cét effect, tra. uailloient aux mines d'argét \& d'or qui eftoien au Peru en grande abondance, lefquels l'Ingua 


\section{des Indes. Liure VI. 294}

retenoit de ce qu'ils auoient debefoin pour rs defpens; \& tout ce qu'ils tiroient d'or $\&$. rgent eftoit pourluy. Par ce moyen il y a eu ce Royaume de fi grands threfors, que c'eft jinion de plufieurs, que ce qui tomba entre mains des Efpagnols, combien que çaic elté grand nombre, cóme nous f̧̧auons, n'eftoit ila dixiefme partie de ce queles Indiens enlyrent \& cacherent, fans qu'on l'aye peu defurir, neantmoins toutes les diligences que larice y a enfeignees pour ce faire. Mais la is grande richelfe de ces barbares eftoir, que rs vaffeaux eftoier tous leurs efclaues, du traI defquels ils ioüiffoient à leur contentemét; ce qui eft admirable, ils fe feruoient d'eux d'v. relle façon, que cela ne leur eftoit pas feruile, mais plufioft vne vie fort delicieufe. Or ur entédre l'ordre des tributs que les Indiens yoient à leurs Seigneurs, on doit fçauoir que s quel'Ingua conqueftoir quelques villes, il diuifoit toutes les terres en trois parties; la emiere d'icelles eftoit pour la Religion \& cemonies; de telle forre que le Pachayachaqui, i eft le Createur, \& le Soleil, le Chuquilla, ii eft le tonnerre, le Pachamama, \& les morts autres Guacas \& fanctuaires euffent chacun urs propres terres, \& le fruict defquelles fe ftoit, \& confommoit en facrifices, \& en la urriture des miniftes \& Preftres: car il anoit Indiens deputez pour chaque Guaca \& fánuaire, \& la plus grande partic de ce reuenu $\{e$ fpendoit en Cufco, où eftoit l'vniuerfel \& ge. ral fanctuaire ; \& l'autre en la mefme ville où 


\section{Hiftoire naturelle}

il fe cueilloir, pource qu'à l'imitation de Cufs il y auoit en chaque ville des Guacas \& oratı res du mefme ordre, \& auec les mefmes fo Cíns, qui eftoient feruis de la mefme façon, ceremonies, que celuy de Cufco, qui eft chofe admirable, \& dont l'on eft bien inform comme on l'a trouué en plus de cent villes, quelques-vnes diftantes deux cents lieiies Cufco. Ce que l'on femoit \& recueilloit en terres, eftoit mis en des maifons comme depo taires, baîties pour cér effect, \& eftoit cela vi grande partic du tribut que les Indiens payoii Ie ne peux dire combien fe montoir cefte pa tie, pource qu'elle eftoir plus grande en des $\mathrm{c}$. droits, qu'en autres, $\&$ en quelques lieux efts prefque le tout, \& cefte partie eftoir la premi re que l'on mettoit à profit. La feconde part desterres \& heritages eftoit pour l'Ingua, del quelle luy \& fa maifon eftoient fuftantez, me me fes parents, les feigneurs, les garnifons, foldats. C'eft pourquoy c'eftoit la plus gran, portion de ces tributs, ainfi qu'il appert par quantiré de l'or, de l'argent, \& autres tribu qui eftoient és maifons à ce deputees, lefquell font plus longues, \& plus larges, que celles l'on garde les reuenus des Guacas. L'on porto ce tribut fort foigneufement en Cufco, ou bis éslieux où il en eftoit de befoing pour lesfo dats. \& quand il y en auoit quantité, on le gas doit dix \& douze ans, iufques au temps de ni ceffité. Les Indiens cultiuoient \& approfitoiet ces terres de l'Ingua, apres celles des Guaca pendant lequel temps ils viuoient, \& eftoier 


\section{des Fndes. Liure VI.}

urris aux defpés de l'Ingua, du Soleil, ou des tcas, felon les terres qu'ils labouroient. Mais rieillards, les femmes $\&$ les malades eftoient ruez \& ex empts de ce tribut; \& combien ce qu'on recueilloit en ces terres, fuft pour gua, ou pourle Soleil, ou Guacas, neantins la proprieté en appartenoit aux Indiens, eurs predeceffeurs. La troifiefme parcie des es eftoit donnee par l'Ingua pour la commuité, \& n'a-on point defcouuert fi cefte por3 eftoit plus grande, ou moindre, que celle Ingua, ou Guacas: tourefois il eft certain. l'on auoit efgard à ce qu'elle fult fuffifante ir la fuftentation \& nourriture du peuple. cun particulier ne poffedoit chofe propre de e troifiefme portion, ny iamaisles Indiens ${ }^{3}$ polfederent, fi ce n'eftoit par grace peciale Ingua, \& toutefois cela ne pouuoit eftre en$e ́$, ny diuifé entre les heritiers. On departoit chacun an ces tetres de communauté, en Ilant à vn chacun ce quil luy eftoit de befoing ir la nourriture de fa perfonne \& famille. ainfi felon qu'augmentoit, ou diminuoit la iille, l'on hauffoit, ou retranchoit la part: car auoit des mefures determinees pour chaque fonne. Les Indiens ne payoient point de tride ce qui leur eftoit departy: car tour leur out eftoit decultiuer , $8 \pi$ maintenir en bon at les terres del'Ingua \& des Guacas, \& de tre les fruicts d'icelles aux depofitairts. land l'annee eftoit fterile, on donnoit de ces fmes fruicts ainfi referuez, aux necefficeux, utåt qu'il y en auoit toufiours de füperabon- 


\section{Hiftoire naturelle}

dant. L'Ingua faifoit la diftribution dubef ainfi que des terres, qui eftoit de le conter \& uifer, puis ordonner les pafturages \& limi pour le beftial des Guacas, de l'Ingua, \& dec que ville; c'eft pourquoy vne partic du reus eftoit pour la religion, vne autre pour le $\mathrm{K}$ \& l'autre pour les mefmes Indiens. Le mel ordre eftoit gardé entre les chaffeurs, n'eft permis d'enlewer, ny de tuer des femelles. rouppeaux des Inguas \& . Guacas eftoient grand nombre, \& fort feconds; pour cefte c feils les appelloient Capaëllama : mais ceu commun \& public eftoient en petit nombre de peu de valeur, parquoy ils les appelloi Bacchailama. I'Ingua prenoit vn grand fo: pour la conferuation du beftial, d'autant c c'eftoit, \& eft encores toute la richelfe de Royaume, \& comme il a efté dit, ils ne fas fioient point de femelles, \& ne kes tuoiét poi ny ne les prenoient à la chaffe. Sila clauelee rongne, qu'ils appellent carache, venoit à qu que befte, elle deuoit eftre à l'inftant enter: route viue, de peur qu'elle ne ballaftle m: d'autres. Ils tondoient le beftial en leur faif $\&$ en diftribuoient à vn chacun pour filer \& tre de la matiere \& eftoffe pour le feruice de famille, y ayant des vifizeurs pour f'enque fils l'accompliffoient, lefquels chaftioient negligents. L'on tiffoit \& faifoit des eftoffes 1. Haine du beftial de l'Ingua, pour luy, \& pc les fiens, l'vne fort fine, \& à deux faces, qu appelloient cübi; \& l'autre grofliere \& moyt ne, qu'ils appelloient Abafca. Il n'y auoit auc 


$$
\text { des Indes. Liure VI. }
$$

ombre de ces eftoffes ou habits arrefté, finon : que l'on departoit à vn chacun. La laine qui ftoit eftoir mife aux magazins, dequoy les E[agnols les trouuerent encores tous pleins, \& toutes les autres chofes neceffaires à la vie umaine. Il y aura peu d'hommes d'entende-ient qui ne foient efmerueillez d'vn fi notable bien ordonné gouuernement, puis que les idiens (fans eftre Religieux, ny Chreftiens) ardoient en leur façon cefte perfection, de ne :nir aucune chofe en propre, \& de pouruoir à utes leurs neceffitez, entretenans fi abondament les chofes de la Religion, \& celles de leur oy \& Seigneur.

es arts \& offices quiexerçoient. les Indiens.

\section{CHAPITRE XVI.}

17. Es Indiens du Peru auoient vne perL 2ection, qui eftoit d'enfeigner à vn - I chacun des petits enfans tous les arts \& les meftiers qui eftoient vtiles, \& ecelfaires pour la vie humaine: la raifon eftoir ource qu'il n'y auoit point entr'eux d'artifans articuliers, commele font entre nousautres es coufturiers, les cordonniers, les tifferans, \& utres; mais tous apprenoient tout ce quils uoient de befoin pour leurs perfonnes \& maions, \& fe pouruoyoient à eux-mefmes. Tous çauoient tiftre \& faire leurs habits, c'eft pouruoy l'Ingua les fourniffant de laine, leur don- 


\section{Hiftoire naturelle}

noit des habits. Tous fçauoient labourer la tes $\mathrm{re}_{2} \&$ l'approfiter, fansloüer d'autres ouurier Tous baftiffoient leurs maifons, \& les femms eftoient celles qui en fçauoient le plus, le: quelles n'eftoient point nourries en delice mais feruoient leurs maris fort foigneufemen I.es autres arts \& meftiers qui n'eftoient poir pour les chofes communes \& ordinaires del vie humaine, auoient leurs propres compagne \& manufacteurs, comme eftoient les orfev re les peintres, les pottiers, les barquetiers, les ci teurs, \& les ioüeurs d'inftruments. Il y ato. auffi mefme des tifferans $\&$ architedtes, pou les ouures exquifes, defquels fe feruoient li Seigneurs mais lecommun peuple, comme a efté dit, auoir chez luy tout ce quil luy eftoit d befoing, pour fa maifon, fans qu'illuy conuin rien acheter. Ce qui dure encores aujourd'huy de forte que nul n'a befoing d'autruy pour le chofes neceflaires, pour fa perfonne, \& pour 1 maifon, comme eft de chaulfure, veftement, $\varepsilon$ de maifon, de femer, de recueillir, \& de faire le ferremens \& inftruments à ce neceff́aires. Le Indiens imitent prefque en cela les inftitution des Moineș anciens, defquels il eft traicté en! vie des Peres. A la verité c'eft vn petrple pe auare, \& peu delicieux; à raifon dequoy ilst $f$ contentent de paffer le temps affez doucement \& gertes fils choifffoient cefte façon de viur par eflection, \& non pas par couftume, ny pa nature, nous dirions que ce feroit vne vied grande perfection, veu qu'elle eft affez idoin pour receuoirla do atrine du fainet Euangile, 
des 7 ndes. Liure $V I$.

ontraire, \& fi ennemie de l'orgueil, de l'auarie, \&z de la volupté. Mais les Predicateurs ne onnent pas roufroursbon exemple, felon la octrine qu'ils prefchent aux Indiens. C'eft vne hofe remarquable; que combien que les Indiés jierit fi fimples en leur mode \& habits, toutejis on y void v ne gráde diuerfiré entre les Proinces, fpecialement en leur habit de tefte : car n quelques endroits ils portent vn long tuffu, uquel ils font plufieurs cours; en d'autres vn utre tiflu large qui ne fait qu'vn tour; en d'autes comme de petits mortiers ou chapeaux; en uelques endroirs comme des bonnets hauts \& onds; \& en d'autres comme des fonds de facs, tuec mil autres differences. Ils auoient v ne loy Atoitte \& inuiolable, qu'aucun ne peutt chanor la mode \& façon d'habits de fa Prouince, ncore qu'il f'en allaft viure en vne autre; ce que Ingua eftimoit eftre de grande importance our l'ordre, $\&$ bon gouuernement de fon coyaume, \& l'obferuent encores aujourd'huy; ien que ce ne foit pas auec vn tel foing qu'ils uoient accouftumé.

Des poftes or Chafquis dont les Inguas fe jeruoient.

ChAPITRE XVII. .

त्र L y auoit yn grand nombre de pofies, (1) \& courriers, dont l'Ingua fe feruoit en tout fon Royaume, lefquels ils appelloient Chafquis, \& eftoient ceux qu ortoient les mandemens aux Gouuerneurs, \& $P p$ 


\section{Hiftoire naturelle}

rapportoient leursaduis \& aduertiffements à cour. Ces Cltafquis eftoient mis \& pofez à cha cune courfe qui eftoit à lieuie $\&$ demie l'vne d l'autre, en deux petites maifons, où ils eftoien quatre Indiens, lefquels on y commettoit d chaque contree, \& eftoientelchangez de moi en mois. Ayans receu le paquet ou meffage, il couroient de toure leur force iufques à ce quil l'eulfent baillé àl'autre Chafquis, eftanstoul jours appareillez \& au guet ceux qui deuoien courir. Ils couroient en vn iour $\&$ vne nuict: cinquante lieuies, combien que la plufpart de $c$ pays-là foit fort afpre. Ils feruoient auffi pou apporter les chofes que l'Ingua vouloit auoi promptement; c'eft pourquoy il y auoit tour jours en $\mathrm{Cu}$ fco du poiffon de mer, frais de deu: iours, ou peu dauantage, bien qu'il en fuft efloi gné de plus de cent lieuies. Depuis que les Efpa gnols y font entrez, l'on a encore vfé de ce Chafquis aux temps des feditions, \& en eftoi grand befoing. Le Viceroy Dom Martin les mi ordinaires à quatre liecies l'vn de l'autre, pou porter \& rapporter les defpefches, qui eft in chofe fort neceffaire en ce Royaume, encore qu'ils ne courent pas auec la legereté que fai foient les anciens, \& quils nefoient pas en grand nombre, neantmoins ils font bien payez \& feruent comme les ordinaires d'ESpagne, oi lon donne les lettres qu'ils portent aे quatre, or cing lieiies. . 


\section{des indes. Liure VI.}

Dela iuffice, loix, \& peines que les Inguas on ordonnés, os de leursmariages.

Chapitre XVIII.

THodenare o v r ainfi comme ceux qui fal. 13 foičt quelque bon feruice en guetr. (1.) (a) re, ou à l'adminiftration de la Re(ur (2) publ. eftoient honorez, \& reGom. Lis 3 pêfez de charges publiques; de terres qui leur eftoient donnees en propres, d'armes $\&$ marques d'honneur, de mariages auec femmes du lignage de l'Ingua: ainfi donnoient. ils de feueres chaftimens à ceux qui eft oient def.obeïlfans $\&$ coulpables. Ils puniffoiét de mort les homicides, les larcins, les adulteres, \& ceux qui cómetroient incefte auec les afcendans, ou der. cendans en droite ligne, eftoient auffi punis de mort. Mais ils ne tenoient point pour adultere d'auoir plufieurs femmes, ou concubines; \& elles n'encouroient point la peine de mort pour eftre trouuees auec d'autres, ains feuleñnét celle qui eftoit la vraye \& legitime efpoufe, aue la- $^{-}$ quelle proprementils contractoient mariage: car ils n'en auoient point plus d'vne, laquelle ils efpoufoient, \& receuoient auec vne particuliere folemnité \& ceremonie, qui eft oit que lefpoux fe tranfportoit à la maifon d'elle, \& de là la menoit auec luy, luy ayant premierement mis au pied vne ottoya. Ils appellent otroya la chauffure dont ils vfent par delà, qui eft vn chauffon ou fouliẹc ounert comme ceuxdes fre:

$\mathrm{P} p$ if 


\section{Hiftoire naturelle}

res de fain ât Fráçois; fi l'efpoufe eftòit pucelle, fon ottoya eftoit de laine: mais fi elle ne l'eftoit, il eftoit fait de jonc. Toutes les autres femmes, ou cócubines du mary honorvient, \& feruoient celle-là comme femme legitime, qui feule aufi apres le deceds du mary, portoit le dueil de noir l'efpace d'vn an , \& ne fe marioit point qu’apres ee temps paffé,\& eftoit communemét plus ieune que le mary. L'Ingua donnoit de fa main cefte fernme à fes gouuerneurs \& capitaines, \& les gounerneurs \& Caciquesaffembloient en leurs villes tous les ieunes hommes \& ieunes filles en vne place, \& leur donnoient à chacun fa femme, auec la ceremonie fufdite, de luv chauffer ceft ottoya, \& de cefte façon contractoiët leurs màriages. Si cefte femme eftoit trouluee auec vn autre que le mary, elle eftoit punie de mort, \& l'adultere auffi: \& bien que le mary leur pardonnaft, elles ne laifoient pas d'eftre punies, mais elles eftoient difpéfees de la mort. Ilsdonnoient vne femblable peine à celuy qui commettoit in. cefte auec fa mere, ayeule, fille, ou petite fille: car il n'eftoit deffendu entr' eux de fe marier, ny de concubiner auecles autres parentes: mais le premier degré feulement eftoit deffendu. Ils ne permettoient point aufft que le frere euft cògnoiffance auec $f_{a}$ four, en quoy ceux du Peru fe trompoient fort, croyans que les Inguias \& Seigneurs pouuoient legitimement contracter inariage auec leurs fours, voire de pere, \& de mere: car à la verité il a toufiours efté tenu pour illicite entre les Indiens, \& deffendu de contrabter au premier degré; ce qui dura iuf- 


\section{des Fndes. Liure VI. 299 .}

quau temps de'Topa Ingua Yupanguí, pere de Guaynacapa, \& ayeul d'A tahual pa, au têps du quel les Épagnols entrerent au Peru, pource que ce Topa Ingua Yupágui fut le premier qui rompir cefte couftume, \& fe maria auec Mamaoello fa four du cofté paternel, \& ordonna que les Seigneurs Inguas fe peuffent marier auee leurs foursde pere, \& non point d'autres. Ce qu'il filt de fa part, \& de ce mariage euft pour fils Guaynacapa, \& vne fille appellee Coya Cuffillimay; fe fentant proche de la mort, il commanda que fes enfans de pere \& de mere fe mariaffent enfemble, \& donna permiffion au refte des principaux de fon Royaume, de fe pounoir marier auec leursfours de pere. Et d'autant que ce mariage fut illicite, \& contre la loy naturelle, Dieu voulut mettre fin au Royaume des Inguas, pendant le tregne de Guafcar Ingua, \& Atahual pa Ingua, qui eftojt le fruict procreé de ce mariage. Qui youdra plus exactement enrendre la façon des mariages entre les Indiens du Peru, quill life le traitré que Polo en a efcrir à l'inftance de pom Hierofme de Loayfa Archecheuefque des Rois, lequel Polo en firt vne fort curieufe recherche, comme il a fair de plufieurs autres chofes des Indiens. Ce qui importe biens d'eftre cogneu, pour euiter l'erreur \& inconuenient où plufieurs tombent, qui ne f̧̧achans quelle femme entre les Indiens eft l'erpoufe legitime, ou la concubine, font marier l'Indien baptizé auec fa concubine, en laiffant là la legitime efpoufe. Par là voit- on auffi te peu de raifon qu'ont eu quelques- vns qui ont pretendy. 


\section{Hifloire naturelle}

dire que l'on deuoit ratifier le mariage de ceux qui fć baptifoient, encore qu'ils fuffent frere \& four.Le contraire a efté determinć par le Syrio.

Conc. Lim. de prouincial de Lyma, auec beaucoup de rai6).?. 2 . fon, puis qu'il eft ainfi qu'entre les Indiens mefme ce mariage n'eftoit pas legitime.

Deliorigine des Inguas Seigneurs du Peru, of de leurs conqueftes of vidioires.

\section{Chapitre Xix.}

sonere $A_{R}$ le commandement de la Maje10) Até Catholique du Roy Dom Philip- Io Ete recherche quilil a efté poffible, de lorigine, couftume, \& priuileges des Inguas, ce que l'on n'a peu faire fi bien comme l'on euft defiré, à caufe que ces Indiens n’auoient point d'efcritures : toưcesfois l'on en a reçouuré ce que j'en diray icy, par leurs quippos 2 regiftres, lefquels, comme jay dit, leur feruent de liures. En premier lieu, il ny auoit point anciennemét au Peru aucun royaume, ny Seigneur à qui tous obeyffent, mais eftoient cômurnautez, comme il y a encor aujourd'huy au royaume de Chillé, \& prefque en toutes les Prouinces que les Efpagnols ont conquifes en ces Indes Occidentales, excepté le Royaume de Mexique. Parquoy on doit f̧̧auoir qu' il f'eft trouué aux Indes trois genres de gouuetnement, \& façon de viure. Le premier \& meilleur a efté de Royaume, ou Monarchie, comme fut celuy des Inguas, $\&$ 
des 7 ndes. Liure VI. $\quad 300$ elay de Motecuma, combien quils furfent en a plus-part tyranniques. Le fecond eftoit de Communautez, où ils fe gouvernoient par l'adis \& authorité de plufieurs, quifont comme Confeillers. Ceux-là en têps de guerre élifoien on Capitaine, a qui toure vre nation, ou Praince obcyffoir, \& en temps de paix chaque vil. e ou congregation fe regiffoit, \& fegounernoir foy-melme, yayant quelques hómes prin. tipaux, que le vulgaire refpecte, \& quelquesfois, mais peu founet, aucuns d'eux faffemblent pour les affaires qui font d'importäce, a afin d'aduifer ce qui leur eft conuenable. Le troifiefme genre de gouucrnemér eft du tour barbare, qui eft compofé d'Indiés fans loy, fans Roy, \& fans licu arrefté, qui vont par trouppes, comme beftes fauruages. A ce que jay peu comprendre, les premiers habitans des Indes eftoient de ce genre, comme le font encores aujourd huy vne grande partie des Brefilliens, Chyraguanas, Chunchos, Y Ycaycingas, PIIlcoçones, \& la plus grande partie des Floridiens, \& tous les Chichimaquas en la neuue Efpagne. De ce genre fo forma l'autre forte de gouuernement en Communautez, par l'induftrie \& Cçauoir de quelques principaux d'entr'eux, efquels sil y a quelque peu plus d'ordre, \& qui tiennent vnlieu plus arrefté, comme le font aujourd huy ceux d'Auracano, \& de Teucapel en Chillé; \& c'eftoient au nouneau Royaume de Grenade les Mofcas, \&z les Ortomittes en la neuue Épagne, \& en tous ceux-cyil y a moins de fiertie, \& beaucoup plus de raifon qu'és aurrès. De ce P $\mathrm{p}$ iij 


\section{Hiftoire naturelle}

genre par la vaillantife \& f̧̧auoir de quelque excellens hommes fortit l'autre gouuernemen plus puiffant qui inftitua le royaume \& la mo narchie que nous trouuafmes en Mexique \& a Peru, pource que les Inguas mirent toute ceft terre en leur fubjection, \& y eftablirent leur loix \& gouuernemét. Il fe trouue par leurs me moires que leur regne a duré plus de trois cent ans, mais n'a pas atteint iufques à quatre cents combien que leur feigneurie ayt efté vn lon temps fans feftendre plus auant que cinq, or fix lieires au tour de Cufco. Leur commence. ment \& leur origine a efté en la vallee de Cuf $\mathrm{Co}$, d'où peu à peu ils conquefterent la terre qui nous appellons Peru, \&z pafferent plus outr que Quirto, iufques à la riuiere de Pafto, ver: le Nort, \& paruindrent iufques à Chillé vers 1 Sud, qui feroient prefque mil lieïes de long. Il f'eftendoit e largeur iufques à la mer du Sud. quileur eft au Ponent, \& iufques aux grandes campagnes qui font de l'autre part de la chaifne des Andes, où l'on voit encor aujourd'huy le chafteau qui fe nomme le Pucara de l'Ingua, qui eft vne fortereffe qu'il filt baftir pour deffenfe, \& frontiere vers l'Orient. Les Inguas ne f'aáuancerent point plus outre de cefte part, pourl'abondance des eaux, marefcages, lacs, \& riuieres qui courent en ces lieux; de forte que la largeur de ce Royaume ne feroit pas droittement de cent lieües. Ces Inguas furpafferent routes les autres nations de l'Amerique, en police \& gouúernement, \& beaucoup dauantage en valeur \& en armes, combien que les Canaris 


$$
\text { des Indes. Liure VI. }
$$
jui eftoient leurs mortels ennemis, \& quifaioriferent les Efpagnols, n'ayent iamais voulu ecognoiftre, ny confeffer cét aduantage fur ux, de telle façon que fi encor auiourd'huy ils viennent à tomber fur ce dilcours \& compa:aifons, \& qu'ils foient vn peu inftiguez, \&z aninez, ils s'entrétueront à milliers fur cefte difoure qui font les plus vaillans, ainfi qu'il cft arriué en Cufco. L'artifice \& couleur de laquelle les Inguas fe feruoient pour conquefter \& fe faire Seigneurs de toute cefte terre, fut en feignant que depuis le deluge vniuerfel, duquel tous les Indiens ont cognoiffance, le monde auoir elté reftauré \& repeuplé par ces Inguas, \& que fept d'iceux fortirent de la calierne de Pacaricambo, à raifon dequoy tout le refte des hó tnes leur deuoient tribut \& vaffellage, comme à leurs progeniteurs: outre cela, ils difoient \& affermoient que eux feuls tenoient la vraye Religion, \& fçauoient comment Dieu deuoir eftre feruy \& honoré, \& que pour cefte occa. fion ils y deuoient inftruire tous les hommes. C'eft vne chofe infinie que le fondemét qu'ils dónent à leurs couftumes \& ceremonies, "\& y auoir en Cufco pluş de quatre cents oratoires, comme en vne terre fainete, \& tous les lieux y eftoiét remplis de lestrs myfteres. Comme ils alloient conqueftans les Prouinces, auffi alloient-ils introduifans leurs mefmes Guacas, \& couftumes. En tout ce Royaumele principal idole quils adoroient, eftoit le Viracocha Pachayachachic, qui fignifie Creatcur du monde, \& apres luy le Soleil. C'eft pourguoy ils 


\section{Hifoire naturelle}

difoient que le Soleil recenoit fa vettu \& for eftre du Createur, ainfi queles autres Guacas \& quils eftoient intercefleurs enuers luy.

\section{Dupremier Ingua, \& de fes fucceffeurs. \\ CHAPITRE XX.}

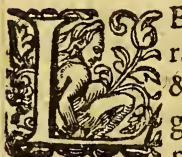

E premier hóme que les Indien. acontent eftre le cúmencemen \& le premier des Inguas, fut $\mathrm{Man}$ gocapa, duquel ils feignent qu'a pres le deluge il fortit de la cauer. ne, ou feneftre de Tambo, qui eft elloignee di $\mathrm{Cufco}$, enuiron de cinq ou fix lieuës. Ils difen que ceftuy-là donna commencement à deus principaux lignages, \& familles d'Inguas, les vns defquels furent appellez Hanancufco, \& les autres Vrinculco. Du premier lignage vin. drent les Seigneurs, qui cốquefterent, \& gou. uernerent cefte Prouince, \& le premier qu'il: font chef, \& fouche du lignage de ces feigneur: que ie dys, s'appelloit Ingaroca, lequel fonda vne famille, ou Aillo, quils appelient, nómes Viçaquiquirao. Ceftuy-là encor qu'il ne fuß pas grand feigneur, fe feruoit neantmoins aues de la vaiffelle d'or \& d'argent, \& ordonna en mourăt, que tout fon threfor fuft deftiné pous le feruice de fon corps, \& pour la nourriture de fa famille: fon fucceffeur en fit de mefme, \& fe courna certe façon de faire, en couftume gene. zale, cóme iay dit, que nul Ingua ne peult he 
des Fndes. Liure VI. 302 or desbiens \& maifon de fon predecelleur, is qu'il fondaft vne nouvelle maifon. Au nps de cét Inguaroça les Indiens auoient des les d'or, \& luy fucceda Yaguarguaque, homdefia vieil, \& difent qu'il eftoit appellé de nom là, qui fignifie larme de fang, pource eayant efté vne fois vaincu, \& prins parfes nemis, de dueil \& ennuyil en pleura du fang. fut enterré en vn bourg appellé Pollo, qui au chemin d'Omafuyo, \& fonda la famille pellee Aocaillipanaca. A ceftuy fucceda vn a fils Viracocha Ingua, qui fut fort riche, fit faire beaucoup de vaiufclle d'or \& d'ar$\mathrm{nt}$ : il fonda le lignage, ou famille de Coccoinaca. Gonfalles Pizarre cherchale corps de fuy-cy, pour la renommee du grand threfor ii eftoit enterré auec luy, \& apres auoir donde cruels tourments à plufieurs Indiens, fin il le trouua en Xaquixaquana, où le mefe Pizarre fut apres vaincu en bataille, prins : fait executer par le Prefident Guafca. GonIles Pizarre fit brufler le corps de ce Viracha Ingua, \& les Indiens prindrent depuis es cendres, lefquelles ils mirent en vn petir afe, \& les conferuerent, y faifans de grands crifices, iufquà ce que Polo y remedia, \& ux autres idolatries qu'ils faifoient fur les orps des autres Inguas, lefquels anec vne adirable addreffe \& diligence, il tira des mains es Indiens, les trouuans fort entiers , \& ort embaufmez, enquoy il efteignit vn grand iombre d'idolatries qua ils y faifoient. Les ndiens srouuerent maunais que cet Inguga 


\section{Hiftoire naturelle}

s'intitulaft Viracocha, qui eft le nom de l, Dieu, \& luy pour s'en excufer, il leur fir enti dre que le mefme Viracocha luy eftoit app: en fonge, quiluy auoit commandé de pren. fon nom. A ceftuy fucceda Pachacuti In Yupangui,qui fut fort valeureux, conquera \& grand politique, inuenteur de la plus gr: de partie des couftumes, \& fuperfitiós del idolatrie comme ie diray incontinent.

De Pachacuti Ingua rupangsi, oo dece 9 aduint depuis fon temps iufquia Guaynacapa.

Chapitre XXI.

9 A с н A C T I Ingua Yupanguireg - 1 foixante $\&$ dix ans, \& conquefta bia coup de pays. Le commencement res conqueftes fut par le moyen d'vn fien fre aifné, qui ayant du viuant de fon pere tenu feigneurie, \& de fon confentement faifoit guerre, fut defconfit en vne bataille quil eu contre les Changuas, qui eft la nation qui po fedoit la vallee d'Andaguayllas, diftante de tr re ou quarante lieuës de Cufco, fur le chemi de Lima. Cét aifné ayant ainfị efté def́cunfit, retira auec peu d'hommes, ce que voyant fo frere puifné Ingua Yupangui, pour fe fair feigneur, inuenta \& mit en auant qu'vn iov luy eftant feul \& ennuyé, le Viracocha Crea teur, auoit parléà luy, fe plaignant que cóbie quil fuft le feigneur vriuerfel, \& Creareur d 


\section{des 7 ndes. Liure VI.}

ites choles, \& qu'il euft fait le Ciel, le Soleil, ande \& les hömes, \& que lef̣tout furt fous uifsăce, toutefois ils ne luy rêdoient l'obeïfce qu'ils deuoient, au contraire, ils honoent \& adoroient efgalement le Soleil, le nere, la terre, \& les autres chofes qui n'aent aucune autre vertu que celle quil leur artoit, \& qu'ill luy faifoir fçauoir, qu' au Ciel il eftoit, l'on l'appelloit Viracocha Pachayachic, qui fignifie Createur vniuerfel, \& afin : les Indiens creuffent que c'eftoir chofe ye, qu'il ne doutaft bien qu'il fult tout feul, euer des hómes fous ce titre, quill luy donoit la victoire contre les Changuas, quoy ils fuffent pour lors victorieux, \& en fi grand nbre, \& le feroit Seigneur de ces Royaus, pource qu'il luy enuoyeroit des hommes luy ayderoient fans eftre veus, \& firtant fur cefte couleur \& fantafie, il commenl'affembler vn grand nöbre de peuple, dont reffa vne puiftànte armee, auec laquelle il int la victoire, fe faifant feigneur du Royau, oftant à fon pere, \& 2 à fon frere la feigneizPuis apres il conquefta, \& defconfit les anguas, \& dés lorsil ordonna que le Viraha feroir tenu pour feigneur vniuerfel, \& les ftatuës du Soleil \& du tonnerre luy feent reuerence \& honneur. Dés ce temps fil'on commença de mettre la ftaruë du Viocha plus haut que celle du Soleil, du ton:re, \& du refte des Guacas. Et iaçoit que cét ¿ua Yupangui euft donné des meftairies, res \& beftiaux zu Soleil, au tonnerre, \&x au- 


\section{Hifoire naturelle}

tres Guacas; il ne dedia toutesfois aucune ch fe au Viracochạ, dónant pour raifon, quiiln auoit point de befoing ; par ce qu'il eftoit 1 gneur vniuerfel, \& creatcur de toutes chol Il declara à fes foldats apres l'entiere victo des Changuas, que ce n'auoient point efté e qui auoient vaincu, mais certains hommes $b$ bus quele Viracocha luy auoit enooyez, que perfonne ne les auoit peu voir que luy, quels du depuis s'eftoient conuertis en pierr parquoy il conuenoit les chercher, \& qu'il recognoiftroit bien, \& pat ce moyen affemt \& ramaffa aux montagnes vne grande mul tude de pierres, quil choifit, \& les mit po Guacas, lefquels ils adoroient, \& leur lac fioient, ils les appellerent. les Pururaucas, \& portoient en la guerre auec grande deuotio tenans pour certain quils auoient obtenu victoire par leur aide. L'imagination \& fiat decet Ingua eut tant de puiffance, que par moyen il obtint de fort belles victoires. Ceft fonda la famille appellée Ynacapanaca, \& vne grandéftatuë d'or, qu'il appella Indillap taquelle il mit en vn brancard d'or, fort rich $\&$ de grand prix , duquel or les Indiens prit dirent beaucoup pour porter àXaxamalca,por la liberté \& rançon d'Athahulpa, quand Marquis François Pizarre le tint prifonniet Le licentié Polo trouua en Cufco dans fa ma fon, fes feruiteurs \& Mamacomas, qui feruoii à fa memoire, \& trouua que le corps auoit eft tranfporté de Patallacta, à Totocache, où de puis les Efpagnols ont fondée la parroiffe 


\section{des Indes. Liure VI!}

las. Ce corps eftoit fi entier, \& bien accornodé, auec certain betum, quil fembloit eftre jut vif. Il auoir les yeux faits d'vne petite tcild'or, fi proprement agencee, qu'ils seraloient des propres yeux naturels. Il awoit en refte vn coup de pierre qu'il euft en vne gueri\& eftoir gris, \& chenu, fans auoir perdu yn :ul cheueu, non plus que sil ne fuift mort que ece iour-là mefine, combien quil y euft plas e foixante $\&$ dixhuiat ans quil eftuit decedé. e fufdit Polo enuoya ce corps auec ceux de uelques autres Inguas, en la cité de Limas par commandement du Viceroy, le Marquis ae ianette, qui eftoit chole fort neceflaire, poiss efraciner l'idolatrie de Cufco, \& plufieurs ETagnols ont veu ce corps, auec les autses eria hofpital fainct André, que fonda ce Marquis, ombien quils fuffent defia bien gaftez. Dorm hilippe Caritopa, qui fur arriere-fils, ou biurriere fils de cér Ingua, affermoit que les riheffes que celuy laifa a $f_{a}$ famille, eftoient randes, \& qu'elles deuoient eftre en la puifance des Yanaconas, Amaro \& Toto, \& a as res. A cét Ingua fucceda Topaingua Yupanui, auquel vn fien fils appelléde mefine nown, acceda, qui fonda la famille appellee Capac tillo. 


\section{Fiftoire naturelle}

Du plus grand or plus illinftre Ingua, appelu Guaynacapa.

Chatitre XXil.

ERe 3 Ce dernier Ingua, fucceda Guay (2) (9.) nacapa, qui vaut autant à dire 4. queieune homme, riche \& va. 19. leureux, \& fut tel à la verité plu: 30 - 20 que nulde fés predeceffeurs, ny de fes fucceffeurs. Il fut fort prudent, \& mit vr fort bon ordre par tous les endroits de fon R oyaume, fut hóme hardy \& determiné, vail. lant \& fort heurewx en guerre. Parquoy il ob. tint de grãdes victoires, il eftendit fon Royaume beaucoup plus que tons fes predeceffeurs enfemble n'auoient fait, \& mourut au Royaume de Quitto, qu' il auoit conquefté, eftăt efloigné de fa Cour de quatre cés lieües. Les Indiēs louurirent apres fon decez, \& en laifferent le cour \& les entrailles en Quitto, \& le corps fut apporté en Cufco, lequel fut mis au renommé temple du Soleil. L'on voit encor auiourd'huy plufieurs edifices, chauffees, fortereffes, \& cuutes notables de ce Roy, \& fonda la famille de Teme Bamba. Ce Guaynacapa fut adoré des fiens pour Dieu, eftant encor en vie, chofe que les vieillards afferment, \& qui ne s'eftoit point faicte à l'endroit d'aucun de fes predeceffeurs. Quand il mourut, ils tuerent mil perfonnes de fa maifon pourl'aller feruir en l'autre vie, lefquels mouroient ainfi fort volontiers pour alIer à fon feruice. Tellement que plufieurs s'offroyent 


\section{des Indes. Liure. VI.} in feruice. Tellement que plufieurs f'offroient la mart pour le mefme effect, outre ceux qui y toient deftinez. Et eftoit vne cho fe admirable ue fa richefle \& fon threfor. Et d'autant que eu de temps a presfa mort les Efpagnois y enerent, les Indiens prirent beaucoup de peiné our faire difparoiftre le tout, combien qu'il en euft vre grande partie qui fut portee $\mathrm{d} \mathrm{Xa}$ imalca, pourla rançon de Atahulpa fonfils. yelques hommes, dignes de foy, afferment u'il auoit en Cufco plus de trois cens fils, \& arere-fils. Sa mere appellee Mamaoello, fut en'eux fort eftimee. Polo enuoya en Lyma les orps d'icelle, \& de Guaynacapa , fort bien em. aufmez, \& defracina vne infinité d'idolatrie ue l'on faifoit en cét endroit. A Guaynacapa icceda en Cufco vn fien fils nommé Titocuisidalpa, qui depuiss'appella Guafpar Ingua, fon rrps fut bruslé par les Capitaines de Atahulpa, ai fut aufsifils de Cuaynacapa, \& lequel fe re. ella en Q gitto contre fon frere, \& marcha coneluy auec vne puiffante armee. Il arriua que, guifquits \& Chilicuchi, Capitaines de Atahul, prindrent Guafpar Ingua en la Cité de Cur, apres qu'il eut efté receu pour Seigneur $8 c$ oy (car il eftoit legitime fucceffeur) ce qui uffa en tout fon Royaume vn grand dueil, $f$ pealement en fa court. Et comme toufiours en urs recefsitez ils auoient recours aux facrifis, ne fe trouuans alors affez puiflans pour meteleur Seigneur en liberté, tant pour les forces es $C$ apitaines qui le prindrent, comme pourla rofle armee qui verioit auec A tahulpa. Ils del:

$$
\text { Q4 }
$$




\section{Hiftoire naturelle}

bererent (voire quelques-vns difent que ce ful par le commandement de cét Ingua) de faire vr grand \& folemnel facrifice au Viracocha $\mathrm{Pa}$ chayachachic, quifignifie Createur vniuerfel, luy demandant que puis qu' ils ne pouvoient de liurer leur Seigneur, il enuoyaft du Ciel de hommes quile deliuraffent de prifon. Et comms ils eftoient en grande ef perance fur ce facrifice, $i$ leur vint nouuelle comme vn certain peuple qu eftoit venu parmer, auoit mis pied à terre, \& prins prifonnier A tahulpa : pour cefte occalio ils appellerent les Efpignols Viracochas, croya qu'ils eftoient hommes enuovez de Dieu, tan pour le petit nombre qu'ils eftoient à prendr Atahulpa en Xaxamalca, comme pource que cela aduint incontinent apres leur facrifice furdit fait au Viracocha. Et de là vint qu'ils com. mencerent d'appeller les Efpagnols Viracochas comme ils le font auiourd'huy. Et à la verité, $f$ nous leur eufsions donné vn bon exemple, \& te que nous deuions, ces Indiens auoient bien rencontré, difans que c'eftoient hommes enuoye: de Dieu. Et eft vne chofe fort confiderable, qu la grandeur \& prouidence divine, comme il dif pofa l'entrce des noftres au Peru, laquelle euf efté im pofsible, n'euft eft é la diffenfion des deus freres, \& de leurs partifans, \& l'opinion fi grande qu'ils eurent des Chreftiens, comme d'homme du Ciel; obligez certes en gagnant la terre de Indesà prendre peine de faire gagner beaucour d'amesau Ciel. 


\section{des Indes. Liure VÎ.}

Des dermiers fucceffeurs des Inguas.

ChAPITRE XXIII.

Fir E refte de ce fubiet eft affez amplement traitté par les autheurs Efpagnols aux hiftoires des Indes, \& d'autant que cela outre la prefente intention, ie diray feuleent de la fuccefsion qu'il y eut des Inguas. Ataalpa eftant mort en Xaxamalca, \& Guafcar en ufco, \& François Pizarre auec les fiens s'eftant nparé du Royaume, Mangocapa fils de GuayIcapa les afsiegea en Cufco, '\& les tint fort eflez, mais en fin il quitta tout le pays, \& fere2 en Vilca-bamba aux montagnes, efquelles il maintint à caufe de l'afpreté \& difficile ac$z$ d'icelles, \& là demeurerent les fucceffeurs guas, iufques à A maro, qui fut prins \& execuen la place de $\mathrm{Cufco}$, auec ine incroyable suleur, \& regret des Indiens, voyans publiqueent faire iuftice de celuy qu'ils tenoient pour igneur. A pres cela l'on en emprifonna d'aues du lignage de ces Inguas; i'ay cogneu Iom Charles, petit fils de Guaynacapa, \& Is de Polo, quife fit baptifer, \& fauorifa toufurs les Efpagnols contre Mangocapa fon ere. Lors que le Marquis de Canette gouanoit en ces pays, Sarritopaingua fortit de ilca bamba , \& vint foubs affeurance à la Citế is Roys, ou luy fut donnee la vallee Yucay, d'autres chofes, à quoy fucceda vne fienne

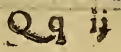




\section{Hiftoire naturelle}

fille. Voila la fuccefsion qui eft auiourd'huy co gneiie de cefte fi grande $\&$ riche famille des In guas; defquels le regne dura plus de troiscen ans, oti l'on conte onze fuccefleurs en ce Roya u me, iufquesà ce qu'il ceffa dutout. En l'autr. partiallite \& V rincuifo, qui comme a efté dit c: deflus, eut fon origine mefme du premierMan. gocopa, l'on conte huiet fucceffeurs en cefte ma niere: A Mangocapa fucceda Cinchoroc?, àce. ftuy, Capac Yupanguy, à ceftuy, Luquy $Y$ upan guy,à ceftuy, Maytacapaefte Tarcogumam, au quelfucceda un fien fils, qu'ils ne nommét point àce fils fucceda Dom Iean Tambo Maytapa naca. Cela fuffife pour l'origine \& fuccefsio des Inguas qui gouuernerent la terre du Peru avec ce qui a efté dit de leurs loix: gouuerne ment, $\&$ maniere de viure.

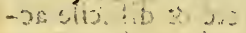

De la maniere de Republique qua auoient les Mexiquains.
CHAPITREXXIII.

Ombien que l'on pourra voir pa (3) I' Inftoire qui fera efcrite du Royau - (1) me, facectsion, \&originé des Mexi 20. quains, teur maniere de Republiqu a goưuernement, fieft ce toutesfois que ie di ray icy fommairement ce qui me femblera plu remarquable en general ${ }^{\text {; }}$ dont il fera cy apre plusamplement difcouru en l'hiftoire. La pre miere chofe par laquelle on peut juger que 
des fndes. Liure. VI.

uuernement des Mexiquains a efté fort poli,eft l'ordre qu' ils auoient, \& gardoient inuio: lement d'eslire vn Roy. Pource que depuis premier qu'ils eurent, appellé Acamapach, ques au dernier qui fut Moteçuma, feconä de nom, il n'y en eut aucun qui vint au Royaupar droit de fuccefsion, ains feulement y veient par vne legitime numination, \& eslection. fte eslection au commencement eftoit aux ix du commun, combien que les principaux Tent ceux qui conduifoient l'affaire. Dudeis au temps d'Yfcoalt quatriefme Roy, parle infeil \& ordre d'vn fage \& valeureux homme, 'ils auoient appellé Tlacael, il y eut quatre ecteurs certains \& arreftez, lefquels aueç deux igneurs, ou Roys, fujetsau Mexiquain; qui oient celuy de Tefcaco, \& celuy de Tacu, auoient droit de faire cefte eslection. Ils ef jient ordinairement pour Roys, desieunes mmes, pource que les Roys alloient toujours guerre, \& eftoit prefque la principale occan pourquoy ils les vouloient. C'eft pourquoy prenoient garde qu'ils fuffent propres \& sines à la guerre, \& qu ils prinflent plaifir, \& glorifiaffent en icelle. A pres l'eslection ils faient deux manieres de feftes, l'u ne en prenant ffefsion de l'eftat Royal, pour laquelieilsalent au temple, \& faifoient de grandes cere. onies, \& facrifices fur le brafier a ppellé diuin, il y auoit toufiours du feu deuine l'autel de lole, \& apres, quelques R hetoriciens quifeidioient en cela, faifoient plufieurs oraifons \& rangues. L'autre fefte \& la plus folemnelle,

Qqiij 


\section{Hiftoire naturelle}

eltoir de fon couronnement, pour laquelle deuoit premierement vaincre en bataille, $\&$ am ner vn certain nombre de captifs, quel'on deuc facrifier à leurs dieux, \& entroit en triompl auec vne grande pompe, luy faifans vne foler. nelle reception, tant ceux du temple, lefqur alloient tous en procefsion, touchans $\&$ ioüa de plufieurs fortes d'inftrumens, \& encenfans chantans comme les feculiers, \& les courtifar. qui fortoient auec leurs inuentions à receuoir Roy victorieux. La couróne \& enfeigne Roy le eftoit en façon-de mitre pardeuant, \& eftc par derriere coupee, de forte qu'elle n'eftoit $\mathrm{p}$ toute ronde, car le deuant eftoit plus haut, \& a loit s'esleuant comme en poincte. Le Roy ، Tefcuco auoit le priuilege de couronner de main le Roy de Mexique. Les Mexiquainso efté fort loyaux \& obeyffans à leurs Roys, \&: fe trouue point qu'ils leur ayent fait de trahifo Les hiftoires racontent feulement qu'ils tafch rent de faire mourir par poifon leur Roya pellé Ticocic, pour auoir efté coüard \& de pr d'effect. Mais il ne fe trouue point quil y ait, entr'eux de diffenfions, \& partialitez par amb tion, combien que ce foit chofe affez ordinaire communautez: au contraire elles racötent con mel'on verra en fun lieu, qu'vn homme le me: leur des Mexiquains, refufa le Royaume, h femblant qu'il eftoit expedient à la Republiq d'auoir vn autre Roy. Au commencement q les Mexiquains eftoient encor pauures, \& af petits compagnons, les Roys eftoient fort mod rez à leur entretien, \& en leur cour, mais coms 


\section{des Indes. Liure VI.}

ils augmenterent en pouuoir, ils augmenterent aufsi en appareils \& en magnificence, iufques à paruenir à a grandeur de Motecuma, lequel quan il n'euft eu autre chofe que la maifon des animaux, c'eftoit vne cho'e alfez fu perbe, \& telle qu'on $n$ en a iamaisveu d' :utre femblable. Car il y alloit en cefte fienne $m \rightarrow$ ifon de toutes fortes de poifons, d'oyfeaux de Xacamamas, \& de beftes, comme en vne autre arche de Noé. Pour les poiffons de mer, il y auoit des eftangs d'caule fa. lee, \& pour ceux des riuieres, des eftangs d'eaüe donce. Les oyfeaux de proye y auoient leurs viandes, \& les beftes fieres aufsi en fort grande abondance, \& grand n more d'Indiens eftuient occupez à entretenir ces animaux. Quand il voyoit qu'il n'eftoit pas pofsible d'entretenir, ou noursir quelque forte de poifsó, d'oyfeau, ou de befte fauuage, il en faifoit faire l'image \& la femblance richement taillee en des pierres precieufes, en argent, en or , en marbre ou en pierre : \& pour toutes fortes d'entretiens, il auoit desmaifons \& palais diuers, les vns de plaifir, les autres de dueil \& trifteffe, \& lesautres poury traitter les affaires du Royaume. Il y auoit en ce palais plufie ars chambres, felon la qualité des Seigne urs qui le feruoient auec vn eftrange ordre \& diftinction.

Qq iiij 


\section{Hiftoire naturelle}

\section{Destiltres \& dignitez quieftoient entre les Mexiquains.}

\section{Chapitre XXV.}

Wh Es Mexiquains ont efté fort curieux

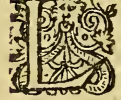
de departir les grades $\&$ dignitez entre les nobles. \& les Seigneurs, à fin que l'on recogneuft ceux d'entr'eux aufquels l'on deuoit faire plus d'honneur. La dignité des quatre eslecteurs eftoit celle qui eftoit la plus grande \& la plus honorable apresle Roy, $\&$ les eslifoit-on ircontinent a pres l'eslection du Roy. Ils eftoient ordinairement freres; ou fort proches parens du Roy, \& les appelloient $\mathrm{Tla}$ cohecalcalt, qui fignifie Prince de laces que l'on iette, ou darde, qui eft vne forte d'armes, dont Ils vfoient foument.La dignité d'a pres eftoit celle de ceux qu'ilappelloient 'Tlacatecati, quieft à dire, circoncifeurs, ou coupeurs d'hommes. La troifiefme dignité eftoit de ceux qu'ils appelloient Ezuahuacalt; qui fignifie, ef pandeur de fang par efgratignement, Tous lefquels tiltres \& dignitez eftoient exercez par des hommes de guerre. Il y auoit vnautre quatriefme intitulé Tlilancalqui, qui vaut autant à dire, que Sei* gneur de la maifon noire, ou de la noirceur, à caufe d'vn certain encre, duquel les Preftres s'oignoient , \& qui feruoit en leurs idolatries. Toutes ces quatre dignicez eftoient du grand Confeil, fansl'aduis defquels le Roy ne faifoit, 


\section{des Indes. Liure. VI. 309}

y pounoit faire aucune chofe d'importance, $\&$ Roy eftant mort, l'on en deuoit eslire en $f_{2}$ lace vn qui fuft en quelqu' vne de ces quatre dinitez. Il y auoit aufsi, outre ceux-là, d'autres onfeils, \& audience, \& difent quelques-vns qu'il , en auoit autant comme en Efpagne, \& qu'ily uoit diuers fieges \& iurifdictions auec leurs Zonfeillers \& Alcades de court, \& d'autres qui eur eftoient foubmis, comme corrigidors, alcales Maieurs, Lieutenans \& Alguafits Maieurs, \& lautres qui eftoient encor inferieurs \& foubfnis à ceux-cy auec vn fort bel ordre. Tous lefunels defpendoient des quatre premiers Princes jui afsiftoient au Roy. Ces quatre tant feuleaent auoient iurifdiction \& puiflance de conlamner à la mort, \& les autres leur enuoyoient les memoires des fentences qu'ils donnoient: tumoyen dequoy en certain temps l'on faifoit ntendre au Roy tout ce qui fe paffoit en fon 2oyaume. Il y auoit mefme vn bon ordre $\&$ olice eftablie fur le reuenu du Royaume : car y auoit des ofliciers departis par toutes les rouinces, comme des Receueurs, \& Threfoiers, qui recueilloiět les tributs \& rentes Royaes. L'on portoit le tribut en la court pour le noins de mois en mois, lequel eftoit de tout ce ui croift \& s'engendre en la terre, \& en la mer, ant de ioyaux \& d'habits, que de viandes. Ils ftoient fort foigneux de mettre vn bon ordre en e qui touche leur religion, fuperftition \& ido. atrie : \& pour cefte occafion y atoit vn grand ombre de miniftres qui auoient la charge d'eneigner au peuple les couftumes \& ceremonies 


\section{Hijtoire naturelle}

de leurloy. C'eft pourquoy fur ce qu'vn Pre Itre Chreftien vn iour fe plaignoit que les In diensn'eftoient pas bons Chreftiens, \& ne prof coient point à la loy de Dieu : vn vieillard Indie. luy refpondit fort à propos en cestermes: Que li Preftres (dic il) employent ausart de foun o de diligence. faire les Indiens chrefizens, que les miniftes des idols employẽt à enfougner leurs ceremonies, car auec la moitiéd four qui ils y prendront, ils nous rendrout les meilleurs Chre fiens dus monde, poutce que la loy de IEsvs-CHRIs ef beaucous merlleure: niais les Indiens ne l'apprenner. point à faute de gens qui la leur enfergnent. En quo: certainement il dit verité, à noftre grand hont \& confufion.

Comment les Mexiguains faifoient la gueryt or de leurs ordres de Chewalerie.

\section{Chapitre XXVI。}

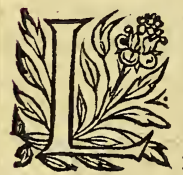

Es Mexiquains donnoient le pre mier lieu d'honneur à l'art \& pro fefsion militaire : c'eft pourquo: lesnobles eftoient les principau: foldats, $\&$ les autres qui n'eftoien point nobles par la valeur \& reputation qu il acqueroient en guerre, paruenoient en des di. gnitez \& honneurs: de forte qu'ils eftoient tenu pournobles. Ils donnoient de belles recompen fes à ceux qui auoient fait valeureufement, lef quelsiouyffoient de privileges que nui autre n pounoit auoir : ce qui les encourageoit beau coup. Leurs armes eftoient des razoirs de cail 


\section{des Indes. Liure. VI.}

quils mettoient des deux coftez d'vn bafton, qui eftoit furieufe, qu'ils afferment que d'vn feul coup ils en coú poient le col à vn cheual. Ils auoiêt de fortes \& pefantes mafliës, des lances en façon de pi ques, \& d'autres façons de dards à ietter, à quoy ils eftoient fort adroits, \& faifoient la plus-pare de leur combat auec des pierres. Il auoient pour armes deffenfiues de petites rondelles ou efcus, \& quelque façon de falades \& morions enuironnez de piumes. Ils fe veftoient de peaux de tigres ou lyons, \& d'autres animaux fauudges. Ils venoient incontinent aux mains auec l'ennemy, \& eftuient fort exercez à courir \&à luicter. Car leur principale façon de vaincre n'eltoit pas tant en tuant, comme en prenant des captifs, defquels ils fe feruoient en leurs facrifices, comme il a efté dit. Motecuma mit la cheualerie a fon plus haut poinct, en inftituant certains ordres militaires, comme de Commandeurs, auec certaines marques \& enfeignes. Les plus honorables d'entre les Cheualiers eftoient ceuxqui portoient la couronne de leurs cheueux attachee auec vn petit lizet rouge, 8 auec vn riche plumache, d'où pendoient fur leurs efpaules des rameaux de plumes, \& des bouriets de mefme. Ils portoient autant de ces'sourlets cóme ils auoient fuit d'actes fignalez en guerre. Le Roy mefme eftoit de ceft ordre de cheualerie, commel'on peut voir en Chapultepec, où eftoient Motecuma \& fon fils accouftrez de ces façons de plumaches, taillez en vne roche, qui eft vne chofe digne de voir. Il y anoit vn autre ordre de cheualerie, qu'ils ap: 


\section{Hiffoire naturelle}

pelloient leslyons \& les tigres, lefquels eftoient communement les plus valeureux, \& qu'on remarquoit le plus en guerre, où ils alloient, portans toufiours leurs marques \& armoiries. Il y auoit d'autres Cheualiers, comme les Cheualiers Gris, qui n'eftoient en telle eftime comme ceux-cy, lefquels aucient les cheueux coupez en rond par deffus l'oreille. Ils alloient à la guerre, portans de mefmes marques que les autres Cheualiers, toutesfois ils n'eftoient point armez que iufques à la ceinture, mais les plus honorables s'armoient entieremêt. Tous les Cheualiers pouuoient porter de l'or \& de l'argent, \& fe veftir de riche cotton, fe feruir de vafes peints $\&$ dorez, \& porter desfouliers à leur mode; mais le commun peuple ne pounoit fe feruir que de vafes de terre, ne leur eftant pas permis de porter des fouliers, \& ne pouuoient fe veftir que deNequen, qui eft vne matiere grofsiere. Chacun ordre de ces Cheualiers auoit fon logis au Palais, marqué de leurs marques, le premier eftoit appellé,le logis des Princes, le fecond, des Aigles,le troifiefme, des lyons \& tygres, \& le 4. des Gris. Les autres officiers communs eftoient en bas, logez en des moindres logis : \& fi quelqu'vnfe logeoit hors de fon lieu, il encouroit peine de
mort. 


\section{des Indes. Liure. VI}

Du graind ordre, of dilizence que les Mexiquains employoient à nourrir la ieuneffe.

Chapitre. XXVII.

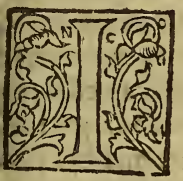

L n'y a chofe qui m'aye dóné plus d'occafió d'admirer, ny que i’aye trouuee plus digne de loüange 2 de memoire, que l'ordre \& le foing que les Mexiquains auoient à nourrir leurs enfans. Car ils recognoffoient bien que toute la bonne efperance d'vne Republique confifte en la nourriture $\&$ inftitutió de la ieuneffe; ce que Platö traicte affez am plement: en fes liures, de legibus. Et pour cefte occafion ils s'eftudierent \& prindrent peine d'esloigner leurs enfans, des delices, $\&$ de la liberté, qui font les déux peftes de cét aage, en les occupans en des exercices honneftes, \& profitables. Pour cét effect il y auoit aux Temples vne maifon particuliere d'enfans, comme des efcholles, ou colleges, qui eftoit feparée de celle des ieunes hommes, \& des filles du Temple, dont nous auơs amplement traicté cy-deuant. Il y auoit en ces efcholles vn grand nombie d'enfans, que leurs peres y menoient volontairement, lefquels auoient des pedagogues \& maiftres; qui les enfeignoient en tous loüables exercices; à eftre bien nourris, porter refpect aux fuperieurs, à feruir \& à obeïr, leur donnans à cefte fin certains preceptes \& enfeignements. Et afin qu'ils 


\section{Hiftoire naturelle}

fuffent agreables aux Seigneurs, ils leur apprenoient à chanter, \& à dancer, \& les dreffoient aux exercices de la guerre, qui à tirer vne flefche, vn dard, ou bafton bruslé par le bout, \& à bien manier vne rondelle $\&$ vne efpee.Ils ne les laiffoient gieres dormir, à fin qu'ils raccouftumaffent au trauail dés l'enfance, \& qu'll ls ne fufsẻt point hŏmes de delices. Outre le nombre cómun de ces enfans, il y auoit aux mefmes colleges d'autres enfans des Seigneurs, \& nobles, lefquels eftoient plus particulierement traictez. On leur portoit leur manger $\&$ ordinaire de leurs maifons, \& eftoient recommandez à des vi illards \& anciens pour auoir efgard fur eux, lefquels continuellement les admöneftoient d'eftre vertueux, de viure chaftement, d'eftre fobres au manger, de ieufner, \& de marcher pofémët, \& auec mefure. Ils auoient accouftumé de les exercer au trauail, $\& \in n$ des exercices laborieux : \& quand ils les voyoient inftruits en tous ces exercices ils conf 1 . deroient attentiuemét leur inclination, \& sillsen voyoient quelques vns auoir l'inclination à la guerre, a pres qu'ilsauoient atteint l'aage fuffifant, ilsrecherchoient l'occafion de les ef prouuer, en les enuoyant à la guerre, foubs couleur de porter des viures, \& des munitions aux foldats, à fin qu'ils viffent là ce qui s'y paffoit, \& le trauail que l'on enduroit. Et à fin qu'ils perdiffent la crainte, ils les chargeoient aufsi de pefants fardeáux, à fin que monftrans leur courage en cela, ils fuffent plus facilement recelis en la com: pagnie des foldats. Parce moyen il aduenoit à plufieurs d'aller chargez à l'armee, \& retournes 


\section{des Indes. Liure VI.}

apitaines, auec marques d'honneur. Quelques. ns d'iceuxfe vouloient tellement faire pirojre, qu'ils demeuroient prins ou morts, \& teoient pour moins honorable de demeurer prionniers. C'eft pourquoy ils fe faifoient pluft oft iettre par pieces, que de tomber captifs entre smains de leurs ennemis. Voilà comment les nfans des Nobles qui auoient l'inclination à la uerre, yeftoiét employez.Les autres qui auoiét fur inclination aux chofes du temple, \& pour le ire, à noftre mode, à eftre Ecclefiaftiques, a pres u'ils auoient atteint l'aage fuffifant, eftoient tiz du college, \& les mettoit on au logis du mple, quieftoit pour les Religieux, \& leur onnoit on alorsleurs ordres \& marques d'Eclefiaftiques. Là ils auoient leurs Prelats \& maires, quil leur enfeignoiēt ce qui eftoit de la pro: fsion où ils deuoient demeurer, $y$ ayants efté edies. Ces Mexiquains prenoient vn grăd foing nourrir les enfans; que fi auiourd'huy ils fuioient encor cét ordre, en fondant les maifons \& olleges, pour linftruction de la ieuneffe, fans oubte que la Chreftiente floriroit beaucoup ntre les Indiens. Quelques perfonnes pieufes ont commencé, \& le Roy \& fon Confeill l'ont 'uorifé, mais d'autant que c'eft vne chole où il. 'y a point de profit, il s'aduance bien peu, \& y a l'on affez froidement. Dieu nous vueille ef larcir les yeux, a fin que nous voyons que cela it à noftre cófúfion, veu que nous autres Chretiens ne faifons point ce que les enfans des teneres faifoient à leur perdition, en quoy nous hous oublions de noftre deuoir. 


\section{Hiftoire naturelle}

Des feftes, \& dances des Indiens.

Chapitre XXVIII.

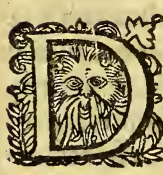

'Autant que c'eft vne chore qu defpend en partie du bon gouuer. nement, d'auoir en 1 a Republi. que quelques ieux, \& recreations quand il en eft temps;il ne fera ma. â propos que nous racontions fur ceftematiere, ce que faifoient les Indien's, principalement le: Mexiquains. L'on n'a point defcouuert és Inde: aucune nation qui viue en communautez, qui n'ayt fon entretien, \& fa recreation, en ieux, dances, \& exercices de plaifir. I'ay veu au Peru des ieux qu'ils faifoient en façon de combat, aufquels les hommes des deux coftez s'enfla mboiêt quelquesfois d'vine telle façon, que bien foutent leur Paella (qui eftoit le nom de cét exèrcice) venoit à eftre dangereufe. I'ay veu aufsi plufieurs fortes de dances, efquelles ils contre-faifoient, \& reprefentoient certains meltiers, \& offices, comme de bergers, laboureurs, pefcheurs, \& chaffeurs, \& faifoient ordinairement toutes ces dances, auec vn fon $\&$ vn pas fort pefant, \& fort graue. Il y auoit d'autres dances $\&$ ma fcatades, quills appelloiét guacones, dont-les mafques; $\&$ les geftes eftoient pures reprefentations du drable. Il y auoit mefme des hommes qui dancoient fur les efpaulles les rns des autres en la façon 


\section{des Indes. Liure VI.}

açon qu'ils portent en Portugal, ce qu'ils apellent les Paéllas. La plus grande partie de ces ances eftoient fiperftitions \& efpeces d'idotrie, pource qu'ils honoroient leurs idoles i Guacas en cefte façon. Pour cefte occafion as Prelats fe font effurcez de leur ofter, le plús u'ils ont peu, de ces dances, combien qu'ils les iiffent à caufe qu'vne partie ne font que ieux e recreation, car touf joursils dancent, \& balent à leur mode. Ils vent en ces dances de plueurs fortes d'inftruments, dont les vns font omme fluftes ou petits canons, les autres comie tambours, \& les autres comme cornets enortilles : mais communement ils y chantent ousa la voix, \& y en a vn ou deux qui chantent remierement la chanfon, puis tous les autres iy refpondent. Quelques-vnes de ces chanons eftoient fort ingenieufement compofées $\tau$ contenants des hiftoires : d'autres eftoient leines de fuperftitions, $8 x$ les autres n'eftoient ue pures folies. Les noftres qui conuerfent ntr' eux, ont effayć de mettre les chofes de no. re faincte Foy en leur façon de chant. Ce qua affez bien profité, d'autant qu'ils employent s iours entiersà les chanter \& reciter, pour grand plaifir \& contentement quils prenent à ce chant. Ils ont mis mefmes à leur lanue de nos compofitions de mufique, comme es Huictains, Chanfons \& Rondeaux, lefquels sont fort proprement tournez, qui eit à la veté vn beau \& fort neceffaire moyen pour in: ruire le peuple. Ils a ppelloient communemẽ u Peru des dances, Tagui, és autres Prouinces 


\section{Hifroire natureile}

Areittos, \& en Mexique Mittotes. Et n'y a point eu en aucun autre lieu vne telle curiofité de ces ieux \& dances, comme en la neuue Efpagne, 'où l'on voit encore auiourd'huy de: Indiens $\sqrt{1}$ brauesfauteurs, que c'eft vne chofe admirable. Les vas dancent fur vne corde, les autres fur vn pieu haut $\&$ droit en mille façons. Lesautres auec la plante des pieds \& les iarets, manient, iettent en haut, \& reçoiuent vn trons fort pefant: ce quifemble incroyable, fi ce n'eft en le voy ant. Ils font plufieurs autres demon. Atrations de leur grande agilité, en fautant, voltigeant, faifans des fouples-fauts, tantoft portans vn grand \& pefant faix, tantoft endurans descoupsqui feroient fuffifants pour rompre du fer. Mais l'exercice de recreation le plus vité entre les Mexiquains, eft le folemne: Mittoté, qui eft vne forte de bal qu'ils efti. moient fibrave \& fihonorable, que le Roy mefme y dançoit quelques fois, non pas tou. tesfois par force, comme le Roy Dom Pedro d'Arragon auecle Barbier de Valence. Ce bal ou Mittoté fe faifoit ordinairement és. cour: dutemple, \& en celles des maifons Royales qui eftoient les plus f pacieufes. Ils pofoient au milieu de la cour deux diuers inftruments, vn qui eftoit en façon de tambour, \& l'autre en façon d'vn baril fait tout d'vne piece, \& creu. ré par dedans, lefquels ils mettoient fur vne figure d'homme, ou d'animal, ou deffus vne co. lomne. Ces deux inftruments eftoient fi bier accordez enfemble, qu'ils rendoient en leus fon vne affez bonne harmonie, \& faifoient auec 


\section{des Fndes. Liure $V \hat{I}$.}

es inftrumens plufieurs $\&$ diuerfes fortes d'aits $<$ de chanfons. Ils chantoient \& baloient rous 3 u fon \& à la cadence de ces inftrumens, d'v el ordre \& d'vn fi bel accord, tant aux voix, u'au mouuement despieds, que c'eftoit vne hofe plaifante à voir. Ils faifoient en ces danes deux cercles ou roúes, l'vn defquels eftoit u milieu, proche des inftrumens, auquel les nciens \& Seigneurs chantoient \& dançoient uns prefque fe mounoir: l'autre eftoit du refte u peuple à l'entour, affez elloigné du premier, uquel ils dançoient deux à deux plus legereient, \& faifoient diuerfes façons de pas, auec ortains fauts à la cadence. Tous lefquels enmble faifoient vn fort grand cercle. Ils fe veoient pources dances, de leurs plus precieux abits \& ioyaux, \& felon le moyen \& pounoir vn chacun, eftimans cela vne chofe fort ho orable: \& pour cefte occafion ils apprenoient sdances dés leur enfance. Et combien que la us grande part d'icelles fe faifoiét à thonneur leurs idoles, neantmoins cela n'eftoit pas intitution, mais cornme il a eftédit, c'eftoit re recreation \& paffe-temps pour le peuple. 'eft pourquoy il n'eft pas propre de les ofter tout aux Indiens, mais on doit bien prendre arde qu'ils n'y menent parmy quelques fuperitions. I'ay veu faire ce bal ou Mittorté en la ur de l'Eglife de Topetzotlan, qui eft vn urg à fept lieües de Mexique, \& me fembla is lors que c'eltoit chofe bonne d'y occuper entretenir les Indiens ésiours de feltes, puis 3ils ont befoin de quelque recreatió: \& d'aw: 


\section{Hifoires naturelle}

tantplus que celle-là eft publique, \& lansl preiudice d'autruy, il y a moins d'inconuenien qu'en d'autres qu'sls pourroient faire eux feul: fil'on leur oftoit celle-là. C'eft pourquoy $i$ faut conclure, fuiuant le Conferl du Pape Gre goire, que c'eft vne chofe fort propre de laiffe aux Indiens ce qu'ils ont de couftume \& vfa ges, pourueu quils ne foient point mentz $\mathrm{d}$ leurs erreurs anciens, $\&$ defaire en forte qu leurs feittes \& paffe-têps f'acheminent à 1 hon neur de Dieu, \& des Sain Dts defquels ils cele brent les feftes. Cecy pourra fuffire en genera des mæurs \& couftumes politiques des Mexi quains. Et quant à leur origine, accroiffemen \& Empire, d'autant que c'eft vne matiere plu ample, \& qui fera belle \& plaifante d'entendr dés fon commencement, nous en traitteron au liure fuiuant. 


\section{Hifoire naturelle}

font chofes des Indiens. Comme nous voyon queles autheurs qui traittent des chofes natu relies, efcriuent non feulement des animau: genereux, des plantes fignalees $\&$ des pierre precieufes, mais auffi des animaux vils, des her bes communes, des pier res $\&$ chofes vulgaires d'autant qu'il y a toufiours en icelles quelque. proprietez dignes d'eftre remarquees. Aint quand il n'y auroit autre chofe en cecy que it traitte, que d'eftre vne hiftoire \& $r$ non point de fables \& fictions, c'eft toufious vn fubicet qu n'eft pas indigne d'eftre efcrit. ny d'eftre leu.II a encor vne autre raifon plus particuliere: c'el que l'on doit dauantage eftimer en cecy ce qu eft digne de memoire, d'autant que c'eft vne na tion peu eftimee, \& d'autant mefme que c'el vne matiere differente de celle de nofte Euro pe, cóme auffi le font ces nations:enquoy nou: deuons prendre plus de plaifir $\&$ de contente ment d'entendre le fond de leur origine, leu façon de viure, leurs heureufes \& malheureu fes aduantures. Et n'eft pascefte matiere feule. mét plaifante \& agreable, mais auffi eft vtile \& profitable, principalement à ceux qui ont l: charge de les regir \& gouuerner:car la cognoif fance de leurs actes inuite à donner credit aus noftres, \& enfeigne en partie comment ils doi uent eftre traittez, voire elle ofte beaucoup $d x$ commun \& fol mefpris, auquel ceux del'Euro peles ont, ne iugeans pas que ces peuples ayen aucune chofe de raifon. Car certainemét on ne peut mieux trouuer l'efclarciffement de ceft opinion, que par la vraye narration des faits, \& 


\section{des Fndes. Liure. VII.}

yeftes de ce peuple. Ie traicteray donc auec layde du Seigneur, le plus breuement que ie pourray, de l'origine, progres, \& faits notables des Mexiquains, par où l'on pourra cognoiftre le temps, \& la difpofition que le haut Dieus voulut choifir pour enuoyur à ces nations la lumiere de l'Euangile de I E \& V S-C HR I S T fon filsvnique noftre Seigneur, lequel iefupplie acheminer noftre petit trauail, de forte quil puiffe reüflir à la gloire de fa diuine grandeur, \& à quelque vtilité de ces peuples, aufquelsil a communiqué fa fainde loy Euangelique.

Des anciens habitans de la nemue Efpagne, \& comment les $N$ aututlacas $y$

vindrent.

\section{CHAPITRE II.}

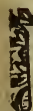

Es anciens, \& premiers habitans des Prouinces que nous appellons neute Efpagne, furent des hommes fort barbares, \& fauuages, qui viuoient \& s'entretenoient feulement de la chaffe. A cefte occafion eftoient appellez Chichimecquas. Ils ne femoiét, ny ne cultiuoient point la terre , \& ne viuoient point enfemble, d'autant que tout leur exercice eftoit de, chaffer, en quoy ils eftoient fort adroits. 1ls habitoient aux plus afpres lieux des montagnes, viuăts beftiallemenr, fans nulle police, \& alloient tous nuds. Ils faifoient la chaffe aux beftes rouffes, aux lievres ${ }_{2}$.

$\mathrm{R}_{\&} \mathrm{iiij}$ 


\section{Hiftoire naturelle}

connins, bellettes, taupes, chats fauuages, \& anx oyfeaux, voire aux beftes immondes, comme aux couleuures, lezards, locuftes, \& vers, dont ils fe nourriffoient, auec quelques herbes $\&$ racines. Its dormoient aux montagnes en des cauernes, \& en des buiffons: \& les femmes mefmes alloient à la chaffe auec leurs maris, laiffans leurs perits enfans attache $z$ aux rameaux d'vn arbre, dans qualque petit pannier de ionc', qui fe paffoient d'eftre allaittez iufques à ce qu'elles retournaffent de la chaffe. Ils n'auoient aucuns fuperieurs, \& ne recognoiffoiêt, ny n'adoroient aucuns dieux, \& n'auoient point de couftumes, ny de religion. Il y a encor auiourd'huy en la neuue Efpagne de cefteforre de gens, qui viuent de leur arc \& flefches, lefquels font fort dommageables : pour-autant qu'ils falfemblent par compagnies, pour faire quel que mal, ou vollerie, \& n'ont peu les Efpagnols par force, ny fineffe, les reduire à quelque police \& obey france. Car comme ils nont point villes, ny de refidéces, côbattre auec eux eft proprement, chaffer aux beftes fauuages, qui Pefcartent, \& fe cachent aux lieux les plus afpres, \& couuerts de la Sierre. Telle eft la façon' de viure encor auiourd'huy en beaucoup de Prouinces des Indes, \& eft traitté principalement de cefte forte d'Indiens, aux liures, de pro* curanda Indoorum falute. Au lieu où il eft dit, quails ont de befoing d'efte contraints $\&$ affujectis parquelque force honnefte, \& qu'il eft necef faire de les enfeigner premieremét à eftre hommes puis apres à eftre Chreftiés. L'on veut dire 


\section{des Indes. Liure VII.}

ue ceux qu'ils appellent en la neuue Efpagne, )ttomies, eftoient de cefte forte, lefquels comzunement font de pauures Indiens habitans en ne terre afpre $\&$ rude, \& neantmoins font en ffez grand nombre, \& viuent enfemble, ayans ntr'eux quelque police; \& ceux qui les conoiffent, ne les trouuent pas moins idoines \& apables és chofes de la Chreftienté, que les aues qui font plus opulents, \& qu'on tient pour iieux policez. Venans donc à noftre fujet, les 'hichimecas \& Ottomies qui eftoient les preiiers habitans de la neuue Efpagne, d'autant u'ils ne femoient, ny labouroient la terre, lailrent le meilleur, \& le plus fertile de cefte con:ee fans le peupler; ce que les nations qui vinrent de dehors occuperent, lefquels ils appelient Nauatalcas, d'autant que c'eftoit vne naon plus ciuile, \& plus politique, \& fignifie ce 1or, peuple qui parle bien, au refpect des aues nations barbares, \& fans raifon. Ces fecóds eupleurs Nauatalcas vindrent des autres ters efloignees, qui gifent vers le Nort, où l'on a laintenant defcouuert vn Royaume, qu'ils apell. nt le nouneau mexique. Il y a en cefte con. ee deux Prouinces, l'vne appellee Aztlan, qui out dire, lieu de herons; l'autre Tuculhuacan, ai fignifie, terre de ceux qui ont les ayeuls diins. Les habitans de ces Prouinces ont leurs aifons, leurs terres labourables, dieux, couumes, \& ceremonies, auecle mefme ordre \& olice que les nauatalcas, \& font diuifez en fept znages, ou nations; \& pource qu'il y a vn vfaen cefte Prouince, que chacun de ces ligna. 


\section{Hiftoire naturelle}

gesafon lieu, \& fon territoire feparé, les $\mathrm{Na}$ natlacas peignent leur origine $\&$ pt emier terri roire en figure de cauerne, $\&$ difent qu'ils for tirét de fept cauernes pour venir peupler la ter re de Mexique, dequoy ils font mention en leu hiftoire, où ils peignent fept cauernes, \& le hommes qui en fortent. Par la fupputationd leurs fiures il y a plus de 800 . ans que ces Naual lacas fortirent de leur pays, qui feroit, le redui fant à noftre conte, l'an de noftre Seigneur $82 c$ Quand ils partirent deleur pays pour venire Mexique, ils tarderent 80 . ans en chemin, \&1 caufe quils demeurerent fi long temps en leu voyage, fur que leurs dieux (lefquels fans dout eftoient diables qui parloient vifiblemét à eux leur auoient perfuadé qu'ils allaffent recherchä de nouuelles terres qui euffent de certains $f$ gnes. C'eft pourquoy ils venoient recognoil lans toute la terre, pour rechercher les figne que leurs idoles leur auoient donné, \& és lieu qu'ils trouuoient de bonne habitation, ils peu ploient, \& labouroient la terre, \& cốme ils del couuroient toufiours de meilleures contrees, $i$. delaiffoient celles qu'ils auoient ainfi premiers ment peuplees, y laiffant neantmoins toufiour quelques-vns, principalement les vieillards m: lades \& fatiguez, mefmes y plantoient \& bafti foient, dont on void encor aujourd'huy des re Ates par le chemin quils tindrent, \& employe rent 80 . ans en cefte façon de cheminer fi à loi fir, ce qu'ils euffent peu faire en vn mois, par c moyen ils entrerent en la terre de Mexique lannee de neuf cents deux, felon noftre conte 
des Indes. Liure VII. $\quad 318$

Comment les fix lignages de $N$ auatlacas perzplerent la terre de Mexique.

Chapitre III.

Es fept lignages que jay dit, ne fortirent pas tous enfemble; les premiers furent les Suchimilcos, qui fignifie, gent defemences de (25) Heurs. Ceux-là peuplerent le ri-
uage du grand lac de Mexique vers le Midy, \& uage du grand lac de Mexique vers le Midy, \&
fonderent vne Cité de leur nom, \& plufieurs bourgades. Lóng temps apres arriuerent ceux dufecond lignage, appellez Chalcas, qui fignifie, gent des bouches, lefquels fonderent aufi vne autre Cité de leur nom, departans leurs limites \& territoires auec les Suchimilcos. Les troifiefmes furent les Tepanecas, qui fignifie, gent du pont, lefquels peuplerent le riuage du lac versl'Occident, \& f'accreurent tellement, qu'ils appellerent le chef \& metropolitaine de leur Prouince, Azcapuzalco, qui vaut autantà dire que fourmilliere, \& furent vn long temps fort puiffans. A pres ceux-là vindrent ceux qui peuplerent. Tefcuco, qui font ceux de Culhua, qui veut dire, gent courbee, pource qu'en leur paysil y auoit vne montagne fort recourbee. Et de cefte façon fut ce lac enuironné de ces quatre nations, peuplans seux-cy l'Orient, \& les Tepanecas le Nort. Ceux de Tefcuco furent eftimez fort courtifans: carleur langue \& pro 


\section{Hiftoire naturelle}

nonciation eft fort douce, \& mignarde. Apre: arriuerent les Tlalluicas, qui lignifie, gent de la Sierre. Ceux-là eftorent les plusrudes, \& grof. fiers de tous; \& comme ils trouuerent toutes les plaines occupees au rour dulaciufqu'aux Sierres, ils pafferent de l'autre cofté de la Sierre, ou ils trouuerent vne terre fort fertile, Spacieufe \& chaude, en laquelle ils fonderent \& peupleren plufieurs grands bourgs, appellans la metro po. litaine de leur Prouince, Quahunachua, qui eft autant à dire que lieu où fonne la voix de l'ai. gle, que noftre vulgaire appelle, \& par corruption, Quernauaca; \& eft cefte Prouince celle qu'on appelle aujourd'huy le Marquizat. Ceux de la fixiefme generation, qui font les Tlalcaltecas, qui vaut autant à dire que gent de pain, pafferent la Sierre vers l'Orient, trauer fans toure la Sierre Menade, où eft le fameux Vulcan, entre Mexique \& la Cité des Anges, où ils trouzerent de bon pays, \& $f^{\prime} y$ eftendirent bien auát plufieurs edifices.' Ils y fonderent plufieurs villes \& Citez, dont la metropolitaine fappella de leur nom Tlafcala. Cefte-cy eft la nation qui fauorifa les Efpagnols à leur entree, \& par l'ayde defquels ils gagnerent ce pays; parquoy iufques aujourd'huy ils ne payent point de tribut, \& jouyffent d'vne exemption generale. L.ors que routes ces nations peuplerent ces pays, les Chinchimecas anciens habitans ne leur firent aucune refiftance, mais ils fenfuyoient, \& com me tous efpounantez, ils fe cachoient au plus coltuert des rochers. Mais ceux qui habitoient del'autre cofté de la Sierre, où les Tlafcaltecas 


\section{des Indes. Liure VII.}

thabituerent, ne permirent point ce que le re. te des Chichimecas auoient permis; au conraire ils fe mirent en deffenle pour conferuer cur pays, \& comme ils eftoient geants, comme aconte leur hiftoire, ils voulurent ietter par force les derniers venus, mais ils furent vaincus jar la rufe \& fineffe des I lafcaltecas, lefquels feignirent de faire paix auec eux, puis les condierent en vn grand banquet; \& lors qu'ils eftoient occupez aे leurs yurongneries, il y eut des hommes qui auoient efté mis en embufche rcefte fin, quileur defroberent finement leurs armes, qui eftoient de grandes maffuës, des ron. delles, des efpees de bois, \& autres telles fortes d'armes. Cela fait, ils fe ietterent à l'impourueu fur eux, \& les Chichimecas fe voulans mettre en deffenfe, \& ne trouuans point leurs armes, Penfuyrent aux montagnes \& forefts prochaines, où mettans la main aux arbres, les rompoient \& arrachoient, comme fic'eulfent efté feuilles de laictuëes. Mais en fin comme les Tlafcaltecas alloient armez, \& en ordre, ils déGrent tous les geants, fans en laiffer vn feul en vie. Ce qu'on ne doit trouuer eftrange, ny pous fable de ces geants : car on y troune encores aujourd'huy des os d'hommes morts d'vne incroyable grandeur. Lors que j'eftois en Mexique, en l'annee quatre vingts \& fix, on trouua vn de ces geants enterré en vne de nos meftairies, que nous appellons I efus du mont, duquel on nous apporta vne dent à voir, laquelle fans y adjoufter, eftoit auffi grande que le poignet d'vnhomme, \& felon cefte proportion toutle 


\section{Fiftoire naturelle}

refte lequel ie veis, \& m'efmerueillay de ceft difforme grandeur. Les Tlafcaltecas donc pa cefte viftoire demeurerent paifibles, \& tous le autres lignages auffi. Ces fix lignages que j'a: dit, conferuerent toufiours amitié entr'eur marians leurs enfans les vns auecles autres, \& departans leurs limites paifiblement, puis f'e ftudioient par vne honnefte emulation d'ac croiftre \& d'illuftren leur Republique. Lés bar. bares Chichimecas voyans ce qui palfoit, com. mencerent de prendre quelque police, \& à f veftir, ayans honte de ce qu'auparauant, \& iuf. ques alors, ils n'auoient eft é honteux, \& ayan: perdu la crainte par la communication de ces autres peuples, commencerent d'apprendre d'eux plufieurs chofes, \& faifoient defia leurs maifonnettes, ayans quelque police $\&$ gouuer. nement. Ils efleurent auffi des Seigneurs, quils recognoifloient pour chefs \& fuperieurs; au moyen dequoy ils fortirent prefque entierement de cefte vie beftiale, toutesfois ilsrefidoient toufiours aux montagnes, \& enla Sierre reparez des autres. Neantmoins ie tiens pour certain que cefte crainte eft prouenuë desautres nations \& Prouinces des Indes, dont les premiers furent hommes fauuages, lefquels ne viuans que de chaffe, entrerent, penetransles terres \& pays fort afpres, defcouurans vn nòuueau monde, \& habitans en iceluy prefque comme beftes fauuages, fans toicts \& fans maifons, fans terres labourables, fans beftial, fans Roy, loy, ny Dieu, ny raifon. Du depuis, quelques autres cherchans de meilleures \& nouuel. 


\section{des Fndes. Liure VIT.}

es terres, peuplerent lepays fertile, introduians vn ordre politic, \& quelque façon de $\mathrm{Re}$ ublique, encoses qu'elle fuft fort barbare. Par pres ces mefmer hommes, ou d'autres nations jui eurent plus d'entendement $\&$ d'induftrie jue les autres, f'employerent a affujettir, \& oprimer les moins puiffans, iufques à fonder des 2oyaumes, \& des grands Empires. Ainfi en adint en Mexique, au Peru, \& en quelque enIroit, où fe trouuent des Citez, \& des Repü. liques fondees parmy ces barbares. Ce qui me onfirme en mon opinion, laquelle $j$ 'ay amplenent deduite au premier liure, que les preniers habitansdes Indes Occidentales vindrene ar terre, \& que par confequent toure la terre les Indes fe continuë auec celle d'Afie, d'Euro,e \& d'Afrique, \& le nouueau monde auec le rieil, combien que l'on n'ayt encores defcoujert à prefent aucun pays quitouche, \& fe joine auec les autres mondes, ou que fil y a mer intre deux, elle eft fi eftroitte, que les beftes fre es \& fauuages la peuuent facilement paffer a 12ge, \& les hommes en des mefchans bafteaux. Mais laiffans cefte Philofophie, retournons ?े noftre hiftoire. 


\section{Hiftoire naturelle}

De la fortie des Mexiquains, de leur chemin. or dupeuplement de ceux de Mechonacan.

CHAPITRE IV.

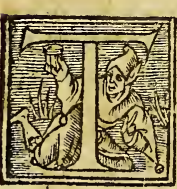

Ro is cents deux ans apres qu lesfix lignages fufdits furent for tis de leur pays pour peupler ] neuue Efpagne, le pays eftar defia fort peuplé, \& reduit quelque forme de police, ceu de la feptiefme cauerne ou lignee y arriueren: qui eft la nation Mexiquaine, laquelle, comm les autres, fortit de la Prouince de Aztlan, \& Teuculhuacan, nation politique, courtifane 8 fort belliqueufe. Ils adoroient lidole Vitzili putzli, duquel a efé fait ample mention cy de uant; \& le diable qui eftoit en cét idole, parloit \& regiffoit affez facilement cefte nation. Cé idole donc leur commanda de fortir de leu pays, leur promettant qu'il les feroit Princes \& Seigneurs de toutes les Prouinces quauoien peuplé les autres fix nations; qu'il leur donne. roit vne terre fort abondante, beaucoup d'or: d'argent, de pierres precieules, de plumes, \& ds riches mantes; fuiuant quoy ils fortirent, por. rans auec eux leuridole dans vn coffre de jonc, qui eftoit porté par quatre des prıncipaux Pre. ftres, aufquels il fe communiquoir, \& leur reueloit en fecret le fuccez de leur chemin, \& voyage, les aduifant de ce quì leur deuoit advenir. Il leur donnoir mefmes des loix, \& leur 


\section{des fndes. Liure VIII.}

nfeignoit les couftumes, ceremonies \& facrices qu'ils deuoient obferuer. Ils n'aduăçoient, y ne fe mouwoient aucunement, fansl'aduis c commandement de cét idole. Il leur difoit uand ils dewoiene cheminer, \& quand en quelue lieu ils deuoient f'arrefter, en quoy ils luy beyfoient du tour. La premiere chofe qu'ils ifoient, où que ce fuft qu'ils arriuaffent, eftoit edifier vne maifon, ou tabernacle, pour leur ux'pieu, quils dreffoient toufiours au milieu u camp, \& y mettoient l'arche fur vi autel, de mefme façon qu'on en vîe en la faincte Eglife hreftienne. Cela fait, ils faifoient leurs feences de pain, \& des legumes dönt ils vfoient, : eftoient tant addonnez à l'obeyffance de leur ieu, que fil leur commandoit de recueillir, ils cueilloient: mais fil leur commandoit de leer le camp, tout demeuroit là pour femence : nourriture des vieillards, malades, \& fatiuez, qu'ils alloient laiffans à tout propos de eu en autre, afin qu'ils peuplaffent; pretendans ar ce moyen que toute la terre demeureroit euplee deleur nation. Cefte fortie \& peregriation des Mexiquains femblera parauenture mblable à la fortie d'Egypte, \& au chemin ue firent les enfans d'Ifrac̈l, veu que ceux-la omme ceux cy, furent admonneftez de fortirs : chercher la terre de promiffion, \& les vins \& s autres portoient pour guide leur Dieu, condroient l'arche, \& luy faifoient tabernacle, 8 les aduifoit, leur donnant des loix \& des cemonies; \& les vns \& les autres confomment vn grand nombre d'annees fur ce voyago 


\section{Hifoire naturelle}

de lêar terre promife, oùlon recognoift de 1 reffemblance de plufieurs autres chofes, en c que les hiftoires des Mexiquains racontent, 8 ce que la diuine Efcriture rapporte des Ifraëlite: Et fans doute c'eft vne chofe veritable, quel diable Prince d'orgueil f'eft efforcé par les fu perftitions de cefte nation, de contrefaire \& es. fuiure ce que le tres-haut \& vray Dieu filt aue fon peuple: car comme il a efté traitré cy del fus, Satan a vne eftrange enuie de fe compares $\&$ f'efgaler à Dieu, d'où cét ennemy mortel pretendu fauffementvfurper la communicatio: $\&$ familiarité quill luy a pleu auoir auec le hommes. Seft il iamais veu diable qui conuer faft ainfi auec leshommes, comme ce diabl Virzilipuztli? L'on peut bien voir quel il eftoit parce que l'on n'a iamais veu, ny ouy parler d couftumes plus fuperfitieufes, ny de acrifice plus cruels, \& inhumains, que ceux que ceftur enfeigna aux fiens. En fin elles furent inuentee par l'ennemy du genre humain. Le chef \& capi taine que ceux-cy fuiuoient, auoit nom Mexi d'où vint par apres le nom de Mexique, \& ce luy de fa nation Mexiquaine. Ce peuple don cheminant ainfi a loifir, comme auoient fair le fix autres nations, peuplans \& cultiuans la terr en diuers endroits, dont y a encore aujourd'hu: des apparences \& ruines, \& apres auoir endur beaucoup de trauaux \& de dangers, vindrent es fin arriuer en la Prouince de Mechoacan, qu vaut autant à dire, que terre de poiffon, pourc qu'il y en a grande abondance en de beaux 8 grandslacs, ou $f e$ contentans de la fituation 8 


\section{des Indes. Liure VII.}

raifcheur de la terre, ils f'y voulurent repoer \& arrefter : toutefois ayans confulté leur dole fur ce point, \& voyans qu'il n'en eftoir pas content, ils luy demander ent qu'il leur pernift à tout le moins d'y laiffer de leurs hommes qui peuplaffent vine fi bonne terre; ce qu'il leur iccorda, leur enfeignant le moyen comment ils eferoient; qui fut comme les hommes \& les emmes feroient entrez pour fe baigner en vn ac fort beau, qui fappelloit Pafcuaro, ceux qui :efteroient en terre, leur defrobaffent tous leurs a abits, \& incontinent leuaffent le camp, \& f'en allaffent fans faire aucun bruit. Ce qui fut ainfi ait, \& les autres qui ne penfoient en la tromperie, pour le contentement qu'ils prenoient à e baiguer, quand ils fortirent, \& fe trouverent tefpoiillez de leurs habits, \& ainfi mocquez \& delaiffez de leurs compagnons, ils demeurerent ort mal contents, \& indignez de cela ; de forte que pour faire demonftrarion de la haine qu'ils conceurent contr'eux, ils difent qu'ils changerent de façon de viure, voire de langage. A cour le moins c'eft vne chofe certaine que toufours les Mechoacanes ont efté ennemis des Mexiquains; c'eft pourquoy ils vindrent congratuler le Marquis de Vallé, apres la victoiro abrenuë, quandil gagna Mexique. 


\section{Hiftoire naturelle}

De ce qui arriua en Malinalco, en Tula, 0 en Chapultepec.

CHAPITRE V.

75 $\mathrm{L}$ y a de Mexouacquan en Mexique, plus de cinquante lieïes, \& fur le che. min eft Malinalco, où il leur aduin: que fe plaignants à leur idole divne femme tres grandeforciere, qui venoit en leur compagnie, portant le nom de four de leur Dieu, pource quauec fes maunais arts elle leus faifoir de grands do mmages, pretendár par cerrains muyens fe faireadorer a'eux commeleur deeffe; l'idole parla en fonge à l'vn de ces vieillards qui portoient l'arche, \& luy commanda que de fa part il confolaft le peuple, leur faifant de nouu eau de grandes promeffes, \& qu'ils laiffaffent cefte fienne four auec fa famille, comme cruelle \& mauuaife, en leuant le camp de nuioz en grand filence, fans laiffer aucune apparence par où ils alloient. Ils le firent ainfi, \& la forciere fe trouuant feule auec fa famille, delaiffee de la façon, peupla là vne ville qui fut appellee Malinalco, \& les habitans de laquelle font tenus pour de grands forciers, eftans yffus d'vne telle mere. Les Mexiquains, d'autant qu'ilsfeAtoient beaucoup diminuez par ces diuifions, \& pour le nombre des malades, \& gens fatiguez qu'ils alloient laiffans, fe voulurent refaire, farreftans en vn lieu appellé Tula, qui fignifie, lieu de ioncies. Là leus idole leur commanda quils 


\section{des Frides. Liure VII.}

rreftaffent vne grande riuiere, afin quelle $\mathrm{fe}$ efpandift dedans vne grandc plaine, \& auecle .oyen qu'il leur enfeigna, ils enuironnerent 'eau vne colline appellee Coatepec, \& en fient vn grand lac, lequel ils planterent tout a 'entour de faulx, d'ormes, fapins, \& autres arres. 11 commença à $f$ y engendrer beaucoup de oiffon, \& y venir plufieurs oyfeaux; de forte u'il fy fift vn lieu delicieux. C'eft pourquoy affiette de ce lieu leur femblant affez agreable, $z$ eftans laffez de rant cheminer, plufieurs parerent de peupler là, \& ne paffer plus outre; deuoy le diable fe falcha fort, \& menaffant les 'reftres de mort, leur commanda qu' ils remifent la riuiere à fon cours, \& leur dift qu'il doneroit ceft nuict le chaftiement à ceux qui uoient efté defobeyffans, tel qu'ils le merioient. Or comme le mal-faire eft fi propre au iable, \& que la Iuftice diuine permet bien fou. ient que ceux -là foient mis entre les mains d'vn el bourreau, qui le choiffifent pourleur dieu: larriua que fur la minuidt ils ouyrent en cerain endroit du camp, vn grand bruit, \& au ma in allans celle part, ils trouuerent morts ceux uui auoient parlé de demeurer là. La taçon omme ils auoient efté occis, fut, qu'on leur uoit ouuert l'eftomach, \& en auoit-on tiréle œur. Et de là ce bon Dieu enfeigna à ces pau.res malheureux les façons des facrifices qui uy plaifoient, qui eftoit en ouurant l'eftomach leur tirer le cour, ainfi qu'ils l'ont depuis pratiqué en leurs horribles facrifices. Ayans veu e chaftiment ainfi fait, \& que la campagne $S[\mathrm{iij}$. 


\section{Hiftoire naturelle}

reftoit defechee, à caufe que le lac f'eftoit vuidé ils confulterent leur sieu de fa volonté, leque leur commanda de paffer outre, ce quilis firent \& peu à peu aduancerent, iufques à arriuer: Chapultepec, à vne lieuie de Mexique, lieu ce lebre pour fa recreation \& frailcheur. Ils fe for tifierent en ces montagnes pour crainte des na tions qui habitoient cefte contree, lefquelle leur eftoient toutes contraires, principalemen d'autant qu'vn nommé Copil, fils de cefte for ciere lailfee en Malinalco, auoit blafmé, \& ma parlé des Mexiquains : car ce Copil, par le com mandement de famere, quelque temps apre vint à la fuitte des Mexiquains, \& f'efforça d'in citer contr' eux les Tapanecas, \& les autres cir conuoifins, iufques aux Chalcas; de forte quil vindrent en main armee pour deftruire les $\mathrm{Me}$ xiquains. Le Copil cependant fe mit en vn colline qui eft au milieu du lac, appellee Aco pilco, attendant la deftruction de fes ennemis \& eux par l'aduis de leur idole, allerent contr luy, \& le prenans au defpourueu, le tuerent, \& en apporterent le cœur à leur dicu, lequel com manda qu'on le iettaft au lac. Et feignent que d là feft engendree vne plante appellee Tunal, oi du depuis fut fondee Mexique. Ils vindrent au: mains auec les Chalcas, \&r autres nations, \& auoient les Mexiquains efleu pour leur Capitai ne vn vaillant homme appellé Vitzilonilti, qu en vne charge fut pris, \& tué par les ennemis mais pour cela les Mexiquains ne perdir ent $\mathrm{pa}$ courage, ains combatans valeureufement, mal gré leurs ennemis rompirent leurs efcadrons, \& 


\section{des Indes. Liure V11.}

324

menans au milieu \& corps de la bataille, les vieillards, femmes, \& perits enfans, palferent outre iufques à Atlacuyauaya, ville des $\mathrm{Cul}$ huas, lefquels ils trouuerent folemnifans vne fefte, auquel lieu ils fe fortifierent. Les Chalcas, ny les autres nations ne les fuiuirent plus, mais eftans defpitez de fe voir deffaits parvn fi petit nombre de gens, eux qui eftoient en fi grande multitude, fe retirerent en leurs villes.

De la guerre que les Mexiquains eurent contre ceux de Culbuagan.

Chapitre Vi.

M 7 Es Mexiquains, par le confeil de (1) lidole, enuoyerent leurs meffa1) gers au Seigneur de Culhuacan, 1) 1 rer, lequel apres en auoir commu. niqué auec les fiens, leur accorda le lieu de Tiçaapan, qui fignifie, eaux blanches, en intention quils fe perdiffent, \& y mouruffent tous, pour autant quil y auoit en ce lieu vn grand nombre de viperes, de couleuures, \& d'aurres animaux venimeux quif'engendroient en vne colline qui eftoit proche de la. Mais eux eftans perfuadez, \& enfeignez de leur diable, receurent de fort bonne volonté ce quileur fut offert, \& addoucirent par art diabolique tous ces animaux, fans qu'ils leur fiffent aucun dommage, voire les conuẹtrirent en viande, \& en man;

Sf iiij 


\section{Hiftoire naturelle}

geoient à leur contentement, \&z appetit. C que voyant le Seigneur de Culhuacan, \& quils quoient femé \& cultuué la terre, il fe refolut de les receuoir en fa Cité , \& de contracter amitié auec eux. Mais le dieu queles Mexiquains ado. roient (comme il a accouftumé de ne faire aucun bien, finon pour en tirer du mal) dift à (es Ireêtres que ce n'eltoir pas là le lieu où il vou. loit qu'ils demeuraffent, \& qu'ils en deuoient fortir en faifant la guerre. C'eft pourquoy ils deuoient chercher vne femme, qu'ils nomme. roient la deeffe de difcorde, \& pourtant ils ad. uiferent d'enuoyer demander au Roy de Culhuacan, fa fille, pour eftre la Royne des Mexiquains, \& mere de leur Dieu, lequel receut volontiers cefte ambalfade, \& incontinent leur enưoỳa fa fille bien ornee \& bien accompagnee. - a mefme nuict qu'elle arriua, par l'ordonnance de l'homicide qu'ils adoroient, ils la tuerent cruellement. Et apres l'auoir efcorchee fort proprement, comme ils (çauent faire, ils en veftirent de la peau vn ieune homme, quils couurirent par delfus des habillements d'elle; 2 de ceftefaçon le polerent aupres del'idole, le dedians pour deeffe \& mere de leur bieu, \& toufrours depuis l'adorerent, en failans vn idole quilsappelloient Toccy, qui veutdire, noftre ayeuile. Non contens de cefte cruauté, ils inuiterent malicieufemient le Roy de Culhuacan, pere de la ieune fille, de venir adorer fa fille, qui eftoit defia confacree deeffe, lequel venane auec de grands prefens, \& bien accompagné des fiens, fut mené en vne chappelle forr obscure, 


\section{des frides, Liure VII.}

où eltoit leur idole, afin qu'il offrift facrifice à $\mathrm{F}_{a}$ ille, qui eftoit en ce lieu. Mais il arriua que l'encens qui eftoit en vn brafier, \& fouyer, felon leur couftume, s'alluma; de forte que par cefte clarté,il recongneut le poil de fa fille, \& ayant par ce moyen defcouuert la cruauté, \& la tromperie, fortit de là, s'efcriant hautement, puis inec tcas les gens frappa furieulement fur les Mexiquains,iufques à les faire retirer au lac,telement que peus'en tallut qu'ils ne $s^{\prime} y$ noyafent. Les Mexiquains fe deffendoient, iettans :ertaines dardilles, dót ils fe feruoiér à la guere, defquels ils offenfoient beaucoup leurs enemis. Mais en fin ils gagnerent terre, \& delaifans'ce lieu la, s'en allerent coltoyans de lac, fore araffez \& moüillez les femmes \& petits enfans leurans \& iettans de grands cris contr'eux \& contre leur Dieu, quiles auoit mis en telles de treffes. Ils furent contrains de paffer vne riuiee, qui ne fe pounoit gueyer, $c^{\prime}$ eft pourquoy ils aduiferent de faire de leurs rondelles, \& de oncs, certains petits batteaux, efquels ils paffe. ent.Pais apres en tournoyant, eftans partis de Julhuacan, arriuerent à Iztacalco, \& finalemét us lieu, ou eft auiourd'huy l'Hermite fainct Anthoine à l'entree de Mexique, \& au quar. ier qu'ils appellent auiourd'huy fainct Paut, endant lequel temps leur idole les confoloit n leurs traaaux, \& les animoit, leur faifant tomefles de grandes choles. 


\section{Hifoire naturelle}

De la fondation de Mexique.

Chapitre VII.

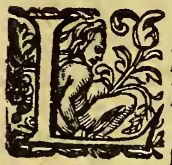

E temps eftant defia venu, quele pere de menfonge deuoit accom plir la promeffe qu'il auoit faired fon peuple, lequel ne pouuoitplus fupporter tant de tournoyement, de trauaux, \& de dangers, aduint que quelques vieillards Preftres, ou forciers, eftans entrés dás $\checkmark n$ lieu plein de glaieuls efpais, rencontreren $n$ cours d'eau fort claire \& belle, qui fembloi argentee, \& regardans à l'entour, veirét que les arbres, le pré, les poiffons, \& tout ce qu'ils regardoient eftoit fort blanc. Eftans efmerueillez de cela, ils leur fouvint d'vne prophetie de leur Dieu, par laquelle illeur auoit donné cela pour fignal, du lieu où ils deuoient repofer, \& fe faire Seigneurs des autres nations. Alors pleurans de ioye, retournerent vers le peuple auec ces bonnes nouuelles. La nuict enfuiuante Vitzilipuztli s'apparut en fonge à vnPreftre ancien, \& Iuy dift, qu'ils cherchaffent en celac vn Tunal, qui naiffoit d'vne pierre (qui eftoit à ce qu'il luy dift, le lieu mefme, où par fon commandement ils auoient ietté le cœur de Copil fils de la forciere leur ennemie.) Et que fur ce Tunal ils verroient vn aigle fort beau, quife paiffoit là, de certains beaux petits oyfeaux, \& que quand ils verroient cela, quils creuffent que c'eftoit lo fieu où leur Citédeuoit eftre baftie, laquelle 


\section{des Fndes. Liure VII.}

deuoit furmonter les autres, \& eftre remarquable au monde. Le matin venu, le vieillard affem bla tour le peuple, depuis le plus grand, iufques au plus petit, \& leur fit vne longue harangue fur lé fubiect de la grande obligation qu'ils auoient à leur Dieu, \& de la reuelation que luy indigne en auoit eüe cefte nuid, concluant que tous deuoient fe mettre à rechercher ce lieu bien heureux qui leur eftoit promis. Cequi caufa telle deuotió \& allegreffè tous, que fans dilayer ils fe mirent incontinent à l'entreprinfe, \& fe diuifans en bandes commencerent aे rechercher, fuiuant les fignes de la reuelatiö, le lieu defiré. Parmy l'efpaiffeur desioncs \& glaieuls de celac, ils rencontrerent ce iour là le cours d'eaïe du iour de deuant, fort different toutesfois, d'autant qu'il n'eltoit pas blanc, mais vermeil comme fang, lequel fe feparoit en deux ruifeaux, dót il y en auoit vn qui eftoir de couleur azuree, forr obfcure, ce qui les fit beaucoup, efmerueiller, \& denota vn grand iny ftere à ce qu'ils difoient. En fin apres auoir beaucoup cherché çà \& là , apparut le Tunal naiffant d'vne pierre, fur lequel il y auoit vn aigle Royal, ayant les aifl es ouuertes \& eftédues, tourné deuers le foleil, en receuant fa chaleur. Alentour de cét aigle, il y auoit beaucoup de plumes riches, blanches, rouges, iaunes, bleües, \& vertes, de la mefme forte de celles dont ils font des images, lequel aigle tenoit en fes griffes vn fort bel oyfeau. Lefquels le virent, \& recogneurent que c'eftoir le lieu, quileur auois efté predit parl'oracle : ilsfe mirenta genoux 


\section{Hiftoire naturelle}

cous failans grande veneration à l'aigle, laquel le leur inclina la tefte, en regardant de tous co ftez. Il y eut alors de grands cris \& demontra tions, \& actions de graces au Createur, \& à leu grand Dieu Vitzilipuztli, qui en tout leur eftoi pere, \& leur auoit toufiours dit verité Ils ap pellerent pour cefte occafion la Cité qu'ils fon derentlà, Tenoxtiltan, qui figuifie Tunal es pierre, \& iufques auiourd'huy ils portent en leurs armes vne aigle fur vn Tunal, auec vn oy. feau en vne griffe, \& affis de l'autre fur vn 'Tu. nal. Le iour fuiuant, par la commune opinion ils firent vn hermitage ioignant le Tunal de l'aigle, à fin que l'arch e de leur Dieu y repofaft, iufques à ce qu'ils euffent le moyen de luy faire vn fomptueux temple, \& ainfi firent ceft hermitage de guazons \& de mottes quils couurirent de paille, puis apres ayans confulté leur Dieu, ils delibererent d'acheter de leurs voifins de la pierre, du bois \& de la chaux, en troc de poiffons, de grenoüilles $\&$ de chevrettes, mefme auffi de canards, poules d'eaiie, courlieux \& autres diuers genres d'oyleaux marins. Toutes lefquelles chofes ils pefchoient \& chaffoient auec grande diligence en ce lac, auquel il y en a en grande abondance. Ils alloient auec ces chofes és marchez des villes \& Citez des Tapanequas, $\&$ de ceux de Tezcuco leurs circóuoifins, $\$ 2$ auec beaucoup d'artifice affemblerent peu aे peu ce qu'ils auoient de befoing pour l'edifice de leur Cité : de forte qu'ils baftirent de pierre \& \& de chaux vne meilleure chappelle pour leur jdole, \& s'employerent à remplir auec des plan. 


\section{des Indes. Liure. V.II.}

ches \& du bloc, vne grande partie de ce lac.Cela fait, l'idole parla vne nuict à vn de fesPreftres en ces termes: Dy anx Mexiquains que les fergneurs fe diüifent chacurs awec fes parens $\mathcal{O} \sim$ amis, $\mathcal{O}$ quills $j e$ Separent en quatre quartiers principaux à l'entour de las maifon que mane $Z$ faite pour mon repos, $\sigma$ que chaque quartier edifie en fon quartier felon fa volonté. Ce qui fut mis en execution, \& ceux-là font les quatre quartiers principaux de Mexique, que l'on appelle auiourd'huy fainct Iean, faincte Mariela Ronde, fainct Paul, \& fainct Sebaftien. Apres cela, les Mexiquains eftans ainfi diuifez en ces quatre quartiers, leur Dieu comman da qu'ils repartiffent entr'eux les dieux qu'il leur declareroit, \& qu'ils nommaffent à chaque quartier. principal des quatre, d'autres quartiers particuliers où leurs dieux fuffent adorez. Par ainf fous chacun de ces quatre quartiers principau ily en auoit plufieurs petits qui y eftoient comprins, felon le no mbre des idoles que leur Dieu leur commanda d'adorer, lefquels ils appcllerent Calpultetco, qui vaut autant à dire que Dieu des quartiers. Ên cefte maniere la Cité de Mexique Tenoxtiltan fut fondee, \& vint à grande augmentation. 


\section{Hifoire naturelle}

Dela fedition de ceux de Tlatelulco, of du pre mier Roy que les Mexiquains efleurent.

Chapitre VIII.

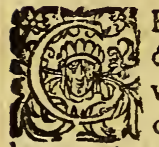

Efte diuifion desquartiets eftant fai Ote en l'ordre deffufdit, quelque: vieillards \& anciens eurent opinior qu'au departement deslieux l'on $\mathrm{n}$ leur auoit pas porté le refpect qư'ils meritoient: pour cefte occafion eux \& leurs parens fe mu tinerent \& aller ent rechercher vne nouuelle re fidence: \& comme ils alloient par le lac,ils trou uerét vne petite terre ou terraffe qu'ils appellë! - Tloteloli, où ils peuplerent, luy donnans le nom deTlatelulco, qui eft à dire lieu de terraffe. Cela fut la troifiefme diuifió des Mexiquains depui: qu' ils partirent deleur pays: celle de Mechoua. can ayant efté la premiere, \& celle de Malmalco la feconde. Ceux-là qui fe feparerent \& s'en al. lerent en Tlatelulco eftoient des hommes renommez \& d'vn mauuais naturel : par ainfi ils exerçoient enuers les Mexiquainsleurs voifins, le pire voifinage qu'ils pouuoient. Ils ont eu toufiours des debats contr'eux, \& iufques auiourd'huy durét encor leurs inimitiez \& ligues anciennes. Voyans donc ceux de Tenoxtiltan, que ceux de. Tlatelulco leur eftoient fort contraires, \& qu' ils alloient multipliăs, eurent crainte qu'auec le temps ils ne vinffent à les furmonter, \& fur ceft affaire s'affemblerent en confeil, où ils aduiferent qu'il eftoit bú d'ellire vn Roy, 


\section{des Indes. Liure. VII.}

auquel ils obeyffent, \& qui fuft craint de leurs ennemis, d'autant que par ce moyen ils feroienz plus vnis \& plus forts entr'eux, \& les ennemis ne fe hazarderoient tant en leur endroit. Eftans ja deliberé d'enire vn Roy, ils prindrent vn au. tre aduis fort vtile \& affeuré,de ne l'eflire poinz d'entr'eux, pour euiter les diffentions, \& pous gagner auec le nouueau Roy quelqu'vre des autres natiós voifines defquelles ils fe voyoien circuits, \& eux deftitue $z$ de tout fecours. Tous cófideré,tant pour appaifer le Roy de Culhua can, qu'ils auoient grandement offen fé, ayans tué \& efcorché la fille de fon predeceffeur, \& luy ayäs fait vne fi lourde moquerie, cóme mefme pour auoir vn Roy qui fuft de leur fang Mexiquain, de la generation defquels il y en auoir beaucoup en Culhuacan, qui y reft oient encor du tempsquils vefcurent en paix aueceux, ils arrefterét d'eflire pour Roy vn ieune hóme appellé Acamapixtli,fils d'vn grand Prince Mexiquain, \& d'vne Dame fille du Roy de Culhua. can. Incontinent ils luy enuoyerent A mbaffa. deurs auec vn grand prefent, pour demáder ceft höme, lefquels firent leur a mbaffade en ces ter. mes: Grand seigneur, nous autres vos va Jaux \& foruiteurs, les. Mexiquains, mis $\sigma$ re $\beta$ sorre $Z$ dedans les herbiers $\mathcal{O}$ rofeaux du lac, feuls, $\mathcal{O}$ delarfé $\chi$ de coutes les nations dus monde, mais feulement conduits $\mathcal{F}$ achemsneZ par noftre Dien ars liew oì fommes, qui tombe en los iurradiztion de ros limites d' Afrapufalco eF de Tefcu$0:$ oresque vous nous are $Z$ permis d'eftre, $\sigma$ de demensrer en iceluy, nous ne voulons point, ny n'eft pas raifonnable ds viure fans chef $O$ Jans seigneur quis rours sem- 


\section{Hiftoire naturelle}

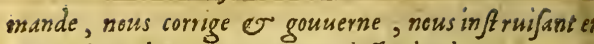
nojtre façon de viure, $\mathcal{G}$ nous deffende de nos ennemis Partant nowis venons à vous, Sgachans quien voftre con o maifon il y a desenfans de noftre generation, apparen teZ $\mathcal{O}$ allie $Z$ auec la voftre, qui font fortus de nos en trailles e des voftres; de softre fang $\sigma$ dus voftre, entr lefguels nous a uons cognoiffance d'vo petit fils voftre 0 nostre, appellé Acamapixtli. Nous vous fupplions don que vous nous le dornie Z pour seigneur, lequel nous efri merons comme il mertte, puis quill eft de la lignee de seigneurs Mexiquains o des Roys de Culbuacan. L Roy ayant mis l'affaire en deliberation, \& trou uant que ce ne luy eftoit point chole mal à pro pos des'allier auec les Mexiquains qui eftoien vaillăs, leur refpondir qu'ils menaflent fon petit fils à la bonne heure, combien qu'il adiouftaft, que fi c'euft efté vne femme, qu'il ne leuı euft pas baillee, fignifiant l'acte fi enorme racó. té cy deffus, \& acheua fon difcours en difant: s'en alle mon petit fils, quill ferue voftre Dien, $\mathcal{C}$ foit fon Lieutenant, qu'il regiffe o gounerne les creatures deceluy pour qui nous vinons; seigneur dela nuict, du nour o des vents, quill aille $\sigma$ Jout seigneur de l'ean $\sigma$ de la terre, $\sim$ quill poffedela nation Mexiquaine, emmenezle à la bonne beure, or aye Z le foin de le traitter cöme fils $\sigma$ petit filsmen. Les Mexiquains luy rendirent graces, \& tout enfemble luy demanderent quil le mariaft de fa main, à raifon dequoy il luy dóna pour femme vne Dame des plus nobles d'entr'eux. Ils menerent le nouueau Roy \& la Royne auec tout l'honneur qui leur eftoit poffible, \& leur firent vne folemnelle reception, fortans tous iufques aux plus petits, aे roirle Roy, le- 


\section{Hiftoires naturelle}

roit. En apres ils luy firent le ferment, \& luy $m$ rent felon leur mode la couronne Royale fur tefte, qui eft femblable à la couronne de feigneurie de Venife. Le nom d'A camixtli pr mier Roy, fignifie poignee de rofeaux : c' pourquoy ils portent en leurs armes vne ma tenant plufieurs fagettes de rofeau.

De l'efrange tribut que les Mexiquains payoient à ceux d'Azcapuzalco.

CHAPITRE $1 \mathrm{X}$.

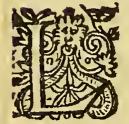

Es Mexiquains rencontrerent $-\mathrm{fi}$ bi en l'eflection de leur nouueau Ro qu'en peu de tempsils commencer à prendre forme de Republique, à fe faire renommer parmy les eftrangers, caufe dequoy leurs voifins meus d'enuie \& crainte, traitterent de les fubjuguer, fpecial ment les Tapanecas, qui auoient pour $\mathrm{Ci}$ Metropolitaine Azcapuzalco,aufquels les M xiquains payoient tribut comme hommes $v$ nus de dehors, \& demeurans en leur terre. C le Roy d'Azcapuzalco craignant leur puiffa ce qui alloit croiffant, voulut opprimer les $\mathrm{M}$ xiquains, \& en ayant deliberé auec les fiens, uoya dire au Roy Acamixtli que c'eftoir tro peu de chofe que le tribut ordinaire quils he payoient, \& que de là en auant ils luy deuoie auffi apporter des fapins \& des faulx, pour edifices de fa Cit'́, \& outre cela qu'ils luy d soient faire vniardin en l'eaüe, femé de diue 


\section{des Indes. Liure. VII.}

es herbes \& de legumes, \& luy deuoient amener par eau, ainfiaccommodé par chacun an, fans y manquer: que s'ils y failloient, il les de-lareroit fes ennemis, \& les raferoit du tour. Les Mexiquains receurent beaucoup d'ennuy $x$ de fafcherie de ce commandement, tenant sour chofe impolfible ce quill leur demandoit, \& que ce n'eftoit autre cliofe que de chercher ne occafion pour les ruiner : mais leur Dieu Vitzilipuztli les confola, s'apparoiffant cefte uict a vn viellard, auquel il commada qu'il dift le fa part au Roy fon fils, quil ne fift point de lifficulté d'accepter le tribut, \& quill leur ayde. oit, \& rendroit le tout facile:ce qui aduint de. uis. Car eftant venule temps du tribut, les Mexiquains porterent les arbres que l'on leur uoit commandé, \& qui plus eft, le iardin fait n l'eaüe, \& porté en icelle, auquel y auoit eaucoup de mays, qui eft leur bled defia gre. é auec les efpics. Ily auoit auffi du chili, ou xi,des blettes, tomates frifolles, chias, coures, \& beaucoup d'autres choles toutes parreües \& en leur faifon. Ceux quíi n'ont point eu lesiardins qui fe font au lac en Mexique au silicu de l'eauie, ne croiront, \& tiendront pour ontesce que i'efcris, ou s'ils le croyent, ils diont que c'eft vn enchantement du diable quils doroient. Mais reallement \& de fait ceft cho. fort faifable, \& à l'on veu plufieurs fois faire e ces iardins mouuans en l'eau. Car ils iettent ela terre deffus du ionc \& du glaieul, d'vne elle façon, qu'elle ne fe deffait point en l'eau, fement \& cultiuent cefte terre : de forte que. 


\section{Fiftoire naturelle}

le grain y croift \& meurit fort bien. Puis apr ils l'enleuent d'vn lieu en autre. Mais il eft bie vray que de faire facilement ce iardin grand, que les fruicts y croiffent bien, eft chofe qui fa iuger qu'il y auoit du fait de Vitzilipuztli lequ ils appellent autrement Patillas, principaleme n'en ayăt iamais fait, ny veu de sêblables. Le Ro d'Azcapuzalco s'efmerueilla beaucoup quan ils vid accomply ce quil auoit tenu pour impo fible, \& dift aux fiens que ce peuple auoir grand Dieu qui leur rendoit tout facile, difas aux Mexiquains, que puifque leur Dieu leur de noit toutes chofes parfaictes, qu'il vouloit qu l'annee enfuiuant au temps du tribut, ils luy a portaffent dansle iardin vne cane $\&$ vn hero auec leurs oufs couuez, qui deuoient eftrec telle forte, qu'elles efcloúiffent leurs perits e arriuant, fans y faillir aucunement, fur peir d'encourir fon indignation. Les Mexiquai furent fort troublez \& triftes d'vn fi fuperbe difficile commandement qu'il leur faifoir: má leur Dieu,comme il auoit accouftumé, les cor forta de nuict par vn des fiens, \& leur dift qu' prenoit tout cela en fa charge, qu'ils ne perdi fent point courage, mais qu'ils creuffent pot certain qu'il viendroit vn tempsque les Azc puzilcos payeroient de leurs vies ces defirs nouueaux tributs. Le temps du tribut eftant ve nu, comme les Mexiquains portoient tout que l'on leur auoit demádé de leurs iardinages l'on troutua parmy les ioncs \& glaieuls du iar din, fans fçauoir comment ils y eftoient demet rez, vne cane \& va heron counuansleurs cufs, 


\section{des Indes. Liure. VII}

heminans, arriuerent à Azcapuzalco, où inconinent leurs œufs furent efclos. Dequoy le Roy l'Azcapuzalco eftant efmerueillé outre-mefu'e, dift derechef aux fiens, que ces chofes eftoient lus qu'humaines, \& que les Mexiquains com. nençoient comme pour fe faire Seigneurs de outes ces Prouinces. Neantmoins ilne dimiua aucunement l'ordre de ce tribut, \&. Jes $\mathrm{Me}$ riquains, pour ne fe trouuer affez puiffans, enlurerent \& demeurerent en cefte fubiction \& eruitude l'efpace de cinquante ans. En ce temps e Roy Acamapixtli mourtit, ayant augmenté a Ciré de Mexique de plufieurs edifices, rües, onduits d'eaties, \& de grande abondance de nunitions. Il regna en parx \& repos quarante ins, ayant toufiours efté zelateur du bien \& uugmentation de fa Republique. Comme il : ftoit proche de $f a$ fin, il fit vne chole memorasle, qui fut quayant des enfans legitimes, auffuels il euft peu laiffer la fucceffion du Royaune, neantmoins ne le voulut pas faire, mais au, contraire il dift librement a la Republique, que :omme ils l'auoient librement efleu, ainfi qu'ils. flcuffent celuy qui leur fembleroit eftre le plus propre pour leurbon gouuernement; les admo. neftant qu'en ce faifant ils euffent efgard au oien de la Republique, \& fe monftrant fafché de ne les laiffer libres du tribut \& fubiection, trefpaffa, leur ayant recommandé fa femme $\&$ les enfans, \& laifia tout fon peuple defconforté pour fa mort-

T $\mathrm{r}$ iij 


\section{Fiffoire naturelle}

Du fecod Roy, ó dece qui aduint en fon regn Chapitre. $\mathrm{X}$.

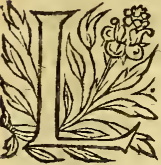

Es obleques du Roy deffun acheuees, les anciens, les princ paux du Royaume, \& quelqu partie du peuple, saffemblerer pour eflire vin Roy,où le plus ar cien propofa la neceffité en laquelle ils eftoien \& $q$ quil conuenoit eflie pour chef de leur $\mathrm{Cit}$ vne perfonne qui euft pitié des vieillards, de femmes veufues \& des orphelins, \& quifuft pe re de la Republique, pource qu'ils deuoiêtr eftr les plumes de fes aifles, les fourcils de fes yeux, $\varepsilon$ la barbe de fonvifage:qu'il eftoit neceffaire qu' fuit valeureux, pource quils auoient befoin bien toft fe preualoir de leurs bras, feló que leu auoit prophetifé leur pieu. Leur refolution e: fin fut d'elire pour Roy vn fils du predeceffeus vfans enuers luy d'vn auffi bó office, en luy don nant fon fils pour fucceffeur, comme il fit enues fa Republique, fe confiant en icelle. Ce ieun homme s'appelloit Vitzilouitli, qui fignifie plu meriche. Ils luy mirent la couronne Royale 8 l'oignirent, comme ils ont accouftumé de fair à tous leurs Reys, auec vne onction qu'ils ap pelloient divine, d'autant que c'efto, la $\mathrm{m}$ efm onction, de laquelle ils oignoient leur idole Incontinét vn Rhetoricien fit vne elegante ha rangue, l'exhortant d'auoir bon courage pou. les tirer des trauaux, feruitude $\&$ mifere, efquel les ils viuoient eftans opprimez des Azcapuzal. $\cos$, \& icelle acheuee, tous luy firent l'hommag 


\section{des Indes. Liure VII.}

\& la recognoiffance. Ce Roy n'eftoit point marié, \& fon Confeil fut d'opinion qu'il feroit bon dele marier auec la fille du Roy d'Azcapuzal$c o$, a fin de l'auoir pour amy, \& $\alpha$ d'obtenir par cefte alliance quelque diminution de la pefante charge destributs qu'il leur impofoit, combien qu'ils eurent quelque crainte, qu'il ne defdaignaft de leur donner fa fille, à caufe qu'ilsefto:ét fes vaflaux : toutesfois le Roy d'Azcapuzalco f'y accorda, apres qu'ils luy eurent demandé fort humblement, \& auec des paroles honneftes, lequel leur donna vne fienne fille appellee A yanchigual, laquelle ils menerent auec grande fefte \& refiouiffance en Mexique, \& firent la ceremonie, \& folemnité du mariage, qui eftoit d'attacher $\&$ noüer vn coing du manteau de l'homme auec vn autre, du voile de la femme en figne de lien de mariage. Cefte Royne engendra vn fils, le nom duquel ils furent demander à fon ayeul, le Roy d'Azcapuzalco, \& iettans les forts comme ils auoient accouftumé, (pource quils obferuoient fort les augures, principalement fur le nom de leurs enfans) il voulut que fon petit fils f'appellaft Chimal popoca, qui fignifie rondelle quiiette fumee. $\mathrm{La}_{\mathbf{a}}$ Royne fa fille voyant le contentement que le Roy d'Azcapuzalco monftra de ce petit fils, print de là occafion de luy demander, qu'il luy pleuft de foulager les Mexiquains de la charge di pefante destributs, puis qu'il auoit defia vn petit fils Mexiquain, ce que le R oy fit de bonne volonté, par le Confeil des fiens, leur laiffant an lieu du tribut qu' ils payoient, vne fubjection It iiij 


\section{Hifoire naturelle}

deluy porter chacun an vne couple de canard $\& z$ des poiffons, en recognoilfance qu'ils eftoien fes fubiects \& qu'ils habitoient en fa terre. $\mathrm{Pa}$ ce moyen les Mexiquains demeurerent for foulagez \& contens, mais le contentement leu dura bien peu, pource que la Royne leur pro rectrice mourur peu de temps apres, \& l'anne enfuitante mourut aufi le Roy de Mexique Vitzilouitli, laiffant fon fils Chimalpopoca aa gé de dix ans. Il regna treize ans, \& mourut aag de trente ans, ou peu plus. Il fut tenu pour vr bon Roy \& diligent au feruice de fes dieux, def quels ils auoient opinion que les Roys eftoien les reffemblances, \& que l'honneur que l'on fai. foit à leur Dieu, fe failoit au Roy, qui eftoit fa femblance. C'eft pourquoy les Roys ont efté $f$ affectionnez au feruice de leurs dieux. Ce Roy fut curieux de gaigner les volontez de fes voi. fins, \& de trafficquer auec eux, enquoy il aug. menta fa Cité, faifant que les fiens s'exerçaffent en chofes de guerre parmy le lac, preparants, \& difpofans les hommes pour ce qu'ils pretendoient obtenir, comme bien toft l'on verra.

Dutroifiefme Roy Chimalpopoca, . de fa cruello mort, \& de liocoafion de la guerre que firentles Mexiquains.

ChAFITRE XI.

EsMexiquains pour fucceffeur du Roy (2) 3) mort,efleurét fon fils Chimalpopocay par vn meur aduis \& deliberatió com:- 


\section{des Indes. Liure VII.}

mune, encores qu'il ne fuft qu'vn enfant de dix ans, ayăs opiniơ qu'il eft oit tou frours neceffaire de conferuer la grace du roy d'Azcapuzalco, en faifant fon petic fils Roy. Par ainfi ils le mirent en. fon throfne, luy donnant des enfeignes de guerre auec vn arc $\&$ des flefches en vne main, \& v ve efpee de razoirs, dont ils ont accouftumé d'vfer, en la droite, fignifians par cela, comme ils difent, que par les armes ils pretendoient fe mettre en hiberté. Ceux de Mexique auoient grande difette d'eau, pource que celle du lac eftoit bourbeufe \& fangeufe, \& par confequét mauuaife à boire. Pour à quoy remedier ils firent que le Roy enfant enuoyalt demander à fon ayeul le Roy d'Azcapuzalco, l'eau de la montagne de Chapultepec, qui eft à vne lieiie de Mexique, comme il a efté dit cy deffus; ce qu'ils obtindrent facilement, \& par leur diligence firent $v n$ aqueduct de falcines, glaieul, $8 \varepsilon$ gazon, parlequel ils firent venir l'eau en leur Cité. Mais d'autant que $l_{2}$ Cité eftoit fondec furlelac, \& que l'aqueduct le trauerfoir, il fe tompoit en beaucoup d'endroits, \& ne pouwoient fefiouyr de l'eau comme ils defiroient, \& auoient de beloing. Sur cefte occafion, foil qu'ils la recherchaffent tout expres pour queellèr les Tapanecas, ou fuft qu'ils f'efmeulfient ur peu d'occafion; en fin ils enuoyerent vne imbaffade au Roy d'Azcapuzalco, fort refoluë, tifans qu'ils ne pouuoient faccommoder de eau dont il leur auoit fair grace, à caufe que le :anal feftoit rompu en beaucoup d'endroits; partant luy demandoient qu'illes pourueuft de 


\section{Hiftoire naturelle}

bois, de chaulx, \& $r$ de pierre, \& quill leur en voyaft fes ouuriers, afin que par leur moyen il fiffent vn canal de pierre \& de chaulx, qui ne $f$ peuft rompre. Ce meffage ne pleutt gueres ar Roy, \& encore moins aux fiens, leur femblan que c'eftoir vn melfage outrecuidé, \& des pro. pos fort infolents pour des valfaux à l'endroiß de leur Seigneur. Les principaux du Confei doncques eftans indignez de cela, difoient que ceftoir defia beaucoup de hardieffe, puis que ne fe contentans de ce qu' on leur auoit permi: de demeurer en terre d'autruy, \& qu'on leu auoit donné de l'eau, ils vouloient dauantage quion les allaft feruir. Quelle chofe eftoit cela, $\& 2$ dequoy prefumoit vne nation fugitiue \& enferree entre les bourbiers, qu'ils leur feroien bien entendre, fils eftoient propres pour eftre ouuriers, \& que leur orgueil f'abbaifieroir, en leur oftant la terre \& la vie. Sur ces termes \& cholereils fortirent, laiffans le Roy, lequel ils auoient vn peu pour fufpect, à caufe du peti fils. Er eux feparément confulterent de nouueau ce qu'ils deuoient faire, où ils deliberezent de faire crier publiquement que nul Ta. paneca euft à traitter, ny faire commerce aue aucun Mexiquain, qu'ils n'allaffent en leus - Ciré, \& ne les receuffent en la leur, fur peine de la vie. Par où l'on peut entendre que le Roy ne commandoit pas abfolument fur ce peuple, \& qu'il gouuernoit plus en façon de Conful, ou de Duc, que de Roy, combien que de puis auec la puiffance f'augmenta auffi le commandement des Roys, iufques à deuenir tyrans 


\section{des Fndes. Liure VII.}

parfaiots, commel'on verra aux derniers Rois. Car ç'a efté toufiours vne chofe ordinaire entre les barbares, que telle qu'a efté la puiffance, tel a efté le commandement, voire-mefme en nos hiftoires d'Efpagne fe trouue en quelques. Roys anciens la façon de regner dont ces $\mathrm{T} a-$ panecas vferent. Er les premiers Roys des Romains furent de mefme, fauf que Rome des Roys declína aux Confuls \& v n Senar, iufques à ce que du depuis elle vintà la puiffance des Empereurs. Mais ces barbares de Roys moderez declinerent à Tyrans. Et eftant l'vo \& l'au . tre gouuernement, le meilleur, \& le plus feur eft le regne moderé. Or retournans à noftre hiftoire, le Roy d'Azcapuzalco voyant la deliberation deș fiens, qui eftoit de tuer les $\mathrm{Me}$ xiquains, les pria que premierement ils defrobalfent fon petit fils le ieune Ray, \& apres quils fiffent aux Mexiquains ce quils voudroient. Prefque tous faccorderent en cela pour donner contentementau Roy, \& pour la pitié qu'ils auoient del'enfant: mais deux principaux y contredirent bien fort, affermans que c' eftoit vn mauuais confeil, pource que Chimalpopoca, bien qu'il fuft de fon fang, eftoit du cofté de la mere, \& que le cofté du pere deuoit eftre preferé. Parquoy ils conclurent que le premier qu'il conuenoit tuer, eftoit Chimalpopoca Roy de Mexique, \& protefterent d'ainfil le faire. Le Roy d'Azcapuzalco fut fi fafché de cefte refiftance qu'ils luy firent, \& du confeil \& refolution quils prindrent, que de là à peu de remps, de douleur \& de defpir il tomba malade, 


\section{Ffifoire naturelle}

dont il mourut. Par la mort duquel les Tapane. cas fracheuans de refoudre, commirent vne grande trahifon: car vne nuictle ieune Koy de Mexique dormant fans garde, \& fans fe douter de rien, ceux d'Azcapuzalco entrerent en for Palais, \& le tuerent foudainement, fen retour. nans fans eftre apperceus. Le matin venu que les nobles de M exique furét falüer le Roy com. me ils auoient accouftumé, ils le trouueren mort auec de cruelles bleffures, \& lors ils f'efcrierent, theuans wn pleur qui remplit toute l: Cité, \& vous aueuglez de cholere, fe mirent incontin ent en armes pour venger la mort de leu Roy. Coinme ils marchoient defia pleins de fu. reur, \& fans ordre, leur fortit au deuant vn des principaux Chcualiers des leurs, tafchant de les appaifer par vne fage remonftrance : oì alle vous (dit-il) ô Mexiquains, repofer vos ceeurs, regarde 7 que les cho fes qur font failtes fans confideration, ne jont pai bien condusctes, ny riont point de bons fuccer. Reprime? voftre douleur, confiderans qu'encores que voftre Roy fou mort, l'illuftre fang des Mexiqudins n'eft pas finy en luy. Nous auons des enfans des Roys deffuncts, par la condurite defquels fuccedans an Royaume, vous fere? mieux ce que pretendez, ayans vis chef qui vous guide aे voftre entreprife. $N$ allez pas anns areuglez: deporteZ-vous, o e fli fei premierement vn Roy o S Seigneur qui vous gride, $\mathbb{V}$ encourage contre vos ennemis. Cependant difommule $Z$ dif crettement, faijans les obfeques de voftre Roy mort, dont wous voye $Z$ le corps prefent: car par cy apres il fe trounera wre meilleure occafson d'en faire la vengeance. Par ce moyen les Mexiquains ne pafferent point plus putre, \& farresterent pour faire los ob feques de 


\section{des Indes. Liure VII.}

leur Roy. A quoy ils conuierent les Seigneurs . de Tefcuco \& ceux de Culhuacan, \& leur raconterent l'acte fi enorme $\&$ cruel que les Tapanecas auoient commis, les inuitans à auoir pitié d'eux, \& à f'indigner contre leurs ennemis; à quoy ils adjoufterent, que c'eftoit leur intention de mourir, ou de venger vne fi grande mefchanceté, leur demandans qu'ils ne fauorifaffent le party fi injufte de leurs contraires, \& que de leur part ils ne les requeroient point qu'ils leur ay daffent de leurs armes \& hommes, mais feulement qu'ils fuffent attentifs à regarder ce qui fe pafferoit, \& quils defireroient pour leur entrerien, qu'ils ne leur bouchaffent, ny empefchaffent le commerce, comme auoient fait les Tapanecas. A ces railons ceux de Tefcuco \& Culhuacan leur demonftrerent beaucoup de bonne volonté, \& qu'ils en efroient fort fátisfaits, leur offrant leurs Citez, \& tout le commerce qu'ils en defireroient, afin qu'à leur volonté ils fe pourueuffent de prouifions \& de munitions par terre \& par eau. A pres cela ceux de Mexique les prierent qu'ils demeuraffent auec eux, \& affiftaffent à l'eflection du Roy quils vouloient faire; ce qu'ils accorderent auffi pour leur donner contentement. 


\section{Hiftoire naturelle}

Du quatriefme Roy nommé Izcoalt, \& de l. guerre contre les Tapanecas.

\section{Chapitis XII.}

Vur $\mathrm{E} v \mathrm{x}$ qui fe deuoient trouruer en l'efle Otion, eftans tous affemblez, fe leua vs (19) vieillard, tenu pour v n grand orateur (c) lequel, felon que racontent les hiftoi. res, parla en cefte maniere: La lumiere de vos yeus vous manque, $\hat{o}$ Mexiquains, mais non pas celle duc ceur car poféle cas que vous aueZ perdus celuy que eftoit lalu. miere, $\mathcal{\sigma}$ leguide decefte Republique Mexiquaine, cell du cosur neantmoins vous eft demeuree, pour confideres qui sils ont tué vn bomme, d'autres fone demeure Z apres luy. qui pourront suppleer fort aduantagenfement la faute qui nous arons deluy. La noblefe de Mexique n'eft pas fini pour cela, ny le Jang Royal efteint. TourneZ lesyeux, o regardeZ autour de vous, $\sigma$ vous verre $Z$ la noblefe Mexiquaine mife en ordre, non point vn, deux, mais plujieurs Oo excellens Princes, flls dus Roy Acamapaxtli, noftre vray o legitime Sergneur. Icy vous pourre $Z$ choifir à voPire volonté, difant, te veux ceftuy-cy, or non cet autre. Que $f$ vous ane $Z$ perdw vn pere, wy vons trounere $Z$ pere $\mathcal{O}$ mere. Faiteseftat, $\hat{o}$ Mexiquarns, que le solen 'seft eclipfe $\mathbb{\sigma}$ obfcurcy fur la terre pour vn peu de temps, $\mathcal{O}$ guincontinent retournera la lumiere fur icelle. Si Mexique a eftéobfsurcie par la mort de voftre Roy, forte bien to f le Soleil, ellife $Z$ vn autre Roy. Regarde $\chi$ bien à qui, o Jur qui vous iettere $Z$ lesyeux, $\sigma$ enuersqui s'incline vof tre cour, car ceftuy-là eft celuy que voftre Dien vit Tllipultlia a flew. Et dilatant encore ce difcours, cét ora: 


\section{des Indes. Liure VII.}

teur acheua au contentement d'vn chacun. En fin par la refolution de ce confeil fur efleu Roy Ifcoalt, qui fignifie couleuure de razoirs, !equel eftoit fils du premier Roy Acamapixtli, quil auoit eu d'vne fienne efclaue; \& bien quil ne fuft pas legitime, ils le choifirent, pource quil eftoit plus aduátageux que les autres en meurs, valeur \& magnanimité de courage. Tous monftrerent quiils en eftoient fort contens, \& fur tous, ceux de Tefcuco; pour autant que leur roy eftoit marié auec vne four d'Ifcoalt. A pres que ce Roy fut couronné, \& mis en fon fiege Royal, fe leua vn autre orateur, qui traitta de l'obligation que le Roy auoit à fa Republique, \& du courage quil deuoit monfter aux trauaux, difant entre autres chofes: Regardes qu'duiourd'buy nous fommes dépendans de toy, parauanture lauferas.tu tomber la charge qun eft fur tes eßpaules; larferasotu peris le vieillard o la vielle, loorphelin $\sigma$ la vefue? Ryes pitié des enfans qui vont grapinant parmy l'alve, lefgurels periront, fi nos ennemis nous furmontent. Or fus denc, setgneur, commence à deployer of effendre ton manteau, pour prendre fur tes eppaules tes enfans, qui font les pantires $\checkmark$ le commun populaire, le fquels font a JencereZ de í ombrage de ton manteaw, ov en la fraicheur de ta benignité. Continuant fur cefujet bcaucoup dautres paroles, lefquelles (comme en fon lieu a efté dit) ils apprenoient par cour, pour l'exercice de leurs enfans, \& apres les enfeignoient comme vne leçon, à ceux qui commençoient d'apprendre cefte faculté d'orateurs. Cependant les $T a$ panecas eftoient refolus de deftruire la nation Mexiquaine; \& pour cét effet ils aúoient dreffó 


\section{Hifoire naturelle}

beaucoup d'appareils. Parquoy le nouneau ro traitta de declarer la guerre, \& venir aux main auec ceux quiles auoient tellement offenfez Mais le commun peuple voyant queleurscon traires les furpaffoient beaucoup en nombr 'd'hommes, \& en machines de guerre, eftans e' pouuentez, vindrent vers le Roy, \& luy de manderent par importunité qu'il n'entreprinf point vne guerre fidangereufe, qui feroit de ftruire leur pauure Cité \& nation. Surquoeftans interrogez quel aduis il conuenoit pren dre; refpondirent que le Roy d'Azcapuzalce eftoit fort pitoyable, quils luy demandaffen paix, \& f'offriffent de le feruir, en les tirant hor: de ces glaieuls, \& quil leur donnaft des maifon: $\&$ des terres parmy les fiennes, afin que parce moyen ils défpendiffent tous d'vn Seigneur. E pour obtenir cecy, ils portaffent leur Dieu en fa littiére, pour interceffeur. La clameur du peu. ple euft tel pouuoir, principalement $y$ ayant quelques nobles qui approuuoient leur opinion, quel'on fift incontinent appeller les Prefires, \& apprefter la littiere, \& leur Dieu, pour faire ce voyage. Comme cela fappreftoit, \& que tous confentoient à cét accord de paix, \&t de faffujettir aux Tapanecas; vn ieune homme gaillard, \& de bonne façon, f'efleua parmy le peuple, lequel auec vne fort bonne grace parla ainfi : Ou'eft cecy, $\hat{o}$ Mexiquains, eftes vous fols? comment telle coüardife eft elle entree parmy nous? nous dewons nous aller rendre ainfin aux $A$ 'TapuZalcos? Puisfe rournant versle Roy, luy dift : Commer, seigneur, permettez-rous telle choje? permettiz à ceperple, o 
luy dites qu'il larfe rechercher vn moyen pour noftre bonneur $\sigma$ pour noftre deffenge, $\sigma$ que nous ne nons met ions poino of follement, $\mathcal{O}$ fi honten $\mathrm{fement}$ entre les mains de nos ennemis. Ceieune homme fappelloit $\mathrm{Tl}_{2}$ caellec, nepueu du mefme Roy, \& fur le plus raleureux Capitaine, \& du plus grand confeil, que iamais les Mexiquains ont eu, commecy ipres l'on verra. Animé donc Ifcoalt, parce jue fon nepueu luy auoit dit fi prudemment, etint le peuple, en difant quiils luy laiffaffent remierement efprouuer vin autre meilleur noyen. Et puis fe tournant vers la noblefle des iens, leur dift: Vous effes icy tous qui eftes mes parens, o le meilleur de Mexique: celuy qua aura le courage de

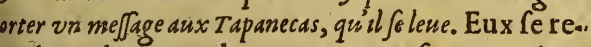
ardans les vns les autres, ne fe remuoient oint, \& n'y eut aucun qui youluft f'offrir au oufteau. Alors ce ieune homme Tlacaellec fe euant, foffrit à y aller, difant que puis qua il deoit mourir, qu'il importoit peu que ce fuft ausurd'huy, ou demain: car pour quelle occaon fe deuoit -il tant conferuer? quil eftoit tout reft, \& qu'il luy commandaft ce qu'il luy plaioit. Et iaçoit que tous iugeaffent cét acte pour netemerité, neantmoins le Roy fe tefolut de enuoyer, afin qu'il cogneuft la volonté \& difofition du Roy d'Azcapuzalco, \& de fes homres, eftimant quil eft oit meilleur d'aduanturer vie de fon nepueu, quel'honneur de fa Reublique. Tlacaellec eftant apprefté, print fon aemin, \& paruenu aux gardes qui auoient ommandement de tuer quelconque Mexiuain qui vinft vers eux 2 par artifice, ou antre- 


\section{Hiftoire naturelle}

ment, leur perfuada quils le laiffaffent entres vers le Roy, lequel f'efmerueilla de le voir, \& ouyt fon ambaffade, qui eftoit de luy demande: paix foushonneftes conditions; lequel refpon. dit qu'il le communiqueroit aueclesfiens, \& qu'il retournaft l'autre iour pour la refponfe Lors Tlacaellec demanda feureté, mais il n'er peut obtenir d'autre, finon qu'il vfaft de fabon ne diligence. Auec cela il retourna en Mexique donnant parole aux garde's de retourner. Li Roy de Mexiquele remerciant de fon bon cou rage, le renuoya pour auoir la refponfe, \& luy commanda que fi elle eftoit de guerre, qu'i donriaft au Roy d'Azcapuzal co certaines arme: pour fe deffendre, \& lay oignift, \& emplumaf la tefte, commeils faifoient aux hommes morts luy difant, que puis qu'il ne vouloit point paix, qu' ils luy ofteroient la vie, \& aux fiens. E encores que le Roy d'Azcapuzalco euft defiri la paix, pour eftre de bonne condition, les fien: neantmoins l'efguillonnerent de forte, que refponfe fut de guerre declaree. Ce qu'eftan ouy par le meffager, il fift tout ce quelon Ro: luy auoit commandé, declarant par cefte cere monie de donner armes, \& oindre le Roy auer l'onction des morts, que de la part de fon Ro] ille déffioit. Parquoy ayant tout acheué, celuj d'Azcapuzalco fe laiffant oindre, \& emplumer donna au meffager en payement de bonnes ar mes, \& cependant l'aduifa de ne retourne. point par la porte du palais, pource que plu fieurs l'attendoient la pour le mettre par pieces mais qu'il fortift en fecret par vne petite faul. 


\section{des Indes. Liure VII. '}

porte qui eftoit ouuerte, en vne des courts de Con Palais. Ce ieune homme le fift ainfi, \& tournoyant par des chemins cachez, vint à fe mettre en fauueté, à la veuie des gardes, \& de lt les déffia, difant: Tapanecas $\mathcal{O} \Lambda$ Trcapuialcos, vous faites mal voftre office de garder, ك̧̧ache Z donc que vous dewe $\chi$ tous mourir, or quill ne demeurera vn Tapaneca in vir. Cependant les gardes fe ietrerent fur luy, \& fe porta fi valeureufement en leur endroict, qu'il en tua quelques-vns, \& voyant qu'il y accourroit beaucoup de peuple, fe retira gaillardement à fa Cité, où il porta nouuclles quela guerre eftoit declaree auec les Tapanecas, \& 8 yu'il auoir déffić leur Roy.

De la bataille que les Mexiquains donnerens anx Tapanecas, of de la grande victoire quils obtindrent.

Chapitre XiII. E deffy entendu parle vulgaire de auecques leur coliardife accouftumee, pour luy demander congé de fortir de fa Ciré, tenans pour ertain leur ruine \& leur perdition. Le Roy les :onfula \& anima tant qu'il peut, leur promettăt juil leur dóneroit liberté, en furmontant leurs nnemis, \& qu'ils ne doutaffent point d'eftre aincus. Le peuple repliqua : Et fi nous fommes yaimcus, que ferons-nous? Si nons fommes vaincus ( $\mathrm{r} e \mathrm{f}_{\text {: }}$ $Y$ is ij 


\section{des Fndes: Liure VIII.}

pondit le Roy) désmaintenant nous-nous obligeons de nous mettre en ves mains, afin que vous nous mettie Z? mort, $\sigma$ mangre $Z$ nos chairsen desplats, of que vous vous vengie $Z$ de nous autres. Il fera donc ain $f$ (dirent-

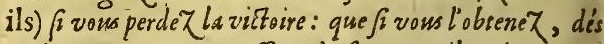
maintenant nous-nous offrons à eftre vos tributaires, trawailler en vos marfons, faire vos femences, $\sigma$ parter vos armes o bagage quand vous ire $z$ à la guerre, pour touf iours, $\sigma$ à lamais nous autres, $\sigma$ nos defcendans. Ces accords faits entre le peuple \& les nobles (lefquels ils accòmplirent depuis de gré, ou par for. ce entier ement, comme ils le promirent) le roy nomma pour fon Capitaine general Tlacaellec, \& tout le camp eftant mis en ordre, \& par efcadrons, donna les charges de Capitaines aux plus valeureux de fes parens \& amis, puis leur fift vne belle harangue, par laquelle il les anima, \& leur accreut de beaucoup le courage qu'ils amoient defia bien preparé, \& ordonna quils obeyffent tous au commandement du General quili auoit eftably : lequel fepara fes gens en deux, \& commanda aux plus valeuréux $\&$ hardis qu'en fa compagnie ils affailliffent les premiers, \& que tout le refte demeuraft arrefté auec le Roy If coalt, iufques à ce qu'ils viffent les premiers donner fur leurs ennemis. Marchans donc en ordre, ils furent defcouverts de ceux d'Azcapuzalco, lefquels incontinent fortirent furieufement de leur Cité, portans de grandes richeffes, d'or, d'argent, \& d'armes de beaucoup de valeur, comme ceux qui auoient l'Empire de toute cefte contree. Ifcoalt donna de fignal de la bataille, auec vn petit tambour 


\section{des Indes. Liure VII. $\quad 339$}

qu'il portoit fur fes efpaules, \& incontinent efeuerent vn grand cry, f'efcrians, Mexique, Mekique, donnerent fur les Tapanecas; \& bien que es Tapanecas fuffent en bien plus grand nomore qu'eux fans comparaifon, toutefois ils ne aifferent de les rompre, \& les firent retirer en eur Citć. Puis venans ceux qui eftoient deneurez derriere, crians Tlacaellec, victoire, idoire, tous d'vn coup entrerent en la Cité, où ar le commandement du Roy, ne pardonneent à hommes, ny vieillards, femmes, ny enans : car ils les mirent tous au trenchant de efpee, pillerent \& faccagerent la Cité, qui toit tres-riche. Et non contens de cela, ils forirent à la pourfuitte de ceux qui f'en eftoient uys, \& retirez en l'alpreté des Sierres, ou monagnes qui eftoient proches de là, frappans fur ceux, dontils firent vne cruelle boucherie. Les apanecas d'v ne montagne où ils f'eftoient reirez, ietrerent les armes, \& demanderent les ies, ['offrans à feruir lcs Mexiquains, leur doner des terres \& des iardins, de la pierre, de la haulx \& du mefrain, \& de lestenir toufiours our leurs Seigneurs. A cefte occafion Tlaaellec fift retirer fes gens, \& ceffer la bataille, ur donnant les viesfoubs les conditions defifdites, lefquelles ils iurerent folemnellement. uis apres ils retournerent aे Azcapuzalco, \& uec leurs defpoiiilles fort riches \& victorieus̀ à la Cité de Mexique. Le iour enfuiuant le oy fift affembler les principaux \& le peuple, a quels il remit en auant l'accord qu'auoit fait ommun, leur demanda fils eftoient contens Vi iij 


\section{Hifoire naturelle}

d’y perfifter, le commun dit qu'ils l'auoient pro: mis, \& que les nobles l'auoient bien merité; parquoy ils eftoient contens de les feruir perpetuellement, dequoy ils firent vn ferment quils ont depuis gardé fans y contreuenir. Cela fait, If́coalt retourna à Azcapuzalco, \& par le confeil desfiens, departit toutes les terres des vaincus \& leurs biens, entreles vainqueurs; la prin cipale partic tomba au Roy, puis à Tlacaellec, \& apres, au refte des nobles, felon quils feftoient fignalez en la guerre. Ils donnerent mefme des terres aे quelques plebeiens, pour feftre portez vaillamment, aux autres difribuerent du pillage, \& en firent peu d'eftat, comme de gens couiards. Ils deftinerent mefme des terres en commun pour les quartiers de Mexique, \&: à chacun les fiennes, afin qu'auec icelles ils aydaffent au feruice \& facrifices de leurs Dieux. Ce fur l'ordre qu'ils garderent toufiours de là en auant, au departement des terres \& defpoüilles de ceux qu'ils auoient vaincus \& affujettis. Par ce moyen ceux d'Azcapuzalco demeurerent fi pauures, qu'il ne leur reftoit aucunes terres pour labourer, \& le pire fut, que l'on leur ofta le Roy, \& le pounoir d'en eflire d'autres que celuy de Mexique. 
De la guerre of victoire que les Mexiquains eurent contre la Cité de Cuyoacan.

ChAPITRE XIV.

84y 9 A (N) puzalco, toutesfois ils en auoient (6) d'autres qui auoient leurs Sei25 gneurs particuliers, comme $\mathrm{Ta}$ cuba, \& Cuyoacan. Ceux là ayans veu l'efchec paffé, euffent bien voulu que ceux d'Azcapuzalco euffent renounellé la guerre contre les Mexiquains, \& voyans qu'lls ne f'y preparoiént point, comme vne nation du tout rompuc̈ \& desfaite, ceux de Cuyoacan delibererent de faire à part foy la guerre, pour laquelle ils f'efforcerent d'inciter les autres nations circonuoifines, lefquelles ne voulurent point fe mouuoir, ny quereller les Mexiquains. Cependant croiffant la haine \& enuie de leur profperité, ceux de Cuyoacan commencerent à mal-traicter les femmes qui alloient à leurs marchez, fe mocquans d'elles, \& en faifans autane aux hommes fur lefquels ils auoient la domination. Pour laquelle occafion le Roy de Mexique deffendit quaucun des fiens n'allaft en Cuyoacan, \& quils ne receuffent en Mexique aucuns d'eux. Ce qui donna occafion à ceux de Cuyoacan de fe refoudre du tout a la guerre. Mais premierement ils les voulurent prouoquer par quelque honteufe mocquerie, qui fant $\mathrm{V} u$ iiij 


\section{Hifoire naturelle}

de les conuier en vne de leurs feftes folem: nelles, où apres leur auoir fait vn beau báquet, \& les auoir feftoyez auec vne grande dance a leur mode, ils leur enuoyerent pour le deffert des habits des femmes, \& les contraignirent de les veftir, \& retourner ainfi veftus en femmes, en leur Cité, leur reprochans qu'ils n'eftoienr que des coüards, \& des effeminez; de n'auoir ofé prendre les armes, y ayans efté affez prouo. quez. Ceux de Mexique difent qu'en recompenfe ils leur firent vne autre lourde mocquerie, en leur mettant aux portes de leur Cité de Cuyoacan, certaines chofes qui fumoient, par le moyen defquelles plufieurs femmes auorterent, \& plufieurs tomberent malades. En fin le tout vint iufques au poinct de guerre declaree; de forte qu'ils fe donnerent vne bataille, où ils employerent toute leur puiffance de part \& d'autre, \& en icelle, Tlecaellec par fa magnanimité, \& rufe de guerre, obtint la victoire : car ayant laiffé le Roy ifcoalt combatant auec ceux de Cuyoacan, falla mettre en embufcade auec quelque peu de vailläs foldats, \& en tournoyãt leur vint donner en queiie, où chargeant fur eux, il les filt retirer en leur Cité. Maisvoyant quils pretendoient fe retirer au Temple, qui eftoit bien fort, fe ietta fúr eux accompagné de trois valeureux foldats, \& leur gagna le deuant, fe faififfant du Temple, où il mitle feu, \& les força de f'en fuyr parmy les champs, où faifant grand efchec fur les vaincus, les fuiuirent deux lieïes dans le pays, iufques à vne colline, où les vaincus iettans les armes, \& croifans les bras 


\section{des Indes. Liure. VII. $34 \overrightarrow{\mathrm{I}}$}

fe rendirent aux Mexiquains, \& auec beaucoup de larmes, leur démanderent pardon de l'outrecuidance qu'ils auoient euë en les traictant comme femmes, $\&$ s'offroient à eftre leurs efclaues, fi bien qu'en fin les Mexiquains leur pardonnerent. De cefte victoire les Mexiquains remporterent de tres-riches defpouilles, d'habits, d'armes, de l'or, de l'argent, des ioyaux \& des plumaches riches, auec vn grand nombre de captifs. En cefte bataille il y eut trois des principaux de Culhuacan qui vindrent ayder aux Mexiquains, pour gaigner honneur, lefquels furent remarquables fur tous. Et du depuis eftans recogneuz par Tlacaellec, \& ayant fait preuue de leur fidelité, leur donna les deuifesMexiquaines, 2 les eut toufiours à fon cofté, où ils combatirent en tous lieux valeureufement. L'on recogneut bien que toute la viatoire deuoit eftre attribuee au general \& à ces trois. Car entre tant de captifsqu'il y auoit, il y en auoit les deux tiers qui furent gagnez par ces quatre, ce quile preuuafacilement par la rufe dont ils vferent: car en prenant vn captif, incontinent ils luy coupoient vn peu de cheueux, \& les bailloient aux autres. Ainfi il fe trouua que ceux qui auoient les cheueux coupez reuenoientà ce nombre, d'où ils acquirent vne grande reputation \& renommee de valeureux. Ils furent honorez comme vainqueurs, en leur donnant de bonnes portions de depouilles, \& desterres, ainfi que les Mexiquains ont de tout temps accouftumé de faire, qui donnoie occafion à ceux qui combattoient, de fe faite 


\section{Hiftoire naturelle}

renommer, \& gagner dela reputation aux ar mes.

De la guerre of victoire que les Mexiguains eurent contre les Suchimilcos. CH ITRE XV.

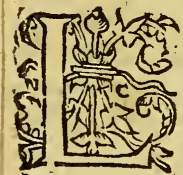

A pation des Tapanecas eftan fubjuguee, les Mexiquains eu. rent occafion d'en faire autani aux Suchimilcos, lefquels comme il a efté dit, furent les pre. miers de ces fept cauernes ou lignages qui peuplerent cefte terre. Les Mexiquains toutesfois ne rechercherent pas l'occafion, combien qu'ils pouuoiét prefumer comme vainqueurs, de paffer plus outre, mais les Suchimilcos les efmeurent, pour leur malheur, commeil arriue aux hommes de peu de fçauoir, \& qui regardent de trop pres, lefquels pour ne preuoir le dommage quils imaginoient, tomberent en iceluy. Les Suchimilcos furent d'opinion que pour les victoires paffees, les Mexiquains entreprendroiét de les affubjettir, \& delibererent entr'eux ceft a ffaire. Il y en eut quelques-vns qui dirent quil euft efté bon dés lors de les recognoifte pour fuperieurs, \& d'approuuer leur bon heur, neantmoins le contraire fut refolu, \& s'aduancerent pour leur donner bataille. Ce qu'entendu par Ifcoalt Roy de Mexique, il enuoya contre eux fon general Tlacaellec,auec fon armee, \& vindrentà donner bataille au mefme champ, qui feparoit leurs limites, lefquelles deux armees 


\section{des Indes. Liure. VII. 342}

eftoient affez efgales en hommes \& en armes, mais elles furent bien diuerfes en l'ordre \& ma。 niere de combattre; pource que les Suchimilcos chargerent tous enfemble en vn monceau fans ordre, \& T lacaellec diuifa les fiens par efcadrós auec vn bel ordre:par ainfi ils rompirent incontinent leurs contraires, les faifans retirer en leus Cité,en laquelle ils entrerent alors, \& les fuiui-, rent iufques à les enfermer au temple, où ils mirent le feu, \& les firent fuyr aux mótagnes, \& en fin les reduifirent à ce point, qu'ils fe rendirent les bras croifez. Le Capitaine Tlacaellec retournant en grand triomphe, les Preftres allerent aus deuát le receuoir, auec leur mufique de fluftes, en encenfant deuant luy, les Capitaines principaux faifans d'autres ceremonies $\&$ monftres d'allegreffe, qu'ils auoient accouftumé de faire, \& lc Roy auec eux, s'en allerent tous au temple,rendre graces à leur faux dieu. Car le diable a toufiours efté fort defireux de cela, \& de s'attribuer l'honneur de ce quil n’a point merité, attendu que c'eft le vray Dieu qui donnela victoire,\& qui fait regner ceux quail luy plaift, \& nó pas luy. Le iour enfuiuant le Roy Ifcoalt fut en la Cité de Suchimilco, \& là fe fift iurer Roy des Suchimilcos, \& pour les confoler, leur promit faire du biê,en figne dequoy il leur cómanda qu'ils fiffentvne grăde chauffee, qui trauerfaft de Mexique d Suchimilco, qui sót quatre lieües, afin quil y eur plus de cominerce \& cómunication entr'eux. Ce que firent les Suchimilcos, \& en peu de temps le Gouuernement des Mexiquains leur fembla fi bon, qu'ils s'eftimerent 


\section{Hiftoire naturelle}

heureux d'anoir changé de Roy \& de Republi. que, \& quelques circonuoifins pouffez d'enuie, ou de crainte à leur perdition, ne furent pas faicts fages du malheur de ces autres, comme ils deuoient. Cuitlauaca eftoit vne Cité dans le lac, laquelle (encor que le nom \& habitation foit changee) dure encor. Ils eftoiět fort adroits à nauiger parle lac, \& pourtant illeur fembla quils pourroient endommager beaucoup les Mexiquains par eau. Ce quele Roy ayant entendu, il euft voulu y enuoyer incontinent fon armee pour combattre contr'eux : mais $\mathrm{Tl}_{2}$ caellec eftimant peu cefte guerre, \& reputant chofe honteufe de mener vne armee contre ceux-là, il s'offrit de les vaincre auec les enfans feuls, \& le mit à effect. Il s'en alla au temple, \& tira du Conuent ceux d'entre les enfans qu'il trouua propresà ceft affaire, aagez depuis dix ans iufques à dix-huict, lefquels fçauoient guider \& mener des batteaux ou canoës, \& leur enfeigna certaines rufes. L'ordre qu'ils tindrent à cefte guerre, fut, qu'il s'en alla en Cuitlauaca auec ces enfans, où par fes rufes il preffa fes ennemis en telle façon qu'il les fit fuyr, \& comme il les pourfuiuoit, le Seigneur de Cuitlauaca luy vint au deuant, \& fe rendit, lay , fa Cité, $\&$ fon peuple: par ce moyen ceffa la pourfuitte. Les enfans retournerent auec beaucoup de defpouilles \& plufieurs captifs pour leurs facrifices, qui furent receuz folemnellement auec vne grande proceffion, mufique \& parfums, \& allerent adorerleurs dieux en prenant de la terre qu'ils mangeoient, \& fe tirant du fang du 


\section{des Fndes. Liure. VII.}

deuant des iambes auec les lancettes des Pretres, \& faifans d'autres fuperftitions quils auoient accouftumé de faire en telles folemnitez. Les enfans furent fort honorez \& encouragez, \& le Roy les embraffa \& baifa, \& fesparens $\&$ alliez les accompagnerent. Le bruit de cefte victoire courut par tout le pays, comme Tlacaellec auoit fubjugué la Cité de Cuitaluaca auec des enfans, dont la nouuelle \& confideration des chofes paffees, ouurit les yeux à ceus de Tezcuco, nation principale \& fort accorte,pour leur façon de viure. Tellement que e Roy de Tezcuco fut le premier qui fut d'ooinion quils fe deuoient affubjettir au Roy de Mexique, \& l'y conuier auec fa Cité. Parquoy de l'aduis de fon Confeil, ils enuoyerent des Am baffadeurs, bons orateurs, auec des prefens conorables pour s'offrir aux Mexiquains comne fubjects, leur demandans paix \& amitié: cea fut accepté gracieufement, combien que par e confeil de Tlacaellec, pour effectuer cela, il fit neceremonie que ceux de 'Tezcuco fortiroiét en armes auec ceux de Mexique, \& qu'ils fe cósattroiët \& rendroient incontinent, qui fut vn cte \& ceremonie de guerre, fans qu'il y eut auun fang refpandu d'vne part, ny d'autre. Paruoy le Roy de Mexique demeura foutuerain eigneur de Tezcuco, \& ne leur ofta point léur Roy, mais le fit de fon Confeil priué, tellement unils fe font toufiours conferuez de cefte faon iufques au temps de Meteçuma fecond, duant le regne duquelles ESpagnols y entrerent. Ayans aflubjetty la terre \& la Cité de Tezcuco, 


\section{Hiffoire naturelle}

Mexique demeura Dame de toure la terre \& de! villes qui font à l'entour du lac où elle eft fon. dee.Ifcoalt ayant donc ioüy de cefte prof perité, \& regné douze ans, mourut laiffant le Royau. me que l'on luy auoit donné, bien augmenté, par la valeur \& confeil de fon neueu Tlacael. lec (comme a efté raconté) qui fut d'aduis \& trouua meilleur que l'on efleut vn autre Roy que luy, comme nous dirons $\mathrm{cy}$ apres.

Ducinguiefme Roy de Mexique appellé Moteçuma, presrier de ce nom.

\section{Chapitre XVI.}

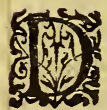

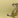
au Roy de Tezcuco \& au Roy de Tacuba, par fpecial priuilege, Tlacaellec affembla ces fix perfonnages, comme celuy qui auoir la fouue. raine authorité,aufquels ayant propofé l'affaire fut effeu Moteçuma premier de ce nom, neuels du mefrne Tlacaellec.Só eflectió fut fort agreable à tous, "a l'occafion dequoy ils firent des feAtes tres-folemnelles \& plus magnifiques que les precedentes. Incontinent qu'ils l'eurent eflea, ils le menerent auec grande compagnieau remple, ou deuant le fouyer diuin quils appelJoient, (où ily auoir toufiours du feu iour \& nuict) le mirent en vn throfne Royal, le reueftans d'ornemens royaux. Et eftant la, le Roy fe rira du fang des oreilles $\&$ des iambes, auec des 


\section{des fndes. Liure VI I.}

ongles ou griffes de tigres, qui eftoit le facrice 344 auquel le diable fe plailoit d'eftre honoré. Les preftres, les anciens \& les Capiraines luy firent leurs harangues, le congratulans tous de fon eflection. Ils auoient accouftumé en telles eflections de faire de grands banquets \& des dances, où ils confommoient beaucoup de luminaires. Du temps de ce Roy fut indroduite $l_{3}$ couftume qu'ils auoient que le roy deuoit aller en perfonne faire la guerre à quelque Prouince, d'où il amenaft des captifs pour folemnifer a fefte de fon couronnement, \& pour les fo. lemnels facrifices de ce iour là. Pour cefte caufe le Roy Moteçuma alla en la Prouince de Chalco, les habitans de laquelle s'eftoient declarez fes ennemis, où àyant combatu valeureu. Cement, il amena vn grand nombre de captifs, defquels il offrit \& celebra vn notable facrifie le iour de fon couronnement, combien que our lorsil ne fubiugua pas toute la Prouince de Chalco, d'autant que c'eftoit vne nation fort belliqueufe. Plufieurs venoient à ce couonnement de diuerfes Prouinces, tant proches, qu'efloignees, pour voir cefte fefte, en laquelle tous ceux qui y venoient, eftoient abondamment \& magnifiquement nourris \& reuctus, principalement les pauures, aufquels lion donnoir des habits neufs. Pour cefte caufe lion pportoir ce iour là en la Cité les tributs du Roy auec vn bel ordre $\&$ appareil, qui confitoit en des eftoffes à faire des habits de toutes ortes, du Cacao, de l'or, de l'argent, de riches lumaches, de grands fardeaux de cotton, de 


\section{Fiftoire naturelle}

laci, des concombres, de plufieur fortes de le. gumes, de plufieurs fortes de poiffons de mer, \& de riuiere, d'vne quantité de fruicts, \& de la venaifon fans nombre, fans faire compte d'vn nombre infiny de prefents que les autres Roys \& feigneurs enuoyoiêt au nouueau Roy. Tout ce tribut marchoit de rang felon les Prouinces, \& au deuant les maiftres d'hoftel, \& les receueurs auec diuerfes marques $\&$ enfeignes d'vn fort bel ordre, tellement que c'eftoit vne-de: plusbelles chofes de la fefte, que de voir l'en. tree des tributs. Le Roy eftant couronné, i] s'employa à conquefter plufieurs Prouinces, $\&$ d'autant qu'il eftoit vaillant \& vertueux, il alla toufiours augmentant de plus en plus, \& fe feruoit en toutes fes affaires du confeil $\&$ de l'induftrie de fon general Tlacaellec, lequel il ayma \& eftima toufiours beaucoup, cŏme il en auoit aufsi bien occafion. La guerre oû il s'oc $\alpha$ cupaile plus, \& quiluy fut plus difficile, fut celle de la Prouince de Chalco, en laquelle luy aduint de grandes chofes, dont il y en a vne entre autres fort remarquable, qui fut queles $\mathrm{Cbal}$ chas ayans prins en guerre vn frere de Motecuma, ilss'aduiferent de le creer \& enire pour leur Roy, parquoy ils luy firent demander fort courtoifement's il vouloit accepter cefte charge. Il leur refpondit apres qu'ils l'en eurent fort importuné, \& qu'ils y perfiftoient toufiours, que fr à bon efcient ils le vouloient eslire pour Roy, quils plantaffent en la place vn arbre ou pieu fort hault, auquel ils filfent accommoder \& dreffer comme vn petit theatre 


\section{des Indes. Liure VII.}

át coúpeau où l'on peuft monter. Les $C$ hat penfans que ce fult quelque ceremonie pour fe aire dauantage valoir, le mirent incontinent $\mathrm{z}$ effect, \& luy affemblant tous fes Mexiquains au cour du pieu, monta au coupeau auec vn chapeau defleurs en fa main, \& de là il parla aux iens en cefte façon : $O$ valeureux Mexiquains, ceux $y$ me veulent eflire pour levir Roy: maisles Dieux ne venent pas permettre que pour eftre Roy ie commette aiscune rabifon contre mon pays, aucontraire ie veux que vous ppreniez de moy qu'il conuient pluffofi endurerla mores we d'ayder à fes ennemis. Difant cela, fe ietta du. naut en bas, fe brifant en mille pieces; duquel peAtacle les Chalcas eurent telle horreur \& efpit qu' incontinent ils fe ietterent fur les $\mathrm{Me}$ iquains, qu'ils mirent tous à mort à coups de ances, comme hommes qu'iis eftimerent trop lautains, fuperbes, \& inexorables, difans qu'ils uoient les caurs endiablez. Il aduint que 18 uik enfuiuante ils ouytent deux chathuants ui crioient de triftes cris; ce qu'ils interpreteent pour figne malheureux, \& pour vn prefage e leur prochaine deftruction, comme il adint : car le Roy Moteçuma alla en perfonne ontreux auec toute fa puiffance, où il les vainuit, \& ruina tour leur Royaume, \& palfant oue la Sierre Menade, il alla toufiours conqueant iufques à la mer du Nort. Puis retouriane ers celle du Sud, il gagna $\&$ alfujettit plufieurs, rouinces; tellement qu'il fe fift tres-puiffant oy, le tout auecl'ayde $\&$ confeil de Tlacael c qui a prefque conquis tout l'Empire Mexiuain. Toutefois il fut d'opinion ( ce qui fut ase $x \times$ 


\section{Hiftoire naturelle}

comply) que l'on ne conqueftaft point la Prouince de Tlafcalla, afin que les Mexiquains euf. fent vne frontiere d'ennemis, où ils exerçaffent $\&$ tinffent toufiours en allarme la ieuneffe $\mathrm{Me}$ xiquaine, \& afin mefme qu'ils euffent quantité de captifs pour faire les facrifices à leurs idoles; efquels, comme il a efté dit, ils confommoient vingrand nombre d'hommes qui deuoient eftre prins en guerre, \& par force. L'honneur fe doit attribuer à ce Moteçuma, ou pour mieux dire, zे ce Tlacaellec fon general, du bel ordre \& police qui eftoit en ce royaume Mexiquain, com. me auffi des confeils \& belles entreprifes qui $\Upsilon^{\prime} y$ font executees, mefme du grand nombre des Iuges \& Magiftrats qui y eftoient autant bien ordonnez, qu'en aucune Republique, voire qui fuft des plus floriffantes del'Europe. Ce mefme Roy augmenta beaucoup la maifon Royale, \& luy donna beaucoup d'authorité, ordonnant plufieurs \& diuers officiers, defquelsil fe feruoit auec vn grand appareil \& ceremonie. Il ne fut pas moins remarquable, touchant ta deuotion \& feruice de fes idoles, d'autant qu'il ac. creut le nombre des miniftres, leur inftituant de nouuelles ceremonies, aufquelles il portoit vn grand refpeet. Il édifia ce grand temple dedié ż Peur Dieu Vitzilipuztli, duquel il a efté faict mention en l'autre liure. Il facrifia en la dedication de ce temple vn grand nombre d'hommes quil auoit prins en diuerfes victoires. Finalement iouyffant de fon Empire en grande profperité, il tomba malade, \& mourut, ayant regné yingt. huictans, bien autre que ne fut fon 


\section{des Indes. Liure VII.}

cceffeur Ticocic, qui neluy reffembla, ny en leur, ny en bon-heur.

mme Tlacaellec refufa d'efre Roy, 6 d' l'eflection er geftes de Ticocic.

\section{Chapitre XViI.}

E en confeil auec les Seigneurs dé Tezcuco, \& de Tacuba, où prefidoit Tlacaellec, \& procederent à acaellec fut efleu par toutes les voix, comme ritant mieux cefte charge que nul autre. Il la ufa pourtanit, leur perfuadant par raifons perentes, qu'ils en deuoient eflire vn autre, parqu'il difoir qu'il eftoit meilleur, \& plus expent qu'vn autre fuft Roy, \& que luy fuft fon cuteur \& coadjuteur, cúme il auoit efté iuf:alors, que non pas de le charger de tout, puis e fans eftre Roy, il ne fe tenoit pas moins ligé de trauailler pour fa Republ. que fill'eit. C'eft vne chofe fort rare de refufer la prinauté \& le cómandement, \& de vouloir bien rter la peine \& le foucy, fans en auoir Phonir \& la puiffance. Et y en a bien peu qui veut quitter à vn autre la puiffance \& l'authoriu'ils peuuét feulement retenir en leur main or que ce fuft chofe profitable à la Republi- Ce barbare furpafía en cela les plus fages atre les Grecs \& les Romains, \& eft $\nabla$ xí les $X * i j$ 


\section{Hiftoire naturelle}

con qu’on peut faire à Alexandre, \& à Iules $C$ far, d'efquels l'vn eftimoit peu de chofe de cor mander à tout vn monde, \& fit cruelleme perdréla vieà fes plus chers, \& plus fidelles fe uiteurs, pour quelques legers foupçons qu' vouloient regner; \& l'autre fe declara enner. de fa patrie, difant que f'il eftoit permis à l'hor me de faire quelque chofe contre le droict \& raifon, ce deuoit eftre pour regner. Telle eft foif \& le defir que lés hommes ont de comma der. Bien que cét acte de Tlacaellec pouuc auffi proceder d'vne trop grande confiance, foy, luy femblant que fans eftre Roy ill'efte affez, veu qu'il commandoit prefque aux Ro $\&$ eux luy permettoient porter certaines enfe gnes, comme vn tyare, qu'il leur appartenc de porter feulement. Neantmoins cét acte m rite beaucolip de loüange, \& d'eftre bien con. deré, en ce qu'il auoit opinion de pouuoird uantage ayder à fa Republique, eftant fubject qu'eftăt fouverain Seigneur. Et tout ainfi qu's vne Comedie celuy là merite plus de gloire $q$ xcprefente le perfonnage qui importe le plu encores qu'il foit d'vn pafteur, ou d'vn payfa. $\&$ laiffe celuy du Roy, \& du Capitaine, à celt qui le $f_{\text {çait faire. Ainfi en bonne Philofoph }}$ les hommes doiuent auoir efgard fur tout a bien public, \& f'appliquer en l'office \& eft. quils entendent le mieux. Mais celte Philof phie eft la plus efloignee de ce qui fe practiqu aujourd huy'. Cependant venons à noftre di cours, \& dịfons qu'en recompenfe de fa modi fie, \& pour le refpect que Iny portoient 


\section{des Indes. Liure VII.}

necteurs Mexiquains, ils demanderent a Tlatellec, que puis qu'il ne vouloit regner, qu'il ift celuy qui luy fembleroit propre; $\&$ il dona fa voix à un fils du Roy deffanct, qui pour irs eftoir encores fort ieune, appellé Ticocic. ur quoy ils repliquerent que fes efpaules toient bien forbles pour vn figrand fardeau. lacaellec refpondit que les fiennes eftoient là our luy ayder à porter la charge, comme il 1øit fait aux deffuncts. Aumoyen dequoy ils -indrent leur refolution, \& fur efleu Ticocic, iquel furent faites toutes les ceremonies acuftumees. Ils luy percerent la narine, \& pour nement ils y mir ent vne efmeraude; qui eft la ufe pourquoy aux liures Mexiquains ce Roy t denoté par la narine percee. Il fut fort diffent de fon pere \& predeceffeur, ayant efté rearqué pour homme coüard, \& peu belliteux. Il alla faire la guerre pour fon couronment, en vne Prouince qui f'eft oit rebellee, il perdit beaucoup plus des fiens, quil ne int de captifs. Neantmoinsil retourna, difant iil amenoit le nombre des captifs qu'il eftoit quis pour les facrifices de leur coronnement, ainfi il fut coronné auec vne grande folemniMais les Mexiquains mal contens d'auoir vn oy fi peu guerrier, traitterent de luy aduancer mort par paifon. Pour cefte occafion il ne ra point au Royaume plus de quatre ans, ù l'on void bien que les enfans ne fuiuent $p a s$ afiours le fang \& la valeur deleurs peres; \& e tant pluś grande a efté la gloire des predeTeurs, plus abominable eft la lafcheté \& pus: $\mathrm{X} x$ iij 


\section{Hifoire naturelle}

fillanimité de ceux qui leur fuccedent au cor mandement, \& non pas au merite. Mais cel perte fut bien reftauree par vn freredu deffunć qui eftoit auffi fils du grand Moteçuma, appel Axayaca, \& lequel fur efleu par l'opinion Tlacaellec, où il rencontra miẹux qu’au prec dent.

Dela mort de T lacaellec, \& des actes d'Axay. $\mathrm{ca}$, feptiefme Roy des Mexiquains.

Chapitre XVIII.

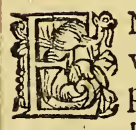

$N$ ce temps Tlacaellec eftoit defia fo vieil, \& à caufe de fa viellefle l'on portoit en yne chaire fur les efpaule pour fe trouuer au Confeil, \& aux a faires qui fe prefentoient. En fin il tomba mal: de, où le nouvieau Roy, qui n'eftoit pas encos couronné, le vifitoit fouuent, \& refpando beaucoup de larmes, d'autant qu'il luy ferr bloit qu'il perdoit en luy fon pere, \& le pere la patrie. Tlacaellec luy recommanda affectues fement fes enfans, principalement l'aifné , qi f'eftoit monftré valeureux aux guerres paffee. le Roy luy promit de l'auoir pour recomman dé, \& pour confoler dauantago le vieillard, luy donnà en fa prefence la charge \& les enfe: gnes de fon Capitaine general, auec toutes le preéminences de fon pere, dequoy le vieillar demeura tellement content, que fur ce conter. tement il acheua fes iours. Que frils ne fuffer 


\section{des Fndes. Liure VII. 348} paffez de cefte vie en l'autre, ils euffent peufe renir bien-heureux, attendu que d'vne fi pecite, \& fi pauure Cité en laquelle il nafquit, il fift, \& eftablit, pàr fa valeur \& magnanimité, vn fi grand, fi riche \& fi puiffant Royaume. Les Mexiquains luy firent des obleques comme au fondateur de cét Empire, plus fomptueufes, \& plus magnifiques, qu'ils nauoient fait à aucun des Roys predecefeurs, \& incontinent apres Axayaca, pour appaifer le deiil que tout le peuple mexiquain portoit de la mort de fon Capitaine, delibera de fairele voyage, comme il eftoit de befoing pour fon couronnement. C'eft pourquoy il mena fon armee auec grande diligence en la Prouince de Tequantepec, diftante de Mexique de áeux cents lieües, \& là il donna la bataille à vn puiffant exercite, \& nombre infiny d'hommes quif'eftoient affemblez, tant de ceAte Prouince, comme des circonuoifines, pour Poppofer aux Mexiquains. Le premier de fon camp quif'aduança pour fe mefler au combat, fut le mefme Roy défiant fes ennemis, defquels il feignit fuyr lors qu'ils le chargerent, iufques à les attirer en vne embufche, ou il y auoit plufieurs foldats cachez fous de la paille, lefquels fortirent à l'impourueu, \& ceux qui alloient fuyans, tournerent tefte; tellement quils arrefterent au milieu d'eux ceux de Tequantepec, $\&$ les chargerent fort viuement, en faifant d'eux vne cruelle boucherie. Er pourfuiuant leur viatoire, ils razerent leur Cité \& leur temple, \& chaftierent rigoureufement tous les circonioifrns, puis ils tirerent outre $\&$ fans farrefter aus:

$$
\mathrm{X} \times \text { iiij }
$$




\section{Hiftoire naturelle}

cunement, allerent conqueftans iufques à Gua: culco, qui eft vn port aujourd'huy fort cogneu en la mer du Sud. Axayaca retourna de ce voyage à Mexiqué auec de grandes defpoüilles \& richeffes, oủ il fur honorablement coronné auec de fomptueux, \& magnifiques appareils de facrifices, de tributs \& autres chofes, où plufieurs vindrent voir fon couronnement. Les Rois de Mexique receuoient la couronne de la main des Rois de Tezcuco, qui auoient celte preéminence. Il fift beaucoup d'autres entreprinfes, où ilobtint de grandes victoires, eftant toufjours le premier qui conduifoir fon armee, \&c affailloit fes ennemis; d'où il acquit le nom de vres-valeureux Capitaine. Et non content de fubjuguer les eftrangers, il reprima, \& mit le frein aux fiens qui f'eftoient rebellez, ce que iamais aucun de fes predeceffeurs n'auoit peu, ny ofé faire. Nous auons defia dit cy deuant comme quelques feditieux feltoient feparez de la Republique Mexiquaine, qui fonderent vne $\mathrm{Ci}$ té proche de Mexiqué, laquelle ils appellerent Tlatelulco, \& fut à l'endroict où eft aujourd'huy fainct Iacques. Ceux-là f'eftans reuoltez, tindrent vn party à part, \& faccreurent \& multiplierent beaucoup, ne voulans iamais recagnoiftre les Seigneurs de Mexique, ny leur prefter obeyffance. Le Roy Axayaca les enuoya donc requerir qu'ils ne fulfent diuifez, mais que puis qu'ils eftoient d'vn merme fang, \& $\mathrm{v}$ n peuple, qu'ils fe ioigniffent, \& recogneuffent le Roy de Mexique. Surquoy le Seigneur de Tlacelulco fint vne refponfe pleine de grand mef- 


\section{des Indes. Liure. VII:}

pris \& orgueil, deffiant le Roy de Mexique 2 combattre en duel, \& incontinent affembla fes hommes, commandant à vne partie d'iceux quils allaffent fe cacher dans les herbiers du $\mathrm{lac}$, à fin d'eftre mieux counerts. Où pour fe mocquer dauantage des Mexiquains, il leur commanda prendre des figures de corbeaux, d'oyes, \& d'autres animaux, comme des grenoüilles, \& autres femblables, penfans par ce moyen furprendre les Mexiquains, lors qu'ils pafferoient par les chemins \& chauffees du lac.' Ayant entendu le deffy \& la rufe de fon contraire, il partit fon armee, donnant vne partie à fon general, fils de Tlacaellec, \& luy commanda de rompré, \& de charger fur cefte embufca. de du lac. Luy d'autre cofté, auec le refte de fes gens par vn chemin qui n"eftoir point hanté, salla camper deuant Tlatelulco. Incontinent il fit appeller celuy quil lauoit defié, afin quill accomplift fa parole, \& cóme les deux Seigneurs de Mexique \& de Tlatelulcu s'aduancerent, ils commanderent chacun aux fiens, quils ne fe remuafient iufques apres auoir veu lequel des deux feroit le vainqueur, ce qui fut fait, \& tout aufi toft ces deux Seigneurs vindrent $l^{\prime} y n$ contre l'autre valeureufement, où ayans iongue.ment combattu, en fin celiuy de Tlatelulco fuft contraint tourner les efpaules, d'autant que celuy de Mexique les chargeoir plus furieufement qu'il ne pouuoit fupporter. Ceux de Tlarelulco voyans fuyr leur Capitaine, perdiren courage, \& tournerent auffi le dos: mais les $\mathrm{Me}$ viquains les fuyuants de prés les chargerent fu- 


\section{Fiffoire naturelle}

rieufement. Neantmoins le Seigneur de Tla: relulco n'elchappa pas des mains d'Axayaca. Car fe penfantfauuer, ils fe retira au haut du têple où Axayaca le fuiuit de prés, quil'attaignie \& le faifit d'vne grande force, puis le ietta du haut da temple en bas, \& fit mettrele feu puis apres au temple, 8 à la Cité. Cependant que cela fe paffoit à Tlatelulco, le General Mexiquain eftoit fort efchauffé à la vengeance de ceux quái l'auoient pretēdu déffaire par rufe, \& par tromperie, \& apres les auoir forcez par armes de $1 e$ rendre, \& de luy demăder mifericorde, le Gene. ral leur dift qu'il ne leur pardóneroit point, que premierement ils n'euffent fait les offices des figures qu'ils reprefentoient, parquoy il vouloit quils criaffent cóme lesogrenoüilles, \& les corbeaux, \& chacun felon les figures qu'ils auoient prinfes, d'autant qu'ils n'auroient point de cớpofition qu'en ce faifant. Ce qu'il filt pour les affronter, \& mocquer de leur rufe. La crainte \& neceflité enfeigne toures chofes, tellemét qu'ils chanterent, $8 \mathrm{t}$ crierent auec toutes les differèces de voix que l'on leur cómanda, pour a uoir leurs vies fauues, combiê qu'ils fuffent fort defpitez du pafferéps que leurs ennemis prenoient d'eux. Ils difent que iufques auiourd'huy durent encor les brocards des Mexiquains enuers les Tlatelulcos, qui le portent impatiemment, lors que l'on leur ramentoit ces chäts \& cris d'animaux. Le Roy Axayaca prit plaifir à cefte rifee, \& in. continent apres s'en retournerent en Mexique en gráde refiouyffance. Ce Roy fut eftimé pour vn des meilleurs qui ayent commandé en Mexi- 


\section{des Indes. Liure. VII.}

quie. Il regna onze ans, \& luy fucceda vn qui fue beaucoup moindre que luy en valeur $\&$ vertus.

Des faidts or actes d' Autzol, buictiefme Roy de Mexique.

CHAPItRE XIX.

STEA NTR les quatres Eflectcurs de 3. Mexique, qui, commeil a efté dit, (3) 150 auoiérle droit d'eflire au Royau130 me celuy qu'ils vouloient, il y en Be fections, nommé Autzol. Ceftuy fut efleu des autres, \& fut celte election fort agreable à tout le peuple : car outre ce qu'il eftoit fort vaillant, tous l'eftimoiét courtois, \& officieux enuers vn chacun, qui eft vne des principales códitions requifes à ceux qui gouuernent, pour fe faire aymer \& obeyr. Or pour celebrer la fefte de fon couronnement, il s'aduifa de faire le voyage, 8 aller chaftier l'outrecuidance de ceux de Quaxulatlan, Prouince fort riche \& abondante, qui eft auiourd'huy la principale de la neuue Efpagne. Ceux là auoient volléles officiers \& maiftres d'hoftel qui apportoient le tribut à Mexique, \& auec cela s'eftoient rebellez. Il eut de grandes difficultez à reduire cefte nation, pource qu'ils s'eftoient mis en vn lieu, où va grand bras de mer empefchoir le pallage aux Mexiquains. Pour lequel trauerfer Autzol fit auec vn eftrange trauail $\&$ induftrie fonder en 


\section{Hiftoires naturelle}

Yeauie, comme vne iffette de fafcines, de terre, \& autres måteriaux, par le moyen duquel œuure il peut luy $\&$ fes gens paffer vers fes ennemis, \& leur donner bataille, où il les vainquit, \& chattia à fa volonté , puis s'en retourna d Mexique en triomphe, \& auec grandes richeffes, pour eftre couronné Roy, felon leur cou. ftume. Autzol eftendit fon Royaume par plufieurs conqueites quilifit, iufques à parue. nir à Guatimalla, qui eftà trois cents lieuës de Mexique, Il ne fut pas moins liberal, que vaillant, car lors que les tributs arriuoient, (lefquels comme il a efté dit, venoient auec vn grand appareil, \& abondance) il fortoit de fon Palais, \& faifoit aiffembler en quelque lieu tout le peuple, puis commandoit que l'on apportaft là tous les tributs, lefquels il departoit à ceux qui auoiét neceffité.ll dónoit aux pauures des eftoffes à faire des habirs, des viandes, \& de tout ce qu'ils auoient de befoing en grande quantité, \& les chofes de prix, comme l'or, largent, les ioyaux, \& les plumaches eftoient departis entre les Capiraines, foldats, \& feruiteurs de fa maifon, felon le merite d'vn cha. cun. Cét Autzol fut mefme grand politic, \& fit abbatre les edifices mal ordonnez, \& en reedifier de nouucau d'autres fort fomptueux. Il luy fembla que la Cité de Mexique auoit trop peu d'eaüe, \& que le lac eftoit fort bourbeux, parquoy il fe delibera d'y faire venir vn gros cours d'eauie, dont fe feruoient ceux de Guyoacan. A cefte fin il fit venir vers luy le principal decefte Cité, qui eftoit vn fameux forcier, \& 


\section{des Fndes. Liure. VIIr.}

luy ayant propofé fon intention, le forcier luy dift quil regardaft bien ce qu'il faifoit, pource que cefte affaire eftoit de grande difficulté, \& qu'il entendift, que s'il tiroit ce ruiffeau de fon cours ordinaire, \& le faifoit aller en Mexique, il noyeroit la Cité. Il fembla au Roy que ces: excufes n'eftoient que pour euiter l'effect de fon deffein, parquoy en eftans irrité le renuoya, \& quelques iours apres enuoya à Cuyoacan vn Preuolt pour prendre le forcier, lequel ayant entendu pour quelle occafion venoient les miniftres da Roy, les fit entrer en fa maifon, puis fe transforma \& fe prefenta à eux en forme d'vn aigle terrible, dequoy le Preuoft $\&$ fes gens efpouuentez, s'en retournerent fans le prendre. Autzol irrité en renuoya d'autres, aufquels il fe prefenta en figure d'vn tigre tresfurieux, \& ne luy oferent non plus toucher. Les troifiefmes y furent, \& le trouuerent en forme d'vn ferpent horrible, dont ils eurent grande frayeur. Le Roy efmeu dauantage de ces façons de faire, enuoya dire à ceux de Cuyoacan, que s'ils ne luy amenoient le forcier lié, il feroit rafer leur Cité : pour crainte dequoy, ou foit que luy de fa volonté, ou foir qu'il y euft efté forcé des fiens, en fin fe laiffa emmener au Roy, quile fit incontinent eftrangler, puis apresil accomplit fon deffein, faifant cauer vn canal, par où cefte eaïe peuft coulerà Mexique, par le moyen duquel il fit venir vn gros cours d'eaüc au lac, lequel ils conduirent auec de grandes ceremonies \& fuperfitions, où il y auoit des Preftres qui alloient en- 


\section{Hiftoire naturelle}

cenfansle long du riuage, les autres facrifians des cailles, du fang defque les ils oignoient les bords du canal, \& les autres fonnants des cornets, accompagnoient l'eaúe de leur mufique. Vn des principaux alloit veftu d'vn habit dela façon qu'ils attribuoient à la deeffe de l'eaïe, \&: tous la falïoicnt, luy difans qu'elle fuft la bien venuë. Toutes lefquelles chofes font peintes \& figurees és annales de Mexique, le liure defquel. les eft auiourd'huyà Rome, quia efté mis en la facree Bibliotheque, ou Librairie Vaticane, où vn Pere de noftre Compagnie qui eftoit venui deMexique le vid, \& les autrés hiftoires lefquellesil expliquoit, \& faifoit entendre au Bibliothecaire de fa Saincteté, quife plaifoit infinimét d'entendre ce liurc, lequel il n'auoit iamais peu comprendre. Finalement l'eäie fut amenee en Mexique, mais elle y fourdit en telle abondance, que peu s'en falluft qu'elle ne noyaft la Cité, comme l'autre auoit predit, \& en effect elle ruina vne grande partie d'icelle, à quoy in. continent ils remedierent par l'induftrie d'Aut. zol; d'autant quil fit faire vn canal \& iffuë, pour en faire couler les eaux, au moyen dequoy il repara les baftimens qui eftoient tombez, d'vn outurage exquis, eftans auparauant de mefchans edifices. Par ainfr il laiffa fa Cité enuironnee d'eaïe, comme vne autre Venife, \& fort bien baftie. Son regne dura onze ans, qui s'acheua au dernier \& plus grand fucceffeur de tous les Me. xiquains. 


\section{des Indes. Liure VII.}

Del'efection du grapd Moteçuma, dernier Roy de Mexique.

\section{CHAPITREX $X$}

Ifor $\mathrm{V}$ temps que les Efpagnols entrerent If en la neuue Efpagne, qui fut en l'an du Seigneur, mil cinq cents dix-huiot, Moteçuma fecond de ce nom, \& dernier Roy des Mexiquains, ie dy dernier, car ia çoit que ceux de Mexique, apres fa morr, en ef. leurent vn autre, voire de viuant mefme de Mo. teçuma, qu'ils declarerent ennemy de la patrie, commel'on verra cy apres. Mais celuy qui luy fucceda \& celuy qui vint captif entreles mains du Marquis de Vallé, n'eurent quele nom \& til. tre de Roys, d'autant quele Royaume eftoit ja prefque tout rendu aux Efpagnols. Tellement qu'auec raifon nous contons Muteçuma pour le dernier Roy, \& cŏme tel, il vint au periode de la puiffance $\&$ grandeur des Mexiquains, ce qui eftadmirable pour eftre arriué entre barbares. A cefte caufe, \& que celle-1à eftoit la faifon que Dieu auoit choifie pour enuoyer la cognoiffance de fon Euágile, \& regne de İ rsvs. CHRIST en cefte contree, ie racóteray plus diftinctement les actes de Moteçuma, que des autres. Auparauant qu'il fult Roy, il eftoit de fon naturel fort graue, \& fort pofé, \& parloit peu, tellement que quand il opinoit au priué Confeil, où il afliftoit, les propos \& difcours faifoient admirer vn chacun, fi bien que deflors il eftoit craint, \& refo 


\section{Hiftoire naturelle}

pecté. Il fe retiroir ordinairement en vne cha: pelle, quiluy eftoir deftinee au temple de Vitzilipuztli, ou ils difoient que leur idole par. loit auec luy, \& à cefte occafion eftoit eftimé fort religieux, \& deuot. Pour fes perfections donc, \& pour eftre tref noble, \& de grand courage, fon eflection fut briefue, \& facile, comme d'vne perfonne fur laquelle tous auoient les yeux fichez, pour eftre digne d'vne telle charge. Ayant entendu fon eflection, il fe cacha aus temple, en cefte chapelle; fuft qu'ille fit par difcours, \& $q$ quil apprehendaft vne charge fi arduc̈, \& difficile, comme eftoit de regir vn tel peuple : ou fuft, comme ie croy, par hy pocrifie, \& pour monftrer qu'il ne defiroit en rien l'Empire. En fin ils le trouuerent là, \& le prindrent $\&$ menerent à fon confiftoire, laccompagnant auec toute la refiouyffance qui leur fut poffi ble. Il marchoit auec vne telle grauité, quils difoient tous, que le nom de Moteçuma luy conuenoit fort bien, qui vaut autant à dire que Seigneur courroucé. Les Eflecteurs luy firent vne grande reuerence, luy faifans entédre qu'il auoit efté efleu. De là il fut mené deuant le fouyer des Dieux pour encenfer, où il leur offrit facrifices, en fe tirant du fang des orcilles, \& des mollets des iambes, felon leur couftume. Ils le reueftirent de fes ornements Royaux, \& luy ayans percé les narines par le cartilage, ils y pendirent vne efmeraude tres-riche, couftume certes barbare \& fafcheufe, mais le defir de commander empelche de fentir telleschofes. Apres quill fut aflis en fon throfne, il ouyt les orais = 


\section{des Indes. Liure. VII.}

oraifons \& harangues que l'on luy fit, lefquel. les auff, felon qu'ils auoiér accouftumé, eftoient elegantes, \& artificieufes. La premiere fut prononcee par le Roy de Tefcuco, laquelle ayant efté conferuee pour la fraifche memoire, \& eftant bien digne d'eftre ouye:ie la refereray icy. de mot à mot, \& dit ainfi : La concordance $\sigma$ vnité de voix fur con eflection, donne affez à entendre (tresmoble adolefcent) legrand beur que tout le Royaume ers doit receusour, tant pour auour mertié, $\sigma$ eftédigne que rus luy commandafes, que pour la refiouyfJance $\sqrt{2}$ gener alle que tous demonftrent, a caufed'icelle. En quoy à la verité ils va tellement dilatant, que pour gouwerner vn monde, comme il eft, $\mathcal{O}$ porter vne chargeji pefante, iln'et pas de befoing d'ene mondre dexterite, or magnanimité, zue de celle qui refide en ton ferme 0 v valeureux cour, ny ' vo entendement moins repofe', $\sigma$ de moindre prudense mede la tienne. Ie voy $\mathcal{C}$ recognoy clairement, que le o ieus coint-purfani ayme cefte Cite', pris quisil luy a donné a clarté, de chorfir ce qui luy eftors conucmble. Car qui At celuy qui necroira qu'vn Prince, qui awant que de rener, anoit penetréles neuf voutes du Ciel, ne doine ufsi bien obtenir aniourd' buyles chofes qui font terrienes, pour fecourir fon peuple, en s'aidant à cefte fin de for nsendemét fi bon o fi fubtil, veu quialy eft oblige par le euoir o la charge de Roy? Qui ne croira anfsi que le gräd inage que tu as toufiours valeureufement monftré en faires dimportance, ne se manquera point auiourd' buy chofes oit twen as tant debefoing? Qui penfera quien se celle valeur priffe deffaill $l^{\prime}$ 'ayde o le fecours a las eufue oò lorphelin? Qui ne fe perfuadera que l'Emre Mexiquain ne foit parneun an fommet de fon ausbo. 


\section{Hiftoire naturelle}

sité,puis que le seigneur des chofes crcées, $i$ a departy vno telle of $\sqrt{2}$ grandegrace, que par ton feul regard, tu fais efmerueiller ceux qui te contemplent? Refouiyy toy done, $\hat{0}$ terre beureuse, à qui le Creatcur a donné vn Prince, qui te fera vne coulonne ferme, fur laquelle tu eeras appuyee, quir fera ton pere, Oo ta deffenfe, duquel tus feras fecourive aub befoing, quifer a plus que frere enuers les fiens, par pitié $\sigma$ fa clemence. Tu as vn Roy, qui à caufe de fon estat, ne fe donnera point aux delices, $\sigma$ qui ne demeurers point eftendu en vn lict occupé en vices, \& en pafetëps: an contraire, an melieu de fon plus doux $\sigma$ plus profond fom. meil, fon cour trefaillira, of fe refueillera, pour le foucy quil doit anoir de toy, o ne entira point le gouft du plus

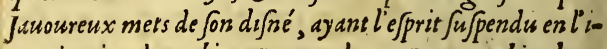
magination de ton bien. Dy moy donc, Reyaume bien heu reux, fi ie n'ay pas raifon de dire que tu te refirouyfes, $\sigma$ te recrees à prefent, d'auoir trourué vn tel Roy: Et toy gene. reux adolef fent, $\mathcal{O}$ tref-puilfant seigneur noftre, ayes confiance $\sigma$ bon courage, que prifgue le seigneur des chofes creées t' a donné cefte charge, il te donnera au $\beta$ Bi la proüeffe $\sigma$ la magnanimité requife pour l'exercer, o peux bien esperer que celuy qui au temps palfé a vfé de fi grandesliberalute'zenuers toy, ne tedeniera point fes plis grands dons, puis quilli' a mis en vone charge figrande, de laquelle purfes tu iouyr plufieurs années. Le Roy Moteçuma fur fort ententif à ce difcours, lequel eftant acheué,ils difent qu'il fé troubla d'vne telle forte, que voulant par trois fois refpondre, il ne peut parler, eftant vaincu des larmes que l'aife \& le contentement a bien fouuent accouftumé de caufer en demonftration de gräde humilité. En fin, eftant reuenu à foy, il-dift brefuement: Je fcrois trop areuglé, bon Roy de Te? curco $_{2} \sqrt{3}$ ie ne cognoif: 


\section{des 7ndes. Liure VII. $\quad \overline{354}$}

is, $O$ entendois, que les chofes que vous m'aue $Z$ dittes, int vne pure faueur quil vous plaift me prefter, purs n'entre tant d'bommes fi nobles, OF. figenereux quil a en ce Royaume, vous aueZ eflew le monns sufffant, qui t moy, $\mathcal{O}$ '̀ la verité,ie me fens tellement inca pabled'vecharge de figrande importance, que ie ne $\int \varsigma_{\text {say }}$ que faire: utre chofe que de fupplier le Createur deschofes creées, quivil refarorife, $\sigma$ demande à rous quills le fuplient par moy. es paroles dites, il recommença de rechef d leurer.

\section{Comment Moteçuma ordonna' le feruice} de fa maifon, of de la guerre quib fit pour fon courorine. ment.

Chapitre XXI.

Eluy-là qui en fon ellection fit vne 1928 telle demonftration d'humilité, \& (1) 45 douceur, fe voyant Roy commença - dis incontinent à defcourir fes haus penlees. La premiere fut qu'il commanda ail n'y euft aucun Plebeien qui feruift en $f_{2}$ aifon, ny euft office Royale, ainfi que fes preeceffeurs en auoient vfé iufques alors, lefquels blafma de s'eftre feruis de gens de baffe contion, \& voulut que tous les Seigneurs \& plus huftes perfonnages de fon Royaume, demeuRenten fon Palais, \& exerçaffent les offices 


\section{Hiftoire naturelle}

de fa court \& de fa maifon. A quoy s'oppofa vn vieillard de grande authorité, qui auoit efté fon precepteur, luy difant qu'il regardaft bien à ce qu'il faifoit, \& qu'il fe mettoit en danget d'vn grand inconuenient, d'autant que c'eftois feparer de foy , \& enloigner tout le vulgaire, \& gent populaire, tellement quils ne l'oferoien: régarder en la face, fe voyans ainfi reiettez de liny. Il repliqua, que c'eftoit ce qu'il entendoit faire, \& qu'il ne permettroit pas que les Ple. beïens allaffent ainfi meflez parmy les nobles, comme ils auoient fait iufques alors, difant que le feruice qu'ils faifoient eftoit felon leur conditiōn, qui caufoit que les Roys ne gagnoient aucune reputation, \& ainfi demeura ferme en fa refolution. Auffi toft il fit commander à ceux de fon Cófeil, quils oftaffent tous les Plebeiens des offices \& charges qu'ils exerçoient, tant en fa maifon qu'en fa court, \& qu'ils en pourueuffent des 'Cheualiers, cequi fut fait. Apres il alla en perfonne à l'entreprife necelfaire pour fon cóuronnement. En ce temps s'eftoit reuoltécontre la couronne, vne Prouince fort elloignee, vers la mer Occeane du Nort, où il mena auecluy la fleur de ces hommes, fort leftes \& bien accommodez. Il y fit la guerre auec vne telle valeur \& dexterité . qu'en fin il fubiuga toute la Prouince, \& chaftia rigourcufement les rebelles, retournant auec vn grand nombre de captifs pour les facrifices, \& beaucoup d'autres défpoüilles. Toutēsles Citez luy firent de folemnelles receptions à fon retour, \&lès Seigneurs d'icelles lay donnerent beaie à latier; . 


\section{des Indes.Liure VII. 355}

luy faifans offices de feruiteurs; chofe non encor vfitee par aucun de fes predeceffeurs. Telle eftoit la crainte \& le refpect qu'ils luy portoiét. L'on fit en Mexique les feftes de fon couronnement auec vn tel appareil de danfes, comedies, entremets, luminaires, \& inuentions par plufieurs $\&$ ditiers iours: Et y arriua vne fi grande richeffe de tributs, apportez de tous fes Royaumes, quil y vint des eftrangers incogneus à Mexique, \& leurs ennemis mefines y vindrent en grand nombre, en habit diffimulé, pour voir ces feftes, comme ceux de Tlafcalla, \& ceux de Mechouacan. Ce qu'ayant efté defcoutert par Moteçuma,il cormmanda qu'on lés logeaft \& traictalt benignement; \& honorablement, comme fa propre perfonne. Il leur fit mefme faire de belles galleries, pareilles aux fiennes, defquellesils peuffent voir $\&$ contempler les feftes. Parainfi ils entroient de nuiat en ces feltes, commele Roy, faifans leursieux \& mafcarades. Et pource que i'ay fait mention de ces Prouinces, il ne fera mal à propos d'en. tendre, que iamais ceux de Mechouacan, de Tlafcalla, \& de Tapaeca, ne fe voulurent rendre aux Mexiquains, mais au contraire comba. tirent toufiours valeureufement contr'eux,voire quelquesfois les Mechouacans vainquirent ceux de Mexique, comme firent auffi ceux de Tapaeca. Auquel lieu le Marquis Dom Fernäde Cortés, apres que luy \& les Efpagnols eurent efté chaffez de Mexique, pretendit fonder 12 premiere Cité d'Efpagnols, qu'il appella, fí bien m'en fourient, Segura de la Frontiere, mais

$$
\text { Yy iij }
$$




\section{Hiftoire naturelle}

eefte peuplade dura peu de temps, parce qui ayant depuis reconquefté $M$ exique, tous les $E f$ pagnols y allerent habiter. En fin ceux de $T_{a}$ paeca,de Tlafcalla, \& de Mechouacan ont tou. joursefté ennemis des Mexiquains, encor qui Moteçuma dift à Cortés, qu'il ne les auoit pa: fubiuguez tout à propos, afin d'auoir en eux vr exercice de guerre, \& nombre de captifs.

\section{Des meeurs \& grandeur de Moteçuma. -}

\section{Chapitre XXII.}

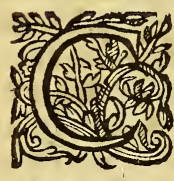

puny de mor. fes pieds en terre, mais eft oit toujours porté fus les efpaules de quelques Seigneurs, \& s'il defcé. doit, ils luy metroiét de riches tapis, fur lefquel: il marchoit. Quand il faifoit quelque voyage: luy \& les Seigneurs de fa compagnie, alloient comme dans vn parc, ou circuit qui eftoit fait tout a propos, \&le refte du peuple alloit hors du parc, l'enuironnant d'vn cofté \& d'autre. Ia. maisil ne veftoit vn habit deux fois, ny man. geoit, ny beuuoit en vn vafe ou plat plus d'vne fois, tout y deuoit eftre toufiours neuf, \& donnoir à fes feruiteurs ce quiluy auoit feruy vne fois, de façon qu'ils eftoient ordinairemët riches ' \& magnifiques. Il eftoit extrememét diligent à faire obferuer les loix, \& quăd il retournoit vi- 


\section{des Indes, Liure. VII.}

356

etorieux de quelque guerre, il faignoit aucunesfois de s'aller esbattre,puis fe defguifoit pour voir fi les fiens, penfans quil ne fuft prefent, laiffoient \& obmettoient à faire quelque chofe de la fefte ou reception; que s'il y auoit quelque excez ou quelque deffault, il en faifoit la punition rigoureufement. Et a fin de cognoiftre méme comment fes miniftres faifoient leurs offices, il fe defguifoit bien fouwent, envoyoit offrir des dons \& prefens aux Iuges, les prouoquant d faire quelque chofe de mal. Que s'ils tomboient en faute, ils eftoient incontinent punis de mort fans remiffion, \& les faifoit mourir fans auoir efgard qu'ils fuffent Seigneurs, ou fes parens, voire de fes propres freres. Il conuerfoit \& fe familiarifoit peu auecles fiens, \& peu fouuent fe laiffoit voir,eftant ordinairement retiré pour penfer au gouuernement de fon Royaume.Ourre ce qu'il eftoit grand iufticier \& fort braue, il fut fort belliqueux \& bien fortuné, au moyen dequoy il obtint de grădes viatoires, \& paruint aे cefte grandeur, qui eft defcrite aux hiftoires d'Efpagne. Delaquelle il me femble que ceferoit chofe inutile d'efcrire daunantage: feulement $i$ 'auray foin de reciter $c y$ apres ce que les liures $\&$ hiftoires des Indiens racontent, \& dequoy nos efcriuains Efpagnols ne font aucune mention, pour n'auoir fuffifamment entendu les fecrets de cefte contree, qui font chofes fort dignes d'eftre cogneuies, comme l'on verracy apres.

Yy iiij 


\section{Hiftoire naturelle}

Desprefages \& prodiges eftranges qui adwindrenten Mexique auant que leur

Empire prinft fir.

Chafitre XXIII.

Dest. 18.

Fiserof.10.

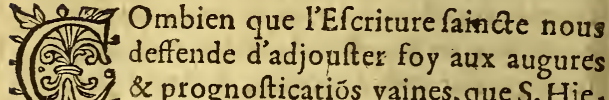
-

Zib.9. dedemanft. Ewang.demonft.r.

\section{.} point les fignes du Ciel comne font les Gétils: Neantmoins la mefme Efcriture enfeigne, que. les fignes monftreux \& prodigieux ne font pas du tout à mefprifer, \& que bien fouvent ils ont accouftumé de preceder quelques changeméts vniuerfels, \& les chaftieméts que Dieu veut fai$\mathrm{re}$, ainfi que le remarque fort bié Eufebe de Cefaree, d'autant que le mefme Seigneur du Ciel $\&$ de la terre enuoye de tels prodiges \& nourueautez au Ciel, aux elemés, aux animaux, \& en fes autres creatures, à fin qu'en partie cela ferue d'aduertiffement aux hómes, \& en partie quils foient vn commencemét de la peine \& du chaftiement,par la peur \& l'efpouuentement qu' ils

2.Macha's: apportent. Il eft efcrit au fecód liure des machabeés, quauparauant ce grand changement \& perfecutió du peuple d'Irrael,qui fur caufee par la tyrannie d'Antiochus, furnommé Epiphanes, lequel les fainctes lettres appellent, tacine de peché, il arriua que par quarante iours entiers.

2. HAac.s. Pon vid par tout Hierufalem de grands efcadrons de Cheualiers en l'air, lefquels auec des armes dorees, leurslances \& efcus, \& fur des 


\section{des Indes. Liure VII.}

cheuaux furieux, ayansleurs efpees tirees; fe frappoient, \& offenfoient, efcarmouchans les vns contre les autres, \& difent que ceux de Hierufalem voyans cela, fupplioient Dieu quil appaifaft fon ire, \& que ces prodiges tournaffent en bien. Il eft efcrit mefme au liure de Sapien- $S_{a p} .5 \%$ $\mathrm{ce}$, que quand Dieu voulut tirer fon peuple d'Egypte, \& chaftier les Egyptiens, quelques vifions terribles \& efpouuentables fapparurent à eux, comme desfeux qui furent veus hors heure en formes horribles. Iofephe au liure dela guerre des Inifs, raconte plufieurs \& grands prodiges qui preceder ent la deftruction de Hierufalem, \& la derniere captiuité de fon malheureux peuple, que Dieu eut en horreur pour itfte occafion, duquel Eufebe de Cefaree, \& les autres racontent les mefmes paffages, authori- E'ufeb.li.r. fans fes prognoftics. Les Hiftoriens font pleins de femblables obferuations aux grands changemens d'Eftats, ou Republiques, comme Paul Orofe, qui en raconte plufieurs, \& fans doute cefte obferuation n'eft pas vaine, ny inutile : car iaçoit que ce foit vanité, voirefuperftition deffenduë par la loy de noftre Dieu, de croire legerement à ces prognoftics \& fignes, toutefois és chofes fort grandes, comme és changemens de nations, Royaumes, \& loix fort notables; ce n'eft pas chofe vaine, mais bien pluftoft certaine $\&$ bien affeuree, de croire que la fageffe du treshaut ordonne, \& veüille permettre ces chofes, qui donnent quelque nouuelle \& prefage de ce qui doit arriuer, pourferuir, comme j'ay dit, d'aduertiffement aux vns, \& de chaftiment aux 


\section{Hiftoire naturelle}

autres, \& à tous de tefmoignage que le Roy des Cieux a foucy des affaires des hommes, lequel rout ainfi qu'il a ordonné de tres. grands \& efpoúuentables prefages pourle plus grand chan. gement du monde, qui fera le iour du iugement, ainfiluy plaift-il de donner de merueilleux prefages, pour denoter d'autres changemens moindres en diuers endroits du monde, qui font toutefois remarquables, lefquels il difpofe felon 12 loy de fon eternelle fageffe. L'on doit auffi entendre, que combien que le diable foit pere de menfonge, neantmoinsle Roy de Math. x. gloire luy fait bien fouuent confelfer la verité LuC. 4 .

contre fa volonté, laquelle il a declaree plufieurs fois de pure crainte, comme il fift au de. fert par la bouche des demoniacles, criant que Iefus-Chrift eftoit le Sauueur, qui eftoit venus atz. 16. pour le deftruire. Comme il filt par la Pythoniffe, qui difoit que Paul prefchoit le vray Dieu. Comme quand il fapparut, \& tourmenta la femme de Pilate, laquelle il fift interceder pour Iefus, homme iufte. Et comme plufieurs hiftoires, outre les facrees, rapportent diuers tefmoignages des idoles, en approbation de la Religion Chreftienne, dequoy Lactance, Profpere, $\&$ autres font mention. Que l'on life Eufebe aux liures de la preparation Euangelique, \& ceux de fa demonftration, où il eft traitté amplement de cefte matiere. I'ay dit cecy tout 2 propos, afin quaucun ne mefprife ce que raconrent les Hiftoires \& Annales des Indiens, touchant les prefages \& prodiges eftranges qu'tls eurent de da prochaine fin, \& raine de leus 


\section{des Indes. Liure VII.}

Royaume, \& du Royaume du diable qu'ils adosoient tout enfemble. Lefquels me femblent dignes d'eftre creus, \& que l'on y adjoufte foy, cant pour eftre aduenus y a peu de temps, \& que la memoire en eft encores toute fraiche; que pource que c'eft vne chofe fort vray-femblable, que le diable fe lamentaft d'vn fi grand changement, \& que dieu par vn mefme moyen commençaft à chaftier des idolatres fi cruels \& abominables. C'eft pourquoy ie les raconteray icy comme chofes vrayes. Il aduint donc que Moteçuma ayant regné plufieurs annees en grande profperité, \& tellement encué en fes fantaifies, qu'il fe faifoit feruir \& craindre, voire adorer comme fil euft efté Dieu ; le Seigneur Tout-puiffant commença dele chaftier, \& de l'aduertir auffi, permettant que les mefmes diables qu'il adoroit, luy annonçaffent les triftes nouuelles de la perdition de fon Royaume, \& le courmentaffent par des prognoftics qui n'auoient iamais efté veus, dequoy il demeura fi trifte \& fi troublé, qu'il en deuint tout hors de fon fens. L'idole de ceux de Chóllola, qu'ils ap. pelloient Quetzacoalt, annonça qu'il venoit vne gent eftrange pour poffeder fes Royaumes. Le Roy de Tezcuco, qui eftoit grand Magicien, $\&$ auoit accord auec le diable, vint vn iour vifirer Moteçuma à heure extraordinaire, \& l'afreara que fes Dieux luy auoient dit qu'il y auoir de grandes pertes qui f'appreftoient pour luy, \& pour tout fon Royaume. Plufieurs forciers \& enchanteurs luy en alloient dire autant, entre Lefquels il y en eut vn qui luy annonça fort par- 


\section{Hiftoire naturelle}

siculierement ce qui luy aduint da depuis. Et comme íl eftoit auec luy, laduertit que les poulces des pieds \& des mains luy deffailloient. Mo. zeçuma ennuyé de telles nouuelles, faifoit pren. dre tous ces forciers, mais incontinent ils difparoiffoient en la prifon, dequoy il prenoit telle rage, que ne les poutant tuer, il faifoit mourir leurs femmes \& leurs enfans, \& deftruire leurs maifons $\&$ leurs moyens. Or fe voyane importuné, \& agité de" ces aduertiffemens, il voulut appaifer l'ire de fes Dieux, \& pour cefte caufe il f'efforça de faire apporter vne grande pierre, pour fur icelle faire de grands facrifices. Pour en venir à bout", il enuoya grand nombre de peuple pour l'amener, auec des engins \& inftruments, lefquels ne la peurent aucunement mouuoir, bien que f'y eftans obftinez, ils y euffent rompu plufieurs engins. Mais commeils perfeueroient toufiours de la vouloir enleuer, ils ouyrent vne voix ioignant la pierre, qui difoit qu'ils ne trauaillaffent point en vain, \&e qu'ils ne la pourroient point enleuer, pource que le Seigneur des chofes creées ne vouloir plus que l'on fift ces chofes là. Moteçuma ayant entendu cela, commanda que l'on fift les facrifices en ce lieu; \& difent que la voix parla derechef, difant: We vous ay-ie pas dit que cerreft point le volontédru seigneur des chofescreées, que cela fe faffe, of afin que vous croyeZ qu'il eft ainfi, ie me laifferay porter guelque per, pris apres vous ne me pourre $Z$ moursoir. Ce qui aduint ainfi : car incontinent ils la menerent quelque peu d'efpace affez facilement, puis apres ils n'y peurent que faire, iufques à c6 


\section{des Indes. Liure VII.}

que par beaucoup de prieres elle fe laifra porter iufques à l'entree de la Cité de Mexique, où fubitement elle tomba dansle lac, \& la recherchans, nela peurent retrouuer, mais fut trouueedepuis au mefme lieu d'où ils l'auoient tiree, dequoy ils demeurerent tous confus, \& efpouuantez. En ce mefme temps apparut au ciel vne flambe defeu tres-grande, \& fort luifante, en façon de pyramide, laquille commençoit à apparoiftre à la minuict, \& alloit toufiours montant, iufques au matin leuer du foleil qu' elle demeuroit au midy, où elle difparoiffoit. Elle fe monftra de cefte façon chaque nuict par l'efpace d'vn an entier, \& toutes les fois quelle apparoiffoit, le peuple iettoit de grands cris, comme ils auoient accouftumé, croyans que c'eft oit vn prefage de grand malheur. Il aduint mefme que le feu fe print au temple, fans qu'il y euft aucur au dedans, ny hors proche d'iceluy, ny qu'il y fuft tombé aucun efclair, ny tonnerre. Surquoy les gardes feftans efcriees, il y accourut grand nombre de peuple auec de l'eau, mais rien n'y peut remedier; tellement qu'il fut du tout confommé, \& difent qu'il fembloit que le feu fortift des mefmes pieces de bois, \& qu'il f'enflamboit dauantage par l'eau quel'on y iettoit. L'on vid fortir vne comette en plein iour, qui couroit du Ponent vers l'Orient, iettant grande quantité d'eftincelles, \& difent que fa figure. eftoit comme d'vne queiie fort longue, ayane au commencement trois teftes. Le grand lac qui eftoit entre Mexique \& T ezcuco, fans qu'il y euf aucun vent, \& fans trenblement de rerre, 


\section{Hifoire naturelle}

ou aucune autre caule apparente, commença foudainement à boüillir, \& 8 creuteht tellement ces bouillons, que tous les edifices qui eftoient proches diceluy, tomberent par terre. Ils difent quel'on ouyt en ce temps plufieurs voix, comme d'vne femme angoiffee, qui difoit quel ques fois: o mes enfans, ià eft venule temps de voftre deftruEton. Et d'autres fois difoit: 0 mes enfans, où vous porteray-ie, afin que vous ne vous acbeure $\bar{z}$, de perdie du tout? Il apparut mefme diuers monftres auee deux teftes, qui eftans portez deuant le Roy, difparoiffoient auffi toft. Tous ces monftres furent furpaliiz par deux autres fort eftranges, dont l'vn fut que les pefcheurs du lac prindrent vn oyfeau grand comme vne gruë, \& de la couleur mefme, mais d'vne eftrange façon, \& non iamais veúe. Ils le porter ent à Moteçuma, qui pour lors eftoit au Palais quils appelloient de pleurs \& de deüil, lequel eftoit tout tendu de noir; d'autant que comme il auoit plufieurs $\mathrm{Pa}$ lais pour la recreation, il en auoit auffi plufieurs pour le temps d'affliction, dont il eftoit alors alfez chargé \& tourmenté, à caufe des menaffes que fes Dieux luy faifoient par de fi triftesaduertiffemens. Les pefcheurs arriuerent fur le poinct de midy, \& mirent deuát luy cét oyfeau, qui auoit au faifte de la tefte vne chofe comme luifante \& tranfparente, en façon de miroir, où Moteçuma vid les cieux \& les eftoilles, dequuy il demeura tout eftonné, puis tournant les yeux au ciel, \& ne voyant point d'eftoilles, recommença à regarder en ce miroir, où il vid qu'il venoit vn peuple en guerre deuers l'Orient, \& 


\section{des Indes. Liure VII.}

quili venoit armé, combatant, \& tuant. Il fift appeller fes deuins \& prognoftiqueurs, dont il en auoit vn grand nombre, lefquels ayans veu toutes ces choles, \& ne fçachans donner raifon de ce qui leur eftoit demandé, incontinent l'oyfeau difparut, tellement qu'ils ne le virent oncques depuis, dont Moteçuma demeura fort trifte \& defconforté. L'autre prodige qui luy aduint, fut qu'v n laboureur qui auoit le renom d'homme de bien, le vint trouuer, \&luy raconta qu'eftant le iour de deuant a faire labou. rage, vngrand Aigle vint volant vers luy, qui le print en fes griffes, \& fans le bleffer, le porta en vne certaine cauerne, où le laiffa, prononçant cét Aigle ces paroles: Tres-puifjant seigneur, iay apporté celuy que tum'as commandé. Et l'Indien laboureur regarda de rous coftez à qui il parloit, mais il ne vid perfonne. Alorsilouyt vne voix qui luy dift: Cognois-tu cét homme que tu voids la eftendu en terre? Et regardant en icelle, vid vn homme endormy, \& fort vaincu. du fommeil, auec les enfeignes Royales, des fleurs en la main, \& vn bafton de fenteurs \& parfum ardent, commeils ont accoufumé d'vfer en ce pays, lequel le laboureur regardant, recogneut que c'ctoit le grand Roy Moteçuma. Parquoy il refpondit incontinent, apres l'auoir regardé: Grand seigneur, ceftuy-cy reffemble a noftre Roy Moteçuma. La voix recommença à dire: Tu dis vray, regarde quel il eft, or comme tule voids endormy or affoupy'; fans auoir foing des grands maux, des trauaux quil luy font preparés. Il eft maintenant temps qu'il paye le grand nombre des offerses qu'il a faites d 


\section{Hiftoire naturelle}

Dier, Or quil reçoiue la peine de es tyrannies, o de fort grand orgueil, o neantmoins tu voids comme il a si pers de foncy de cela, ơ quilleft fi aueugléen fes mijeres, qqu'il sia defia plus de fentiment. Mais afin que tule puirfes mieux vour, prends se baffon de fenteiurs qu'al tient ardens en a main, $\mathcal{O}$ luy mets contre le vifage, $\mathcal{O}$ lors tu verras qu'll nele fentira pas. Le pauure laboureur n'ofa approcher, ny faire ce que l'on luy difoit, pour la grande crainte qu'ils auoient tous de ce Roy: mais la voix recommença à dire: $N^{3}$ ajes pornt de crainte, car ie fuis fans comparaifon plus que ce Roy, ie le puis deftruire, $\mathcal{O}$ le deffendre, parquoy fais ce que re re commande. Sur ce commandement le payfan prend. ce bafton d'odeur de la main du Roy, \&. luy. mit ardent contréle nez, mais il ne fe meut, ny monftra aucun fentiment. Cela fait, la voix luy dift, que puis qu'il vo yoit combien ce roy eftoit endormy, qu'il l'allaft refueiller, \& luy racontaft ce qu'il auoit veu. Alors l'Aigle par le mefme commandement reprit l'homme en fes griffes, le remettant au propre lieu où il l'auoit pris, \& pour accompliffement de cequi luy auoit efté dit, venoit là pour l'en aduertir. Ils difent qu'alors Moteçuma fe regarda au vifage, \& trouua qu'ill'auoit bruflé, ce qu'il n'auoit iufques alors fenty; dequoy il demeura extremement trifte, \& ennuyé. Il peut eftre que ce quele rufticraconta, luy eftoit arriué en imaginaire vifion, \& n'eft pas incroyable que Dieu ordonna parle moyen d'vn bon Ange, ou permit par le moyen du mauuais, qu'on donnaft cét aduertiffement au ruftic, pour le chaftiment du Roy, quóy qu'infidelle; veu que nous lifons en la diuine 


$$
\text { des Fndes. Liure }
$$

Ecriture que des hommes infidelles $\&$ pecheurs ont eu de femblables apparitions \& reuelations, comme Nabuchodonofor, Balaam $8 \mathrm{r}$ l if de Siï niffe de Saül. Et quand quelque chofe de ces ap. 3. Reg. ${ }_{2} 8$; paritions neferoit arriué fi expreffément, à tout le moins il eft certain que Moteçuma eur beaucoup de grădes trifteffes $\&$ farcheries, pour plufieurs \& diuerfes reuelations qu'il eut, que fón Royaume \& $f_{2}$ loy fe deuoiét bien toft acheuer.

De la nounelle que Motecuma receut de l'arriuge des E/pagnols en faterre, or de l'Ambaffade qu'il leur enuoya.

\section{CHAPITRE XXIV。}

V quatorziefme an du regne de Mote$\Delta$ çuma, qui fut l'an de noftre Sauueur, 2023 I517. apparurent en la mer du Nort des nauires, \& des hommes defcendans; dequoy les fubjets de Moteçuma furent beaucoup efmerueillez, \& voulans fenquerir, \& fe fatisfaire dauantage qui ils eftoient, ils furent aux nauires dans des canoes, portans plufieurs rafraifchiffemens de viandes, \& d'eftoffes à faire des habits, feignans de les leur aller vendre. Les Efpagnols es recueillirent en leurs nauires, \& en payenent de leurs viandes \& eftoffes qui leur furent igreables, ils leur donnerent des chaifnes de ierres faulfes, rouges, azurees, vertes $\&$ iaulies, que les Indiens croyoient eftre pierres pre ieufes. Et les Efpagnols finformans qui eftoit eur Roy, \& de fa grande puiffance, leur doat

$$
z z
$$




\section{Hiftoire naturelle}

nerent congé, en leur difant quils portaffent ces pierres à leur Seigneur, \&. luy diffent que pour le prefent ils ne poutoient l'aller voir, mais qu'incontinent ils retourneroient, \& le vifitcroient. Ceux de la colte allerent incontinent à Mexique auec ce melfage, portans la reprefen. tation de tout ce quils auoient veu, depeinte en Aes draps qu'ils auoient, tant des nauires, \& des (hommes, que des pierres quils leur auoient don. nees. Le Roy Moteçuma demeura par ce meffage fort penfif, \& leur commanda quils ne le diuulgaffent, \& nele diffent à perfonne. Le iout enfuiuant il affembla fon Confeil, \& leur ayans monftré les draps \& les chaifnes, mit en delibe. ration ce qu'il deuoit faire, où il fut refolu de donner ordreà toutes lés coftes de la mer, que les habitans y fuffent au guet, \& que quelque chofe qu'ils viffent, ils en aduifaffent incontinét le Roy. L'annee enfuiuante, qui fur au cúmencement de l'an is 18 . ils virent paroiftre en la mes la flotte où eftoir le Marquis de la Vallé, Dom Fernande Cortés auec fes compagnons. Nou. uelle qui troubla beaucoup Moteçuma, \& con fultant auec les fiens, ils dirent tous que fans fau te leur ancien \& grand Seigneur Quezalcoali eftoit venu, lequel leur auoir dit qu'il retourne roit du cofté d'Orient, où il f'en eftoit allé. 11 , auoit entre les Indiens vne opinion, qu'vrn grăc Prince les auoit au temps paffé laiffez, \& pro. mis qu'il retourneroit, de l'origine \& fonde ment, de laquelle opinion fera dit en vn autr lieu. C'eft pourquoy ils enuoyerent cinq prin cipaux Ambafladeurs, auec des prefens riches 


\section{des Indes. Liure VII. $\quad 362$}

pour le cógratuler de fa venuë, leur difant qu'ils 1 çauoient bien que leur grand Seigneur Quetzalcoalt venoit la, \& que fon feruiteur Moteçuma l'enuoyoit vifiter, fe tenant pour fon feruiteur. Les Efpagnols entendirent ce meffage par le moyen de Marina Indienne qu'ils menoient auec eux, \& eçauoit la langue Mexiquaine; \& Fernande Cortés trouuant que c'eftois vne bonne occafion pour leur entree, comman. da qu'on luy ornaft fort bien fa chambre, \& eftant affis auec grande authorité \& ornement, fift entrer les A mbaffadeurs, lefquels n'obmirent rien de fhumilier, finon de l'adorer pour leur Dieu. Ils luy firent leur ambaffade, difans que fon feruiteur Moteçuma l'enuoyoit vifiter, \& quil terioit le pays en fon nom, comme fon Lieutenant; qu'il f̧auoit bien que c'eltoit le To. pilcin qui leur auoit efté promis il y auoit plufieurs ans, lequel les deuoit venir reuoir.Par ain. fi quils luy apportoient les habits qu'il auoit accouftumé de porter, quand il conuerfoit auec eux, le fuppliät qu'il les receuft pour agreables, en luy offrant plufieurs prefens de gräde valeur. Cortés refpondit, receuant les prefens, \& donnant à entendre qu'il eftoit celuy qu'ils difoient? dequoy ils demeurerét fort contens; \& fe voyäs receus $\&$ traittez de luy amiablemét (car en cela, auffi bien qu'és autres chofes, ce valeureux Capitairie a efté digne de loüange) que fi l'entreprinfe euft paffé outre, qui eftoit de gagnes par amitié ce peuple, il femble quill f'eftoit of fert la meilleure occafion que lion fe pourrois: imaginer, pour affubjettir cefte terre a l'Euas

$$
z_{\text {. }} \text { ij }
$$




\section{Hiftoire naturelle}

gile par paix, \& par amitié: mais les pechez de ces cruels homicides \& efclaues de Satan, vóuloient eftre chaltiez du ciel, comme auffi ceux de plufieurs Efpagnols qui n'eftoient pas en petit nombre. Ainfiles hauts iugemens de Dieu difpoferent le falur de ces peuples,ayans premie-

Rom. XI. rement retranché les racines endommagees, \& comme dit l'A poftre, la mauuaiftić $\&$ aueuglement des vos fut la faluation des autres. En fin le iour d'apres l'ambaffade furdite, tous les $\mathrm{Ca}$ pitaines \& principaux de la flotte vindrent dans PAdmiralle, \& entendans l'affaire, \& combien ce Royaume de Moteçuma eftoit puiffant \& riche, illeur fembla que c'eftoit chofe conuenable d'obrenir reputation d'hommes braues \& vaillans enuers ce peuple, \& que par ce moyen encores qu'ils fuffent peu, ils feroient craints \& receus en Mexique. A cefte fin ils defchargerent toute l'artillerie des nauires; \& comme c'eftoit chofe qui iamais n'auoit efté oüie par les Indiěs, ils demeurerent auffi efpouuentez, que fi le ciel fuft to mbé fur eux. Apres, les Efpagnols fe mirent à les défier, afin qu'ils cöbatiffent auec eux, \& les Indiens ne f'y ofans hazarder, ils les battirent $\&$ mal-traitterent, leur monftrans leurs efpees, lances, pertuifanes $8 r$ autres armes dont ilsles efpouuenterét beaucoup. Les pauures Indiens furent pour cét effet fi craintifs \& efpouuentez, qu'ils changerent d'opinion, difans que leur Seigneur Topicin ne venoit point en cefte rro upe, mais que c'eftoient quelques dieux leurs ennemis qui venoient là pour les deftruire. euád les Ambalfadeurs retournerent en Mexique, 


\section{des Indes. Liure VII. $\quad 363$}

Moteçuma eftoit en la maifon de l'audience, \& auant qu'ils luy donnaffent l'ambaffade, le malheureux commanda de façifier en fa prefence vn nombre d'hommes, puis auec le fang des facrifiez arroufer les Ambaffadeurs, penfant par cefte ceremonie (quils auoient accouftumé de faire en de folemnelles ambalfades) auoir bon. ne refponfe. Mais ayant entendu le rapport \& information de la forme des nauires, hommes, $\&$ armes, il demeura tout confus \& perplex: puis ayant eu confeil là deflus, ne trouua autre meilleur moyenque procurer d'empefcher l'en. tree à ces eftrangers, parles arts magiques, \& coniurations. Ils auoient accouftumé fouuent de fe feruir de ces moyens, d'autant qu'ils auoiét grande cómunication auec le diable, par l'ayde duquel ils obtenoient quelquesfois des effeets eftranges. Ils affemblerêt donc tous les forciers, magiciens \& enchanteurs, \& perfuadez de Moteçuma, prindrêt en leur charge de faire retour. ner ces gens là en leur pays. Pour cét effect ils furent en certain lieu qui leur fembla eftre propre pour inuoquer les diables, \& exercer leurs arts, chofe digne de confideration. Ils firêt tout ce quils peurent, \& fceurent, mais voyans que nulle chofe ne pouupit empefcher les ChreItiens, ils furent vers le Roy, luy difans que ceux-là eftøient plus qu'hommes, pource que rien neles endómageoit, pour toutes leurs coniurations \& enchantemens. Alors Motẹçuma f'aduifa d'vne autre rufe, qui fut que feignant d'eftre fort content de leur venuë, il enuoya commander à tous fes Royaumes quils feruif$\mathrm{Z}$ z iij 


\section{Hiftoire naturelle}

ent ces dieúx celeftes qui eftoient venus en leúr rerre. Tout le peuple eftoit en grande trifteffe \& furfaut, \& venoient fouuent nouuelles que les $E$ fpagnols f'enqueroient foutuent où eftoit le Roy, de fa façon de viure, de fa maifon, \& de fes moyens. Il eftoit extremement fafché de ce. la, \& luy confeilloient les fiens, \& d'autres Negromanciens, qu'il fe cachaft, luy offrant à cefte fin de le mettre en lieu ou creature ne le pourroit iamais trouuer. Cela luy fembla chofe vile, parquoy il fe determina à les attendre, encores que ce fuft en mourant. En fin il fortit de fes maifons \& Palais Royaux, pour loger en dautres, les lailfans pour loger ces dieux, comme ils difoient.

\section{De l'entree des Efpagnols en Mexique.}

\section{CHAPITRE XXV.}

117 $\mathrm{E}$ ne pretends point traitter les faits \& 20 geftes des Épagnols qui conquefterée 2. La neuue Efpagne, ny les aduentures tole eftranges qui leur arriuerent, ny le courage $\&$ valeur inuincible de leur Capitaine Dom Fernande Cortés, d'autant que de cela il y a beaucoup d'hiftoires \& relations, cóme celles que le inefme Cortés efcriuit à Charles V. Empereur, bien qu'elles foient d'vn ftile rond, $\& e$ affez ęloigné d’arrogáce; lefquelles dónent fuffifante cognoifsăce de ce qui fe paffa, en quoy il fut digne d'eternelle memoire. Mais feulement pour accóplir mon intention, il refte de dire ce 


\section{des Indes. Liure VII. $\quad 364$}

que les Indiens raconten n'a efté iufqu'aujourd'huy redigé par efcrit en noftre vulgaire. Moteçuma donc ayant entendu les victoires du Capitaine, \& qu'il venoir, f'aduançant pour fa cóquefte, quil fieft oir confederé \& joint auec ceux de Tlafcalla fes capitaux ennemis, \&r auoit chaftié rudement ceux de Chollola fes amis; fimagina de le tromper, ou efprouuer en luy enuoyant vn homme prin. cipal, veftu, \& accommodé des mefmes ornemens, \& en feignes Royales, qui feignit eftre Moteçuma: laquelle fiction ayant efté defcouuerte au Marquis par ceux de Tlafcalla qui l'accompagnoient, le renuoya apres l'auoir douce. ment \& prudemment reprins de l'auoir ainfi voulu tromper; dequioy Moteçuma demeura tellement confus, que pour la crainte de cela il retourna aे fes premieres imaginations de vouloir faire retirerles Chreftiens, par le moyen $\&$ inuocation des enchanteurs \& forciers. Parquoy il affembla vn plus grand nombre d'iceux quil n'auoit fait la premiere fois, en les menaffant que fils retournoient vers luy fans accomplir fon commandement, il n'en r'efchapperoir vn feul, à quoy ils promirent d'obtemperer. Et pour cét effect tous les officiers du diable fen allerent au chemin de Chalco, qui eftoit par où deuoient paffer les Efpagnols, où montansau faifte d'vne cofte, leur apparut Tezcalipuca, ivn de leurs principaux dieux, comme venant deuersle camp des Efpagnols, en lhabir de Chalcaș, qui auoit les tetins ceints auec huiet tours d'vne corde de ione; il venoit comme hors de $\mathrm{Z} z \mathrm{iiij}$ 


\section{Hiftuire naturelle}

foy, \& comme vn homme infenfé, \& enyuré de rage \& de furie. Arriué qu'il fut à l'efcadron des Negromanciens \& forciers, il farrefta, \& leur dift en grand cholere: Pourquoy vous autres rezenés-vous icy? Qu'eft ce que Moteçuma pretend faire par voftre moyen? Il seft troptard adüsé : car defia il eft determiné que l'on luy ofte fon Royaume or fon honneur, anec toust ce quilil poffede, pour punition des grandes tyrannies qu'il a commifes contre fes vafjax, $n^{\prime}$ ayant pas gouwernéen feigneur, mais comme tralffre $\sigma$ tyran. Les enchanteurs alors oyans ces paroles, cogncurent que c’eftoit leur idole, \& l'humilians deuăt luy, luy baftirent à l'inftant au mefme lieu vnautel de pierre, qu'ils couurirent de fleurs quils cueil. lirent à l'entour ; luy au contraire ne faifant pas d'eftat de ces chofes, commença derechef à les rancer, difant: Qu'eftes-vous verius faire icy, traiftes, retounneZ, retourneZ incontinent, o regarde Z Mexique, afin que vous entendiez ce qui doit adwenir d'elle. Et difent qu'ils fe retournerent deuers Mexique pous la regarder, \& qu'ils la virent bruflante \& toute enflambee de viues flâmes. Alors le diable difparut, \& eux n'ofans paffer plus outre, firent fçauoir cela à Moteçuma; ce qu'ayant entendu, il fut vn long temps fans parler, regardant pen$f_{1} f$ en terre, puis dift, que ferons-nous donc, fi les'dieux \& nos amis nous delaifent, \& qu'au contraire ils aydent \& fauorifent nos ennemis? Ie fuis defia refolus, \&z nous deuons tous refoudre à ce point, quarriue ce qui pourra arriuer, nous ne deuons point fuyr, ny nous cacher, ny. monftrer aucun figne de coüardife. l'ay feulement pitie des vieillards, \& des petits enfans 


\section{des Indes. Liure. VII.}

qui n'ont ny pieds, ny mains pour fe deffendre, \& difant cela, fe teut, pource quil commençoí à fe tráfporter en extafe, En fin le Marquis fapprochant de Mexique, Moteçuma s'aduifa de faire de neceffité vertu, $\&$ fortit pour le rece. uoir comme à trois ou quatre lieies de la Cité, allant d'vne graue majefté, porté fur les efpaules de quatre Seigneurs, $8 z$ eftant couuert d'vn riche poëlle d'or \& de plumeries. Lors qu'ils f'entre\&encontrerent, Moreçuma defcendit, \& tous deux fe faliierent l'vn l'autre fort courtoifemét: Dom Fernande Cortés luy dift qu'il ne fe fouciaft de rien, \& qu'il n'eftoit là venu pour luy ofter fon Royaume, ny diminuer fon authorité. Moteçuma logea Cortés i $x$ fes compagnons en fon Palais Royal, qui eftoit fortmagnifique, \& luy s'en alla loger en d'autres maifons priuees quil auoit. Les foldats defchargerent cefte nuidt-là l'artillerie par refiouy ffance, dequoy les Indienss'ef pouuenterent beaucoup, n'eftans pas accouftumez d'ouyr vne telle mufique. Leiour ev fuiuant Cortés fit affembler Moteçuma \& 1 S Seigneurs de fa Court en vine grande fale, où hy eftant affis en vne haute chaire, leur dift qu'il eftoir feruiteur d'vn grand Prince quiles auoit enuoyez en ce pays pour faire de bonnes ceuures, \& qu’ayant trouué en iceluy ceux de Tlafcalla qui eftoient fes amis, lefquels fe plai gnoiet fort des torts \& griefs que ceux de Mexi que leur faifoient continuellement, à cefte occafion il vouloit entedre lequel d'entr'eux auoir le rort, à fin de les appointer enfemble; pour de It en auant ne fe trauailler \& guerroyer les yns 


\section{'Hiftoire naturelle}

Les autres, \& que cependant luy \& fes freres (qui eftoient les Efpagnols)demeureroient toujours là lans les endommager, au contraire les ayderoient en ce qu'ils pourroient. Il mit peine de faire bien entendre ce difcours à tous, fe feruát de ces interpretes \& truchemëts. Ce qu'encendu par le Roy \& les autres Seigneurs Mexiquains, ils furent extremement contés, \& monfrerent grands fignes d'amitié z̀ Cortés \& aux frens. Plufieurs font d'opinion que s'ils euffent fuiuy l'affaire comme ilsl'auoient commécé ce iour là, ils euffent peu facilement ordonner du Roy $\&$ du royaume pour leur donner la loy de IEsvs-Chrit fans grande effufion de fang. Mais ies iugements de Dieu font grăds, \& les pechez des deux parties eftoient en grand nombre; par ainf n'ayans fuiuy leur pointe, l'affaire fut differé, combien qu'en fin Dieu fit mifericorde à cefte nation, luy cómuniquant la lumiere de fon fainct Euangile, apres auoir fait iugemét \& pu nition de ceux quile meritoient, \& qui auoient trop enormement offenfé la diuine reuerence. Tant y a que quelques occafiós s'efmeurent, dót plufieurs plaintes, griefs \& foupçons nafquirét d'vn cofté, \& d'autre. Ce que voyant Cortés, \& que les volontez des Indiens commençoient à fe diftraire d'eux, il luy lembla neceffaire de s'affeurer, en mettant la main furle Roy Moteçuma,lequel fut faifi, \& mis les fers aux pieds, acte certes efpouuentable au monde, \& qui eft efgal -à l'autre fien, d'auoir bruflé fes nauires, \& s'eftre enclos au milieu de fes ennemis, pour vaincre ou pour mourir. Le pire fut que à caufe de la 


\section{des Fndes. Liure. VII. 366}

venué inopinee d'vn Pamphilo Naruzes en la vera $C r u x$, pour alterer $\&$ mutiner le pays fut de befoing que Cortés s'abfentaft de Mexique, \& quil laifaft le pauure Moteçuma entre les mains de fes compagnons, quin'auoient pas la difcretion, ny la moderation telle que luy, pas ainfil l'affaire vint à telle diffention, qu'il n'y eut plus aucun moyen de faire paix.

De la mort de Moteçuma, \& fortic des Efpagnols de Mexique.

CHAPITRE XXVI,

M-T. Ors que Cortés eftoit abfent de Mexique, celuy qui eftoit demeuré fon Lieutenant, fut d'opiniō de donner vn rude chaftiement aux Mexiquains, \& fit tuervn grand nombric de la nobleffe en vn bal qu'ils firent au Palais, qui fut fi exceffif, que tout le peuple fe mutina, \& d'vne furieufe rage prindrent les armes pour fe véger \& tuer les efpagnols. Par ainfi les affiegerér au Palais, les preffans de fi pres, gque le dommage que les Efpagnols leur faifoient de leur artillerie $\&$ de leurs arbaleftes, ne les pou. uoit diftraire, ny faire retirer de leur entreprinfe, à quoy ils perfifterent par plufieurs iours leur empefchant les viures, fans permetrre qu'il y entraft ou fortift aucune creature. Ils fe batroient auec des pierres, des dards à ietter, à leur façon, des efpeces de lances qui font comme des Gefches; où il y a quatre ou fix razoirs tres-ay, 


\section{Hiffoire naturelle}

gus, qui font telles queles hiftoires racontent, qu'en ces guerres vn Indien d'vn coup de ces razoirs emporta prefque tout le col d'vn cheual, \& commeils combattoient vniour en cefterefo. lution \& furie, les Efpagnols pour les faire ceffer, firent monter Moteçuma, auec vn autre des principaux Seigneurs Mexiquains, au haut d'v. ne platte forme de la maifon, couuerts des ron. delles de deux foldats qui efioient auec eux.Les Mexiquains voyans leur Seigneur Moteçuma, sarrefterent \& firent grand filence. Alors Moreçuma leur fir dire parce Seigneur principal, quils s'appaifaffent, \& qu'ils ne fiffent la guerre àx E⿰pagnols, puis quills voyoiét que luy eftă prifonnier ; cela ne leur pouuoit proffiter. $\mathrm{Ce}$ qu'eltant entendu par vn ieune homme appellé Quicuxtemoc, lequel ils parloient defia d'eflire pour leur Roy, dift à haute voix à Moteçuma, qu'il fe retiraft comme vn vilain, qué puis qu'il auoit efté fi coiiard que de fe laiffer prendre, ils ne luy deuoient plus obeyr, mais pluftoft luy dá. ner le chaftiement qu'il meritoit, l'appellät fem. me, pour plus grădeignominie, \& cómença alors à enfoncer fon arc, \& à tirer cótre luy, \& le peuple recómençà ietter des pierres, \& pourfuiure leur combat. Plufieurs difent qualors Moteçuma fut frappé d'vn doup de pierre, dont il mourut; les Indiens de Mexique afferment le contraire, mais qu'il mourut depuis de la façon que ie diray incontinent. Alùaro \& le reftedes Efpagnols fe voyans fi preffez, enuoyerent don. ner aduis au Capitaine Cortés, du grand dăgez où ils eftoient, lequel ayant auec vne merueil. 


\section{des Indes. Liure VII.}

leufe dexterité \& valeur, donné ordre en l'affaire de Naruacs, \& recueilly pour lúy la plus grande partie defes hommes, vintà grandes iourneesfecourir les fiens en Mexique, où attendant le temps que les Indiens fe repofoient (car c'eftoir leur vfage en la guerre, de fe repofer de quatre iours en quatre iours) il s'aduanca vn iour par grande rufe \& magnanimité, tellemét que luy \& fes gens entrerent au Palais où les Efpagnols s'eftoient fortifiez, parquoyils monftrerét plufieurs fignes de refiouyffance, en defchargeant l'artillerie: mais comme la rage des Mexiquains s'augmentoit, \& qu'il n'y auoit nul moyen de les appaifer, mefmes queles viures leur deffailloient du tout, fans qu'ils euffent efperance de pounoir plus fe deffendre, le Capitaine Cortés delibera de fortir vne nuid fans bruit. Parquoy ayant fait des ponts de bois, pour paffer deux grands courants d'eaiie fort dangereux, il fortit fur la minuict auec toutle plusgrand filence qu’il peut, \& ayant jà la plus. part de fes gens paffé le premier pont, ils furent apperceus d'vn e Indientie auant que de pafter le fecond, qui s'en alla criāt que leurs en nemis s'en fuyoient, à laquelle voix s'affembla \& accourus tout le peuple d'vne terrible furie, tellemét que paffant le fecond pont, ils furent tellemét chargez \& preffez, qu'il demeura plus de trois cenis hommes morts \& bleflez en vn licu où eft auiourd'huy vn petit hermitage, que forr mal à propos l'on appelle auiourd'huy des Martyrs. Plufieurs des Efpagnols pour conferuer l'or $\& 5$ des ioyaux qu'ils auoient, ne peurent efchapper, 


\section{Ffifoire naturelle}

$\&$ d’autres retardás pour le recueillir, \& appor ter, furent prins par les Méxiquains, \& cruelled mét facrifiéz deuár leurs idolés. Les Mexiquains trouuerent le Roy Moteçuma mort, \& bleffé comme ils difent de coups de poignards, qui eft leur opinió, que cefte nuiet les Ef pagnols le tue. rent auec d'autres Seigneurs. Le Marquis en la relation qu'il enuoya a l'Empereur, dit au contraire, \& que les Mexiquains luy tuerent celle nuict vn fils de moteçuma, qu'il emmenoit auec d'aurres Seigneurs, difant que toute la richeffe d'or, pierres, \& d'argét, qu'ils emportoient, tóba au lac, où iamais da depuis ne parut. Quoy qu'il en foir, Moteçuma finit miferablement, \& paya au iulte iugement du Seigneur des cicux ce qu' il meritoit, pour fon grand orgueil, \& tyrannie. Car fon corps eftát venu en la puiffance des Indiens, ils ne voulurent luy faire les obfeques de Roy, non pas d'homme commun, ains le ietterent par grand mefpris $\&$ collere. Vn fien feruireur ayant pitié du malheur de ce Roy qui auoit efté auparauant craint, \& adoré cóme Dieu, luy fit là vn feu, \& mit fes cendres où il peut, en vn lieu affez mefprifé. Retournant donc aux Efpagnols qui efchapperét, ils furent grandemét fariguez \& trauaillez, pource que les Indiens les fuyuir ent obftinément deux ou trois iours, fans les laiffer repofer vn moment, \& alloient fi fatiguez à caufe du peu de viures, que bien peu de grains de mays eltoient departis entreux pour leur manger. Les relations des Efpagnols, \& des Indiens s'accordét, que noftre Seigneur les deliura en cés endroit miraculeufement, la mere de 


\section{des Indes. Liure. VII.}

mifericorde, \& royne des Cieux, Marieles deffendant en vne mótaignette, où à trois lieuës de Mexique eft auiourd'huy fondee vne Eglife en memoire de cela, auec tiltre de noftre Dame de fecours. Ils fe retirerêt versleurs anciés amys de Tlafcalla, où ils fe retirerét par leur ayde, \& pas la valeur, \& rufe de Fernáde Cortés, puis retournerét faire la guerre en Mexique par eau, \& par terre, auecl'inuention des brigantins qu'ils mirent dans le lac, \& apres plunieurs cóbars \& plus de foixante dangereufe batailles, ils gagnerét du tout la Ciré de Mexique le iour de fainct Hippolyte, treziefme du mois d'Aouf, mil cinq cễts vingt \& vn. Le dernier Roy des Mexiquains ayăt obftinément fouftenu la guerre, en fin fut prins en vne gräde Canoe, où il s'enfuyoit, lequel eftát amené, anec quelques autres des principaux Seigneurs, deuant Fernande Cortés, le roytellet d'vne eftrange magnanimité, facçant vrie dague s'approcha de Corrés, \& luy dift, In qques awiour. d'buy iay faict ce que iay peus pourladeffenfe des miens, maintenant ie ne füis plus obligé a faire dauã tage que de te donser cefte dague pour me tuer d'icelle. Cortés luy refpondit qu'il ne le vouloit pas tuer, \& que cen'z. uoit point efté fon intention de les endómager, mais que leur obftination fi folle eftoit coupz . ble de tant de mal, \& de la perfecution qu'ils. auoient foufferte; qu'ils fçauoient bien combien de fois il les auoit requis de paix, \& d'amitié, puis cómanda qu'on les gardât, \& qu'on le traiEtaft fort bié luy \& les autres qui eftoiét efchap. pez. Plufieurs chofes aduindrent en cefte conquefte de Mexique, eftranges \& admirables, car 


\section{Fiftoires naturelle}

ie né tiens point pour menfonge, ny pour addition,ce que difent plufieurs, qui efcriuent que Dieu fauorifa l'affaire des Efpagnols par plufieurs miracles, d'autant qu'il leur eftoit impoffible de vaincre tát de difficultez, fans la faueur du Ciel , \& de s'affubjectir au commencement cefte terre, auec fi peu d'hommes. Car combien que nous autres fuffions pecheurs, \& indignes de telle faueur, toutesfois la caufe de noftre Dieu, la gioire de noftre foy, le bien de tant de milliers d'ames, comme eftoient ces natiōs, què le Seigneur auoit predeftinees, requeroient que pour paruenir à ce changement que nous voyós à prefent arriué,il y furuinft des moyens fupernaturels, \& propres à celuy qui a ppelle à la co gnoiffance de luy les aueugles, \& prifonniers, \& leur dóne la lumiere \& liberté par fon S. Euăgile, \& afin quel'on puiffe mieux entédre cecy, \&c $y$ adioufter foy, ie raconteray quelques exemples qui me femblent à propos de cefte hiftoire.

De quelques miracles que Dieu a monftrezés Indes en faueur de la foy, fans le merite de ceux qui les firent.

\section{ChapItre XXVII.}

Aincte Croix de la Syerre eft vne Pro(5) uince fort grande, \& fort eflongnee, 2. Ro au Royme du Peru, quis'auoifine auec diuerfes nations d'infideles, lefquels n'ont point encor la lumiere de l'Euangile, depuisle temps quei'en fuisparty files 


\section{des fndes. Liure. VII.}

Peres de noftre Compagnie, qui font là pour cét effect, ne leur ont enfeigné. Toutesfois cefte Prouince de faincte Croix eft Chreftienne, 8: y a plufieurs Efpagnols \& Indiens baptifez en grand nombre. La façon comment le Chriftianifme y entra, fut telle. Vn foldat de mauuaife vie, refident en la Prouince de Charcas, craignant la iuftice, qui ponr fes delicts le rechercheit, entra bien auant dans le pays, \& fut recueilly gracieufement des Barbares de cefte contree, \& voyant l'Erpagnol qu'ils enduroient alors vne gráde neceflité par faute d'eaut, \& que pour faire pleuuoir ils faifoient beaucoup de ceremonies fuperiticieufes, comme ils ont accouftumé, illeur dift que sils vouloient faire ce quill leur diroit, qu'incontinent ils auroient de l'eau, ce qu'ils s'offrirent de faire fort volontairement. Alors le foldat fit vne grande Croix, quil planta en vn lieu eminent, leur difant qu'ils fiffent là leur adoration, \& quils demandaffent de l'eau, ce qu'ils firent, chofe merueilleufe, incontinent tomba de l'cau fi abondamment, que les Indiens prindrene telle deuotion à la faincte Croix, qu'ils auoient recours à icelle pour toutes leurs neceffitez, \& obtenoient tout ce qu'ils demandoient, tellement qu'ils rompirent leur idole, \& commencerent à porter les Croix pour enfeignes, $\&$ à demander des Predicateurs qui les enfeignaffent, \& baptifaffent. Pour cefte oscafion la Prouince a efté iufques auiourd'huy appellee faincte Croix de la Syerre. Mais afin que lon yoye par qui Dieu faifoir ces merueilles, il A2 2 


\section{Hijtoire naturelle}

neferamalà propos de dire comment ce fola dat, apres auoir quel ques'années fait ces miracles d'Apoftre, n'ayant point toutesfois amendéfa vie, fortir de la Prouince des Charcas, \& continuant fes mauuaifes façons de faire, fut mis publiquement all gibet en Pottoli. Polo qui le cognoiffoit, efcrit tout cecy comme chofe notoire, \& qui arriua de fon temps. Cabeca deVaça, qui fut depuis gounerneur au Paraguey, efcript en la peregrination eftrange qui luy aduint en la Floride, auec deux ou trois autres compagnons qui refterent feuls d'vne armée; où ils pafferent dix ans auec les Barbares, cheminans, \& penetrans iufques à la mer du Sud, $\&$ eft autheur digne de foy, que les Barbares les forceăs de guarir certaines maladies, les menaçans quels'ils ne le faifoient, qu'ils leur ofteroientlavie, d'autre part ne fçachans aucune, partie de Medecine, \& n'ayans aucuns appareils pour l'exercer, forcez de la neceffité, fe firent Medecins Euangeliques, difans les oraifons de l'Eglife, \& failans le figne de la Croix, au moyen dequoy ils guarirent ces malades, pour le bruit \& renommée dequoy ils furent contraints d'exercer cefte office par toutes les villes où ils paffoient, qui furent innumerables, enquoy le Seigneur les ayda miraculeurement, defortequ'ils eftoient eux-mefmes efmerueillez pour eftre de vie commune, voire l'vn d'eux vn negre; Lancero eftoit vn foldat au Peru,duquel on ne fçait d'autres merites, que d'eftre foldat, il difoit fur les playes certaines bonnes paroles, \& faifant le figne de la Croix les gua: 


\section{des Indes. Liure. VII. $390^{\circ}$}

tiffoit incontinent; d'oùl'on difoit comme par prouerbe;le Pfalme de Lancero. Eftant examiné par ceux qui tiennent rang \& ont authorité en l'Eglife, fon office, \& fes ouures furent ap: prouuées. Quelques per Connes dignes de foy racontent, \& l'ay ouy dire mefrnes, qu'en la Cité de $\mathrm{Cufco}$, lors que les Efpagnols y eftoient affiegez \& preffez de fi pres, que fans l'ayde du Ciel,il leur eftoit impoffible d'en pouuoir efchapper, les Indiens iettoient du feu fur les toicts des maifons, où s'eftoient retirez les Efpagnols, qui elt l'endroit où ef auiourd'huy batiela grande Eglife: \& bien que le toid fult de certaine paille, qu'ils appellent la chicho, \& que les flambeaux quils y iettoient deffus eftoient de bois de pin fort fameux \& fort gros, toutesfois iamais aucune chole ne print en feu,ny ne fut bruflée, à caufe qu'il y auoit vne Dame en haut qui eftaignoit le feu incontinent, \& cela fut vifiblement apperceu des. Indiens, qui le refererent depuis, en eftans fort efmerueillez. L'on fçait de certain par les relations de plufieurs, \& par les hifoires qui en font ef crites, qu'en diuerfes batailles que les Efpagnols eurêt, tant en la neuue Ef pagne qu'au Peru,les Indiens contraires veirét en l'air vn cheualier monté fur vn cheual blanc, vne efpée en la main, combat tant pour les Efpagnols, d'où eft venuë la grä de veneration qu'ils portêt aux Indes au glorieux Apoftre S. Iacques. D'autresfois ils veirent en quelques batailles l'image de noftre Dame, de laquelle les Chreftiens ont receu en cesparties d'incomparables faueurs \&benefices, que fi l'on

A a 2 ij 


\section{Hiftaire naturelle}

racontoit par le menu toutesles cuures du Ciel comme elles font aduenuës, ce feroit vn difcours fort long. Il fuffit d'auoir dit cecy à l'occafion de la grace que la Royne de gloire fit aux noftres, lors qu'ils eftoient preffez \& pourfuiuis des Mexiquains, ce quei'ay mis en auant, afin de faire entêdré que noftre Seigneur a eu foucy de fauorifer la foy \& Religion Chreltienne, defendant ceux quila tenoient, encor que paraduanture ils ne meritaffent pas par leurs œuures de relles faueurs \& benefices du Ciel. C'eft pourquoy l'on ne doit pas condamner fi abfolument toutes ces choles des premiers conquerans des Indes,ainfi que quelques Religieux \& hommes doetes ont fait par vn bon zele, fans doute, mais par trop affecté; car combien qu'en la plus-part ils furent hommes auares, afpres, \& fort ignorăs de la façon de proceder que l'on deuoit obferuer entre les infideles, qui iamais 'z'auoient offenfé les Chreftiens, toutesfois l'on ne peut pas nier que de la part des infiáeles, il n'y ayt eu beaucoup de mauuaiftié contre Dieu, \& contre les noftres,ce qui les cótraignit vfer de rigueur \& de chaftiment. Et ce qui eft dauantage, le Seigneur de tous, encor queles fideles fuffent pecheurs, voulut fauorifer leur caufe \& party, pour le bien des infideles mefmes, qui depuisfe deuoient conuertir au fainet Euangile par" cefte occafion: car les chemins de Dieu font hauts, \& Leurs traces merueilleufes. 
des Indes. Liure. VII.

$D_{\text {e la façon que la diuine pronidence dipofa les }}$ Indes,poury donner entree à la Religion Chreftienne.

Chapitre XXViII.

M $E$ mettray fin a cefte hiftoire des In2. I des declarant le moyen admirable par 12 1 equel Dieu difpofa \& prepara l'en1: Le trée de l'Euangile en icelles, ce que l'on doit bien confiderer, afin de louier \& recognoiftre la prouidence \& bonté du Creareur. Chacun pourra entendre par la relation $\&$ difcours que iay efcrit en ces liures, tant aus Peru,comme en la neuue Efpagne, lors que les Chreftiens y mirent premierement le pied, ces Royaumes \&. Monarchies eftoient paruenuës au fommet $\&$ periode de leur puiffance ; veu que les Inguas polfedoient au Peru,depuis le Royaume de Chillé iufques plus outre que Quitto, qui font mil lieuës de pays fuiuy. Eftans fi abondans en or \& argent, fomptueux feruices, $\&$ autres chofes, que rien plus, comme en $\mathrm{Me}$ xique Moteçuma commandojt depuis la mer Occeane du Nort, iufques à la mer du Sud, eftát craint \& adoré, non pas comme homme, mais pluftoft comme Dieu. Ce fur alors que le treshaut Seigneur iugea que cefte pierre de Daniel qui rompit les Royaumes \& Monarchies du monde, rompilt aufi ceux de cét autre nouneau monde. Et tout ainfi comme la loy de Chrift vint quand la Monarchie Romaine eftoit paruenuë à fon fommet, ainfi en aduint-il és Indes Az a iij 


\section{Hiftoire naturelle}

Occidentales, \& vrayement apperçoit-on en cela vne vraye prouidence du Seigneur. Car n'y ayant lors au monde, c'eft à dire en Europe, qu'vn chef \& feigneur temporel, ainfi que les facrez Docteurs le remarquent, cela fut caufe que l'Euangile fe peut facilemér communiquér à tant de peuples \& nations, ce qui eft auffi arriué és Indes, ou ayans donné la cognoiffance de Chrift aux chefs \& Monarques de tant de Royaumes, cela fur caufe que par apres plus facilement l'on communiqua l'Euangile à tout le peuple, voire y a icy vne chofe particuliered noter, que comme les feigneurs de Mexique \& de Cufco alloient conqueftans de nouuelles terres, ils y alloient auffi introduifans leur langue: car iaçoit qu'il y euft, comme il y a encor de prefent, vne grande diuerfité de langues particulieres \& propres, neantmoins la langue courtifane de Culco courut, \& court encor aujourd'huy plus de mil lieuës, \& celle de Mexique ne s'eftendoit gueres moins, ce qui n'a pas efté de petite importance, mais a beaucoup pro. fité pour faciliter la predication en ce téps que les Predicateurs n'ont pas le don de plufieurs langues, comme ils auoient anciennement. Qui voudra Çauoir quelle ayde ça efté pour la predication \& conuerfion de ces peuples, que Ia grandeur de ces deux Empires que iay dit, pour la grande difficulté que l'on a experimentée à reduire en Chrift les Indiens, qui ne recognoiffoient point vn Seigneur, s'en aille en la Floride, au Brefil, aux Andes, \& en plufieurs autres endroits, où par la prẹdication l'on n'a 


\section{des. Fndes. Liure VII.}

pas faict vn tel effect en cinquante ans, coma me on a fairau Peru, \& en la neuue Efpagne en moins de cinq. Sils,veulent dire que la richeffe de cefte terre en a efté caufe, ie ne le nie pas du tout,toutesfois il eftoit impoffible qu'il y euft tant de richeffe, \& qu'uls l'cuffent peu có feruer, sil n'y euft eu Monarchie. Cela mefme eft vn acheminement de Dieu pour ce temps cy,auquel les Predicateurs de l'Euangile font fi froids $\&$ fi peu zelez, qu'il y aye des marchands lefquels auec la chaleur del'auarice, $\&$ le defir du commandement, cherchent, $\&$ defcouurent de nouueaux peuples, où nous paffions auec noftre marchandife.Car comme dit $S$. Augúftin, la prophetie d'Efaye eft accomplie, en ce que l'Eglife de Chrift s'eft dilattée, non feulement en la dextre,mais auffi en la feneftre, qui eft cómeil declare, s'accroiftre par des moyens humains \& terriens, que l'on cherche plus ordinairement que Iefus-Chrift. C'a eftéauffigrande prouidence du Sẹgneur, que quand les premiers Efpagnols y arriuerent; ils trouuerent de l'ayde entre les mefmes Indiens, à caufe de leurs partialitez \& grandes diuifions. Cela eft tout cogneu au Peru, que la diuifion d'entre les deux freres A tahulpa, \& Guafca, efár nousuellement decedé le grand Roy Guanacapa leur pere, fuft caufe de donner l'entree au Marquis Dom Fran. çois Pizarre, \& aux Efpagnols, d'autant qu'vn chacun d'eux defiroir fon alliance, \& qu'ils eftoient occupez à fe fair la guerre livn à l'autre. L'on n'a pas rnoins experimenté en la neuue Elpagne, que l'ayde de ceux de la Prouince do $A$ a a iii

Ang.t.2. de con. Enă. c.36. 


\section{Hiftoire naturelle}

Tlafcalla, à caufe de la perpetuelle inimitió qu'ils auoient contre les Mexiquains, caufa aus Marquis Fernande Cortés, \& aux fiens, la vCtoire \& feigneurie de Mexique, \& fans eux il leur euft efté impoffible de la gagner, voire feulement de fe maintenir au pays. Ceux-la fe trompent beaucoup qui eftiment peu les Indiens, \& qui iugent que par l'aduantage que les Efpagnols ont fur eux de leurs perfonnes, cheuaux $\&$ armes offenfiues $\&$ deffenfiues, ils pourront conquefter quelconque terre $\&$ nation d'Indiens. Chillé eft encor là , ou pour mieux dire Aranco, \& Teucapel, qui font deux villes, fur lefquellesnos Efpagnols n'ont pas fçeu gagner vn pied de terre, combien qu'il y aye plus de vingt-cinq ans qu'ils y font la guerre, fans s'y efpargner. Car ces Barbares ayans vne fois perdu la crainte des cheuaux $\&$ des arquebufes, \& fçachans que l'Efpagnol tombe auffi bien qu'vn autre d'vn coup de pierre, ou auec vne fleche, ils fe hafardent \& entrent dans les piques, faifans leurs entreprinfes. Combien d'annees y áil que l'onleue des hommes en la neuue Ef pagne quel'on mene contre les Chychymequos, qui font vn petit nombre d'Indiens tous nuds, armez feulement de leurs arcs \& flefeches, toutesfois iufques auiourd'huy ils n'ont peu eftre vaincus, au contraire de iour en iour ils deuiennent plus hazardeux \& déterminez? Mais que dirons nous des Chucos, des Chyraguanas, \& des Pilcocones, \& de tous les autres peuples des Andes? Toute la fleur du Peru n'y a-elle pas efté, menant auec foy fi grand appareil d'armes 


\section{des Indes. Liure VII.}

\& hommes, comme nous auons veu? Que firent-ils? Auec quel profit retournerent-ils? Ils en reuindrent certainement bien heureux de n'y auoir laiffé la vie, y ayans perdu leur bagage, \& prefque tous leurs cheuaux. Qu'aucun n'eftime pasqu'en parlant des Indiens l'on doiue entendre des hommes de rien: mais fill le penfe, qu'il vienne, \& en faffel'efpréuue. Il en faut done attribuer la gloire à qui elle appartient, qui eft principalement à Dieu, \& à fon adinirable difpofition : car fi Moteçuma en Mexique, \& l'Ingua ar: Peru, fe fuffent employez à refinter aux Efpagnols, \& leur empefcher l'entree, Cortez \& Pyzarre y euffent peu profité, encore qu'ils fưffent excellents Capitaines, d'auoir mis feulement pied en terre. $\mathrm{C}^{\prime} \mathrm{a}$ efté mefme vn grand ayde pour faire receuoir aux Indiens la loy de I efus-Chrift, que la grande fubjection qu'ils auoient à leurs Rois \& Seigneurs, \& mefine la fujection \& feruitude qu'ils auvient au diable, à fes tyrannies, \& à fon ioug fi pefant. Ce fut vne excellente difpofition de la Sapience diuine, laquelle tire du profit du mal d'autruy qu'elle n'a pas femé. Il eft certain qu'il n'y a aucun peuple des Indes Occidentales, qui ayt efté plus idoine à l'Euangile, que ceux gui ont efté plus fujets à leurs Seigneurs, \& qui ont efté chargez de plus grandes charges, tant de tributs \& feruices, comme de couftumes \& vfages fanguinolents. Tout ce que poffederent les Rois Mexiquains, \& ceux du Peru, eft aujourd'huy le plus cultiué de la Chreftienté, \& où il y a moins de "ifeculté au gouuernemér, \& police 


\section{Hiffoire naturelle}

Ecelefiaftique. Les Indiens eftoient defia fi laffés d'endurer le ioug tres-pefant, \& infupportable des loix de fatan, des facrifices, \& ceremonies, dont nous auons parlé cy-deflus, qu'ils confultoient entre eux de chercher vne autre loy, \& vn autre Dieu, à qui ils feruiffent. C'eft pourquoy la loy de Iefus-Chrift leur fembla, \& $\mathrm{fem}$. ble encor aujourd'huy iufte, douce, nette, bonnc, \& toute pleine de biens. Et ce qui eft difficile en noftreloy, qui eft de croire des myfteres fi hauts \& fouverains, a efté bien facile entre eux, d'autant que le diable leur auoit fait comprendre d'autres chofes plus difficiles. Et ces mefmes chofes quil auoir defrobees de noftre loy Euangelique, comme leur façon de communion, \& confeffion, leur adoration de trois en vn, \& telles auttes chores femblables, lefquelles contre la volonté de l'ennemy, ont aydé à faire plus facilement receuoir la veritéà ceux qui lesauoient receuz en la menterie. Dieu en toutes fes auures eft fage, \& admirable, lequel furmonte l'aduerfaire auec fes propres armes, l'arrefte auec fon lacs, \& l'efgorge auec fa propre efpee. Finalement noftre Dieu (qui auoit creé ces peuples, \& qui fembloit fi long temps les auoir mis en oubly) quand leur heure a efté venuë, a voulu faire que les mefmes diables ennemis des hommes qu'ils tenoient fauffement pour dieux, donnaffent témoignage contre leur. volóté, de fa vraye loy, du pounoir de Chrift, \& du triomphe de fa Croix, ainfi qu'il appert clairement par les prefages, propheties, fignes \& prodiges cy delfus racontez, auec plufieurs aw; 


\section{des Indes. Liure VII.}

tres qui font aduenús en diuers endroids, \& que les mefmes miniftres de fatan, forciers, magiciens, \&z autres Indiens l'ont confellé. Et ne peut-on nier (car c'eft chofe tres-euidente, \& notoire par tout le monde) que le diable n'ofe fifller, \& que les practiques, oracles, refponfes, \& apparitions vifibles, qui eftoient fi ordinaires ca coute cefte infidelité, ont celfé és lieux où le figne de la croix a efté planté, où il y a des Eglifes, \& où l'on a confelíć le nom de Chrift. Que fil y a encor aujourd'huy quelque fien miniftre maudit, qui participe encores de quelque chore de cela, ce n'eft que dedans les cauernes, foinmets des montagnes, \& aux lieux cachez, $\&$ du tout efloignez du nom \& communion des Chreftiens. Le Seigneur fouuerain foit benit, pour fes grandes mifericordes, \& pour la gloire de fon fainct nom; \& à la verité fi l’on gouuernoit, \& regiffoit ce peuple, tant temporellement que fpirituellement, de la façon que porte la loy de Iefus-Chrift auec vn ioug fi doux, \& vne charge filegere, \& qu'on ne leur donnalt point plus de poids \& de charge, que ce qu'ils peuuent porter, ainfi qu'il eft porté \& commandé par les patentes du bon Empereur de bonne memoire, \& qu'auec cela ils prinffent la moitié du foucy qu'ils employent à faire profit de leurs pauures fueurs, \& trauaux, pour leur ayder à leur falut, ceferoit la Chreftienté la plus paifible \& heureufe de tout le monde. Mais nos pechez bien fouuent font occafion que Dieu ne depart pas fes graces fi abondamment qu'il feroit. Ioutefois ie dis vne chole qui eft vraye, 


\section{Hifoire naturelle}

\& le tiens pour certain, que jaçoit que la pre: miere entree de l'Euangile en beaucoup d'endroits n'a pas efté accompagnee de fincerité, \& de moyens Chreftiens, defquels l'on fe deuoir feruir, fi eft-ce que la bonté de Dieu a tiré du bien de ce mal, \& a fait que la fujerion des Indiens leur aye efté vn parfait remede \& faluation. Que l'on confidere vn peu ce que de noftre temps l'on a de nouueau conuerty en la Chreftienté, tant en Orient qu'au Ponent, 8 c combien il y a eu entr'eux peu de feureté, \& de perfeuerance en la foy \& religion Chreftienne, és lieux où les nouueaux conuertis ont eu entiere liberté de difpofer de foy, felon leur liberal arbitre. La Chreftienté fans doute va croilfant \& augmentant, \& rapporte chaque iour plus de fruict entre les Indiens affujettis, \& au contraire fe va diminuant, \& menaçant ruine és autres qui ont eu descommencemens plus heureux; \& encore que les commencemens ayent efté laborieux és Indes Occidentales, toutesfois le Seigneur n'a laiffé d'enuoyer incontinent de bons ouuriers \& fideles miniftres fiens, hommes faincts \& Apoftoliques, comme furent Frere Martin deValence de l'ordre de fainct François, Frere Dominique de Getançois de l'ordre de fainct Dominique, Frere Iean de Roa de l'ordre de fainct Augultin, auec d'autres feruiteurs du Seigneur, qui ont vefcu fainctement, \& y ont ouuré des chofes plus qu'humaines. Des Prelats mefmes fages, \& des Preftres fort faincts, \& dignes de memoire, defquels nous oyons des miracles remarquables, \& propres actes d'A pa- 


\section{des Fndes. Liure VII. $\quad 375$}

itres, voire en noftre temps en auons cogneu \& communiqué de cefte qualité. Mais pource que mon intention n'a efté plus outre que de traiOer ce qui touchel'hiftoire propre des melmes Indiens, \& de venir iufques au temps que le Pere de noftre Seigneur Iefus-Chrift voulut leur. communiquer la lumiere de fa parole, ie ne pafo feray plus outre, laiffant pour vn autre temps, ou pour vn meilleur entendemení, le difcours de I'Euangile aux Indes Occidentales, fuppliant le fouuerain Seigneur de tous, \& priane fes feruireurs qu'ils fupplient humblement fa diuine Majefté qu'il plaife à fa bonté vifiter fouuent, \& augmenter par fes dons du ciel, la nouuelle Chreftienté que les derniers fiecles one plantee aux bornes de la terre. Soit au Roy des fiecles gloire, honneur, \& empire pour toufjours, \&à iamais. Amen.

\section{F I N.}

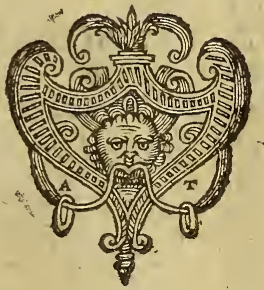




\section{3) W. \\ TABLE, DES CHUSES PLVS REMARQVABLES CONTENVES en cefte Hiftoire naturelie $\&$ morale des Indes.}

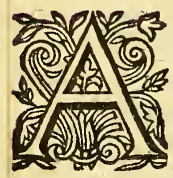

Bödăce d'eaux fous la Zone Torride 57 Abfurditez de l'Ille Atlantique de Platon Abus des Efpagnols au Peru,prenansl'efté pour l'hy. uer

Acamapach I. Róy de Mexique

Accorà fait entrele Roy de Mexique \& fon peuple, deuant qu'entreprendre vne guerre

Adlaguagi efpece de mona. ftere de femmes 233 . b. 234 Actes genereux de Fernande Cortez

$366 . a$ Action de gracesfolemnelles apres vnevictoire 342.3
Adoration des mòrts com mencee $\&$ augmentee 218 。 b. 219

Adulteres punis de mort 298. b

Agilité des guenons, \& de leurs traicts prefque incroyables 200.a.b l'Aigle fus vn Tanal, armoiries de Mexique, \& pourquoy $326 . \mathrm{a}$. b l'Ail fort eftimé des Indiens $165 . a . b$

l'Air combien neceffaire la vie del'homme $7 \mathrm{r} . \mathrm{b}$ l'Air efmeu de mouuement celefte, fuffit foubs la ligne Equinoxiale pour códuire vn nauire $\quad 86$. b. 88.b Aleos petits chiens dont les Indiês ont grăd foing 191.b 


\section{des matieres.}

Amaro Ingua executé par les Efpagnols dans Cufco 306.6

Ambre, efpece de gomme medicinale, \& odoriferente 182. a. b Amendes croiffans dans les Cocos Amendes de Chacapoyas, tenuës pour le plus rare fruict qui foit au monde. $178 . \mathrm{b}$

les Anciens n'ont peu faire vn voyage de propos deliberé , faute d'aiguille $37 . a$

les Anciens ne nauigeoient ģu'auec rames

Anciens Docteurs plus ftudieux des fainctes lettres, que des demonftrations de Philofophie

2. b

Animaux venimeux conuertis par art du diable, en bonne nourriture

\section{2}

Animaux parfaicts ne peuuent pas eftre engendrez de mefme que les imparfaicts, felon l'ordre de nature
plufieurs efpecesd'Animaux fe trouuent és Indes, dons il n'y en a point en l'Europe

195. a. b

Annona, fruict appellé par les Efpagnols, blanc manger, à caufe de quelque reffemblance

l'An des Indiens diuifé en dix-huict mois

l'An des Perufiens plusparfait $\&$ plus approchant du noftre, que celuy des Mexiquains $277 \cdot a \cdot b$ Apopanaca, qui eftoit le fuperintendant des Monafteres des femmes 233. b

Apachitas, fommets de montagnes adorez 216 . \& 217

Arbre d'enorme grandeus I8s.b

l'Arc du ciel auec deux co. leuures, eftoient les armes de l'Ingua Roy du Peru 214. a

Arcades aux baftimens, incogneúes aux Indiens 292.a.b

l'Argent, pourquoy apres l'or eft prifé fur tous les autres meraux $\quad 1 ; 6.6$ l’Argent plus prifé en ces. 


\section{Table}

tains endroits, que non meuuent d'eux-mémes pasl'or

136.6

l'Argent plus commun ordinairement que non pas jor

$136 . b$

l'Argent comment eft affiné par le feu 137 . a. \& comment auec le vif-argent137. b. 154. \& I5. Argent de diuerfes fortes 147. $a$

effay de l'Argent comment fe fait is6. $b$ Ariftote non refuté pas $\mathrm{La}$ ctance, rouchant le lieu dela terre

is. $\mathrm{b}$

Armes des Mexiquains 309.

310

Armee en l'air, prefages d'vne grande ruine 356 . \& 357

Art militaire fort honoré des Mexiquains $309 . b$ Art de recognoiftre les eftoilles, inuenté par les Pheniciens

$34 . a$ chaque Indien fçauoit tous les Arts neceffaires à la vie humaine, fans quil luy fuft befoing de fe feruir d'autruy

296. b

les Aftres, felon quelques Docteurs de l'Eglife, re

1. b

Auantage que les Chreftiés eurent aux Indes pour y planterla foy $247 \cdot \mathrm{a} \cdot \mathrm{b}$ fainct Auguftin doute fi le ciel circuit la terre de toutes parts

2. 2 fainct Auguftin beaucoup plus fubril que Lactance is. b

Aufteritez exercees par les Mexiquains pour conferuer leur pudicité $\quad 238$ cupide Auarice d'vn certain Preftre, penfant tirer de l'or d'vn Volcan 123.a Axi, efpicerie d'Inde $\quad 167$. \& 168

l'Amant trace comme vn chemin en l'eau $35 . \mathrm{a}$ l'A ymant communique vne vertu au fer, de regarder toufiours vers le Nort 35 . a

l'vfage de la pierre d'Aymant aे nauiger, n'eft ancien. $36.2 i$

B

D Al folennel en Mexique où le Roy mefme dan- 


\section{Des matieres.}

çcit. 313.6 Balance terrible où le diable faifoit confeffer les Iappnois. $\quad 355 . \mathrm{a} . \mathrm{b}$ Balaine comment prife par les Indiens, \& auec quelle induftrie. $\quad 1_{4}, a . b$ comme ils la mangent, là mefme.

Barques des Indiens appellees Canoës. 42.6 Bataille fans efpandre fang, faite feulement pour ceremonie à la reddition de Tefcuco.

343.2 Baufme de Paleftine, \& celuy des Indes, fort differents. i Is. Il fert de chrefme és Indes aux Sacremens de Baptefme, Confirmation, \& a autres. $181 . \mathrm{b}$ Le blanc meilleur quele rouge. 182.2 Belle occafion aux Efpagnols d'antubjectir les Indiens par douceur, fis leurs pechez l'euffent permis. $262 . a . b$ Befaar pierre qui fe trouue en l'eftomach de quelques animaux , tres-fouueraine contre le poifon. 205. bo d'où elle naift. 206. b. comme elles s'appliquent, \&quelles font les plus excellen. tes. 207.a furquoy elles fe forment. $\quad 207.6$ Beftail Coigneufement conCerué par les Inguas. 295. b

Beltes fauuages adorees par les Indiens, \& pourquoy. 217.2

Betum dit Coppey en Indien. 108. 2

Biffexte incogneu aux Indiens.

278.2

Bochas \&z Suches poiffons fignallez du lac de Titicaca.

106. $a$

Boncos Religieux du diable és Indes. 235.a. 6 Bourrellet, marque du R $\phi y$ Ingua, comme font icy le fceptre \& la couronne. 24 1.b. \& 289.6

Bois rares \& odoriferans qui naiffent és Indes. 185 . a. $b$

Brancars d'or maffif. $134: 2$ les Brifes \& vents d'abas font deux noms generaux qui comprennent les vents d'vn cofté \& d'autre.

$\mathrm{Bb}$ 8 4. 


\section{Table}

Bruine fort profitable aux Lanes du Peru. 117. a.b

terres incogneuès ; \&

pourquoy 23. a Caufe des inondations du $\mathrm{Nil}$

C

Caufe affeuree de l'Hyuer $\&$ de l'Efté s6.a

Acao, fruit fort eftimé és Indes', \& qui fert de monnoye 171.b

Cacaui, pain fait d'vne racine $162 . b$

Calabaffes ou Citrouiilles d'Inde, \& de leurgrandeur $167 . a \cdot b$

Calculdes Indiens fort ingenieux \& fort prompe $289.2 . b$

Camey, fecond mois des Indiens

$262 . b$

Canards en grande abondance au lac de Titicaca, \& comme on les chaffe 106. a

Cannes de fucre de grand reuenu

$189 . a$

Canopus, eftoille qui fe void au ciel du nouneau monde.

10.2

Cap de Comorni autresfois appellé le Promon. toire de Cori

les Carthaginois deffenditent de nauiger aux

Caufe des tremblemens de terre

124.6

Caymans ou lezards, reffemblans aux Crocodiles dont Pline parle.ro3.a

Cendre iettee en abondance par les Volcans. 122. $a \cdot b$

Ceremonie Mexiquaine de fe tirerdufang en diuers endroits. 343. b. $\& 342 . \mathrm{b}$ \& $352 . b$

Ceremonies des Indiens en la fepulture des morts 221. b \& 222.

Ceremonies qui fe faifoient aux facrifices des hommes

243.244

Chachalmua, premiers \& fuprefmes Preftres, \& des habits dont ils vfoient auxfacrifices 244. a. b Charge des moutons d'Inde combien grande, \& quelles iournees ils font ainfi chargez 204. b Chafquis poftes des In: 


\section{des matieres.}

diens, qui portoient les Chinchilles, petits animaus nouuelles par tout 287 b.de leur eftabliffement. 267

Chaffe des Lyons vifitee entre les Indiens $\quad 192.6$ Chemin des E. pagnols pour aller aux Indes, \& leur retour

$80 . a, b$

Cheuaux beaux \& forts fe trouuent és Indes 191 a Cheueux des Preftres horriblemét longs, \& oinets de refine

$256 . a . b$

Chica, boiffon fort bonne pour le mal de reins 162.3

Chichimequas anciens habitans de la neuue Efpagne, \& de leur vie barbare

$216 . a, b$

Chicocapo:e, fruit reffemblantau cotignac 176 a.b

Chiens dangereux, \& auffi pernicieux que les loups I9I.a.b

Chiens dangereux en l'ine de Cuba, Efpagnolle, \& autres

43.6 Chillé Royaume de mefme temperature que celuy d'ECpagne $\$ 4 . \underline{b}$ dont la peau eft exquife I99.a.b

Chocholate, boiffon des In: diens dont ils font grand eftat

le Ciel eft rond, \&z re tourne furles deux poles $3 . a$. prouué plus par experience que par demonftration. ibid.

le Ciel entoure la terre, felonles Efcritures Ga le Ciel de tous coftez eft en haut

le Ciel n'enloigne pas plus la terre d'vn colté que d'autre

11.a

Cinabre ou vermeillon appellé par les Indiens Ly-

rapi Ifo.b

Coca, fruict qui feruoit de monnoye aux Mexiquains $132 \mathrm{~b}$ Coca, certaine feüille done les Perufiés fe feruoient pourmonnoye $132 . b$ Coca petite fueille dont les Indiens font grand traffic 172. 2. il encourage \& renforce

Cocas, Palmes des Indes, \& de leurs rares pros $\mathrm{Bb}$ ij 


\section{- Table}

prictez. $\quad 177 \cdot b, \& 178$ Cochenille, graine qui croilt en l'arbre de Tunal.

174.6

Cour arraché aux hommes facrifiez, \& d'où vient la ceremonie.

323. a

Colleges de Mexique ordonnez pour apprendre des harangues bien dictes aux ieunes enfans. 284. a

Colomnes d'Hercules limites de l'Empire Romain, \& du monde ancien.

I6. \& 17

Combat du Caymant \& d'vn Tygre.

103. $\mathrm{a}$

Combat d'vn Indien contre vn Caymant. I03.b Combien de contentement apporte la contemplation des œuures de Dieu, au pris de celles du monde.

Combien chaque Samedy s'enregiftroit d'argent d Potrozi, du temps du Gounerneur Pollo. I42.a Pollo.

142.2

Comedies fort frequentes à la Chine. 28 , a les Cometes en l'air 6 meuuent de l'Orient en Occident.

89.2

Comment les hommes onc peu palfer aux Indes. $3 \%$. \& 32.

Comment fe font peupeupler les Indes.

49.2

Comment les Indiens peuuent defigner les noms propres auec leurs characteres. 2\&I. a

Communion imitee par les efclaues de Satan. 249. a b \& $252, b$

Cóparaifon familiere pour prouuer l'effect naturel des pluyes en la Zone Torride.

$6 \mathrm{I} . \mathrm{b}$

Comparaifon du Royaume de Mexique auec celuy du Peru.

288. b

Concile de Lyma rompe le mariage fait entre le frere $\&$ la four, \& pourquoy:

$299 . b$

Concombred'Inde. 66.a.b Confeffion des Indiens. 253. \&254. lingua ne feconfelfoit point.

254 pechez dont fe Confeffolét les Indiens, $\quad 253 . \mathrm{b}$ bain apres la Confeffion de l'Ingua.

254.2 


\section{des matieres.}

confiteor, comment fe peut il n'y a point eu de Crea? efcrire en efcriture de tiondepuis la premiere. Mexique. $284 \mathrm{~b}$

Le Conte des Indiens dont ils fe feruent pour lettres, ne peut aller plus outre que quatre cents ans.

so

le Cotton croift és arbres. 174. \& 175 . il fert pour fai. re de la toille. I75.a Corps mort extremement bien coǹferué. $304 . a$ Couróne de Mexique femblable à celle de la Seigneurie de Venife. 329 a Couronnement des Roys de Mexique fait en grande Colemnité, \& auec effufion d'vne infinité de fang humain. 344. a Courriers des Indes fort viftes, bien que fe fuffent pietons.

287.6 Coya, principalle femme de l'Ingua, de laquelie le fils luy fuccedoit au Royaume, mais apres loncle feulement. $289 . \mathrm{a} . \mathrm{b}$ auant la Creation il n'y auoit ny temps, ny lieu, chofe difficile à l'imagination. IS. 2 40.6

Crimes punis de mort par les Indiens- 298. a Croifee, eftoille notable du nouneau Ciel. I0. a

Cruauté des Indiés en leurs facrifices.

226. $a$

Cruautez execrables en la tuerie des hommes. 244. 245.246.

Cruelle ceremonie d'arrofer les ambaffadeurs de fang, penfant pour cela auoir meilleure refponfe.'

263.2

$\mathrm{Cu}$ grand temple de $\mathrm{Me}$. xique, $\&$ de fes fingularitez. $236 . a . b$

Cugno, certain pain de quelques Indiens fait de racines.

116.2

Cufchargui eft vne chair fechee dont vfent les Indiens.

204.2

Cufco ancienne habitation des Roys de ce pays-là. iIs.b

\section{D}

Dnfes \& recreations publiques neceffaires en toutes Republi: $\mathrm{Bb}$ b iij 


\section{Table}

213.8214
Dantes, animaux fauuages, prefque remblables à des mulets, \& de leurs cuirs

I99. $a$

Deluge allegué par les Indiens, dont il fe void quelque apparence 49. a.b

Dent de Geant d'vne enorme grandeur $319 . \mathrm{b}$

Departement des terres d'Azcapuzalco apres la viatoire obtenuë par If coalt

Defcounerte des Indes Oc. cidentales prophetifee par Seneque

Defcouvertes de nouuel. les terres, faickes plus par tempelte quaurrement

Deffein de lautheur $73 . b$ Deftroit de Magellan defcouuert par vn gentilhomme Portugais, qui portoit le mefme nom $9 \% \cdot 2$

Deftroit du Pole Arctique, quion s'imagine en la Floride, non encorerecogneu

Deftroit de Gibaltar appel. lé anciennement Colom: nes d'Hercules 94.2 habitans d'autour le deftroir de Magellan, quels \& comment veltus. 99. b le Diable ialoux contre Dieu, hayt les hommes d mort 210. \& 211. Idolatrie diuifee en plufieurs chefs

2II a.b

le Diable parloit és Guacas des Indiens $223 . \mathrm{b}$ 229.2

Difference delettres, peinctures, \& characteres 278. b

Difficulté de 'rçauoir d'où font venus les Indiens, à caufe qu'ils n'ont point vfé de lettres

48

Difcours de la defcounerte du Magellan par Sarmiento $\quad 96.8297$

Diuifion du Peru és Lanos, Sierras \& \& Andes II 4 . b

Diuifion du peuple $29 x$. a.b

Diuifion de la ville de Mexique en 4. quartiers, faicte par le commandement de leur Dieus 327.2 


\section{des matieres.}

Diuifions des terres con- Effects naturels procedez queftees par les Inguas de caufes toutes con$294.2 . b$ traires

$59 . \mathrm{a} . \mathrm{b}$

Diuinations exercees par les Elements participent les Indiens, \& comment mefmes du mourement $257 . a .6$

Diuorces pratiquez entre les Mexiquains, \& comment

\section{$257 \cdot a \cdot b \quad 2,23 \cdot b$} du premier mobile. 84. b

Enfans Cacrifiez au Soleil

Diuorces pratiquez entre les Mexiquains, \& comment

les faincts Docteurs non à reprendre pour eftre differents en opinions Philofophiques 2.b Dorado grande terre incogneïe

120.2

le Drach Anglois, de noftre temps a paffé le deftroit de Magellan, \& d'autres de puis luy. $\quad$ gs.\& 96.

\section{E}

l'FAu de mer rafraifpour eftre Cheualiers. 262. 2

Entree des Efpagnols en la neuue Efpagne fut 'an I 18

352.2

Entrée de Cortés en Mexique 365.2 .6 Erreur des Anthropomorphites

Erreurs de l'imagination 14

paffage d'Efaye, expliqué pour l'amplification de 'Puangile 130. \& 135 E ehit,bien qu'elle foit fallee

67.2

Eauës de Guayaquil tresfouueraines pour le mal Napolitain 208. $\mathrm{b}$ Eclipfe de la Lune, preuue certaine de la rondeur du ciel $4.2 \div 308.6$ pour monter hors des mines 146.2 hiftoire d'Efdras apocryphe 48. $a$ les Electeurs du Roy de Mexique eftoient ordinairement - fes parens

$\mathrm{BbD}$ iiij 


\section{Table}

Entection des Roys de Mexique, \& des feftes qui fe faifoient à leur efta. bliffement. 307. \& 308 . Election du premier Roy de Mexique." 328. \& 329 l'Efcriture des Chinois eftoit du haut en bas, \& celle des Mexiquains du bas en haut. $286 . \& 287$ es 'Efcritures faindtes faur fuiure l'efprit qui viuifie, non la lettre qui tuë. $9 . b$

'Efmeraude anciennement plus prifée quauiourd'huy.

$157 . \mathrm{ab}$ rare ioyau d'vn plat d'Efmeraude qu'ils ont à Gennes. is $8 . a$ les Mexiquains fe perçoient les narines, pour $y$ pendre des Efmeraudeş. is $8 . a$

'Elpagnol chaque an, l'vn portant l'autre, tire vn million d'argent de Pottozi.

I 43.2

Erpagnols nays aux Indes appellez Crollos. $176 . \mathrm{b}$ Efpagnols tenus pour Dieux. 43.a262.8263 Efpagnols appellez des
Indiens, Viracochas en fans de Bieu, \& à quelle occalion. zos. $b$

l'Efguille, feul guide du $\mathrm{Na}$. uire.

trois fortes d'Eftoffes faiOtes de laine. 296.2 Eftoilles adorees des Indiens pour diuerfes raifons.

214.a. b

Eftrange difference de deux regions proches, done l'vne faict le Dimanche, quand l'autre fait le Samedy. 120. b \& I2T.a.b

l'Euangile enfeigné aux Indiens lors quils ont efté plus puiffans, comme il fut aux Romains, leur empire eftant à fon plus haut periode. $37 \mathrm{I} . \mathrm{b}$ Euangile accreu à dextre \& feneftre, que fignifie. 372. a

Exercices aufquels on apprenoit la ieuneffe. 3Ir.b

Explication d'vn paffage de faint Paul allegué con. tre la rotondité du ciel. 9. $a$

Explication du Pfalme 


\section{des matieres.}

105. fur le mefme fubject Feu du Ciel qui confomma 9.b

quelques Geans pour leurs pechez 39.a

Fontaine merueilleufe, iettant l'eau chaude, laquelle fe conuertit en rocher $107 . b$

Figuier admirable, dontla moitié porte fruict en vne faifon, \& l'autre partie en l'autre 188.6

Fille du Roy de Culhuacan maffacré par les Indiens, qui fut occafion de guerre 324.325

Fleune de la Magdeleine appellé grande riuiere, entre fort auant dans la mer fans meller fon eau en allcune façon 57.a.b Fleuue des Amazones, \&c fon emboucheure large de foixante $\&$ dix lieües $110 . a$ Fleuues fort grands le moin. dre furpaffant les plus grands de toute l'Europe Iro.a

Fleurs de l'Lurope viennent mieux aux Indes, quicy: mefme

179.2. 74. a Floridiens ont efté fans als.-
nt du cune cognoiffance de l'o Feu d'enfer fort different du noftre

$124 . a \quad 130.6$ 


\section{Table}

le Flux \& reflux n'eft point mouuement local, mais vne alteration \& ferueur des eaux

101.6

diuerfité de Flux \& reflux des mers I0.0.b

Fontaine de betum 108. a

Fontaine de fel en Cufco 108. $b$

Foretts horriblemét efpaiffes és Indes 184 .ab.

Foreft d'orangers és Indes 187 . les cerifes ont peu pro. fité aux Indes, \& pourquoy $187 . a$

Forme de ce qui eft defcouuert en la terre du Peru 127.a.b

François Hernandes, Autheur d'vn rare liure, où toutes les plantes, racines \& liqueurs medicinales des Indes font pourtraites 183

Froidure de la Zone Torride, quirend digne de moquerie l'opinion d'ariftote $63^{\prime} \cdot a$

Fruits d'Europe qui ont tres-bien multiplié és Indes $186 . a$

CEnsarriuez ancienneIment au Peru $\quad 39.2$ Gòmmes \& huilles medicinales, \& odoriferentes, auec leurs noms 182 . b. \& 18 ;

Gonzallez Pizarre vaincu, $\&$ déffaict, où fon auarice luy auoir fait commettre rant de cruautez fur les In. diens

302. $a$

Gouuerneurs des Prouinces comment eftablis par les Inguas 290.6 Guacas, ou fanctuaires fort bien entretenus 295.2 Guaca, adoratoires des Indiens

213.6

Guaneos, \& Occunas, cheures fauuages 44.a Guayac appellé, lignum fanctum II8. a Guayaquil, chefne d'Inde qui eft fort odoriferant $185 . a$

Guayauos fruict d'Inde affés bon 175.6 Guaynacapa, grand \& valeureux Ingua, \& de la vic 304.b. \&305. il fut adoré 


\section{des matieres.}

comme Dieu, eftant enco- Harangue du Roy de Tefres en vie ibid.

Guayras, fourneaux pour affiner

Guerres des Mexiquains le plus fouuent n'eftoient qu'afin de prendre les captifs pour facrifier $243, a, b$. \& $246 . b$

$\mathrm{H}$

TAbit de tefte fort di-

1 uers en diuerfes Prouinces des Indes $29 \%$. a.vn Indien ne pounoit changer l'habit de fa Prouince, encore qu'il f'en allaft viure en vin autre

ibid. Hiftoire de Mexique com-

Harangue des Mexiquains au Roy de Culhuacan, demandäs fon petits fils pour Roy 328.2

Harangue d'vn vieillard faite à Acamapixtli, premier Roy de Mexique 329.2 Harangue d'vn Cheualier Mexiquain, pour retenir le peuple irrité du cruel maffacre de leur Roy 334.6 Harangue d'vn vieillard dexiquain, pour l'eflection d'vn Roy nouueau $335 . \mathrm{b}$ cuco faite à Moteçuma, touchant fon ellection au Royaume Hardieffe merueilleufe des hommes au palfage de Pongo - $\quad$ I06.b Hatuncufqui Aymorey, fixiefme mois des Indiens, refpondant à noftre mois de'May 262. b

Hiftoire des Indiens n'eft pas à mefprifer, \& pourquoy $3 \mathrm{I} 5 . \mathrm{a} . \mathrm{b}$

Hiftoire de Mexique, mife pour fingularité en la Bibliotheque du Vatican 35 r.b pofee

Hommes \& femmes facrifiez à la mort des Inguas, pour les aller feruir en l'autre vie

$220 . a . b$

Hommes faits dieux, puis facrifiez

Hommes facrifiez, en apres mangez par les Preftres 245. a

Humeur des Iuifs du tout contraire à celle des Indiens.

47.6 


\section{Table}

Hypocrifie de Moteçuma femmes

dernier Roy de Mexique Ignorante \& abfurde doisz.a.b Otrine des Philolophes anciens

Imagination vieille $\&$ folle $14 . \mathrm{b}$

Tloufie des Indiens les

Immortalité de l'ame a efté

1 vns contre les autres, pour le renom de la vaillantife

Iardins portez fur l'eau au milieu d'vn lac

Iardins faicts fur l'eau d'vn merueilleux artifice, \& qui fe peuuent mouuoir, - 8 mener où l'on veut 330.2

Idole porté par quatre Preftres pour conduite, lors que les Mexiquains cherchoient vne meilleure ter. re, comme d'autres enfans d'Ifraëel

320.321

Idoles des Roys Inguas reuerees comme eux-mefmes

227

Icuneffe fort foigneufemét inftruite en Mexique 311 。 312

Teufnes des Indiens deuant la fefte d'Yca 238 . b Jeufnes des Indiens fe faifoient fans toucher à leurs creiie par les Indiens 220.2

Indes, que fignifie, \& ce que nous entendons parvn tel mot

Inde Occidentale a efte la plus grande partie gou. uernee par le peuple feulement, \& n'y a eu en tout que deux Royaumes 288 . a.b

les Indes font des terres laides, richement dorees de Dieu, pour eftremaries au fainct Euangile 131.a

Indiens fort peu defireux de l'argent

les Indiens ont vefcu en trouppes, fans Republique, comine font ceux de la Floride, du Brefil \& autres so.b

Indiens fort braues nageurs 105.2

les Indiens en toutes feftes 


\section{des matieres?}

portent des bouquets Ingua, pour auoir occa 179. b

les Indiens n'ont point eu de mor propre pour dire Dieu $212 . b$ les Indiens font de plus gräd entendement quon ne les eftime

275.2

Inguas Rois du Peru, adorezapres leur mort $219 . \mathrm{b}$ les Inguas eftoient merueilleufement refpectez du peuple, \& pourquoy 298.2

le regne des Inguas a duré plus de trois cents ans 300.6

les Inguas efpoufoient leurs fours 289. a. ils $\mathrm{n}$ heritoient point des meubles de leurs predeceffeurs, mais faifoient vn mefnage nouueau ibid.b. \& 30 r b. 302.2

Inondation du Nil, chofe naturelle, quoy qu'elle femble contre la nature 55. a

Integrité des femmes fort honoree des Mexiquains 260. 2

Inuentions grandement fuperftitieufes de Yupangui fion d'ofter le Royaume à fon pere, \& à fon frere 303. a.b

Ioncs appellez Totora par les Indiens

85.6

Iouier le foleil auparauant quil naiffe, Prouerbe, \& d'où il eft veniu \& 230

229.

Iours \& nuicts tous efgaux toure l'annee fous l'Equinoxe

Iours d'Efté fort courts au Peru

cinq Iours de l'annee fuperflus, aufquels les Indiens ne faifoient rien $275 . \mathrm{b}$

Ine de Sumatre; celebree foubs le nom de Taprobane

23.2

Ifle Atlantique de Platon, où elle fe peút prendre 25. a

Ine Atlantique de Platon, n'eft qu'vne pure fable, quoy quil femble l'auoir defcrite comme veritable $45 . b$

Ine de fafcines faide aué vn grand \& exceftit tra. uail, pour patler vnear- 


\section{Table}

meefurmer 350.2 .6 meux ont erré

274

Ines fortunees, pour quel- Liberalitez d'Autzol, hui. le caufe appellees Cana- etiefme Roy de Mexique ries

$23 . b=35 . b$

Iuftice par qui exercee en Liures des Indiens commét Mexique 309.2 peuuenteftrefaits fansletIuftice fort exacte de Mote- tres 280.6 çuma dernier Roy de Me- Lyons du Peru fort diffemxique

356.2

$\mathbf{L}$

TAc tres-chaud au milieu d'vne terre froide 106.b

Lac de Mexique ayant de deuxfortes d'eau 107.a reuenu du lac de Mexique $107 . a$

grands lacs au hautdes montagnes, \& d'otì ils naiffent 106.a.b

La ctance fe rit \& fe mocque de l'opinion des Peripateticiens, touchant le ciel 2. a

Lactance refuté, touchant les Antipodes

14. I. 5 . Langue Mandarine elt l'er. criture des Indiens, qui n'eft que par characteres 280.6

les Legiflateurs les plus fa: blables à ceux d'Afrique $43 . \mathrm{b}$

Lyons gris \& fans crinsibid.

Agie vaine contreles 1 Chreftiens 363 . 2.b. 364

Maifon admirable remplie de toutes fortes d'animaux comme vne autre arche de Noé 308.2

Malaca autresfois appellé le doréCherfonefe 23.2 Mamacomas eftoient les anciennes, \& comme meres des filles renfermees $233 \mathrm{~b}$

Mameys, fruict reflemblant aux pefches 175 . a. à quoy il fert ibid. Monati, monftrueux poiffon qui paift aux champs 102. 2. il reffemble fors 
des matieres.

\$achair lors que l'on en ciens

mange $\quad$ 102. $\mathrm{b}$ le Matin plus agreable en Mandarins, officiers Indiens auecques combien de difficulté fe peuuent rendre capables de tels eftats 280.2

Mangocapa premier Ingua, $\&$ ce qu'ils feignent de luy 49.5. $301 . b$

Manguez, arbre degrandes merueilles $173 . \mathrm{a}$. combien de chofes il fournit, \& quelles

$133 . b$

Mariage illicite des Inguas auecques leurs fæurs 299.

Mariages des Indiens, \& en quelle façon ils fe cele. broient

260. 2

Mariages entre les Indiens deffendus tant feulement au premier degré $\quad 298$. b

Europe, 8 le plus fafcheux au Peru

Matines de minuiat practiquees par les miniftres du diable

232. 233

Mays, bled d'Inde 160 . a. b. comment ils le mangent 16 x. a. comment ils fien fer. uent à faire leur boiffon Í́. b

le Mays \& le beftail feruent de mille chofes aux Indes 162. a

Mechoacanes ennemis des Mexiquains, \& pourquoy 322. a

Medecins fort experts auttrefois és Indes 183.2

la Mer aux anciens, tenuë pour non nauigable outre le deftroit de Gibaltar Í.b

Marque certaine \& affeuree pour difcerner ce qui a efté porté aux Indes depuis qu'elles font defcou. uertes, \& dont il n'y en auoit point auparauant 129.2

Marques \& fignes de quelques nauigations des an-

le mal que l'òn endure fur Mer', d'ul caufé $90 . a$ Mer Oscearie Princeffe des eaux' 94. a Mers chaudes, \& d'autres froides deux grandes Mers, pioches defepilieiies $94 . b$. prefomptueux deffeings 


\section{Table}

deles faire joindre enfem - vnlac

107.2 ble

diuerfité de Mers

ibid. Miel d'Inde fort afpre, \&z

la Mer iamais ne fenloigne les Mineraux imitent les delaterre deplus demille plantes en leur façon de lieiies

12.2

Mefnage des Indiens pour la drapperie

203.204

Metal pauure, \& metal riche, quels

137. b

le Metal plus il eft proche de la fuperficie de la terre, plus il eft riche, \& plus profond il eft au contraire

I $45 . \mathrm{a}$

les Metaux pourquoy font creez

I29.b

les Metaux ne fe trouuent qu'en terres Pteriles, \& pourquoy

131. 132

l'eau empefche fort la traiete des Metaux, \& pourquoy

142.6

Meuriers plantez par les Efpagnols en la neuue ECpagne, ont merueilleufement profité pour les vers à foye \$88. b

Mexi, chef des peuples qui vindrent peupler la Mexique, duquel ils ont tiré leur nom

231. b

Mexique, ville fondee fur

croiftre 128. a.b

Mines efgarees, \& d'autres fixes

137.2

richeffe de quelques, $\mathrm{Mi}$ nes anciennes, qui n'approche pas neantmoins $\grave{2}$ celle de Potofi I4I. \& 142

trauail trop excéflif des $\mathrm{Mi}$ nes

145.146

Mines de vif-argent en EC. pagne 150.6

Moquerie plaifante des $\mathrm{Me}$ xiquains contre les Tlatelulcos, apres les auoir vairi. cus

349.6

Moine de Mexique, de leur veftement, office, \& difcipline ibid. Mois des Indiens de vinge iours

275.6

Molins à moudre les metaux

155.6

Monde noureau, felon les anciens, inhabirable r. 2. imaginé d'eux, comme vne maifon couuerte du ciel. ibid. $b$ gran: 


\section{des matieres.}

grande partie du Monde encor aे defcouurir

13. 2 .

Monnoye, mefure de toútes choles

130. a

la Mort eftoir la punition des filles referrees qui failloient

$134 . \& 135$

Mort volontaire de plufieurs Indiens pour aller feruir leurs Roysen l'au-

- tre monde

Mort de Chimalpopoca; ieune Roy de Mexique tué traiftreufement par les Tapanecas

a. $b$

Mort de Moteçuma dernier Roy de Mexique 367. a. $b$

Moutons au Peru feruans d'afnes à porter des charges

Moutons d'Indes profitables fur tous autres animaux 203: a.b

trouppes de Moutons chargez de diuerfes marchandifes ainfi que des mulets 204. 2

Moyenne regió de l'air plus froide, \& pourquoy 68.2
N

$\mathrm{N}_{\text {Arine percee a in Me- }}$

1 xiquain, pour y pendre vne Efmcraude 347. a.352.b

La Nature inferieure fert toufrours d'entretien à la fuperieure 228. $b$

Nauatalcas, peuples qui po. licerent la neuue Efpagne

Nauire appellé Viotoire, fit tout le tour de la terre

3. $b$

Nauigatió auiourd'huy fort facile

Nauigation de Salomon, quelle peut eftre $37 \cdot \mathrm{a} . \mathrm{b}$ Nauires Efpagnols tenus des Indiens pour rochers à la premiere veuë

43. $a$

Neuue Efpagne quelle $117 . b$

le Nitre refroidit l'eaus 67.2

Nobleffe Mexiquaine máts facree en vn bal par les Efpagnols 366 Noix des Indes fort mal plaifantes, font appellees par les Indiens, empoiConnees

177:2. 


\section{Table}

Nort, vent fee \& froid 4. $b$

Noftre Dame, fecours des Efpagnols pourfuiuis des Indiens

Nordefter, que fignifie, \& Nortoelter

Nouneau monde prefque tout fitué fur la Zone Torride.

g1.a

au Nouueau monde ne s'eft point defcouuert de mer Mediterannee

\section{2}

Nuicts d'Efté fort fraifches zu Peru, au refpect de celles del'Europe 70.6

Nuict de fix mois en la region Pollaque 18.b 1. Nuict comment caufee 4.2

0

Bieotion contre Arifote fans folution 68.b

Occafion de guerre entre les Tapenecas \& Mexiquains

roccean aux Indes eft diuifé en la mer du Nort, \& la mer du Sud

131.2 Oignement dont vfoient les Indiens pour fe ren? dre capables de parler aus diable 257.2. ce mefme oignement armoit de cruauté les Preftres, \& leur faifoit perdre toute crainte ibid. Onction de Vitzilouitli fecond Roy de Mexique. $33 \mathrm{~s} \cdot \mathrm{b}$

Onguent fait de petites beftes, dont les Preftres In. diens eftoient oincts 257.2

Ophir eft en l'Inde Orienta: le

Opinion d'aucuns que le Paradis terreftre eft fous l'Equinoxe, non fans raifon 69.a.b.\& 7r.a.b l'Or fe trouue en trois $f_{2}$. çons, en paille, en pepins, \& en pierre $134 . \&$ 135

l'Or de Carauanale plus ce: lebre du Peru.

135.2 l'Or \& l'argent eftimé par. tout le monde 130.2 l'Or \& l'argent ne feruoie aux Indiens que d'orne: ment 132.6 les Indiens point d'autre monnoye que 


\section{des matieres.}

dor \& d'argent 133.a images de plume d'Oyfeau YOr pourquioy prifé fur faits d'vn artifice admitousles metaux $\quad 133 . \mathrm{b}$ rOr \& l'argent en nature combien de degrez au deffous de l'homme 128 b. \& $129 . a$

comme on raffine l'Or en poudre

d'Orient au Ponent fur mer, on a roufiours le vent en pouppe, du Po. nent à l'Orient au contraire, \& pourquoy 86 2. b

Ordres differents des Preftres de Mexique, \& de leur office ordinaire 232 : 2.6

Ordre de la Cheualerie Mexiquaine, \& des marques qu'ils auoient 310

les Oyfeaux endurent facilement de demeurer dans l'eau, \& pourquoy 193.b

Oyfeaux merueilleufement petits, \& d'autres merueilleufement grands. 196. a

Oyfeaux extremement bien variez en couleurs 196.6

196.8 197

Oyfeaux laids à merueille, mais fort profitables pourleur fiente 197.6 \& $198 . a$

Oyfueté chaffee, comme fort dangereufe par les Inguas, pour contenis plus facilement le peuple

290.6

\section{P}

P Achacamac,grand San: 212.b

Pajos, animaux opiniaftres \& comme on les gou: uerne

Pain de mays que les Pre: fres donnoient folem:nellement aux eftrangers, image de la Communion

Palais diuers de recreation \& d'affliction $359 . \mathrm{b}$ Palliflade horrible toute de tefte de morts 23 r.a Papas, racines dont quelques Indiens font de certain pain qu'ils appellent Cugno 116.2 GeE ij 


\section{Table}

Papas efpece de pain 163.6 164.2

Papas en Mexique eftoient les fouuerains Preftes des Idoles

$230 . \mathrm{b}$ $232 . b$

Paragucy, fleuue de l'Amerique, inonde comme le Nil

Paraguey, fleuue grand à merueille

$57 . a$

Pallage de Pariacaca fort dangereux pour le mal que le vent y fait endu- rệr 90.91

Pariacaca,vn des plus hauts endroits de la terre 92. a

Paroles d'vn homme qui a auoit defiale cour arraché

248. 2

Pafte de mays, appellé par les Indiens, chair de leur Dieu Vitzilipuztli 25 r. b. cefte pafte deuoit eftre mangee au point du iour, \& eftoit deffendu de ne manger rien autre iufques apres midy

$252 . a$

Pafturages communs és Indes, qui rendent toutes chairs 2 bon marché,

189.6

Palaas, fruit delicat \& bon à l'eftomach 176.2

Peinture, liure des idiots $279 . a$

Penitences enioinctes par les Confeffeurs Indiens $254 . a b$

les Perdrix ne fe voyét point au Peru 44. $a$ vn Pere perdant fes enfans, eftoit tenu pour grand pecheur $\quad 254.2$ il tuoit fes enfans pour fe fauuer la vie ibid.

Pericoligero, animal fort pefant 199.b

la Perle anciennement plus prifee qu'auiourd'huy isg a.b. combien l'abondance rend les chofes viles

Is7.b

les Perles s'engendrent dans les huifties

is 9.2 diuerfes fortes de Ferles I59.a

Perroquets qui vont par bande 44.2 Perroquets volants par bädes comme pigeons, 193. b

Peru abondant en vin 117.6 Peru abondant en mines 


\section{des matieres.}

d'or 2 d'argent plusque "grandeur, \& delartifice toute autre terre des In - _ des Indiens à les ioindre des

I3I.a en leurs baftimens, fans

Peru, quelle partie du monde ceeft

II 4.2

le Peru, noin deriué d'vn fleuue du pays, non pas d'Ophir, comme quelques vns eftiment 26 Perufiens fort foigneux d'ëtretenir \& confeeuer leur hiftoire par traditió, fans lettres, ny characteres $285 . a$

ciment

a.b

292.

Pourquoy auiourd huy les Pilotes font affis fur la pouppe, \& non pasfus la proiie comme anciennement

34.6

Pines, ou pommes de pin d'Inde 165.8166 Pinchao, idole du Soleil, : de l'artifice dont il eftair le trauail exceffff qu'il y ad pefcher les perles "I59. b. \& 160.2

Plaifante façon de pelcher des Indiens $104 \cdot \mathrm{b}$

Pierres fuperftitieufement offertes aux palfages, pour auoir beau chemin $217 \cdot 3$

Pierre qui fe taille $\&$ couppe comme bois 108.2 Pierres my-or, \& my-pierres

$134 . b$

Pierres fignificatiuas, auec lefquelles les Indiens ap. prennent quelque chofe par cœur

\section{- 286.2 - 521 .}

Pierres d'vne merueilleufe pofé 229.6

Plaifan traict d'vn Portugais, parlequel il s'exempta d'eftre facrifié 220 . b

le Plane produit fruit toute l'annee $170 . b$ reffemblance \& diffemblan. ce des Planes des Indes, aux Planes anciens 169 . a.b

les Planetes ne fe meutrent d'elux-mefmes en va corps corruptible :... 4. \& 5

Pourquoy nos plantes prof fitent mieux aux Indes, que celles de delà en Enrope $16 j \cdot a$ C CC iij 


\section{Table}

Plebeiens exclus du feruice du Roy, \& de tout office parMoteçuma 354. a. b ils n'ofoient regarder le Roy en face fur peine

de mort $355 . b$
Pline meart en vne trop carieufe recherche 123.6 Pluyes, caufees par la chaleur en la Torride ss.b il ne Pleut, neige, tonne, ny ne grefle iamais au Peru.

Plufieurs chofes rares en nature, cogneües plus parhazard que par induAtrie

Pons volans

le Pole du Sud n'eft marqué d aucune eftoille fixe I. $b$

Poles Arotique, \& AntarEtique. 3. a. ceftuy-cy reuoqué en doute par $S$. Auguftin eod. aux deux Poles il y a terre \& mer $13 . b$ Pongo, paffage des plus dágereux du monde fur le Aleuve des Amazones rog.b

Pont de paille fort affeu- ré pour paffer vn courane d'eau rapide' $\quad 58.2$ Portugais fort experts en l'art de nauiger $10 . \mathrm{b}$ Pottozi, montagne celebre pour fes riches mines $1_{3} \&$ comment fes mines furent defcouuertes $\&$ enregiftrees 140.8 I $_{4 I}$ Poulles trounees aux Indesà la defcouuerte, lefquelles ils appelloient Gualpa , \& leurs œufs Ponto

Prefages menaçans la ruine des Eftats, ne font point à mefprifer comme chofes vaines

a.b

357

Preftres comme aumofniers pres de chaque Seigneur Indien

222.2 -

comment les Preftres des idoles confultoient leurs Dieux

229.2

Pretexte des Inguas pour aggrandir leur feigneu. rie, fut leur Religion, qu'ils difoient la meilleure

$30 \pi .2$

Principes des vents infiniment cachez aux hommes 7.6. $\mathrm{b}$ 


\section{des matieres:}

Proceffions des Indiens. 250.6

Proceffion penitencielle, faicte pour obtenit pardondespechez 267.a.b Prodiges horribles, \& en grand nombre, arriuez deuant la ruine de Mecque

$359 . \& 360$ profits qui fe peuuent tirer de la lecture de ces exe. crables fuperftitions Indiennes

273.a. b Proprieté plus rare de l'Aimant ignoree des Anciens prouince proche de Mexique, laiffee fans conquefter, pour exercer touf. iours la ieuneffe a la guerre, \& pour auoir auffi où prendre des captifs pour facrifier 345.b prolomee \& Auicenne ont renu la Torride fort habitable

64.2

Punas, defert du peru, où lair tuë les hommes, \&z les animaux mefme $93 . \mathrm{b}$ pyramide de feu apparuẹ aut ciell l'efpace d'vn an, deuant la ruine de l'Empire Mexiquain 359.2
Valitez, fymboles, \& diffymboles improuuees $68 . b$

Quantité d'or qui vient tous les ans des Indes en EFpagne $135.8 \times 1 ; 6$ Quatre principales veines à pottozi, \& leur profon. dité 144.b

Querzaalcoalt, Diea des marchands, \&z où il eftoir adoré $225 . b$

Quippos, rameaux feruans conime de regiftres pour memoire de ce qui fe paffoirau Peru 285. a.b. $\mathrm{R}$

diuerfes $D$ Acines fort és Indes profitables Racines adorees par les In: diens

217.2

noftre Raifon ignorante mefme és chofes naturelles

37.2

Rayme, premier mois des Indiens, \& fe rapporte au mois de Decembre 262. 2

Regions fort delicieufes des Indes

Ccc iiij 


\section{Táble}

Regions fous l'Equinoxe Roches efleuces au milieus fort remperees $\quad 63 . b$

la Religion feruoit aux In. diens de pretexte pour fairela guerre 50. a

Remede contre le changement que caufe le vent en Pariacaca.

91. b

Rencontre de deux riuieres honorees des Indiens, pár vn particulier rếpect

$24 \mathrm{r} . \mathrm{a} \cdot \mathrm{b}$

Richeffe de quelques Ifles de la neuue Efpagne 118

Richeffe incroyable des Perufiens lors quils furent prins par les Efpagnols

$R$ is fort commun és Indes

$164 . a$

Riuiere des Amazones, nommee diuerfement 57. b. dicte Monarque des fleunes ibid. Fleuues admirables en la Vorride $57 \cdot a \cdot b$ Riuiere des A mazones, diEte Maragnon I06.a Riuieres, collines, grandes pierres, \& fommets de montagnes adorez par les Indiens $226 . b$

de la mer, fans qu'on y puiffe trouner fond autour

Rofes comment venuës és Indes

Rotondité du ciel incogneiie aे quelques Docteurs del'Eglife 1. \& 2. de mefmele mouuement ibịd.

Robiie des Indiens où eftoiét marquees les annees 276 a. leur opinion que le monde deuoit finir à la fin de cefte Roüe $276 . b$ Royauté outrageufement par vn Mexiquain, qui aima mieux fe precipiter cruellement à la mort $345 . \mathrm{a}$

Roys des Indiens, tenus pour femblances des Dieux. $332 . \mathrm{b}$ Ruine efmerueillable d'vr gros bourg plein d'enchanteurs 126.6

\section{$S$}

Acrifices des hommes $\int$ comment fe faifoient 23r.b.343. \& 244 Sacrifices diuers que fai- 


\section{des matieres.}

foient les Indiens pour di - Soing incroyable des Mexiuerfes occafions 239.240. \& $24 \mathrm{I}$

Sacrifices fort couftumiers aux Indiens en leurs neceffitez

$305 . a . b$

Sageffe de ce fiecle foible és chofes diuines, \& mefme és humaines

20

Sainos, eftranges animaux de chaffe, \& comme on les peut tuer

I98. a.b

Salce pareille, herbe falutai. taire pour le mal de $\mathrm{Na}$ ples

108.b

Sang humain beu par l'efclaue qui deuoit eftre facrifié

272.a

Sciences cogneiies des Chi nois

282.2

la Sechereffe ne fuir pas la proximité du foleil $\$ 3.2$ faincte Croix de la Sierre, Prouince de.Charcas, \& comment conuertie à la foy $369 . \mathrm{a} . \mathrm{b}$

Singeries du diable à l'imitation de Iefus-Chrift 228 . a. b

Soccobones dextrement inuentees pour tirer le metail plus facilement 145 . a.b quains a faire apprendre d leurs enfans leurs idolatres ceremonies 309.a.b Solanus, vent de Leuár 79.a le Soleil plusil eft proche de nous, plus il efchauffe, \&z brufle $51 . b$ contraires effects du Soleil en la Zone Torride, \& aux terres hors les Tropiques S4.a.b

la grande force du Soleil caufe l'humidité fous l'Equinoxe

59.2 Soleil adoré fort comimune. ment par les Indiens 213.6 Sorciere, føur de lidole qui fonda la ville de Malinal$c o$, où n'y a rien que des forciers 322.6 effects admirables d'vn Sorcier

$35 \mathrm{I}, 2$

Sorciers en grand nombre, \&r del'empefchemét qu'ils ont dóné à l'amplification del'Euangile

259. a Source du Nil recherchee parCefar 19.a Source comme bleüe, autre rouge commefang 109 Sources, chaude \& froide l'vne contre l'autre, aus 


\section{Table}

bairfgs de l'Ingúa 108.b pour vne mefme Prouing Suject du quatriefme liure 129.2

Succhilles, bouquets des In. diens 379.a. ils en font fort amateurs, \& en offrent par honneur aux grands, \& a leurs hoftes

Superfitions faites à la conduite d'vne eau au trauers de Mexique

351.2 .6

\section{$T$}

TAbaco, arbriffeau qui 1 porte vn contre-poifon

$183 . \mathrm{b}$

Taches noires en la voyela. ctee ducofté du Sud ro. \& II

Tharfis enquelques endroits fignifie la pierre Chryfolite, ou Iacinthe, autresfois la mer qui eft de cefte couleur à la reuerberation du foleil

s. b

Tharfis de P'Efcriture n'elt pas Tharfo ville de Cilicie 28. a

Tharfis \& Ophir, mots generaux en la fainete Efcriture

$27 \cdot b$

Tharfis \& Ophir entendus

ce en la faincte Efcriture 27. $a$

Tlafcaltecas, fixiefme generation des Mauatalcas, \& fut celle qui donna entree aux Efpagnols 318.b.com : ment ils vainquirent les geans de la Sierre 3 I9.a Tlacaellec, le plus vaillant Capitaine qu'ayent eules Mexiquains, \& de fa belle refolution 337.338 . fa va leur, \& fa rufe guerriere contre les Cuyocans 340. a. $b$

déffy de Tlacaellec faiot au Roy d'Afcapuzalco $337 . \mathrm{b}$ fa fubtilité pour remarquer le nombre de prifon. niers qu'il auoit pris $34 \mathrm{I} .2$ fa conquefte d'vne ville, auec des enfansfeulement 342. a. b. comme il refufa la coronne $346 . \mathrm{a} . \mathrm{b}$ Tembos, felon l'opinion des Indiens, race la plus ancienne des hommes. 49. $b$

Traffic le plus commun des Indiens n'eftoit qu'erchange fans argent toutefois 132.b 


\section{des matieres.}

Tauaco, herbequi endortla Inles fort elloignees de la chair

Temperature toute contraire en moins de cinquante lieiies

IIs.a

Temple de Cufco femblable au Pantheon de Rome

$229 . \mathrm{b}$

lieux maritimes plus fubjets aux Tremblemés, \& pourquoy

126.2

Tremblemens de terre fort eftranges

I25. a.b

1a Terre, comment foultenue

6.6

Ia Terre du Pole Antarctique n'eft pas toute couuerte d'eaux

II. $b$

la Terre en fa longitude eft toufiours de femblable téperature, mais en fa latitude non

18.a

Terre d'excellente temperature encore à defcouurir 20. b

12 Terre auec l'eau fait vn globe

$63 . b$ le continent des Terres fe joint en quelque endroit, ou pour le moins fauoifine de fort pres

Terres encores 1 defcouurir 42. 2

Terre ferme ne font point habitees 42.b Terres du Prefte-Ian fort chaudes

66.b

Terres encores incogneiies I19.a.b

Tezcallipuca, dieu des iubilés de Mexique, \& de fes ornemens

$224 . b$

Tiburon, poiffon merueilleufement gourmád $102 . b$ Titicaca, lac d'efmerueillablegrandeur 88.a.b

Trinité imitee par le diable, \& adoree par les Indiens en trois ftatuës du foleil $262 . \mathrm{b}$

la Torride peuplee, \& d'agreable demeure, contre l'opinion des Philofophes S2. $b$

la Torride pourquioy temperee 64 . a b.66. a. b. 69.a en la Torride on nauige $f_{2}$ cilement d'Orient en.Occident, non au contraire, \& pourquoy 81.82 quen la Torride mefme la proximité du foleil ne catfe pas toufiours tant d'humiditez

62.a.b

12 Torride fort habitee $20, a$ 


\section{Table}

quelques endroits de la Tor. ride extremement fecs, encores que le refte foir fort hamide

$6 r .2$ qui a meu les anciens de croire la Torride inhabitable

la Torride eft plunieufe lors que le foleil en eft plus proche

Trois fortes d'animaux qui fe trouuent és Indes 189.6 Troisfortes de terres és Indesiu.b. leursqualitez 112. a

Tozi, principale deeffe des Mexiquains

$226 . a$

Trois chofes ordinairement meflees en toutes les ceremonies des Indiens 260. 26 I

Trois genres de gouuernemens recogneuz és Indes 299.300

Tunal, arbre d'eftrange forme.174. a. de combien de forte ilyena ibid.

Tygres au Peru plus cruels enuers les Indiens que les Efpagnols 43. b Tygres peuuent paffer fept, $\&$ huia lieiies de mer à nage 44.6
Tygres furieux contre les Indiens, \& non contre les Efpagnols

192.b

\section{V}

T Aches rechercheesfeut? $V$ lement pour le cuir 43.6

Vaches domeftiques \& fauuages I90. a. b. de ces $\mathrm{Va}$ ches fauuages fe tire vn grand renenu en cirirs 190. b

trouppeaux de Vaches fans maiftre és Inles de Cuba, Iamaïque \& autrés 43.6

Valeurs des Indiens $372 . \mathrm{b}$ Vallees plus chaudes que les montagnes, \& pourquoy 67.6

Vallees, meilleures habitations du Peru - IIs.b Varieté de temperature des - terres Equinoxiales 66.b Venis d'abas contraires aux versà foye $\quad 89.2$ Vent dangereux qui tuë, \& conferue les corps fans corruption 93. a.b le Vent du Ponent ne fouffle point en la Torride 79.2 


\section{des matieres.}

Vents appellez brifes en la Victoiredes Mexiquains fur Torride, viennent d'Orient

79.a les Tapanecas

339.2

Vicugnes, efpece de mouquatre Vents principaux $82 . b$

huiat Vents en huiat points notables du ciel, \& leurs noms

83.2 le Vif-argent fuyt les autres

les Vents de terre en la Torride foufflent pluftoft de nuict que de iour, \& ceux - de mer au contraire, \& pourquoy 88.a.b le Vent corrompt mefmele fer

89.90 proprieté d'vn Vent, lequel foufflant fait pleuuoir des pulces

le Vent du Sud rend la colte du Peru habitable

214 vn mefine Vent f'acquiert diuerfes proprietez, felon le lieu où il court $75 . a$ diuers Vents en la terre de la Torride 88. a trente deux Vents pofez par lespilotes

82. a.b. trois principales caufes dela difference $\&$ diuerfes proprietez des Vents 77.2 eftranges diuerfitez de temperature caufees par les Vents tons fauuages 201 .vertu de leur laine 202.a. la chair eft fort founeraine pour le mal des yeux ibid. metaux, hormis lor \& l'argent 149.6 le Vif-argent fe tourne en fumee, puis la fumee fe tourne en vif-argent iso.a le Vif-argent \& le vermillon naifent en vne melme pierse

le Vif-argent vray metal, 8: plus pefant que tous autres

148

proprieté merueilleufe du Vif-argent à fe joindre au. tourdel'or $\quad$ i 48.6 combien l'Épagnol tire des mines du Vif argent Is2.a Vignes fans fruict en la neuue Efpagne $117 . \mathrm{b}$ Vignes du Peru \& de Chillé portent tresbon vin $187 . \mathrm{b}$ Vignes de la vallee d'Yca, qui viennént fans eftreiamais arrofees d'aucune pluye, \& comment il re peut faire

283.a 


\section{Table des matieres.}

Vignes qui portent fruict tous les muis de lannee 188. b

pourquøy on ne faict point de Vin du raifin qui croift en la neuue Efpagne 187.6 Viracocha, nom que les Indiens dónoient au dieu fuprême,auec d'autres excellens \& fignificatifs d'vn grand pounoir

212.a

vitzilipuztli, principalidole de Mexiques, \& de tous fes ornemens 124.6

Viures pofez au tombeau des morts pour les nourrir apres la mort 221.2

Voix entéduë, prefageant la ruine de Moteçuma 3 ;8.b

Voracité desTiburons102.b

Volcan de Guatimala plus admirable que tout autre 122. $\mathrm{b}$

matiere qui entretient les Volcans

$124 \cdot a \cdot b$

Voyage d'Hannon Carthaginois, admirable en fon temps

22.6

Voye lactee, appellee chemin fainct Iacques

Vros, peuples brutaux qui ne feftiment pashommes 58.6.

Vtilité de toute hiftoire na: turelle

$$
\mathrm{x}
$$

$\chi^{A m a b i o i s, ~ p e l e r i n s ~ c o n . ~}$ 1 traincts de dire leurs pechez fur vne roche $254^{\circ}$ 255

\section{$Y$}

V Ca \& Árica, \& leur fa: 1 çon de nauiger en des cuirs

Ytu, grande fefte des In: diens, quils faifoient en neceffité, \& des preparatifs à icelle

Yupangui Ingua a efté en Mexique comme vn autre Numa à Rome, pour l'eftabliffement des loix 249. 261

\section{Z}

7 Ephyre, vent doux \& 2 fain

Zone Torride aux anciens inhabitable, \& les raifons pourquoy - 17.6

la Zone Torride en des endroits temperee, en d'autres froide, \& en d'autres chaude

63,6 


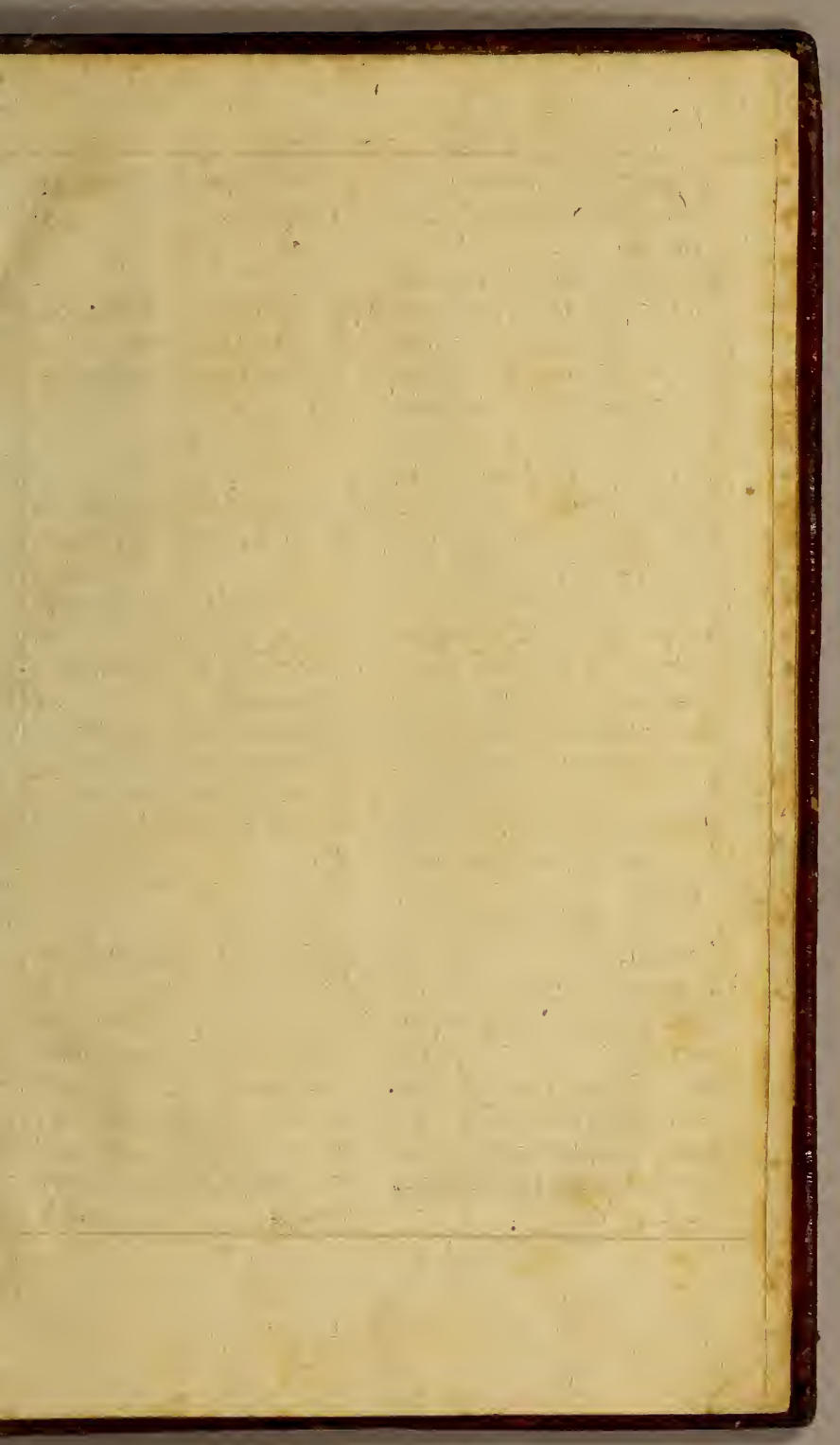




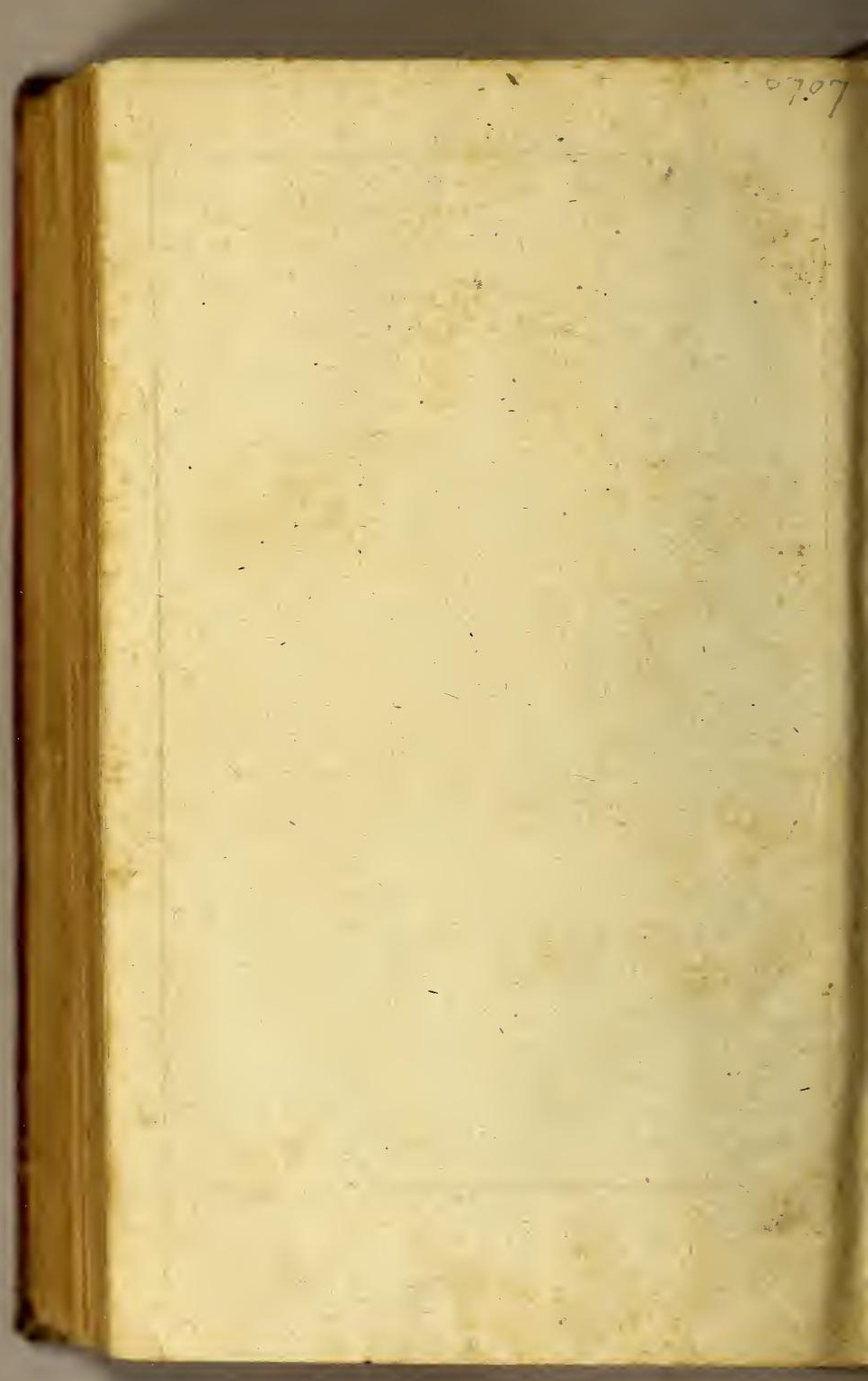




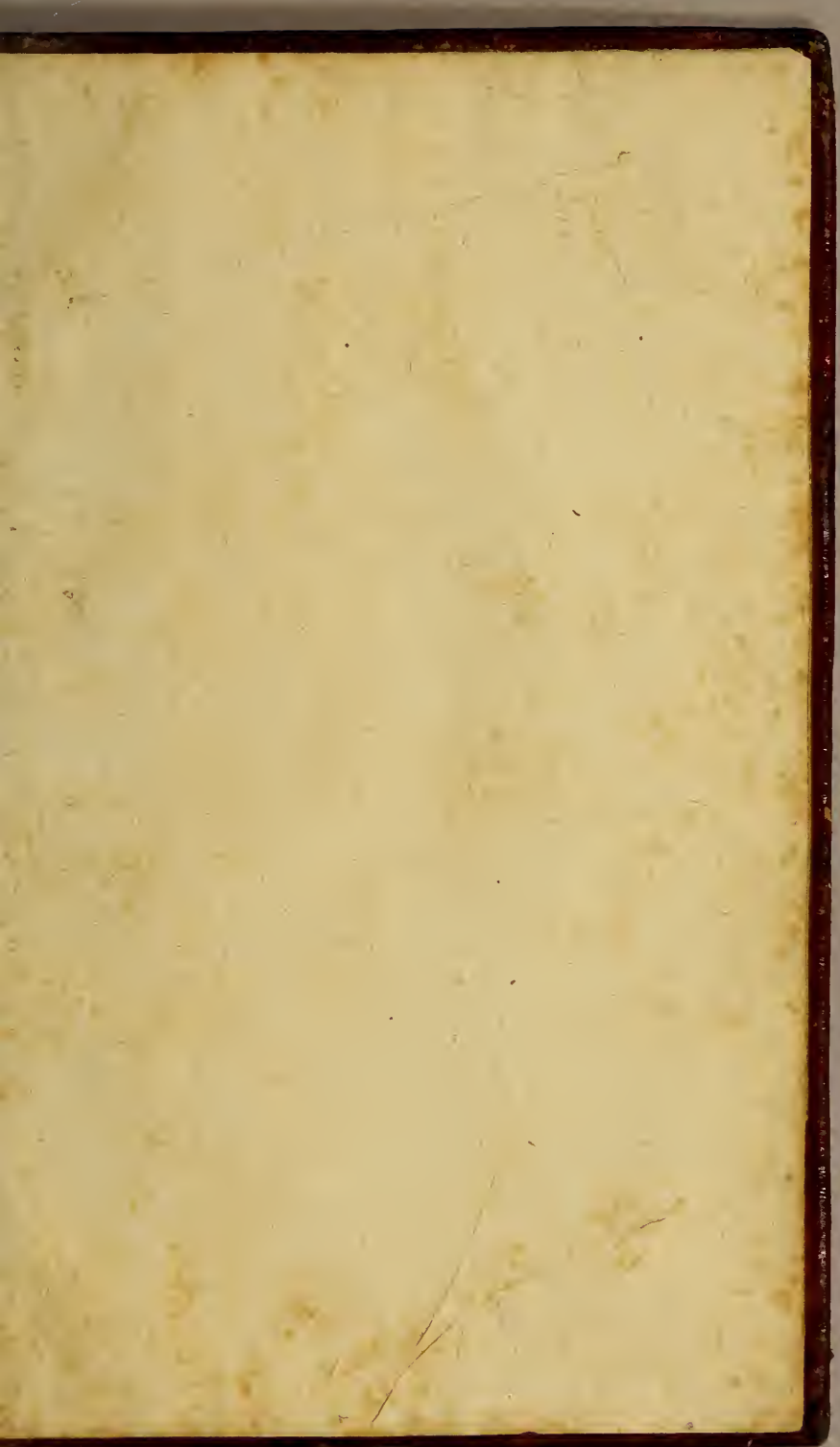




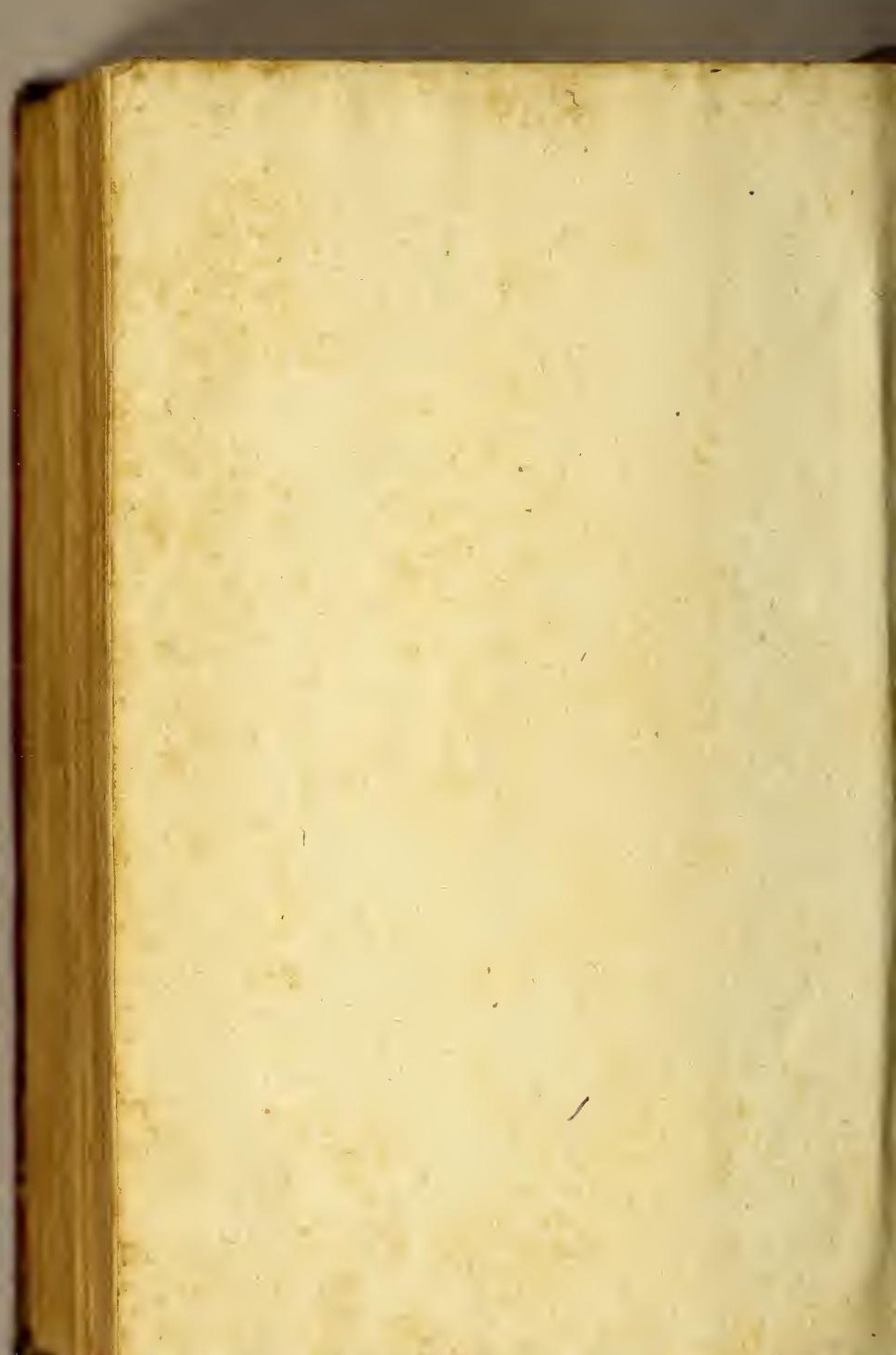




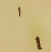

. 


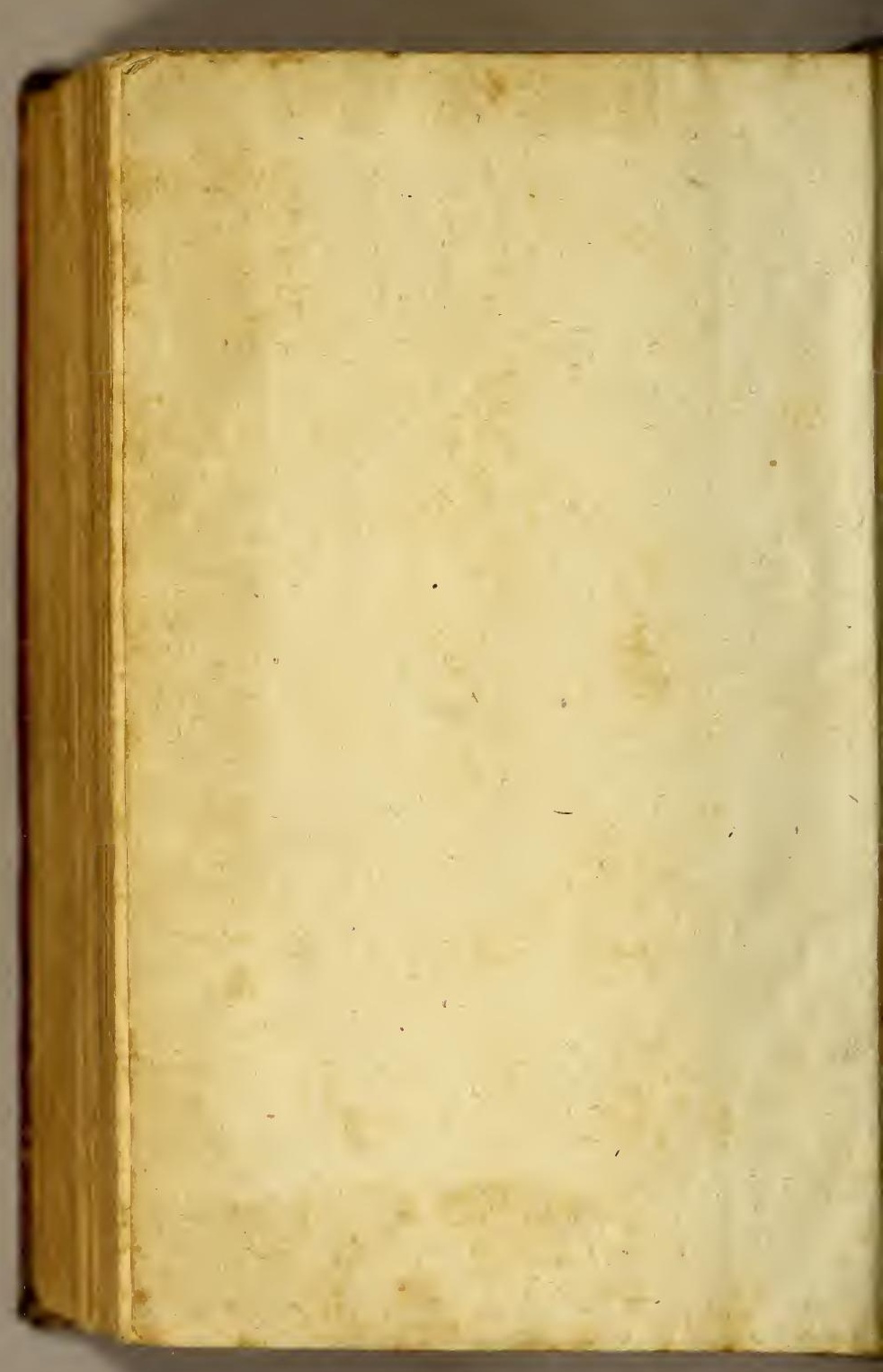




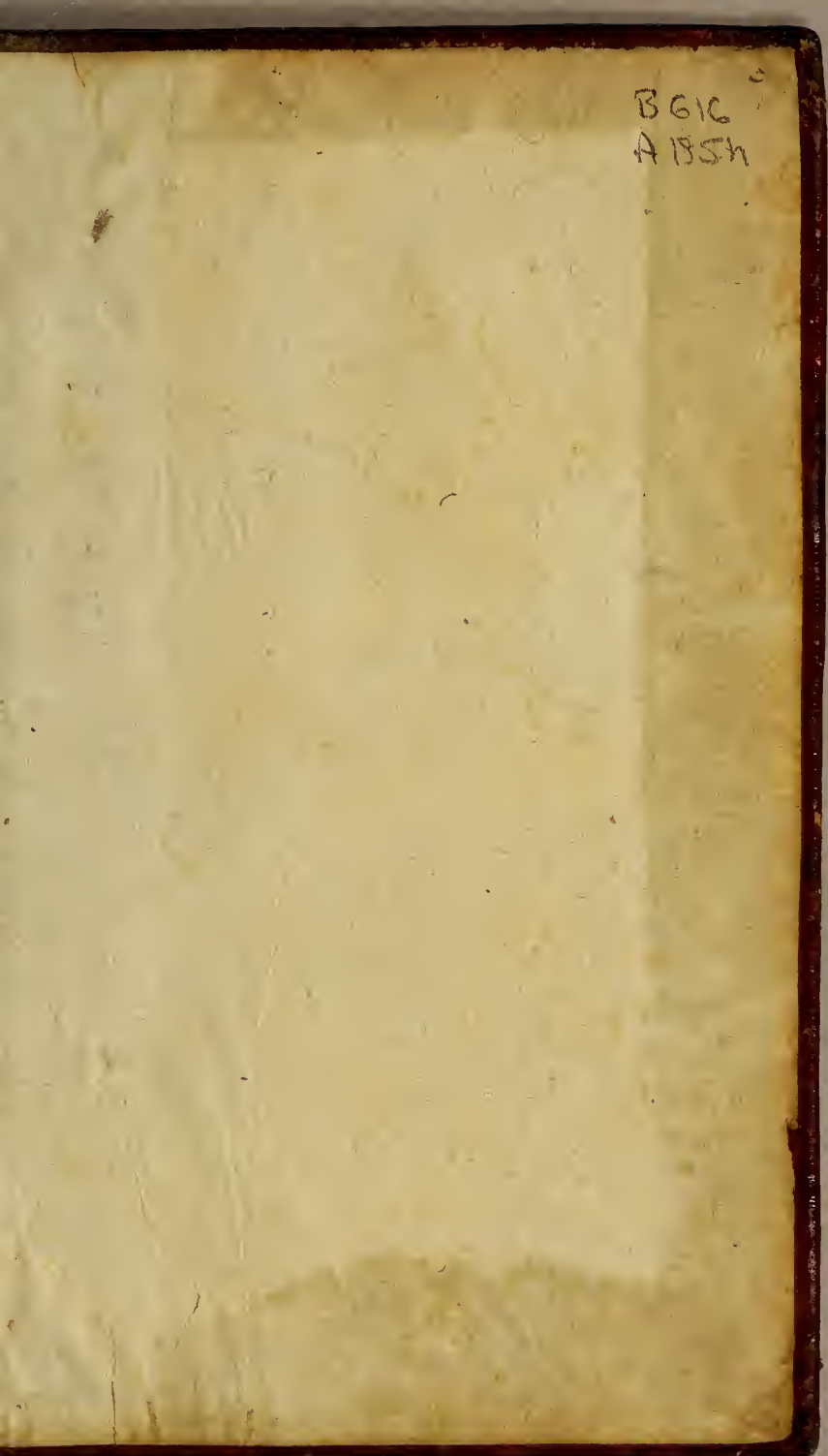




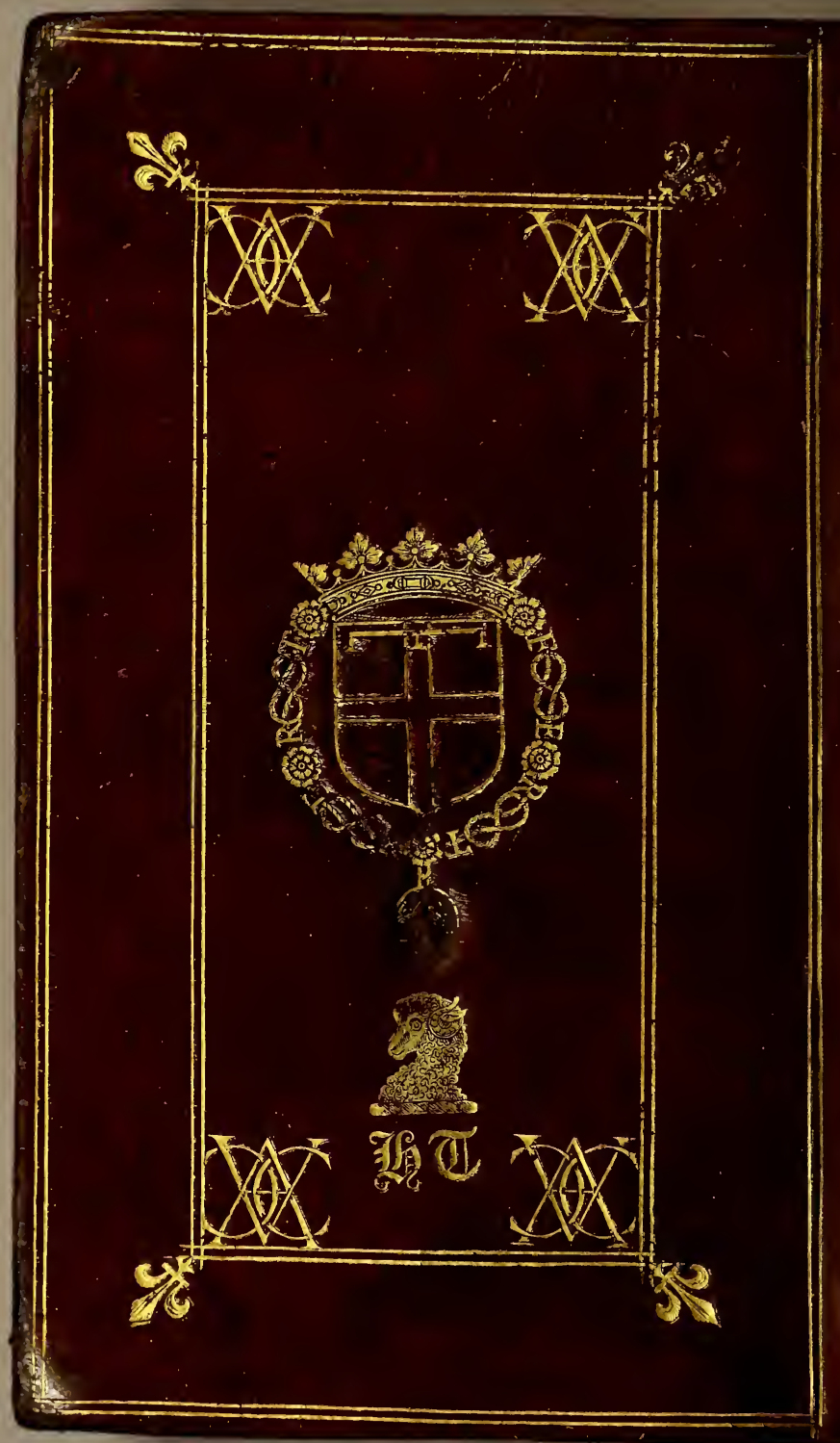

